\title{
CONSUMER INTENTIONS TO USE ELECTRONIC BANKING CHANNELS: THE ROLE OF TASK-CHANNEL FIT
}

\author{
By \\ Hartmut Hoehle
}

A thesis submitted to Victoria University of Wellington in fulfilment of the requirements for the degree of Doctor of Philosophy in Information Systems

Victoria University of Wellington 


\section{Acknowledgements}

I would like to express my gratitude to those who helped me to complete this thesis.

To Sid Huff, my primary supervisor, thank you for patiently working through the theoretical and methodological challenges with me, imparting to me some of your wisdom, and taking me under your wing.

To Hans Lehmann, my secondary supervisor, thank you for your moral support and encouragement to keep going.

To my friend and former mentor Eusebio Scornavacca, who provided important input during the initial phase of this project.

To my examiners, Mary Tate, Ron Thompson, and Viswanath Venkatesh, thank you for the insightful feedback and your suggestions to further improve this work.

To Victoria University of Wellington and the School of Information Management, for this great opportunity and the financial support.

To my parents, family, friends, and research participants. 


\begin{abstract}
The increase in electronically mediated self-service technologies in the banking industry is changing the way banks service consumers. Despite a large body of research on electronic banking channels, no study has been undertaken to explore the importance of the fit between electronic banking channels and banking tasks. Nor has there been research into how taskchannel fit and other factors influence consumer intentions to use electronic banking channels.

Integrating task-technology fit theory with acceptance and adoption research, this research develops and tests a research model that explains how the task-channel fit (TCF) and other factors impact on consumers' intentions to use electronic banking channels. An exploratory study was first conducted, investigating industry experts' perceptions towards the concept of task-channel fit of electronic banking channels. The findings demonstrate that the concept was perceived as being highly relevant by bank managers. A research model was then developed drawing on the existing literature on electronic banking channels. Following this, five exploratory focus groups were conducted in order to assess the initial conceptualization of the research model.
\end{abstract}

Subsequently, a survey questionnaire instrument was developed using judgment rounds and two pretest evaluations. Central to the scale development was the measurement of the TCF construct. Drawing on IS strategy and alignment literatures, a parallel instrument was created in order to determine TCF across several unique dimensions.

A pilot study assessed responses from 280 consumers using Internet banking for two different banking tasks. Overall, the scales demonstrated high reliability and showed adequate construct validity. The analysis of the pilot study suggested that the TCF construct and other antecedents of consumer intentions to use Internet banking explained a substantial amount of variance in the dependent variable.

The scales were refined in light of the pilot study. In the main study, 340 responses were collected from consumers using Internet banking for account inquiries or financial loans. The results showed that the TCF construct was a strong predictor of consumers' perceptions on the usefulness of Internet banking and their attitudes towards these services for both banking tasks. Overall, the TCF construct and other identified variables accounted for at least $63 \%$ of variance in the dependent variable. 


\section{Table of Contents}

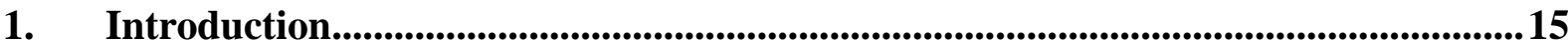

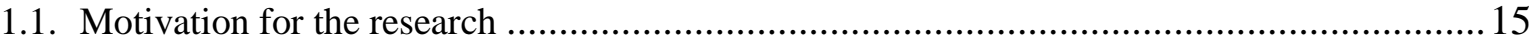

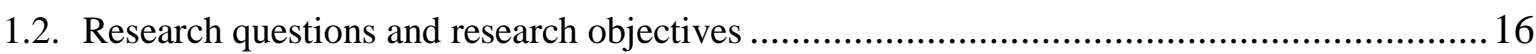

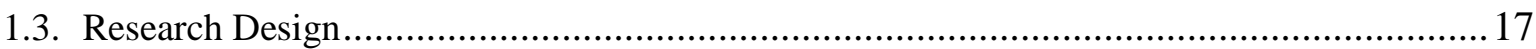

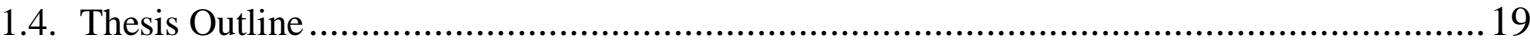

2. Literature Review ..........................................................................................................................22

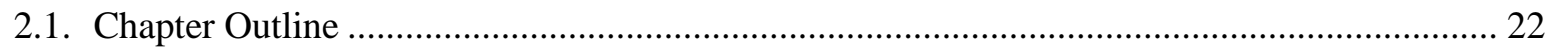

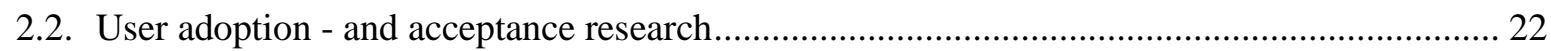

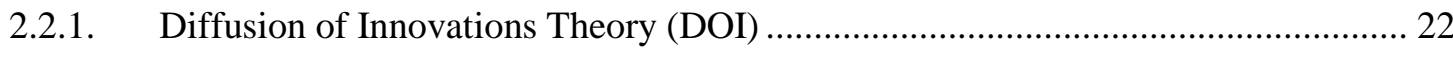

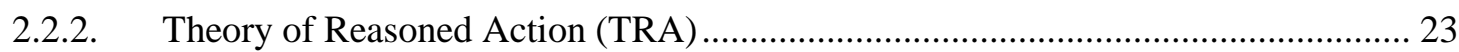

2.2.3. Technology Acceptance Model (TAM) ……..................................................... 24

2.2.4. Unified Theory of Acceptance and Use of Technology (UTAUT) .......................... 26

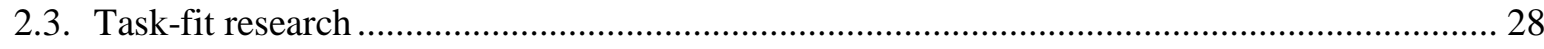

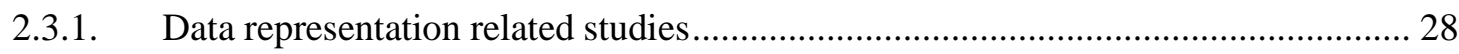

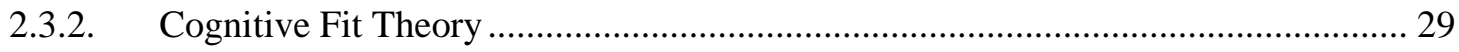

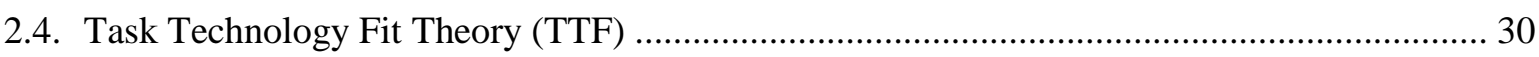

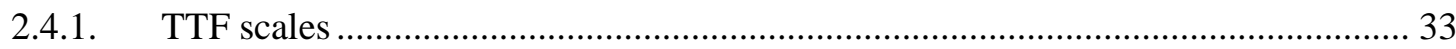

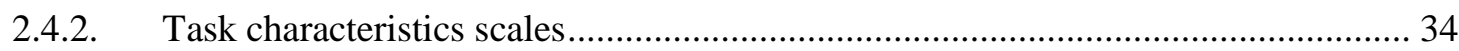

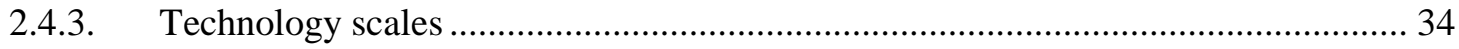

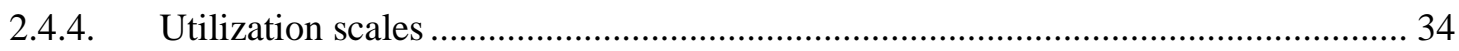

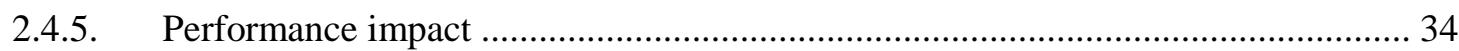

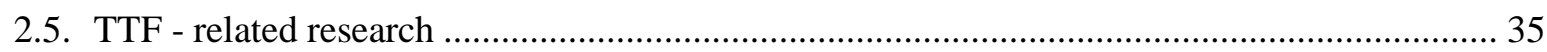

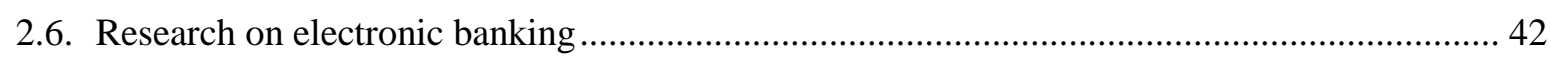

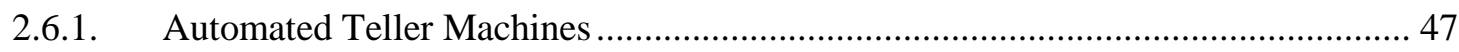

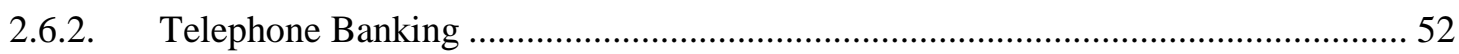

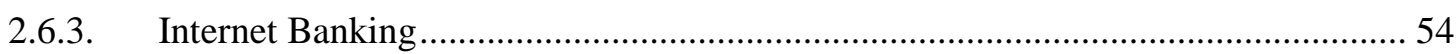

2.6.3.1. DOI related research on Internet Banking services....................................................................................... 55

2.6.3.2. TAM related research on Internet Banking services .................................................................................... 58

2.6.3.3. TPB / TRA related research on Internet Banking services........................................................................ 61

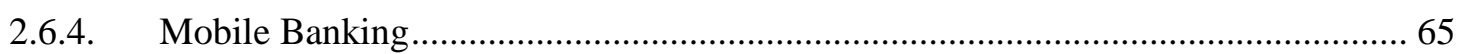

2.6.5. Summary of the literature on electronic banking .................................................. 70

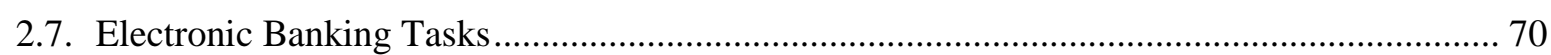

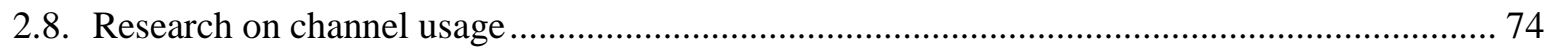

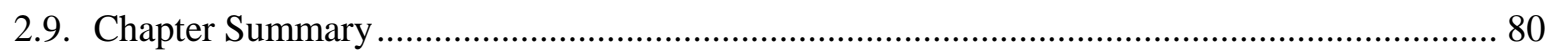

3. Conceptual Model and Research Hypotheses ........................................................8.

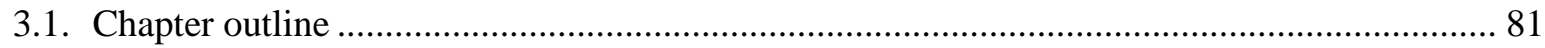

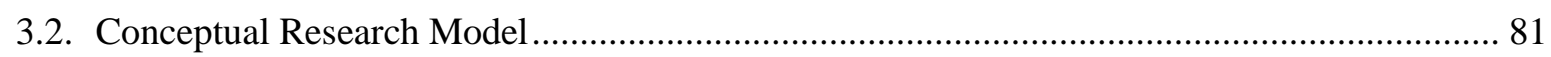

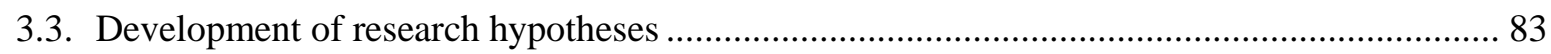

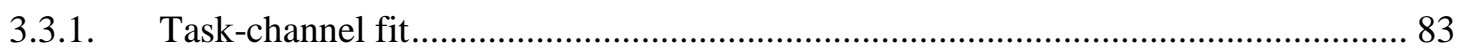




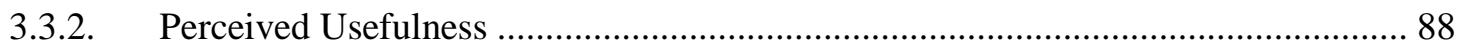

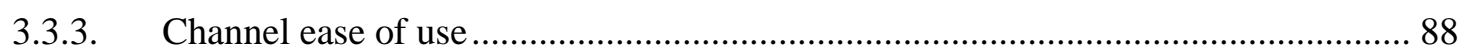

3.3.4. Attitude towards channel use ........................................................................... 89

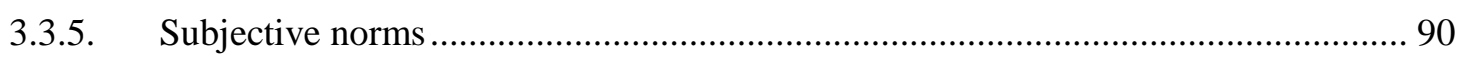

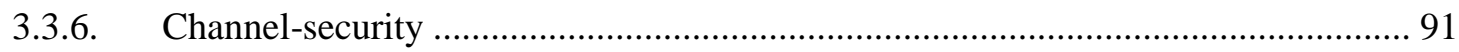

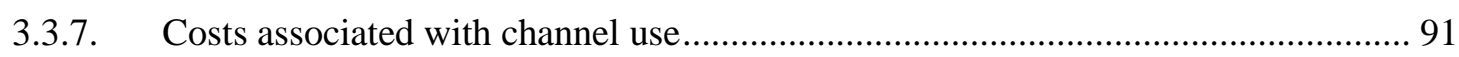

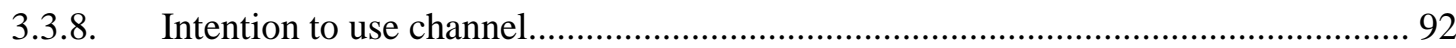

3.4. Conceptual research model including the associated hypotheses.......................................... 94

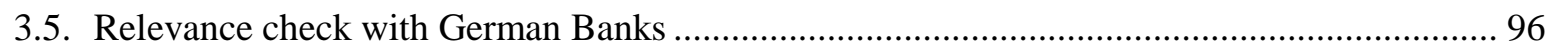

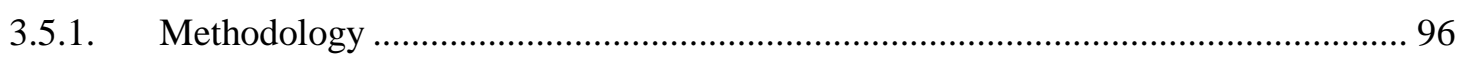

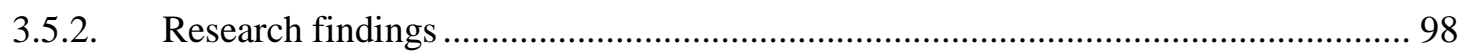

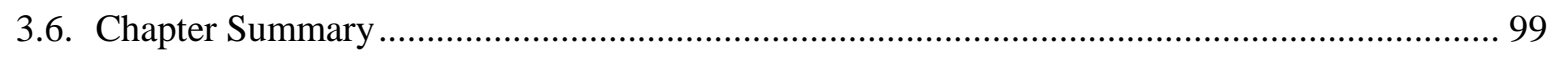

4. Research perspective and instrument development ...................................................101

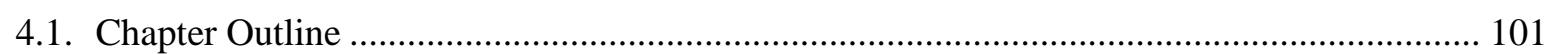

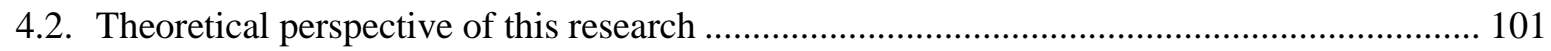

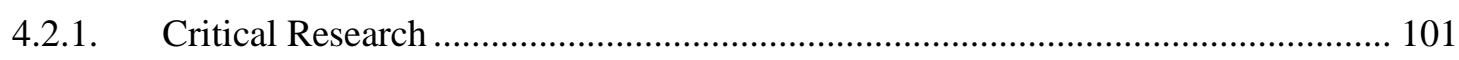

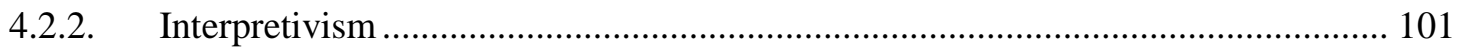

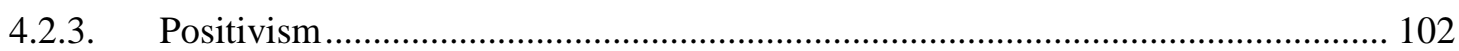

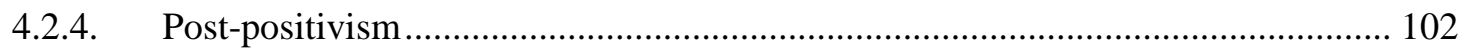

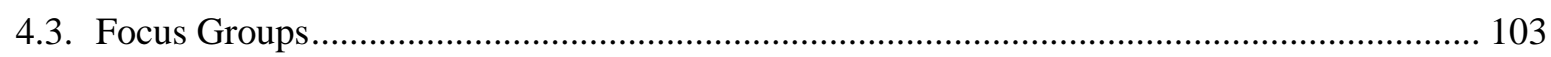

4.3.1. Research findings - Focus group discussions ................................................. 106

4.3.1.1. Dimension 1 - Task complexity .............................................................................................................. 107

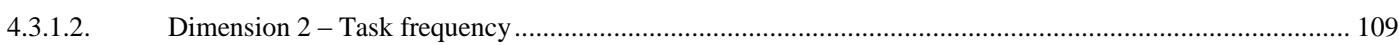

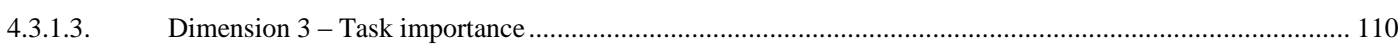

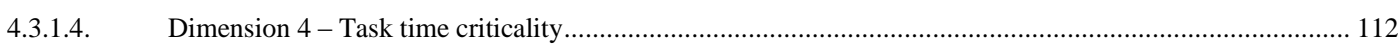

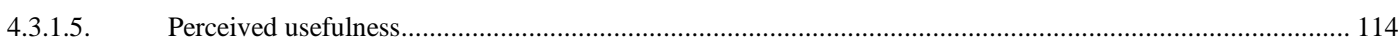

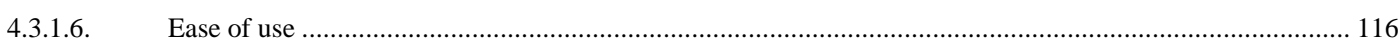

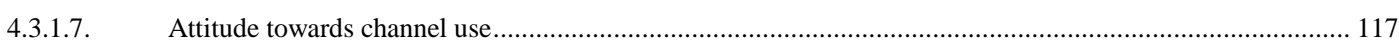

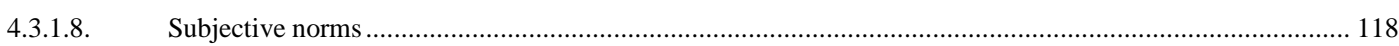

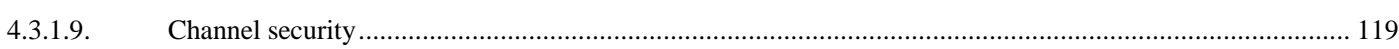

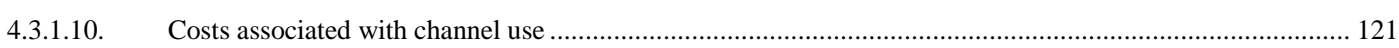

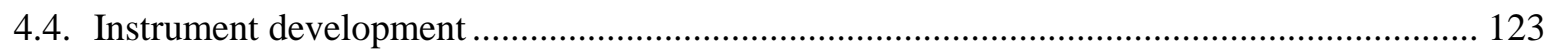

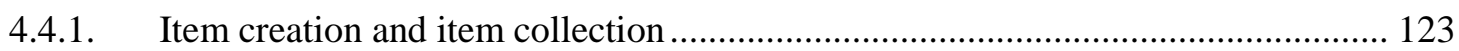

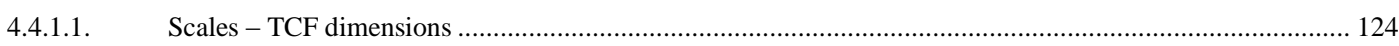

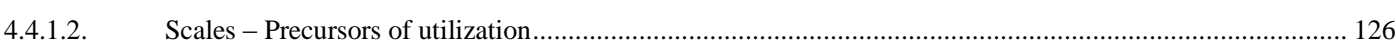

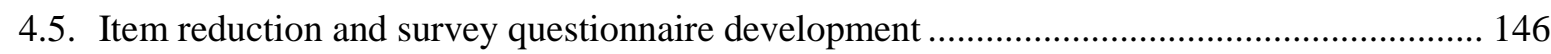

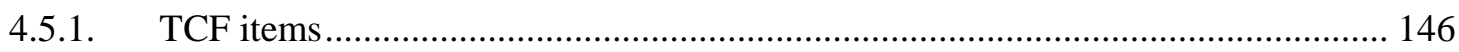

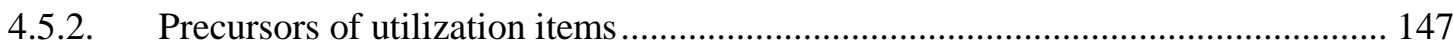

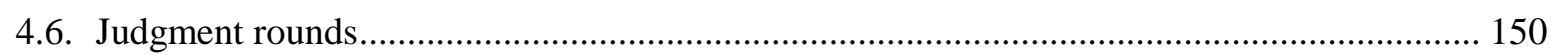

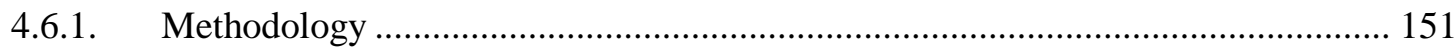

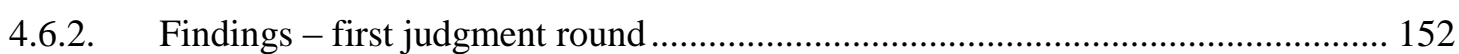

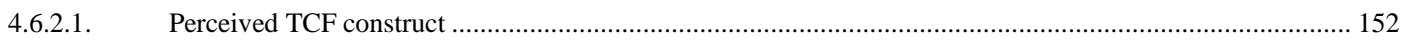

4.6.2.2. Precursors of utilization, intentions to use and questionnaire structure................................................... 154

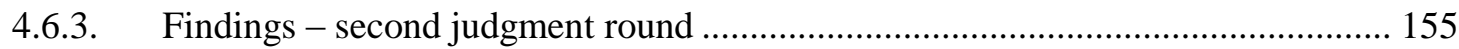

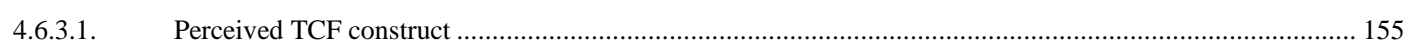

4.6.3.2. Precursors of utilization, intentions to use and questionnaire structure .............................................. 155 


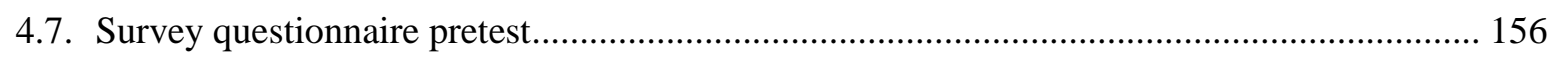

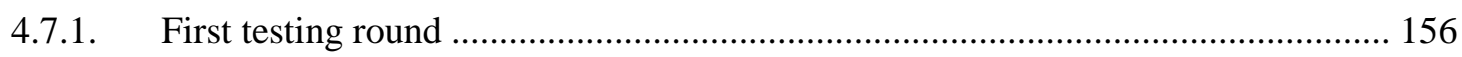

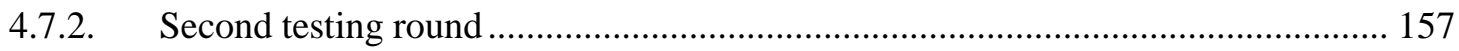

4.7.2.1. Feedback on section 1 of the questionnaire .................................................................................... 159

4.7.2.2. Feedback on section 2 of the questionnaire ............................................................................................. 159

4.7.2.3. Feedback on section 3 of the questionnaire ........................................................................................... 160

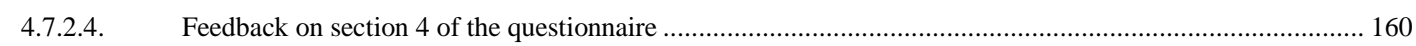

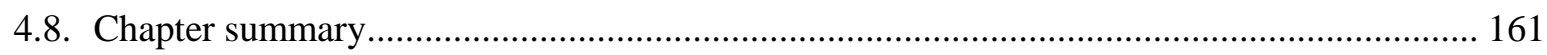

5. Fit assessment, pilot-study and data analysis...............................................163

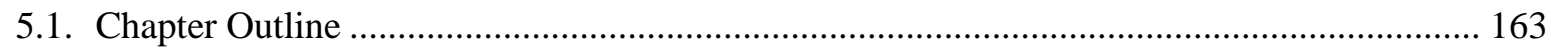

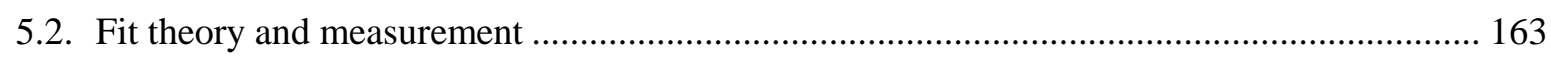

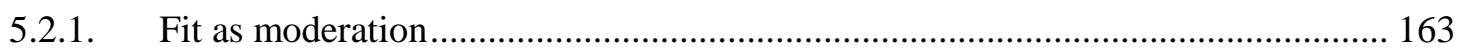

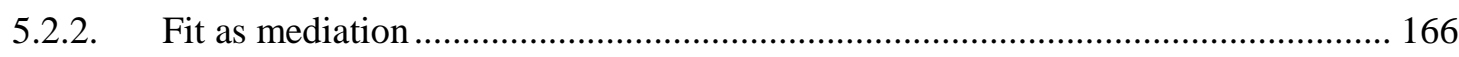

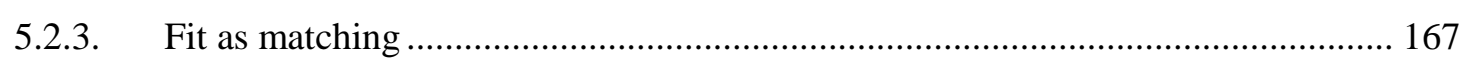

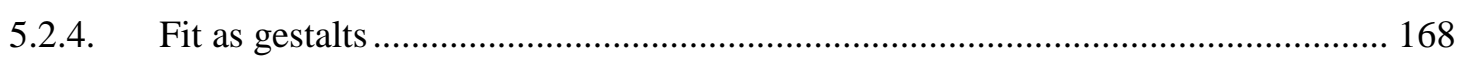

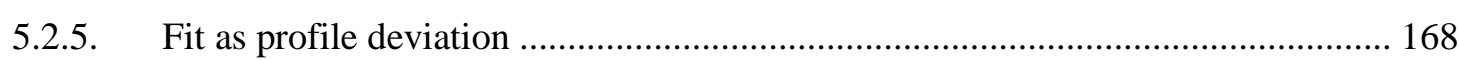

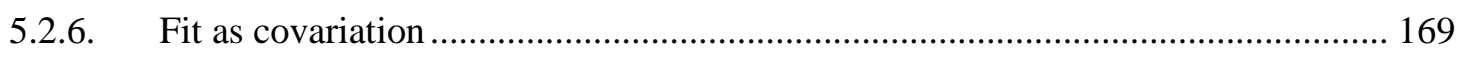

5.2.7. Direct (reflective) fit measures....................................................................... 170

5.2.8. Fit theory summary and identification of research gap ....................................... 171

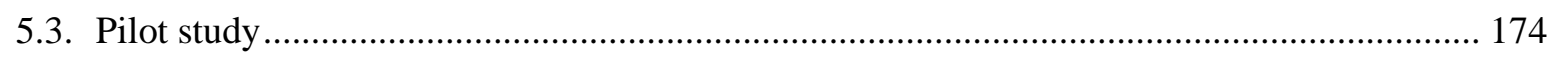

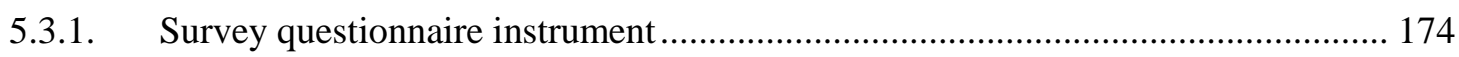

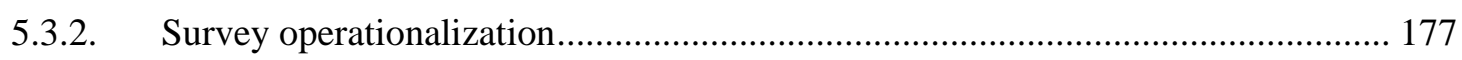

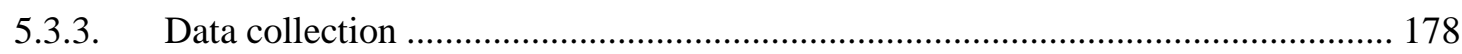

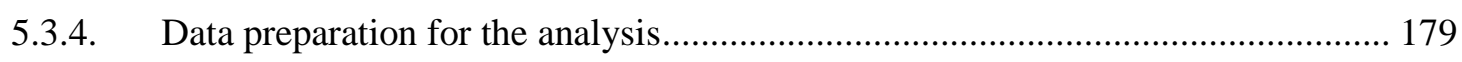

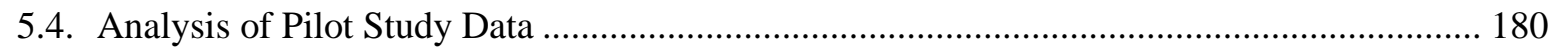

5.4.1. Task-channel fit operationalization.................................................................. 183

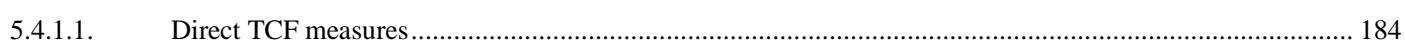

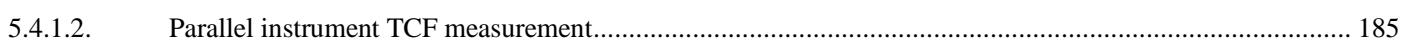

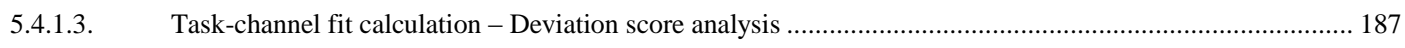

5.4.1.4. Task-channel fit calculation - Moderation approach ....................................................................... 192

5.4.2. Structural Equation Modeling - PLS ................................................................ 197

5.4.2.1. Factor analysis - confirmatory factor analysis (CFA) ..................................................................... 199

5.4.2.2. Construct validity assessment - reflective constructs ................................................................................ 200

5.4.2.3. Construct validity assessment - formative constructs........................................................................... 201

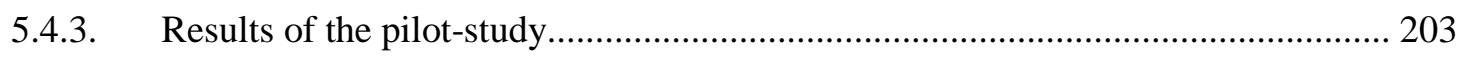

5.4.3.1. Construct validity assessment - reflective constructs ............................................................................... 204

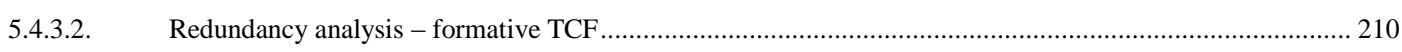

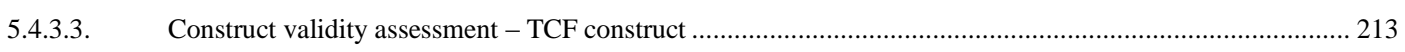

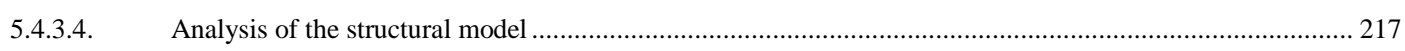

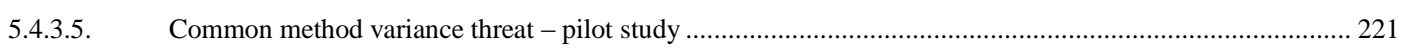

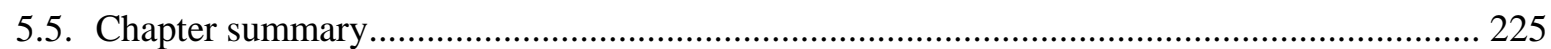

6. Testing the task-channel fit theory in context of Internet banking.........................227

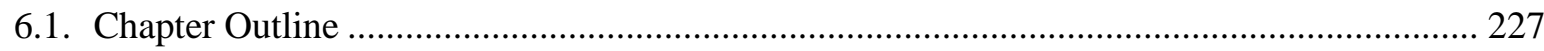

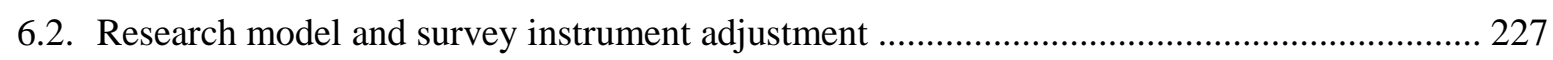

6.2.1. Obtaining feedback on the pilot study............................................................. 227 
6.2.2. Adjustment of the formative measures............................................................... 230

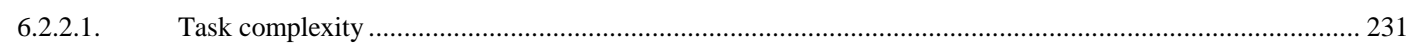

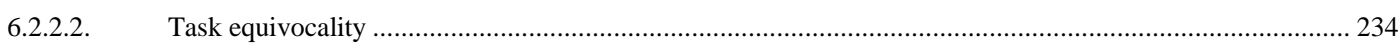

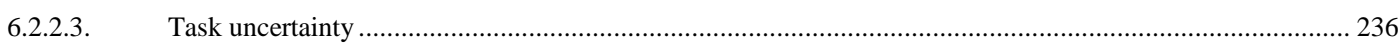

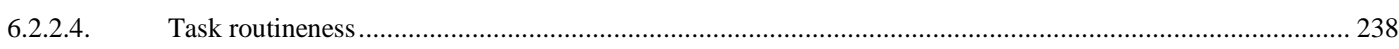

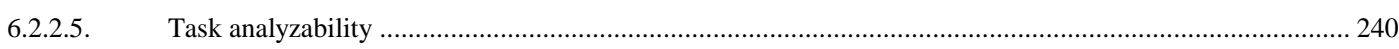

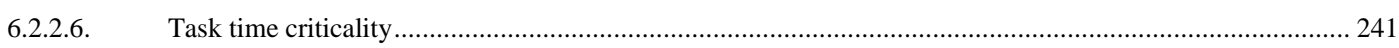

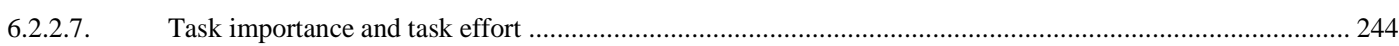

6.2.3. Adjustment of the reflective measures ………................................................. 245

6.3. Revised research model and complete survey Instrument................................................... 246

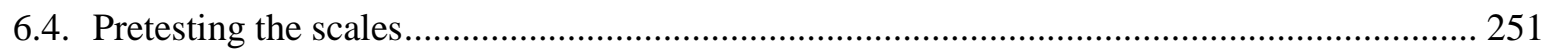

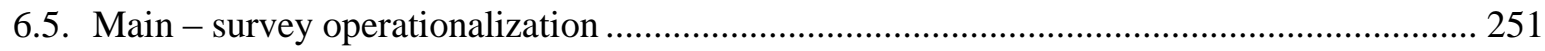

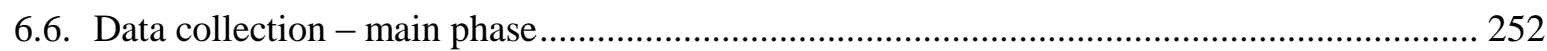

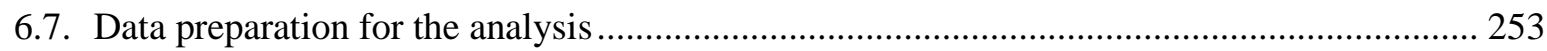

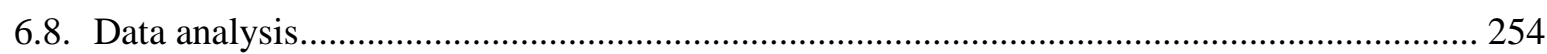

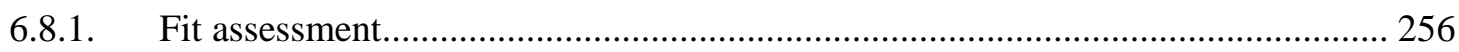

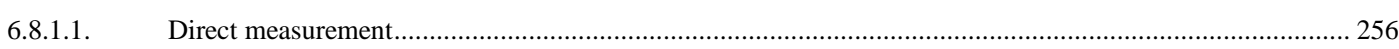

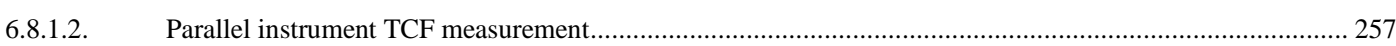

6.8.2. Construct validity assessment - reflective constructs ......................................... 259

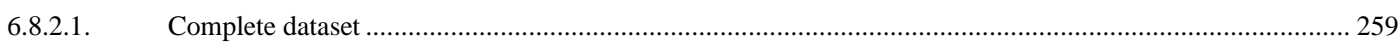

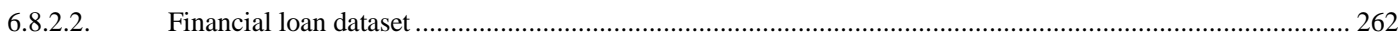

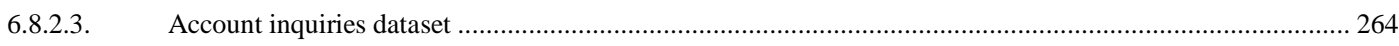

6.8.3. Construct validity assessment - formative TCF................................................. 266

6.8.3.1. Measurement approach 1 - examining individual moderation scores......................................................267

6.8.3.2. Measurement approach 2 - examining average moderation scores ................................................... 270

6.8.4. Structural model: complete dataset - individual and mean moderation scores...... 274

6.8.5. Structural model: task specific - individual moderation scores ............................ 277

6.8.6. Structural model: task specific - mean moderation scores .................................... 279

6.8.7. Multi-group comparison - an analysis of task-specific TCF models ..................... 281

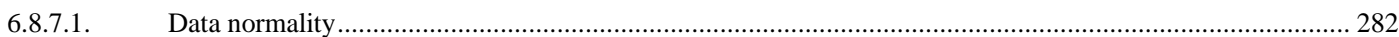

6.8.7.2. Acceptable goodness of fit .............................................................................................. 282

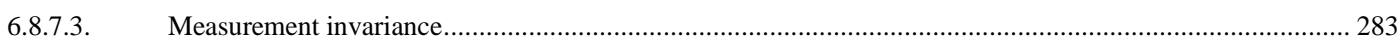

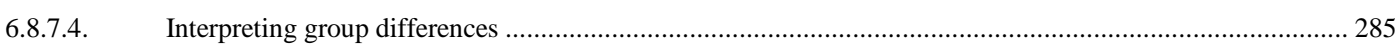

6.8.7.5. Financial loan dataset vs. account inquiries dataset ................................................................................. 286

6.8.8. Common method variance threat …………................................................... 288

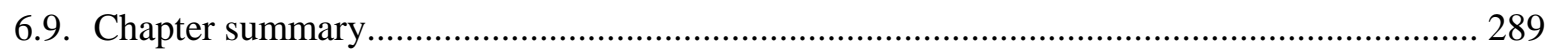

7. Discussion and interpretation of the findings ..................................................292

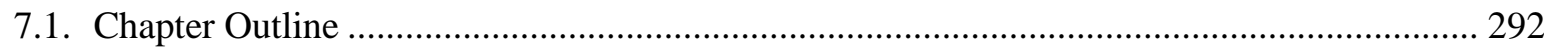

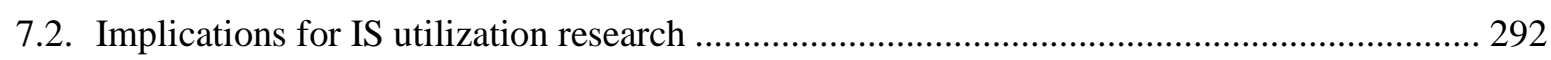

7.2.1. Overuse of traditional adoption / acceptance theories.......................................... 294

7.2.2. Genralizability vs. precision of traditional IS adoption / acceptance theories ....... 294

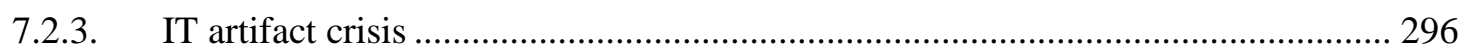

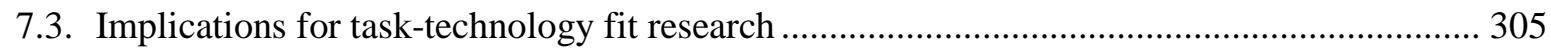

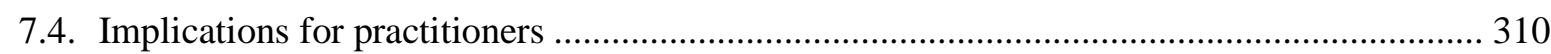

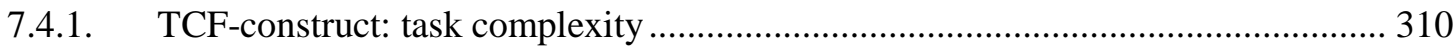

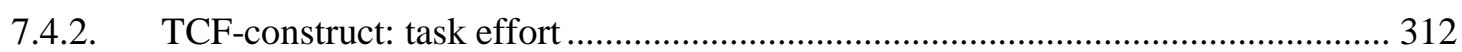




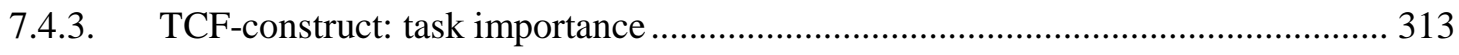

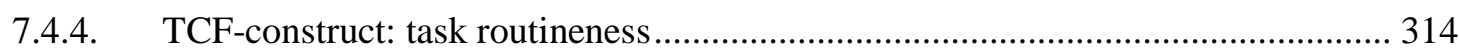

7.4.5. TCF-construct: task time criticality.............................................................. 315

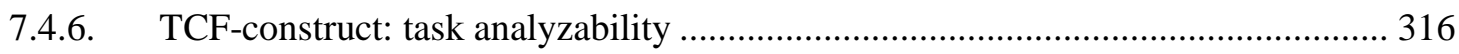

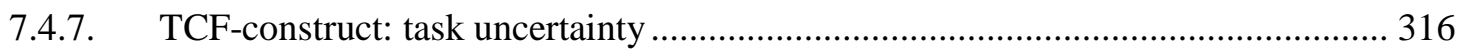

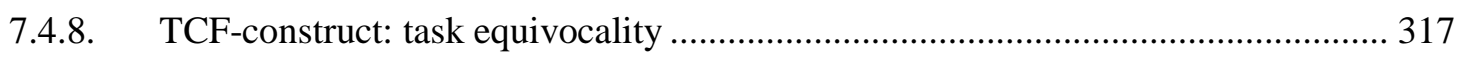

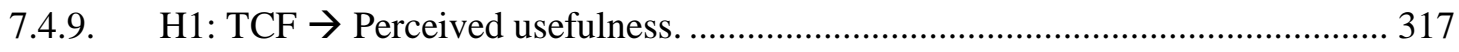

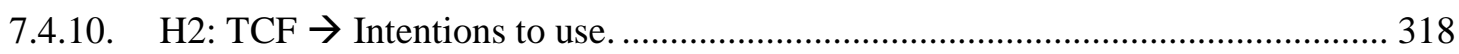

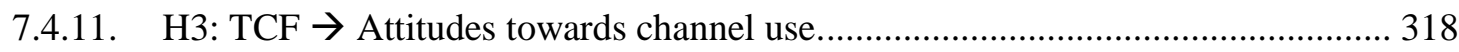

7.4.12. H4: Perceived usefulness $\rightarrow$ Intentions to use .................................................. 319

7.4.13. H5a: Perceived ease of use $\rightarrow$ Intentions to use. ................................................. 319

7.4.14. H5b: Perceived ease of use $\rightarrow$ Perceived usefulness. ........................................... 320

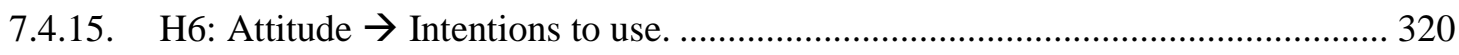

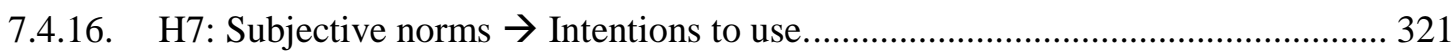

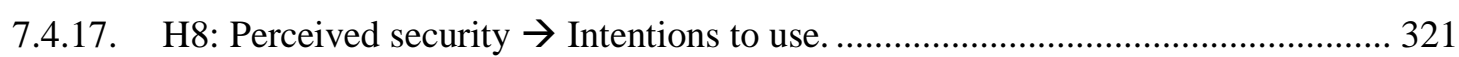

7.4.18. H9: Costs associated with use $\rightarrow$ Intentions to use............................................. 322

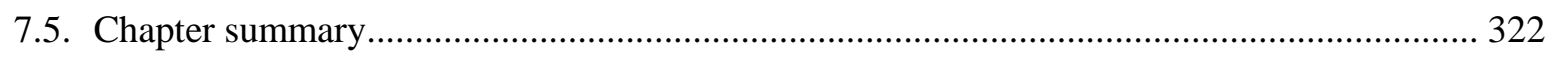

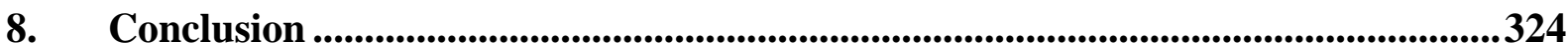

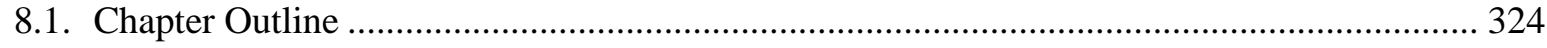

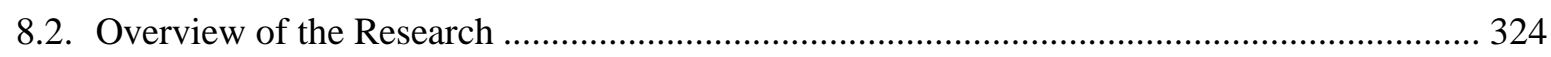

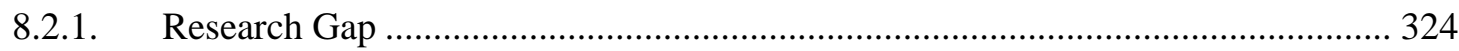

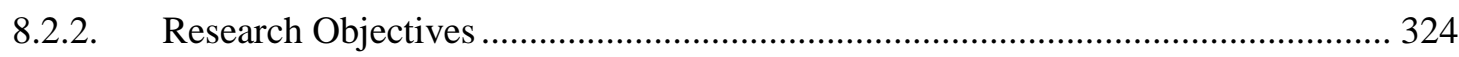

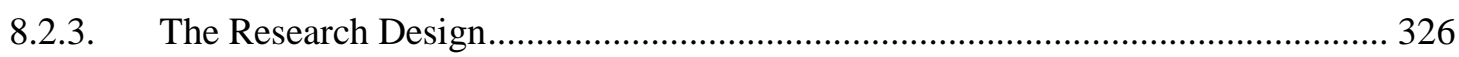

8.2.4. The Research Findings and Model Evaluation.................................................. 326

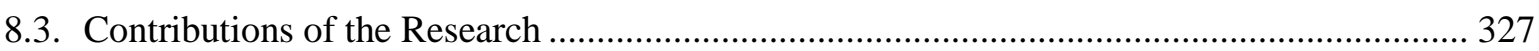

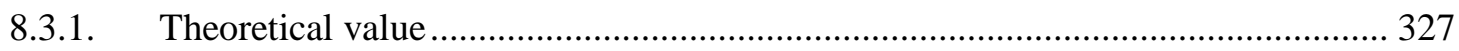

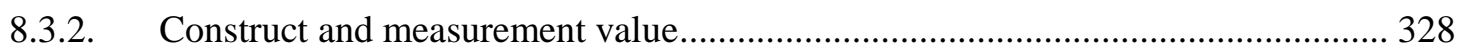

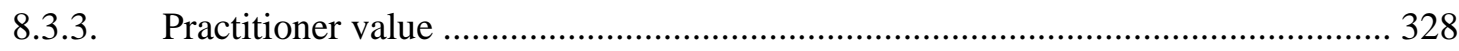

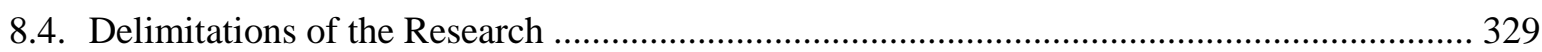

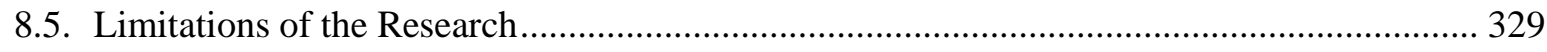

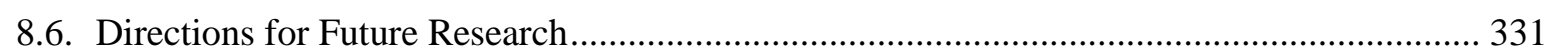

8.6.1. Testing the task-channel fit theory in different industries and countries ............... 331

8.6.2. Extending the task-channel fit theory to the corporate banking environment......... 331

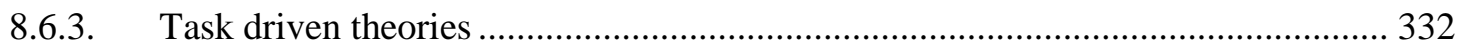

8.6.4. Polynomial regression techniques and surface response modeling........................ 332

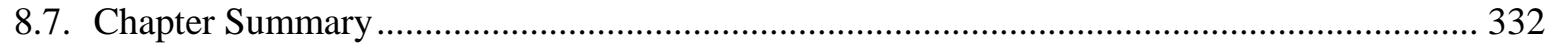

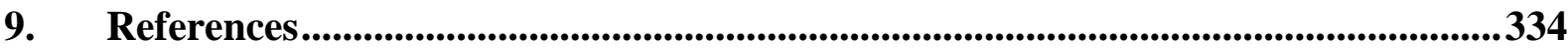

10. Appendices......................................................................................................................................356

10.1. Participant information sheet: relevance checks with German banks .................... 356

10.2. Interview guide: relevance checks with German banks ....................................... 357

10.3. Participant information sheet: focus group discussions ......................................... 358

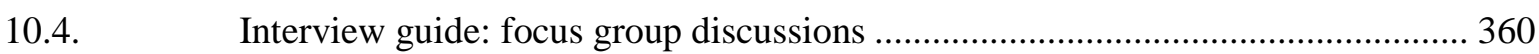


10.5 .

Discussion on the deviation score analysis

10.6 . 


\section{Table of Figures and Tables}

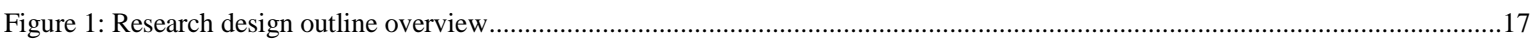

Figure 2: Theory of Reasoned Action (TRA) (Fishbein and Ajzen 1975) ................................................................................23

Figure 3: Technology Acceptance Model (TAM) (Davis, Bagozzi et al. 1989) .............................................................................24

Figure 4: TAM 2 - Extension of the Technology Acceptance Model (Venkatesh and Davis, 2000) ...................................................25

Figure 5: Unified Theory of Acceptance and Use of Technology (Venkatesh, Morris et al. 2003) ....................................................2

Figure 6: Cognitive fit theory: the general problem solving model (Vessey 1991) .........................................................................29

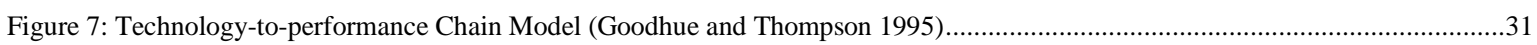

Figure 8: Measurements and analyses conducted by Goodhue and Thompson (Goodhue and Thompson 1995) ...................................33

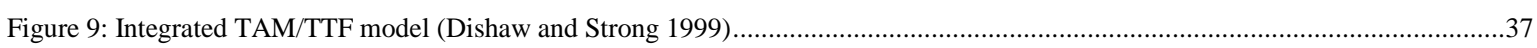

Figure 10: Model of task-technology fit, user evaluations, and performance (Goodhue, Klein et al. 2000) ..........................................38

Figure 11: The technology to performance model (D'Ambra and Wilson 2004) ..............................................................................39

Figure 12: Combined TAM/TTF e-commerce acceptance model (Klopping and McKinney 2004).....................................................39

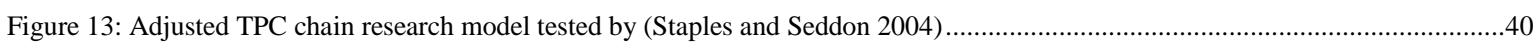

Figure 14: Various interfaces consumers have to access each electronic banking channel .....................................................................46

Figure 15: Model of overall satisfaction formation for ATMs - A cross country analysis (Goode, Snee et al. 2001) ..............................49

Figure 16: A Research Model of Technology-Based Self-Service (Dabholkar and Bagozzi 2002)......................................................50

Figure 17: Attitude towards self-service technology model (Curran and Meuter 2005) ...........................................................................53

Figure 18: Framework for the adoption of Internet Banking Services (Tan and Thompson 2000) .....................................................56

Figure 19: Theoretical model proposed for Internet banking adoption (Hernandez and Mazzon 2007) ................................................56

Figure 20: Extended TAM model determining the customer acceptance of Internet banking (Suh and Han 2002) ................................58

Figure 21: TAM modification to measure customer's intention to use Internet banking (Cheng, Lam et al. 2006) .................................59

Figure 22: Extended TAM model tested in Saudi Arabia (Al-Somali, Gholami et al. 2008)..............................................................60

Figure 23: Service-quality attributes for consumer satisfaction toward Internet banking (Liao and Cheung 2008) ................................61

Figure 24: Modified TPB model to explain behavioral intention to use Internet Banking (Shih and Fang 2004) .................................62

Figure 25: Model explaining behavioral intention to use mobile banking services (Tang, Lin et al. 2004).......................................67

Figure 26: The relative advantage of electronic channels: a research model (Choudhury and Karahanna 2008) .....................................76

Figure 27: A model of product channel selection for financial services (Black, Lockett et al. 2002) ...................................................77

Figure 28: Interaction channel choice in a multichannel environment model (Albesa 2007) ..............................................................79

Figure 29: Conceptual research model for the task-channel fit concept of electronic banking channels ...............................................82

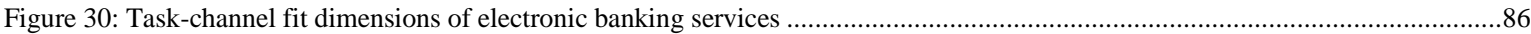

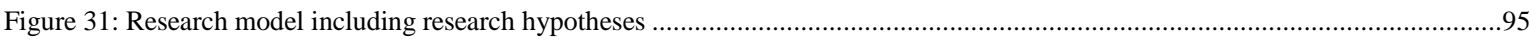

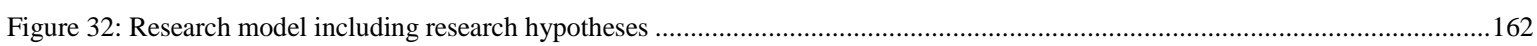

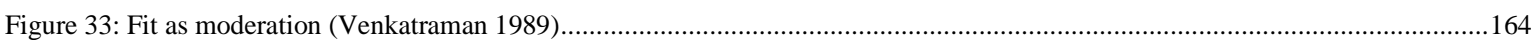

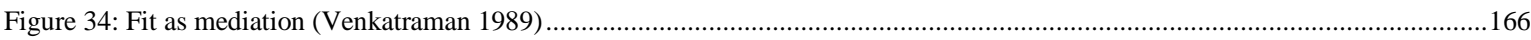

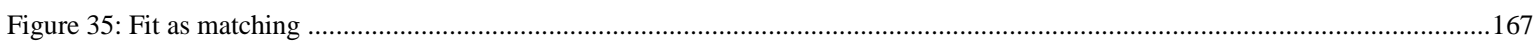

Figure 36: Comparison of reflective and formative model (Diamantopoulos, Riefler et al. 2008) …….............................................183

Figure 37: Under and overfit assumption for negative and positive deviation scores ......................................................................190

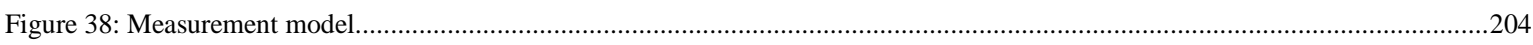

Figure 39: Adapted redundancy analysis for selecting individual moderation scores.....................................................................211

Figure 40: Formative TCF construct: measuring TCF using individual moderation scores ............................................................213

Figure 41: Formative TCF construct: measuring TCF using average moderation scores ...............................................................215

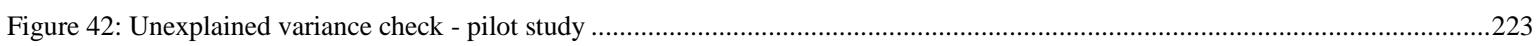

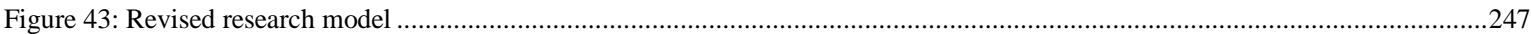

Figure 44: Formative TCF construct/individual moderation scores - main study …………………….........................................267

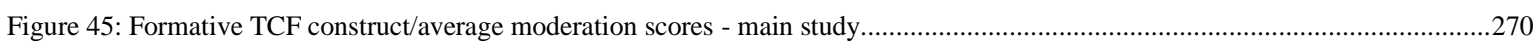

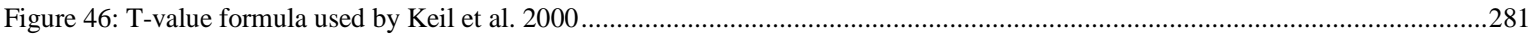


Figure 47: PLS-MGA formula developed by Henseler et al. (2009)

Figure 48: Interplay between generalizability, precision and simplicity in IS theories............................................................295

Figure 49: Generation shift of IS utilization theories: Interplay between generalisability, precision and simplicity in IS theories ...........303

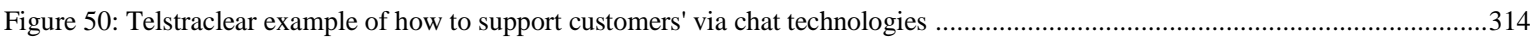

Table 1: Major features of the Technology-to-performance Chain model (Goodhue and Thompson 1995) ...........................................32

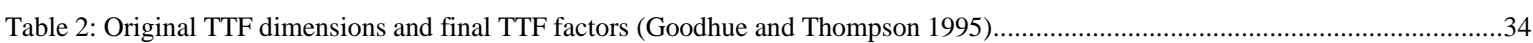

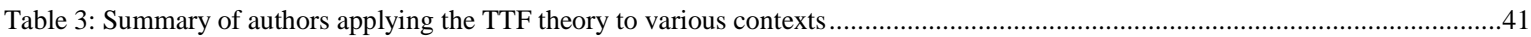

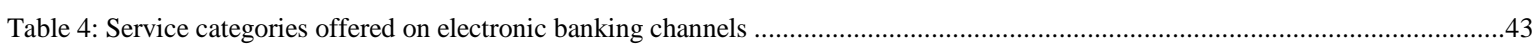

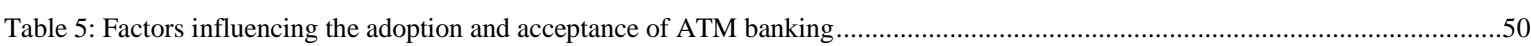

Table 6: Factors influencing the adoption and acceptance of Telephone banking ...................................................................53

Table 7: Factors influencing the adoption and acceptance of Internet banking applications ...............................................................63

Table 8: Factors influencing the adoption and acceptance of mobile banking applications..............................................................68

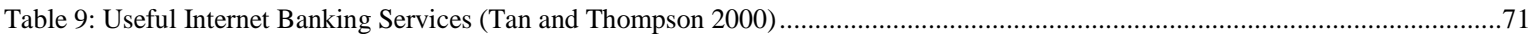

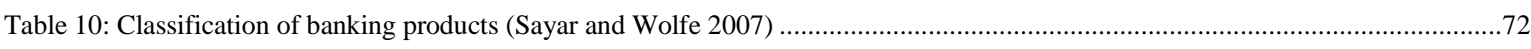

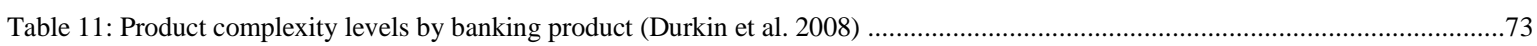

Table 12: Supporting references for the constructs used for the TCF research model..................................................................93

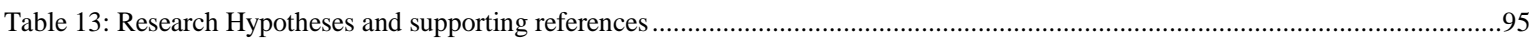

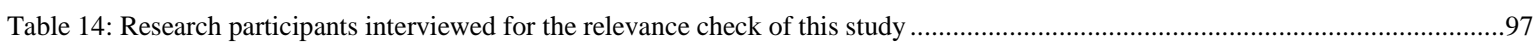

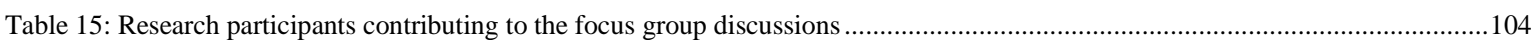

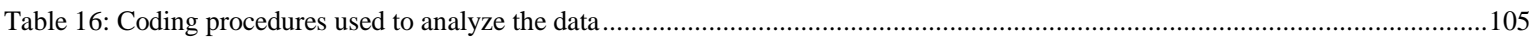

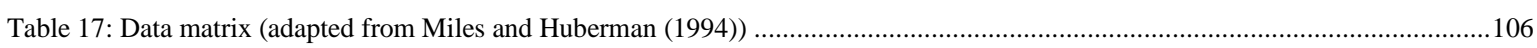

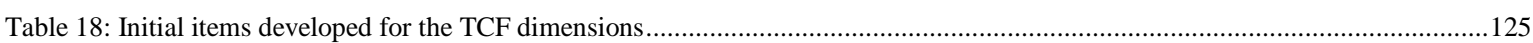

Table 19: Scale to measure a perceived usefulness construct (Davis 1989) ................................................................................126

Table 20: Scale to measure a perceived usefulness construct (Bhattacherjee 2001) .....................................................................127

Table 21: Scale to measure a perceived usefulness construct (Bhattacherjee 2001) ........................................................................127

Table 22: Scale to measure a perceived usefulness construct (Limayem, Cheung et al. 2003) ...................................................128

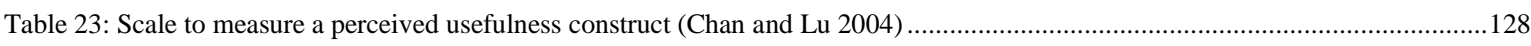

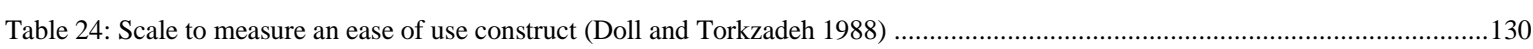

Table 25: Scale to measure an ease of use construct (Davis 1989)

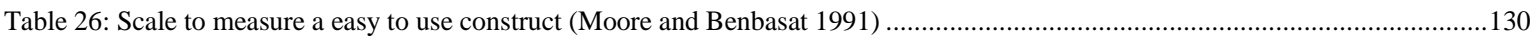

Table 27: Scale to measure the effort expectancy construct (Venkatesh, Morris et al. 2003) ..............................................................131

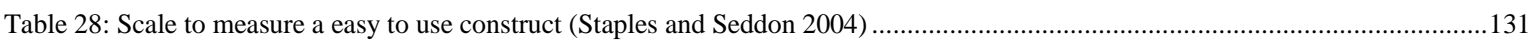

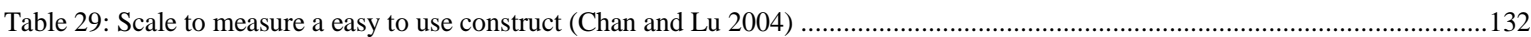

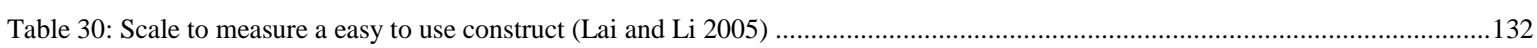

Table 31: Scale to measure an attitude construct (Taylor and Todd 1995) …..........................................................................133

Table 32: Scales used to assess the attitude towards Internet banking construct (Lai and Li 2005) ..................................................134

Table 33: Scales used to assess the attitude towards Internet banking construct (Cheng, Lam et al. 2006) ..........................................134

Table 34: Scale to measure a subjective norms construct (Hartwick and Barki 1994) ....................................................................135

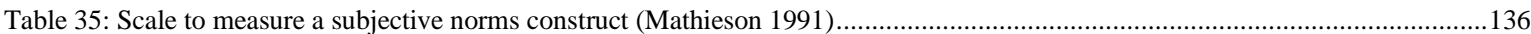

Table 36: Scale to measure a subjective norms construct (Venkatesh, Morris et al. 2003)...............................................................136

Table 37: Scale to measure a subjective norms construct (Limayem et al. 2003)...........................................................................137

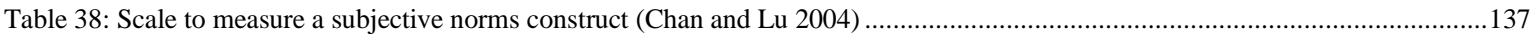

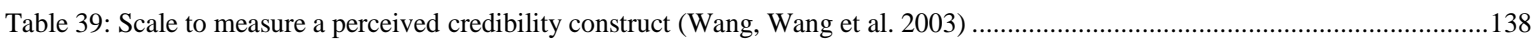

Table 40: Scale to measure a risk construct related to Internet banking (Curran and Meuter 2005) ..................................................138

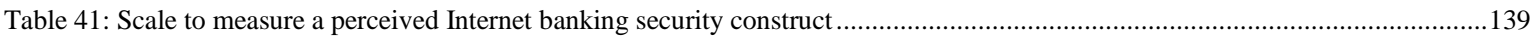

Table 42: Scale to measure a perceived Internet banking security construct (Vatanasombut, Igbaria et al. 2008) ..............................139 
Table 43: Scale to measure the perceived financial costs construct (Luarn and Lin 2005).

Table 44: Scale to measure the perceived financial costs construct (Wang, Lin et al. 2006) ......................................................140

Table 45: Scale to measure the intention to use construct (Mathieson 1991) ...................................................................................141

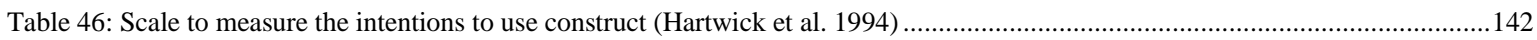

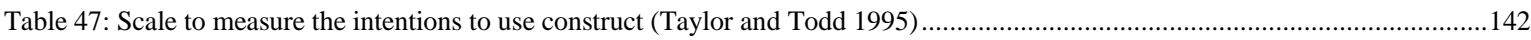

Table 48: Scale to measure the intentions to use construct (Venkatesh, Morris et al. 2003) ...............................................................142

Table 49: Scale to measure the intentions to use construct (Thompson, Compeau et al. 2006) ...........................................................143

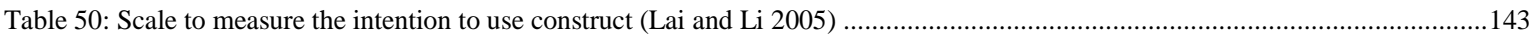

Table 51: Scale to measure the intention to use construct (Cheng, Lam et al. 2006) .........................................................................143

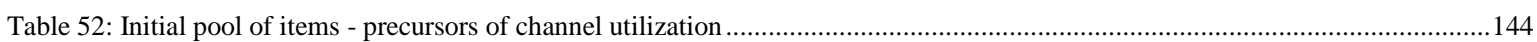

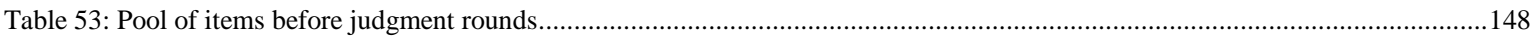

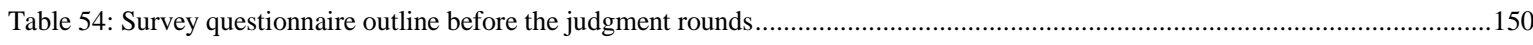

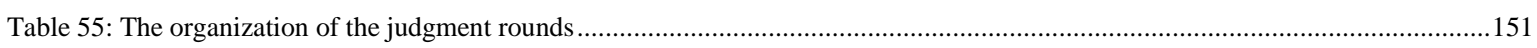

Table 56: Parallel items used to determine strategic alignment (Chan, Huff et al. 1997) ...........................................................164

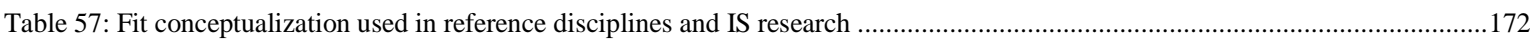

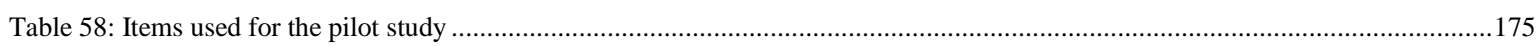

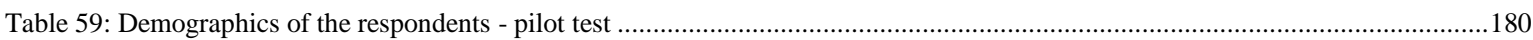

Table 60: Respondents' familiarity with each banking task and Internet banking ..................................................................181

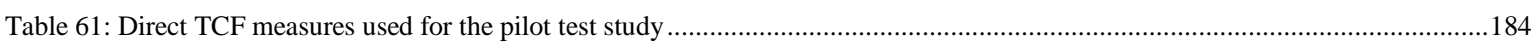

Table 62: Matching items used to determine the Task-channel Fit of electronic banking channels .....................................................185

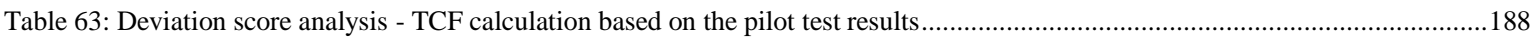

Table 64: Moderation approach using product terms - TCF calculation based on the pilot test results .................................................193

Table 65: Summary of the fit calculation approaches and the underlying theoretical assumptions ....................................................194

Table 66: T-values for the reflective measures - Financial loan dataset/Pilot test ......................................................................205

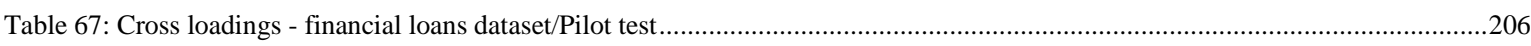

Table 68: Correlations of the latent variables and reliability measures for the financial loan dataset..................................................207

Table 69: T-values for the reflective measures - account inquiries dataset / Pilot test.............................................................208

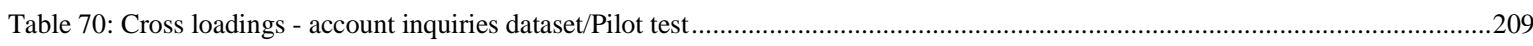

Table 71: Correlations of the latent variables and reliability measures for the account inquiries dataset .............................................210

Table 72: Redundancy analysis - identification of the individual moderation score items............................................................212

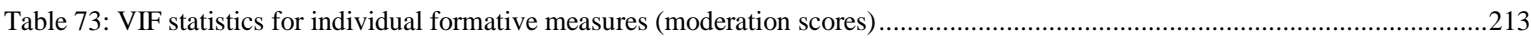

Table 74: Formative measures t-values and item weights - individual moderation scores........................................................213

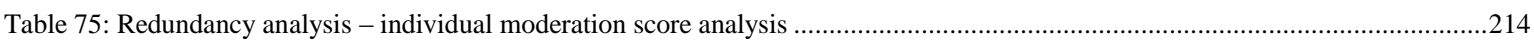

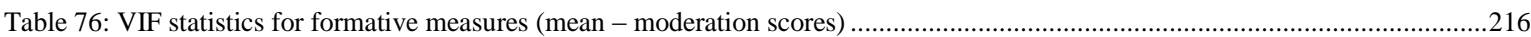

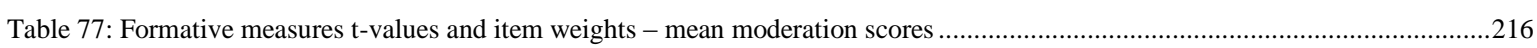

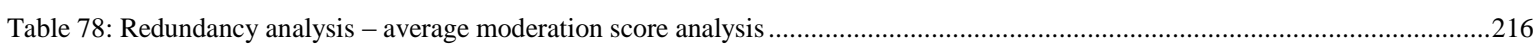

Table 79: Structural model results - individual moderation scores / pilot study …................................................................218

Table 80: Variance explained by each construct - individual moderation scores / pilot study.............................................................219

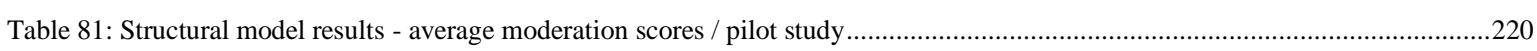

Table 82: Variance explained by each construct - average moderation scores / pilot study ......................................................220

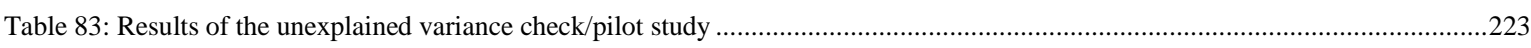

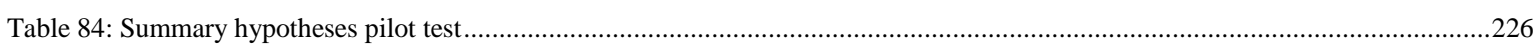

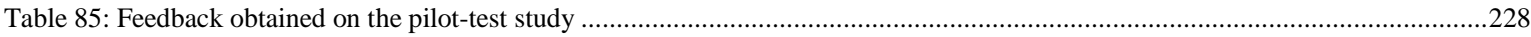

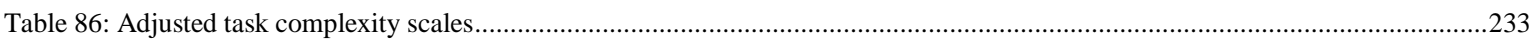

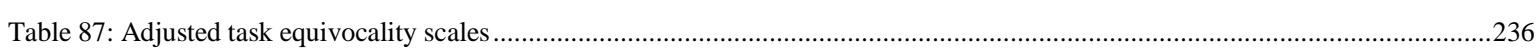

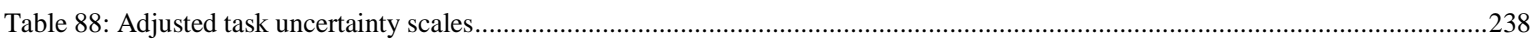

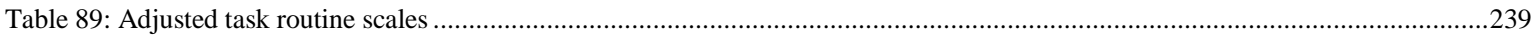


Table 90: Adjusted task analyzability scales.....

Table 91: Adjusted task time criticality scales ....................................................................................................................24

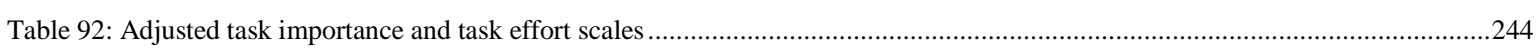

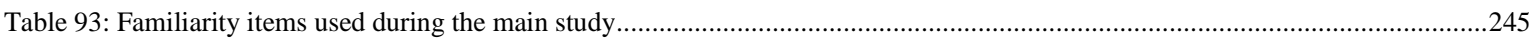

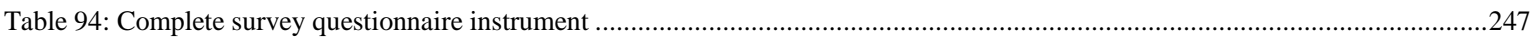

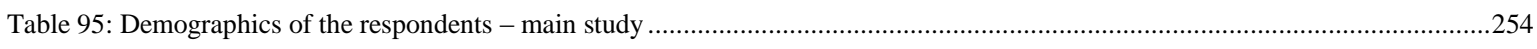

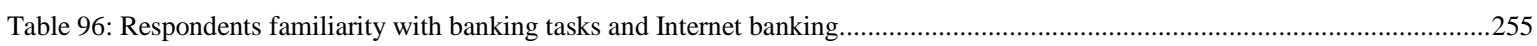

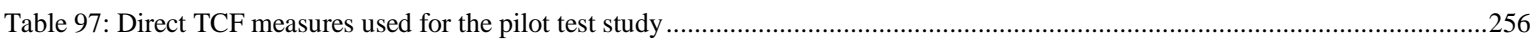

Table 98: Parallel items used to determine the Task-channel Fit of electronic banking channels ..................................................257

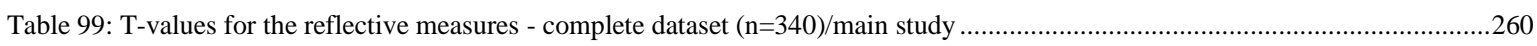

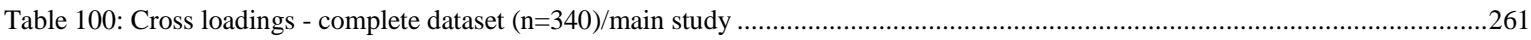

Table 101: Correlations of the latent variables and reliability measures for the complete $(n=340)$ dataset - main study ......................262

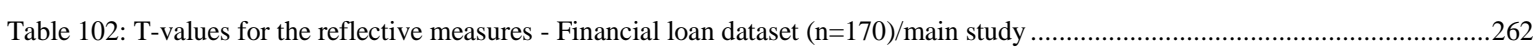

Table 103: Cross loadings - financial loans dataset $(n=170) /$ main study .........................................................................................263

Table 104: Correlations of the latent variables and reliability measures for the financial loan dataset - main study............................264

Table 105: T-values for the reflective measures - account inquiries dataset/main study ...............................................................2264

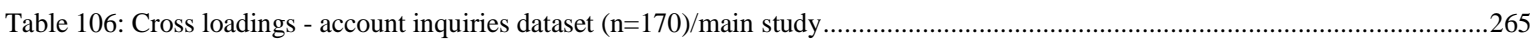

Table 107: Correlations of the latent variables and reliability measures for the account inquiries dataset - main study .......................265

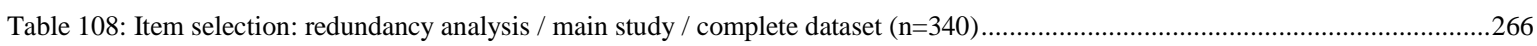

Table 109: VIF statistics for formative measures (individual product scores)/main study ...............................................................268

Table 110: Formative measures t-values and item weights - individual moderation scores/main study ............................................268

Table 111: Redundancy analysis - individual moderation score analysis/main study ....................................................................269

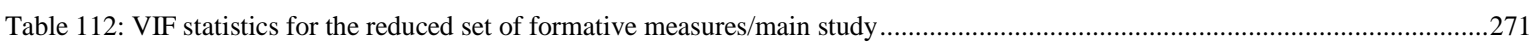

Table 113: Formative measures t-values and item weights -average moderation scores/main study ...............................................271

Table 114: Redundancy analysis -mean moderation score analysis/main study .........................................................................22

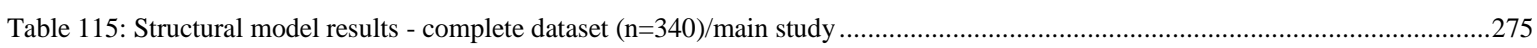

Table 116: Variance explained by each construct - individual moderation scores/main study/complete dataset...................................276

Table 117: Structural model results - individual moderation scores/main study ...........................................................................277

Table 118: Variance explained by each construct - individual moderation scores/main study ........................................................278

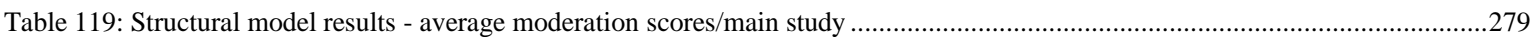

Table 120: Variance explained by each construct - average moderation scores/main study ...............................................................280

Table 121: Variance explained by each construct - sub-group comparison............................................................................28

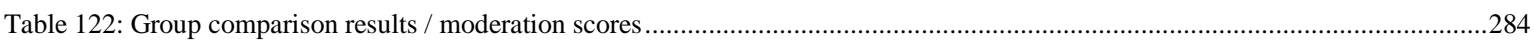

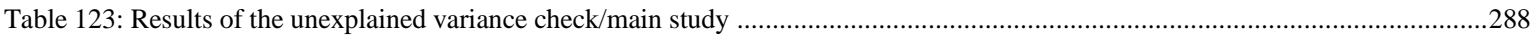

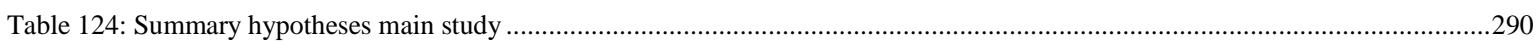

Table 125: Some measurement scales used by Burton-Jones and Straub 2006) ..............................................................................29

Table 126: Inspection of the traditional acceptance and adoption theories with regards to individuals, IS artifacts, and technology .......299

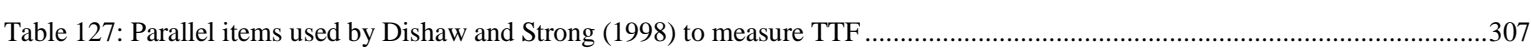

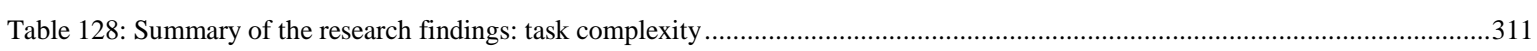

Table 129: Summary of the research findings: task effort .........................................................................................................312

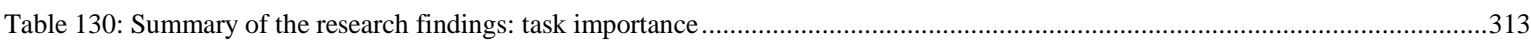

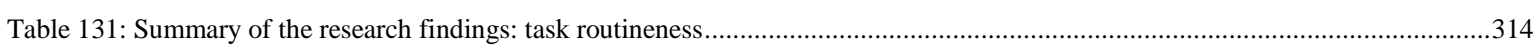

Table 132: Summary of the research findings: task time criticality ...........................................................................................315

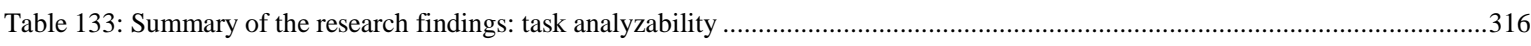

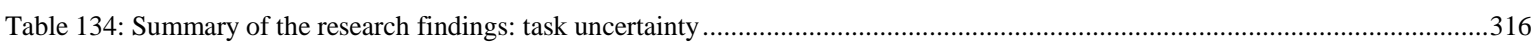

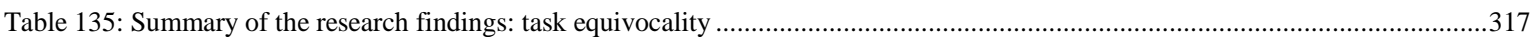

Table 136: Summary of the research findings: Hypothesis 1 (TCF-->PU) .....................................................................................317 
Table 137: Summary of the research findings: Hypothesis 2 (TCF-->INT)

Table 138: Summary of the research findings: Hypothesis 3 (TCF-->ATT)

Table 139: Summary of the research findings: Hypothesis 4 (PU-->INT).

Table 140: Summary of the research findings: Hypothesis 5a (EOU-->INT)

Table 141: Summary of the research findings: Hypothesis 5b (EOU-->PU)

Table 142: Summary of the research findings: Hypothesis 6 (ATT-->INT)

Table 143: Summary of the research findings: Hypothesis 7 (SN-->INT) .

Table 144: Summary of the research findings: Hypothesis 8 (SEC-->INT)

Table 145: Summary of the research findings: Hypothesis 9 (COST-->INT)

Table 146: Summary of the hypotheses investigated by this study

Table 147: Summary of the r-square values explained by each construct 


\section{Introduction}

\subsection{Motivation for the research}

Since the early 1970s, the proliferation of new information and communication technologies within the financial industry has significantly influenced the way banks service consumers. In particular, self-service technologies have enabled banks to pursue an electronically mediated multi-channel strategy and nowadays ATMs, telephone banking, Internet banking, and mobile banking are all efficient means for selling products and servicing customers.

The first self-service technologies emerged in the 1970s when banks installed the first automated teller machines (ATM) (Railton 1985), followed by telephone banking services in the 1980s (Ahmad and Buttle 2002). In the 1990s, banks extended their existing distribution channels further by offering consumers access to their accounts through Internet-based banking applications (Tan and Thompson 2000; Bhattacherjee 2001; Bhattacherjee 2001; Suh and Han 2002). Over the past decade, banks have begun to provide mobile banking applications, to enable consumers to bank using mobile technologies such as mobile phones, PDAs, and smart-phones (Laukkanen and Lauronen 2005; Scornavacca, Barnes et al. 2006).

For the consumer, these electronic banking channels eliminate the need to visit a branch, and offer convenient access to bank accounts. Banks also benefit from self-service technologies as they can cut costs incurred by the traditional branch network (Forrester Research 2007; Forrester Research 2009; Frost and Sullivan 2011). For instance, E*TRADE's implemented a newly designed telephone banking service in 2009. As a result the company saved approximately $\$ 30$ million per year because it successfully moved clients to this electronically mediated channel (Frost and Sullivan 2011).

However, usage rates suggest that banks are missing out on the opportunity to move even more customers to electronic banking channels. For example, each month $73 \%$ of all European banking customers use ATM machines, although only 24\% use Internet banking services (DB Research 2006). Similarly, although most North American and Australasian retail banks offer phone banking and mobile banking services, only 5-10\% of all consumers have used them (Forrester Research 2007).

Moreover, consumers favor specific electronic banking channels for specific product categories. For instance, Internet banking applications are used for simple product categories (e.g. domestic transactions) as well as more complicated products categories such as 
international payments, credit card applications and financial loans (DB Research 2006; Forrester Research 2007). In contrast, complex financial transactions are seen to be difficult to perform on mobile phones due to their hardware limitations such as small screens and clumsy input mechanisms (Barnes 2003; Mallat, Rossi et al. 2004; Scornavacca, Barnes et al. 2006). In consequence, consumers tend to use mobile devices for simple banking transactions in situations where they need instant access to their accounts and other banking channels are not in reach (e.g. checking their account balance before purchasing goods at a point of sale) (Forrester Research 2007; Forrester Research 2009). These varying usage patterns suggest that each electronic banking channel has inherent capabilities that align with certain types of banking activities - and clash with others.

This suggests the notion of a 'fit' between a given electronic banking channel and specific banking tasks. Consistently with previous studies where some type of 'fit' has been found to exert a positive influence on intentions and/or utilization (Goodhue and Thompson 1995; Staples and Seddon 2004), it is anticipated that perceived fit between electronic banking channels and banking tasks will positively influence individuals' use behavior.

Despite a substantial body of knowledge on electronic banking services, to date there have been no rigorous studies investigating the fit between electronic banking channels and banking tasks. Nor has there been sufficient research into how the task-channel fit (TCF) (perhaps in combination with other factors) influences consumers' intention to use electronic banking channels. This research aims to address this gap.

\subsection{Research questions and research objectives}

Electronic banking channels have been deployed by banks for more than three decades. Still, research on information systems as well as marketing has not developed a theory assessing the factors influencing consumers' intentions to use electronic banking channel. Further, little is known how the perceived task-channel fit of electronic banking channels influences consumers' intentions to use electronic banking channels.

Given this gap, the overarching research question guiding this study is:

- What factors influence consumers' intentions to use electronic banking channels?

and the two subsidiary questions:

- What influence does the task-channel fit of electronic banking channels have on consumers' intentions to use them? 
- What effect have perceived usefulness, ease of use, attitude towards use, subjective norms, security, and associated costs on consumers' intentions to use electronic banking channels?

To address these research questions, a research model was developed and empirically tested to assess the factors impacting on consumer intentions to use electronic banking channels. Central to this model was the perceived task-channel fit construct.

\subsection{Research Design}

The research design of this study comprised three major phases. Figure 1 visualizes the research design before it is outlined in more detail below.

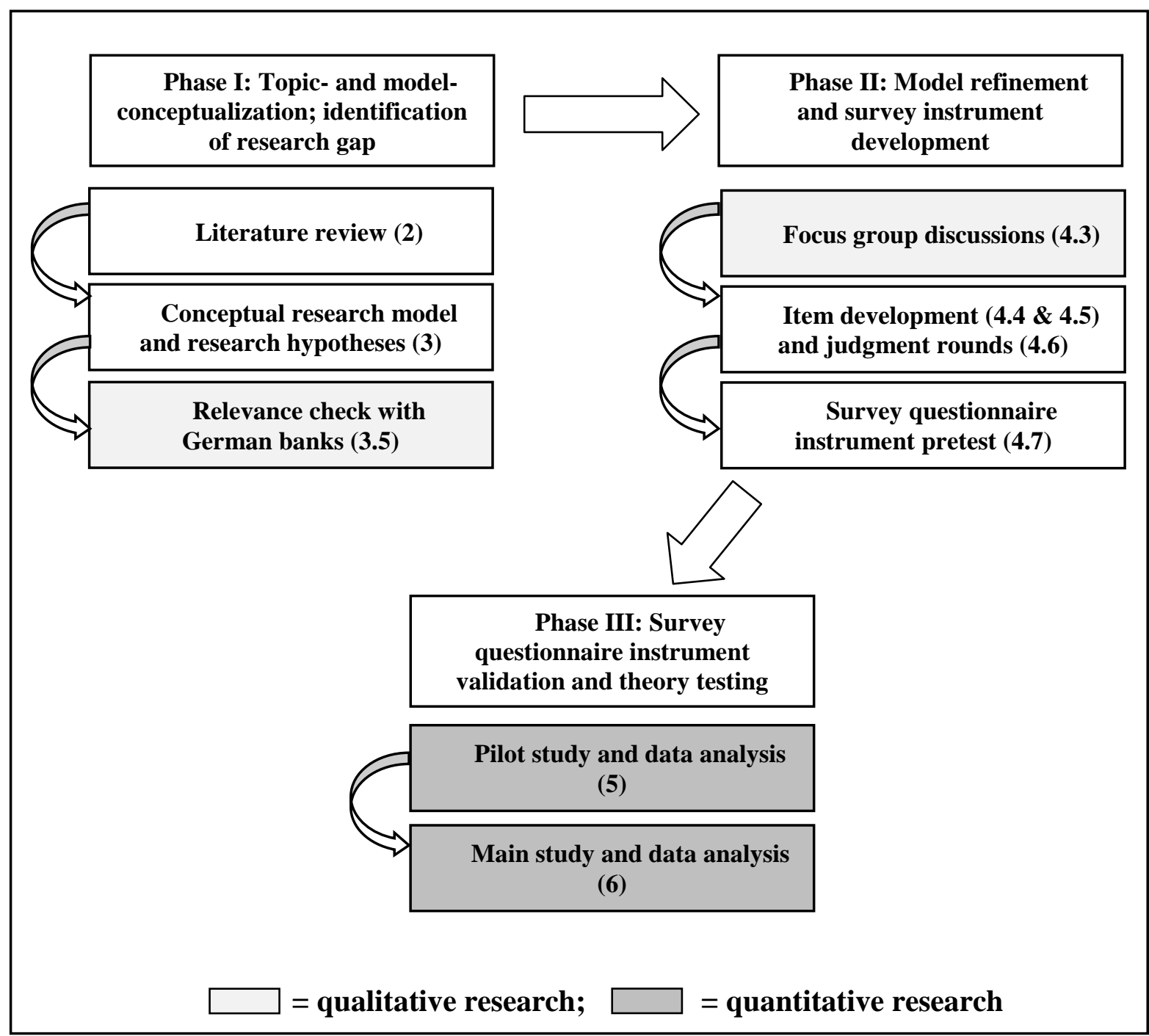

Figure 1: Research design outline overview

During the first phase, a comprehensive literature review was conducted to inform the conceptualization of the research model. The literature review focused on the body of knowledge around the adoption and acceptance research models, task-technology fit and 
related studies, as well as e-banking literature (chapter 2). Based on this, the conceptual research model was developed (chapter 3) with focus on the newly conceptualized taskchannel fit construct.

The task-channel fit concept was subsequently discussed with nine managers working for three German banks (chapter 3.5). These discussions aimed to check the relevance of this research for practitioners. The TCF concept was perceived as a valuable concept for banks and the managers confirmed that banks lack of well established instruments to judge which products fit each banking channel best.

The primary goal of the second phase was to refine the initial conceptualization of the research model and to thoroughly develop a survey questionnaire instrument. Using a convenience sampling strategy (Hufnagel and Conca 2001), five focus groups were organized consisting of consumers using electronic banking channels in New Zealand (4-6 participants per panel). The focus group sessions were recorded, transcribed and analyzed using coding procedures as outlined in chapter 4.3. The analysis of the qualitative data confirmed the initial conceptualization of the research model and four major TCF dimensions were identified: 1 . Task-complexity, 2. Task-frequency, 3. Task-importance, and 4. Task-time criticality.

Based on the outcome of these discussions and literature from research disciplines such as information systems, management, electronic commerce and psychology, items were developed to measure each TCF dimension (section 4.4). While these items were newly created, existing scales were adapted from the extant literature to measure the remaining constructs of the research model (perceived usefulness, ease of use, attitude towards channel use, subjective norms, channel security, costs associated with channel use, and intentions to use electronic banking channels).

The pool of items was reduced in consultation with supervising staff (section 4.5) before two judgment rounds were used to assess the content validity of the newly developed items as well as to purify the wording of them (Moore and Benbasat 1991). The judgment rounds involved two discussion rounds consisting of several academics and practitioners working for banks (see section 4.6 for more detailed information). Next, the usability of the survey questionnaire was evaluated through two pretested rounds consisting of electronic banking users in New Zealand (as reported in section 4.7).

The third phase of this study aimed to quantitatively test the survey questionnaire instrument and evaluate the research hypotheses (chapter 5). Initially, a large-scale pilot-test 
was conducted to evaluate the conceptual research model and the psychometric properties of the scales. Thus, 280 responses were collected from consumers using Internet banking services for two different banking tasks. A major goal of this research was to develop an instrument for measuring the perceived fit between banking tasks and electronic banking channels (a more detailed discussion on formative constructs is provided in section 5.4.1.). Two sets of TCF measures were created, one formative (in combination with a parallel instrument) and one reflective (direct measurement). The formative items intended to capture different aspects of TCF and should individually represent a finer level of measurement granularity compared to the reflective items.

The formative TCF measures intended to specify why consumers perceive a fit between a given banking task and an electronic banking channel. This approach provides a more detailed, robust and rich picture of the TCF construct. In contrast, the set of reflective items provides a higher-level overview of perceived TCF (as explained in 5). PLS was used to assess the data obtained during the pilot study and the analyses demonstrated that the scales were highly reliable and confirmed construct validity.

The scales were then refined in light of the pilot-study (section.6.2) using feedback from several senior IS researchers. For the main study, 340 responses were collected from consumers using Internet banking and two different banking tasks (account inquiries and financial loan applications). The data collection was operationalized through a consumer panel in New Zealand.

The findings suggested that the identified task-channel fit dimensions contributed substantially to the corresponding TCF construct. What is more, the data analyses confirmed that the task-channel fit construct and other variables explained at least $63 \%$ of variance in consumers intentions to use Internet banking for each banking task.

\subsection{Thesis Outline}

In addition to this chapter, the dissertation is presented in the following eight chapters. A brief indication of the contents of each chapter is provided.

Chapter 2 presents the relevant literature with the purpose of establishing the theoretical foundations of this research. The theoretical foundation will include theory on:

- user adoption and acceptance research;

- $\quad$ task-fit studies;

- the original task-technology fit theory (and related research); 
- $\quad$ electronic banking services and electronic banking tasks;

- $\quad$ Research on channel usage.

Chapter 3 covers the development of the conceptual model which is based on the literature review. Consideration is given to the task-channel fit construct as well as other important variables influencing consumers' intention to use electronic banking channels. Next, an exploratory investigation was conducted to discover practitioners' perceptions towards the proposed task-channel fit concept and the research in general. Finally the model and the research hypotheses are presented.

Chapter 4 briefly outlines the theoretical perspective of this research before describing the research method used during the qualitative phase of this study. Next, five focus group discussions were conducted to confirm the initial conceptualization of the research model. The findings of the focus groups discussions are discussed in here. This is followed by the instrument development including the scales for the TCF dimension and the precursors of utilization. Lastly, two judgment rounds were conducted to assess the content validity of the scales and two pretests are reported which were carried out prior to the pilot study.

Chapter 5 initially discusses fit theory and reflects on seven approaches to measure fit between two or more variables. Next, it is outlined how data was collected for the pilot study before the data is analyzed. Initially the parallel instrument is explained before it is outlined how task-channel fit was computed for the pilot study. Next, the measurement model is assessed using confirmatory factor analysis. Subsequently, the structural aspects of the research model are investigated using PLS.

Chapter 6 reports the main study of the quantitative phase of this research. Initially, it is reported how the scales were refined in light of the pilot study. Next, the scales were pretested in order to check their face-validity and the functionality of the online survey questionnaire application. Afterwards, the data collection of the main phase is described before the measurement and structural model is assessed. Lastly, a group-comparison between the account inquiries and financial loans datasets was conducted to examine structural invariance in the research model.

Chapter 7 discusses the findings of the research. Particularly, the findings are discussed in relation to:

- Implications for IS utilization research

- Implications for task-technology fit theory 
- Implications for practitioners

Finally, the conclusion (chapter 8) provides an indication of what the research has achieved in terms of answering the research questions. Limitations of the research are noted and future research directions are outlined. 


\section{Literature Review}

\subsection{Chapter Outline}

This chapter reviews and discusses the literature relevant to this study. In order to develop a firm understanding of the accumulated literature in this field, several research streams have been considered for this review.

- User adoption and acceptance research

- Task-Fit research

- Task-Technology Fit Theory (TTF)

- TTF related research

- Research on electronic banking

- Research on electronic banking tasks

- Research on channel usage

\subsection{User adoption - and acceptance research}

Much of the literature in this research area investigated user attitudes and beliefs to predict user adoption and user acceptance of specific information systems and technologies (Robey 1979; Cheney, Mann et al. 1986; Swanson 1987; Davis 1989; Davis, Bagozzi et al. 1989; Thompson, Higgins et al. 1991). Four seminal contributions are reviewed in here: the diffusion of innovations, theory of reasoned action, the technology acceptance model as well as the unified theory of acceptance and use of technology.

\subsubsection{Diffusion of Innovations Theory (DOI)}

Having its origins in sociology, the Diffusion of Innovations (DOI) theory has been used since the 1960s to explore a variety of innovations, ranging from agricultural tools to organizational innovation (Rogers 1995). DOI theory stated that innovations would be communicated through various channels over time and within a particular social system (Rogers 1995). Since consumers would possess different degrees of willingness to adopt innovations, Rogers (1995) segregated consumers into five categories of individual innovativeness starting from early to late adopters: innovators, early adopters, early majority, late majority and laggards).

Additionally, Rogers (1995) identified five factors determining the rate of adoption of innovations: relative advantage, compatibility, trialability, observability, and complexity. While the first four factors would generally positively correlated with rate of adoption, complexity would commonly negatively affect the diffusion rate (Rogers 1995). 
Diffusion rates could, however, be impacted by other phenomena. For instance, changes in habits and individual needs could change the individual's attitude towards an innovation over time. Similarly, a new innovation could affect the adoption rate of an existing innovation (Rogers 1995).

Moore and Benbasat (1991) drew upon DOI theory to develop an instrument to measure the adoption of information technology. Support was found for the following factors impacting on the adoption of IT: relative advantage, ease of use, image, visibility, compatibility, results demonstrability and voluntariness of use (Moore and Benbasat 1991).

Since Moore and Benbasat's (1991) study, these constructs have been used by several researchers testing the adoption of information systems in various contexts including electronic banking applications (Liao, Shao et al. 1999; Brown, Cajee et al. 2003; Mattila 2003; Mattila, Karjaluoto et al. 2003; Borreguero and Peláez 2005; Curran and Meuter 2005; Jaruwachirathanakul and Fink 2005; Wan, Luk et al. 2005; Cheng, Lam et al. 2006; Amin 2007; Bhatti 2007; Lee, Lee et al. 2007; Malhotra and Singh 2007; Yiu, Grant et al. 2007; Durkin, Jennings et al. 2008). This illustrates the relevance of Roger's DOI (and Moore and Benbasat's (1991) modification) to this research.

\subsubsection{Theory of Reasoned Action (TRA)}

Although not focusing on Information Systems specifically, the theory of reasoned action has been frequently used to explain the user intentions for deploying information systems (Sheppard, Hartwick et al. 1988; Davis, Bagozzi et al. 1989; Ajzen 1991; Venkatesh, Morris et al. 2003). The original theory was developed by Fishbein and Ajzen (1975) and is shown in Figure 2.

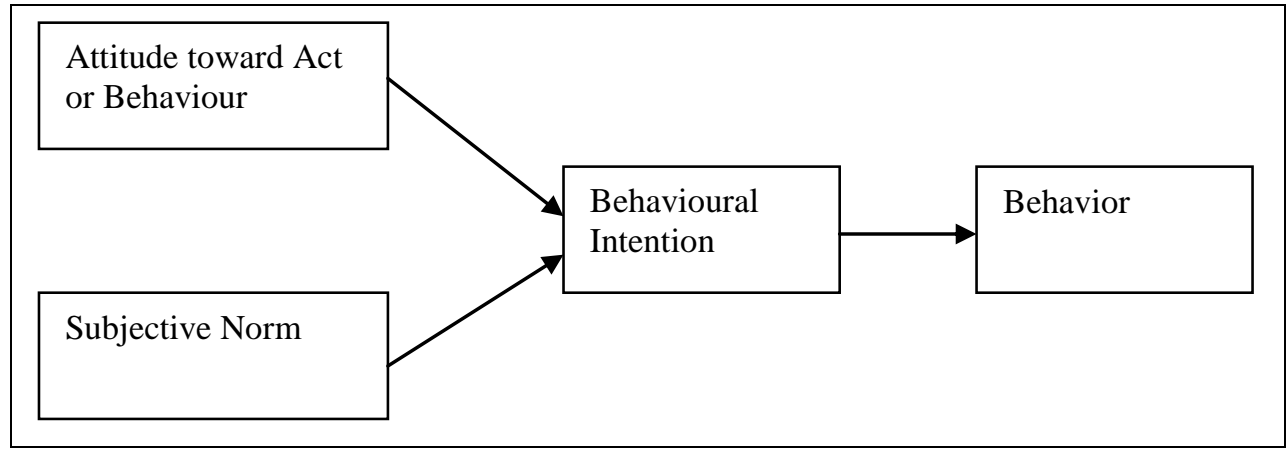

Figure 2: Theory of Reasoned Action (TRA) (Fishbein and Ajzen 1975)

TRA argued that individual behavior would be driven by behavioral intentions (Fishbein and Ajzen 1975). Fishbein and Ajzen (1975) defined attitude towards behavior "as the individual's feelings about performing a behavior". On the other hand, subjective norm was 
explained as "an individual's perception of whether the behavior should be performed". This would be driven by the motivation that an individual has to comply with opinions from people who are important to the individual (Fishbein and Ajzen 1975).

Behavioral intentions were assumed to indicate how hard people would be willing to try, of how much of an effort they would be planning to exert, in order to perform the behavior. As a general rule, the stronger the intention to engage in a behavior, the more likely should be its performance (Sheppard, Hartwick et al. 1988).

Subsequent to the original TRA theory, Ajzen (1991) extended the TRA theory establishing theory of planned behavior (TPB). TPB added a perceived behavioral control construct to the TRA. Ajzen (1991) argued that behavioral intention can find expression in behavior only if the behavior in question is under volitional control, (e.g. if the person can decide at will to perform or not perform the behavior). In many instances behavior would be influenced by non-motivational factors such as availability of resources (Ajzen 1991).

\subsubsection{Technology Acceptance Model (TAM)}

One of the most significant adaptations of Ajzen and Fishbein's (TRA) (1975) is the technology of acceptance model originally developed by Davis and Bagozzi (1989).

This theory aimed to predict how users accept and use a technology. The model suggested that when users are presented with a specific technology, a number of factors influence their decision to use it (Davis, Bagozzi et al. 1989).

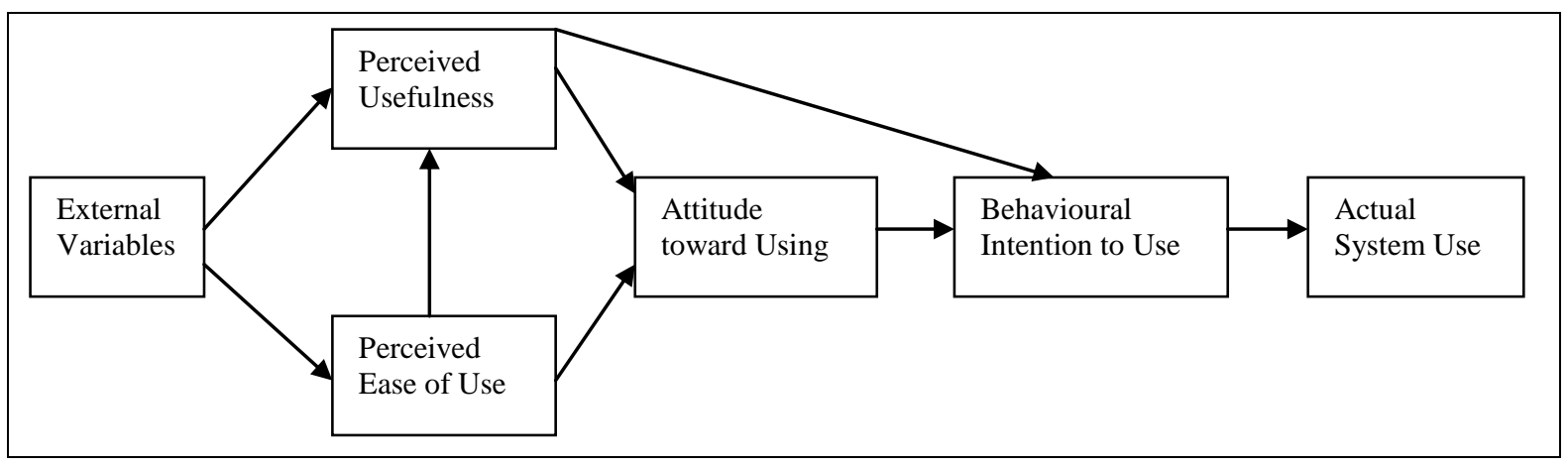

Figure 3: Technology Acceptance Model (TAM) (Davis, Bagozzi et al. 1989)

As shown above, TAM argued that perceived usefulness and perceived ease of use are of primary relevance for computer acceptance behaviors. Perceived usefulness was defined as "the degree to which a person believes that using a particular system would enhance his or her job performance" (Davis, Bagozzi et al. 1989). Perceived ease of use (EOU) referred to "the degree to which a person believes that using a particular system would be free from 
effort" (Davis, Bagozzi et al. 1989). Both, perceived usefulness and perceived ease of use would determine an individual's intention to use a system. Perceived usefulness was also seen as being directly impacted by perceived ease of use (Davis, Bagozzi et al. 1989).

TRA and TAM, assumed that when someone forms an intention to act, that they will be free to act without limitation. However, in reality constraints such as limited ability, time, environmental or organizational limits, and unconscious habits will restrict individuals to act as they wish to (Goodhue and Thompson 1995; Benbasat and Barki 2007).

The Technology Acceptance Model (TAM) is often referred to as one of the most influential and most often used theories in information systems (Venkatesh, Morris et al. 2003; Benbasat and Barki 2007).

TAM2 extended the original TAM theory and was developed by Venkatesh and Davis (2000). This model conceptualized several antecedent variables predicting the perceived usefulness construct. TAM2 predicted that subjective norms, image, job relevance, output quality, and result demonstrability precede perceived usefulness of Information Systems (Venkatesh and Davis 2000). Figure 4 visualizes TAM2.

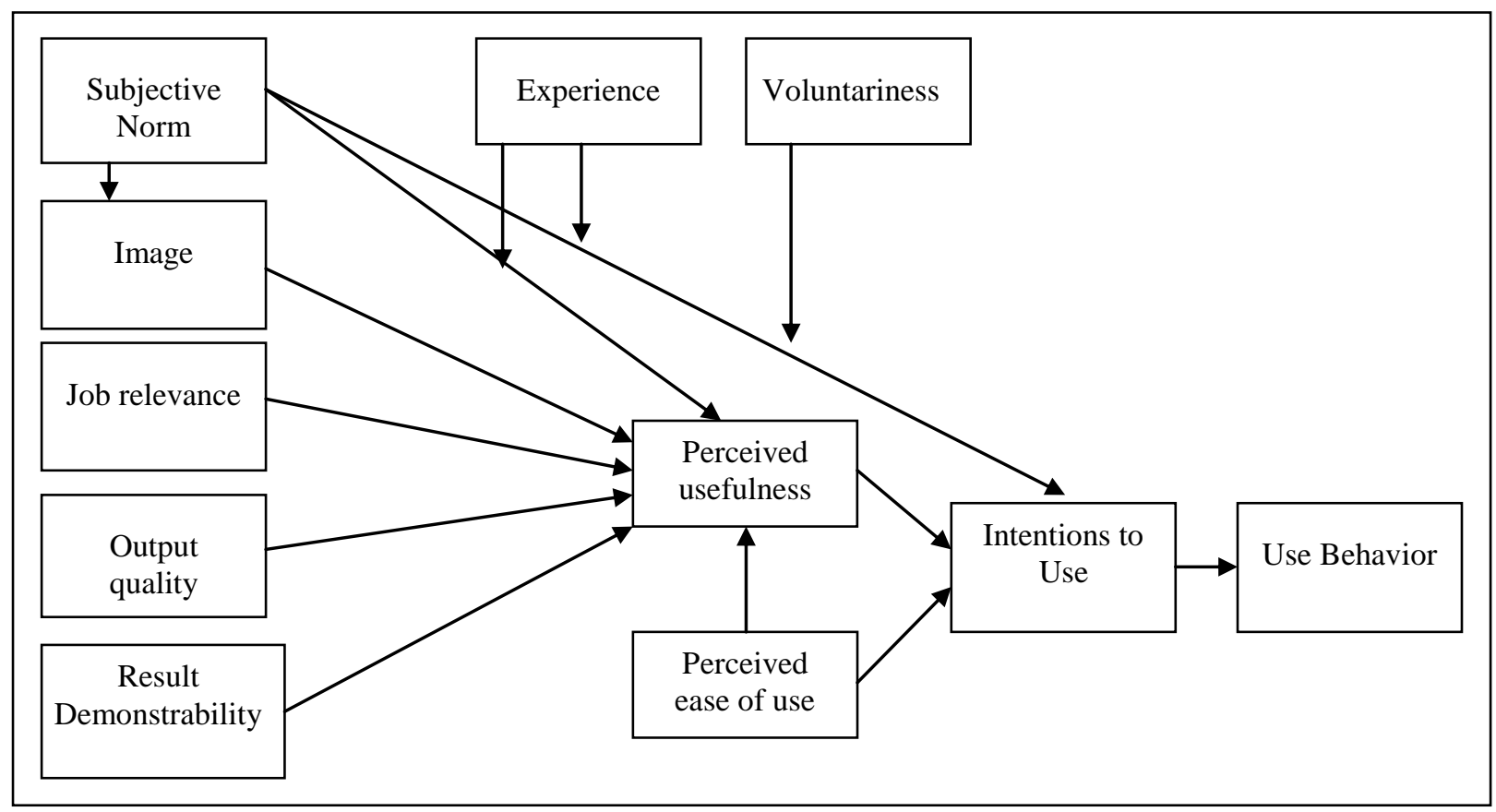

Figure 4: TAM 2 - Extension of the Technology Acceptance Model (Venkatesh and Davis, 2000)

Venkatesh and Davis (2000) tested TAM2 using longitudinal data collected in the context of four different IS systems in voluntary and mandatory use settings. The model was 
supported for all four organizations accounting for more than $40 \%$ of the variance in the utilization construct.

\subsubsection{Unified Theory of Acceptance and Use of Technology (UTAUT)}

The Unified Theory of Acceptance and Use of Technology (UTAUT) was developed through a consolidation of eight models that earlier research had employed to explain IS usage behavior. To develop the theory, Venkatesh et al. (2003) firstly reviewed user acceptance literature. This review included the previously discussed theories DOI, TRA, and TAM/TAM2 as well as the motivational model, theory of planned behavior (TPB), a combined theory of planned behavior/technology acceptance model (C-TAM-TPB), model of PC utilization (MPCU), and social cognitive theory (SCT).

This analysis illustrated that seven constructs appeared to be significant direct determinants of intention or usage (performance expectancy, effort expectancy, social influence, and facilitating conditions, attitude toward using technology, self-efficacy, and anxiety). Of these, Venkatesh et al. (2003) found that the first four constructs played a significant role as direct determinants of user acceptance and usage behavior.

Afterwards, a unified model (Unified Theory of Acceptance and Use of Technology UTAUT) was formulated integrating elements across the eight models. Using the original data from the aforementioned theories, the UTAUT model outperformed the eight individual models. A subsequent empirical validation using data gathered from two additional organizations confirmed the theory (Venkatesh, Morris et al. 2003).

The UTAUT model is illustrated below in Figure 5: 


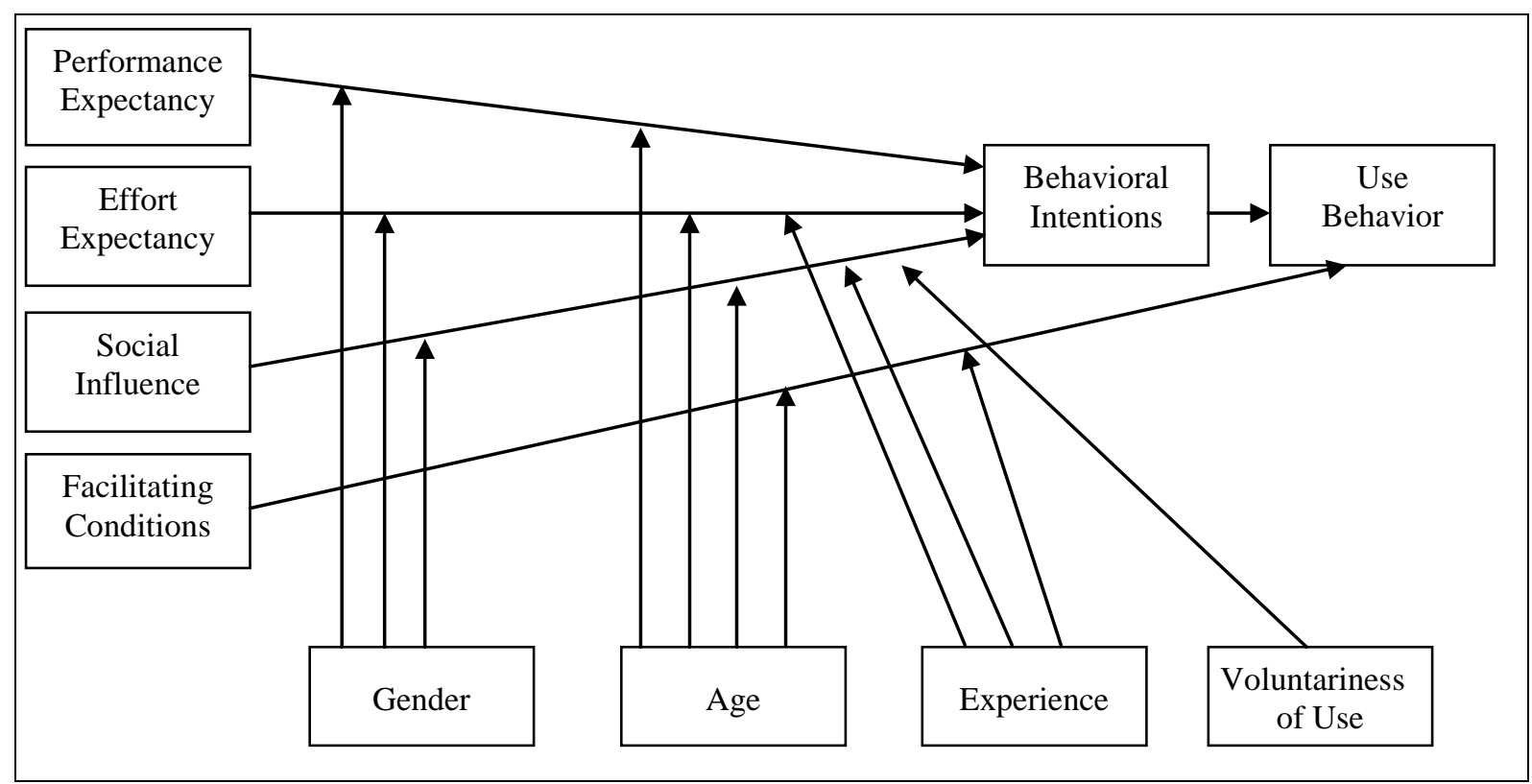

Figure 5: Unified Theory of Acceptance and Use of Technology (Venkatesh, Morris et al. 2003)

As shown above, the theory argued that four key constructs (performance expectancy, effort expectancy, social influence, and facilitating conditions) would be direct determinants of usage intention and behavior (Venkatesh, Morris et al. 2003). Gender, age, experience, and voluntariness of use were posited to mediate the impact of the four key constructs on usage intention and behavior (Venkatesh, Morris et al. 2003).

\section{Implications for this study}

Since this study proposes a task-channel fit theory, the above mentioned theories form the theoretical foundation of this research. Together with the theories discussed in the forthcoming section, the aforementioned theories affect the model suggested by this research (Figure 29). Particularly, the precursors of channel utilization outlined in sections 3.3.2.3.3.8. are influenced by the above mentioned theories. For instance, perceived usefulness and perceived ease of use have their roots in the TAM theory. Both constructs have consistently been demonstrated to have a positive influence on intentions to use information systems. Likewise, various studies have found positive correlations between subjective norms and intentions to use constructs across a variety of research settings. Thus, these constructs were included within the research model ${ }^{1}$.

Having discussed acceptance and adoption theories, the following section will review the literature on task-fit related to specific technologies.

\footnotetext{
${ }^{1}$ As a result of the widespread application of the above mentioned theories, concerns have been raised regarding the
} 


\subsection{Task-fit research}

In comparison to the adoption and acceptance research streams, the task-technology fit focus has attracted fewer researchers (Tornatzky and Klein 1982; Benbasat, Dexter et al. 1986; Dickson, DeSanctis et al. 1986; Jarvenpaa 1989; Cooper and Zmud 1990; Vessey 1991). The majority of research in this field has investigated the 'fit' relationship between tasks and technologies by researching how data representation would influence decision making.

\subsubsection{Data representation related studies}

Benbasat et al. (1986) conducted a series of three laboratory experiments investigating the influence of graphical and color-enhanced information presentation styles on decision quality, decision making time, use of information, and user perceptions. By using a variety of information presentation designs for the same decision making tasks, this research suggested that data representation would impact on user performance (Benbasat, Dexter et al. 1986).

The authors argued that meaningful graphical representation of data would facilitate the decision making process if graphical reports were designed to directly assist in solving tasks. Moreover, if information were represented in colorful graphical reports, the time to make decisions would be reduced (Benbasat, Dexter et al. 1986). This illustrated how data representation styles correlated with the tasks to be performed in the experiment (Benbasat, Dexter et al. 1986).

Dickson et al. (1986) conducted three experiments comparing computer-generated graphics to traditional tabular reports (Dickson, DeSanctis et al. 1986). The first experiment in their research compared tables and bar charts for their effects on readability, interpretation accuracy, and decision making (Dickson, DeSanctis et al. 1986). Surprisingly, the research participants observed both data representation methods equally effective and no differences were identified for interpretation accuracy or decision quality. However, the research participants rated tabular reports as easier to read and understand than graphical reports (Dickson, DeSanctis et al. 1986). The second experiment compared line plots to tables for their effects on interpretation accuracy and decision quality. The decisions made by the research participants illustrated that graphical reports outperformed those with tables (Dickson, DeSanctis et al. 1986). The third experiment compared graphical and tabular reports for their ability to convey a message to the reader. Only in situations in which much information was presented to the research particpants, graphs outperformed tables (Dickson, DeSanctis et al. 1986). 
Jarvenpaa (1989) examined the effects of graphical formats and tasks demands upon decision processes and decision outcomes. Therefore, an experiment was conducted in which research participants made choices under differing task and graphical format conditions. The results of this study suggested that information presentation would influence the decision making time as well as how spectators evaluated the presented information (Jarvenpaa 1989). Furthermore, the task characteristics and the interactions between the presentation format significantly influenced the decision making process (Jarvenpaa 1989).

\subsubsection{Cognitive Fit Theory}

Synthesizing prior research on information representation and tasks, Vessey (1991) developed the cognitive fit theory. The underlying assumption for the theory was that although graphical and tabular representations contain identical information, the presentation of the information would be fundamentally different. Graphical representations such as graphs emphasize spatial information which "facilitate viewing the information contained therein at a glance without addressing the elements separately or analytically" (Vessey 1991). On the other hand, tables emphasize symbolic information which would support extracting specific data values (Vessey 1991). Similarly, based on the on the type of information, tasks could be divided into spatial and symbolic tasks.

Spatial tasks would assess the problem area as a whole rather than as specific data values (those often said to be facilitated by graphs) (Vessey 1991). Symbolic tasks would involve extracting specific data values (those said to be facilitated by tables) (Vessey 1991).

Thus, the cognitive fit theory argued that performance on a task will be facilitated when there is a match/fit between the information emphasized in the representation type and that required by the task type. As a result of a high correspondence/fit between task and information presentation format, individual users perform tasks more effectively (Vessey 1991). Figure 6 illustrates the proposed problem solving model developed by Vessey (1991).

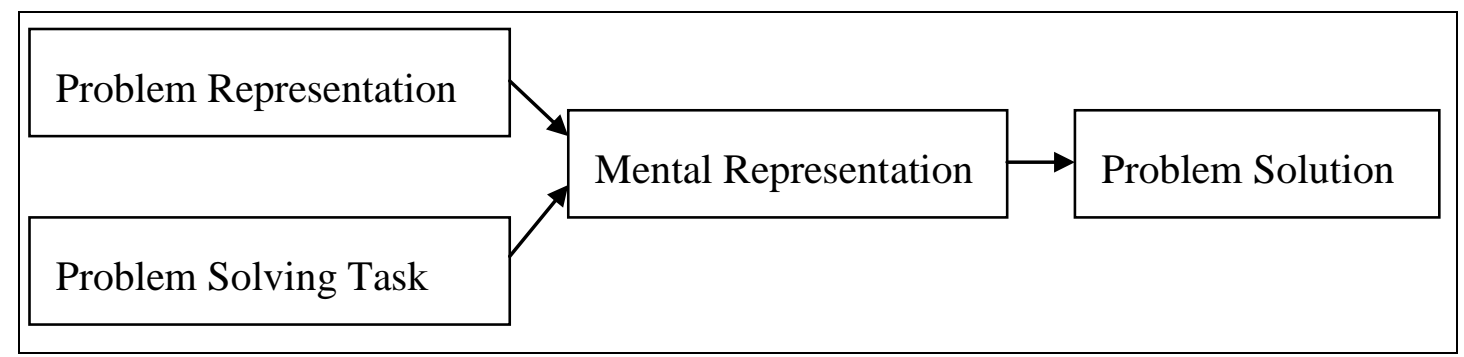

Figure 6: Cognitive fit theory: the general problem solving model (Vessey 1991) 
Since its creation, the cognitive fit theory has been used by various researchers in the IS related literature (Dennis and Carte 1998; De, Sinha et al. 2001; Shaft and Vessey 2006). It is interesting to note that Huber (1983) already questioned research on the user's cognitive style and the design of management information systems and decision support systems. His examination of the literature led to the conclusions that: "(a) the currently available literature on cognitive style is an unsatisfactory basis for deriving operational design guidelines, and (b) further cognitive style research is unlikely to provide a satisfactory body of knowledge from which to derive such guidelines" (Huber 1983).

Especially the arguments for Huber's (1983) second assumption challenged the justification for further research on cognitive style. Cognitive style could be described as the way individuals think, perceive and remember information, or their preferred approach to using such information to solve problems (Huber 1983). His arguments were associated with the fact that cognitive style would be only one of many individual differences that may be relevant to designing information systems (Huber 1983). For example, response to uncertainty, academic background, intelligence, previous training and a number of other individual differences would be similarly related to human information processing and decision-making behavior (Huber 1983).

\section{Implications for this study}

This section reviewed task-fit research and cognitive fit theory. While this literature stream has little implications for the current study, it was assumed that the discussion would inform the following section on task-technology fit theory.

\subsection{Task Technology Fit Theory (TTF)}

Drawing from the above mentioned research streams, Goodhue and Thompson (1995) developed the Task-Technology-Fit theory. The primary goal of this theory was to investigate how technologies support individuals in performing their tasks. The underlying concept of the TTF theory is particularly important for this study since the task-channel fit concept applies the original TTF concept to electronic banking and questions how electronic banking channels match banking tasks. Therefore, the TTF theory is discussed in depth in here.

In order to investigate the linkage between information technology and user performance, Goodhue and Thompson (1995) based their TTF theory on research from two separate streams: a) the user adoption and acceptance research (discussed in section 2.2.) investigating the user beliefs and attitudes to predict the utilization of information systems (Fishbein and 
Ajzen 1975; Robey 1979; Bagozzi 1982; Baroudi, Olson et al. 1986; Swanson 1987; Davis, Bagozzi et al. 1989), and b) the fit focus (discussed in section 2.3.) evident in research investigating the impact of data representation on peoples performance (Tornatzky and Klein 1982; Benbasat, Dexter et al. 1986; Dickson, DeSanctis et al. 1986; Jarvenpaa 1989; Cooper and Zmud 1990; Vessey 1991).

Goodhue and Thompson (1995) argued that the adoption and acceptance focus omitted that more utilization of a poorly designed system would not necessarily lead to higher performance. On the other hand, fit focus research alone would often miss out that systems must be utilized before they can impact on performance. In order to combine utilization and task-fit theories, Goodhue and Thompson (1995) suggested the Technology-to-Performance Chain (TPC) Model (displayed in Figure 7).

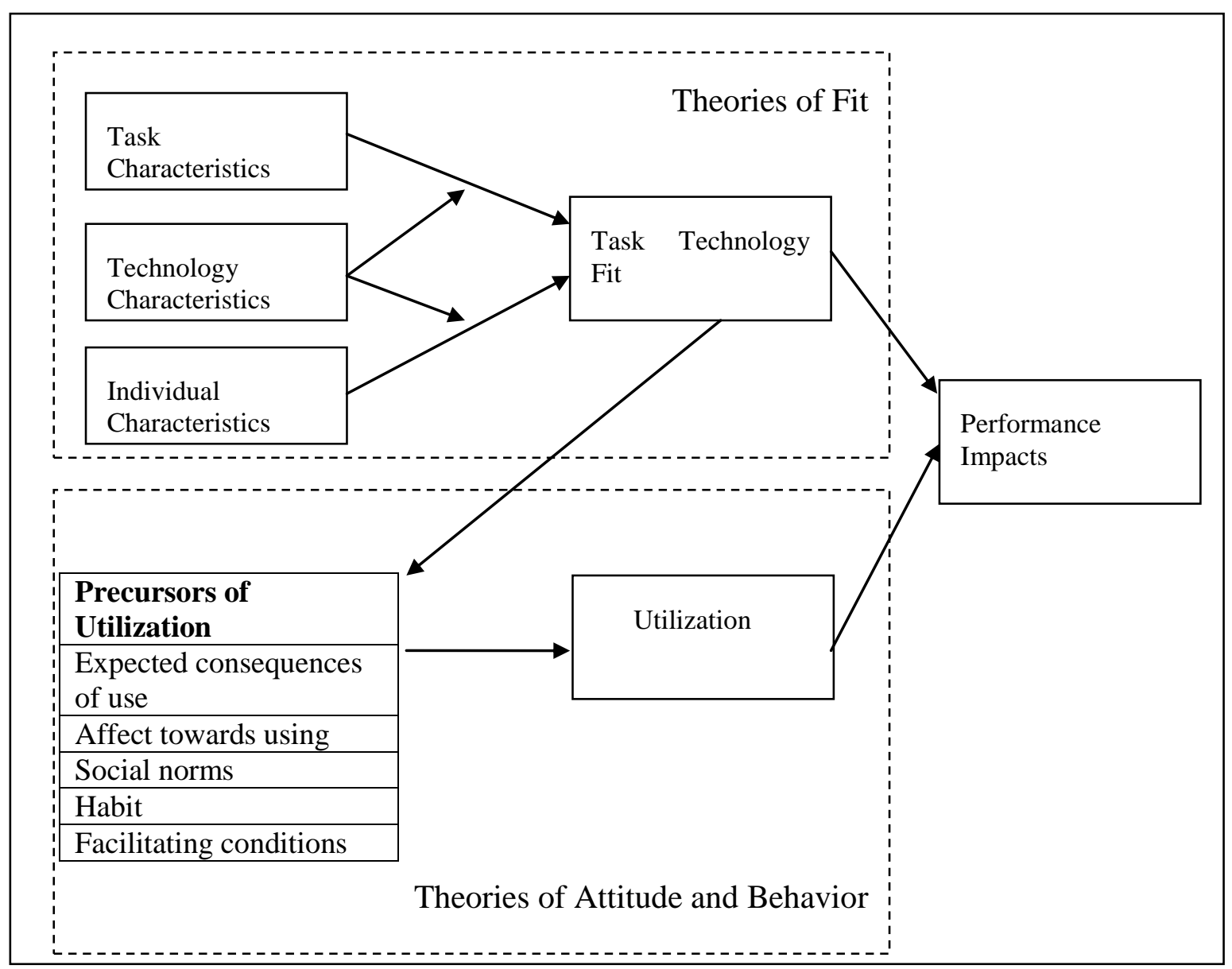

Figure 7: Technology-to-performance Chain Model (Goodhue and Thompson 1995)

Starting from the left hand side, the model theorizes how technologies lead to performance impacts at the individual level. By capturing both research streams, the model recognized that technologies must be utilized and fit the task they support to have a performance impact. 
Hence this model would provide a more accurate picture of the way in which technologies, user tasks, and utilization relate to changes in performance (Goodhue and Thompson 1995).

The major features of the TCP were described by Goodhue and Thompson (1995) as follows:

Table 1: Major features of the Technology-to-performance Chain model (Goodhue and Thompson 1995)

\begin{tabular}{|c|c|}
\hline Major features & Detailed explanations \\
\hline Techno & $\begin{array}{l}\text { "Technologies are viewed as tools used by individuals in carrying out their } \\
\text { tasks. In the context of information systems research, technology refers to } \\
\text { computer systems (hardware, software, and data) and user support services } \\
\text { (training, help lines, etc.) provided to assist users in their tasks." }\end{array}$ \\
\hline Tasks & $\begin{array}{l}\text { "Tasks are broadly defined as the actions carried out by individuals in turning } \\
\text { inputs into outputs. Task characteristics of interest include those that might } \\
\text { move a user to rely more heavily on certain aspects of the information } \\
\text { technology." }\end{array}$ \\
\hline Indiv & $\begin{array}{l}\text { "Individuals may use technologies to assist them in the performance of their } \\
\text { tasks. Characteristics of the individual (training, computer experience, } \\
\text { motivation) could affect how easily and well he or she will utilize the } \\
\text { technology." }\end{array}$ \\
\hline $\begin{array}{c}\text { Task-Technology } \\
\text { fit }\end{array}$ & $\begin{array}{l}\text { "Task-technology fit }(T T F) \text { is the degree which a technology assists an } \\
\text { individual in performing his or her portfolio of tasks. More specifically, TTF is } \\
\text { the correspondence between task requirements, individual abilities, and the } \\
\text { functionality of the technology." }\end{array}$ \\
\hline Utiliz & "Utilization is the behavior of employing the technology in completing tasks." \\
\hline $\begin{array}{r}\text { The ante } \\
\text { utiliz }\end{array}$ & $\begin{array}{l}\text { "The antecedents of utilization can be suggested by theories about attitudes } \\
\text { and behavior. Both voluntary and mandatory utilization are reflected in TTF - } \\
\text { Mandatory use can be thought of as a situation where social norms to use a } \\
\text { system are very strong and overpower other considerations such as beliefs } \\
\text { about expected consequences and affect." }\end{array}$ \\
\hline $\begin{array}{l}\text { The imp } \\
\text { on ut }\end{array}$ & $\begin{array}{l}\text { "The impact of TTF on utilization is shown via a link between task-technology } \\
\text { fit and beliefs about the consequences of using a system. This is because TTF } \\
\text { should be one important determinant of whether systems are believed to be } \\
\text { more useful, more important, or give more relative advantage." }\end{array}$ \\
\hline $\begin{array}{l}\text { Performance } \\
\text { impact }\end{array}$ & $\begin{array}{l}\text { "Performance impact in this context relates to the accomplishment of a } \\
\text { portfolio of tasks by an individual. Higher performance implies some mix of } \\
\text { improved efficiency, improved effectiveness, and/or higher quality. High TTF } \\
\text { increases the likelihood of utilization, but it also increases the performance } \\
\text { impact of the system regardless of why it is utilized. At any given level of } \\
\text { utilization, a system with higher TTF will lead to better performance since it } \\
\text { more closely meets the task needs of the individual." }\end{array}$ \\
\hline
\end{tabular}

The authors tested a reduced model consisting of the major core components of the TPC (as illustrated in Figure 8). 


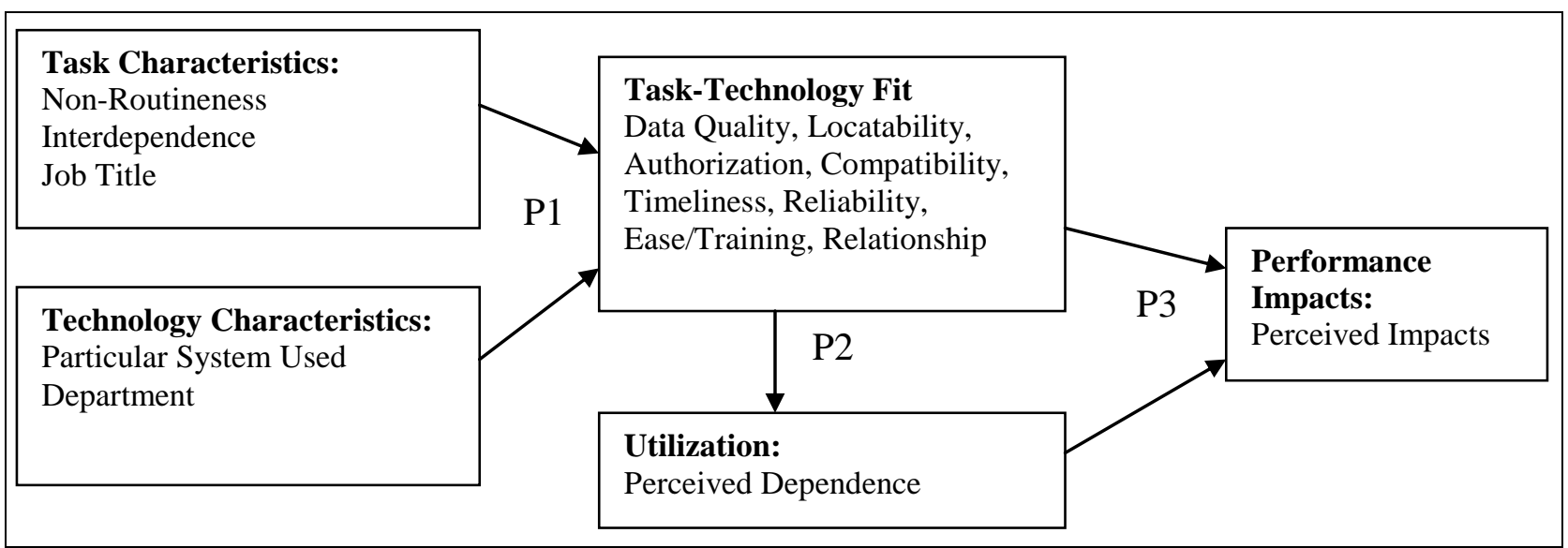

Figure 8: Measurements and analyses conducted by Goodhue and Thompson (Goodhue and Thompson 1995)

As illustrated above, the authors hypothesized that TTF would be affected by both task characteristics and characteristics of the technology (as indicated above - P1) (Goodhue and Thompson 1995). Furthermore, TTF would influence the utilization of information systems by individuals (as indicated above - P2). Lastly, TTF would have additional explanatory power in predicting perceived performance impacts beyond that from utilization alone (as indicated above - P3) (Goodhue and Thompson 1995).

These hypotheses were tested utilizing user evaluations of over 600 users, employing 25 technologies, working in non-IS departments in two separate organizations (Goodhue and Thompson 1995). To develop the survey, modified measures from previous research were adapted where possible. Moreover, new scales were developed for measuring the TTF dimensions (Goodhue and Thompson 1995). The following scales were used to evaluate the TTF construct.

\subsubsection{TTF scales}

To test the TTF, altogether 48 questions were assembled to measure 21 dimensions of TTF (Goodhue and Thompson 1995). Using factor analysis, the authors dropped 14 questions (and 5 dimensions) (Goodhue and Thompson 1995). The remaining 34 questions (including 16 of the original 21 original dimensions) were collapsed into eight distinct factors of TTF (as illustrated in below mentioned Table 2 (Goodhue and Thompson 1995). 
Table 2: Original TTF dimensions and final TTF factors (Goodhue and Thompson 1995)

\begin{tabular}{|l|l|c|}
\hline 8 Final TTF factors & 16 Original TTF Dimensions & $\begin{array}{l}\text { Cronbach's } \\
\text { Alpha }\end{array}$ \\
\hline Quality & $\begin{array}{l}\text { Currency of the data } \\
\text { Right data is maintained } \\
\text { Right level of detail }\end{array}$ & .84 \\
\hline Locatability & $\begin{array}{l}\text { Locatability } \\
\text { Meaning of data is easy to find out }\end{array}$ & .75 \\
\hline Authorization & Authorization for access to data & .60 \\
\hline Compatability & Data compatability & .70 \\
\hline $\begin{array}{l}\text { Ease of use/ } \\
\text { Training }\end{array}$ & $\begin{array}{l}\text { Ease of use } \\
\text { Training }\end{array}$ & .74 \\
\hline Production Timeliness & Production timeliness & .69 \\
\hline Systems Reliability & Systems reliability & .71 \\
\hline Relationships with users & $\begin{array}{l}\text { IS understanding of business } \\
\text { IS interests and dedication } \\
\text { Responsiveness } \\
\text { Delivering agreed-upon solutions } \\
\text { Technical and business panning assistance }\end{array}$ \\
\hline
\end{tabular}

\subsubsection{Task characteristics scales}

To measure task characteristics, three questions on non-routineness (lack of analyzable search behavior) and two questions on interdependence (with other organizational units) were used (Goodhue and Thompson 1995).

\subsubsection{Technology scales}

Due to the fact that altogether 25 technologies were utilized by respondents, the authors made the simplifying assumption that the characteristics of any given system are the same for those who use that system (Goodhue and Thompson 1995). Thus, instead of trying to characterize each system, respondents were asked to quantify the number of systems used (Goodhue and Thompson 1995).

\subsubsection{Utilization scales}

Goodhue and Thompson (1995) conceptualized utilization as the extent to which the information system has been integrated into each individual's work routine, whether by individual choice or by organizational mandate. By asking users to rate how independent they felt when using each system, the authors aimed to capture how compulsory system usage was as part of their job descriptions.

\subsubsection{Performance impact}

Due to the fact that objective measures of performance were unavailable, three questions were used that asked individuals to self-report on the perceived impact of computer systems and services on their effectiveness, productivity, and performance in their job (Goodhue and Thompson 1995). 
To analyze the data, multiple regression techniques were applied. As a result, the authors found moderate support for proposition 1 suggesting that task and technology characteristics do influence user ratings of TTF (Goodhue and Thompson 1995).

On the other hand, the results provided little support for research proposition 2, indicating that more empirical research is required to address how TTF influences the utilization of information systems by individuals (Goodhue and Thompson 1995). One obvious explanation for this was that a direct linkage between TTF and utilizations may not be justified in general and that TTF may not dominate the decision to utilize technology in an organizational context. This explanation seemed to be particularly true for environments where system use was mandatory (Goodhue and Thompson 1995). Research proposition 3 was strongly supported indicating that performance impacts are a function of both task technology fit and utilization, not utilization alone (Goodhue and Thompson 1995).

\section{Implications for this study}

Goodhue and Thompson's (1995) task-technology fit study integrated the extant literature on adoption and acceptance research. The authors tested the task-to-performance chain in an organizational context where use is mandatory. The present study intends to adapt the TTF to examine not specific technologies, but rather delivery channels. The specific context is voluntary use of electronic banking channels at the individual level.

Since its introduction, the TTF model has been cited and applied in the context of a diverse range of information systems (Goodhue 1998; Zigurs and Buckland 1998; Dishaw and Strong 1999; Zigurs, Buckland et al. 1999; D'Ambra and Wilson 2004; D'Ambra and Wilson 2004; Karimi, Somers et al. 2004). Multiple researchers have tested TTF constructs and used modifications of TTF or combined the TTF model with other models such as the TAM (Dishaw and Strong 1998; D'Ambra and Rice 2001).

Section 2.5. discusses articles that tested or conceptualized TTF constructs as part of their studies. This literature should help to comprehend how the TTF can be modified and applied to different situations.

\subsection{TTF-related research}

Zigurs and Buckland (1998) suggested a theory of task/technology fit in group support systems (GSS) environments based on attributes of task complexity and their relationship to relevant characteristics of GSS technology. While the proposed TTF theory in GSS environments was not tested empirically, particularly the comprehensive literature review on 
the task and fit related literature supported the authors' arguments for the proposed theory (Zigurs and Buckland 1998).

Based on the discussion on the task related literature, the authors focused on the central importance of task complexity. Therefore, the authors sub-categorized task complexity into simple tasks, problem tasks, decision tasks, judgment tasks and fuzzy tasks. The theory argued that depending on the tasks, different GSS technologies would be more or less appropriate to support each task. For instance, simple tasks should result in the best group performance when using a GSS configuration emphasizing communication support (Zigurs and Buckland 1998). Problem tasks should be best supported by using a GSS configuration supporting information processing. Decision tasks should result in the best group performance when deploying a GSS configuration emphasizing information processing and process structuring (Zigurs and Buckland 1998). Fuzzy tasks would be best assisted using a GSS configuration supporting communication support and information processing (Zigurs and Buckland 1998).

Subsequent to Zigurs and Buckland's (1998) study, Zigurs et al. (1999) tested the TaskTechnology Fit theory for GSS technologies by using a literature sample of published GSS experiments. The sample included thirty-seven research studies that were published from 1987 and 1992 on GSS environments (Zigurs, Buckland et al. 1999). Using a coding instrument, the studies identified in the literature were related to the suggested tasks dimensions (simple tasks, problem tasks, decision tasks, and fuzzy tasks) (Zigurs, Buckland et al. 1999). The results provided good support for the theory and supported e research propositions established in Zigurs and Buckland's theory (1998).

Ferratt et al. (1998) investigated how computer based information systems (CBIS) fit to support managers in their decision making tasks. To measure the TTF, user evaluations of CBIS were used to assess how these systems would support managers in their decision making process. The authors argued that the higher the user evaluation, the better the systems would fit to the manager's tasks. Tasks were tested through fourteen items that focused on the decision making process (e.g. strategic, tactical, and operational decisions). Instead of defining the CBIS characteristics, the authors used applications to support decision making related to their job (e.g. word processing, spreadsheets, email etc.). Utilization was indicated in the participant's use in hours per week of various types of hardware.

Shirani et al. (1999) conducted an experiment with hundred and forty eight graduate students to examine the interaction between task structure and technology to support 
synchronous and asynchronous group communication. Email and group support system (GSS) technologies in combination with two levels of task structure (less structured and more structured) were used to measure the task technology fit of such technologies related to group communication (Shirani, Tafti et al. 1999). The results showed that students who used this technology to communicate with each other generated more ideas than groups supported by email (Shirani, Tafti et al. 1999).

Dishaw and Strong (1999) combined the TAM model with the TTF and tested the new model in an organizational use setting. They argued that TAM (Davis 1989) and the TaskTechnology Fit (TTF) (Goodhue and Thompson 1995) were the most influential theories to explain information technology utilization within the information systems research discipline. Combining both theories, would help to better understand why individuals use information technology for particular tasks (Dishaw and Strong 1999). The following Figure 9 illustrates the integrated model suggested by Dishaw and Strong (1999):

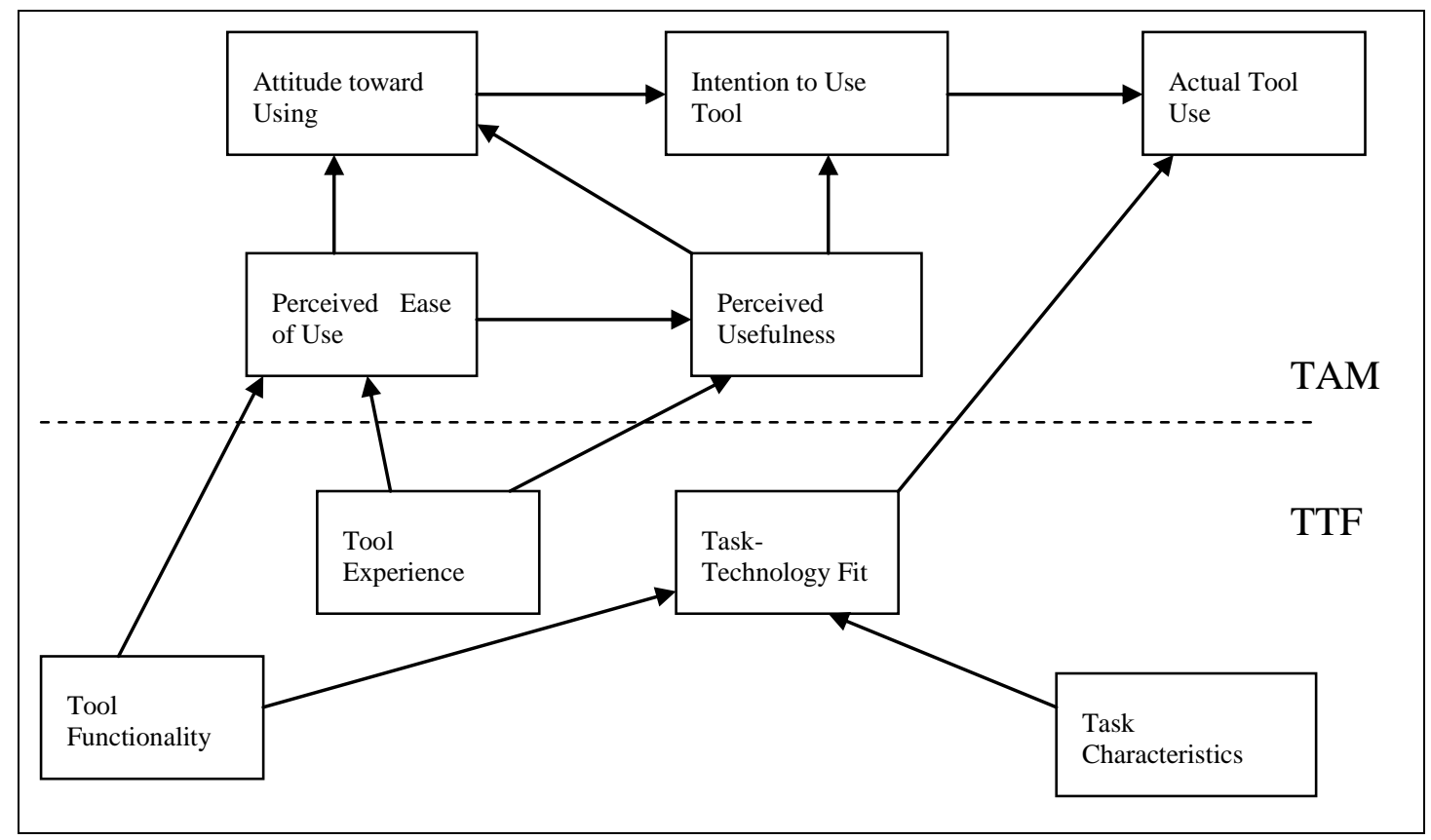

Figure 9: Integrated TAM/TTF model (Dishaw and Strong 1999)

The authors examined the integrated model using path analysis. Before assessing the combined model, the authors tested each model separately using the data collected for this research. The analyses showed that the extended model provided a better fit than either TAM or TTF alone (Dishaw and Strong 1999).

Goodhue et al. (2000) analyzed user evaluations of information systems as surrogates for objective performance. User evaluations would be frequently used as measures of information 
systems success (Goodhue, Klein et al. 2000). Therefore, the authors developed the below mentioned research model:

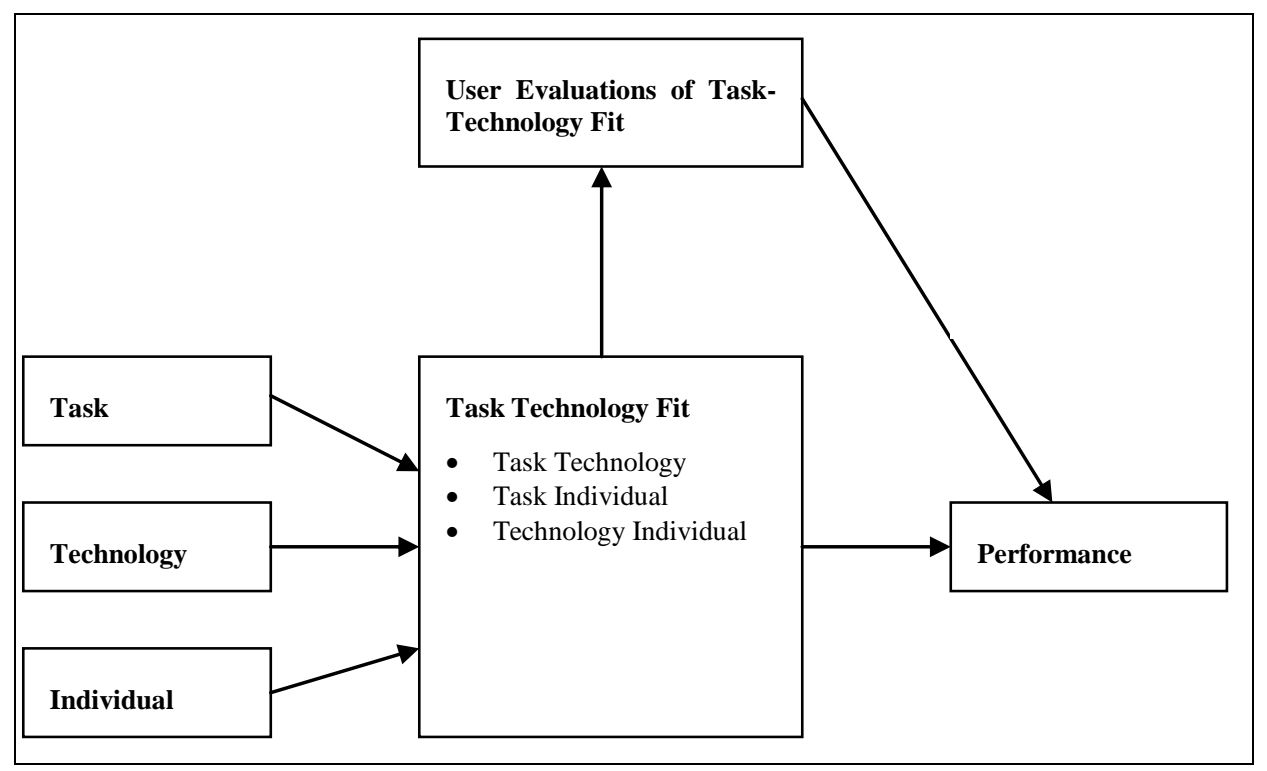

Figure 10: Model of task-technology fit, user evaluations, and performance (Goodhue, Klein et al. 2000)

To test the linkages between TTF, user evaluations of information systems, and objective performance, the authors designed a laboratory situation in which the TTF construct was manipulated to cause changes in the constructs. For this experiment 155 pairs of undergraduate business students participated in four 1hour lab sessions performing a variety of tasks with different technologies (Goodhue, Klein et al. 2000). The results illustrated that the link between user evaluations and performance was not as clear as expected.

D'Ambra and Wilson (2004a) proposed a model integrating the concept of uncertainty and information seeking into the task-technology fit (TTF) model to evaluate Web usage within the non-work domain of personal travel planning and purchase (as shown below in Figure 11). 


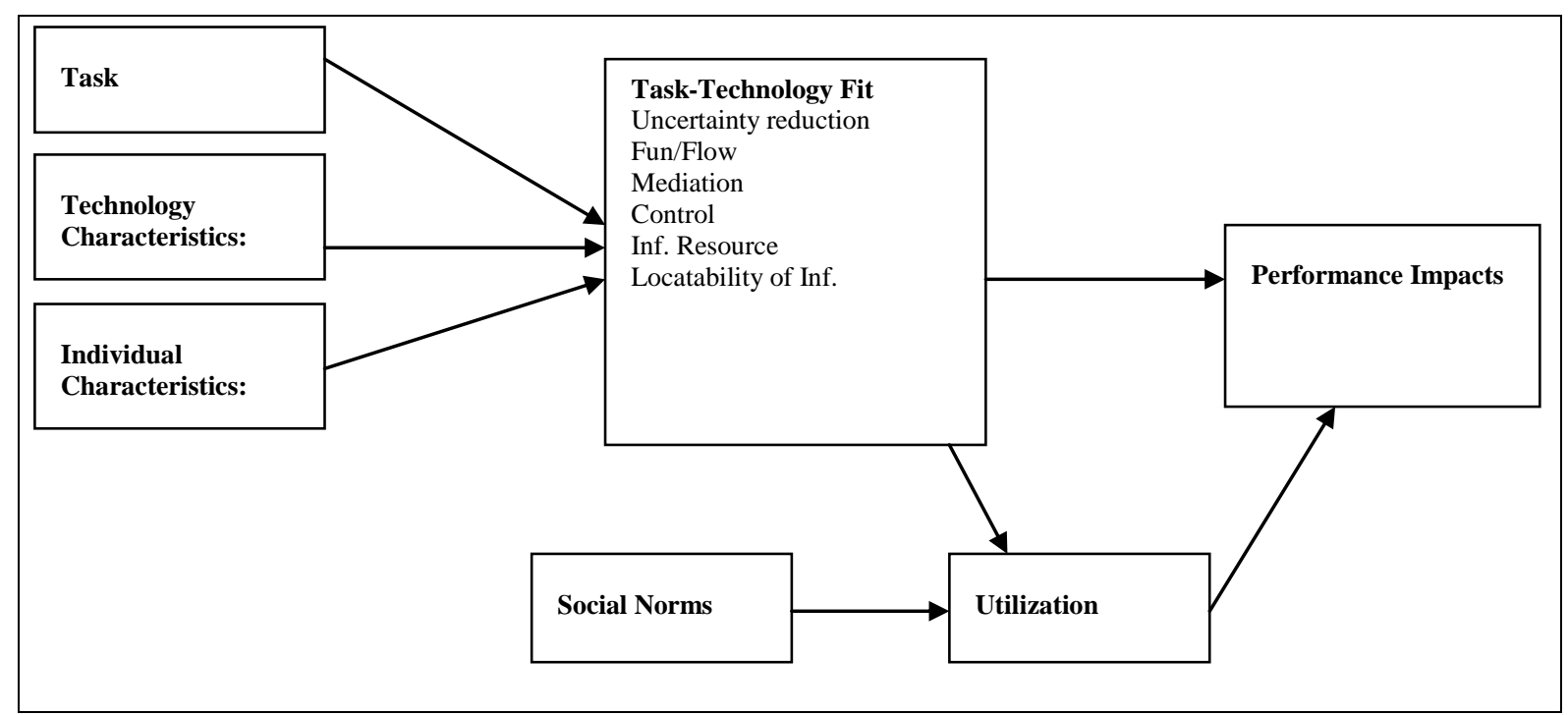

Figure 11: The technology to performance model (D'Ambra and Wilson 2004)

As tasks, the authors chose web usage and information seeking related to travel planning (D'Ambra and Wilson 2004). Technologies were characterized as tools (hard- and software) used by individuals managing their travel plans. Individual skills and experience with the web were positively related to TTF (D'Ambra and Wilson 2004). Task-technology fit was defined as the "correspondence between task requirements, individual abilities and the functionality of the web" (D'Ambra and Wilson 2004). To test the model, the authors collected data from 217 respondents. The results confirmed that travel tasks, uncertainty reduction, the Web as an information resource all had a significant impact on users' perception of performance (D'Ambra and Wilson 2004).

Klopping and McKinney (2004) treated consumer e-commerce as a technology adoption process and evaluated the suitability of TAM and TTF to understand how and why people participate in electronic commerce. To better understand online shopping activity, this study tested a modified TAM model through a web-based survey of 263 undergraduate students (Klopping and McKinney 2004).

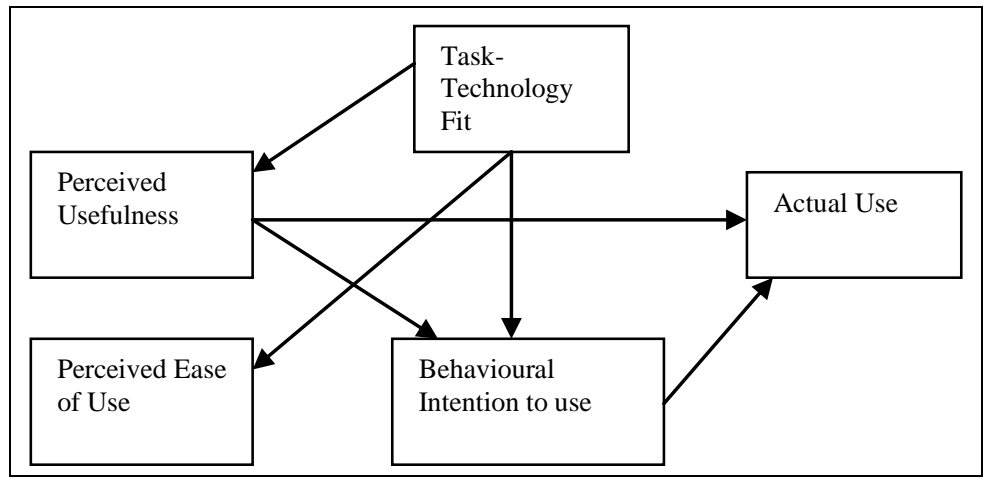

Figure 12: Combined TAM/TTF e-commerce acceptance model (Klopping and McKinney 2004) 
As shown above, a TTF measure was added to the TAM model. The authors hypothesized that TTF would positively predict the intention and actual to use, positively relate to perceived ease of use as well as to the intention to use online shopping (Klopping and McKinney 2004). The results of this study confirmed these assumptions and the data analysis resulted in a good model fit for the above mentioned constructs.

Staples and Seddon (2004) tested the technology-to-performance chain as suggested by Goodhue and Thompson (1995) in voluntary and mandatory use settings. The below mentioned research model (Figure 13) was investigated by surveying university staff (mandatory) and students (voluntary) regarding their usage of library services.

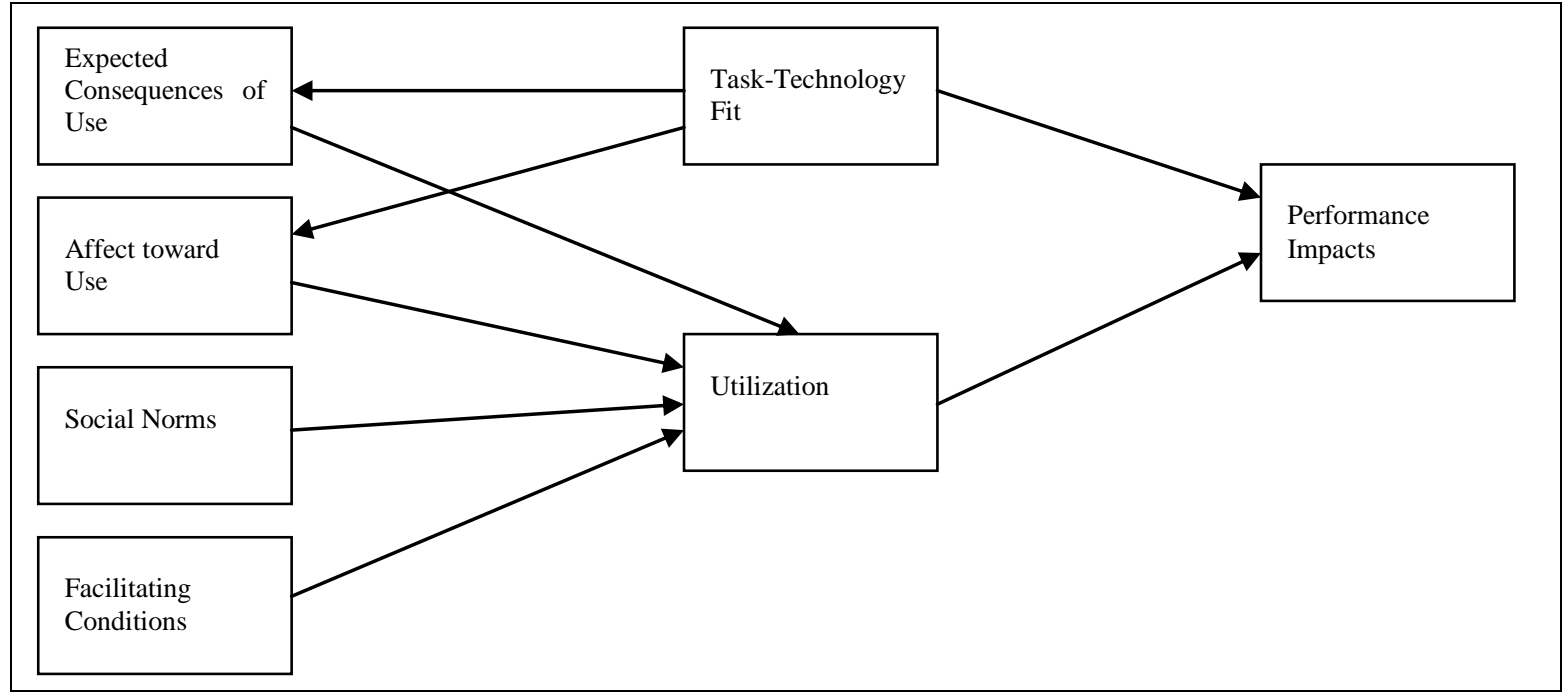

Figure 13: Adjusted TPC chain research model tested by (Staples and Seddon 2004)

In both settings, strong support was found for the impact of TTF on performance, as well as on attitudes and beliefs about use (Staples and Seddon 2004). In mandatory settings, social norms also impacted significantly on utilization while beliefs about use only had a significant impact on utilization in the voluntary use setting.

Similar to Goodhue and Thompson, Staples and Seddon (2004) also used a multi-faceted measure to identify a TTF within the context of their study. They used four facets of TTF originally proposed by Goodhue and Thompson (work compatibility, ease of use, ease of learning as well as information quality). To test these dimensions, twelve questions (three questions per facet) were suggested to the research participants.

In summary, since its development, the TTF theory has been investigated by several researchers in different settings (Dishaw and Strong 1998; Dishaw and Strong 1998; Zigurs and Buckland 1998; Shirani, Tafti et al. 1999; Lim and Benbasat 2000; D'Ambra and Wilson 2004). Particularly, the various ways researchers have previously evaluated TTF constructs 
demonstrated that the assessment of this concept can be approached differently ${ }^{2}$. The following Table 3 summarizes the ways other authors applied the TTF theory to different contexts. It also shows the range of ways authors examined technology, tasks, and individuals.

Table 3: Summary of authors applying the TTF theory to various contexts

\begin{tabular}{|c|c|c|c|c|}
\hline Authors & Technology & Tasks & Individuals & Research Outcome \\
\hline $\begin{array}{l}\text { (Ferratt and } \\
\text { Vlahos 1998) }\end{array}$ & $\begin{array}{l}\text { Computer-based } \\
\text { Information } \\
\text { Systems }\end{array}$ & $\begin{array}{l}\text { Managerial Decisions: } \\
\text { "Managers' actions of } \\
\text { interest are their decision- } \\
\text { making activities." }\end{array}$ & $\begin{array}{l}\text { Managerial Staff } \\
\text { in Greece and the } \\
\text { US }\end{array}$ & $\begin{array}{l}\text { The results indicated that the } \\
\text { fit between managerial } \\
\text { decision-making activities, } \\
\text { and IS had considerable } \\
\text { room for improvement. }\end{array}$ \\
\hline $\begin{array}{l}\text { (Mathieson } \\
\text { and Keil } \\
\text { 1998) }\end{array}$ & $\begin{array}{l}\text { Two systems and } \\
\text { two tasks. }\end{array}$ & $\begin{array}{l}\text { Creating database queries } \\
\text { to answer questions in a } \\
\text { given problem domain }\end{array}$ & $\begin{array}{l}\text { Undergraduate } \\
\text { business students } \\
\text { enrolled in an } \\
\text { information } \\
\text { technology } \\
\text { course. }\end{array}$ & $\begin{array}{l}\text { This research confirmed that } \\
\text { perceived ease of use was } \\
\text { also a function of } \\
\text { task/technology fit. }\end{array}$ \\
\hline $\begin{array}{l}\text { (Zigurs and } \\
\text { Buckland } \\
\text { 1998) }\end{array}$ & $\begin{array}{l}\text { Group Support } \\
\text { Systems (GSS) }\end{array}$ & $\begin{array}{l}\text { Group decision making } \\
\text { process: tasks complexity } \\
\text { in relationship to relevant } \\
\text { dimensions of GSS } \\
\text { technology }\end{array}$ & $\begin{array}{l}\text { Individuals within } \\
\text { Groups }\end{array}$ & $\begin{array}{l}\text { No empirical data collected } \\
\text { for this research. }\end{array}$ \\
\hline $\begin{array}{l}\text { (Zigurs, } \\
\text { Buckland et } \\
\text { al. 1999) }\end{array}$ & $\begin{array}{l}\text { Group Support } \\
\text { Systems (GSS) }\end{array}$ & $\begin{array}{l}\text { Group decision making } \\
\text { process: tasks complexity } \\
\text { in relationship to relevant } \\
\text { dimensions of GSS } \\
\text { technology }\end{array}$ & $\begin{array}{l}\text { Individuals within } \\
\text { Groups }\end{array}$ & $\begin{array}{l}\text { The literature survey partly } \\
\text { confirmed the GSS task } \\
\text { technology fit theory. }\end{array}$ \\
\hline $\begin{array}{l}\text { (Shirani, } \\
\text { Tafti et al. } \\
\text { 1999) }\end{array}$ & $\begin{array}{l}\text { Group Support } \\
\text { Systems (GSS) vs } \\
\text { Email }\end{array}$ & $\begin{array}{l}\text { Less structured and more } \\
\text { structured tasks. }\end{array}$ & MBA students & $\begin{array}{l}\text { GSS was better suited for } \\
\text { groups to generate ideas for } \\
\text { problem solving than for } \\
\text { those groups supported by } \\
\text { email. }\end{array}$ \\
\hline $\begin{array}{l}\text { (Goodhue, } \\
\text { Klein et al. } \\
\text { 2000) }\end{array}$ & $\begin{array}{l}\text { Information } \\
\text { Systems }\end{array}$ & $\begin{array}{l}\text { Answering a series of } \\
\text { managerial questions. To } \\
\text { address the questions, users } \\
\text { were required to use } \\
\text { different technologies }\end{array}$ & $\begin{array}{l}\text { Undergraduate } \\
\text { business students }\end{array}$ & $\begin{array}{l}\text { The linkage between user } \\
\text { evaluations and user } \\
\text { performance was not as clear } \\
\text { as expected. }\end{array}$ \\
\hline $\begin{array}{l}\left(D^{\prime} \text { Ambra }\right. \\
\text { and Rice } \\
\text { 2001) }\end{array}$ & Web services & Web use & $\begin{array}{l}\text { Undergraduate } \\
\text { business students } \\
\text { (Focus group }+ \\
\text { survey) }\end{array}$ & $\begin{array}{l}\text { User-training, information } \\
\text { quality and ease of use } \\
\text { positively affected the TTF } \\
\text { of individuals using Web } \\
\text { services. }\end{array}$ \\
\hline $\begin{array}{l}\text { (D'Ambra } \\
\text { and Wilson } \\
2004 ; \\
\text { D'Ambra and } \\
\text { Wilson 2004) }\end{array}$ & Web services & $\begin{array}{l}\text { Information seeking and } \\
\text { web usage related to } \\
\text { personal travel }\end{array}$ & Travelers & $\begin{array}{l}\text { Task complexity and web as } \\
\text { an information resource all } \\
\text { had a significant impact on } \\
\text { users' perception of } \\
\text { performance. }\end{array}$ \\
\hline $\begin{array}{l}\text { (Klopping } \\
\text { and } \\
\text { McKinney } \\
\text { 2004) }\end{array}$ & Online shopping & Online shopping behavior & Students & $\begin{array}{l}\text { The study found strong } \\
\text { support for the use of a } \\
\text { modified TAM / TTF model } \\
\text { to predict user behavior in e- } \\
\text { commerce environments. }\end{array}$ \\
\hline $\begin{array}{l}\text { (Maruping } \\
\text { and Agarwal }\end{array}$ & $\begin{array}{l}\text { Team } \\
\text { communication }\end{array}$ & $\begin{array}{l}\text { Internal communication } \\
\text { within groups }\end{array}$ & $\begin{array}{l}\text { Group members in } \\
\text { a work }\end{array}$ & $\begin{array}{l}\text { No empirical data collected } \\
\text { for this research. }\end{array}$ \\
\hline
\end{tabular}

\footnotetext{
${ }^{2}$ Section 5.2. provides an in depth discussion on several fit computation techniques.
} 


\begin{tabular}{|l|l|l|l|l|}
\hline 2004) & & & environment & \\
\hline $\begin{array}{l}\text { (Staples and } \\
\text { 2004) }\end{array}$ & $\begin{array}{l}\text { Library central } \\
\text { cataloguing system } \\
\text { as well as } \\
\text { word/excel }\end{array}$ & $\begin{array}{l}\text { The study investigated two } \\
\text { different systems. The } \\
\text { systems for mandatory use } \\
\text { were library central } \\
\text { cataloguing system. For the } \\
\text { voluntary use settings word } \\
\text { processor and excel } \\
\text { spreadsheets were used. }\end{array}$ & $\begin{array}{l}\text { Librarians and } \\
\text { students }\end{array}$ & $\begin{array}{l}\text { TPC model was supported } \\
\text { although constructs varied in } \\
\text { mandatory/voluntary setting. }\end{array}$ \\
& & & \\
& & & \\
\hline
\end{tabular}

\section{Implications for this study}

The task-technology fit theory is the foundation for the task-channel fit concept. Most researchers applying TTF have studied the fit between tasks and specific technologies. This study intends to adapt the TTF to examine not specific technologies, but rather delivery channels. The specific context is voluntary use of electronic banking channels at the individual level.

Goodhue and Thompson's (1995) study, as well as the various modifications, provide examples for measuring task-technology fit. The vast majority of studies assessed the TTF directly by using dimensions or facets corresponding to the TTF. Thus, this study will also measure the task-channel fit construct through several dimensions (see section 3.3.1.). Furthermore, by characterizing tasks and technologies, many studies suggested important aspects of the TCF. For instance, task complexity [suggested by Zigurs and Buckland (1998)] is proposed as one TCF dimension.

Having discussed its origins, the TTF itself as well as TTF related research, the following sections review the literature relevant to the adoption and acceptance research on electronic banking channels.

\subsection{Research on electronic banking}

Before discussing the literature on electronic banking, this section initially defines electronic banking channel usage and explains what this study associates with this term. Next, the existing literature on each electronic banking channel will be reviewed and discussed.

Electronic banking channels enable consumers to perform various banking activities mediated by electronic self-service technologies such as ATMs, telephone, Internet and mobile applications (Liao, Shao et al. 1999; Southard and Keng 2004; Turban, King et al. 2008).

This study defines an electronic banking channel as an IS artifact that provides representations of one or more banking task domains. This implies that electronic banking channels provide features that are designed to support functions in those banking task 
domain(s) (Burton-Jones and Straub 2006). A banking task is a goal-directed banking activity performed by a consumer. An electronic banking channel user is an individual person who employs an electronic banking channel to perform a banking task (Burton-Jones and Straub 2006).

Most common electronic banking applications allow consumers to check their bank accounts, pay bills online, secure a loan electronically and much more (Turban, King et al. 2008). Interestingly, multiple expressions such as 'electronic banking channel', 'electronic banking services', 'electronic banking applications', and 'electronic banking' were used inconsistently throughout the existing literature on electronic banking.

Southard and Siau (2004) divided the services offered on electronic banking channel into the following main categories: informational, administrative, and transactional. The following Table 4 exhibits the associated services for each category:

Table 4: Service categories offered on electronic banking channels

\begin{tabular}{|c|c|}
\hline Services Category & Banking tasks \\
\hline Informational & $\begin{array}{ll}\text { - } & \text { General Bank Information and History } \\
\text { - } & \text { Financial Education Information } \\
\text { - } & \text { Interest Rate Quotes } \\
\text { - } & \text { Financial Calculators } \\
\text { - } & \text { Current Bank and Local News } \\
\end{array}$ \\
\hline Administrative & $\begin{array}{ll}\text { - } & \text { Account Information Access } \\
\text { - } & \text { Applications for Services } \\
\text { - } & \text { Personal Finance Software Applications }\end{array}$ \\
\hline Transactional & $\begin{array}{ll}\text { - } & \text { Account Transfer Capabilities } \\
\text { - } & \text { Bill-pay Services } \\
\text { - } & \text { Corporate Services (e.g., Cash Management, Treasury) } \\
\text { - Online Insurance Services } \\
\text { - Online Brokerage Services } \\
\text { - Online Trust Services }\end{array}$ \\
\hline
\end{tabular}

As above indicated, the informational area consists of general bank information usually obtainable in printed form at a physical bank (Southard and Keng 2004). These electronic brochures usually contain background information and a description of available services. Informational services do not require the bank to provide interaction with its internal network and are non-related to specific customer bank accounts. Because the entire information is available to the general public, informational services have relatively low complexity and low security requirements from a bank's perspective (Southard and Keng 2004). 
Administrative services consists of features that enable bank customers to perform routine activities such as obtaining personal account balance information and ordering checks (Southard and Keng 2004). These features require interaction with the bank's database and infrastructure which means that customers are required to $\log$ in to their accounts (Southard and Keng 2004). These services also include features such as mortgage calculators that providing additional information to the customers.

The transactional area consists of features that allow customers to actually perform financial transactions. As with the administrative services, these features require access to and interaction with the bank's internal network. Therefore, high security levels are required since these transactions potentially change the bank's financial statements (and hence customers' account balances) (Southard and Keng 2004).

The following sections define and explain each electronic banking channel:

Automated Teller Machines are computerized telecommunication devices allowing customers of financial institutions to directly use a secure method to access cash as well as their bank accounts (Moutinho and Meidan 1989; Davies, Moutinho et al. 1996; Goode, Moutinho et al. 1996; Curran and King 2008). The first generations of ATMs appeared in the late 1960s and were first installed by Barclays Bank in the United Kingdom (Railton 1985). While the initial machines were simply known as cash dispensers', the most significant development came in the mid-1970s when banks introduced more advanced ATM's using plastic magnetic stripe cards. The biggest improvement of these models was that consumers could access account information and order checkbooks (Railton 1985).

Nowadays, most ATMs are self-service banking terminals performing various financial transactions including informational, administrative and transactional services such as cash withdrawals, deposits, dispensing of foreign currency, and providing electronic and paper based account information for customers. ATMs are activated by inserting bank cards into the ATM (Moutinho 1992). The card contains the customer's account details and can be used in combination with the customer's personal identification number (PIN). Over time, ATMs have appeared not only at bank locations, but in shopping centers, airports, gas stations, and other public locations where people gather (Morisi 1996; Almossawi 2001; Prager 2001).

Telephone banking are services provided by financial institutions allowing customers to perform banking activities over the telephone (Patricio, Fisk et al. 2003; Forsyth 2004; Lassar, Manolis et al. 2005; Van Birgelen, Jong et al. 2006). Telephone banking applications make 
use of an automated phone answering system with phone keypad response or voice recognition systems (Ahmad and Buttle 2002; Forsyth 2004; Lassar, Manolis et al. 2005). To ensure security, consumers have to authenticate through a numeric or verbal password. Through phone banking services, customers are able to do banking 24/7 at places convenient and private to them such as their home. It is important to note that voice-to-voice conversations between banking customers and bank staff (e.g. call-center personnel) are considered as face-to-face branch banking and not as part of telephone banking.

Internet banking is a service that allow consumers to perform a wide range of financial and non-financial services through a bank's website (Bradley and Stewart 2002; Mattila 2003). With the rapid diffusion of the Internet, web-based banking has fast become an alternative channel to provide banking services and products (Tan and Thompson 2000; O'Reilly, Finnegan et al. 2001; Thornton and White 2001; Mattila 2003; Rotchanakitumnuai and Speece 2004; Walker and Johnson 2005).

To access Internet banking applications, customers use web-browsers usually installed on personal desktop computers, laptops or tablet computers. When first introduced, Internet banking was used mainly as an information presentation medium in which banks marketed their products and services on their Web sites. Nowadays, informational, administrative and transactional services can be used on Internet banking applications (Southard and Keng 2004).

Mobile banking services are considered as a channel whereby the customer interacts with a financial institution via a mobile device, such as a mobile phone or personal digital assistant (PDA) (Barnes and Corbitt 2003; Scornavacca and Barnes 2004; Scornavacca and Hoehle 2007). Customers using mobile banking applications interact with their banks through voiceless applications such as text or wap based banking services ${ }^{3}$ (Hoehle and Lehmann 2008).

Due to overlapping technical capabilities of electronic banking channel, particularly mobile banking, telephone banking and Internet banking are difficult to differentiate. This is the case since mobile phones have similar features than landline telephones and more recent mobile phones enable users to access the Internet while being on the move.

The following Figure 14 illustrates how each electronic banking channel can be accessed and shows the various interfaces consumers have to access each electronic banking channel.

\footnotetext{
${ }^{3}$ Wireless Application Protocol (wap) is an open international standard allowing mobile devices such as cell phone to browse the world wide web.
} 


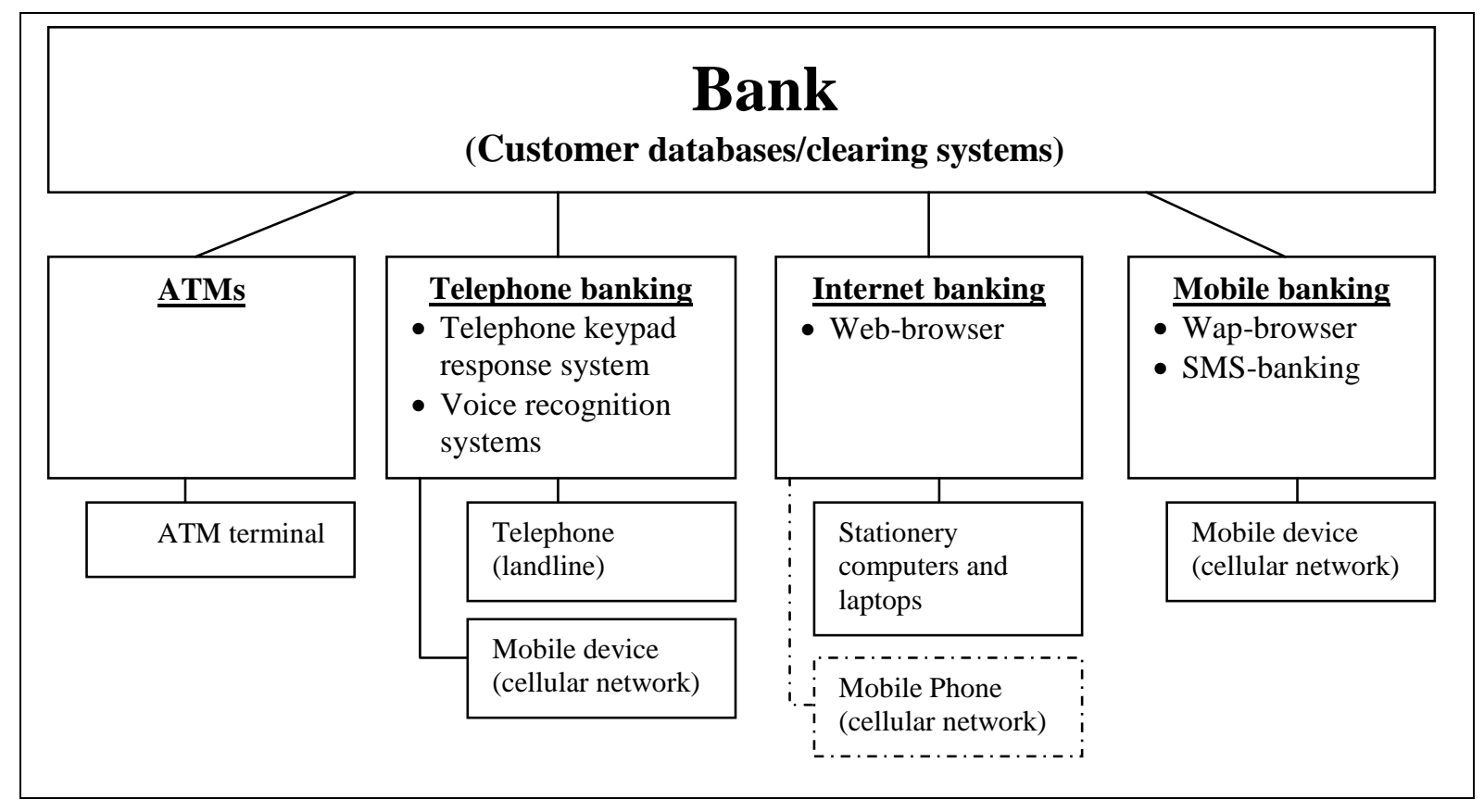

Figure 14: Various interfaces consumers have to access each electronic banking channel

ATM machines possess unique technological characteristics and they differ clearly from the remaining electronic banking channels. As explained beforehand, the ATM banking channel can be exclusively accessed through ATM terminals.

On the other hand, telephone banking services are based on phone keypad response or voice recognition systems. These self-service technologies can be accessed through telephones (landlines) or mobile phones/PDAs (cellular network).

Internet banking services are considered as a channel whereby bank customers access their accounts through web-enabled technologies. Normally, consumers access web-based internet banking through stationery computers or laptops.

However, it is technically possible to use Internet banking on more recent mobile devices. These mobile devices (e.g. I-Phone) can access web-sites through the browsers installed on these devices (e.g. Internet explorer, safari, firefox etc.). However, most banks have mechanisms in place that automatically re-route consumers with mobile devices to wap-based banking applications. If consumers access the bank's web-site, the bank's server recognizes the consumer's system and links it to the most appropriate portal (web/wap). Wap-services are tailored for the unique technical capabilities of mobile devices (e.g. small screens, clumsy input mechanisms, and limited data transmission capabilities). Although technically viable, it is very unlikely that many customers perform web-based banking on mobile devices (as indicated with dotted lines in Figure 14). 
As shown above, the mobile banking channel (including wap- and sms-banking) can be only accessed through mobile devices such as mobile phones and PDAs.

The following sections review the literature on electronic banking services. This review is organized in four parts. Initially, literature investigating automated teller machines is discussed before telephone banking services are considered. The subsequent section examines existing studies on Internet banking services before relevant literature on mobile banking applications is presented.

\subsubsection{Automated Teller Machines}

ATMs are computerized telecommunication devices that allow customers of financial institutions to directly use a secure method to access cash as well as their bank accounts (Moutinho and Meidan 1989; Davies, Moutinho et al. 1996; Goode, Moutinho et al. 1996; Curran and King 2008).

The incentives for financial institutions to deploy ATMs include cost reductions and more efficient business processes. Consumers benefit from ATMs by having access to cash and their personal accounts 24/7. Moreover, waiting times during business hours are reduced through ATMs since they often process financial transactions faster and more accurately than bank tellers (Marr and Prendergast 1991; Curran and King 2008). Thus, banks encourage customers to use ATMs by making paper-based transactions more expensive and offering discounts on transactions carried out on ATMs (Morisi 1996; Moutinho and Smith 2000).

However, the limited input mechanisms, perceived insecurity, and location dependence are frequently emphasized as being the greatest barriers for the adoption of ATMs from the consumer point of view (El-Haddad and Mohammed 1992; Almossawi 2001; Coventry, Angeli et al. 2003; Little 2003; Wan, Luk et al. 2005; Rahman 2006). Still, these obstacles have not persuaded consumers against ATMs because nowadays more than $70 \%$ of all bank customers frequently use ATMs to perform their banking transactions (Antonides, Amesz et al. 1999).

As a result of these developments, much academic research has been undertaken to investigate the adoption and acceptance of ATMs from a consumer perspective. For example, many studies investigated how elderly people use ATM machines and how demographics influence the utilization of ATMs (Zeithaml and Gilly 1987; Coley, Wright et al. 1997; Lake, Mehta et al. 1998; Antonides, Amesz et al. 1999). These studies confirmed that few elderly used ATMs, virtually all of whom stated convenience as the reason (Zeithaml and Gilly 1987; 
Coley, Wright et al. 1997; Lake, Mehta et al. 1998; Antonides, Amesz et al. 1999). In contrast, the majority of the elderly non-adopters seemed skeptical of ATMs and preferred their usual way of banking. These individuals enjoyed interacting with the human teller and were not willing to bank via ATMs if they could continue with the traditional face-to-face encounter (Zeithaml and Gilly 1987; Coley, Wright et al. 1997; Lake, Mehta et al. 1998; Antonides, Amesz et al. 1999).

In addition to consumer demographics, attitudes towards ATM technology, education and familiarity with other technology were very useful predictors of use of ATMs (Marshall and Heslop 1988). The authors argued technology savvy consumers tended to perceive ATM machines as less complex than individuals who were unfamiliar with technology (Marshall and Heslop 1988). Similarly, Thornton and White (2001) predicted higher future usage rates for ATM machines amongst those customers who had favorable attitudes towards convenience, change, computers, and technology, and who felt more confident using electronic banking and were knowledgeable about methods of accessing their money. On the other hand bank tellers had higher usage rates amongst those customers who had a favorable attitude towards service (Thornton and White 2001).

Leblanc (1990) analyzed the perceptions and motivations of users and non-users towards the use of ATM machines. The results revealed significant differences between both. The user group were generally more educated and believed that the ATM improved service quality, presented no inherent risks to users, and would be compatible with their banking needs - being simple, fast and easy to use (Leblanc 1990). Leblanc (1990) found the main reasons for consumers using ATMs were matters of convenience - 24hour ATM access and the avoidance of (traditional banking) queues. In contrast, non-users perceived ATMs as too complex and risky (Leblanc 1990). El Haddad and Mohammed (1991) confirmed Leblanc's (1991) findings in a different cultural context and added that the main reason not to use ATMs was the human teller encounter in physical branches (El-Haddad and Mohammed 1992). Furthermore, nonusers often found ATMs as too complex and they were not satisfied with data representation on ATMs (El-Haddad and Mohammed 1992). Whereas Wan, Luk and Chan (2005) confirmed this, adding that ATMs were the most widely adopted electronic banking channel in Hong Kong.

Goode et al. (2001) extended their UK based work and applied the below mentioned research model (Figure 15) to Hungary. Their model linked seven variables (overall expectations, perceived risk, confidence, recommendations to others, level of charges, 
frequency of use, and full use of service) to overall customer satisfaction related to the use of ATM machines.

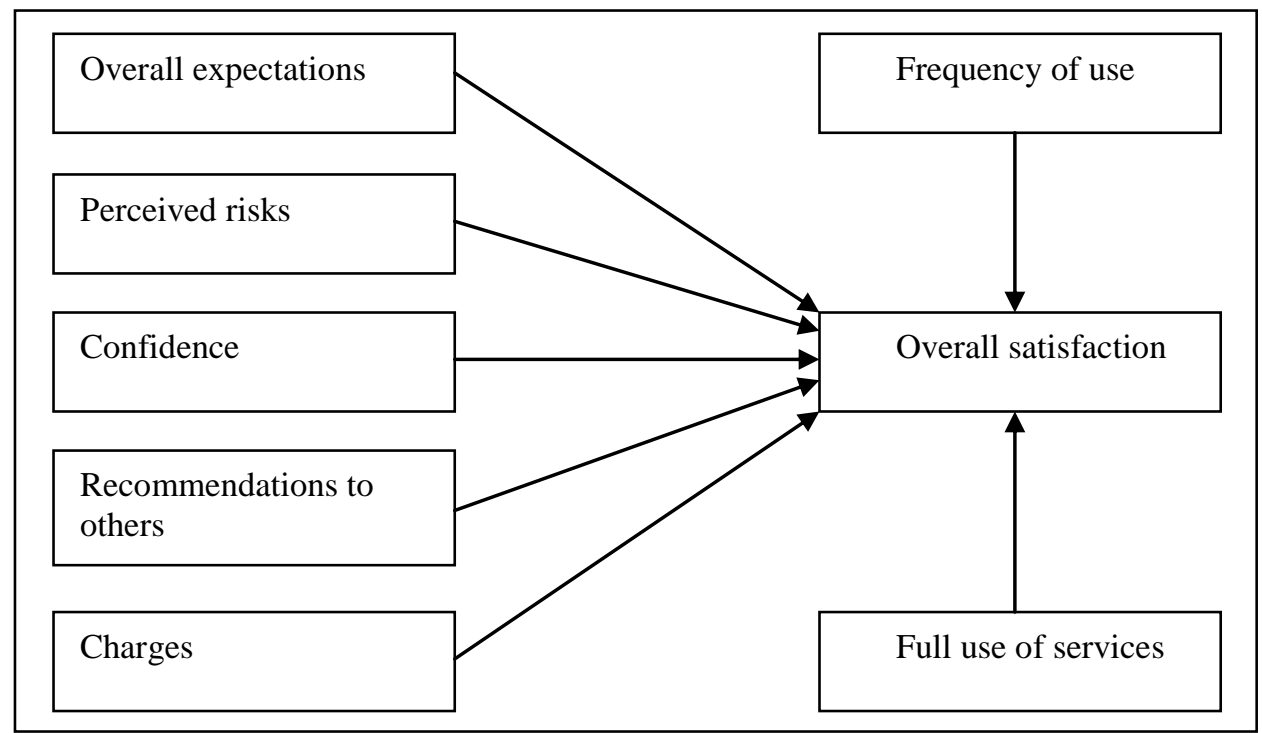

Figure 15: Model of overall satisfaction formation for ATMs - A cross country analysis (Goode, Snee et al. 2001)

Their findings indicated that Hungarian customers' on average used ATMs much less frequently than UK customers. Hungarian customers appeared to use ATMs 2-4 times per month, whereas UK customers seemed to use ATMs 5-10 times per month (Goode, Snee et al. 2001). Additionally, Hungarian customers appeared to be less confident than UK users when using an ATM which may be explained by the different banking system in each country (Goode, Snee et al. 2001). While differences in banking systems were one possible explanation, cultural differences were also considered as an explanation why Hungarians perceived ATMs as riskier and had less confidence in this technology.

Borrowing from TAM and TRA, Dabholkar and Bagozzi (2002) argued that ease of use, performance, and fun would have a positive impact on the attitude toward using ATMs. Similarly consumer traits such as self-efficacy, novelty seeking, need for interaction and selfconsciousness would influence the aforementioned attributes and therefore attitude toward using ATMs (Dabholkar and Bagozzi 2002). Moreover, perceived waiting time and social anxiety would negatively influence the attitude toward using ATMs and consumers' intention to use ATMs. Figure 16 displays the assumptions made for their research. 


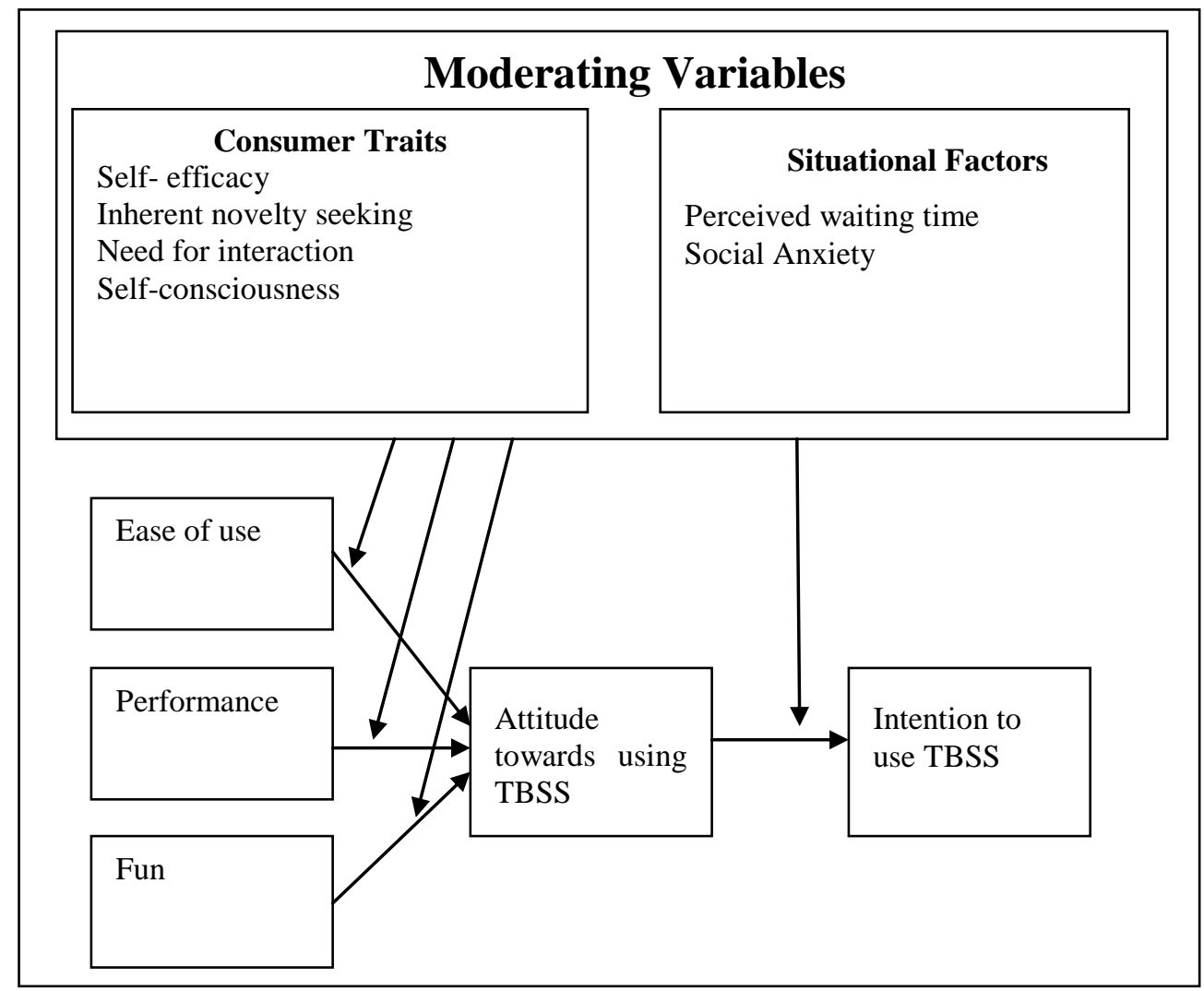

Figure 16: A Research Model of Technology-Based Self-Service (Dabholkar and Bagozzi 2002)

This section investigated the literature on the user adoption and user acceptance of ATMs in various contexts.

In summary, the above mentioned section discusses the existing literature focusing on the user acceptance and adoption of ATMs. The majority of the articles used DOI-, TRA- and TAM constructs as well as demographics to examine the factors influencing the usage of ATM banking services. The following Table 5 summarizes the major factors influencing the adoption and acceptance of ATM banking.

Table 5: Factors influencing the adoption and acceptance of ATM banking

\begin{tabular}{|c|l|l|l|}
\hline Theory & $\begin{array}{l}\text { Factors } \\
\text { influencing the } \\
\text { usage of ATM } \\
\text { banking }\end{array}$ & Definitions & Authors \\
\hline \multirow{6}{*}{ DOI } & $\begin{array}{c}\text { Relative advantage } \\
\text { "The degree to which an } \\
\text { innovation is perceived as } \\
\text { being better than its } \\
\text { precursor" (Moore and } \\
\text { Benbasat 1991) }\end{array}$ & $\begin{array}{l}\text { Rugimbana and Iversen 1994; Rugimbana 1995; } \\
\text { Almossawi 2001; Dabholkar and Bagozzi 2002; } \\
\text { Panigyrakis, Theodoridis et al. 2002; Coventry, Angeli } \\
\text { et al. 2003; Little 2003; Wan, Luk et al. 2005; Rahman } \\
\text { 2006; Chan, Wong et al. 2008; Curran and King 2008; } \\
\text { Dean 2008) }\end{array}$ \\
\cline { 2 - 5 } & $\begin{array}{c}\text { Compatibility with } \\
\text { consumer } \\
\text { values/culture }\end{array}$ & $\begin{array}{l}\text { "The degree to which an } \\
\text { innovation is perceived as } \\
\text { being consistent with the }\end{array}$ & $\begin{array}{l}\text { (Marshall and Heslop 1988; Pepermans, Verleye et al. } \\
\text { 1996; Rogers, Cabrera et al. 1996; Thornton and White } \\
\text { 2001; Dabholkar and Bagozzi 2002; Panigyrakis, }\end{array}$ \\
\hline
\end{tabular}




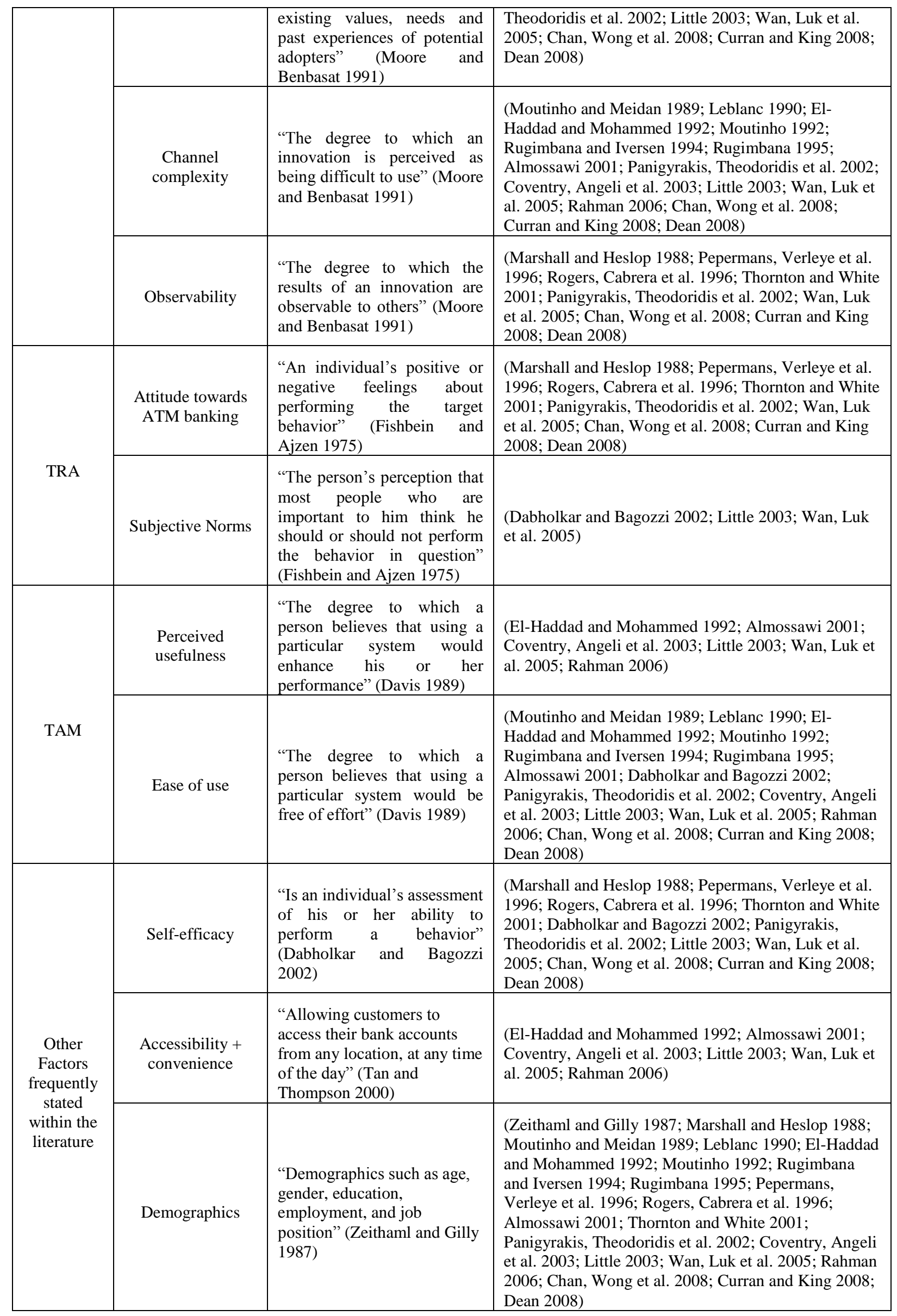




\begin{tabular}{|c|c|c|c|}
\hline & Security & $\begin{array}{l}\text { "Security can be defined as } \\
\text { consumer's perceptions of the } \\
\text { uncertainty and adverse } \\
\text { consequences of buying a } \\
\text { product (or service)" (Littler } \\
\text { and Melanthiou 2006) }\end{array}$ & $\begin{array}{l}\text { (Moutinho and Meidan 1989; Leblanc 1990; Moutinho } \\
\text { 1992; Rugimbana and Iversen 1994; Rugimbana 1995; } \\
\text { Panigyrakis, Theodoridis et al. 2002; Rahman 2006; } \\
\text { Chan, Wong et al. 2008; Curran and King 2008; Dean } \\
\text { 2008) }\end{array}$ \\
\hline
\end{tabular}

\section{Implications for this study}

The discussion on ATM banking services illustrates that various aspects can affect consumers' intentions to use ATM machines. Informed by these studies, several factors are considered within the research model proposed for this study. For instance, the above mentioned studies demonstrated that consumers only use ATM machines if they perceive them as easy to use. Hence, ease of use is considered in the research model (see section 3.3.3.).

Similarly, attitude towards ATM banking and subjective norms are also included within the conceptual research model. Security was often mentioned in the literature as a prerequisite for using ATMs and is thus considered as an important variable related to the use of ATMs.

Having analyzed the literature on ATM banking services, the following section will review the literature on Telephone banking services.

\subsubsection{Telephone Banking}

In contrast to the literature on other electronic banking channels, so far researchers have paid limited attention to phone banking. In consequence, only a few investigations have been published exploring the utilization of this banking channel. Much of the existing literature on phone banking suggested that automated phone answering systems can be difficult to use and often triggering consumer irritations while using these services (Al-Ashban and Burney 2001; Ahmad and Buttle 2002; Lassar, Manolis et al. 2005; Wan, Luk et al. 2005; Van Birgelen, Jong et al. 2006).

For instance, Curran and Meuter (2005) tested the below mentioned model (Figure 17) across ATMs, Phone banking and Internet banking applications. According to the authors, self-service technologies should be easy to use and useful in order to become widely adopted by consumers (Curran and Meuter 2005). The findings indicated that ATMs and Internet banking matched these criteria. In contrast, consumer perceived phone banking systems as clumsy and difficult to use. Therefore, phone banking application would struggle to become widely adopted (Curran and Meuter 2005). 


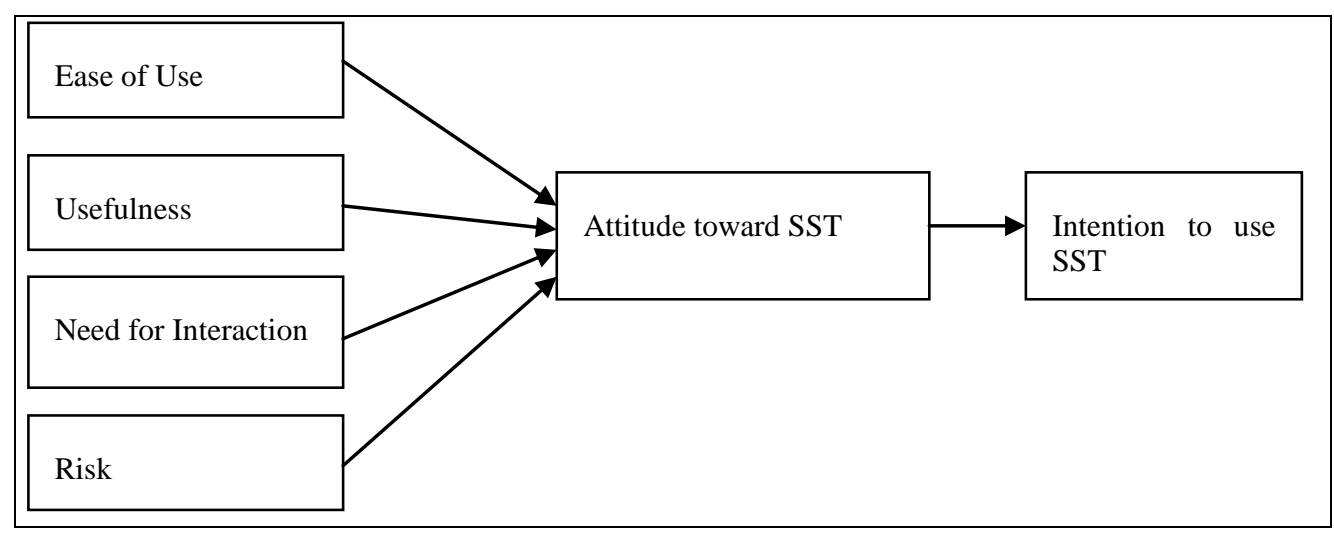

Figure 17: Attitude towards self-service technology model (Curran and Meuter 2005)

The authors concluded by recommending that current phone banking services should change their existing design considerably in order to reach similar utilization rates such as ATMs or Internet banking services (Curran and Meuter 2005). A comparable observation was made by Wan, Luk and Chow (2005) studying the consumer utilization of banking channels in Hong Kong. The authors confirmed that phone banking services were perceived as less user friendly in comparison to other electronic banking channels (Wan, Luk et al. 2005).

In summary, this section discussed the existing literature on telephone banking services. Very few articles assessed phone banking applications from a scientific standpoint. The few studies investigating the user acceptance and adoption of telephone banking applications are summarized in Table 6.

Table 6: Factors influencing the adoption and acceptance of Telephone banking

\begin{tabular}{|c|c|c|c|}
\hline Theory & $\begin{array}{l}\text { Factors influencing the usage } \\
\text { of Telephone banking }\end{array}$ & Definitions & Authors \\
\hline \multirow[b]{2}{*}{ DOI } & Relative advantage & $\begin{array}{l}\text { "The degree to which an innovation is } \\
\text { perceived as being better than its } \\
\text { precursor" (Moore and Benbasat 1991) }\end{array}$ & (Ahmad and Buttle 2002) \\
\hline & Channel complexity & $\begin{array}{l}\text { "The degree to which an innovation is } \\
\text { perceived as being difficult to use" } \\
\text { (Moore and Benbasat 1991) }\end{array}$ & $\begin{array}{l}\text { (Al-Ashban and Burney 2001; } \\
\text { Ahmad and Buttle 2002; } \\
\text { Lassar, Manolis et al. 2005; } \\
\text { Wan, Luk et al. 2005; Van } \\
\text { Birgelen, Jong et al. 2006) }\end{array}$ \\
\hline \multirow[b]{2}{*}{ TAM } & Perceived usefulness & $\begin{array}{l}\text { "The degree to which a person believes } \\
\text { that using a particular system would } \\
\text { enhance his or her performance" (Davis } \\
\text { 1989) }\end{array}$ & (Curran and Meuter 2005) \\
\hline & Ease of use & $\begin{array}{l}\text { "The degree to which a person believes } \\
\text { that using a particular system would be } \\
\text { free of effort" (Davis 1989) }\end{array}$ & $\begin{array}{l}\text { (Al-Ashban and Burney 2001; } \\
\text { Ahmad and Buttle 2002; } \\
\text { Lassar, Manolis et al. 2005; } \\
\text { Wan, Luk et al. 2005; Van } \\
\text { Birgelen, Jong et al. 2006) }\end{array}$ \\
\hline Others & Security & $\begin{array}{l}\text { "Security can be defined as consumer's } \\
\text { perceptions of the uncertainty and adverse } \\
\text { consequences of buying a product (or } \\
\text { service)" (Littler and Melanthiou 2006) }\end{array}$ & (Ahmad and Buttle 2002) \\
\hline
\end{tabular}




\section{Implications for this study}

As discussed above, the factors influencing the utilization of telephone banking services go hand in hand with those affecting consumers to use other electronic banking channels. This section particularly suggested that the degree to which consumers find Telephone banking as easy to use should be considered in the research model (as discussed in section 3.3.3.). Additionally, Ahmad et al. (2002) suggested channel security as an important condition for the utilization of telephone banking services. Therefore, this notion is integrated within the research model as shown in Figure 29.

The above mentioned section reviewed the literature on telephone banking services. The next chapter analyses the acceptance and adoption literature on Internet banking services.

\subsubsection{Internet Banking}

With the rapid diffusion of the Internet, banking in cyberspace has fast become an alternative channel to provide banking services and products (Tan and Thompson 2000; O'Reilly, Finnegan et al. 2001; Thornton and White 2001; Mattila 2003; Rotchanakitumnuai and Speece 2004; Walker and Johnson 2005).

Internet banking allows customers to perform a wide range of banking transactions electronically via a bank's Web site (Bradley and Stewart 2002; Mattila 2003). When first introduced, Internet banking was used mainly as an information presentation medium in which banks marketed their products and services on their Web sites.

Over the last decade, banks have developed Internet banking for financial transactions as well as an informational medium. As a result, registered Internet banking users can now perform common banking transactions such as writing checks, paying bills, transferring funds, opening term deposits, and inquiring about account balances (Tan and Thompson 2000; Lee, Kwon et al. 2005; Liao 2005; Lichtenstein and Williamson 2006). Clearly, Internet banking has evolved into a "one stop service and information unit" that promises great benefits to both banks and consumers (Kim and Prabhakar 2000; Mols 2001; O'Reilly, Finnegan et al. 2001; Bradley and Stewart 2002; Katuri and Lam 2003; Durkin 2004; Flavian, Guinaliu et al. 2005).

For most common Internet Banking applications, users authenticate themselves through single Password Identification Number (PIN) verification. Many banks use additional Transaction Authentication Numbers (TAN) that customers utilize in combination with PINs as a form of single use passwords to authorize financial transactions (Hamilton and Hewer 2000). 
Not surprisingly, Internet Banking has attracted much attention from academics. Over the last decade a large number of studies have been undertaken to investigate user adoption and user acceptance of Internet Banking services. The following section outlines the existing research into: a) DOI related research on Internet Banking services, b) TAM related research on Internet Banking services and c) TBP/TRA related research on Internet Banking services.

\subsubsection{DOI related research on Internet Banking services}

Much literature on the adoption and utilization of Internet banking applications has made use of Roger's (1995) diffusion of innovation theory (Polatoglu and Ekin 2001; Karjaluoto, Mattila et al. 2002; Gerrard and Cunningham 2003; Heaney 2007; Hernandez and Mazzon 2007; Yiu, Grant et al. 2007). For example, Polatoglu and Ekin (2001) set factors initially identified by Roger, namely relative advantage, observability, triability and complexity in relation with Internet banking services in order to survey Turkish consumers'. This study confirmed that younger and well educated banking customers' observed Internet banking as very useful, easy to use and secure (Polatoglu and Ekin 2001).

Tan and Thompson (2000) also explored the factors influencing the adoption of Internet Banking (Tan and Thompson 2000). Instead of focusing solely on the diffusion of innovations theory, they extended Roger's framework by combining it with the theory of planned behavior (TPB) (Ajzen 1991; Rogers 1995). By using constructs from the innovation literature (e.g., relative advantage, compatibility) in combination with subjective norms (e.g., social influence) their study provided a comprehensive way to understand how an individual's attitude, subjective norms and perceived behavioral control would influence intention to use banking services on the Internet (Tan and Thompson 2000).

Their research framework suggested that a person's intentions to adopt Internet banking were determined by three factors. Firstly, user's attitude would describe a person's perception towards Internet banking. Secondly, Internet banking usage would be influenced by the user's subjective norms. Thirdly, perceived behavioral control would affect the adoption of Internet banking services. This would describe beliefs about having the necessary resources and opportunities to adopt Internet banking (Tan and Thompson 2000).

Their research model is displayed in Figure 18 on the following page. 


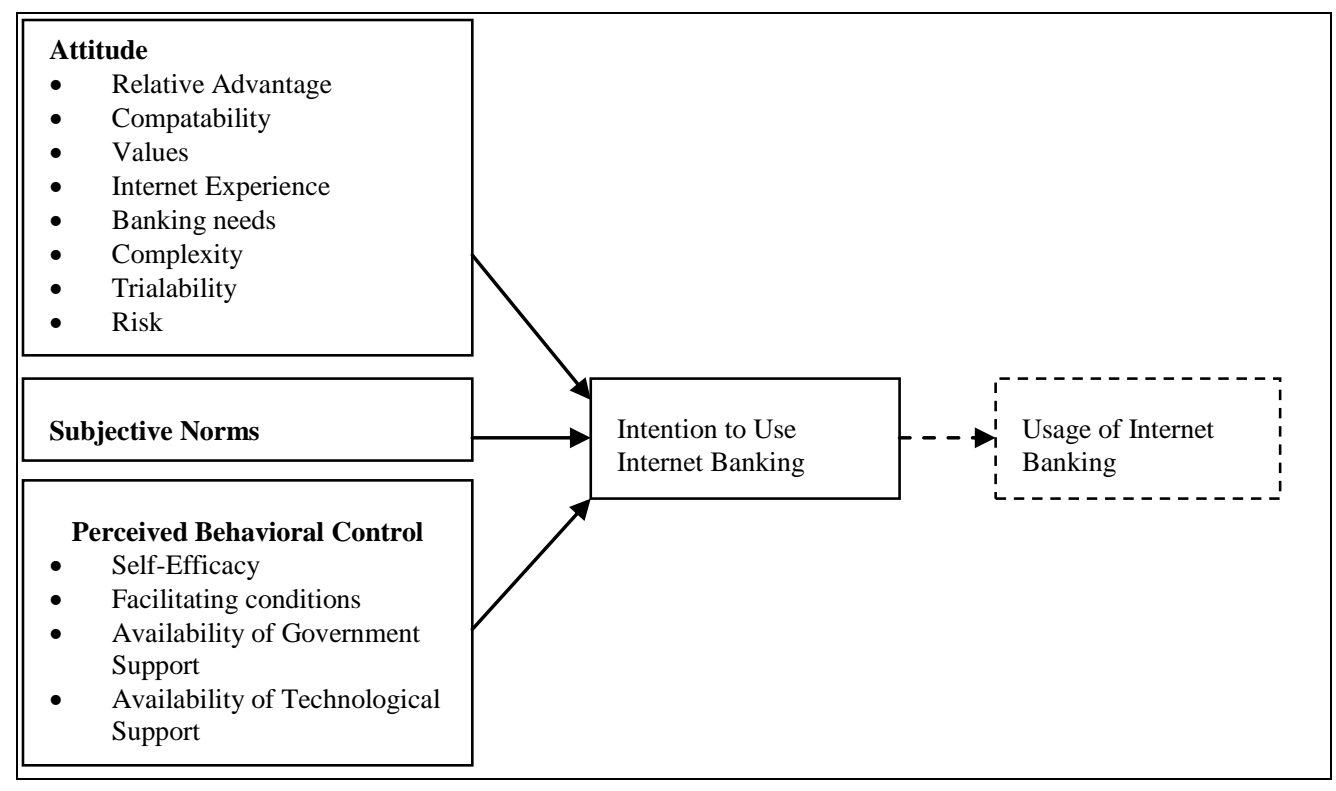

Figure 18: Framework for the adoption of Internet Banking Services (Tan and Thompson 2000)

A more recent adoption study proposed a new method to investigate adoption of Internet banking services by looking into the determinants of Internet banking adoption in Brazil. The research model tested within this study is shown in below mentioned Figure 19.

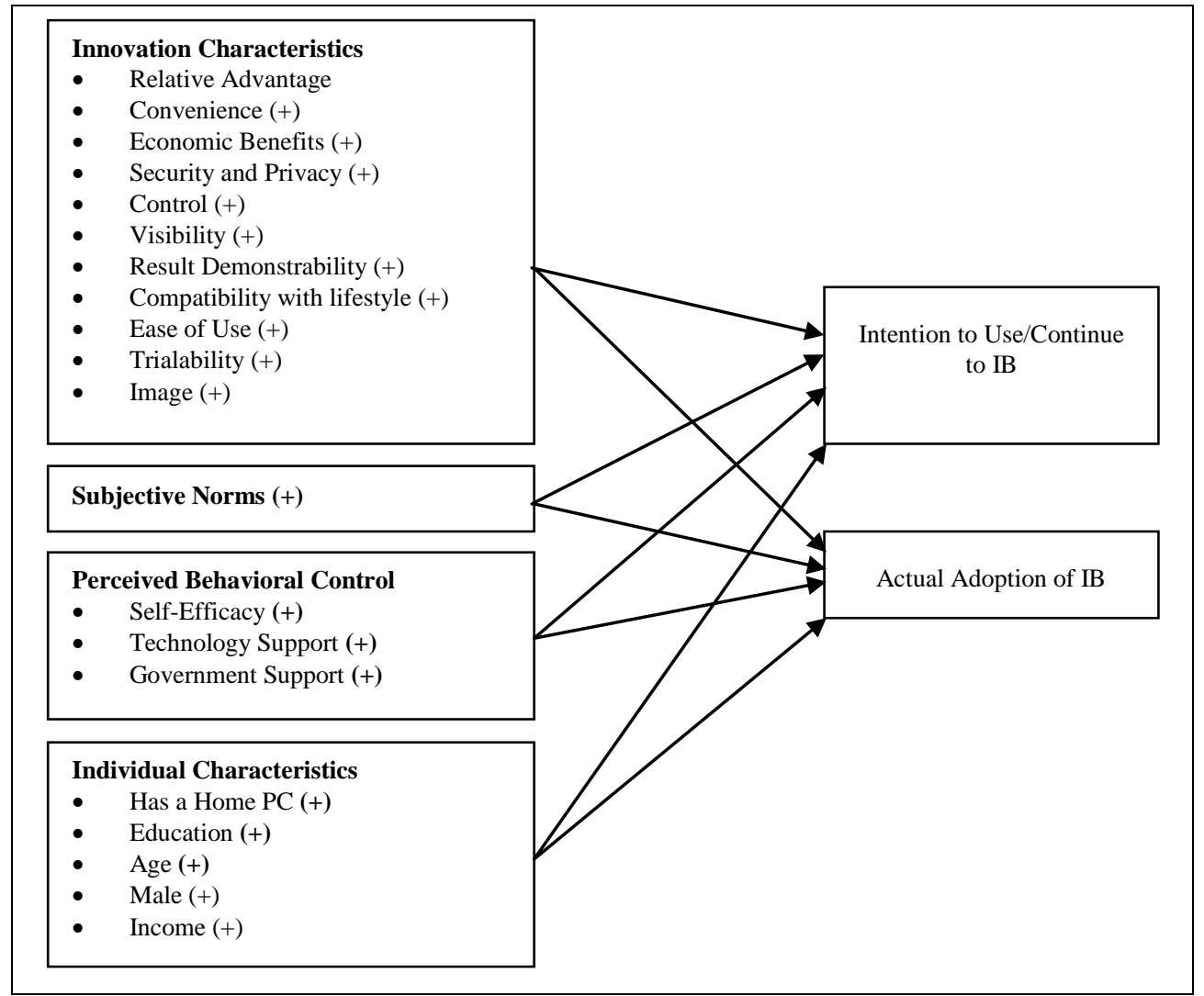

Figure 19: Theoretical model proposed for Internet banking adoption (Hernandez and Mazzon 2007)

The independent variables encompassed four sets based on previous adoption research and are shown on the left hand side. Firstly, influenced by Moore and Benbasat's (1991) adoption 
research on information systems, the innovation characteristics included in the model were: relative advantage, visibility, results demonstrability, compatibility, complexity, trialability and image (Hernandez and Mazzon 2007). Secondly, the model incorporated the idea of breaking down attitudes to enhance its explanatory ability (Hernandez and Mazzon 2007). The subjective norm construct was based on TAM2 (Venkatesh and Davis 2000) while the perceived behavioral control and facilitating conditions constructs were adjusted from a modified theory of planned behavior (Taylor and Todd 1995). Furthermore, a few individual characteristics (owning a home PC, age, income, education and gender) were included in the model as they had proved relevant in previous studies on the adoption of Internet banking services (Taylor and Todd 1995).

The findings showed that the variables influencing the intention to use/continue to use Internet banking were not exactly the same as those that influence actual adoption. Specifically, the results seemed to suggest that intention to use Internet banking was influenced solely by people's beliefs about Internet banking, while its actual adoption was influenced also by individual characteristics (Hernandez and Mazzon 2007). The results of this study also confirmed that the intention to use/continue Internet banking construct was impacted by the following concepts: relative advantage of control, compatibility with lifestyle, image, subjective norm and self-efficacy, relative advantage of security and privacy, results demonstrability, and trialability (Hernandez and Mazzon 2007).

Lichtenstein and Williamson (2006) approached consumer adoption of Internet banking services by conducting an interpretive study in the Australian banking context. This study argued that convenience -particularly in terms of time savings- was the main motivator. Interestingly, accessibility contributed to perceptions of convenience. While male perceptions of convenience were associated with high levels of accessibility and internet self-efficacy, women perceived having access to their banks from home $24 / 7$ as most valuable (Lichtenstein and Williamson 2006). In contrast with previous Australian research, convenience issues were seen as more important to consumers than matters of security, privacy, and trust (Lichtenstein and Williamson 2006). Furthermore, the authors argued that some banking consumers may still be unaware of the existence, features, and benefits of Internet banking services. Lastly, those aware of Internet banking services and its relative advantages, had high levels of internet access and enjoyed the conveniences of Internet banking services (Lichtenstein and Williamson 2006). 
A different perspective was offered by Gerrard et al. (2006) investigating why consumers were resistant to using Internet banking applications. According to this study, the two most frequently mentioned factors were perceptions about the risks associated with Internet banking and the lack of perceived need. Other mentioned factors were lack of knowledge of the service, disinterests, inaccessibility, lack of human touch, pricing and IT fatigue (Gerrard, Cunningham et al. 2006).

Similarly, Kuisma et al. (2007) delved into non-adoption and resistance towards Internet banking from a consumer perspective. The authors of this qualitative research argued that some customers seemed to perceive no relative advantage in switching banking channel from ATM to Internet. Many appeared to prefer the old routine of ATM use or consider Internet an unsafe, inefficient or inconvenient channel (Kuisma, Laukkanen et al. 2007). Furthermore, Internet banking was perceived to increase responsibility for possible mistakes. Despite the advantages of the Internet channel, some customers did not see a performance-to-price value due to the high purchasing costs of computer and Internet connection (Kuisma, Laukkanen et al. 2007). Many ATM customers also seemed to perceive a risk barrier in the adoption of the Internet channel.

\subsubsection{TAM related research on Internet Banking services}

Several research studies have investigated Internet banking services by using modifications of the technology acceptance model (Suh and Han 2002; Eriksson, Kerem et al. 2005; Lai and Li 2005; Cheng, Lam et al. 2006; Amin 2007; Lallmahamood 2007). Suh and Han (2002) for instance argued that trust would be one of the most significant determinants of customer acceptance of Internet banking. Testing the below mentioned TAM extension (Figure 20), the authors' reasoned that trust had a more direct effect on a customer's attitude than perceived ease of use in the Internet banking context (Suh and Han 2002). On the other hand, perceived ease of use had a greater total effect on a customer's actual use (Suh and Han 2002).

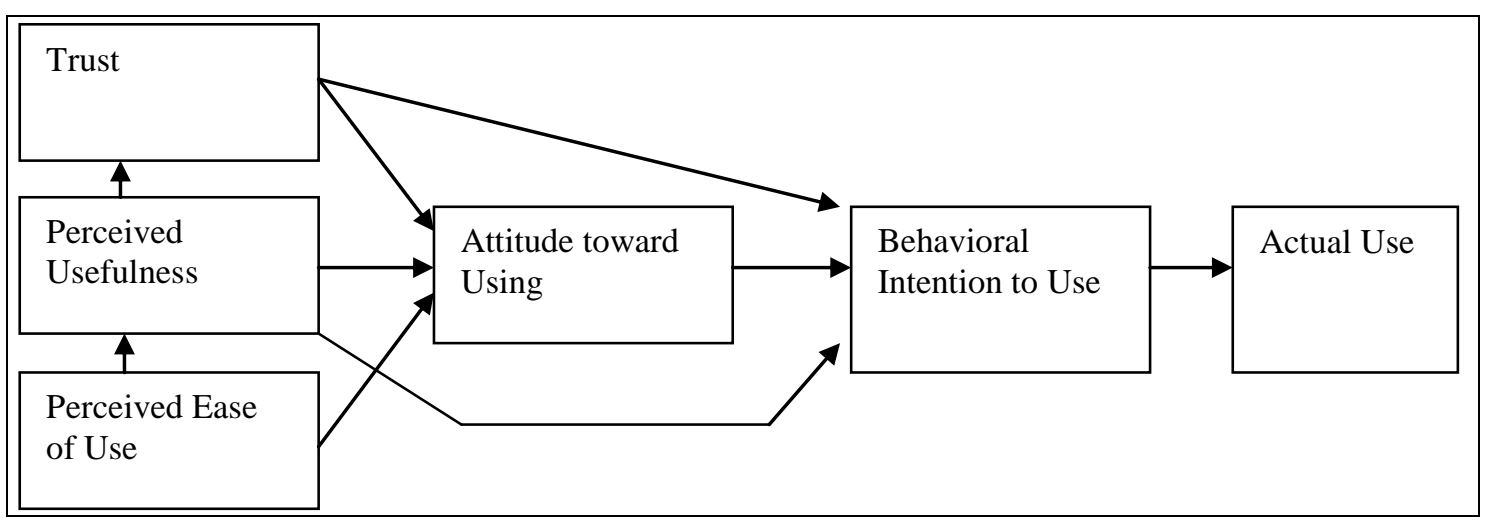

Figure 20: Extended TAM model determining the customer acceptance of Internet banking (Suh and Han 2002) 
Trust was also emphasized by other authors' as being one of the most influential prerequisites for Internet banking from a consumer perspective (Suh and Han 2002; Rotchanakitmnuai and Speece 2003; Flavian, Guinaliu et al. 2005; Liao 2005; Kassim and Abdulla 2006).

Another TAM modification was tested by Eriksson et al. (2005) studying the technology acceptance of internet banking services in Estonia. The findings of this study pointed to the perceived usefulness of internet banking as the primary reason that Estonian bank customers use the internet to satisfy their banking needs (Eriksson, Kerem et al. 2005). Moreover, perceived ease of use of internet banking services did not directly increase the utilization, but it led to greater perceived usefulness, which directly affected the use of internet banking services from a consumer perspective (Eriksson, Kerem et al. 2005). Similarly, consumers' trust had a positive effect on both perceived ease of use and perceived usefulness (Eriksson, Kerem et al. 2005).

Accordingly, Liao and Cheung (2002) investigated consumer attitudes towards the usefulness of and the willingness to use Internet banking. The research involved a survey conducted in Singapore whose advanced infrastructure has led to very low telecommunications cost. The results showed that the expectations of accuracy, security, network speed, user friendliness, user involvement, and convenience were the most important quality attributes for perceived usefulness. In addition, willingness to use Internet banking depended significantly on the aforementioned factors (Liao and Cheung 2002).

Cheng et al. (2006) investigated how customers perceived and accepted internet banking services in Hong Kong. To this end, the authors developed a theoretical model based on the TAM model with an added construct, perceived web security (as shown in Figure 21).

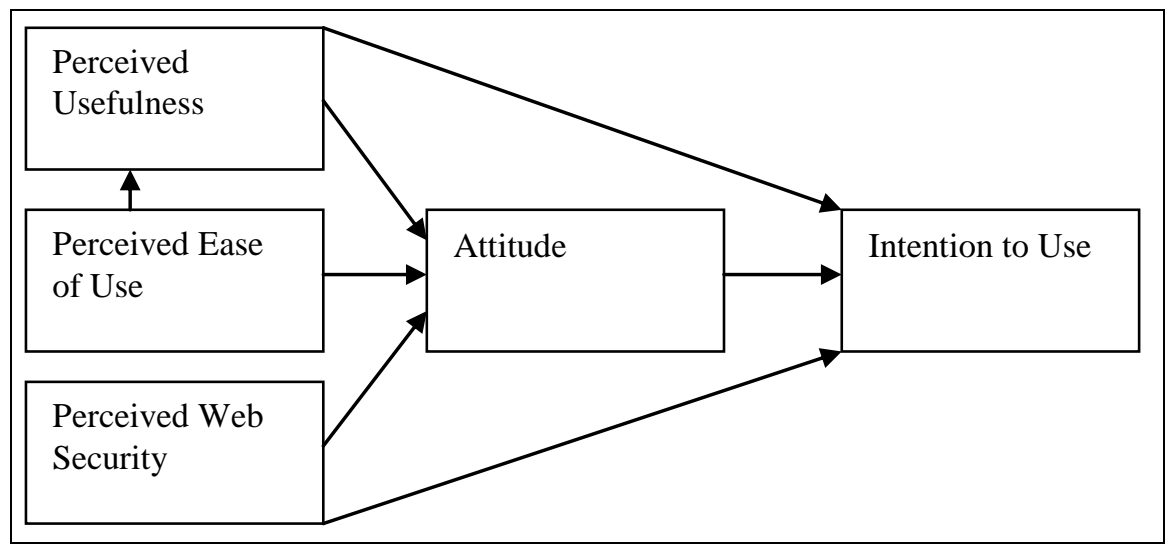

Figure 21: TAM modification to measure customer's intention to use Internet banking (Cheng, Lam et al. 2006) 
The findings confirmed that perceived usefulness and perceived web security positively influenced intentions to use Internet banking services (Cheng, Lam et al. 2006). Moreover, both would positively affect consumer attitude towards Internet banking services. On the other hand, no direct relationship was confirmed between perceived ease of use and the mediating variable attitude towards Internet (Cheng, Lam et al. 2006). A comparable TAM extension was used by Lallmahamood (2007) adding perceived security and privacy constructs to the original TAM model (Davis 1989). This study endorsed that the extended constructs had significant effects on the intention to use Internet banking from a consumer perspective (Lallmahamood 2007).

Katuri and Lam (2003) aimed to identify significant predictor variables for Internet banking activities including the number of transactions as well as the perceived usefulness from a consumer perspective. The results verified that the number of Internet banking transactions were likely to increase for customers who were technicians, married, had higher income and frequent access to Internet from public places (Katuri and Lam 2003).

The acceptance of online banking in Saudi Arabia was tested by Al-Somali et al. (2008) by identifying the factors encouraging customers to use online banking services. Based on the TAM model, the authors developed the below mentioned research model (Figure 22) including extra control variables.

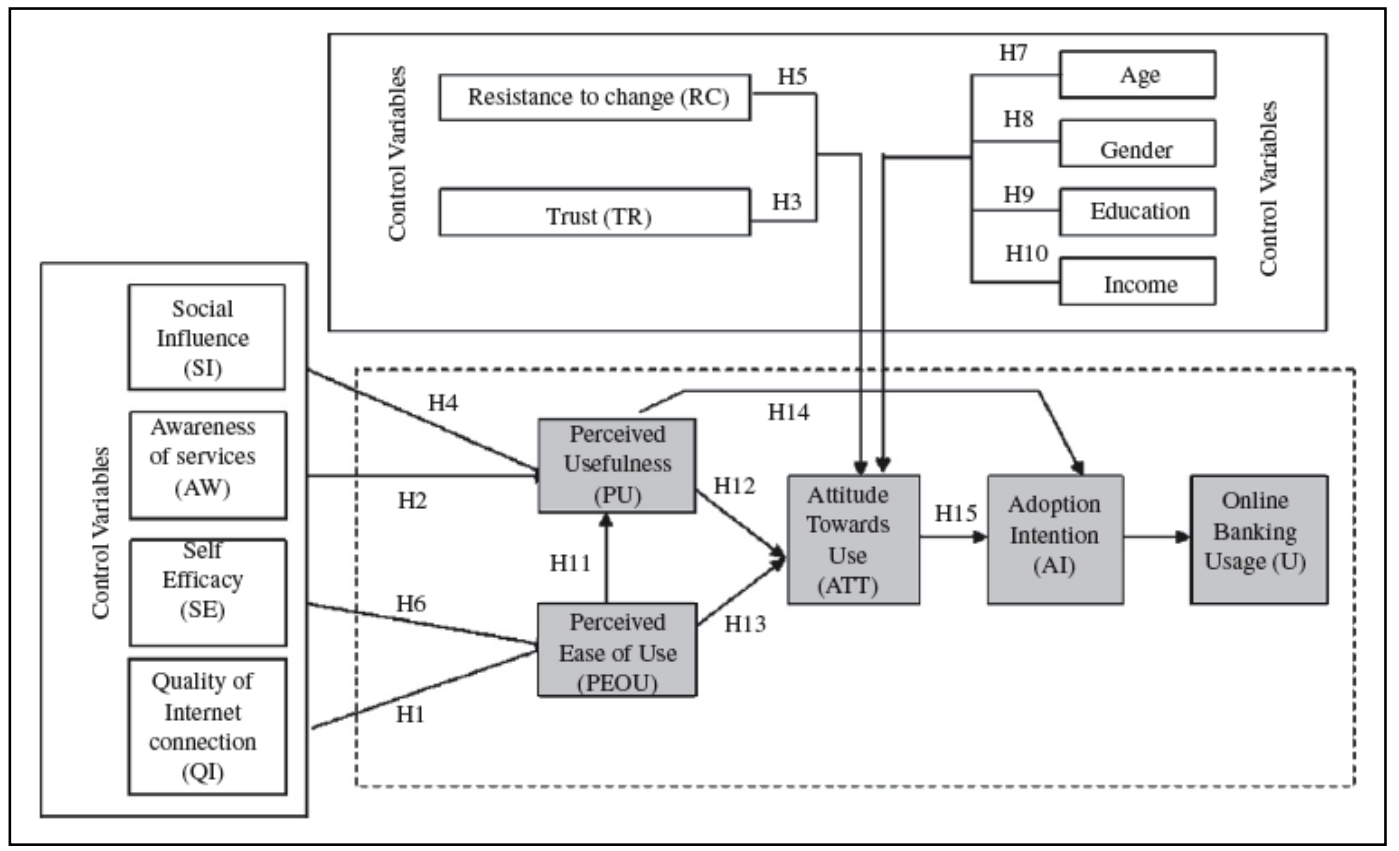

Figure 22: Extended TAM model tested in Saudi Arabia (Al-Somali, Gholami et al. 2008)

To empirically verify the model, 400 customers were surveyed to examine the factors influencing the online banking acceptance (Al-Somali, Gholami et al. 2008). The results of 
this study suggested that the quality of the Internet connection, the awareness of online banking and its benefits, the social influence and computer self-efficacy had significant effects on the perceived usefulness and perceived ease of use of online banking acceptance (Al-Somali, Gholami et al. 2008). Further, education, trust and resistance to change also had significant impacts on the likelihood of adopting online banking (Al-Somali, Gholami et al. 2008).

Based on Servqual and TAM, Liao and Cheung (2008) developed a framework for measuring consumer satisfaction with Internet banking services by suggesting an approach under which service-quality attributes were reduced to a core subset. The authors suggested a framework containing six service-quality attributes as shown on the left hand side in mentioned Figure 23.

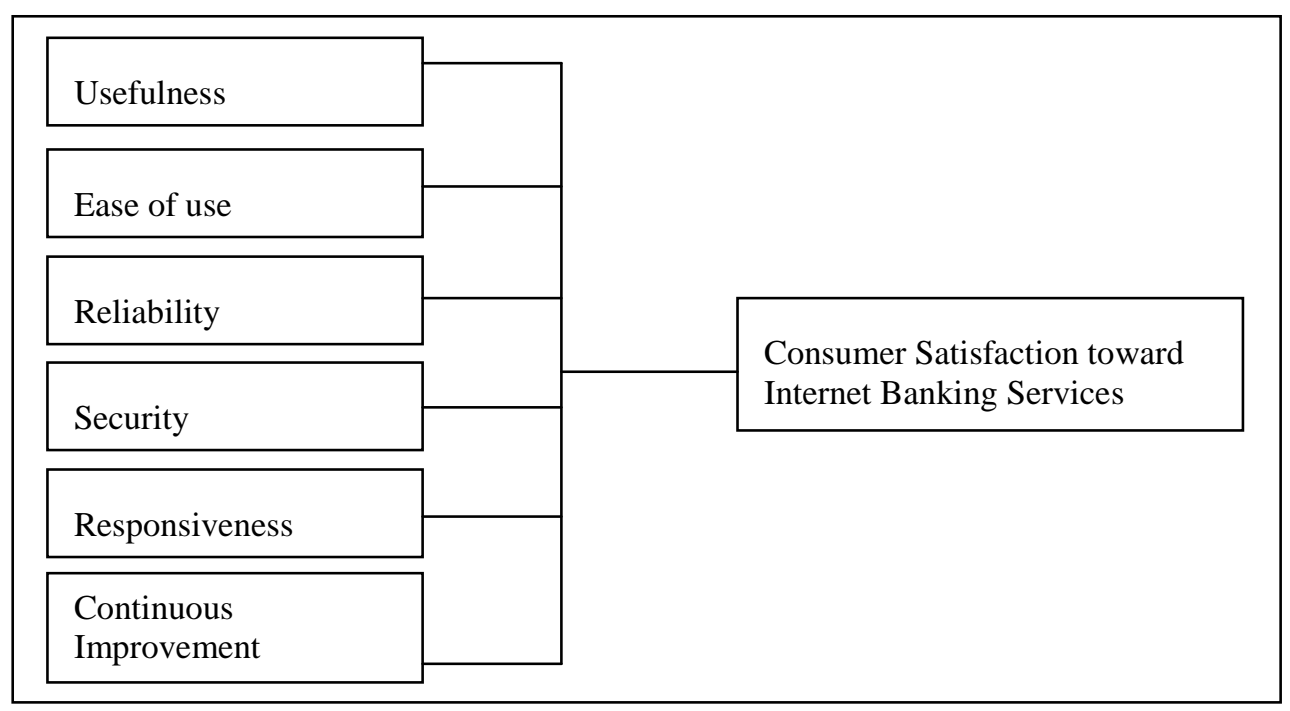

Figure 23: Service-quality attributes for consumer satisfaction toward Internet banking (Liao and Cheung 2008)

To test if the suggested variables were positive determinants of consumer satisfaction toward Internet banking services, the authors surveyed 182 individuals in Hong Kong (Liao and Cheung 2008). The results of this survey confirmed that each property was significant for consumer satisfaction towards Internet banking services (Liao and Cheung 2008).

\subsubsection{TPB/TRA related research on Internet Banking services}

To determine user intention to adopt Internet banking and actual use, Shih and Fang (2004) surveyed personal banking consumers. Attempting to better comprehend how an individual's beliefs, attitudes, and subjective norms influence one's intention to use Internet banking, the authors tested the original theory of planned behavior (TPB) model, the original theory of reasoned action (TRA) model, and a modified TPB model (as shown in Figure 24) by 
surveying banking customers in Taiwan (Shih and Fang 2004). The results suggested that the adjusted TPB model fitted best to explain consumers' behavioral intention, attitude and subjective norm (Shih and Fang 2004).

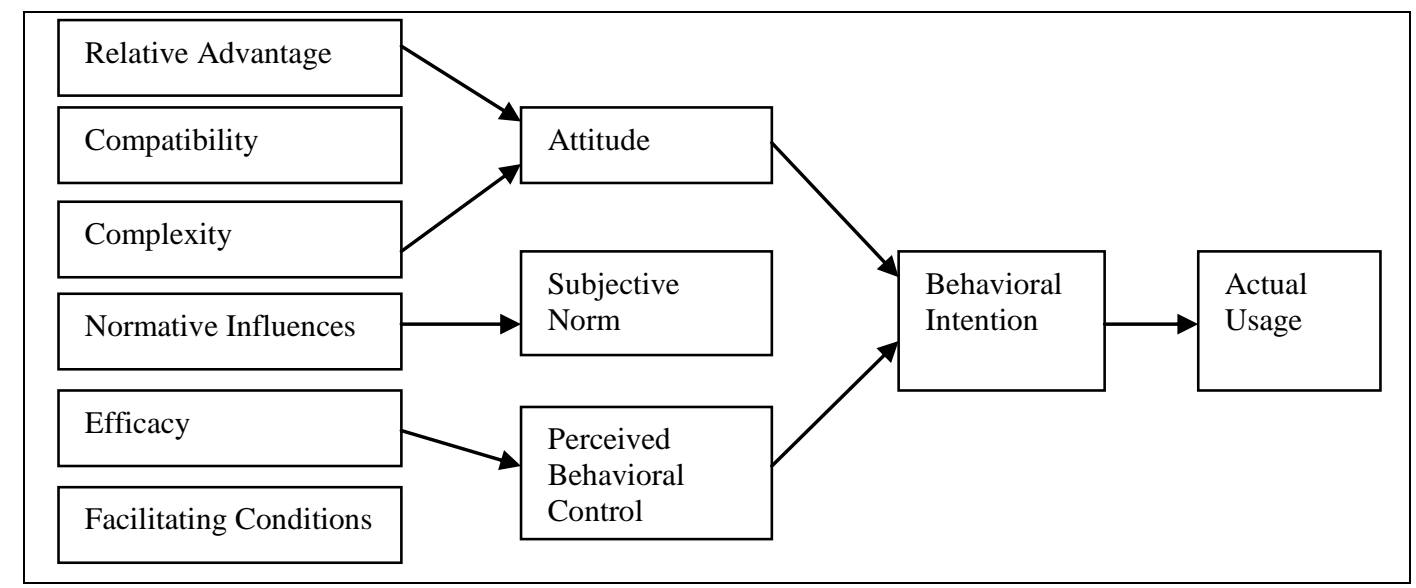

Figure 24: Modified TPB model to explain behavioral intention to use Internet Banking (Shih and Fang 2004)

The paths exhibited in Figure 24 demonstrate the relationships to be found significant within the above mentioned model (Shih and Fang 2004). Relative advantage and complexity were significantly related to attitude. Although efficacy was a determinant of perceived behavioral control, facilitating conditions were not. Attitude and perceived behavioral control were significantly related to behavioral intention. Finally, behavioral intention significantly influenced actual use of Internet banking services (Shih and Fang 2004). Subjective norm was not significantly related to behavioral intention.

Jaruwachirathanakul and Fink (2005) further modified the TPB model when investigating the adoption of Internet banking services in Thailand. Their study confirmed that the features of the website and the perceived usefulness were the most significant attitudinal factors encouraging consumers to use Internet banking services (Jaruwachirathanakul and Fink 2005). On the other hand, external factors such as inadequate access to the Internet, especially broadband, could be seen as impeding factors for the uptake of Internet banking services. Their study also confirmed that the most significant moderating factors were gender, educational level, income and Internet banking experience, but not age (Jaruwachirathanakul and Fink 2005).

Another study researched how to switch customers from physical branches to Internet banking applications. To this end, a research model was developed comprising of the independent factors of customer, transaction, application, and bank; and the dependent variables including the number of Internet banking transaction, perceived usefulness of 
Internet banking, and willingness to use Internet banking services (Katuri and Lam 2007). To test the model, an on-site survey was carried out in physical bank branches to capture the opinion of customers.

The survey results revealed that, for customers with Internet bank accounts, application security was the most significant facilitating variable for them to continue using Internet banking in the future. On the other hand, the variables of proficiency in using computers, application security, and bank image had opposite effects on customers with and without Internet bank accounts (Katuri and Lam 2007). In order to encourage customers without Internet bank accounts to adopt Internet banking, the authors concluded that banks should focus on strengthening the variables of diversified online service, bank responsiveness, bank image, and extra online instruction and feedback for complicated Internet transactions; and reducing the negative effect of web fun / entertainment (Katuri and Lam 2007).

Mäenpää et al. (2008) explored the perceptions and experiences of existing Internet banking users. In particular the moderating role of familiarity with Internet Banking services from a consumer perspective was investigated. A survey of 300 active users of Internet banking services in Finland demonstrated that the level of Internet banking familiarity is positively influenced by: the personal status, auxiliary features of the service, features to support personal finance, and being able to retrieve information about investment products (Mäenpää, Kale et al. 2008). Surprisingly, the remaining three dimensions - convenience, security, and exploration (e.g. discussing investment decisions with others in personal forums) - did not seem to correlate significantly with Internet banking familiarity (Mäenpää, Kale et al. 2008).

Table 7 summarizes the factors influencing the adoption of Internet banking applications found in the existing literature.

Table 7: Factors influencing the adoption and acceptance of Internet banking applications

\begin{tabular}{|c|l|l|l|}
\hline Theory & $\begin{array}{l}\text { Factors influencing } \\
\text { the usage of Internet } \\
\text { banking }\end{array}$ & Definitions & Authors \\
\hline \multirow{6}{*}{ DOI } & Relative advantage & $\begin{array}{l}\text { "The degree to which an } \\
\text { innovation is perceived as } \\
\text { being better than its } \\
\text { precursor" (Moore and } \\
\text { Benbasat 1991) }\end{array}$ & $\begin{array}{c}\text { 2000; Polatoglu and Ekin 2001; Shih and Fang } \\
\text { 2004; Gerrard, Cunningham et al. 2006; } \\
\text { Lichtenstein and Williamson 2006; Eriksson and } \\
\text { Nilsson 2007; Hernandez and Mazzon 2007; } \\
\text { Kuisma, Laukkanen et al. 2007; Sayar and Wolfe } \\
\text { 2007) }\end{array}$ \\
\cline { 2 - 4 } & $\begin{array}{c}\text { Compatibility with } \\
\text { consumer values/culture }\end{array}$ & $\begin{array}{l}\text { "The degree to which an } \\
\text { innovation is perceived as } \\
\text { being consistent with the }\end{array}$ & $\begin{array}{c}\text { (Hamilton and Hewer 2000; Tan and Thompson } \\
\text { 2000; Polatoglu and Ekin 2001; Thornton and } \\
\text { White 2001; Gerrard and Cunningham 2003; }\end{array}$ \\
\hline
\end{tabular}




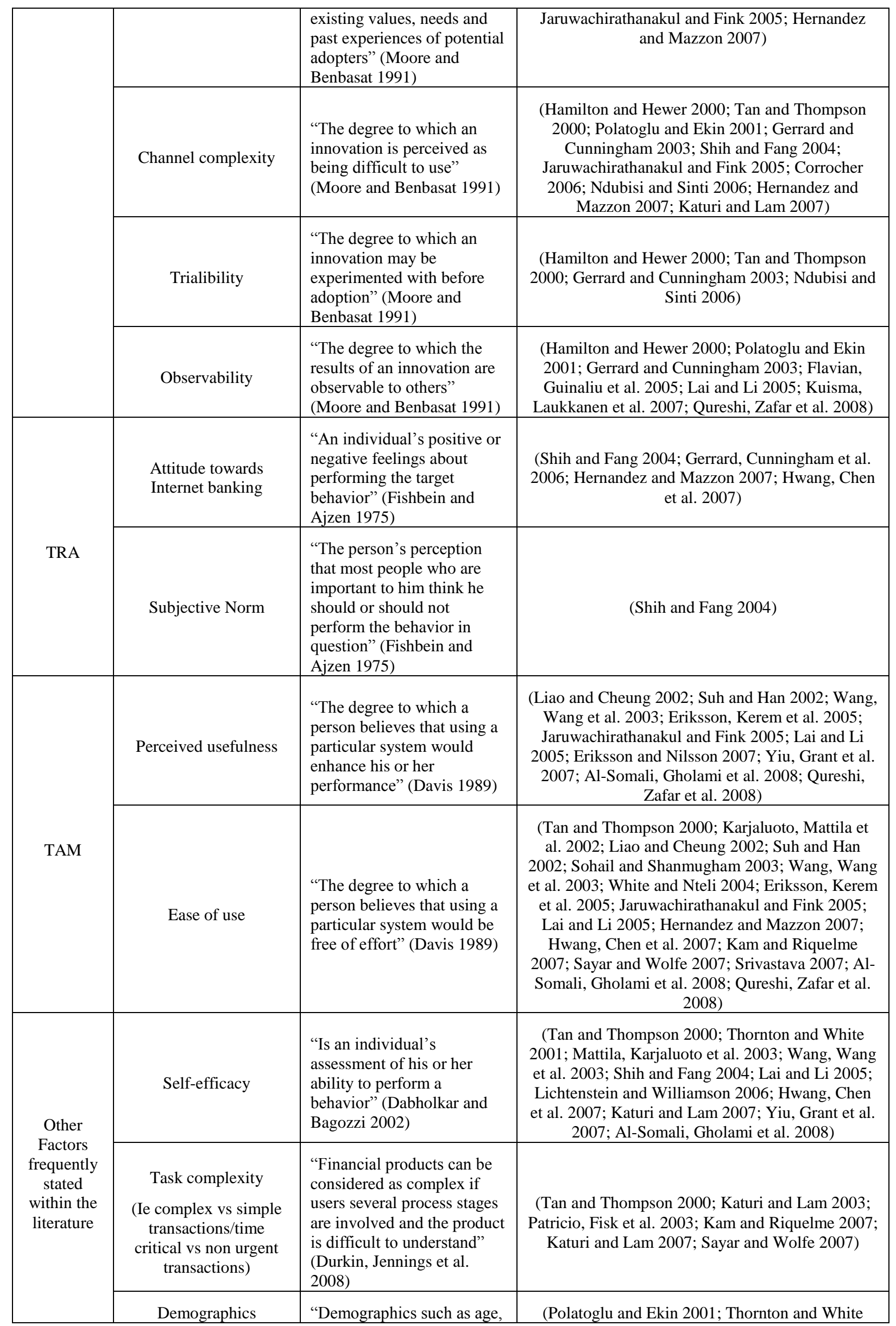




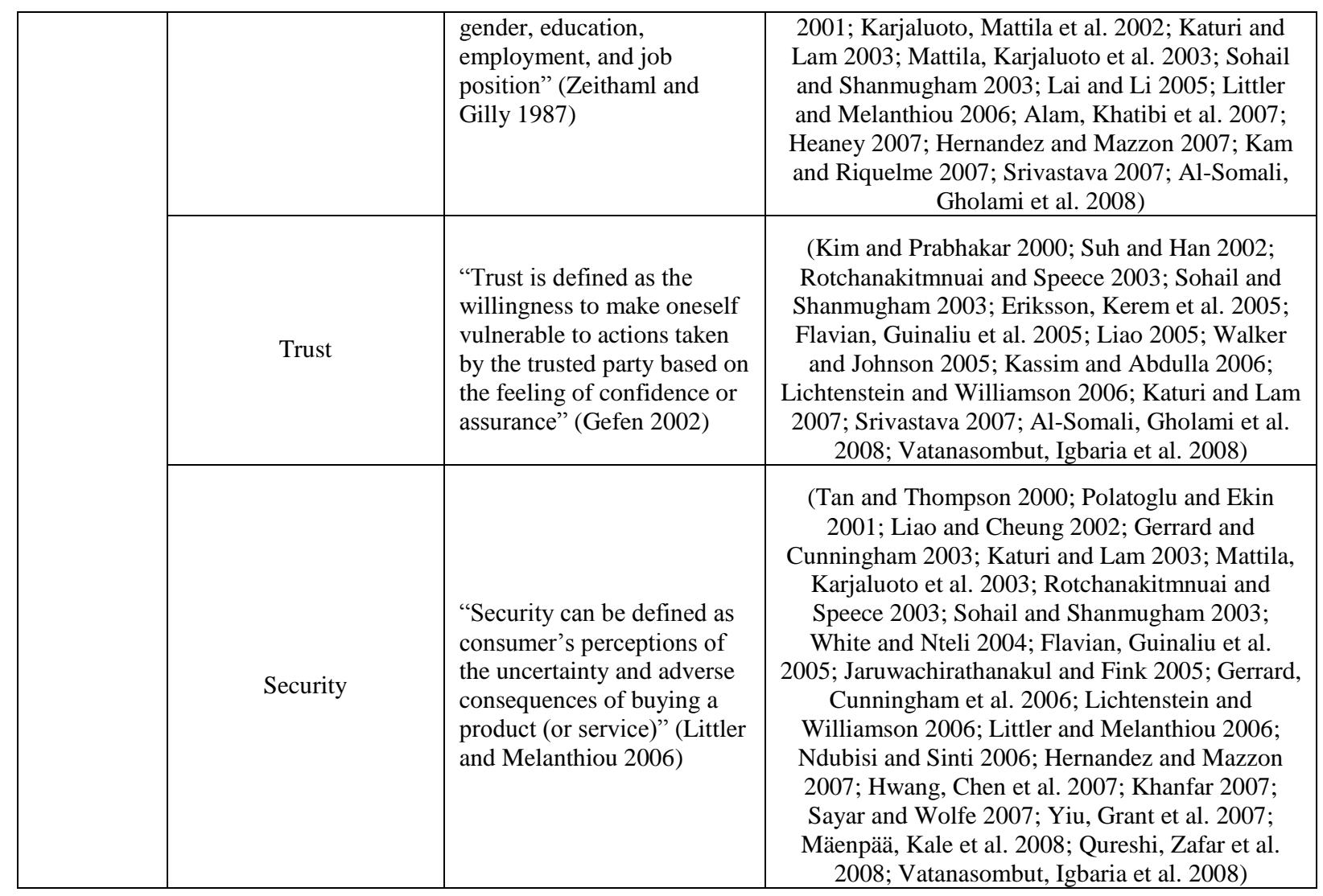

\section{Implications for this study}

The literature on Internet banking affects this research in many ways. Firstly, many of the factors impacting on the adoption and acceptance of Internet applications summarized in Table 7 are integrated within the research model proposed by this study. For example, taskcomplexity is considered as a TCF dimensions described in section 3.3.1. Ease of use and security are proposed to be influential on individuals' intention to use electronic banking channels. Similarly, attitudes towards Internet banking services as well as subjective norms are integrated within the conceptual research model (see Figure 29).

This section has shown that much research has been conducted on the adoption and acceptance of Internet banking services. The following discussion analyzes the literature on mobile banking services.

\subsubsection{Mobile Banking}

In the last decade, the convergence of the Internet and mobile technologies has generated a new channel of electronic commerce often referred to as mobile commerce. One of the most promising applications in this area is mobile banking services because of the ubiquitous and personal nature of mobile technology (Barnes 2003; Mallat, Rossi et al. 2004; Scornavacca, 
Barnes et al. 2006). Mobile banking is a very new phenomenon and the first applications were introduced by banks in the late 1990s (Barnes and Corbitt 2003).

In contrast to phone banking, mobile banking applications are commonly considered whereby customers interact with banks through voiceless applications such as text- or mobile Internet based banking services (Hoehle and Lehmann 2008).

Many authors argued that mobile banking services would allow banks to reduce costs, improving competitiveness, while enabling them to retain the existing customer base (Zhang and Yuan 2002; Huang, Makoju et al. 2003; Shim, Varshney et al. 2006; Tiwari, Buse et al. 2006; Laukkanen, Sinkkonen et al. 2008). Others claim that due to the low adoption rates of mobile banking services in most countries, these applications should be seen as costly experiments for banks attempting to offer customers cutting edge applications (Ensor 2007). On the other hand some consumers may appreciate mobile banking applications since they may conduct financial transactions while traveling such as authorizing money transfers while waiting in queues at supermarkets or trading shares while sitting in airport lounges (Brown, Cajee et al. 2003; Herzberg 2003; Kleijnen, Wetzels et al. 2004; Suoranta and Mattila 2004).

However, the limited input and display capabilities, perceived financial cost, usability and security issues were frequently identified as being the greatest barriers for the adoption of mobile banking services from the consumer's point of view (Tarasewich 2003; Borreguero and Peláez 2005; Hyvärinen, Kaikkonen et al. 2005; Laukkanen and Lauronen 2005; Venkatesh and Ramesh 2006; Laukkanen, Sinkkonen et al. 2008). These barriers might explain the slow uptake of mobile banking services. For example, Forrester Research argued that, in spite of most leading European retail banks offering mobile banking services, only 5\% of internet users were mobile banking consumers in 2007 (Ensor 2007).

The developments of mobile banking services have also drawn the attention of many academics. As a result, in the past ten years, a considerable body of research on mobile banking services has emerged - accounting for nearly 60 peer-reviewed articles published in conferences and journals (Hoehle and Lehmann 2008).

Brown et al. (2003) explored factors influencing the use of mobile banking in South Africa, as a means of understanding how to increase the rate of acceptance. They identified positive factors for mobile banking adoption, including relative advantage, and trialability, as well as consumer banking needs. On the other hand, risk was negatively perceived by consumers (Brown, Cajee et al. 2003; Lee, Lee et al. 2007; Laukkanen, Sinkkonen et al. 
2008). Brown et al. (2003) study in South Africa indicated that underdeveloped markets, which lack existing financial infrastructure, are especially well suited for the adoption of mobile banking services. In these markets few consumers had access to financial accounts. Thus, mobile technologies could potentially revolutionize banking systems, leapfrogging traditional financial services (Brown, Cajee et al. 2003).

A comparable study was undertaken by Lee et al. (2003), researching the limitations consumers face when using mobile banking services within the United Kingdom. This study confirmed that perceived risks negatively impacted on consumers' intentions to use mobile banking services (Lee, McGoldrick et al. 2003).

Other authors used a modified version of the technology acceptance model (TAM) to better predict the mobile banking acceptance (Davis 1989; Kleijnen, Wetzels et al. 2004; Tang, Lin et al. 2004; Luarn and Lin 2005). For instance, Tang et al.( 2004) introduced perceived credibility as a new factor that reflected the user's security and privacy concerns in the acceptance of mobile banking applications. Their research model is illustrated in Figure 25.

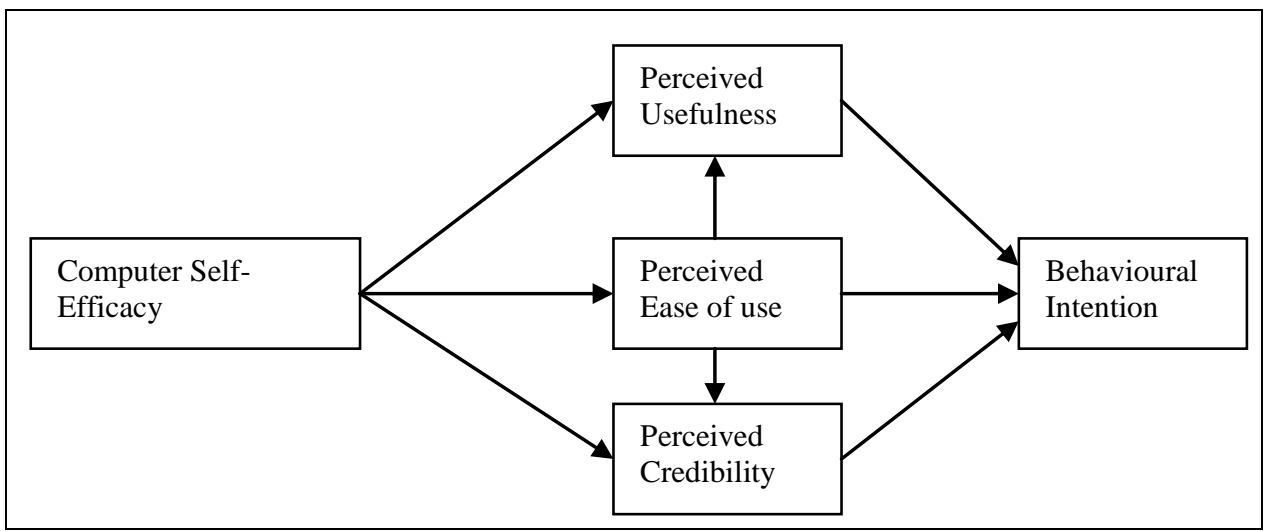

Figure 25: Model explaining behavioral intention to use mobile banking services (Tang, Lin et al. 2004)

Their results strongly supported the above mentioned model in predicting users' intention to use mobile banking services (Tang, Lin et al. 2004). The authors also confirmed a significant effect of computer self-efficacy on behavioral intention to use mobile banking systems through perceived ease of use, perceived usefulness, and perceived credibility (Tang, Lin et al. 2004).

Kleijnen et al. (2004) added perceived cost, system quality and social influence to TAM and confirmed the significant effects of the person's age, computer skills, mobile technology readiness and social influence. High costs were also identified as a barrier for mobile banking because customers would not see relative advantages of mobile banking services over other 
electronic banking services such as ATM banking and Internet banking (Lee, Mattila et al. 2007).

According to the literature on ATMs, many authors confirmed demographic variables such as age and income as a strong indicator for the adoption of mobile banking services (Suoranta and Mattila 2004; Laforet and Xiaoyan 2005; Sulaiman, Jaafar et al. 2007). In contrast to most other studies, Suoranta and Mattila (2004) found that consumers with lower income levels tended to be more willing to use mobile banking services (Suoranta and Mattila 2004). An unusual observation was also made by Laforet and Li (2005), researching the mobile banking use in China. Their study argued that Chinese mobile banking users were predominantly males, not necessarily young and highly educated. Moreover, the lack of awareness as well as the limited understanding of the benefits provided by mobile banking were seen as decelerating factors for the use of mobile banking services (Laforet and Xiaoyan 2005). Another study identified significant differences in attitudes between mature and younger consumers' of mobile banking services (Laukkanen, Sinkkonen et al. 2007).

Some argued consumers value safety, convenience, and efficiency as the most important aspects of mobile banking services (Laukkanen and Lauronen 2005; Laukkanen 2007). Furthermore, location-free access may positively influence consumers willingness to use mobile banking services (Laukkanen and Lauronen 2005). On the other hand, mobile device attributes like tiny displays, slow data connection, weak usability, ineffective input and output mechanisms can hinder the use of mobile banking services (Laukkanen and Lauronen 2005).

The following Table 8 summarizes the factors influencing the adoption and acceptance of mobile banking applications.

Table 8: Factors influencing the adoption and acceptance of mobile banking applications

\begin{tabular}{|c|c|c|c|}
\hline Theory & $\begin{array}{l}\text { Factors } \\
\text { influencing the } \\
\text { usage of mobile } \\
\text { banking }\end{array}$ & Definitions & Authors \\
\hline \multirow{3}{*}{ DOI } & Relative advantage & $\begin{array}{l}\text { "The degree to which an } \\
\text { innovation is perceived as being } \\
\text { better than its precursor" (Moore } \\
\text { and Benbasat 1991) }\end{array}$ & (Kleijnen, Wetzels et al. 2004) \\
\hline & $\begin{array}{l}\text { Compatibility with } \\
\text { consumer } \\
\text { values/culture }\end{array}$ & $\begin{array}{l}\text { "The degree to which an } \\
\text { innovation is perceived as being } \\
\text { consistent with the existing } \\
\text { values, needs and past } \\
\text { experiences of potential } \\
\text { adopters" (Moore and Benbasat } \\
\text { 1991) }\end{array}$ & $\begin{array}{l}\text { (Suoranta and Mattila 2004; Laforet and Xiaoyan } \\
\text { 2005; Sulaiman, Jaafar et al. 2007) }\end{array}$ \\
\hline & Channel complexity & "The degree to which an & (Tan and Thompson 2000; Karjaluoto, Mattila et \\
\hline
\end{tabular}




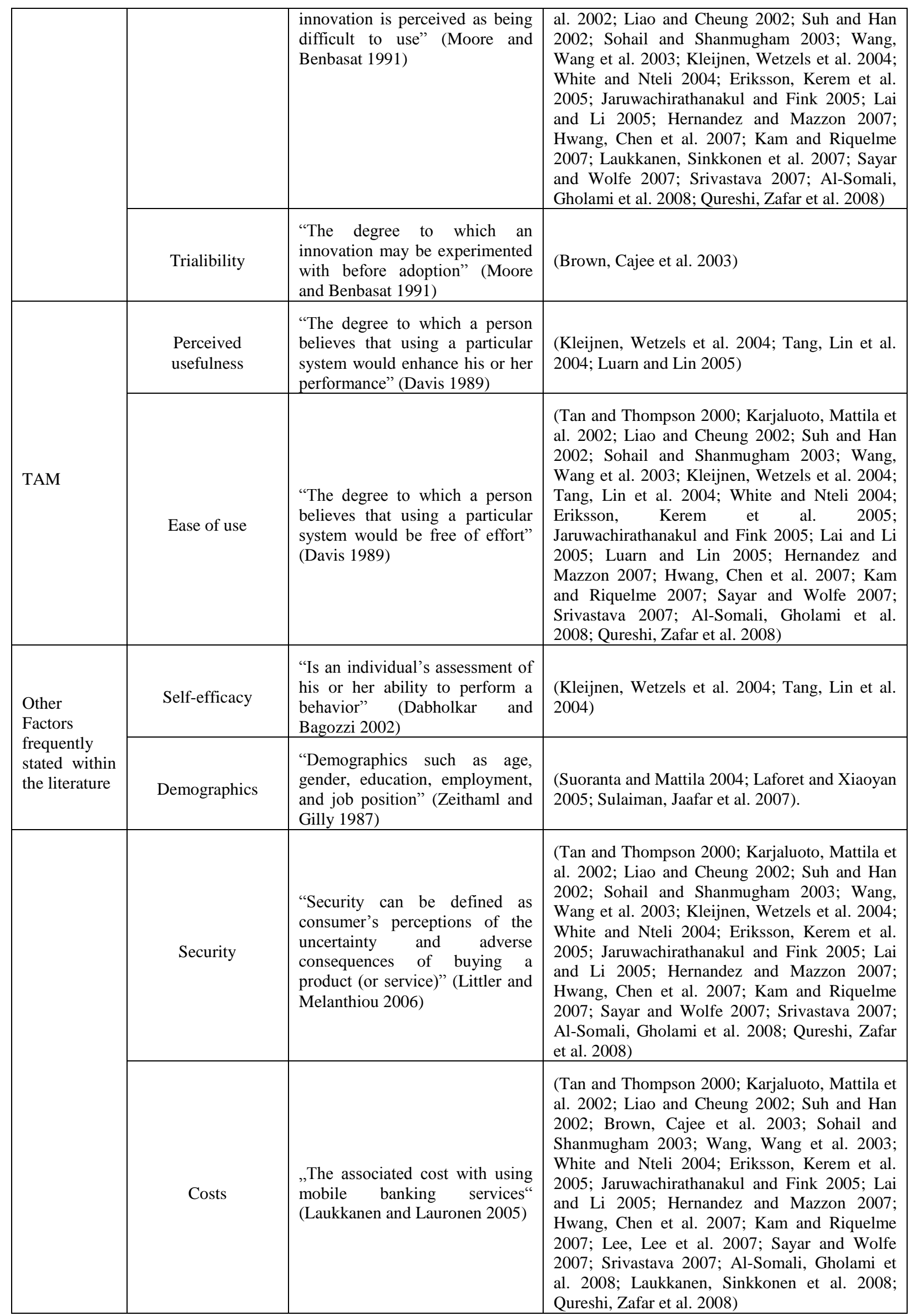




\section{Implications for this study}

Several concepts discussed within the aforementioned section are considered within the research model (Figure 29). For example, ease of use is integrated as a construct impacting on the dependent variable of the research model. Further, the literature on mobile banking services suggested that costs associated with channel use is a major inhibitor for consumers to use mobile banking applications.

\subsubsection{Summary of the literature on electronic banking}

In summary, section 2.6. discussed the adoption and acceptance literature on electronic banking channels. While the literature on telephone banking services is in an embryonic stage, a substantial body of knowledge on the Internet banking services exists. Similarly, many researchers have explored consumers' perceptions towards the concept of ATM banking and more recently mobile banking services.

Many factors identified in this section are considered within the research model developed in section 3. While much literature on the adoption and acceptance of electronic banking channels exists, surprisingly only a few articles considered banking tasks within their investigations. The studies reflecting on electronic banking tasks are discussed in the next section.

\subsection{Electronic Banking Tasks}

This study proposes a task-channel fit concept to assess how electronic banking channels support banking tasks. While the aforementioned sections reviewed the literature on electronic banking channels, this section reflects on the literature available on electronic banking tasks. Banking tasks are banking transactions that consumers perform on electronic banking channels. Since banking tasks differ in their nature (e.g. mortgages are complex while account inquiries are simple), it is important to comprehend their varying characteristics before developing a task-channel fit concept.

For instance, Tan and Thompson (2000) analyzed consumer perceptions of Internet banking consumers to better comprehend their needs and preferences. The below mentioned Table 9 illustrates the list of banking products commonly used by the respondents (Tan and Thompson 2000). 
Table 9: Useful Internet Banking Services (Tan and Thompson 2000)

\begin{tabular}{|l|l|l|}
\hline Internet banking services & Mean & $\begin{array}{l}\text { Standard } \\
\text { deviation }\end{array}$ \\
\hline Account information and balance inquiry & 6.54 & 0.96 \\
\hline Electronic bill payments & 6.13 & 1.30 \\
\hline Summary reports of transactions & 5.78 & 1.51 \\
\hline Fund transfer & 5.63 & 1.60 \\
\hline Check cancellation & 5.59 & 1.65 \\
\hline Checkbook application & 5.41 & 1.65 \\
\hline Financial planning analysis & 4.48 & 1.80 \\
\hline Loan application & 4.38 & 1.92 \\
\hline Share margin trading account & 4.09 & 2.00 \\
\hline
\end{tabular}

As shown above, most consumers rated account information and balance inquiry as being the most useful, followed by bill payments, summary reports of transactions, funds transfer, and check facilities (Tan and Thompson 2000). The authors added that other Internet banking products and services are felt to be useful. These included financial products such as initial public offerings (IPO), unit trusts, bank drafts, and traveler's checks; information on bank and currency rates; as well as wire transfer services (Tan and Thompson 2000).

Howcroft et al. (2003) conducted three focus groups consisting of seven people each. As a result of these discussions, the authors classified financial products into three broad categories. The first broad category was transaction services encompassing current accounts and simple personal loan products (Howcroft, Hewer et al. 2003). These services could be described as very basic transactions where certainty of outcome is high and the process is short term and easy to understand (Howcroft, Hewer et al. 2003). The second classification was named insurance products, which would be slightly more complex than basic transactions. Thirdly, specialist services encompassed investment products, such as stocks, shares, bonds, pensions and longer term lending products such as mortgages (Howcroft, Hewer et al. 2003). These products would typically have more complex search and buy processes given their long-term nature and the uncertainty of outcome. Due to these characteristics, customers would tend to consult bank staff for those transactions as they were difficult to sell via online banking services (Howcroft, Hewer et al. 2003).

Katuri and Lam (2003) characterized transactions according to their degree of importance of transaction amount, degree of importance of transaction type, and degree of importance of transaction cost (Katuri et al. 2003). The authors argued that consumers select -or rejectInternet banking applications depending on the nature of banking transactions (e.g. high/low value payments, urgent payments, perceived importance of the transaction) (Katuri et al. 2003). 
Agarawal et al. (2009) investigated customers' perspectives regarding e-banking services. The findings suggested that consumer view specific transactions (e.g. stock trading) as highly time critical. Stock prices constantly change and consumers view these transactions as highly time-sensitive (Agarwal, Rastogi et al. 2009). In contrast consumers viewed financial loans and mortgages as less time-critical because these products were required in the long-run rather than immediately.

Sayar and Wolfe (2007) compared and evaluated Internet banking services offered by banks in Turkey and the United Kingdom. The authors explored Internet banking services from nine banks in each country. As part of their analysis, the authors classified banking products into several categories (as listed in Table 10).

Table 10: Classification of banking products (Sayar and Wolfe 2007)

\begin{tabular}{|c|l|}
\hline Basic bank products & Account opening/closing/management \\
\hline \multirow{3}{*}{ Credit Products } & Domestic/foreign currency transfer \\
& Standing orders, direct debit \\
& Debit card application \\
& Loan application \\
& Credit card application \\
\hline \multirow{3}{*}{ Investment products } & Deposit account opening/management \\
& Domestic/foreign equity investment \\
& Mutual funds/bonds investments \\
& Insurance investment \\
\hline \multirow{2}{*}{ Other financial products } & Life insurance contract \\
& Traffic insurance contract \\
\hline
\end{tabular}

Firstly, the authors classified basic banking or standard products into one segment including domestic/foreign transfers, standing orders, direct debits, and debit card application (Sayar and Wolfe 2007). More complex products were listed separately subdivided into credit and investment products. Credit related products were further split into loan- and credit card applications while investment products were broken into deposit account management, domestic/foreign equity investment, mutual funds/bonds, and insurance investments (Sayar and Wolfe 2007).

Maenpaa et al. (2008) investigated consumer perceptions of Internet banking services in Finland focusing on consumer familiarity of various Internet banking services. Using crosstabulation, the authors examined the extent Internet banking services were used by user groups (Mäenpää, Kale et al. 2008). The authors classified the familiarity of users into three segments: a) low-, b) medium- and c) high familiarity with Internet banking services.

The results indicated that bill payment and account transfers were the most used Internet banking services with over $90 \%$ of all respondents using these services (Mäenpää, Kale et al. 2008). None of the low-familiar users appeared to be interested in trading shares or mutual 
funds over Internet banking services. In contrast, almost one fifth (17.8\%) of the highly familiar users reported having traded shares or mutual funds via Internet banking services (Mäenpää, Kale et al. 2008). Overall, the responses of this study showed that - apart from paying bills and making account transfers- most customers used Internet banking services to retrieve information about their accounts rather than performing banking transactions (Mäenpää, Kale et al. 2008).

Durkin et al. (2008) examined how complexity of financial products influences consumers' propensity to purchase financial products online. For that reason, a two-stage research study was undertaken consisting of qualitative and quantitative research methods. Within the qualitative phase, the authors explored the nature of the bank-customer relationship and how bankers perceived this to be impacted by product complexity (Durkin, Jennings et al. 2008). The following Table 11 displays the product complexity levels developed as a result of the first stage of this research:

Table 11: Product complexity levels by banking product (Durkin et al. 2008)

\begin{tabular}{|l|l|l|}
\hline \multicolumn{1}{|c|}{ Simple } & \multicolumn{1}{c|}{ Medium } & \multicolumn{1}{c|}{ Complex } \\
\hline Motor Insurance & Life Assurance & Mortgage \\
Home Contents Insurance & Personal Loan & Personal Equity Plan \\
Buildings Insurance & Stocks and Shares & Individual Savings Account \\
Credit Card & & Unit Trusts \\
Premium Bonds & & Pension \\
Post Office Savings & & \\
Bank Saving Accounts & & \\
\hline
\end{tabular}

Combining the findings of the qualitative phase with the existing literature, the authors formulated research propositions that were tested through the use of a survey instrument issued to 5000 of the case bank's customers (Durkin, Jennings et al. 2008). The results indicated that product complexity influenced users choice of Internet banking services over traditional banking channels. The findings illustrated simple products are delivered better through online banking services (Durkin, Jennings et al. 2008). At medium and complex product levels, most consumers would prefer to perform transactions within physical branches having the comfort of consulting banking staff in face-to-face conversations (Durkin, Jennings et al. 2008).

\section{Implications for this study}

The existing literature on electronic banking tasks emphasized the significance of different product attributes when considering channel selection from a consumer perspective. Most researchers categorized banking tasks into simple, medium, and complex products and services. Thus, task complexity is reflected in this study as one dimension of the task-channel 
fit construct (see more detailed discussion in section 3.3.1.). Likewise, research on banking tasks suggested that some banking tasks are performed more often. Thus, task-frequency was identified as another dimension of the task-channel fit construct. Research on banking tasks also suggests that consumers differentiate banking transactions in terms of perceived importance. Mortgages and financial loans were often referred to be important whereas consumers would view domestic transactions and account inquiries as less salient. Hence, task-importance was accepted as another task-channel fit dimension. Lastly, financial transactions such as foreign exchange trades or share brokerage are highly time sensitive due to market volatility, and often require immediate execution. On the other hand, tasks such as transfers, loan applications or insurance acquisitions are less time critical for consumers. Therefore, time-criticality was identified as the fourth task-channel fit dimension.

This section reviewed the literature on banking tasks. The following section will investigate the existing literature studying the factors influencing consumer channel selection.

\subsection{Research on channel usage}

Multi-channeling has greatly affected the way products and services are distributed. This concept has become increasingly common in most product and service driven industries. As a result, much research has been conducted to understand why organizations use multiple channels and how consumers select some channels over others (Jasper and Ouellette 1994; Mattila and Wirtz 2004). Particularly marketing and organizational related research has researched this area.

Within this field, much literature has researched organizational issues related to physical stores and other channels such as mail, telephone, catalogue, and television (Anderson and Weitz 1986; John and Weitz 1988; Klein, Frazier et al. 1990; Rangan, Menezes et al. 1992; Rangan, Corey et al. 1993). For example, some studies applied transaction costs theory to explain channel choice from an organizational perspective (John and Weitz 1988; Klein, Frazier et al. 1990; Rangan, Corey et al. 1993). These studies suggested that product complexity, transaction size, and frequency of usage are particularly important for organizations when choosing the most appropriate distribution channel for their products and services (John and Weitz 1988; Klein, Frazier et al. 1990).

Other studies investigated channel choice from a consumer perspective. For example, Berman (1996) argued that certain products fit specifically well to certain distribution channels. The authors suggested perishable goods will require short channels (e.g. physical 
stores) while non-perishable goods can be distributed through longer channels (e.g. catalogue sales) (Berman 1996). Moreover, high value goods were seen as appropriate to be sold through brick and mortar stores while low value goods were are well suited to be sold through mail and catalogues (Berman 1996).

Balasubramanian (1998) suggested that in absence of transportation cost, consumers would typically purchase from retail stores rather through telephone, mail, catalogue, and television. Sales transactions could be completed quicker in retail stores where consumers also have an opportunity to physically inspect the goods (Balasubramanian 1998). On the other hand, consumers could shop conveniently through channels such as catalogues while facing lower traveling costs (Balasubramanian 1998). Mail, catalogue and television would particularly work well if consumers have no immediate need for a product and if the product quality is a known constant (e.g. music CDs, digital software).

Over the last decade, much research has been conducted to understand how the Internet can be used to extend existing channels. For instance, Balasubramanian et al. (2005) proposed a conceptual framework in which they specify how and why consumers use distribution channels. They argued that increasingly consumers touch and feel products within physical stores and then purchase the products online when they have Internet access (Balasubramanian, Raghunathan et al. 2005). The major motivation for such a behavior is the trait of seeking to acquire products and services inexpensively (Balasubramanian, Raghunathan et al. 2005). On the other hand, consumers would prefer to purchase in physical stores because they may enjoy the social experience (e.g. shopping with friends, talking to sales staff) (Balasubramanian, Raghunathan et al. 2005). Similarly, routines and established shopping schemas might hold back consumers from comparing the costs and benefits of other channels (Balasubramanian, Raghunathan et al. 2005). Also, consumers would pursue different goals during each stage of the purchase process. For example, during the prepurchase phase, consumers would select a channel enabling them to gather information about products conveniently (e.g. Internet storefront). Once they are well informed about the product, consumer may choose a different channel during the purchase stage (e.g. buying the product in a physical store) (Balasubramanian, Raghunathan et al. 2005).

Choudhury and Karahanna (2008) surveyed university staff in order to better understand how and why individuals select electronic channels over traditional brick and mortar outlets. In their study purchasing on electronic channels was not treated as a monolithic decision, rather, the authors assumed consumers make choices across a four step purchase process: 
requirements determination, vendor selection, purchase, and after-sales service (Choudhury and Karahanna 2008). Furthermore, Choudhury and Karahanna (2008) suggested that consumers would use channels based on their perceptions of the relative advantage of the innovation. Therefore, they conceptualized the relative advantage of electronic channels as a multidimensional construct involving three dimensions: convenience, trust, and efficacy of information acquisition (Choudhury and Karahanna 2008). Combining this multidimensional nature of relative advantage with the multistage purchase process, the authors empirically tested the research model below (Figure 26) by approaching research participants for their purchase habits with focus on auto insurances.

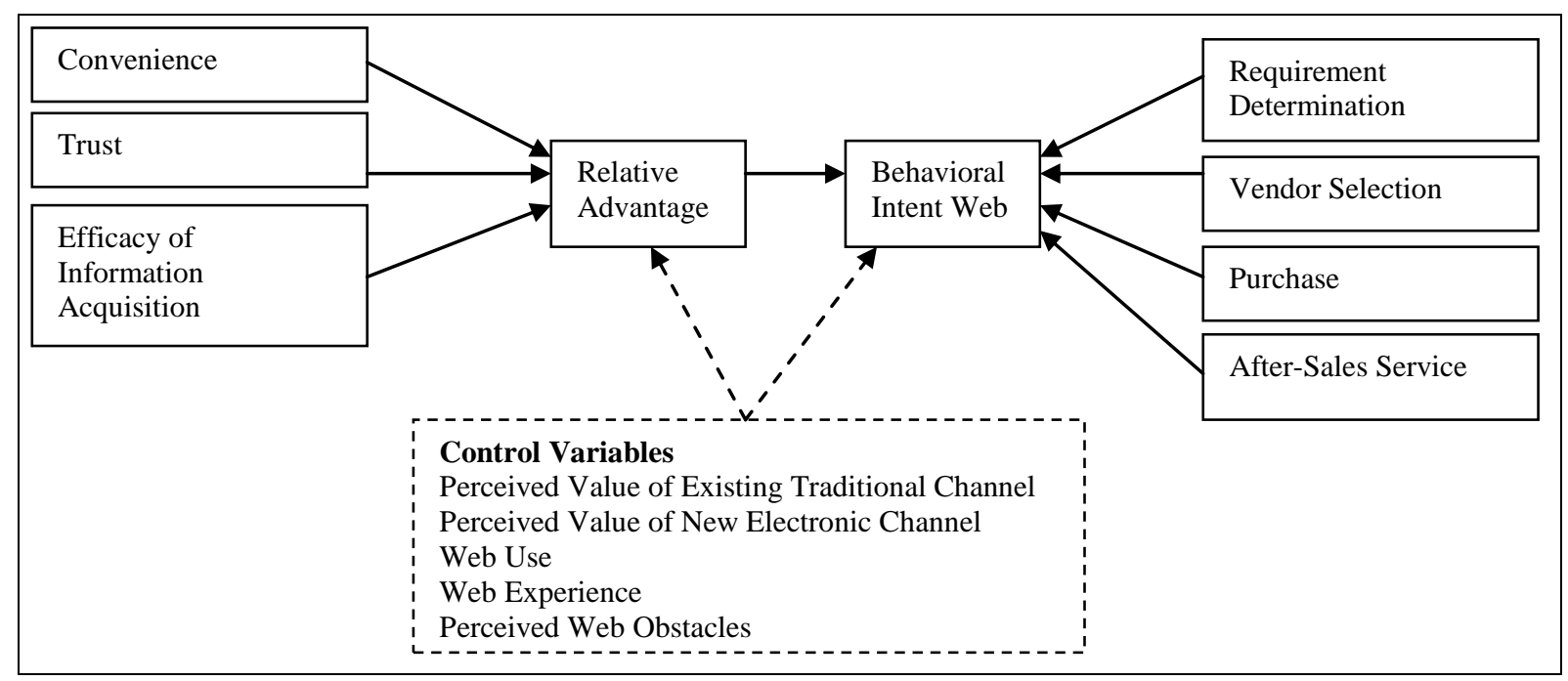

Figure 26: The relative advantage of electronic channels: a research model (Choudhury and Karahanna 2008)

The results of this study led to three conclusions. Firstly, consumers must perceive electronic channels as convenient and trustworthy in order to appreciate a relative advantage of electronic- over traditional channels. What is more, the results of this study confirmed that consumers do not perceive the channel selection process as a single process. Contrary to the authors' assumptions, the findings indicate that consumers seem to divide the purchase process into two broad stages: gathering information and executing transactions (Choudhury and Karahanna 2008). Therefore, the authors suggested reconsidering the above model and possibly modifying the purchase dimension (Choudhury and Karahanna 2008).

As indicated above, much research has investigated consumer behavior related to physical stores and other channels such as mail, catalogue, and Internet across various industries. While further literature in this area exists, most studies confirm that standardized and nonperishable goods are best suited for channels such as mail, catalogues, and Internet. Also, 
consumers feel most comfortable purchasing products online that do not require physical inspection (e.g. clothes).

Instead of discussing further studies researching channel selection in various industries, this literature review continues with research investigating consumer channel selection in the banking industry. In line with the above discussed literature, these studies argued that due to the distinctive characteristics of banking products (e.g. standardized, information based) banking products are particularly well suited for electronically mediated channels.

For instance, Black et al. (2002) investigated channel selection by using the example of financial services. Based on the results of focus group discussions in the United Kingdom, the authors argued that product channel selection is influenced by consumers, products, the organization and the distribution channel itself. The following Figure 27 illustrates the findings gathered by the authors.

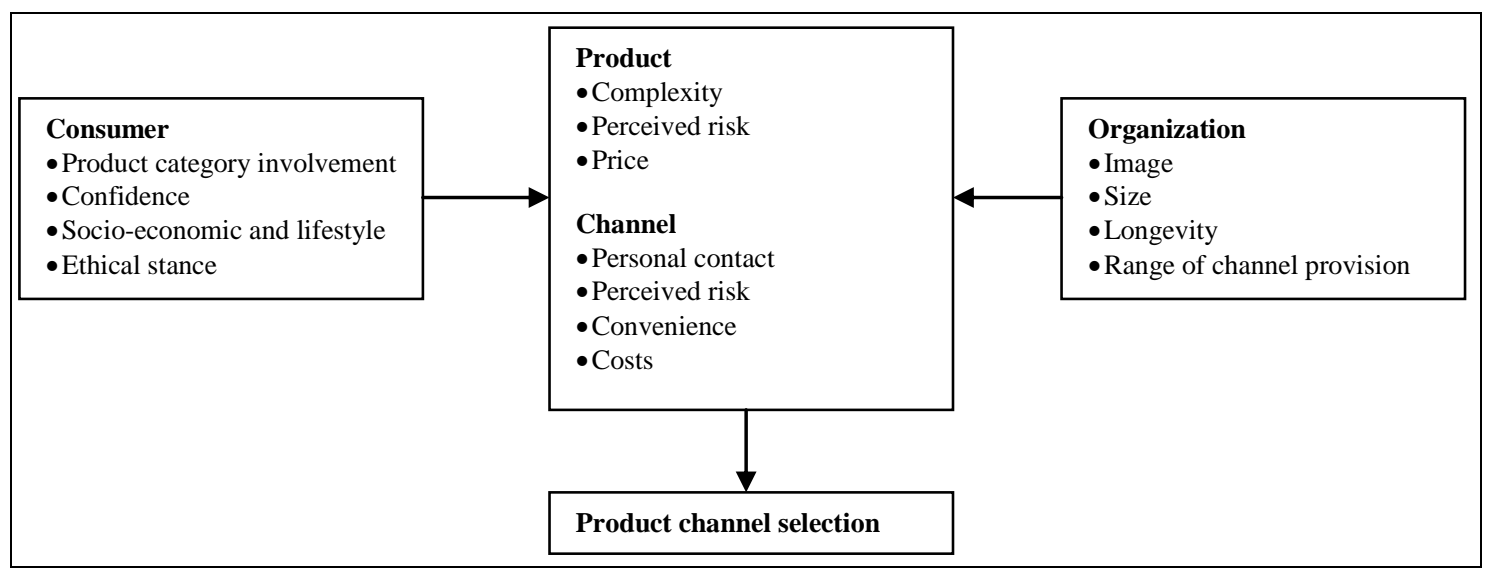

Figure 27: A model of product channel selection for financial services (Black, Lockett et al. 2002)

As displayed on the left hand side, the authors argued that consumers must be confident and comfortable in order to select a channel. Furthermore, a modern lifestyle and correlating time pressure would positively influence consumers to use electronic banking channels since they could use them conveniently $24 / 7$ from home. Similarly, the type of financial product would be a key influencing factor for channel selection. The authors particularly emphasized complexity, perceived risk, and price as product characteristics influencing the consumer channel selection. Further, the organizational image, size, and range of channel provision would affect consumers intentions to use electronic banking channels (Black, Lockett et al. 2002).

Gan et al. (2006) examined consumers' choices between electronic banking and nonelectronic banking services in New Zealand. The authors developed a mail survey which was 
distributed to 1960 households. The authors received 529 usable surveys from which 72 percent were electronic banking users (Gan, Clemens et al. 2006). The results of the analysis indicate service quality, perceived risk factors, employment, and education are the dominant variables influencing consumer choice of electronic banking and non-electronic banking channels (Gan, Clemens et al. 2006).

Van Birgelen (2006) surveyed bank customers towards their satisfaction with channel performance. In their study, the authors assessed clients' behavioral intentions to use Internetand telephone banking services in comparison to physical bank branches (Van Birgelen, De Jong et al. 2006). For non-routine banking services, satisfaction with bank tellers' performance is the most significant driver of intentions (Van Birgelen, De Jong et al. 2006). According to the authors, non-routine services often require interpersonal contact with knowledgeable service employees to discuss customized and complex products and services (Van Birgelen, De Jong et al. 2006). Thus, consumers would prefer to discuss complex banking transactions in face-to-face situations within bank branches.

In contrast, routine services mostly do not require extensive face-to-face contact and customers may even prefer well-functioning and convenient self-service facilities such as Internet banking and telephone banking applications for these (Van Birgelen, De Jong et al. 2006). For standardized services, the work environment played a more important role than the bank teller in determining favorable intentions. Moreover, the results also indicate that the Internet channel seems to be able to complement the bank teller, particularly for more complex services (Van Birgelen, De Jong et al. 2006). In conclusion, well performing technology driven banking services can reduce the necessity of having to visit a physical branch, which customers may appreciate mainly for reasons of convenience (Van Birgelen, De Jong et al. 2006).

Albesa (2007) investigated consumer electronic banking channel preferences and the motives that induce consumers to use physical branches, ATMs or Internet banking services. Clients of saving banks in Spain were approached to better understand how they select banking channels. The results showed consumers who prefer physical branches were driven by the need for social relationships with bank staff. Such consumers enjoyed meeting bank staff face-to-face.

Other consumers were more comfortable using ATMs and Internet banking services as they trusted their privacy would be protected (Albesa 2007). Furthermore, convenience and knowledge of a channel (ATM/Internet banking) were also significant factors when choosing 
a banking channel (Albesa 2007). Figure 28 illustrates the conceptual model derived in this study.

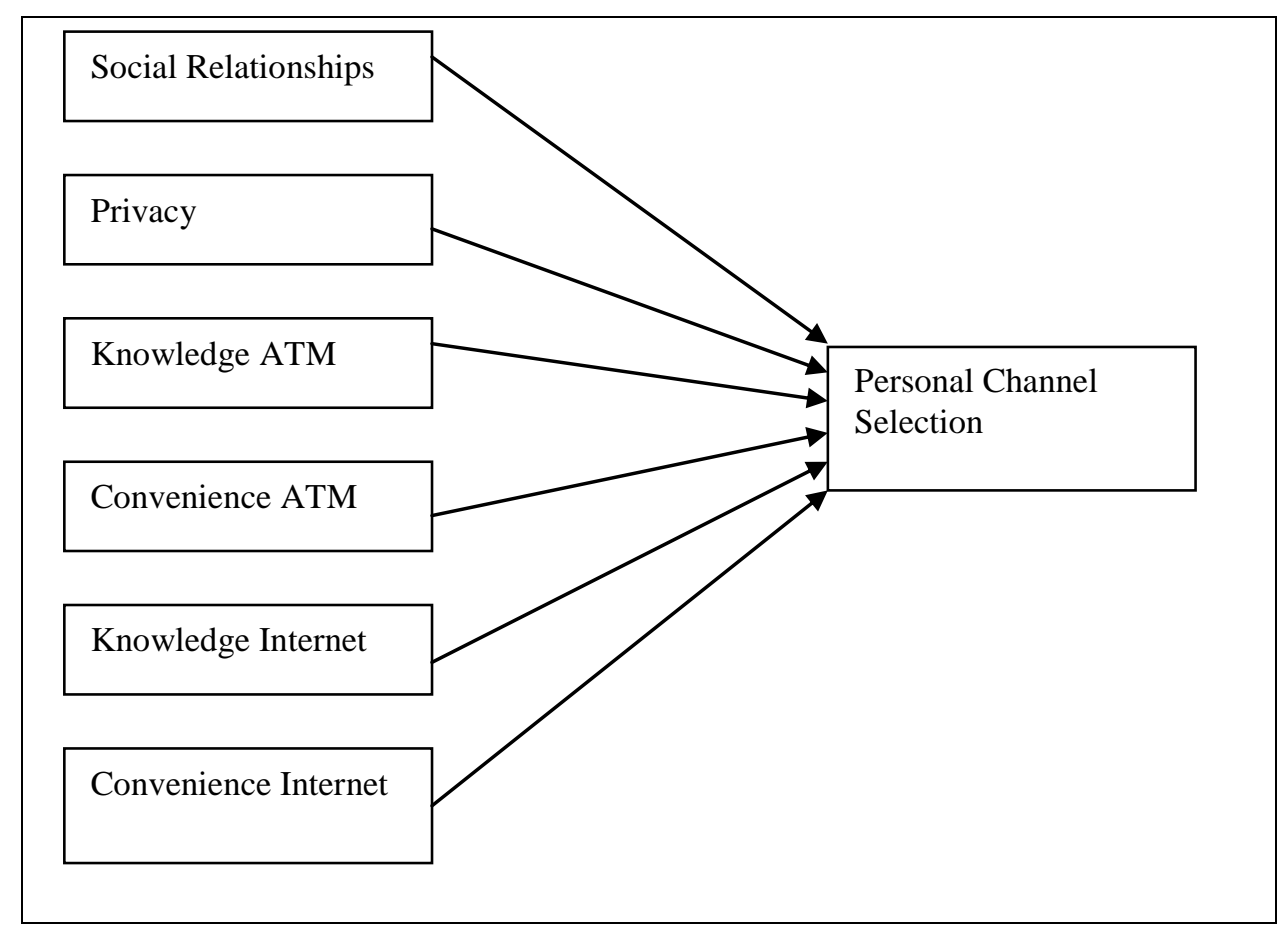

Figure 28: Interaction channel choice in a multichannel environment model (Albesa 2007)

In summary, this section reviewed the literature on channel selection from a consumer perspective. Most research in this area considered consumer related issues such as purchase frequency, size of purchase, and product complexity as the most important drivers for selecting available distribution channels. The studies reviewed in this section also illustrate that the selection- and purchase-process is everything but a monolithic decision. Instead, the purchase process can be understood as different stages that consumers go through including: requirement determination, pre-purchase activity, purchase activity, and after sales activity. Further, the studies on channel selection demonstrated that consumers may choose different channels during each of these stages according to their personal preferences and situational factors (Barczak, Scholder et al. 1997; Morrison and Roberts 1998; Pezullo 1998; Black, Lockett et al. 2002; Lee 2002; Balasubramanian, Raghunathan et al. 2005; Gan, Clemens et al. 2006; Choudhury and Karahanna 2008).

\section{Implications for this study}

The studies discussed in this section illustrated that the characteristics of banking products influence consumers' intentions to use electronic banking channels (Black, Lockett et al. 2002; Van Birgelen, De Jong et al. 2006). In order to assess the task-channel fit construct, 
several dimensions were developed based on the characteristics of banking products (e.g. task complexity discussed in section 3.3.1).

\subsection{Chapter Summary}

The literature review presented in this chapter had the purpose of establishing the theoretical foundations of this research. A number of theoretical concepts that are fundamental for the development of the conceptual model were identified in this chapter.

Section (2.2.) presented literature on the user adoption and acceptance of technology. This included a discussion of the following research models: DOI, TRA, TAM and UTAUT. Subsequently, studies on task-fit were examined to understand how data representation impacts on user performance. Especially data representation studies as well as the cognitive fit theory were reassessed in section 2.3.

Due to its importance for this study, TTF theory (Goodhue and Thompson 1995) was discussed thoroughly in section 2.4. To learn how other researchers applied the TTF theory to other contexts, section (2.5.) reviewed more recent literature related to the original TTF. Section (2.6.1.) analyzed the literature on electronic banking channels including studies on ATMs, telephone banking services (section 2.6.2.), Internet banking (section 2.6.3.), as well as mobile banking applications (section 2.6.4.). The characteristics of electronic banking tasks were discussed in section (2.7.) before research on channel usage (section 2.8.) was evaluated.

In summary, the literature review has demonstrated that there is a gap in the existing literature around the concept of task-channel fit of electronic banking channels. While much literature has investigated the adoption and acceptance of each electronic banking channel independently, little is known how task-channel fit impacts on consumers' intentions to use electronic banking channels. This research aims to address this gap. Drawing upon the literature discussed in this chapter, the following chapter develops the conceptual research model and proposes the research hypotheses. 


\section{Conceptual Model and Research Hypotheses}

\subsection{Chapter outline}

This chapter describes the development of the conceptual research model and identifies research hypotheses that will be used to validate the research model. Based on the extant literature discussed in the previous chapter, four task-channel fit dimensions were identified to measure the task-channel fit construct: 1.Task complexity, 2. Task frequency, 3. Task importance, and 4. Task time criticality.

Next, several other key variables are discussed that impact on consumers' intentions to use electronic banking channels. These precursors of channel utilization include perceived usefulness, ease of use, attitude towards channel use, subjective norms, security, and costs associated with channel use. This is followed by a discussion on the dependent variable intention to use.

The last section of this chapter will report the research findings of relevance checks that were conducted with mangers working for German banks. Nine managerial staff were interviewed about their perceptions towards the TCF concept.

The following sections develop the conceptual research model.

\subsection{Conceptual Research Model}

Informed by the literature review, the conceptual research model shown in Figure 29 was developed.

The model proposes that task-channel fit as well as other precursors of utilization lead to intention to use electronic banking channels at the individual level. While discussed in more depth in section (3.3.1.), the task-channel fit construct is a modification of the TTF concept developed by Goodhue and Thompson (1995). Those researchers demonstrated that a fit between technology and tasks can be measured directly using TTF dimensions (section 3.3.1.). This research borrows from and builds upon their findings.

At the centre of Figure 29, various hypothesized precursors of utilization are shown: perceived usefulness, ease of use, attitude towards channel use, subjective norms, costs associated with channel use, as well as security. The adoption and acceptance theories (section 2.2.) as well as the existing literature on electronic banking channels section 2.6. proposed these precursors. 
On the right hand side, the intention to use electronic banking channel construct is shown. The assumption is that the stronger the intention is to use electronic banking channels, the more likely consumers are going to use electronic banking channels (Dabholkar and Bagozzi 2002; Shih and Fang 2004; Lai and Li 2005; Cheng, Lam et al. 2006). Channel utilization is indicated to be a consequence of individuals' intention to use electronic banking channels.

Much literature found that individuals' intentions reliably predict their actual behavior (Fishbein and Ajzen 1975; Sheppard, Hartwick et al. 1988; Ajzen 1991). In line with this, many Information Systems researchers have used intentions to use variables to predict individuals' actual use behavior in context of Information Systems (Thompson, Higgins et al. 1991; Venkatesh, Morris et al. 2003). The current research also measures intentions to use electronic banking channels to predict individuals' use behavior in context of electronic banking channels. The arrows shown in Figure 29 symbolize the proposed causal relationships between the constructs.

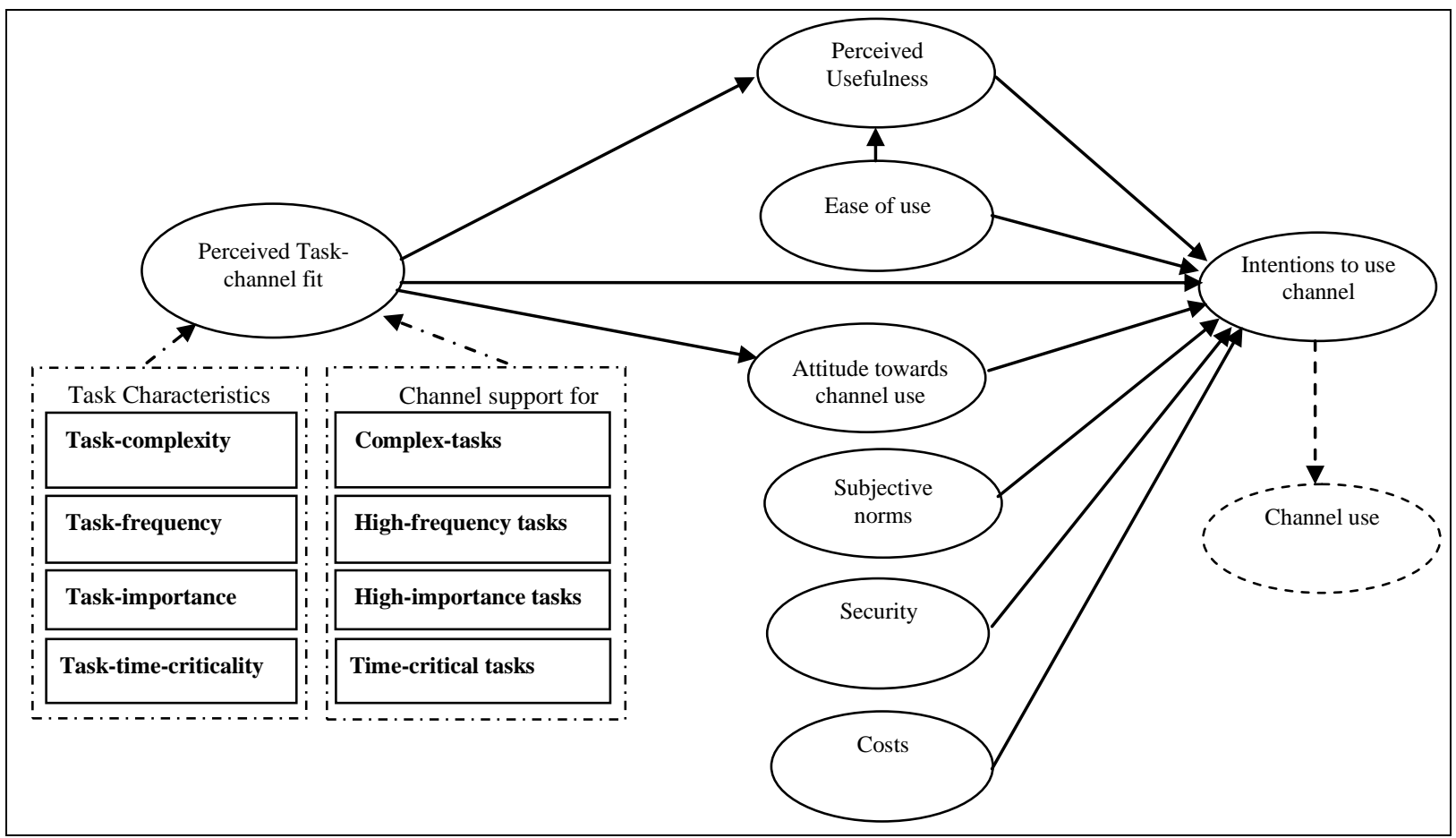

Figure 29: Conceptual research model for the task-channel fit concept of electronic banking channels

Having introduced the conceptual research model, the following sections discuss each construct in more depth and state the research hypotheses. 


\subsection{Development of research hypotheses}

\subsubsection{Task-channel fit}

Drawing from the task-technology fit definition, task-channel fit is defined as the user's perception of the extent of correspondence between a banking task and the suitability of a particular electronic banking channel to support that banking task.

This study defines banking tasks as "a goal-directed banking activity performed by a consumer" (Goodhue and Thompson 1995; Zigurs and Buckland 1998; Zigurs, Buckland et al. 1999; Lim and Benbasat 2000; Dennis, Wixom et al. 2001; Karimi, Somers et al. 2004; Burton-Jones and Straub 2006; Fuller and Dennis 2009).

More specifically, banking tasks include the various kinds of financial and non-financial transactions a consumer may wish to conduct with his or her bank. The existing literature suggests that these tasks differ significantly in their characteristics (Sayar and Wolfe 2007). For instance, account inquiries are simple banking tasks and only a small amount of customer bank interaction occurs when performing these tasks on electronic banking channels. On the other hand, complex tasks such as loans typically require extensive interaction between consumers and banks when executing these transactions (Durkin, Jennings et al. 2008).

Similarly, the level of time-criticality is an important aspect of financial transactions (Tan and Thompson 2000; Liao and Cheung 2002; Kleijnen, Wetzels et al. 2004). For instance, financial transactions such as foreign exchange trades or share purchases are highly time sensitive due to market volatility, and often require immediate execution. On the other hand, transfers, loan applications or insurance acquisitions are less time critical for consumers.

The existing literature on electronic banking suggested that banking tasks can be characterized along a variety of dimensions. Four such dimensions were identified. These dimensions were developed based on a literature review and were subsequently reassessed through five focus group discussions. A more detailed discussion of the focus group process and outcome is given in section 4.3.

The following section discusses each TCF dimension.

\section{Dimension 1 - Task complexity}

Several studies using TTF theory categorized tasks into simple versus complex tasks (Zigurs and Buckland 1998; Shirani, Tafti et al. 1999; Zigurs, Buckland et al. 1999). For

\footnotetext{
${ }^{4}$ Electronic banking channel are defined in section 2.6.
} 
example, Zigurs and Buckland (1998) emphasized the importance of task complexity when considering a task-technology fit for group support systems. The authors subcategorized task complexity into simple tasks, problem tasks, decision tasks, judgment tasks and fuzzy tasks (Zigurs and Buckland 1998; Zigurs, Buckland et al. 1999). While these sub-categories were considered in a group support systems context, banking tasks also vary in their complexity. For example, paying bills or making account status inquiries are simple and not very complex (Durkin, Jennings et al. 2008).

On the other hand, insurance products, loan applications, or acquiring mortgages are multifaceted and should be considered as complex banking tasks (Mäenpää, Kale et al. 2008). Several other authors also emphasized transaction complexity when using electronic banking services. These authors characterized banking transactions into simple, medium and complex transactions (Tan and Thompson 2000; Sayar and Wolfe 2007; Durkin, Jennings et al. 2008; Mäenpää, Kale et al. 2008). Therefore, task complexity was set as one dimension of the TCF construct.

\section{Dimension 2 - Task frequency}

Researchers in various disciplines have investigated how recurring behavior impacts on individuals' actions (Reinsch and Beswick 1990; Rangan, Menezes et al. 1992). For instance, Rangan et al. (1992) argued that frequency of purchase influences on consumers' channel selection. Behavioral frequency has also been noted by IS researchers studying the impact of regular or habitual system usage (Limayem, Hirt et al. 2007; Ortiz de Guinea and Markus 2009).

Research on task-technology fit also suggests that users of specific information systems perceive tasks differently depending on how frequently they perform tasks on the system. Users' would develop a routine if they perform specific tasks regularly (Goodhue and Thompson 1995; Dishaw and Strong 1999; Staples and Seddon 2004).

Similarly, literature on electronic banking found that consumers perform some banking tasks more frequently than others. For instance, many consumers perform account transactions (transferring money between sub-accounts) recurrently while financial loans or applying for mortgages are less frequently performed (Tan and Thompson 2000; White and Nteli 2004; Lichtenstein and Williamson 2006; Van Birgelen, De Jong et al. 2006; Liao and Cheung 2008). Given the extant literature, it seems reasonable to argue that individuals' perceptions of task-channel fit differ depending on how often they perform each task on the 
specific electronic banking channel. Therefore, task frequency was identified as another taskchannel fit dimension.

\section{Dimension 3 - task importance}

Literature on channel distribution has shown that consumers view certain transactions as being more salient than others (Reinsch and Beswick 1990). For instance, buying a car or purchasing a house would be commonly seen as an important transaction by individuals since they would affect a consumer's personal life significantly. On the other hand, buying a candy bar would be less important for most individuals since the purchase decision would not be highly influential for their personal life (Reinsch and Beswick 1990).

Likewise, research on electronic banking suggests that high value transactions (e.g. involving hundreds of dollars) are often viewed as more important than transactions with very low values (Sayar and Wolfe 2007). Also, transactions such as mortgages or financial loans impact significantly and over a longer time-span on a consumer's personal life, hence are perceived as being of high importance, while account inquiries are often seen as lowimportance tasks (Sayar and Wolfe 2007).

Consumers' perceptions of TCF may differ depending on how important they perceive a given banking transaction. Hence, task importance was identified as a third TCF dimension.

\section{Dimension 4 - Task time criticality}

The level of time criticality of a banking task can be understood as the perceived urgency financial transactions require execution (Landry, Rastegary et al. 1991). This concept has been frequently suggested to be an important aspect of financial transactions (Tan and Thompson 2000; Karjaluoto, Mattila et al. 2002; Liao and Cheung 2002; Sohail and Shanmugham 2003; Kleijnen, Wetzels et al. 2004; Tang, Lin et al. 2004; Hernandez and Mazzon 2007; Hwang, Chen et al. 2007; Kam and Riquelme 2007). For instance, financial transactions such as foreign exchange trades or purchasing shares are highly time sensitive due to the market volatilities. Currency rates and stocks prices constantly change, hence such transactions require instant execution. On the other hand, arranging for financial products such as a mortgage is less time-critical since consumers generally take time to plan ahead for those long-term commitments ( $\mathrm{Lin}, \mathrm{Ke}$ et al. 2007). The existing literature on electronic banking has frequently suggested that the level of time criticality impacts on consumers' intentions to use specific electronic banking channels. Thus, the time criticality of banking tasks was adopted as a fourth dimension of TCF. 
In conceptualizing task-channel fit, this research focuses on how consumers perceive each electronic banking channel as suitable in light of the above mentioned task dimensions. As outlined previously, it is reasonable to assume that consumers view certain banking channels as suitable for specific banking tasks (e.g. complex banking transactions) while they see a mis-match for other channels.

Task-channel fit, then, is conceptualized as the aggregate correspondence between a consumer's perception of the characteristics of a banking task (in terms of the four dimensions above) and the suitability of a particular banking channel to support a banking task with those characteristics. Figure 30 displays each TCF dimension and depicts the TCF conceptualization.

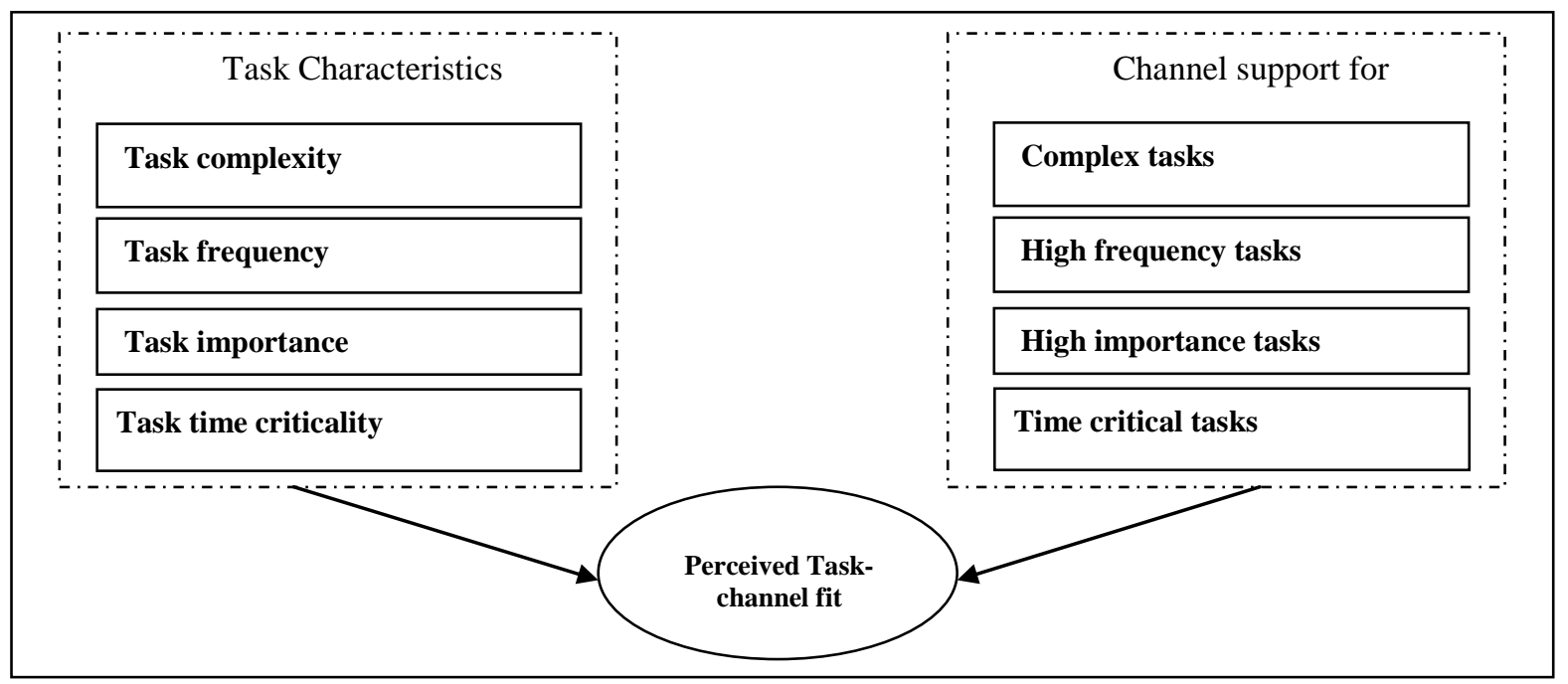

Figure 30: Task-channel fit dimensions of electronic banking services

The conceptual research model (Figure 30) hypothesizes causal relationships between the perceived TCF construct and perceived usefulness, attitude towards channel use and intention to use electronic banking channels. These hypotheses were theoretically grounded in research studying task-technology fit of specific information systems.

For instance, several research studies have linked task-technology fit constructs to other variables. Goodhue and Thompson (1995) suggested that the TTF of a given information system would positively influence users' expected consequences of use and affect towards use. While not empirically tested by Goodhue and Thompson (1995), Staples and Seddon (2004) confirmed a positive correlation between TTF and expected consequences of use as well as affect towards use constructs. The underlying argument was that the better the fit between a task and technology is, the more positive the expected consequences and the higher the users' affect towards using the system would be (Staples and Seddon 2004). 
This study will use perceived usefulness instead of expected consequences of use. Goodhue and Thompson (1995) as well as Staples and Seddon (2004) derived items from Davis (1989) perceived usefulness construct in order to measure their expected consequences of use construct. This shows how closely interlinked these concepts are.

Therefore, it seemed reasonable to hypothesize a positive relationship between the taskchannel fit and perceived usefulness construct. Accordingly, the first hypothesis was formulated as follows:

Research Hypothesis 1 (H1): TCF will be positively associated with perceived usefulness.

As opposed to Goodhue and Thompson (1995) as well as Staples and Seddon (2004), this research used an attitude towards channel use variable instead of using an affect towards channel use construct. Attitude is a broader concept and encompasses an individual's affect toward technology (Venkatesh, Morris et al. 2003). Since Goodhue and Thompson (1995) confirmed a positive relationship between the TTF and the affect towards channel use construct, this research expects a positive relationship between task-channel fit and attitude towards channel use.

Research Hypothesis 2 (H2): TCF will be positively associated with attitude towards channel use.

In addition, Goodhue and Thompson (1995) hypothesized a high task-technology fit would positively influence the utilization of information systems. Likewise, other authors confirmed positive relationships between TTF of specific technologies and utilization constructs (Ferratt and Vlahos 1998; Dishaw and Strong 1999; Shirani, Tafti et al. 1999; Staples and Seddon 2004). Instead of using a utilization construct, Klopping et al. (2004) found also strong support for a positive correlation between TTF and intention to use constructs (Klopping and McKinney 2004).

Therefore, this research hypothesizes a positive relationship between the task-channel fit of electronic banking channels and consumer intention to use them.

Research Hypothesis 3 (H3): TCF will be positively associated with consumer intentions to use channel.

Having conceptualized the TCF construct and its expected causal relationships to other variables in the conceptual research model, the following sections discuss the remaining constructs of the conceptual research model. 


\subsubsection{Perceived Usefulness}

Perceived usefulness is defined as the user's perception of the expected benefits of electronic banking channel use (Bhattacherjee 2001). Many studies on information systems have demonstrated that the perceived usefulness of an information system is an important determinant of individual's intentions to use it (Davis 1989; Thompson, Higgins et al. 1991; Hartwick and Barki 1994; Goodhue and Thompson 1995; Venkatesh, Morris et al. 2003; Staples and Seddon 2004).

Related to electronic banking channels, perceived usefulness is the degree to which an individual believes that using electronic banking channels will help him or her to perform their banking tasks effortlessly (Liao and Cheung 2002; Al-Somali, Gholami et al. 2008). This concept has been well documented by the existing literature on electronic banking channels, suggesting that perceived usefulness would positively influence consumers' intentions to use electronic banking channels (Leblanc 1990; Moutinho 1992; Rugimbana and Iversen 1994; Tan and Thompson 2000; Ahmad and Buttle 2002; Dabholkar and Bagozzi 2002; Kleijnen, Wetzels et al. 2004; Wan, Luk et al. 2005; Rahman 2006; Sayar and Wolfe 2007; Curran and King 2008; Dean 2008).

Therefore, this research hypothesizes that the perceived usefulness of electronic banking channels will positively impact on consumers' intentions to use electronic banking channel channels.

Research Hypothesis 4 (H4): Perceived usefulness of channel use will be positively associated with consumers' intentions to use an electronic banking channel.

\subsubsection{Channel ease of use}

Ease of use is defined as the degree to which an electronic banking channel is perceived as being easy or difficult to use (Davis 1989). Much literature on information systems has demonstrated that the ease of use of specific information systems impact on users' intentions to utilize them (Davis 1989; Venkatesh, Morris et al. 2003). Many studies have shown positive relationships between ease of use constructs and intentions to use variables (Doll and Torkzadeh 1988; Davis, Bagozzi et al. 1989; Thompson, Higgins et al. 1991; Lin, Wu et al. 2005; Thompson, Compeau et al. 2006).

Similarly, much electronic banking literature has been published confirming that ease of use impacts on consumers' intentions to use electronic banking channels (Tan and Thompson 2000; Polatoglu and Ekin 2001; Gerrard and Cunningham 2003; Shih and Fang 2004; 
Jaruwachirathanakul and Fink 2005; Corrocher 2006; Ndubisi and Sinti 2006; Hernandez and Mazzon 2007; Katuri and Lam 2007). Different electronic banking channels are likely to be seen to differ in terms of their ease of use as viewed by consumers. For instance, some consumers may find Internet banking and mobile banking as easy to use while others may find the same channel quite challenging or very difficult.

Therefore, this research hypothesizes a positive relationship between the ease of use of various electronic banking channels and consumers' intentions to use them.

Research Hypothesis 5a (H5a): The ease of use of an electronic banking channel will be positively associated with consumers' intentions to use the channel.

In addition, TAM theory argues that the ease of use of a specific information system impacts on the perceived usefulness of the information system in use. Many other traditional information system research studies have confirmed this linkage. In addition, researchers studying the acceptance of electronic banking channels have substantiated positive relationships between ease of use and perceived usefulness constructs.

Therefore, this research hypothesizes a positive relationship between the ease of use construct and the perceived usefulness variable.

Research Hypothesis 5b (H5b): The ease of use of an electronic banking channel will be positively associated with its perceived usefulness.

\subsubsection{Attitude towards channel use}

TRA theory (Fishbein and Ajzen 1975) has shown that individuals' positive or negative feelings influence intentions towards behavior. Similar suggestions were made by Davis (1989) arguing that attitude towards behavior affects the intentions to use specific information technologies. Other studies also confirmed that a positive relationship between attitude towards system use and utilization constructs related to information systems (Fishbein and Ajzen 1975; Sheppard, Hartwick et al. 1988; Davis 1989; Thompson, Higgins et al. 1991; Compeau, Higgins et al. 1999; Staples and Seddon 2004).

In addition, literature on electronic banking often pointed out that consumers' beliefs and feelings towards electronic banking channels would impact on their intentions to use them (Marshall and Heslop 1988; Thornton and White 2001; Dabholkar and Bagozzi 2002; Shih and Fang 2004; Wan, Luk et al. 2005; Gerrard, Cunningham et al. 2006; Hernandez and Mazzon 2007; Hwang, Chen et al. 2007; Dean 2008). These studies confirmed a positive 
relationship between attitude towards channel use and intention to use constructs in context of electronic banking channels. The underlying argument was that consumers' positive feelings about electronic banking channels positively influence their intentions to use a channel.

Based on the aforementioned studies, it is hypothesized that consumers' (positive or negative) feelings towards electronic banking channels influence their intentions to use them.

Research Hypothesis 6 (H6): Attitude towards channel use will be positively associated with consumers' intention to use the channel.

\subsubsection{Subjective norms}

An individual's subjective norms are perceived normative beliefs ${ }^{5}$ regarding the opinions of others (Fishbein and Ajzen 1975). The subjective norms of an individual are formed either directly (e.g., one individual telling another that he or she should use a particular banking channel) or indirectly (e.g., an individual inferring that others think he or she ought to use the channel).

The acceptance and adoption literature on information systems has recognized how important subjective norms are in relation to the use of specific information systems (Venkatesh, Morris et al. 2003). Many studies found positive relationships between subjective norms constructs and actual utilization rates (Moore and Benbasat 1991; Hartwick and Barki 1994; Venkatesh and Davis 2000; Venkatesh, Morris et al. 2003; Staples and Seddon 2004).

Similarly, research on electronic banking also found that subjective norms impact on the utilization of electronic banking channels (Tan and Thompson 2000; Shih and Fang 2004; Hernandez and Mazzon 2007; Al-Somali, Gholami et al. 2008). These studies argued that subjective norms perceived by individuals positively affect consumer intentions to utilize electronic banking channels (Hernandez and Mazzon 2007). Therefore, this research hypothesizes a positive relationship between subjective norms and consumers' intention to use an electronic banking channel.

Research Hypothesis 7 (H7): Subjective norms will be positively associated with consumers' intentions to use electronic banking channels.

\footnotetext{
${ }^{5}$ Normative beliefs are an individual's perception about the particular behavior, which is influenced by the judgment of significant others such as parents, spouse, friends etc.
} 


\subsubsection{Channel-security}

Research on electronic commerce specifically, as well as broader information systems research, has demonstrated that users must feel secure when using specific information systems (Karahanna, Straub et al. 1999; Wareham, Zheng et al. 2005). These studies argued that consumers would prefer the traditional face-to-face encounter when feeling insecure online.

Similarly, literature on electronic banking has often suggested that consumers' security concerns are an important factor influencing their intentions to use a specific banking channel (Railton 1985; Claessens, Dem et al. 2002; Lee 2004; Muntermann and Güttler 2004; Tang, Lin et al. 2004; Muntermann, Rossnagel et al. 2005; Lallmahamood 2007). Related to electronic banking channels, security can be understood in financial terms, as well as in terms of privacy and the protection of data against unauthorized disclosure, modification, and destruction (Liao and Cheung 2008). The security of personal and sensitive data is a particular concern for consumers when managing their financial transactions through electronic banking channels. Additionally, consumers are often anxious that transactions may not be processed securely by banks.

The literature on electronic banking demonstrated that consumers perceptions on the security level of alternative electronic banking channels differ (Tan and Thompson 2000; Karjaluoto, Mattila et al. 2002; Liao and Cheung 2002; Suh and Han 2002; Lai and Li 2005; Sayar and Wolfe 2007). Some authors suggested that consumers consider banking on ATMs to be securer than other electronic banking channels (Curran and Meuter 2005; Wan, Luk et al. 2005). Similarly, many consumers would still hesitate to perform banking activities on the mobile banking channel due to the perceived insecurity of this channel (Hoehle and Lehmann 2008).

Therefore, this research hypothesizes a positive relationship between perceived channel security and consumers' intentions to use an electronic banking channel.

Research Hypothesis 8 (H8): Perceived channel security will be positively associated with consumers' intentions to use electronic banking channels.

\subsubsection{Costs associated with channel use}

Many studies have argued that costs associated with using a banking channel are an inhibiting factor for consumers (Barnes and Corbitt 2003). For example, while most banks do not charge consumers for utilizing mobile banking applications, consumers often face data 
transmission charges from telecommunication providers (Birch 1999; Barnes and Corbitt 2003; Brown, Cajee et al. 2003; Mallat, Rossi et al. 2004; Borreguero and Peláez 2005; Laforet and Xiaoyan 2005; Laukkanen 2007; Scornavacca and Hoehle 2007). Similarly, charges related to Internet access would often prevent consumers from using Internet banking services from home (Thornton and White 2001; Sayar and Wolfe 2007).

The studies investigating costs associated with channel use found a negative relationship between cost and the use of electronic banking channels. Therefore, it is hypothesized that costs related to electronic banking channel use will be negatively associated with channel use.

Research Hypothesis 9 (H9): Costs associated with channel use will be negatively associated consumers' intentions to use electronic banking channel.

\subsubsection{Intention to use channel}

Fishbein and Ajzen (1975) suggested that behavioral intentions indicate how hard people are willing to try in order to perform the behavior. As a general rule, the stronger the intention to engage in a behavior, the more likely will be its performance (Ajzen 1991).

As discussed in the literature review (section 2.2.2.), many researchers have used Fishbein and Ajzen (1975) TRA theory to study the role of intention as a predictor of behavior related to specific information systems (e.g. usage) (Fishbein and Ajzen 1975; Sheppard, Hartwick et al. 1988; Ajzen 1991; Thompson, Higgins et al. 1991; Venkatesh, Morris et al. 2003; Klopping and McKinney 2004). As a result, multiple studies have confirmed that behavioral intention is strongly correlated with actual usage of specific technologies in voluntary use settings (Sheppard, Hartwick et al. 1988).

Likewise, many researchers have used intentions to use channel constructs to examine consumer behaviors related to the utilization of electronic banking channels. For instance, Dabholkar et al. (2002) investigated factors impacting on consumer intention to use ATM machines. Suh et al. (2002) tested how behavioral intentions to use Internet banking services affect the actual usage. Similar studies were undertaken to research the usage of telephone and mobile banking services (Kleijnen, Wetzels et al. 2004; Tang, Lin et al. 2004). Each of these studies confirmed that positive consumer intentions to use electronic banking channel will lead to higher usage rates (Suh and Han 2002; Shih and Fang 2004; Al-Somali, Gholami et al. 2008). 
Therefore, this research will measure intention to use channel as an indicator of actual channel use. The underlying assumption here is that the stronger consumers' intentions towards channel use are, the more likely consumers will utilize electronic banking channels.

The following Table 12 summarizes the references supporting the constructs discussed above.

Table 12: Supporting references for the constructs used for the TCF research model

\begin{tabular}{|c|c|c|}
\hline Construct & $\begin{array}{l}\text { Supporting References (specific } \\
\text { Information Systems) }\end{array}$ & Supporting References (Electronic Banking) \\
\hline $\begin{array}{l}\text { Task-channel } \\
\text { Fit/Task } \\
\text { technology fit }\end{array}$ & $\begin{array}{l}\text { (Goodhue and Thompson 1995; } \\
\text { Staples and Seddon 2004) }\end{array}$ & $\begin{array}{l}\text { (Tan and Thompson 2000; Sayar and Wolfe 2007; } \\
\text { Durkin, Jennings et al. 2008; Mäenpää, Kale et al. } \\
\text { 2008) }\end{array}$ \\
\hline $\begin{array}{l}\text { TCF Dimension } \\
1 \\
\text { (Task } \\
\text { Complexity) } \\
\end{array}$ & $\begin{array}{l}\text { (Zigurs and Buckland 1998; Shirani, } \\
\text { Tafti et al. 1999; Zigurs, Buckland et } \\
\text { al. 1999) }\end{array}$ & $\begin{array}{l}\text { (Tan and Thompson 2000; Sayar and Wolfe 2007; } \\
\text { Durkin, Jennings et al. 2008; Mäenpää, Kale et al. } \\
\text { 2008) }\end{array}$ \\
\hline $\begin{array}{l}\text { TCF Dimension } \\
\qquad \begin{array}{l}2 \\
\text { (Task } \\
\text { frequency) }\end{array}\end{array}$ & $\begin{array}{l}\text { (Reinsch and Beswick 1990; Rangan, } \\
\text { Menezes et al. 1992; Goodhue and } \\
\text { Thompson 1995; Dishaw and Strong } \\
\text { 1999; Staples and Seddon 2004; } \\
\text { Limayem, Hirt et al. 2007; Ortiz de } \\
\text { Guinea and Markus 2009) }\end{array}$ & $\begin{array}{l}\text { (Tan and Thompson 2000; White and Nteli 2004; } \\
\text { Lichtenstein and Williamson 2006; Van Birgelen, } \\
\text { De Jong et al. 2006; Liao and Cheung 2008) }\end{array}$ \\
\hline $\begin{array}{l}\text { TCF Dimension } \\
\qquad 3 \\
\text { (Task } \\
\text { importance) }\end{array}$ & (Reinsch and Beswick 1990) & (Sayar and Wolfe 2007) \\
\hline $\begin{array}{l}\text { TCF Dimension } \\
\qquad 4 \\
\text { (Task time } \\
\text { criticality) }\end{array}$ & $\begin{array}{l}\text { (Jenkins, Zyanski et al. 1971; Landry, } \\
\text { Rastegary et al. 1991; Gattiker and } \\
\text { Goodhue 2005; Park, Im et al. 2008; } \\
\text { Junglas, Abraham et al. 2009; Yuan, } \\
\text { Archer et al. 2010) }\end{array}$ & $\begin{array}{l}\text { (Tan and Thompson 2000; Karjaluoto, Mattila et al. } \\
\text { 2002; Liao and Cheung 2002; Sohail and } \\
\text { Shanmugham 2003; Kleijnen, Wetzels et al. 2004; } \\
\text { Tang, Lin et al. 2004; Hernandez and Mazzon 2007; } \\
\text { Hwang, Chen et al. 2007; Kam and Riquelme 2007) }\end{array}$ \\
\hline $\begin{array}{l}\text { Perceived } \\
\text { usefulness }\end{array}$ & $\begin{array}{l}\text { (Davis 1989; Thompson, Higgins et } \\
\text { al. 1991; Hartwick and Barki 1994; } \\
\text { Goodhue and Thompson 1995; } \\
\text { Venkatesh, Morris et al. 2003; Staples } \\
\text { and Seddon 2004) }\end{array}$ & $\begin{array}{l}\text { (Leblanc 1990; Moutinho 1992; Rugimbana and } \\
\text { Iversen 1994; Tan and Thompson 2000; Ahmad and } \\
\text { Buttle 2002; Dabholkar and Bagozzi 2002; Kleijnen, } \\
\text { Wetzels et al. 2004; Wan, Luk et al. 2005; Rahman } \\
\text { 2006; Sayar and Wolfe 2007; Curran and King } \\
\text { 2008; Dean 2008) }\end{array}$ \\
\hline Ease of use & $\begin{array}{l}\text { (Doll and Torkzadeh 1988; Davis, } \\
\text { Bagozzi et al. 1989; Thompson, } \\
\text { Higgins et al. 1991; Lin, Wu et al. } \\
\text { 2005; Thompson, Compeau et al. } \\
\text { 2006) }\end{array}$ & $\begin{array}{l}\text { (Tan and Thompson 2000; Polatoglu and Ekin 2001; } \\
\text { Gerrard and Cunningham 2003; Shih and Fang } \\
\text { 2004; Jaruwachirathanakul and Fink 2005; } \\
\text { Corrocher 2006; Ndubisi and Sinti 2006; Hernandez } \\
\text { and Mazzon 2007; Katuri and Lam 2007) }\end{array}$ \\
\hline $\begin{array}{l}\text { Attitude } \\
\text { towards channel } \\
\text { use }\end{array}$ & $\begin{array}{l}\text { (Fishbein and Ajzen 1975; Sheppard, } \\
\text { Hartwick et al. 1988; Davis 1989; } \\
\text { Thompson, Higgins et al. 1991; } \\
\text { Compeau, Higgins et al. 1999; Staples } \\
\text { and Seddon 2004) }\end{array}$ & $\begin{array}{l}\text { (Marshall and Heslop 1988; Thornton and White } \\
\text { 2001; Dabholkar and Bagozzi 2002; Shih and Fang } \\
\text { 2004; Wan, Luk et al. 2005; Gerrard, Cunningham } \\
\text { et al. 2006; Hernandez and Mazzon 2007; Hwang, } \\
\text { Chen et al. 2007; Dean 2008) }\end{array}$ \\
\hline $\begin{array}{l}\text { Subjective } \\
\text { Norms }\end{array}$ & $\begin{array}{l}\text { (Moore and Benbasat 1991; Hartwick } \\
\text { and Barki 1994; Venkatesh and Davis }\end{array}$ & $\begin{array}{l}\text { (Tan and Thompson 2000; Shih and Fang 2004; } \\
\text { Hernandez and Mazzon 2007; Al-Somali, Gholami }\end{array}$ \\
\hline
\end{tabular}




\begin{tabular}{|c|c|c|}
\hline & $\begin{array}{l}\text { 2000; Venkatesh, Morris et al. 2003; } \\
\text { Staples and Seddon 2004) }\end{array}$ & et al. 2008) \\
\hline Security & $\begin{array}{l}\text { (Karahanna, Straub et al. 1999; } \\
\text { Wareham, Zheng et al. 2005) }\end{array}$ & $\begin{array}{l}\text { (Tan and Thompson 2000; Karjaluoto, Mattila et al. } \\
\text { 2002; Liao and Cheung 2002; Suh and Han 2002; } \\
\text { Sohail and Shanmugham 2003; Wang, Wang et al. } \\
\text { 2003; Kleijnen, Wetzels et al. 2004; White and Nteli } \\
\text { 2004; Eriksson, Kerem et al. 2005; } \\
\text { Jaruwachirathanakul and Fink 2005; Lai and Li } \\
\text { 2005; Hernandez and Mazzon 2007; Hwang, Chen } \\
\text { et al. 2007; Kam and Riquelme 2007; Sayar and } \\
\text { Wolfe 2007; Srivastava 2007; Al-Somali, Gholami } \\
\text { et al. 2008; Qureshi, Zafar et al. 2008) }\end{array}$ \\
\hline $\begin{array}{c}\text { Costs associated } \\
\text { with channel } \\
\text { use }\end{array}$ & & $\begin{array}{l}\text { Tan and Thompson 2000; Karjaluoto, Mattila et al. } \\
\text { 2002; Liao and Cheung 2002; Suh and Han 2002; } \\
\text { Brown, Cajee et al. 2003; Sohail and Shanmugham } \\
\text { 2003; Wang, Wang et al. 2003; White and Nteli } \\
\text { 2004; Eriksson, Kerem et al. 2005; } \\
\text { Jaruwachirathanakul and Fink 2005; Lai and Li } \\
\text { 2005; Hernandez and Mazzon 2007; Hwang, Chen } \\
\text { et al. 2007; Kam and Riquelme 2007; Lee, Lee et al. } \\
\text { 2007; Sayar and Wolfe 2007; Srivastava 2007; Al- } \\
\text { Somali, Gholami et al. 2008; Laukkanen, Sinkkonen } \\
\text { et al. 2008; Qureshi, Zafar et al. 2008) }\end{array}$ \\
\hline $\begin{array}{l}\text { Intentions to use } \\
\text { electronic } \\
\text { banking channel }\end{array}$ & $\begin{array}{l}\text { (Fishbein and Ajzen 1975; Sheppard, } \\
\text { Hartwick et al. 1988; Ajzen 1991; } \\
\text { Thompson, Higgins et al. 1991; } \\
\text { Dabholkar and Bagozzi 2002; Suh } \\
\text { and Han 2002; Venkatesh, Morris et } \\
\text { al. 2003; Shih and Fang 2004; Al- } \\
\text { Somali, Gholami et al. 2008) }\end{array}$ & $\begin{array}{l}\text { (Chan and Lu 2004; Tang, Lin et al. 2004; Lai and } \\
\text { Li 2005; Lee 2009) }\end{array}$ \\
\hline
\end{tabular}

The next section displays the conceptual research model and summarizes the associated hypotheses.

\subsection{Conceptual research model including the associated hypotheses}

Figure 31 illustrates the research model to be pilot-tested by this research. In addition to the depicted constructs, the research hypotheses are also stated (H1-H9). 


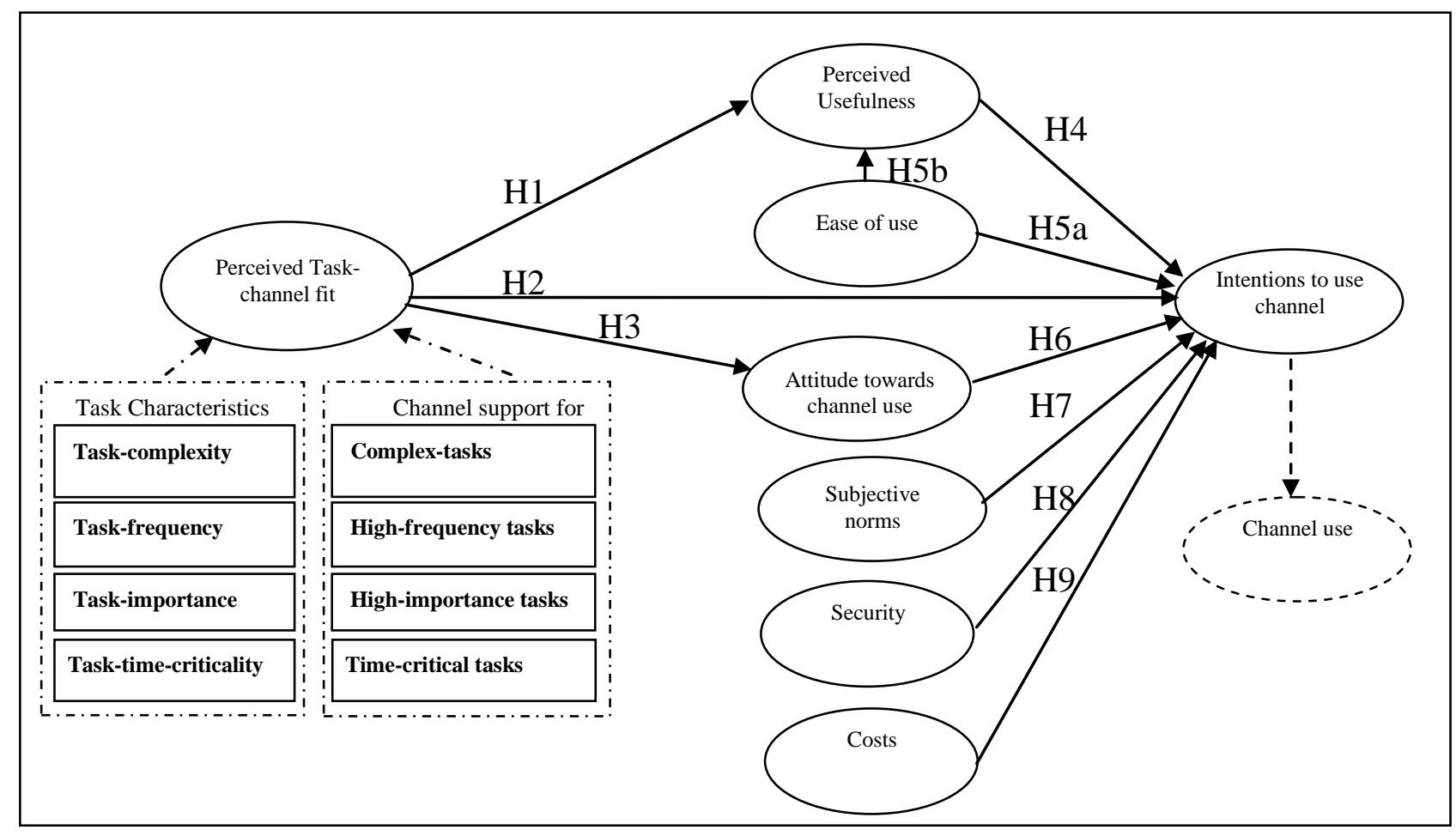

Figure 31: Research model including research hypotheses

Table 13 summarizes the research hypotheses of this research and relates them to studies previously testing causal relationships between similar constructs.

Table 13: Research Hypotheses and supporting references

\begin{tabular}{|l|l|}
\hline \multicolumn{1}{|c|}{ Hypothesis } & \multicolumn{1}{|c|}{ Supporting References } \\
\hline $\begin{array}{l}\text { (H1): TCF will be positively associated with } \\
\text { perceived usefulness. }\end{array}$ & (Goodhue and Thompson 1995; Staples and Seddon 2004) \\
\hline $\begin{array}{l}\text { (H2): TCF will be positively associated with } \\
\text { intentions to use. }\end{array}$ & $\begin{array}{l}\text { (Goodhue and Thompson 1995; Zigurs and Buckland 1998; } \\
\text { Shirani, Tafti et al. 1999; Zigurs, Buckland et al. 1999; Staples } \\
\text { and Seddon 2004) }\end{array}$ \\
\hline $\begin{array}{l}\text { (H3): TCF will be positively associated with } \\
\text { attitude towards channel use. }\end{array}$ & $\begin{array}{l}\text { (Goodhue and Thompson 1995; Zigurs and Buckland 1998; } \\
\text { Shirani, Tafti et al. 1999; Zigurs, Buckland et al. 1999; Staples } \\
\text { and Seddon 2004) }\end{array}$ \\
\hline $\begin{array}{l}\text { (H4): Perceived usefulness of channel use will } \\
\text { be positively associated with consumers' } \\
\text { intentions to use electronic banking channels. }\end{array}$ & $\begin{array}{l}\text { (Davis 1989; Thompson, Higgins et al. 1991; Hartwick and } \\
\text { Barki 1994; Goodhue and Thompson 1995; Venkatesh, Morris } \\
\text { et al. 2003; Staples and Seddon 2004) }\end{array}$ \\
\hline $\begin{array}{l}\text { (H5a): Ease of use will be positively } \\
\text { associated with } \text { intentions to use channel. }\end{array}$ & $\begin{array}{l}\text { (Doll and Torkzadeh 1988; Davis, Bagozzi et al. 1989; } \\
\text { Thompson, Higgins et al. 1991; Lin, Wu et al. 2005; } \\
\text { Thompson, Compeau et al. 2006) }\end{array}$ \\
\hline $\begin{array}{l}\text { (H5b): Ease of use will be positively } \\
\text { associated with perceived usefulness. }\end{array}$ & $\begin{array}{l}\text { (Doll and Torkzadeh 1988; Davis, Bagozzi et al. 1989; } \\
\text { Thompson, Higgins et al. 1991; Lin, Wu et al. 2005; } \\
\text { Thompson, Compeau et al. 2006) }\end{array}$ \\
\hline $\begin{array}{l}\text { (H6): Attitude towards channel use will be } \\
\text { positively associated with intentions to use } \\
\text { electronic banking channels. }\end{array}$ & $\begin{array}{l}\text { (Fishbein and Ajzen 1975; Sheppard, Hartwick et al. 1988; } \\
\text { Davis 1989; Thompson, Higgins et al. 1991; Compeau, } \\
\text { Higgins et al. 1999; Staples and Seddon 2004) }\end{array}$ \\
\hline
\end{tabular}


(H7): Subjective Norms will be positively associated with consumers' intentions to use electronic banking channels.

(H8): Channel security will be positively associated consumer intentions to use electronic banking channels.

(H9): Costs associated with channel use will be negatively associated consumers' intentions to use electronic banking channel.
(Moore and Benbasat 1991; Hartwick and Barki 1994; Venkatesh and Davis 2000; Venkatesh, Morris et al. 2003; Staples and Seddon 2004)

(Wareham, Zheng et al. 2005)
(Tan and Thompson 2000; Karjaluoto, Mattila et al. 2002; Liao and Cheung 2002; Suh and Han 2002; Brown, Cajee et al. 2003; Sohail and Shanmugham 2003; Wang, Wang et al. 2003; White and Nteli 2004; Eriksson, Kerem et al. 2005; Jaruwachirathanakul and Fink 2005; Lai and Li 2005; Hernandez and Mazzon 2007; Hwang, Chen et al. 2007; Kam and Riquelme 2007; Lee, Lee et al. 2007; Sayar and Wolfe 2007; Srivastava 2007; Al-Somali, Gholami et al. 2008; Laukkanen, Sinkkonen et al. 2008; Qureshi, Zafar et al. 2008)

This section introduced the research model to be pilot-tested by this study and stated the hypotheses. The following section reports on a relevance check that was conducted to assess the relevance of the TCF concept for practitioners.

\subsection{Relevance check with German Banks}

To ensure that the outcomes of research projects are valuable to practitioners, Rosemann and Vessey (2008) proposed relevance checks within early phases of research projects. These checks are evaluations by practitioners of the theories, models, and frameworks that the academic community either uses or produces. This way, the relevance of the research can be improved and the researcher can ascertain if the conceptual research project is appreciated by, and would be useful found by, the industry (Rosemann and Vessey 2008).

Therefore, an exploratory investigation was conducted to discover practitioners' perceptions towards the proposed Task-channel fit concept and the research generally. This section describes the methodology used for this and introduces the research participants. Subsequently their evaluations of the TCF concept are outlined.

\subsubsection{Methodology}

To solicit participation, managers from three large German banks were contacted through email or phone. The participants were selected through a convenience sampling strategy (Hufnagel and Conca 1994) and each participant was required to be involved with the strategic planning, maintenance or development of electronic banking channels within their organization. 
Overall, nine managers from three German banks volunteered to be interviewed for the relevance check. During the interviews, initially the task-channel fit concept was introduced and subsequently discussed with each manager. The interviews were held informally. The main objective was to assess how useful practitioners perceive the TCF construct to be.

The interviews took place between June and July 2008. Out of the nine interviews, three were conducted over telephone. These discussions were not tape recorded but field notes were made by the interviewer. Each phone conversation lasted between 10 and 20 minutes.

The remaining six interviews were carried out through face-to-face interviews. Each faceto-face conversation lasted between 50 and 60 minutes and were recorded and transcribed afterwards. Since the interviews took place in German, the researcher translated the transcripts subsequently.

Table 14 introduces the research participants. Banks A and B were traditional banks offering consumers' access through physical branches as well as electronic banking channels. Bank C solely focuses on non-face-to-face channels such as mail, facsimile, email as well as its telephone- Internet- and mobile banking applications.

Table 14: Research participants interviewed for the relevance check of this study

\begin{tabular}{|c|c|c|}
\hline Bank & Participant & Participants job description \\
\hline A & 1 & $\begin{array}{l}\text { A product manager in charge of the development and outsourcing } \\
\text { activities related to electronic banking channels for Bank A. His job } \\
\text { involves the formulation and negotiation of service level agreements } \\
\text { between Bank A and external service provider developing the electronic } \\
\text { banking platforms for Bank A. }\end{array}$ \\
\hline \multirow{4}{*}{ B } & 2 & $\begin{array}{l}\text { A member of the management board and acts as the chief operating } \\
\text { officer of Bank B. He has responsibility for information technology, } \\
\text { human resources and operations. }\end{array}$ \\
\hline & 3 & $\begin{array}{l}\text { A managing director with responsibility for the IT infrastructure in the } \\
\text { private client division of Bank B. In this function, he manages the } \\
\text { technology platform Bank B offers to its clients for electronic banking } \\
\text { services. }\end{array}$ \\
\hline & 4 & $\begin{array}{l}\text { A director of architecture and business development for the private } \\
\text { business division of Bank B. For his job, he monitors new technologies } \\
\text { and applications that may be deployed for electronic banking channels. }\end{array}$ \\
\hline & 5 & $\begin{array}{l}\text { A senior product manager for electronic banking services in the } \\
\text { corporate division of Bank B. In his job, he ensures that multinational } \\
\text { clients can perform various banking transactions on their electronic } \\
\text { banking interfaces with Bank B. }\end{array}$ \\
\hline $\mathrm{C}$ & 6 & A board member and CEO of Bank $\mathrm{C}$ being responsible for business \\
\hline
\end{tabular}




\begin{tabular}{|c|c|l|}
\hline & $\begin{array}{l}\text { development, marketing \& sales and treasury as well as corporate } \\
\text { communications. }\end{array}$ \\
\cline { 2 - 3 } 7 & $\begin{array}{l}\text { A board member of Bank C and his responsibilities include customer } \\
\text { services, human resources, legal services \& organization as well as } \\
\text { institutional business. }\end{array}$ \\
\cline { 2 - 3 } & $\begin{array}{l}\text { A divisional head of customer service of Bank C leading a team that } \\
\text { organizes the day-to-day service support for private client accounts. }\end{array}$ \\
\hline 9 & A product manager for Bank C focusing on mobile banking applications. \\
\hline
\end{tabular}

\subsubsection{Research findings}

Overall, the discussions indicated that the research participants perceived the TCF as a valuable concept for banks. They argued that currently banks do not have well established instruments to judge which products fit each banking channel best.

For instance, participant six argued:

"For us as direct bank, a TCF for electronic banking services would be very interesting. Having such an instrument would tell us which products we should offer on each distribution channel. This is particularly relevant if your distribution channels are primarily electronic media such as phone, Internet and mobile devices...currently we are re-considering which products we should offer on each of those. Having a TCF would be very helpful here."

Accordingly, participant eight said:

"I find the TCF concept interesting. The more I think about it, the more I believe that a TCF instrument would be beneficial to banks. As a bank we constantly check future trends and we need to develop a better understanding of the products we should offer to our clients on each electronic banking channel.....therefore, I believe that the TCF would be useful for our bank."

In addition, the research participants argued that electronic banking services will be more advanced in future and indicated that banks constantly reconsider the product mix for each channel. For example, participant seven reasoned:

"While most people believe that telephone banking is not 'avant-garde' anymore, we believe that Telephone banking is suited even for complex banking products. On our Interactive Voice Response (IVR) system, consumers can perform all banking transactions that we offer on Internet banking services." 
Only one research participant stated that certain products are unsuited for electronic banking channels. He argued that complex banking products are best distributed in face-toface environments:

"There are banking products that are complex per se. These banking products are best suited for interactive banking channels such as call centre or traditional branch. For instance, if consumers would like to discuss mortgages, we believe that a personal face-toface conversation adds value to the client-to-bank relationship. These complex banking products usually require additional explanation because the client becomes involved in a long-term relationship....it also affects their life's tremendously"

This participant recognized that the TCF would be a good way to identify which products are unsuited for electronic banking channels. In consequence, he would expect a very low TCF for very complex banking transactions.

The interviews also revealed that currently banks still "trial and error" their electronic banking applications. The participants pointed out that banks lack of good measurements to indentify consumers' perceptions towards electronic banking channels.

For example, one research participant stated: "While working for another bank, our team spent EUR 300.000 for designing mobile banking applications. Only 27 customers registered for this service from which five customers never used the service. In addition, out of the 22 users 14 were banking staff. As a result, we terminated the service...we will see how this concept develops in future but currently m-banking is everything else but a solution of striking simplicity."

In summary, all nine managers confirmed that a TCF instrument and a study examining the impact of TCF would be beneficial for banks. Apart from the delimitations of this study (e.g. focusing only on electronic banking channels) no manager suggested major modifications of the task-channel fit concept. It was also interesting to note that all managers welcomed the relevance checks and they appreciated their involvement in academic research.

\subsection{Chapter Summary}

This chapter introduced the conceptual research model and established the research hypotheses outlining the relationships between the constructs.

Due to its importance to this research, much attention was paid on the TCF construct. Based on the extant literature discussed in the second chapter, four dimensions were identified 
to measure this construct: 1.Task complexity, 2. Task frequency, 3. Task importance, and 4. Task time criticality.

Subsequently, the precursors of consumer intention to use electronic banking channel were discussed including perceived usefulness, ease of use, attitude towards channel use, subjective norms, security, and costs associated with channel use.

Having discussed the mediating variables, the dependent variable intention to use was introduced and explained. Since much literature has investigated the relationship between intention to use and actual use in various contexts, this research does not test this linkage further and assumes that high intention to use predict higher actual use rates for electronic banking channels.

Section 3.4. summarized the research hypotheses and displayed the model with the associated hypotheses.

The last section of this chapter reported the findings of relevance checks that were conducted with German banks. Nine managerial staff were interviewed about their perceptions towards the TCF concept. Overall, all interviewees confirmed that the TCF theory would be valuable for financial institutions and banks deploying electronic banking channel.

The following chapter outlines the research design proposed for this study. 


\section{Research perspective and instrument development}

\subsection{Chapter Outline}

This chapter initially states the theoretical perspective of this research. In order to re-assess the initial conceptualization of the research model five exploratory focus groups were conducted. The findings of the focus group discussions are analyzed in section 4.3.

Next, a survey questionnaire instrument will be developed. To verify the content validity of the scales, two judgment rounds were conducted consisting of several IS/marketing researchers and practitioners working for banks in New Zealand. Lastly, the developed scales were then pretested during two separate pretest rounds.

Having outlined this chapter, the following sections explain the underlying theoretical assumptions for this research.

\subsection{Theoretical perspective of this research}

The theoretical perspective is the "philosophical view informing the methodology and thus providing a context for the process of grounding its logic and criteria" (Crotty 1998). Among others, the most commonly known perspectives are critical, interpretivism, as well as positivism (and post-positivism).

\subsubsection{Critical Research}

Critical researchers presume that reality is historically constituted and that it is produced and reproduced by people. Although people can consciously act to change their social and economic circumstances, critical researcher believe in their disability to do so because of various forms of social, cultural and political domination. Critical research focuses on the status quo, conflicts and contradictions in contemporary society, thereby transforming the restrictive social conditions (Orlikowski and Baroudi 1991; Meyers 2004).

\subsubsection{Interpretivism}

Interpretive research claims that meanings are constructed by human beings as they engage with the world they are interpreting (Crotty 1998). If not interpreted by observers, the world would have no meaning at all (Crotty 1998). Interpretive research is based on the assumption that our knowledge of reality is based on social constructions: "reality is constructed in and out interaction between human beings and their world, and developed and transmitted within an essentially social context" (Crotty 1998). 


\subsubsection{Positivism}

The positivist stance condenses the spirit or the enlightenment which was unleashed in the seventeenth century throughout Europe. Like the enlightenment, positivism aims to explain the world accurately and tries to understand phenomena scientifically (Crotty 1998).

Positivist researchers presume that reality is objectively given and can be described by measurable properties (Alavi and Carlson 1992; Straub, Gefen et al. 2004). Positivists are concerned about relationships between dependent and independent variables where both must be measurable by the researcher. The vast majority of positivist studies attempt to test theory, aiming to increase the predictive understanding of phenomena. Generally, evidence is sought through formally stated propositions, hypothesis testing, quantifiable measures of variables, and the drawing of inferences about a phenomenon from the sample to a given population (Straub, Gefen et al. 2004).

\subsubsection{Post-positivism}

More recently, many researchers have welcomed a less strict form of positivism accepting that knowledge is fallible and that there is no absolute proof to explain research phenomena. This more or less attenuated form of positivism was developed by the Vienna circle of positivists during the 1920s and 1930s and is known today as post-positivism (Crotty 1998).

One prominent promoter of post-positivism was Karl Popper. He established the "principle of falsification". This concept argues that an advance in science is not a matter of scientists making a discovery and then establishing their concept to be right. Instead, they should make a guess and then try to prove their own guess wrong. Karl Popper once stated: "Good tests kill flawed theories; we remain alive to guess again." (Popper 1980).

While positivist research (both positivism and post-positivism) is commonly linked to quantitative research methods, qualitative researchers can also take on positivist stances since the method chosen to research phenomena should be treated independently of the underlying philosophical assumptions of the researcher (Benbasat, Goldstein et al. 1987; Meyers 2004). However, the epistemological viewpoint and the associated knowledge claims should be identical in positivist research using either qualitative or quantitative research methods.

This research will make knowledge claims based upon the underlying principles of the post-positivism paradigm. Popper's stance in particular appeals to the researcher's worldview. The following section introduces the research methodology chosen for this research. 


\subsection{Focus Groups}

As outlined in section (3.3.1.), initial TCF dimensions were developed to provide a way to assess the TCF construct. However, since these dimensions were solely based upon the existing literature, focus group sessions were organized to re-assess the TCF dimensions, as well as the remaining constructs conceptualized for the research model.

Focus groups comprise a group of individuals selected and assembled by researchers to discuss and comment on the topic that is the subject of the research (Strauss and Corbin 1990; Krueger 1994). The main purpose of focus groups in a research project is to draw upon respondents' attitudes, feelings, beliefs, experiences and reactions. Compared to individual interviews, focus groups extract multiple views within a group context and enable the researcher to gain a larger amount of information in a shorter period of time. Furthermore, focus groups are a suitable way to obtain a consensus on a given topic (Krueger 1994; Putcha and Potter 2004; Rosemann and Vessey 2008).

Calder (1977) argued that focus groups generate qualitative data necessary in exploratory studies, where scientific explanations are required and when the researcher is uncertain of the nature of the constructs to be employed. Researchers should use focus groups in an "explicit attempt to use everyday thought to generate or operationalize theoretical constructs and scientific hypotheses" (Calder 1977).

As noted in the literature review (chapter 2), to date there have been no rigorous studies investigating the perceived fit between electronic banking channels and banking tasks. Therefore, 5 exploratory focus groups consisting of 5-6 electronic banking users were carried out. The primary goal of these sessions was to develop an understanding of how consumers perceive the task-channel fit of electronic banking channels.

It has been argued that between three and six focus groups should be conducted to reach theoretical saturation in exploratory research (Strauss and Corbin 1990; Krueger 1994). When selecting participants the principal concern is to minimize bias rather than produce generalizable results (Krueger 1994). Thus, theoretically motivated purposive sampling methods were employed in selecting participants for this study (Calder 1977). The literature review showed that consumers' age, gender, education, and job generally affects their attitudes and perceptions of electronic banking channels (Thornton and White 2001; Karjaluoto, Mattila et al. 2002; Mattila, Karjaluoto et al. 2003; Lai and Li 2005; Littler and Melanthiou 2006; Heaney 2007). Thus, the focus groups were selected so as to achieve a wide variety of individual characteristics across the different user groups. 
All initial contacts were be made through contacting the research participants via email, telephone or face-to-face conversations. A prerequisite for participation within the focus groups was that each participant had used at least one electronic banking channel for their banking needs and that they were familiar with the most common functionalities of that specific channel. Likewise, it was ensured that all participants had to be involved in the purchasing of financial products in their own household.

The participants' characteristics (e.g. gender, age, education, and job) as well as their experience with each electronic banking channel are summarized in Table 15.

Table 15: Research participants contributing to the focus group discussions

\begin{tabular}{|c|c|c|c|c|c|c|}
\hline \multirow{2}{*}{$\begin{array}{l}\text { Focus } \\
\text { Group }\end{array}$} & \multirow{2}{*}{$\begin{array}{l}\text { Partici } \\
\text { pant }\end{array}$} & \multirow{2}{*}{$\begin{array}{l}\text { Participant's characteristics } \\
\text { (Gender, Age, Education, Job) }\end{array}$} & \multicolumn{4}{|c|}{ Experience with channel } \\
\hline & & & ATM & Phone & Internet & Mobile \\
\hline \multirow{6}{*}{1} & 1 & $\begin{array}{l}\text { F, 25, Bachelor of physical education, personal trainer } \\
\text { - fitness consultant }\end{array}$ & $\mathbf{X}$ & $\mathbf{X}$ & $\mathbf{X}$ & \\
\hline & 2 & M, 34, registered electrician, electrician & $\mathbf{X}$ & $\mathbf{X}$ & $\mathbf{X}$ & \\
\hline & 3 & $\begin{array}{l}\text { M, 30, Bachelor with honours-philosophy, policy } \\
\text { analyst (Government) }\end{array}$ & $\mathbf{X}$ & & $\mathbf{X}$ & \\
\hline & 4 & M, 44, High school, Senior advisor (Government) & $\mathbf{X}$ & $\mathbf{X}$ & $\mathbf{X}$ & \\
\hline & 5 & F, 24, Student (Bachelor/ honours - marketing) & $\mathbf{X}$ & $\mathbf{X}$ & $\mathbf{X}$ & \\
\hline & 6 & M, 25, Student (Bachelor/ honours - marketing) & $\mathbf{X}$ & $\mathbf{X}$ & $\mathbf{X}$ & $\mathbf{X}$ \\
\hline \multirow{5}{*}{2} & 7 & F, 40, Bachelor of Arts, Marketing Analyst & $\mathbf{X}$ & $\mathbf{X}$ & $\mathbf{X}$ & \\
\hline & 8 & F, 54, Secondary school, Editor & $\mathbf{X}$ & $\mathbf{X}$ & $\mathbf{X}$ & \\
\hline & 9 & F, 54, PhD - English literature, University staff & $\mathbf{X}$ & & $\mathbf{X}$ & \\
\hline & 10 & F, 36, Diploma in Fine Arts, Administrator & $\mathbf{X}$ & $\mathbf{X}$ & $\mathbf{X}$ & \\
\hline & 11 & M, 26, Bachelor of Arts, Editor & $\mathbf{X}$ & $\mathbf{X}$ & $\mathbf{X}$ & $\mathbf{X}$ \\
\hline \multirow{5}{*}{3} & 12 & F, 61, Bachelor of Arts, Nurse & $\mathbf{X}$ & & & \\
\hline & 13 & $\begin{array}{l}\mathrm{F} \text {, 55, Teaching Diploma as well as certificate in } \\
\text { automotive engineering, car mechanic }\end{array}$ & $\mathbf{X}$ & $\mathbf{X}$ & $\mathbf{X}$ & \\
\hline & 14 & $\begin{array}{l}\text { M, 46, Masters diploma in Automotive engineering, } \\
\text { Entrepreneur }\end{array}$ & $\mathbf{X}$ & & $\mathbf{X}$ & \\
\hline & 15 & M, 60, certificate/real estate industry, Entrepreneur & & $\mathbf{X}$ & $\mathbf{X}$ & \\
\hline & 16 & $\begin{array}{l}\text { F, 31, Bachelor and Diploma in teaching, secondary } \\
\text { school teacher }\end{array}$ & $\mathbf{X}$ & $\mathbf{X}$ & $\mathbf{X}$ & \\
\hline \multirow{5}{*}{4} & 17 & M, 34,High School, Real estate manager & $\mathbf{X}$ & $\mathbf{X}$ & $\mathbf{X}$ & \\
\hline & 18 & F, 39, High School, Television & $\mathbf{X}$ & $\mathbf{X}$ & $\mathbf{X}$ & \\
\hline & 19 & M, 33, PhD Engineering Science, Software developer & $\mathbf{X}$ & $\mathbf{X}$ & $\mathbf{X}$ & \\
\hline & 20 & F, 26, Bachelor of Arts - tourism, Receptionist & $\mathbf{X}$ & & $\mathbf{X}$ & \\
\hline & 21 & F, 27, Bachelor of arts, Web-des. - Freelancer & $\mathbf{X}$ & & $\mathbf{X}$ & $\mathbf{X}$ \\
\hline \multirow{5}{*}{5} & 22 & M, 34, Bachelor - Film, Television & $\mathbf{X}$ & $\mathbf{X}$ & $\mathbf{X}$ & \\
\hline & 23 & $\begin{array}{l}\text { M, 35, Bachelor in Film and Television, Broadcast } \\
\text { editor for Television channel }\end{array}$ & $\mathbf{X}$ & $\mathbf{X}$ & $\mathbf{X}$ & $\mathbf{X}$ \\
\hline & 24 & F, 29, Masters - Mathematics, Lecturer at tertiary level & $\mathbf{X}$ & $\mathbf{X}$ & $\mathbf{X}$ & \\
\hline & 25 & F, 30, Design Diploma, unemployed & $\mathbf{X}$ & & $\mathbf{X}$ & \\
\hline & 26 & F, 31, Bachelor of Arts, Graphic Designer & $\mathbf{X}$ & & $\mathbf{X}$ & \\
\hline
\end{tabular}

Data collection was carried out through semi-structured focus group discussions featuring open-ended questions. Examples of the non-structured questions presented to the focus group panels are stated below: 
- What banking transactions/products do you perform on each electronic banking channel? And why?

- What do you think influences you to use each electronic banking channel?

Each focus group discussion lasted approximately 60-90 minutes and was moderated by the researcher. The moderation was facilitated by an interview protocol consisting of predefined interview questions (See focus group interview protocol - Appendix). Informed by the literature review, the researcher was able to raise specific questions related to the emerging topics during the interviews.

To analyze the data, coding procedures were used (Denzin and Lincoln 1994; Miles and Huberman 1994; Creswell 2003; Scornavacca and Hoehle 2009). The first step undertaken for the data analysis involved open coding. Open coding is the process of breaking down, examining, comparing, conceptualizing, and categorizing data (Denzin and Lincoln 1994; Miles and Huberman 1994). Afterwards, using axial coding, the transcripts were scrutinized for similarities or differences and then grouped into clusters of conceptual units. The major goal of axial coding is to reassemble data that was disassembled during the open coding process. A data matrix was developed to identify similarities and differences between each participant (Miles and Huberman 1994; Scornavacca and Hoehle 2009). The conceptual research model (Figure 31) facilitated the identification of codes during the axial coding procedure.

Table 16 demonstrates the purpose and contribution of each stage.

Table 16: Coding procedures used to analyze the data

\begin{tabular}{|l|l|l|}
\hline \multicolumn{1}{|c|}{ Stage of Method } & \multicolumn{1}{|c|}{ Purpose of Stage } & \multicolumn{1}{c|}{ Contribution of Stage } \\
\hline Stage 1: Open coding & Fractures data into concepts. & $\begin{array}{l}\text { Data is examined for schemes in a first attempt } \\
\text { to condense the mass of data into categories. }\end{array}$ \\
\hline Stage 2: Axial coding & $\begin{array}{l}\text { Identifying similarities and } \\
\text { differences between the } \\
\text { transcripts. }\end{array}$ & $\begin{array}{l}\text { The data categories identified in stage one are } \\
\text { re-assembled and grouped into concepts or } \\
\text { clusters. }\end{array}$ \\
\hline Stage3: Data matrix & $\begin{array}{l}\text { Visualizing the conceptual } \\
\text { coding in a data matrix. }\end{array}$ & $\begin{array}{l}\text { The data matrix facilitates stage two as the } \\
\text { concepts/clusters can be compared and re- } \\
\text { assessed. }\end{array}$ \\
\hline
\end{tabular}

Table 17 illustrates how the data matrix was used to structure the data into meaningful themes. 
Table 17: Data matrix (adapted from Miles and Huberman (1994))

\begin{tabular}{|c|c|c|c|c|c|}
\hline Concepts & ATM banking & Internet banking & Telephone banking & Mobile banking & Overall \\
\hline 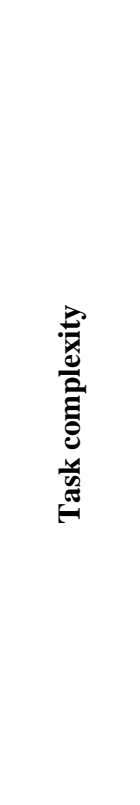 & $\begin{array}{l}\text { "ATM is obviously } \\
\text { good for getting } \\
\text { cash out when it's } \\
\text { in the right place. } \\
\text { Nowadays ATM } \\
\text { machines give me } \\
\text { also the } \\
\text { opportunity to } \\
\text { deposit money } \\
\text { and I have used } \\
\text { that in certain } \\
\text { parts. I think } \\
\text { simple } \\
\text { transactions work } \\
\text { best on ATMs. } \\
\text { For example, I } \\
\text { would not like to } \\
\text { spend much time } \\
\text { on typing in } \\
\text { information into } \\
\text { an ATM } \\
\text { machine..." }\end{array}$ & $\begin{array}{l}\text { "I use Internet } \\
\text { banking every day } \\
\text { for my accounts. I } \\
\text { do all sorts of } \\
\text { things like } \\
\text { domestic } \\
\text { transactions, } \\
\text { international } \\
\text { transactions, I } \\
\text { even organized a } \\
\text { letter of credit } \\
\text { online... and of } \\
\text { course I pay all } \\
\text { my bills online...I } \\
\text { find the Internet } \\
\text { banking straight } \\
\text { forward for all } \\
\text { financial } \\
\text { transactions" }\end{array}$ & $\begin{array}{l}\text { "Telephone banking } \\
\text { is much less } \\
\text { developed than } \\
\text { Internet banking. I'd } \\
\text { say it is much more } \\
\text { archaic and I used } \\
\text { telephone banking } \\
\text { back in the day when } \\
\text { I was a student and } \\
\text { pretty much used it to } \\
\text { check if I had money. } \\
\text { So the only time I } \\
\text { used telephone } \\
\text { banking was to check } \\
\text { if I could go out that } \\
\text { night or not." }\end{array}$ & $\begin{array}{l}\text { "So for me, mobile } \\
\text { banking is } \\
\text { something for quick } \\
\text { and easy day-to- } \\
\text { day tasks whereas } \\
\text { if I am dealing with } \\
\text { loans or mortgages } \\
\text { that's where } \\
\text { Internet banking } \\
\text { comes in because of } \\
\text { its visualization." }\end{array}$ & $\begin{array}{l}\text { The focus group } \\
\text { discussions } \\
\text { demonstrated that } \\
\text { the complexity of } \\
\text { banking products } \\
\text { and services affects } \\
\text { consumers' } \\
\text { perceptions on how } \\
\text { well these tasks can } \\
\text { be performed on } \\
\text { each electronic } \\
\text { banking channel. } \\
\text { Each electronic } \\
\text { banking channel } \\
\text { would have } \\
\text { distinctive } \\
\text { characteristics that } \\
\text { would either match } \\
\text { complex and/or } \\
\text { simple tasks.... }\end{array}$ \\
\hline 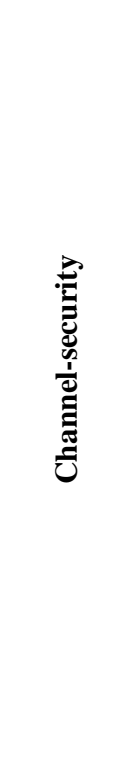 & $\begin{array}{l}\text { "I am more } \\
\text { concerned about a } \\
\text { mugger coming } \\
\text { over when he sees } \\
\text { me using an ATM } \\
\text { machine. I heard } \\
\text { a story that a guy } \\
\text { actually asked a } \\
\text { girl to empty her } \\
\text { account while she } \\
\text { was using an ATM } \\
\text { machine. A few } \\
\text { weeks ago a } \\
\text { friend of mine saw } \\
\text { me at an ATM } \\
\text { machines and he } \\
\text { stood behind me } \\
\text { and shouted..." }\end{array}$ & $\begin{array}{l}\text { "Me personally I } \\
\text { am not paranoid } \\
\text { but I always think } \\
\text { that there is a way } \\
\text { to hack it. I've } \\
\text { always been anti } \\
\text { Internet } \\
\text { banking...not that } \\
\text { you can find much } \\
\text { in my account but } \\
\text { I am concerned } \\
\text { about security. } \\
\text { Funny enough I } \\
\text { have similar } \\
\text { concerns with } \\
\text { telephone banking } \\
\text { as well." }\end{array}$ & $\begin{array}{l}\text { "If you don't know } \\
\text { your correct PIN } \\
\text { using telephone } \\
\text { banking, you will be } \\
\text { transferred to a } \\
\text { human being who } \\
\text { checks you before } \\
\text { giving out any } \\
\text { information....." }\end{array}$ & $\begin{array}{l}\text { "The mobile } \\
\text { banking application } \\
\text { I use has a } 128 \text { bit } \\
\text { encryption which is } \\
\text { the same as } \\
\text { Internet banking. } \\
\text { So for every one } \\
\text { digit you enter into } \\
\text { your mobile phone } \\
\text { there are } 128 \\
\text { around that. So if } \\
\text { you have a 6-12 } \\
\text { long password...If } \\
\text { someone wanted to } \\
\text { crack that the open } \\
\text { - good luck." }\end{array}$ & $\begin{array}{l}\text { The discussions } \\
\text { showed that the } \\
\text { perceived security of } \\
\text { electronic banking } \\
\text { channels is an } \\
\text { important factor for } \\
\text { consumers when } \\
\text { considering using } \\
\text { electronic banking } \\
\text { applications. The } \\
\text { participants } \\
\text { frequently raised } \\
\text { security as an issue } \\
\text { and the focus groups } \\
\text { suggested that } \\
\text { respondents' had } \\
\text { various perceptions } \\
\text { regarding the } \\
\text { security of each } \\
\text { electronic banking } \\
\text { channel. }\end{array}$ \\
\hline
\end{tabular}

By summarizing the depicted rows and columns, the data matrix facilitated synthesizing the concepts/themes identified during the open- and conceptual coding procedures. The findings are presented in the following section.

\subsubsection{Research findings - Focus group discussions}

This section discusses the comments made by the research participants regarding their perceptions of the task-channel fit of electronic banking channels. The following TCF dimensions emerged during the focus group discussions. 


\subsubsection{Dimension 1 - Task complexity}

The focus group discussions demonstrated that the complexity of banking products and services affects consumers' perceptions on how well these tasks are suited for each electronic banking channel.

Many respondents argued that Internet banking services would be well suited for simple (e.g. account statements), medium (e.g. domestic transfers) and complex banking tasks (e.g. applying for financial loans). For example, one participant argued that he would use Internet banking applications to perform banking transactions independent of their complexity levels:

"I think Internet banking is suited for most banking transactions and services. I have got an on-call account, a margin lending account, savings account, as well as a foreign currency account. That is when I trade stocks and currencies. I also manage our flat account with an overdraft online. Internet banking allows me to manage all these things without any issues."

Likewise, other participants argued that they would perceive Internet banking as a good medium to handle a broad variety of financial transactions:

"I use Internet banking every day for my accounts. I do all sorts of things like domestic transactions, international transactions, I even organized a letter of credit online... and of course I pay all my bills online...I find Internet banking straight forward for all financial transactions...although I haven't used it for foreign exchange (FX) transactions yet."

Another participant contributed: "I have bought currencies as well as shares. Whenever I trade shares I use Internet banking."

While these participants did not explicitly mention the complexity of banking transactions, their comments suggested that simple, medium and complex banking tasks align with Internet banking applications. Particularly international transactions and letters of credit are highly complex financial instruments that are primarily used in trade finance (John and Weitz 1988; Klein, Frazier et al. 1990; Black, Lockett et al. 2002).

Similarly, some of the respondents argued that they buy insurance policies and pension funds through online banking applications. These participants saw Internet as one-stop portal where they could buy various financially related products:

"I buy insurance and superannuation products through my bank...anything like that or investment products I first check out my bank online." 
Others indicated that they would perceive Internet banking as an inappropriate medium to conduct sophisticated financial transactions. Instead they would use online banking only to do simple banking tasks complementing other banking channels:

"I use Internet banking for my mortgage. I wouldn't apply for it through the Internet but I go online and check the rates. I don't really changeladjust the mortgage online because the payment stays the same all the time. I do look at my visa account online as well. So basically, I use Internet banking when I want to 'see' things for myself and see what is going on."

On the other hand, ATMs, phone- and mobile-banking channels were seen as less appropriate for complex banking tasks. The discussions illustrated that complex tasks would be difficult to perform on telephone banking applications as these technologies would not visualize account information effectively. For instance, one participant argued:

"Telephone banking is much less developed than Internet banking. I'd say it is much more archaic and I used telephone banking back in the days when I was a student and pretty much used it to check if I had money. I only had one account and never used it to transfer money between accounts. So the only time I used telephone banking was to check if I could go out that night or not. I could never do on telephone banking what I do on the Internet banking telephone banking is just not suited for more complicated banking services."

Mobile banking applications were perceived suitable for simple and medium complex banking tasks. Three out of the four mobile banking users utilized these applications for very basic financial matters (e.g. receiving text messages from their bank to get account related information). On the other hand, one participant argued that he uses mobile banking applications to transfer money between sub-accounts as well as performing domestic transfers.

\section{Summary}

In summary, the focus group discussions confirmed that the level of task complexity is an important aspect when considering banking on electronic banking channels. The group discussions illustrated that the respondents' perceptions varied on how well each electronic banking channel is suited to performing complex banking tasks. Overall, Internet banking was seen to be the best suited channel for complex banking transactions. Some of the respondents used Internet banking to apply for credit facilities and letter of credits. This indicated that Internet banking applications can successfully support sophisticated financial instruments. On the other hand, ATMs and telephone banking were only seen to be useful for very simple 
financial services. Most respondents used these channels exclusively to obtain account information instead of transacting money through these technologies. The vast majority of all respondents could not imagine performing more complicated banking tasks on these channels. The few participants who have used mobile banking applications indicated that they mostly use these applications to perform simple tasks such as obtaining account information. In contrast, one participant argued that he uses mobile banking to manage several accounts, as well as to conduct domestic banking transactions. This indicates that the mobile banking channel could be used for simple and medium-complex financial services.

\subsubsection{Dimension 2 - Task frequency}

The focus groups suggested that consumers do specific banking tasks more frequent than others. Depending on the frequency of performing a given banking tasks, consumers would view specific banking channels as more suited than others. They argued that they would develop a routine if they perform tasks regularly on a given banking channel which would influence their perceptions of the banking channel. After they have repeated the banking tasks several times on a specific banking channel, they would perform these tasks automatically because of learning. The notion of task frequency was a recurring concept within the focus group discussions.

One participant argued:

"I think regularity and how often you have to perform each banking task is very important when using electronic banking channels. Once you have learned how to use them and if you do them frequently...the process becomes habitual. For example, I know exactly which buttons to press when using ATMs or telephone banking. That's because I use them quite often. The procedure stays the same and I know exactly what to do..."

Another participant agreed and contributed:

"I agree. I think that applies to Internet banking as well. I never had issues with that and I find it easy to use. Particularly because I know exactly how it works for most of the things I do with my bank. I recall the steps I have to do all the time when I access Internet banking for my banking transactions... you know where the links are and you remember which information is needed in order to transfer money. It's kind of a routine for me."

This comment was commented by another research participant: 
"True...you do these things automatically...the more you use, the more experience you have...That comes with familiarity and personal experience I suppose."

In addition, the participants argued that the more frequent they would use specific electronic banking channels, the more they would remember certain tasks. As an example they argued that it would be difficult to remember passwords unless using the system frequently:

"I think regularity is very important for remembering passwords because otherwise you just forget them. I was on vacation a few weeks ago and did not need t use my password to access ATMs for 2 weeks. When I got back I had forgotten my password."

Other participants suggested that a frequent usage of an electronic banking channel would lead to higher trust level (in case that all transactions were executed satisfactorily).

"I guess when you first start using an electronic banking channel you will have a certain degree of trust. So do I trust if this system is going to work? Do I know when I push 'send that that transfer' will go through? I think once you have used the channel several times you will trust the channel more. I think that the more you use, the more experience you have, the more you trust the system. So for example, if you had a bad experience with ATMs then you trust the channel less. So I believe it all comes down to familiarity and personal experience I suppose."

\section{Summary}

In summary, the focus groups suggested that consumers perform certain banking tasks more often than others. Frequency of purchase would influence their perceptions of the suitability of banking channels for specific banking tasks since the purchase process would become a routine. The respondents said that the more often they do specific banking tasks on a given channel the better they view this channel as more suited for that task. Having done the tasks often, the entire process would become more habitual and hence they would view the channel as more suited for performing banking transactions.

\subsubsection{Dimension 3 - Task importance}

Many research participants suggested that they would view certain types of transactions as being more salient than others. They suggested a variety of reasons for this. For instance, some participants argued that they perceive high value transactions (e.g. worth several hundred dollars) more important than others. These participants suggested that consumers believe that importance comes with increasing transaction values: 
"When I expect a large payment I check my online account several times a day. I often trade goods on trademe or Ebay and sometimes I sell pretty expensive stuff...so to make sure that I don't send off the goods before I got the money, I check my account several times a day. If it is there and can just fire the goods off once the funds are cleared. On the other hand, if I sell less expensive goods I am usually less concerned about the financial transaction."

Others mentioned that certain banking tasks would be very important to them as they would significantly impact on their personal life. Hence, these transactions should be viewed as very important. Many respondents explained this by using financial loans or mortgages to illustrate why they view these tasks as salient. The following statement emphasizes that the perceived importance would also influence consumers' intentions to use an electronic banking channel:

"I use mostly Internet for my personal banking. Even for very important things like insurance products and superannuation products. I put quite a lot of money into these products as they are necessary to have. Internet is a good medium for those products as you can sit at home and read about them before buying them. On the other hand, two years ago we built a house and we had to apply for a mortgage. Because it was such a huge investment, I wanted to discuss it with my relationship manager face-to-face."

Another participant agreed and said:

"Yes, I totally agree. I've got four mortgages and a business account. I manage all my mortgages through Internet banking...but I wouldn't setup a mortgage online - just face-toface because it wouldn't feel right to do it over the Internet. I still have a personal account manager who looks after my accounts so if I do have anything out of the ordinary or a question about something where I need a human interface then I can just ring her...I do this whenever a very important matters have to be managed".

Another participant suggested that his financial loan would be particularly important to him as it would take him several years to pay it back. He said:

"I do most of my banking transactions online these days. For instance, I have used Internet banking for international transactions to pay someone in Australia. I hardly go to a bank branch. I think the last time I went to a branch was 2-3 years ago. I had to apply for a financial car loan. Two reasons why I applied for it in person .... a) it was an important thing that I wanted to discuss with my relationship manager and b) the bank wanted to talk to me in face-to-face." 
A similar comment was made by another respondent:

"I probably use Internet banking to make payments mostly...standard stuff. We've got a relationship manager for our mortgage in the bank and she rings and we just talk about the mortgage if needed. So we do this face-to-face and she calls us every couple of months. I really appreciate to discuss the very important transactions with her rather than doing it online."

\section{Summary}

In summary, the focus group discussions demonstrated that the respondents viewed certain specific banking transactions as more salient than others. The level of task importance would be influenced by factors such as overall transaction value or the impact a transaction has on a consumer's life. What is more, consumers would choose specific banking channels for important banking tasks while they would refuse other channels when performing salient banking transactions. This suggests that consumers view some banking channels as more suited for salient banking transactions than others.

\subsubsection{Dimension 4 - Task time criticality}

The level of time criticality was considered as another important aspect of financial transactions. Most participants indicated that they perceive some banking transactions as urgent while others were seen as less time critical. In addition, some electronic banking channels would support time-critical tasks particularly well (e.g. Internet and mobile banking) whereas others were seen as less suited for urgent matters (e.g. ATM banking).

For example, some respondents argued that they would often trade shares and currencies online. These respondents appreciated Internet banking services as they would allow them to instantly buy these financial products. Having instant access to financial markets would be particularly important because these markets would be constantly exposed to market fluctuations. The respondents argued that they would monitor the news online and watch stock/currency prices several times a day through their online banking accounts. Depending on the financial markets they could instantly react through the online channel:

"I use Internet banking for my foreign exchange account and frequently buy shares and transfer money and backwards. I'd say I check the prices 2-3 times a day and Internet banking gives me the opportunity to react instantly on changes in the market."

Likewise, mobile banking was perceived as a useful application to handle urgent transactions. One participant argued: 
"And to be honest....the only reason I use mobile banking is to check the currency rates. These transactions are quite urgent and that is the only reason why I use mobile banking. It gives me instant access to information and I can then decide what to do".

Similarly, telephone banking was seen as a suited way for getting instant account information in a case of urgency. This would be particularly true when an Internet connection would be out of reach:

"Telephone banking...I guess it is a very quick and easy way. For example, if you ring up the bank, you put in your PIN number; you hear the balance and know instantly if funds have cleared...that's a quick way to get your balance if you needed to check that."

In addition, some of the respondents argued that - due to their own carelessness - they would often have to instantly transfer money. Some of the respondents appreciated mobile banking services for those occasions, as they would allow them to correct their mistakes on the go:

"The other day I was out at a bar and realized that I haven't paid my phone bill. So I just used my text-banking and paid the bill. That's twenty four and on the go...so for me, mobile banking is something for quick and easy for day-to-day tasks"

Others added that they would occasionally use mobile banking while shopping. They said that mobile banking would be useful if they forgot to transfer money between their saving and current accounts. Having mobile banking applications on the spot would enable them to access their account and transfer money when they needed it.

In contrast, many respondents argued that they would not face situations in which they would need to transfer money urgently since they would plan ahead their financial transactions. One participant used mobile banking applications as an example to explain that he has no personal need to instantly access his banking account:

"Why would you use mobile banking? Its like being on the street and say to yourself: I want to make a deal...yeah right! Unless you are at Wall Street it's just not realistic. Just because the technology is there it doesn't mean that people really need that sort of thing. My brother in law works for the stock exchange and he only needs his cell-phone when colleagues call him during his lunch break. They may ring him to say we've got a problem here and what to we do about it?...that's it...that's as far as it goes."

Another participant commented: 
"Mobile banking, I agree.... this is something for people who are on the spot or when people need to be doing things on the minute."

\section{Summary}

In summary, the focus groups suggested that consumers perceive some financial tasks as very time-critical while others were seen as non-urgent. Particularly financial transactions such as foreign exchange trades or share brokerage were seen as highly time sensitive due to market volatility. These transactions would require immediate execution which could be best performed online or via mobile banking applications. Further, high value payments were often associated with urgency. In contrast, other research participants were less concerned about urgency related to financial transactions.

\section{Implications for this study}

The previous sections analyzed the focus group discussions related to the task-channel fit of electronic banking channels. All focus group panels re-affirmed the task-channel fit dimensions previously developed in section 3.3.1.

While discussing each electronic banking channel and their suitability to support banking tasks, the following task-channel fit dimensions were re-confirmed: task complexity, task frequency, task importance and task time criticality. Even though the focus group discussions primarily aimed to re-assess the task-channel fit dimensions, the participants also discussed the remaining constructs developed in the conceptual research model. These comments are analyzed below.

\subsubsection{Perceived usefulness}

The focus groups demonstrated that consumers must see benefits in using electronic banking channels for their personal finances. The participants argued that they would choose alternative banking channels if they found a specific channel as an ineffective medium for managing their banking activities.

Most respondents viewed Internet banking as useful since it would enable them to bank from home offering convenient access to their accounts through a bank's online portal. The participants argued that Internet banking would help them to manage their time more effectively and they would no longer rely on opening hours of physical branches. In consequence, managing personal finances would become much easier and they appreciated that benefits Internet banking would offer them. 
Fewer participants saw telephone and mobile banking as useful for their personal finances. However, those participants who viewed telephone banking services as beneficial argued that these technologies were available everywhere allowing them to access their bank accounts instantly. For example, one participant clearly saw benefits in using telephone banking services for account inquiries. He argued that he would manually visualize the information provided as he would take written notes while listening to the IVR systems: "I am used to telephone banking and I am happy how it works. It's also great if I haven't got access to the Internet. Phones are everywhere. I must say that I back it up on a piece of paper that I keep in my wallet. So when the 'telephone system' reads out the account statements I'll write them down onto paper to see the transactions. So basically, I use telephone for most things and then often confirm it through the Internet when I want to see things for myself and see what is going on."

ATMs were seen as effective means to obtain cash and account balances. Most respondents argued that they would not use them for transferring money between accounts. They said that the usability of ATM would discourage them to initiate account remittances. A typical comment regarding the usefulness of ATMs was made by participant B: "I use ATMs obviously for withdrawing money. I have also used them overseas but I don't use them for transferring money from one account to another. I just don't like making transfers in gasstations or supermarkets... and that is where I mostly use ATMs."

The discussions also suggested that many participants saw some of the channels as inadequate technologies for banking transactions: "I have not used mobile banking. I tend not to access the Internet with my mobile phone. I never really needed to and I guess there is no real need for me. I find it easier to do it online rather than on my mobile. I prefer when I have things in front of me rather than using it on this tiny device. I might do if I was stuck somewhere but it hasn't happened to me yet."

\section{Summary}

In summary, the focus group discussions showed that consumers must perceive electronic banking channels as useful for managing their personal finances. The participants argued that the benefits of using an electronic banking channel must outweigh the disadvantages. Otherwise, they would use alternative channels to manage their banking transactions. 


\subsubsection{Ease of use}

The degree to which an electronic banking channel is perceived as easy to use was regarded as an important factor impacting on consumers' motivations to utilize an electronic banking channel.

Internet banking services were generally seen as easy to use and most research participants appreciated the straightforward usability of these applications. Many respondents indicated that they manage most of their banking online because they perceived Internet banking as user-friendly. For example, one respondent argued:

"I've got four mortgages and I manage all of them through Internet banking. I've got a revolving credit account and all my rental payments from my property account go into this account. That account pays the mortgage for the other accounts and it also pays its own interest payments.... so although there are a lot of accounts its been made a lot simpler by Internet banking. I find Internet banking easy to use."

There was a general consensus among Internet banking users that these applications were easy to use and they found them straightforward and self-explanatory.

The usability of ATMs, mobile and telephone banking applications was viewed more critically and the discussions illustrated that the respondents were less satisfied when using these systems.

Mobile banking applications were mostly seen as difficult to use due to the hardware limitations of the user device (e.g. small screen size, clumsy input mechanisms, as well as slow data transmission rates). Non-users were particularly averse towards these applications despite the fact that they have never used these systems.

One participant stated: "Every time my mobile phone tells me that it wants to upgrade the software through the WAP-browser I just turn it off. I actually never connected to the mobileInternet from my mobile phone. I believe it is just too slow and not easy to use. That also applies to mobile banking."

Similarly, the respondents argued that ATMs would not be user-friendly due to their basic keypad functions and the limited screen size. For example, one participant argued: "I find ATMs more difficult to use than Internet because of the input mechanisms...For me, it simply takes too long to type in the number for a transaction". 
Some of the participants were curious why banks would not design ATMs more effectively. They reasoned that recurring payments could be set up on ATMs in a similar way as they are currently organized on Internet banking applications:

"It is a lot easier to initiate payments online because I have a list of payees on my Internet banking application. Its probably 60-70 people I have setup in my bank account that I have paid in the past. You can click on them and their details are there. Very easy to use.... the only thing left to do is adjusting the amount you have to pay."

Another participant joined the discussion and said: "It would be probably quite good to pay your bills from an ATM in a similar way. If you had a list with your payees that you could bring up on an ATM I can imagine it would be very easy to use...so if you needed to pay your phone bill you could easily select the service provider and do it on an ATM....rather than going to your post shop."

\section{Summary}

In summary, the focus group discussion suggested that the respondents' perceptions concerning the ease of use of alternative electronic banking channels differed significantly. Most research participants perceived Internet banking services as straightforward and easy to use. A few respondents were more critical towards these services although they mostly critiqued the usability of technology and Internet per se rather than specifically challenging the usability of Internet banking applications.

In contrast, the usability of telephone banking received extensive critique. Most users were unsatisfied with the login mechanisms of these channels and they reported difficulties when trying to access these applications. Similarly, many respondents perceived mobile banking applications as difficult to use despite they have never tested these services. In contrast, those respondents who used mobile banking applications for managing their bank accounts found them uncomplicated and easy to use.

\subsubsection{Attitude towards channel use}

The focus group discussions suggested that individuals' attitudes influence their usage behavior related to electronic banking channels. Some participants seemed to have positive feelings towards specific electronic banking channels while others appeared to dislike using them.

One participant argued: "I think one's attitude is important as well. If you look at my age (34) I do have a complete different attitude to-let's say-younger people. I was born just in 
the generation where we used to have a C64 when I was at school and the data entry was so pre-historic. While my nieces and nephews keep asking me: how can you survive without Internet? Technology is so normal to them and they really like it and they have a much more positive attitude towards technology".

Another participant argued that his personal attitude would be highly influential for his use behavior regarding electronic banking channels. He would feel unpleasant about electronic banking channels:

“ATMs...no, don't want to know them. Not interested. Mobile phone banking, no not interested. I have to deal with alive ones. I suppose it is an age and attitude thing as much as anything else but if I got to do something I prefer to talk to a person. I prefer to relate to people rather than to machines that say push that...push here...".

On the other hand, other participants were more positive about technology as well as electronic banking applications. One participant argued: "I kind of like technology in general and I guess that's part of the reason why I've always been quite happy with Internet banking. The usability and it is more convenient to sit at home rather than going into a branch and work things out with bank staff in face-to-face. I do 90\% of my banking online nowadays."

\section{Summary}

Overall, many respondents indicated that their attitudes (positive or negative) would influence their use behavior towards to electronic banking channels. While most respondents had a positive attitude towards electronic banking some individuals expressed their negative feelings towards managing personal finances on self-service driven technologies.

\subsubsection{Subjective norms}

The focus group discussions indicated that subjective norms would be important for consumers when using electronic banking channels. The participants suggested that their norms would be either directly influenced through banks (e.g. bank staff suggesting that consumers use a particular channel) or indirectly if friends or relatives would tell them about their positive experiences with electronic banking channels.

Some of the respondents indicated that banks try to influence consumers' subjective norms related to electronic banking channels. This would be either done through media campaigns broadcast on television or in personal conversations within bank branches.

"I think it is also important how banks are trying to encourage customers to use Internet banking. For example Bank $A B C$ are really positive about it and staff are trying to encourage 
people using Internet banking while Bank XYZ I find really unfriendly and people there are trying to force us to use Internet banking rather than branch banking. This affects my position on Internet banking as well."

In addition, the participants acknowledged that friends and colleagues would be influential when telling them stories about their experiences with a banking channel: "there are always people who are trying to convince other people to use a channel. For example, everyone nowadays says: I use Internet Banking because of this and that....its really easy to use etc...that sort of thing influences people as well." Another participant agreed and added: "that is probably even more important for the kids".

\section{Summary}

Some respondents suggested that their individual norms are important factors for their use behavior towards electronic banking channels. Particularly comments made by friends and relatives would influence consumers to change their normative beliefs about electronic banking channels. It should be stated that not all focus groups discussed norms and only few comments were made regarding consumers subjective norms.

\subsubsection{Channel security}

The discussions showed that the perceived security of electronic banking channels is an important factor for consumers when using self-service banking technologies. The participants frequently pointed out security as a major issue to consider when using electronic banking channels.

Some respondents observed Internet banking as very unsecure and they felt uncomfortable when using online banking:

"Me personally I am not paranoid but I always think that there is a way to hack it. I've always been anti Internet banking...not that you can find much in my account but I am concerned about security. Funny enough I have similar concerns with telephone banking as well."

In contrast, other respondents were not concerned about the security of Internet banking services. These participants felt secure because of the security mechanisms banks put in place. The following discussion took place in one of the focus groups:

Participant A: "There has been so much written about the security of online banking. Given this, it's like almost that you are expecting it to be safe." 
Participant B: "Also if something goes wrong you expect the bank to fix it."

Others liked the fact that Internet banking applications would show when somebody was last logged in. This would be another level of security that would enable them to feel much securer. Also, some of the respondents explained that they would use additional security keys when using Internet banking applications. These security keys would be based on two-factor authentication providing them with an additional level of security: "For security reasons I am using a security key. So my bank has my account number, password and I have this key generator. Whenever, you generate a number, the system recognizes that it is you. The number changes every ten seconds so you put it in there as well - which is another security measure. That is for Internet and I guess the algorithm is changing constantly...I don't really know how it works but it makes me feel secure."

Others were less concerned about Internet banking security and ignored the opportunity to gain additional security through security keys. The following comment was made during another focus group: "I went to the bank the other day and they have got a new thing called safe key... a little sort of electronic device that changes my password every minute or so. When using this key I could transfer up to $\$ 50000$ a day very securely...but I decided that I did not have \$50000 so I just kept my favourite password."

The security of mobile banking was also perceived differently. Most of the research participants were very skeptical and did not think that these systems would be secure at all. Most people believed that wireless technology is unsecure which discouraged them to use mobile banking applications. In contrast, some of the mobile banking user seemed to be well aware of the security mechanisms of mobile banking applications:

"The mobile banking application I use has a 128 bit encryption which is the same as Internet banking. So for every one digit you enter into your mobile phone there are 128 around that. So if you have a 6-12 digit password...If someone wanted to crack that the open good luck."

\section{Summary}

The focus group participants perceived the security levels of each electronic banking channel differently. Most respondents perceived telephone banking services as relatively secure while Internet banking services were often seen as being unsecure. In addition, the security concerns among the research participants varied significantly. Some research participants were well informed about the security mechanisms and were able to explain the 
functionality of 128-bit encryption related to mobile banking applications. Other respondents were not concerned about security and disregarded additional security mechanisms (e.g. security keys) offered by their banks. The following quote summarizes the varying perceptions related to the security of electronic banking channels well: "I believe that security is relative. While I am not concerned at all, I am sure other people are very much concerned about their security when using online banking."

\subsubsection{Costs associated with channel use}

Many research respondents suggested that costs associated with channel use is an important factor for consumers when using electronic banking channels. Costs would be inacceptable and would deter people from using a channel. Particularly the discussions around mobile banking and ATM usage suggested that consumers are sensitive of costs associated with these banking applications. Some of the research participants were really concerned about costs whereas others ignored associated costs.

Most cost-concerned participants perceived mobile banking applications as expensive. Particularly the costs charged by telecommunication providers for $3 \mathrm{G}$ connections were seen as too high. Due to this, they would not consider using these applications. Interestingly, many comments related to costs were made from research participants who had never used mobile banking services:

Participant A: "I can image that if you used mobile banking through $3 G$ it could be potentially quite expensive...not too sure. In New Zealand, if you have got a $3 G$ connection isn't that expensive to use?",

Participant B: "Yes, for some reason I have a similar perception that mobile banking is expensive... whether it is or not I don't know... and I suspect for some reason it might also be slower and it just takes longer to load the Internet on my phone rather than it does on my PC anyway."

Another participant commented on these statements and said: "Yes, I agree. I think mobile banking itself doesn't cost anything but you are charged for you WAP browsing...so if its going to cost you a certain amount to do a simple transaction which you could do on the internet for free."

During another focus group session a comparable discussion took place. One participant stated: "I find the mobile banking easy to use but I have a little issue with the cost involved 
with mobile banking. I know Internet banking is free so I prefer to do most transactions online rather than using my mobile phone for it."

Another participant agreed and said: "Totally...I never ever caught on to using it. I tried mobile banking for a while about a year ago. I think it was costing me a bit - which caused me to disable it. Considering the involved costs, I just do these things on the Internet rather than on my mobile phone."

Most research participants viewed mobile banking applications as expensive and they indicated that the costs associated with mobile banking usage would be a major disadvantage.

The research participants were also aware of costs associated with ATM usage. These participants argued that getting charged on ATM machines would prevent them from using them because they would choose another banking channel where banks do not charge fees (e.g. face-to-face banking in a branch).

On the other hand, other participants were less concerned about the fees banks charge for ATM usage. These participants explained that they would not worry about these charges and use ATM when they had a need for it. One participant said: "I am not concerned about costs associated with ATM use. Wherever the ATM machine is - I go for it. If it suits me to withdraw money then it doesn't matter to me if I have to pay a fee for it or not. I think it is more important to me to get cash when I want it."

None of the research participants mentioned costs associated with telephone banking applications. Banks normally offer 0800 numbers (which are free to call) and no extra charges would occur when performing banking transactions on the phone.

Likewise, none of the research participants were concerned about costs associated with Internet banking. This was despite the fact that Internet usage is relatively expensive in New Zealand.

\section{Summary and implications for this study}

In summary, the focus group discussions supported the initial conceptualization of the research model. The discussions re-affirmed that consumers' intentions to use electronic banking channels are influenced by multiple variables previously identified within the existing literature on electronic banking.

Four TCF dimensions were re-confirmed by the focus group discussions: 1) task complexity, 2) task time criticality, 3) task frequency, 4) task importance. Furthermore, 
perceived usefulness, ease of use, attitude towards channel use, subjective norms, security, and costs associated with channel use were confirmed as important factors influencing consumers' intentions to use electronic banking channels.

This suggested a quantitative assessment of the research model. A well-accepted technique for quantitatively assessing research models is the use of survey questionnaire instruments (Straub 1989; Pinsonneault and Kraemer 1993; Grover 2000). The following section outlines how the research instrument was developed in context of this study.

\subsection{Instrument development}

Survey research is by far the most common method of collecting primary quantitative data in information systems research (Straub 1989; Pinsonneault and Kraemer 1993; Grover 2000). This method offers a structured and standardized way to ask respondents a variety of questions about their habits, perceptions and attitudes (Malhotra 2004). Questionnaires are relatively simple to administer and respondents can complete the survey in their own tine, at their own pace while maintaining anonymity at the same time (Pinsonneault and Kraemer 1993; Hufnagel and Conca 1994; Grover 2000; Malhotra 2004).

To ensure that survey instruments questionnaires measure "what they are supposed to measure" (Straub 1989), much attention has to be paid to the development of survey instruments. A common procedure to develop a survey instrument is creating a pool of items (Moore and Benbasat 1991). The extant literature should be searched for existing items and scales that had been previously validated by other studies (Moore and Benbasat 1991). During this phase each scale should be analyzed for its reliability and it should be verified if the scales apply to the current research context. If no extant scales exist, researchers are faced with the task of developing new items tailored to the context of the study.

The following section discusses how the item-pool was created. Initially it reports how items were created for measuring the TCF dimensions (since no validated scales could be identified that matched the TCF dimension). The second part includes the compilation of items intended to assess the precursors of channel utilization.

\subsubsection{Item creation and item collection}

Before discussing the scale development, it is important to note that this research aimed to measure individuals' perceptions about each TCF dimension and was less interested in the objective measurement of these concepts. For example, the task complexity of mortgages could be measured by approaching individuals' for their subjective opinions on the task 
complexity that is experienced by the task-doer. This approach would include a person's shortterm memory, span of attention, computational efficiency and so forth. These individual traits moderate the relationship between objective and experienced complexity (Campbell 1988; Jiang and Benbasat 2007; Nadkarni and Gupta 2007).

In contrast, objective task complexity of a mortgage could be assessed by analyzing mortgage requirements from a bank's perspective. This may include adding up the amount of text consumers' are required to read before applying for a mortgage. Another way might be to count the number of fields consumers have to fill out before signing the application document. By adding these scores, one could generate an objective measure for the complexity of mortgage applications. The objective measurement of complexity was less appealing to this research as the precursors of utilization as well as the dependent variable intentions to use construct were also assessed perceptually. Since this applied to all dimensions of the TCF construct, each TCF dimension was evaluated subjectively and not objectively.

\subsubsection{Scales - TCF dimensions}

The search of the existing literature resulted in only few studies previously assessing the TCF dimensions. What is more, much of this research was either conceptual (e.g. Wood 1986), or the scales were developed and validated in dissimilar contexts (e.g. Nadkarni et al. 2007 - investigating perceived website complexity).

Therefore, new items were created to measure the TCF dimensions based on their construct definitions. To do this, an excel spreadsheet was developed listing the TCF construct definitions discussed in chapter 3.

Next, the existing literature and transcripts of the focus group discussions were reviewed for potential keywords describing the TCF dimensions. For instance, time-critical tasks were often referred to be time-critical by the existing literature (Jenkins, Zyanski et al. 1971; Landry, Rastegary et al. 1991; Gattiker and Goodhue 2005; Park, Im et al. 2008; Junglas, Abraham et al. 2009; Yuan, Archer et al. 2010). Hence time criticality items were created to reflect the concept of urgency. Many of the participants within the focus group discussions also mentioned that certain banking tasks require instant execution and should be performed immediately. Hence, these keywords were also integrated within the items developed to measure the time-criticality of a given banking task. The same procedure was followed for the remaining TCF dimensions. Table 18 lists the initial conceptualization of the TCF items. 
Table 18: Initial items developed for the TCF dimensions

\begin{tabular}{|c|c|}
\hline $\begin{array}{l}\text { Definition: } \\
\text { Task } \\
\text { complexity }\end{array}$ & $\begin{array}{l}\text { The level of complexity applied to banking tasks is understood as the } \\
\text { perceived difficulty individuals experience while performing a given } \\
\text { banking task. }\end{array}$ \\
\hline COMP1 & Applying for a mortgage is complicated \\
\hline COMP2 & Applying for a mortgage is difficult \\
\hline COMP3 & Applying for a mortgage is straightforward \\
\hline COMP4 & Applying for a mortgage is easy \\
\hline COMP5 & Applying for a mortgage requires a lot of steps \\
\hline COMP6 & Applying for a mortgage involves much data input \\
\hline COMP7 & Applying for a mortgage typically requires a lot of time \\
\hline $\begin{array}{l}\text { Definition: } \\
\text { Task } \\
\text { frequency }\end{array}$ & $\begin{array}{l}\text { Task frequency refers to the perceived frequency users perform a given } \\
\text { banking task. }\end{array}$ \\
\hline FREQ1 & Applying for a mortgage is a banking transaction I frequently perform \\
\hline FREQ 2 & Applying for a mortgage is a banking transaction I often perform \\
\hline FREQ 3 & Applying for a mortgage is a banking transaction I routinely perform \\
\hline FREQ 4 & Applying for a mortgage is a banking transaction I rarely perform \\
\hline FREQ 5 & I often apply for a mortgage \\
\hline FREQ 6 & I frequently apply for a mortgage \\
\hline FREQ 7 & I routinely apply for a mortgage \\
\hline FREQ 8 & I rarely perform for a mortgage \\
\hline FREQ 9 & I hardly ever apply for a mortgage \\
\hline $\begin{array}{l}\text { Definition: } \\
\text { Task } \\
\text { importance }\end{array}$ & $\begin{array}{l}\text { Task importance refers to the perceived importance of specific banking } \\
\text { transaction for consumers. }\end{array}$ \\
\hline IMP1 & Applying for a mortgage is an important matter to me. \\
\hline IMP2 & Applying for a mortgage is important to me. \\
\hline IMP3 & Applying for a mortgage is a standard banking transaction to me. \\
\hline IMP4 & Applying for a mortgage is a typical banking transaction for me. \\
\hline IMP5 & Applying for a mortgage means a lot to me. \\
\hline IMP6 & Applying for a mortgage is of concern to me. \\
\hline IMP7 & Applying for a mortgage is an important banking transaction for me. \\
\hline $\begin{array}{l}\text { Definition: } \\
\text { Task time } \\
\text { criticality }\end{array}$ & $\begin{array}{l}\text { The level of time criticality applied to banking tasks can be understood } \\
\text { as the perceived urgency transactions require execution. }\end{array}$ \\
\hline TIME1 & I believe that applying for a mortgage must be solved quickly \\
\hline TIME2 & A mortgage has to be executed instantly. \\
\hline TIME3 & A mortgage is a transaction that needs to be executed instantly. \\
\hline TIME4 & I expect that my bank executes a mortgage right on the spot. \\
\hline TIME5 & Applying for a mortgage is an urgent matter to me. \\
\hline TIME6 & Applying for a mortgage is a time-critical matter to me. \\
\hline TIME7 & Applying for a mortgage is time-critical \\
\hline TIME8 & Applying for a mortgage is urgent \\
\hline TIME9 & Applying for a mortgage is not time-critical \\
\hline TIME10 & Applying for a mortgage is not urgent \\
\hline
\end{tabular}

It is important to note that most of the above mentioned items differed only slightly from each other. This was intentional since the judgment rounds and pretests (explained in more depth in sections 4.6. and 4.7.) were designed to identify the most suitable items of the above scales. Further, Table 18 does not list the parallel items created for each measure. The parallel items are explained in more depth in section 5.3.1.

While the items were newly created to assess the TCF dimensions, existing scales for the precursors of utilization were adjusted to the context of this study. This process is explained in the following section. 


\subsubsection{Scales - Precursors of utilization}

The literature review demonstrated that many researchers have previously validated scales for assessing perceived usefulness, ease of use, attitude towards channel use, subjective norms, channel security, costs associated with channel use, as well as intention to use variables. In order to identify adequate scales for this research, these instruments were thoroughly evaluated in terms of their validity and reliability.

\section{Scales for perceived usefulness constructs}

As discussed within the literature review (section 2.2.), many studies on information systems have demonstrated that the perceived usefulness of an information system is an important determinant of individuals' intentions to use it (Davis 1989; Thompson, Higgins et al. 1991; Hartwick and Barki 1994; Goodhue and Thompson 1995; Venkatesh, Morris et al. 2003; Staples and Seddon 2004). Therefore, the existing literature was screened for scales measuring perceived usefulness constructs.

Due to its central role of perceived usefulness in the Technology Acceptance Model (TAM), Davis (1989) developed scales to measure this construct related to information systems use. The instrument development included judgment rounds and a card sorting procedure to assess the content and face validity of the scales. Davis (1989) subsequently pretested the questionnaire instrument and refined the items in light of the tests conducted to assess the scale's convergent validity, discriminant validity, and reliability (Davis 1989). Next, data was collected and the model was tested using the refined scales. The items used to assess the perceived usefulness construct are shown in Table 19.

Table 19: Scale to measure a perceived usefulness construct (Davis 1989)

\begin{tabular}{|l|l|c|c|}
\hline No. & Item wording & Loadings & Authors \\
\hline 1 & $\begin{array}{l}\text { Using Chart-Master in my job would enable me to accomplish } \\
\text { tasks more quickly. }\end{array}$ & 0.91 & (Davis 1989) \\
\hline 2 & Using Chart-Master would improve my job-performance. & 0.98 & (Davis 1989) \\
\hline 2 & Using Chart-Master in my job would increase my productivity. & 0.98 & (Davis 1989) \\
\hline 3 & Using Chart-Master would enhance my effectiveness on the job. & 0.94 & (Davis 1989) \\
\hline 4 & Using Chart-Master would make it easier to do my job. & 0.95 & (Davis 1989) \\
\hline 5 & I would find Chart-Master useful in my job. & 0.88 & (Davis 1989) \\
\hline \multicolumn{2}{|c|}{ Cronbach alpha 0.98 } \\
\hline
\end{tabular}

Many researchers adopted Davis (1989) perceived usefulness scales and adjusted them to various contexts (Taylor and Todd 1995; Venkatesh, Morris et al. 2003; Benbasat and Barki 2007).

For instance, Bhattacherjee (2001b) adapted Davis' (1989) scales and measured how useful consumers perceive Internet brokerage services to be. Despite the fact that TAM items were 
used in a voluntary and non-organizational use setting, Davis' (1989) scales proved to be solid measures in context of Bhattacherjee's (2001b) study. Table 20 lists the items used by Bhattacherjee (2001b).

Table 20: Scale to measure a perceived usefulness construct (Bhattacherjee 2001)

\begin{tabular}{|l|l|l|l|}
\hline No. & Item wording & Loadings & Authors \\
\hline 1 & $\begin{array}{l}\text { Using OBD improves my performance in managing } \\
\text { personal finances. }\end{array}$ & 0.863 & $\begin{array}{l}\text { (Bhattacherjee 2001) adapted } \\
\text { from (Davis, Bagozzi et al. 1989) }\end{array}$ \\
\hline 2 & $\begin{array}{l}\text { Using OBD increases my productivity in managing } \\
\text { personal finances. }\end{array}$ & 0.837 & $\begin{array}{l}\text { (Bhattacherjee 2001) adapted } \\
\text { from (Davis, Bagozzi et al. 1989) }\end{array}$ \\
\hline 3 & $\begin{array}{l}\text { Using OBD enhances my effectiveness in managing } \\
\text { personal finances. }\end{array}$ & 0.764 & $\begin{array}{l}\text { (Bhattacherjee 2001) adapted } \\
\text { from (Davis, Bagozzi et al. 1989) }\end{array}$ \\
\hline 4 & Overall, OBD is useful in managing personal finances. & 0.764 & $\begin{array}{l}\text { (Bhattacherjee 2001) adapted } \\
\text { from (Davis, Bagozzi et al. 1989) }\end{array}$ \\
\hline \multicolumn{2}{|c|}{ CR =0.88; AVE =0.65 } \\
\hline
\end{tabular}

As shown above, Bhattacherjee's (2001b) results re-confirmed the validity and reliability of Davis' (1989) perceived usefulness scales.

In another study investigating online brokerage services, Bhattacherjee (2001a) used a slightly different version of the above mentioned scales to measure a perceived usefulness construct.

Table 21: Scale to measure a perceived usefulness construct (Bhattacherjee 2001)

\begin{tabular}{|l|l|l|l|}
\hline No. & Item wording & Loadings & Authors \\
\hline 1 & $\begin{array}{l}\text { Using my OBD helps me improve my performance in } \\
\text { managing personal investments. }\end{array}$ & 0.866 & $\begin{array}{l}\text { (Bhattacherjee 2001) adapted } \\
\text { from (Davis, Bagozzi et al. } \\
1989)\end{array}$ \\
\hline 2 & $\begin{array}{l}\text { I think that my OBD use improves my productivity in } \\
\text { managing personal investments. }\end{array}$ & 0.809 & $\begin{array}{l}\text { (Bhattacherjee 2001) adapted } \\
\text { from (Davis, Bagozzi et al. } \\
1989)\end{array}$ \\
\hline 3 & $\begin{array}{l}\text { In my opinion, using my OBD increases my effectiveness in } \\
\text { managing personal investments. }\end{array}$ & $\begin{array}{l}\text { (Bhattacherjee 2001) adapted } \\
\text { from (Davis, Bagozzi et al. } \\
1989)\end{array}$ \\
\hline 4 & $\begin{array}{l}\text { I find my OBD useful in managing personal investments. } \\
\text { from (Davis, Bagozzi et al. } \\
1989)\end{array}$ \\
\hline \multicolumn{2}{|c|}{ Cronbach alpha $=0.880$} \\
\hline
\end{tabular}

Although being slightly modified from Bhattacherjee's (2001b) scales, the above mentioned items loaded cleanly on the perceived usefulness construct and the data analysis demonstrated a high reliability (showing Cronbach Alpha close to the 0.9 level).

Limayem et al. (2003) borrowed Bhattacherjee's (2001b) scales to investigate IS usage (Blackboard use in a University context) at the adoption and post-adoption stages. The authors argued that students must perceive Information Systems (Blackboard) as useful in order to form intentions to use them. Table 22 displays the items used for this study. 
Table 22: Scale to measure a perceived usefulness construct (Limayem, Cheung et al. 2003)

\begin{tabular}{|l|l|l|l|}
\hline No. & Item wording & Loadings & Authors \\
\hline 1 & Blackboard is of benefit to me. & 0.90 & $\begin{array}{l}\text { (Limayem, Cheung et al. 2003) } \\
\text { adapted from (Bhattacherjee 2001) }\end{array}$ \\
\hline 2 & $\begin{array}{l}\text { The advantages of Blackboard outweigh the } \\
\text { disadvantages. }\end{array}$ & 0.90 & $\begin{array}{l}\text { (Limayem, Cheung et al. 2003) } \\
\text { adapted from (Bhattacherjee 2001) }\end{array}$ \\
\hline 3 & $\begin{array}{l}\text { Overall, using Blackboard is advantageous. } \\
\text { (Limayem, Cheung et al. 2003) } \\
\text { adapted from (Bhattacherjee 2001) }\end{array}$ \\
\hline \multicolumn{2}{|c|}{$\mathrm{CR}=0.93, \mathrm{AVE}=0.81$} \\
\hline
\end{tabular}

Table 22 also shows that Bhattacherjee's (2001b) scales were re-confirmed in terms of their reliability and validity. In a subsequent study, Limayem et al. (2007) revalidated the above mentioned scales and the research outcome confirmed the strength of Bhattacherjee's scales (Limayem, Hirt et al. 2007).

In addition to these traditional IS studies, much literature on electronic banking services has investigated the linkage between perceived usefulness constructs and consumers' intentions to use electronic banking. Chan et al. (2004) used a perceived usefulness construct to investigate consumers' intentions to use Internet banking services. Perceived usefulness was defined as the degree to which a potential adopter (or user) views Internet banking as offering advantages over previous ways of performing the banking transactions (Chan and $\mathrm{Lu}$ 2004). Items were adapted from Davis et al. (1989), as well as Moore and Benbasat's (1991) study. The items used in this study are listed in Table 23.

Table 23: Scale to measure a perceived usefulness construct (Chan and Lu 2004)

\begin{tabular}{|l|l|l|l|}
\hline No. & Item wording & Loadings & Authors \\
\hline 1 & $\begin{array}{l}\text { Internet banking makes it easier for me to conduct my } \\
\text { banking transaction. }\end{array}$ & 0.85 & $\begin{array}{l}\text { (Chan and Lu 2004) adapted from } \\
\text { (Davis, Bagozzi et al. 1989) }\end{array}$ \\
\hline 2 & $\begin{array}{l}\text { Internet banking gives me greater control over my finances } \\
\text { (Chan and Lu 2004) adapted from } \\
\text { (Davis, Bagozzi et al. 1989) }\end{array}$ \\
\hline 3 & $\begin{array}{l}\text { Internet banking allows me to manage my finances more } \\
\text { effectively }\end{array}$ & 0.89 & $\begin{array}{l}\text { (Chan and Lu 2004) adapted from } \\
\text { (Davis, Bagozzi et al. 1989) }\end{array}$ \\
\hline 4 & $\begin{array}{l}\text { Internet banking is a convenient way to manage my } \\
\text { finances }\end{array}$ & $\begin{array}{l}\text { (Chan and Lu 2004) adapted from } \\
\text { (Davis, Bagozzi et al. 1989) }\end{array}$ \\
\hline 6 & $\begin{array}{l}\text { Internet banking eliminates time constraint; thus I can use } \\
\text { the banking services any time I like }\end{array}$ & $\begin{array}{l}\text { (Chan and Lu 2004) adapted from } \\
\text { (Davis, Bagozzi et al. 1989) }\end{array}$ \\
\hline \multicolumn{2}{|c|}{} \\
\hline
\end{tabular}

To test the research model, Chan et al. (2004) surveyed University students concerning their perceptions of Internet banking services. Before administering the survey instrument, Chan et al. (2004) refined the wording of the items through judgment rounds with senior IS researcher. The assessment of the measurement model demonstrated that all items loaded cleanly onto the perceived useful construct and demonstrated a high reliability of the scales. 


\section{Summary}

In summary, Davis (1989) thoroughly developed scales to measure a perceived usefulness construct as part of the TAM model. Numerous researchers have re-applied Davis' scales in various contexts. While Davis (1989) developed the original scales in a non-voluntary and organizational context, many researcher have validated perceived usefulness scales in a voluntary use setting at the individual level. Bhattacherjee's (2001b) scales seemed to be particularly appropriate since he studied consumers' perceived usefulness of Internet brokerage services. What is more, Limayem et al. (2003), as well as Limayem et al. (2007) used Bhattacherjee's (2001b) scales and re-confirmed their validity and reliability in subsequent studies.

\section{Implication for this study}

Due to the fact that the current study aims to investigate consumers' intentions to use electronic banking channels, it was judged to be inappropriate to adapt measures directly from Davis' (1989) TAM study. Davis' (1989) scales were originally validated in an organizational context. On the other hand, Bhattacherjee's (2001a, 2001b) scales were already adjusted and validated in a voluntary use setting related to individual users (both studies assessed consumers' willingness to use of Internet brokerage services). Therefore, it seemed to be more appropriate to adapt Bhattacherejee's (2001a, 2001b) scales and adjust them slightly to the context of the current study [e.g. by replacing OBD (online banking division) by Internet Banking]. Similarly Chan et al. (2004) validated scales to measure perceived usefulness in an Internet banking context from a consumer perspective. These items were also considered for assessing the perceived usefulness construct.

\section{Scales for ease of use construct}

The literature review has shown that the degree to which an information system is perceived as being difficult to utilize influences users' intentions to deploy the system (Davis 1989; Taylor and Todd 1995; Thompson, Compeau et al. 2006). Similarly, literature on electronic banking has argued that ease of use related to electronic banking channels influences consumers' intentions to use electronic banking channels. In order to identify adequate scales, both literature streams (IS/electronic banking) were screened for existing ease of use measures.

In a very early research, Doll and Torkzadeh (1988) developed a 12-item instrument that measured five components of end-user satisfaction - content, accuracy, format, ease of use, and timeliness. Ease of use was measured through three items (as shown in Table 24): 
Table 24: Scale to measure an ease of use construct (Doll and Torkzadeh 1988)

\begin{tabular}{|l|l|l|l|}
\hline No. & Item wording & Loadings & Authors \\
\hline 1 & Is the system user friendly? & 0.63 & $\begin{array}{l}\text { (Doll and } \\
\text { Torkzadeh 1988) }\end{array}$ \\
\hline 2 & Is the system easy to use? & 0.67 & $\begin{array}{l}\text { (Doll and } \\
\text { Torkzadeh 1988) }\end{array}$ \\
\hline 3 & Is the system efficient? & 0.75 & $\begin{array}{l}\text { (Doll and } \\
\text { Torkzadeh 1988) }\end{array}$ \\
\hline \multicolumn{2}{|c|}{ Cronbach alpha 0.92 } \\
\hline
\end{tabular}

The analysis of the measurement model demonstrated that Doll and Torkzadeh's (1988) scale showed a high level of reliability and all items loaded cleanly onto the ease of use construct.

Davis' (1989) also developed scales to measure the ease of use related to information systems use in an organizational context. As discussed earlier, the scales were thoroughly validated using a card sorting procedure and judgment rounds. The final ease of use scales used for the main study are shown in Table 25.

Table 25: Scale to measure an ease of use construct (Davis 1989)

\begin{tabular}{|l|l|l|l|}
\hline No. & Item wording & Loadings & Authors \\
\hline 1 & Learning to operate Chart-master would be easy for me. & 0.97 & (Davis 1989) \\
\hline 2 & I would find it easy to get Chart-master to do what I want it to do. & 0.83 & (Davis 1989) \\
\hline 3 & My interaction with Chart-master would be clear and understandable. & 0.89 & (Davis 1989) \\
\hline 4 & I would find Chart-Master to be flexible to interact with. & 0.63 & (Davis 1989) \\
\hline 5 & It would be easy for me to become skillful at using Chart-master. & 0.91 & (Davis 1989) \\
\hline 6 & I would find Chart-master easy to use. & 0.91 & (Davis 1989) \\
\hline \multicolumn{2}{|c|}{ Cronbach alpha 0.94 } \\
\hline
\end{tabular}

Davis' (1989) ease of use scales have often been argued to be seminal measures for the IS research discipline (Taylor and Todd 1995; Venkatesh, Morris et al. 2003; Benbasat and Barki 2007). Not surprisingly, various researchers adjusted them to assess the ease of use of information systems in diverse use settings.

For instance, Moore and Benbasat (1991) used Davis (1989) ease of use scales to develop an instrument for measuring the adoption of information technology. Moore and Benbasat (1991) also validated their scales through a card sorting procedure. Next they conducted a series of pilot tests followed by a factor analysis. The authors reported that all items shown in Table 26 loaded cleanly onto the ease of use construct in their study and showed a high level of reliability.

Table 26: Scale to measure a easy to use construct (Moore and Benbasat 1991)

\begin{tabular}{|l|l|l|}
\hline No. & Item wording & Authors \\
\hline 1 & I believe that a PWS is cumbersome to use. & $\begin{array}{l}\text { (Moore and Benbasat 1991) adapted from (Davis } \\
1989)\end{array}$ \\
\hline 2 & $\begin{array}{l}\text { It is easy for me to remember how to perform tasks } \\
\text { using a PWS. }\end{array}$ & $\begin{array}{l}\text { (Moore and Benbasat 1991) adapted from (Davis } \\
\text { 1989) }\end{array}$ \\
\hline 3 & My using a PWS requires a lot of mental effort. & (Moore and Benbasat 1991) adapted from (Davis \\
\hline
\end{tabular}




\begin{tabular}{|l|l|l|}
\hline & \multicolumn{3}{|l|}{} & \\
\hline 4 & Using a PWS is often frustrating. & $\begin{array}{l}\text { (Moore and Benbasat 1991) adapted from } \\
1989)\end{array}$ \\
\hline 5 & $\begin{array}{l}\text { My interaction with a PWS is clear and } \\
\text { understandable. }\end{array}$ & $\begin{array}{l}\text { (Moore and Benbasat 1991) adapted from (Davis } \\
1989)\end{array}$ \\
\hline 6 & $\begin{array}{l}\text { I believe that it is easy to get a PWS to do what I } \\
\text { want it to do. }\end{array}$ & $\begin{array}{l}\text { (Moore and Benbasat 1991) adapted from (Davis } \\
1989)\end{array}$ \\
\hline 7 & Overall, I believe that a PWS is easy to use. & $\begin{array}{l}\text { (Moore and Benbasat 1991) adapted from (Davis } \\
1989)\end{array}$ \\
\hline 8 & Learning to operate a PWS is easy for me. & $\begin{array}{l}\text { (Moore and Benbasat 1991) adapted from (Davis } \\
1989)\end{array}$ \\
\hline
\end{tabular}

Venkatesh et al. (2003) integrated Davis' (1989) ease of use items as well as Moore and Benbasat's (1991) within the effort expectancy construct of the UTAUT model. Venkatesh et al. (2003) adapted items from both articles and used the following items to measure the effort expectancy construct:

Table 27: Scale to measure the effort expectancy construct (Venkatesh, Morris et al. 2003)

\begin{tabular}{|l|l|l|l|}
\hline No. & Item wording & Loadings & Authors \\
\hline 1 & $\begin{array}{l}\text { My interaction with the system would be } \\
\text { clear and understandable. }\end{array}$ & 0.94 & $\begin{array}{l}\text { (Venkatesh, Morris et al. 2003) adapted from } \\
\text { (Davis 1989; Moore and Benbasat 1991) }\end{array}$ \\
\hline 2 & $\begin{array}{l}\text { It would be easy for me to become skillful at } \\
\text { using the system. }\end{array}$ & 0.90 & $\begin{array}{l}\text { (Venkatesh, Morris et al. 2003) adapted from } \\
\text { (Davis 1989; Moore and Benbasat 1991) }\end{array}$ \\
\hline 3 & $\begin{array}{l}\text { I would find the system easy to use. } \\
\text { (Venkatesh, Morris et al. 2003) adapted from } \\
\text { (Davis 1989; Moore and Benbasat 1991) }\end{array}$ \\
\hline 4 & $\begin{array}{l}\text { Learning to operate the system is easy for } \\
\text { me. }\end{array}$ & 0.89 & $\begin{array}{l}\text { (Venkatesh, Morris et al. 2003) adapted from } \\
\text { (Davis 1989; Moore and Benbasat 1991) }\end{array}$ \\
\hline \multicolumn{2}{|c|}{ Internal consistency 0.92 } \\
\hline
\end{tabular}

The scales loaded cleanly onto the effort expectancy construct and showed a high level of reliability. The UTAUT study reconfirmed the validity of Davis' (1989) and Moore and Benbasat's (1991) ease of use scales.

While the scales developed by Davis (1989), Moore and Benbasat (1991), and Venkatesh et al. (2003) were successfully tested in an organizational context, many researchers have applied ease of use scales to non-organizational and voluntary use settings. For example, Staples et al. (2004) adapted two ease of use items from Doll and Torkzadeh (1988) as well as one from Davis et al. (1989) to study task-technology fit of information systems (the items are shown in Table 28).

Table 28: Scale to measure a easy to use construct (Staples and Seddon 2004)

\begin{tabular}{|l|l|l|}
\hline No. & Item wording & Authors \\
\hline 1 & The system is easy to use. & $\begin{array}{l}\text { (Staples and Seddon 2004) adapted from (Doll and } \\
\text { Torkzadeh 1988) }\end{array}$ \\
\hline 2 & The system is user friendly. & $\begin{array}{l}\text { (Staples and Seddon 2004) adapted from (Doll and } \\
\text { Torkzadeh 1988) }\end{array}$ \\
\hline 3 & It is easy to get the system do what I want it to do. & $\begin{array}{l}\text { (Staples and Seddon 2004) adapted from (Davis } \\
1989)\end{array}$ \\
\hline \multicolumn{2}{|r|}{ Cronbach Alpha: 0.84 } \\
\hline
\end{tabular}


This study examined individuals' intentions to use library databases. The authors reported that each item loaded cleanly onto the ease of use construct and also showed a high level of reliability.

Also, Chan et al. (2004) investigated consumers' Internet banking adoption in Hong Kong. As part of the research model, Chan et al. (2004) conceptualized an ease of use construct. As shown in Table 29, Chan et al. (2004) operationalized the ease of use construct through items originally developed by Davis (1989).

Table 29: Scale to measure a easy to use construct (Chan and Lu 2004)

\begin{tabular}{|c|c|c|c|}
\hline No. & Item wording & Loadings & Authors \\
\hline 1 & Internet banking is easy to use & 0.78 & $\begin{array}{l}\begin{array}{l}\text { (Chan and Lu } \\
\text { adapted } \\
\text { 1989) }\end{array} \text { from } \\
\text { (Davis }\end{array}$ \\
\hline 2 & $\begin{array}{l}\text { Internet banking is an easy way to conduct banking } \\
\text { transactions }\end{array}$ & 0.80 & $\begin{array}{lcc}\text { Chan and } \mathrm{Lu} & \text { 2004) } \\
\text { adapted } & \text { from } & \text { (Davis } \\
\text { 1989) } & & \end{array}$ \\
\hline 3 & $\begin{array}{l}\text { Learning to operate Internet banking would be easy } \\
\text { for me }\end{array}$ & 0.79 & 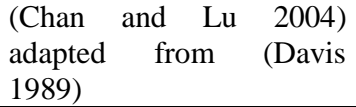 \\
\hline 4 & $\begin{array}{l}\text { I believe it would be easy for me to get Internet } \\
\text { banking to do what I want it to do }\end{array}$ & 0.79 & $\begin{array}{l}\text { (Chan and } \mathrm{Lu} \\
\begin{array}{l}\text { 2004) } \\
\text { adapted } \\
\text { 1989) }\end{array}\end{array}$ \\
\hline 5 & $\begin{array}{l}\text { Using the Internet does not require a lot of mental } \\
\text { effort }\end{array}$ & 0.73 & $\begin{array}{l}\text { (Chan and Lu } 2004) \\
\text { adapted from } \\
\text { (Davis }\end{array}$ \\
\hline
\end{tabular}

Despite the fact that Chan et al. (2004) applied Davis' (1989) TAM scales to individuals using Internet banking voluntarily, all items loaded cleanly onto the ease of use construct and showed a high level of reliability.

Lai and Li (2005) used TAM theory to investigate students' perceptions of Internet banking services. As part of the research model, the authors hypothesized that the perceived ease of use of Internet banking services has a significant relationship to students' intentions to use Internet banking. The authors borrowed items from Davis' (1989) original scale (as shown in Table 30).

Table 30: Scale to measure a easy to use construct (Lai and Li 2005)

\begin{tabular}{|l|l|l|l|}
\hline No. & Item wording & Loadings & Authors \\
\hline 1 & Learning to use Internet Banking is easy for me. & 0.850 & (Lai and Li 2005) \\
\hline 2 & $\begin{array}{l}\text { It is easy to use Internet Banking to accomplish my banking } \\
\text { tasks. }\end{array}$ & 0.868 & (Lai and Li 2005) \\
\hline 3 & Overall, I believe Internet Banking is easy to use. & 0.798 & (Lai and Li 2005) \\
\hline \multicolumn{2}{|c|}{ Cronbach's Alpha 0.90 } \\
\hline
\end{tabular}

The scales were initially pretested and consequently administered to students in Hong Kong. As shown, the scales demonstrated high reliability and loaded cleanly onto the ease of use construct (Lai and Li 2005). 


\section{Summary}

In summary, various researchers have validated scales to assess an ease of use construct related to information systems usage. Particularly Davis' (1989) as well as Moore and Benbasat's (1991) survey instruments have been often reapplied to different use contexts. In addition, several researchers have validated ease of use scales related to individuals' use of electronic banking services. Particularly, Chan et al. (2004) and Lai et al. (2005) tested ease of use measures successfully in their research studies.

\section{Implications for this study}

Ease of use was conceptualized as one construct of the precursors of utilization in the research model. While Davis (1989) and Moore and Benbasat's (1991) scales were tested in organizational settings, scales developed by Chan et al. (2004) and Lai et al. (2005) (both tested in an Internet banking context) appeared to be appropriate for this study. Thus, their ease of use items were slightly adjusted to the context of this study and added to the pool of items.

\section{Scales for attitude towards channel use construct}

As discussed in the literature review, several researchers have developed and validated attitude towards use scales to study individuals' positive and negative feelings towards using specific information systems (Taylor and Todd 1995). Further, studies investigating consumers' acceptance of electronic banking services have published validated survey questionnaire instruments to measure attitude variables.

For instance, Taylor and Todd (1995) tested TAM theory and compared it with two variations of the TPB theory to understand students' intentions to use information systems for their university assignments. As part of their study, the attitude construct was measured through the following items:

Table 31: Scale to measure an attitude construct (Taylor and Todd 1995)

\begin{tabular}{|c|c|c|c|}
\hline No. & Item wording & Reliability & Authors \\
\hline 1 & Using the CRC is a (bad/good) idea. & 0.85 & $\begin{array}{l}\text { (Taylor and Todd } \\
\text { 1995) }\end{array}$ \\
\hline 2 & Using the CRC is a (foolish/wise) idea. & 0.85 & $\begin{array}{l}\text { (Taylor and Todd } \\
\text { 1995) }\end{array}$ \\
\hline 3 & I (dislike/like) the idea of using the CRC. & 0.85 & $\begin{array}{l}\text { (Taylor and } \text { Todd } \\
1995)\end{array}$ \\
\hline 4 & Using the CRC would be: (unpleasant/pleasant) & 0.85 & $\begin{array}{l}\text { (Taylor and Todd } \\
\text { 1995) }\end{array}$ \\
\hline
\end{tabular}


The use setting was voluntary and a non-organizational context. The authors reported that the items loaded cleanly onto the attitude construct ${ }^{6}$ and demonstrated a high level of reliability (Taylor and Todd 1995).

In addition, scales specifically designed to investigate consumers' attitudes towards electronic banking channels have been developed. For instance, Lai et al. (2005) used TAM theory to study students' perceptions of Internet banking services. As part of the research model, the authors hypothesized that students' attitude towards Internet banking services would significantly impact on their intentions to use Internet banking. The items used to measure the attitude towards Internet banking construct are shown below.

Table 32: Scales used to assess the attitude towards Internet banking construct (Lai and $\mathrm{Li}$ 2005)

\begin{tabular}{|l|l|l|l|}
\hline No. & Item wording & Loadings & Authors \\
\hline 1 & In my opinion, it is desirable to use Internet Banking & 0.763 & (Lai and Li 2005) \\
\hline 2 & I think it is good for me to use Internet Banking & 0.783 & (Lai and Li 2005) \\
\hline 3 & Overall, my attitude towards Internet Banking is favorable & 0.806 & (Lai and Li 2005) \\
\hline \multicolumn{2}{|c|}{ Cronbach's alpha 0.95 } \\
\hline
\end{tabular}

Further, Cheng et al. (2006) also used the TAM model to assess consumers' perceptions towards Internet banking services. Attitude towards Internet banking was measured through four items. To validate the instrument, the authors initially pilot tested the scales using a sample of 120 consumers regarding their experiences with Internet banking applications. Using factor analysis, the scales were refined and used for the main study. Table 33 lists the final items used to measure the attitude towards Internet banking construct.

Table 33: Scales used to assess the attitude towards Internet banking construct (Cheng, Lam et al. 2006)

\begin{tabular}{|l|l|l|l|}
\hline No. & Item wording & Loadings & Authors \\
\hline 1 & Using the IB is a good idea & 0.654 & $\begin{array}{l}\text { (Cheng, Lam et al. } \\
2006)\end{array}$ \\
\hline 2 & I would feel that using the IB is pleasant & 0.710 & $\begin{array}{l}\text { (Cheng, Lam et al. } \\
\text { 2006) }\end{array}$ \\
\hline 3 & In my opinion, it would be desirable to use the IB & 0.697 & $\begin{array}{l}\text { (Cheng, Lam et al. } \\
\text { 2006) }\end{array}$ \\
\hline 4 & In my view, using the IB is a wise idea & 0.618 & $\begin{array}{l}\text { (Cheng, Lam et al. } \\
\text { 2006) }\end{array}$ \\
\hline \multicolumn{2}{|c|}{ Cronbach's alpha 0.902 } \\
\hline
\end{tabular}

The results confirmed that the items loaded cleanly onto the attitude towards Internet banking construct and the scales demonstrated a high level of reliability.

\section{Summary}

The literature review showed that attitude towards use constructs are successful predictors of intentions to use behavior variables. Many studies have used attitude variables in

\footnotetext{
${ }^{6}$ The item-to-construct loadings were not published in this article.
} 
organizational use settings or utilized affect towards use construct - which can be seen as a subset of individual's attitudes (Venkatesh, Morris et al. 2003).

Taylor et al. (1995) developed scales in a voluntary use setting investigating students' attitudes towards information systems. These scales were reviewed here since they measured an attitude construct in a conceptually similar context. Further, Cheng et al. (2004), as well as Lai et al. (2005) developed and validated attitude scales to assess consumers' feeling towards Internet banking services.

\section{Implications for this study}

Due to the theoretical overlapping, Cheng et al. (2004) and Lai et al. (2005) attitude towards Internet banking scales were judged to be appropriate measures for this study. Therefore, the items were slightly adjusted to the context of this study and included in the item database.

\section{Scales for subjective norms construct}

Much literature on the acceptance and adoption of information systems suggests how important individuals' subjective and social norms are in relation to the use of specific information systems (Venkatesh, Morris et al. 2003). In consequence, many researchers have developed and validated scales measuring individuals' subjective norms in relation to information systems usage. In addition, a few researchers have also tested subjective norm measures with regards to Internet banking adoption.

For instance, Hartwick and Barki (1994) conceptualized subjective norms as a variable impacting on individuals' intentions to use information systems (Hartwick and Barki 1994). To assess the subjective norms construct, the following items were used in this study:

Table 34: Scale to measure a subjective norms construct (Hartwick and Barki 1994)

\begin{tabular}{|l|l|l|}
\hline No. & Item wording & Authors \\
\hline 1 & What do other people think about your use of the new system? & $\begin{array}{l}\text { (Hartwick and Barki } \\
1994)\end{array}$ \\
\hline 2 & At work, my superiors think that I (should not/should) frequently use the new system. & $\begin{array}{l}\text { (Hartwick and Barki } \\
1994)\end{array}$ \\
\hline 3 & At work, my peers think that I (should not/should) frequently use the new system. & $\begin{array}{l}\text { (Hartwick and Barki } \\
1994)\end{array}$ \\
\hline 4 & $\begin{array}{l}\text { At work, my subordinates think that I (should not/should) frequently use the new } \\
\text { system. }\end{array}$ & $\begin{array}{l}\text { (Hartwick and Barki } \\
1994)\end{array}$ \\
\hline 5 & $\begin{array}{l}\text { At work, my superiors think that I (should not/should) be a heavy user of the new } \\
\text { system. }\end{array}$ & $\begin{array}{l}\text { (Hartwick and Barki } \\
1994)\end{array}$ \\
\hline 6 & $\begin{array}{l}\text { At work, my peers think that 1 (should not/should) be a heavy user of the new system. } \\
\text { (Hartwick and Barki } \\
1994)\end{array}$ \\
\hline 7 & $\begin{array}{l}\text { At work, my subordinates think that 1 (should not/should) be a heavy user of the new } \\
\text { system. }\end{array}$ & $\begin{array}{l}\text { (Hartwick and Barki } \\
1994)\end{array}$ \\
\hline
\end{tabular}


While these items were found to be valid and reliable (Hartwick and Barki 1994), they appeared to be inappropriate for the current study. Any of these items were intended to investigate how work-related peers influence an individual's subjective norms (directly and indirectly). Since consumers use electronic banking channels in a non-work related context, additional scales were investigating subjective norms in a voluntary and individual context were examined.

Mathieson (1991) approached students regarding their intentions to use calculators or spreadsheets in order to perform a given task. The context was non-organizational and students were asked how important subjective norms would be on their intentions to either use a spreadsheet or the calculator (Mathieson 1991).

Table 35: Scale to measure a subjective norms construct (Mathieson 1991)

\begin{tabular}{|l|l|l|l|}
\hline No. & Item wording & $\begin{array}{l}\text { Cronbach's } \\
\text { alpha }\end{array}$ & Authors \\
\hline 1 & $\begin{array}{l}\text { Those people who are important to me would (Stronlgy support/Strongly } \\
\text { oppose) my using [the spreadsheet] rather than my calculator for the } \\
\text { assignment }\end{array}$ & 0.864 & $\begin{array}{l}\text { (Mathieson } \\
1991)\end{array}$ \\
\hline 2 & $\begin{array}{l}\text { I think that those people who are important to me would want me to use [the } \\
\text { spreadsheet] rather than my calculator for the assignment (Strongly } \\
\text { agree/strongly disagree) }\end{array}$ & $\begin{array}{l}\text { (Mathieson } \\
1991)\end{array}$ \\
\hline 3 & $\begin{array}{l}\text { People whose opinions I value would prefer me to use [the spreadsheet] rather } \\
\text { than my calculator for the assignment (strongly agree/strongly disagree) }\end{array}$ & 0.864 & $\begin{array}{l}\text { (Mathieson } \\
1991)\end{array}$ \\
\hline \multicolumn{2}{|c|}{ Cronbach's Alpha 0.864 } & \multicolumn{1}{|c|}{} \\
\hline
\end{tabular}

The analysis confirmed that the items loaded cleanly onto the subjective norms construct and the scales indicated a good level of reliability (Mathieson 1991).

Venkatesh et al. (2003) adapted Mathieson's (1991) scales for testing the UTAUT model. The authors assessed the subjective norms construct through the below mentioned items (in addition to scales for social factors forming the social influence construct).

Table 36: Scale to measure a subjective norms construct (Venkatesh, Morris et al. 2003)

\begin{tabular}{|l|l|l|l|}
\hline No. & Item wording & Loadings & Authors \\
\hline 1 & $\begin{array}{l}\text { People who influence my behavior think that I should } \\
\text { use the system. }\end{array}$ & 0.90 & $\begin{array}{l}\text { (Venkatesh, Morris et al. 2003) based } \\
\text { on (Mathieson 1991) }\end{array}$ \\
\hline 2 & $\begin{array}{l}\text { People who are important to me think that I should } \\
\text { use the system. }\end{array}$ & 0.90 & $\begin{array}{l}\text { (Venkatesh, Morris et al. 2003) based } \\
\text { on (Mathieson 1991) }\end{array}$ \\
\hline \multicolumn{2}{|c|}{ Internal consistency reliability 0.92 } \\
\hline
\end{tabular}

As shown above, the scales showed a high level of reliability and were shown to be valid in terms of convergent and discriminant validity.

Limayem et al. (2003) borrowed items from Taylor et al. (1995) to study students' intentions to use Blackboard at university level. The use setting in this study was at the individual level and voluntary use related to Blackboard. The items used for this study are depicted in Table 37. 
Table 37: Scale to measure a subjective norms construct (Limayem et al. 2003)

\begin{tabular}{|l|l|l|l|}
\hline No. & Item wording & Loadings & Authors \\
\hline 1 & $\begin{array}{l}\text { People who influence my behavior think that I should use } \\
\text { Blackboard. }\end{array}$ & $\begin{array}{l}\text { (Limayem, Cheung et al. 2003) } \\
\text { adapted from (Taylor and Todd } \\
\text { 1995) }\end{array}$ \\
\hline 2 & $\begin{array}{l}\text { People who are important to me think that I should use } \\
\text { Blackboard. }\end{array}$ & $\begin{array}{l}\text { (Limayem, Cheung et al. 2003) } \\
\text { adapted from (Taylor and Todd } \\
\text { 1995) }\end{array}$ \\
\hline \multicolumn{2}{|c|}{ CR=0.95, AVE=0.74 } \\
\hline
\end{tabular}

The assessment of the measurement model demonstrated a high level of convergent validity and the scales indicated a good level of reliability (Limayem, Cheung et al. 2003).

Chan et al. (2004) developed and tested subjective norms scales in context of Internet banking applications. The authors defined subjective norms as: “a potential adopter's (or user's) beliefs that the salient referent thinks he/she should or should not adopt/continue-touse Internet banking". The population of interest in their study was defined as current and potential users of Internet banking in Hong Kong. The authors sampled under- and postgraduate students and asked them about their intentions to use Internet banking services. The subjective norms construct was assessed through the following items:

Table 38: Scale to measure a subjective norms construct (Chan and Lu 2004)

\begin{tabular}{|l|l|l|l|}
\hline No. & Item wording & Loadings & Authors \\
\hline My decision to adopt Internet banking is influenced by: & & \\
\hline 1 & My friends & 0.92 & (Chan and Lu 2004) \\
\hline 2 & My family/relatives & 0.86 & (Chan and Lu 2004) \\
\hline 3 & My colleagues/peers & 0.95 & (Chan and Lu 2004) \\
\hline \multicolumn{2}{|r|}{ Cronbach's alpha 0.93 } \\
\hline
\end{tabular}

Table 38 shows that the scales used by Chan et al. (2004) demonstrated a good level of convergent validity and they were tested highly reliable.

\section{Summary}

The literature review demonstrated that subjective norms are an influential factor for individuals' intentions to use information systems. Several researchers using TRA/TPB theory have developed reliable scales to measure subjective norms constructs in an individual and voluntary use context. Similarly, researchers have shown that normative beliefs are important for consumers using electronic banking channels.

\section{Implications for this study}

The scales developed by Chan et al. (2004) appeared to be particularly appropriate for this current study. Chan et al. (2004) used them to study individuals' subjective norms regarding Internet banking applications. Thus, these scales did not require re-adjustment for the current study and were included within the pool of items. 


\section{Scales for channel security}

As discussed in Chapter 3, consumers' security concerns have often been suggested to be an important factor influencing their intention to use them (Liao and Cheung 2008). Particularly the security of personal and sensitive data is a major concern for consumers when managing their financials electronically (Tan and Thompson 2000; Karjaluoto, Mattila et al. 2002; Liao and Cheung 2002; Suh and Han 2002; Lai and Li 2005; Sayar and Wolfe 2007). Several studies developed scales to assess consumers' security concerns related self-service banking channels such as ATMs, phone, Internet and mobile banking.

For instance, Wang et al. (2003) added a perceived credibility construct to the original TAM model. Using a random sample of Internet banking users in Tawain, the authors assessed the perceived credibility construct with the following items:

Table 39: Scale to measure a perceived credibility construct (Wang, Wang et al. 2003)

\begin{tabular}{|l|l|l|l|}
\hline No. & Item wording & Loadings & Authors \\
\hline 1 & $\begin{array}{l}\text { Using the Internet banking systems would not divulge my personal } \\
\text { information. }\end{array}$ & 1.00 & $\begin{array}{l}\text { (Wang, Wang et al. } \\
\text { 2003) }\end{array}$ \\
\hline 2 & $\begin{array}{l}\text { I would find the Internet banking systems secure in conducting my banking } \\
\text { transactions. }\end{array}$ & 0.90 & $\begin{array}{l}\text { (Wang, Wang et al. } \\
\text { 2003) }\end{array}$ \\
\hline \multicolumn{2}{|c|}{ Composite reliability 0.90 } \\
\hline
\end{tabular}

The perceived credibility items were specifically designed for Wang et al's research. The data analysis showed that the items loaded cleanly onto the perceived credibility construct and demonstrated a high level of reliability.

Curran and Meuter (2005) added a perceived security construct to the TAM model to study consumer adoption of electronic banking channels. Curran and Meuter (2005) pre-tested the scales and refined the measures in light of these tests. Table 40 lists the final security items used for this study.

Table 40: Scale to measure a risk construct related to Internet banking (Curran and Meuter 2005)

\begin{tabular}{|l|l|l|}
\hline No. & Item wording & Authors \\
\hline 1 & I feel secure conducting my banking business using the SST. & (Curran and Meuter 2005) \\
\hline 2 & I feel safe conducting my banking business using the SST. & (Curran and Meuter 2005) \\
\hline 3 & I know that the SST will handle my business correctly. & (Curran and Meuter 2005) \\
\hline 4 & There is little danger that anything will go wrong when I use the SST. & (Curran and Meuter 2005) \\
\hline \multicolumn{2}{|c|}{ Cronbach alpha: 0.85 } \\
\hline
\end{tabular}

The authors stated that each item loaded cleanly onto the security construct ${ }^{7}$. Further, the scales demonstrated a high level of reliability.

\footnotetext{
${ }^{7}$ The items-to-construct loading were not published.
} 
Cheng et al. (2006) used scales to measure consumers' perceived security of Internet banking applications. The authors pilot-tested their instrument using a sample of 120 consumers regarding their experiences with Internet banking applications. Using factor analysis, the scales were refined and used for the main study. Table 41 lists the final items used to measure the security construct related to Internet banking services.

Table 41: Scale to measure a perceived Internet banking security construct

\begin{tabular}{|l|l|l|l|}
\hline No. & Item wording & Loadings & Authors \\
\hline 1 & $\begin{array}{l}\text { I would feel secure sending sensitive information across the INTERNET } \\
\text { BANKING. }\end{array}$ & 0.751 & $\begin{array}{l}\text { (Cheng, Lam et al. } \\
\text { 2006) }\end{array}$ \\
\hline 2 & $\begin{array}{l}\text { The INTERNET BANKING is a secure means through which to send } \\
\text { sensitive information. }\end{array}$ & 0.825 & $\begin{array}{l}\text { (Cheng, Lam et al. } \\
\text { 2006) }\end{array}$ \\
\hline 3 & $\begin{array}{l}\text { I would feel totally safe providing sensitive information about myself over the } \\
\text { INTERNET BANKING. }\end{array}$ & 0.804 & $\begin{array}{l}\text { (Cheng, Lam et al. } \\
\text { 2006) }\end{array}$ \\
\hline 4 & $\begin{array}{l}\text { Overall, the INTERENT BANKING is a safe place to transmit sensitive } \\
\text { information. }\end{array}$ & 0.901 & $\begin{array}{l}\text { (Cheng, Lam et al. } \\
\text { 2006) }\end{array}$ \\
\hline \multicolumn{1}{|c|}{ Cronbach alpha: 0.939 } & \multicolumn{1}{|c|}{ Cam } \\
\hline
\end{tabular}

As shown above, the items loaded cleanly onto the security construct and demonstrated a high level of reliability.

Vatanasombut et al. (2008) extended commitment-trust theory, an expectationconfirmation model, and TAM theory to assess consumers' intentions to use Internet banking applications. As part of their research model, the authors developed scales to measure a perceived security construct. Before administering the survey questionnaire to banking consumers, the authors pilot-tested the scales and refined the items in light of the pilot test. The items used to measure the perceived security construct are shown in Table 42 .

Table 42: Scale to measure a perceived Internet banking security construct (Vatanasombut, Igbaria et al. 2008)

\begin{tabular}{|l|l|l|l|}
\hline No. & Item wording & Loadings & Authors \\
\hline 1 & I feel secure sending sensitive information across the Internet & 0.84 & $\begin{array}{l}\text { (Vatanasombut, Igbaria } \\
\text { et al. 2008) }\end{array}$ \\
\hline 2 & $\begin{array}{l}\text { The Internet is a secure means through which to send sensitive } \\
\text { information }\end{array}$ & 0.87 & $\begin{array}{l}\text { (Vatanasombut, Igbaria } \\
\text { et al. 2008) }\end{array}$ \\
\hline 3 & $\begin{array}{l}\text { I feel secure managing my personal finances with the bank's Online } \\
\text { Banking }\end{array}$ & 0.54 & $\begin{array}{l}\text { (Vatanasombut, Igbaria } \\
\text { et al. 2008) }\end{array}$ \\
\hline 4 & $\begin{array}{l}\text { The bank's Online Banking offers a secure means through which to } \\
\text { manage my personal finances }\end{array}$ & $\begin{array}{l}\text { (Vatanasombut, Igbaria } \\
\text { et al. 2008) }\end{array}$ \\
\hline \multicolumn{2}{|c|}{ Cronbach's alpha 0.83 } \\
\hline
\end{tabular}

As listed above, the scales were shown to be highly reliable and the items loaded cleanly onto the perceived security construct.

\section{Summary}

The existing literature on electronic banking channel adoption has developed scales to measure perceived security constructs related to consumers' use of Internet banking 
applications. These scales were judged to be suited for the current study as they were validated in a theoretically similar context.

\section{Implications for this study}

The scales used by Cheng et al. (2006), Curran et al. (2005), and Vatanasombut et al. 2008 appeared to be well suited for the context of this study. These measures were developed to test perceived security constructs with regards to Internet banking application usage. Thus, these items were integrated into the pool of items.

\section{Scales for costs associated with channel use}

As discussed in Chapter 3, several studies have demonstrated that costs associated with using a banking channel are a factor inhibiting consumers' use of them (Barnes and Corbitt 2003). For example, Luarn et al. (2005) studied individuals' behavior towards mobile banking services. The authors applied the TAM theory to mobile banking context and included a perceived self-efficacy and perceived financial costs construct. The latter construct was assessed through the following items.

Table 43: Scale to measure the perceived financial costs construct (Luarn and Lin 2005)

\begin{tabular}{|l|l|l|l|}
\hline No. & Item wording & Loadings & Authors \\
\hline 1 & It would cost a lot to use mobile banking & 0.63 & (Luarn and Lin 2005) \\
\hline 2 & $\begin{array}{l}\text { There are financial barriers (e.g., having to pay for handset } \\
\text { and communication time) to my using mobile banking }\end{array}$ & 0.96 & (Luarn and Lin 2005) \\
\hline \multicolumn{2}{|c|}{ Composite Reliability 0.88 } \\
\hline
\end{tabular}

The model was tested by surveying consumers with regards to their intentions to use mobile banking services. As shown above, the perceived costs items loaded cleanly onto the intended construct and showed a high level of reliability.

Similarly, Wang et al. (2003) included a perceived financial costs construct to the original TAM model. Using a random sample of Internet banking users in Tawain, the authors assessed the perceived financial costs variable through the following items:

Table 44: Scale to measure the perceived financial costs construct (Wang, Lin et al. 2006)

\begin{tabular}{|l|l|l|l|}
\hline No. & Item wording & Loadings & Authors \\
\hline 1 & $\begin{array}{l}\text { Financial resource (e.g. to pay for communication time, } \\
\text { subscription, and/or service) is not a barrier for me in using } \\
\text { mobile services }\end{array}$ & (Wang, Lin et al. 2006) \\
\hline 2 & $\begin{array}{l}\text { I have enough financial resources (e.g. to pay for } \\
\text { communication time, subscription, and/or service) for using } \\
\text { mobile services }\end{array}$ & (Wang, Lin et al. 2006) \\
\hline \multicolumn{2}{|c|}{ Composite Reliability 0.75 } \\
\hline
\end{tabular}

As illustrated above, the items loaded cleanly onto the perceived financial costs construct and demonstrated a high level of reliability. 


\section{Summary}

The literature review showed that financial costs associated with channel use would influence consumers using electronic banking channels. Only a few research studies have developed and validated scales to test costs associated with channel use constructs in an electronic banking context.

\section{Implications for this study}

Luarn et al (2005) and Wang et al. (2006) developed items that seemed to be well suited for the context of this study since the authors validated the items in an electronic banking context. Therefore, these scales were included within the pool of items.

\section{Scales for intention to use}

The dependent variable for this research is consumers' intentions to use electronic banking channels. Much research has been undertaken to study the role of intention as a predictor of behavior related to information systems usage (Fishbein and Ajzen 1975; Sheppard, Hartwick et al. 1988; Ajzen 1991; Thompson, Higgins et al. 1991; Venkatesh, Morris et al. 2003; Klopping and McKinney 2004; Burton-Jones and Straub 2006).

For instance, Mathieson (1991) compared the TAM model with TPB theory. The author evaluated students' intentions to use spreadsheets/calculators to complete their assignments. Three items were included to measure the intention to use construct as depicted in Table 45 .

Table 45: Scale to measure the intention to use construct (Mathieson 1991)

\begin{tabular}{|l|l|l|}
\hline No. & Item wording & Authors \\
\hline 1 & $\begin{array}{l}\text { I would use [the spreadsheet] rather than my calculator to do the } \\
\text { assignment. (Strongly agree/ Strongly disagree) }\end{array}$ & (Mathieson 1991) \\
\hline 2 & $\begin{array}{l}\text { My intention would be to use [the spreadsheet] rather than my } \\
\text { calculator to do the assignment. (Strongly agree/Strongly disagree) }\end{array}$ & (Mathieson 1991) \\
\hline 3 & $\begin{array}{l}\text { To do the assignment. I would use [the spreadsheet] rather than my } \\
\text { calculator. }\end{array}$ & (Mathieson 1991) \\
\hline \multicolumn{2}{|c|}{ Cronbach's alpha 0.93 } \\
\hline
\end{tabular}

The author confirmed that the items loaded cleanly onto the intention to use construct ${ }^{8}$ and also showed a high level of reliability.

Hartwick et al. (1994) used an intention to use construct to evaluate individuals' willingness to use information systems within organizations. The items were tested in a nonvoluntary and organizational use setting. The items used are shown in Table 46.

\footnotetext{
${ }^{8}$ The item-to-construct loadings were not published in this article.
} 
Table 46: Scale to measure the intentions to use construct (Hartwick et al. 1994)

\begin{tabular}{|c|c|c|c|}
\hline No. & Item wording & Loadings & Authors \\
\hline 1 & How often do you intend to personally use the new system? & & \\
\hline 2 & I intend to use the new system (infrequently/frequently) & 0.75 & $\begin{array}{l}\text { (Hartwick and Barki } \\
\text { 1994) }\end{array}$ \\
\hline 3 & $\begin{array}{l}\text { Do you intend to be a heavy or light user of the system } \\
\text { (heavy/light)? }\end{array}$ & 0.96 & $\begin{array}{l}\text { (Hartwick and Barki } \\
\text { 1994) }\end{array}$ \\
\hline
\end{tabular}

The item-to-construct loadings suggested construct validity and the authors confirmed a high level of reliability for this construct ${ }^{9}$.

Taylor and Todd (1995) compared the TAM model and two variations of the TPB theory to understand students' intentions to use information systems for their university assignments. Table 47 shows the items used for this study.

Table 47: Scale to measure the intentions to use construct (Taylor and Todd 1995)

\begin{tabular}{|l|l|l|l|}
\hline No. & Item wording & Reliability & Authors \\
\hline 1 & I intend to use the CRC this term. & 0.91 & (Taylor and Todd 1995) \\
\hline 2 & $\begin{array}{l}1 \text { intend to use the CRC to print projects, papers or assignments this } \\
\text { term }\end{array}$ & 0.91 & (Taylor and Todd 1995) \\
\hline 3 & 1 intend to use the CRC frequently this term 0.91 Guttman's Lower Bound & 0.91 & (Taylor and Todd 1995) \\
\hline \multicolumn{2}{|c|}{} \\
\hline
\end{tabular}

The use setting was voluntary and non-organizational. The results showed that the items loaded highly onto the intention to use construct and demonstrated a high level of reliability.

Venkatesh et al. (2003) used the items displayed in Table 48 to validate the UTAUT model. This model was tested with individuals in an organizational context.

Table 48: Scale to measure the intentions to use construct (Venkatesh, Morris et al. 2003)

\begin{tabular}{|l|l|l|l|}
\hline No. & Item wording & Loadings & Authors \\
\hline 1 & I intend to use the system in the next <n> months. & 0.90 & $\begin{array}{l}\text { (Venkatesh, Morris et al. } \\
2003)\end{array}$ \\
\hline 2 & I predict I would use the system in the next <n> months. & 0.90 & $\begin{array}{l}\text { (Venkatesh, Morris et al. } \\
2003)\end{array}$ \\
\hline 3 & I plan to use the system in the next <n> months. & 0.92 & $\begin{array}{l}\text { (Venkatesh, Morris et al. } \\
2003)\end{array}$ \\
\hline \multicolumn{2}{|c|}{ Internal consistency reliability 0.84 } \\
\hline
\end{tabular}

The items loaded cleanly onto the intentions to use construct and also demonstrated a high level of reliability.

Thompson et al. (2006) proposed an integrative model combining the TAM model with TPB theory. The model's dependent variable investigated individuals' intentions to use a software application. The model was tested in a voluntary use setting and the authors collected data from students regarding their intentions to use information systems for their studies.

\footnotetext{
${ }^{9}$ See footnote above.
} 
Table 49: Scale to measure the intentions to use construct (Thompson, Compeau et al. 2006)

\begin{tabular}{|l|l|l|l|}
\hline No. & Item wording & Loadings & Authors \\
\hline 1 & I predict that I will use [s/w pkg] on a regular basis in the future. & 0.90 & $\begin{array}{l}\text { (Thompson, Compeau } \\
\text { et al. 2006) }\end{array}$ \\
\hline 2 & $\begin{array}{l}\text { Although I will likely to use outputs from [software package] quite } \\
\text { extensively, I don't see myself directly using [software] package in the } \\
\text { future (R). }\end{array}$ & 0.86 & $\begin{array}{l}\text { (Thompson, Compeau } \\
\text { et al. 2006) }\end{array}$ \\
\hline 3 & $\begin{array}{l}\text { I expect that I will use [software package], or a similar type of product, } \\
\text { quite extensively in the future. }\end{array}$ & 0.88 & $\begin{array}{l}\text { (Thompson, Compeau } \\
\text { et al. 2006) }\end{array}$ \\
\hline \multicolumn{2}{|c|}{ Composite reliability 0.85 (Fornell and Larcker) } \\
\hline
\end{tabular}

As shown in Table 49 the items were closely correlated to the intentions to use constructs and the authors also reported a high level of reliability.

While the above mentioned studies investigated user intentions to specific information systems, the following research investigations were conducted in relations to consumers' intentions to use electronic banking channels.

Lai and Li (2005) used the TAM model to investigate students' perceptions towards Internet banking services. To measure the dependent variable (intentions to use Internet banking) the authors tested the below mentioned items.

Table 50: Scale to measure the intention to use construct (Lai and Li 2005)

\begin{tabular}{|l|l|l|l|}
\hline No. & Item wording & Loadings & Authors \\
\hline 1 & I will use Internet banking on a regular basis in the future. & 0.826 & (Lai and Li 2005) \\
\hline 2 & I will frequently use Internet banking in the future. & 0.767 & (Lai and Li 2005) \\
\hline 3 & I will strongly recommend others to use Internet banking. & 0.811 & (Lai and Li 2005) \\
\hline \multicolumn{2}{|c|}{ Cronbach's alpha 0.94 } \\
\hline
\end{tabular}

As illustrated in Table 50, the items loaded cleanly onto the intentions to use construct and demonstrated a high level of reliability.

A slightly different instrument was used by Cheng et al. (2006). These authors added a perceived security construct to the original TAM model and tested consumer intentions to use Internet banking services. Intention to use was assessed through the following items.

Table 51: Scale to measure the intention to use construct (Cheng, Lam et al. 2006)

\begin{tabular}{|l|l|l|l|}
\hline No. & Item wording & Loadings & Authors \\
\hline 1 & I would use the IB for my banking needs & 0.87 & $\begin{array}{l}\text { (Cheng, Lam et al. } \\
\text { 2006) }\end{array}$ \\
\hline 2 & $\begin{array}{l}\text { Using the IB for handling my banking transactions is something I } \\
\text { would do }\end{array}$ & 0.88 & $\begin{array}{l}\text { (Cheng, Lam et al. } \\
\text { 2006) }\end{array}$ \\
\hline 3 & $\begin{array}{l}\text { I would see myself using the IB for handling my banking transactions } \\
\text { (Cheng, Lam et al. } \\
\text { 2006) }\end{array}$ \\
\hline \multicolumn{2}{|c|}{ Cronbach's Alpha 0.923 } & 0.66 & \\
\hline
\end{tabular}

The scales were pretested and then used for the main study for which the authors surveyed consumers using Internet banking applications. As shown in Table 51, the scales proofed to be very reliable and the items loaded cleanly onto their intended construct (intentions to use). 


\section{Summary}

Much research has developed scales to measure individuals' intentions to use information systems. What is more, many scales have been validated and published for measuring consumers' intentions to use electronic banking channels. These scales seemed to be particularly suited for the current study.

\section{Implications for this study}

The intention to use scales developed by Venkatesh et al. (2003) showed a high level of reliability and loaded cleanly onto the intentions to use variable. While these scales were originally validated in an organizational and non-voluntary use context, researchers studying electronic banking acceptance re-validated these scales. Thus, it was decided to include Venkatesh et al's (2003) intention to use items within the pool of scales.

Further, Lai et al. (2005) validated three intentions to use items in an electronic banking adoption context. Since these scales demonstrated high reliability levels, these scales were also integrated into the item database.

The initial pool of items is depicted in Table 52.

Table 52: Initial pool of items - precursors of channel utilization

\begin{tabular}{|c|c|c|}
\hline Item & Construct /definition/item wording & Based on existing scales \\
\hline & Perceived Usefulness & \\
\hline Def.: & Users' perception of the expected benefits of electronic banking channel use. & \\
\hline PU1 & Using Internet banking improves my performance in managing personal finances. & (Bhattacherjee 2001b) \\
\hline PU2 & Using Internet banking increases my productivity in managing personal finances. & (Bhattacherjee 2001b) \\
\hline PU3 & Using Internet banking enhances my effectiveness in managing personal finances. & (Bhattacherjee 2001b) \\
\hline PU4 & Overall, Internet banking is useful in managing personal finances. & (Bhattacherjee 2001b) \\
\hline PU5 & Internet banking gives me greater control over my finances & (Chan et al. 2004) \\
\hline PU6 & Internet banking allows me to manage my finances more effectively & (Chan et al. 2004) \\
\hline PU7 & Internet banking is a convenient way to manage my finances & (Chan et al. 2004) \\
\hline \multirow[t]{2}{*}{ PU8 } & $\begin{array}{l}\text { Internet banking banking eliminates time constraint; thus I can use the banking } \\
\text { services any time I like }\end{array}$ & (Chan et al. 2004) \\
\hline & Ease of use & \\
\hline Def.: & $\begin{array}{l}\text { The degree to which an electronic banking channel is perceived as being difficult to } \\
\text { use. }\end{array}$ & \\
\hline EOU1 & Internet banking is easy to use & (Chan et al. 2004) \\
\hline EOU2 & Internet banking is an easy way to conduct banking transactions & (Chan et al. 2004) \\
\hline EOU3 & Learning to operate Internet banking would be easy for me & (Chan et al. 2004) \\
\hline EOU4 & I believe it would be easy for me to get Internet banking to do what I want it to do & (Chan et al. 2004) \\
\hline EOU5 & Using the Internet does not require a lot of mental effort & (Chan et al. 2004) \\
\hline EOU6 & Learning to use Internet Banking is easy for me. & (Lai et al. 2005) \\
\hline EOU7 & It is easy to use Internet Banking to accomplish my banking tasks. & (Lai et al. 2005) \\
\hline EOU8 & Overall, I believe Internet Banking is easy to use. & (Lai et al. 2005) \\
\hline \multirow[t]{2}{*}{ EOU9 } & My interaction with Internet banking would be clear and understandable. & (Davis 1989) \\
\hline & Attitude towards channel use & \\
\hline
\end{tabular}




\begin{tabular}{|c|c|c|}
\hline Def.: & Consumers' (positive or negative) feelings towards electronic banking channels & \\
\hline ATT1 & In my opinion, it is desirable to use Internet Banking & (Lai et al. 2005) \\
\hline ATT2 & I think it is good for me to use Internet Banking & (Lai et al. 2005) \\
\hline ATT3 & Overall, my attitude towards Internet Banking is favorable & (Lai et al. 2005) \\
\hline ATT4 & Using Internet banking is a good idea & (Cheng et al. 2006) \\
\hline ATT5 & I would feel that using Internet banking is pleasant & (Cheng et al. 2006) \\
\hline ATT6 & In my view, using Internet banking is a wise idea & (Cheng et al. 2006) \\
\hline ATT7 & I (dislike/like) the idea of using Internet banking. & (Taylor et al. 1995b) \\
\hline \multirow[t]{2}{*}{ ATT8 } & I really dislike using Internet banking $(\mathrm{R})$ & (Thompson et al. 2006) \\
\hline & Subjective Norms & \\
\hline Def.: & $\begin{array}{l}\text { An individual's subjective norms are perceived normative beliefs regarding the } \\
\text { opinions of others. }\end{array}$ & \\
\hline SN1 & My decision to use Internet banking is influenced by: & (Chan et al. 2004) \\
\hline SN2 & My friends & (Chan et al. 2004) \\
\hline SN3 & My family/relatives & (Chan et al. 2004) \\
\hline SN4 & My colleagues/peers & (Chan et al. 2004) \\
\hline SN5 & People who influence my behavior think that I should use Internet banking. & (Limayem et al. 2003) \\
\hline \multirow[t]{2}{*}{ SN6 } & People who are important to me think that I should use Internet banking. & (Limayem et al. 2003) \\
\hline & Security & \\
\hline Def.: & $\begin{array}{l}\text { Users' perception on the security of electronic banking channels in financial terms, } \\
\text { as well as in terms of privacy and the protection of data against unauthorized } \\
\text { disclosure, modification, and destruction. }\end{array}$ & \\
\hline SEC1 & I would feel secure sending sensitive information across the Internet banking. & (Cheng et al. 2006) \\
\hline SEC2 & Internet banking is a secure means through which to send sensitive information. & (Cheng et al. 2006) \\
\hline SEC3 & $\begin{array}{l}\text { I would feel totally safe providing sensitive information about myself over Internet } \\
\text { banking. }\end{array}$ & (Cheng et al. 2006) \\
\hline SEC4 & Overall, Internet banking is a safe place to transmit sensitive information. & (Cheng et al. 2006) \\
\hline SEC5 & I know that Internet banking will handle my business correctly. & (Curran et al. 2005) \\
\hline SEC6 & There is little danger that anything will go wrong when I use Internet banking. & (Curran et al. 2005) \\
\hline \multirow[t]{2}{*}{ SEC7 } & $\begin{array}{l}\text { The bank's Internet banking offers a secure means through which to manage my } \\
\text { personal finances }\end{array}$ & $\begin{array}{l}\text { (Vatanasombut et al. } \\
\text { 2008) }\end{array}$ \\
\hline & Costs associated with channel use & \\
\hline Def.: & All costs associated with channel use from a consumer perspective. & \\
\hline COST1 & It would cost a lot to use Internet banking. & (Luarn et al. 2005) \\
\hline COST2 & $\begin{array}{l}\text { There are financial barriers (e.g., having to pay for handset and communication time) } \\
\text { to my Internet banking. }\end{array}$ & (Luarn et al. 2005) \\
\hline COST3 & $\begin{array}{l}\text { Financial resource (e.g. to pay for communication time, subscription, and/or service) } \\
\text { is not a barrier for me in using Internet banking }\end{array}$ & (Wang et al. 2006) \\
\hline \multirow[t]{2}{*}{ COST4 } & $\begin{array}{l}\text { I have enough financial resources (e.g. to pay for communication time, subscription, } \\
\text { and/or service) for using Internet banking }\end{array}$ & (Wang et al. 2006) \\
\hline & Intentions to use channel & \\
\hline Def.: & Consumers' behavioral intentions to use an electronic banking channel. & \\
\hline INT1 & I intend to use Internet banking in the next $<\mathrm{n}>$ months. & (Venkatesh et al. 2003) \\
\hline INT2 & I predict I would use Internet banking in the next $<\mathrm{n}>$ months. & (Venkatesh et al. 2003) \\
\hline INT3 & I plan to use Internet banking in the next $<\mathrm{n}>$ months. & (Venkatesh et al. 2003) \\
\hline INT4 & I will use Internet banking on a regular basis in the future. & (Lai et al. 2005) \\
\hline INT5 & I will frequently use Internet banking in the future. & (Lai et al. 2005) \\
\hline INT6 & I will strongly recommend others to use Internet banking. & (Lai et al. 2005) \\
\hline
\end{tabular}

Table 18 (TCF items) and Table 52 (precursors of utilization) were integrated into the complete pool of potential items. Microsoft Excel spreadsheet software was used to organize this item collection. To identify the most appropriate scales, information on the construct 
name (e.g. perceived usefulness), the original definition, the authors who previously validated the scales, context in which the original study was conducted, as well as the item-to-construct loadings and reliability scores was collected. This pool included approximately 120 items. The next step in the instrument development included item reduction and the development of the questionnaire structure.

\subsection{Item reduction and survey questionnaire development}

The generated pool of items was discussed in several meetings with supervising staff. The primary goal of these discussions was to identify the most appropriate items for each construct before conducting the judgment round discussions (explained in section 4.6.). Further, the overall number of items needed to be reduced since 120 items was judged to be too many for a consumer survey. The following section discusses the item reduction process. The following paragraphs initially describe the item reduction for the TCF items before discussing the same procedure for the precursors of channel utilization.

\subsubsection{TCF items}

This research intended to formatively measure the TCF construct (explained in more detail in section 5.4.1.1.). It was anticipated that deviation score and moderation score analysis would be used to evaluate the TCF construct formatively. When formatively measuring constructs, it is important to understand that the content validity of a construct highly correlates with the indicators used to measure the construct. Each item contributes to forming the construct. It is essential that entire domain of the construct is covered (Petter, Straub et al. 2007; Diamantopoulos, Riefler et al. 2008).

Hence, it was emphasized that the parallel items ${ }^{10}$ would capture each facet (or TCF dimension) discovered during the focus group discussions. To assure that each TCF dimension was captured adequately, it was decided to use two parallel items for each dimension that form the TCF construct.

Thus, the initial pool of TCF items was carefully re-assessed for conceptual similarities and for the wording of each item. For instance, the initial items included the following measures:

- A financial loan is a complicated banking transaction.

- A financial loan requires a lot of time.

\footnotetext{
${ }^{10}$ Section 5.4.1.2. explains the parallel instrument development in more detail.
} 
While the first item clearly tapped into the task complexity dimension, the second item while originally intended to also measure task complexity - was later recognized as being merely concerned about the length of time individuals require to perform the banking task, which is not necessarily a reflection of complexity. Due to this, it was decided to exclude the latter item. Similar steps were performed for the remaining items/TCF dimensions.

As a result, two items were selected for each TCF dimension (displayed in Table 53).

\subsubsection{Precursors of utilization items}

This research intended to assess the precursors of channel utilization through reflective measures. Following well accepted measurement practices (Straub, Boudreau et al. 2004), it was decided to evaluate each construct through 4-5 reflective items. 4-5 items would allow for excluding 1-2 items per construct in case that the items were found to exhibit weak psychometric properties during the pilot study phase.

Since the initial item compilation resulted in more items for most variables (e.g. nine ease of use items - see Table 52) the most appropriate items for each construct were selected, following discussions with supervising staff.

For instance, it was decided to use Bhattacherjee's (2001) perceived usefulness items for the pilot study phase. The author used four perceived usefulness items that showed strong psychometric properties in his studies (Bhattacherjee 2001; Bhattacherjee 2001). Further, Limayem et al. (2007) retested these measures in a different context and found similarly promising results.

Chan et al. (2004) successfully tested four ease of use items demonstrating that this set of measures successfully measured the perceived ease of use of Internet banking applications. Thus, these scales were selected to measure the ease of use construct.

Lai et al. (2005) used three attitude towards Internet banking items to assess consumers' positive and negative feelings towards Internet banking services. These items were regarded as very suitable for this study. Since Lai et al. (2005) used only three items in their study, these items were combined with an item taken from another measure used by Cheng et al. (2006) (ATT4 - Overall, using Internet banking is a good idea).

It was further decided to include security items developed by Cheng et al. (2004). These authors tested four security items successfully in the context of individual consumers and Internet banking applications. 
Luarn et al. (2005) and Wang et al. (2006) assessed the costs associated with channel use construct in their studies. Each article published only two costs associated with channel use. Both items used by Luarn et al. (2005) were selected for this study. In addition, one item used by Wang et al. (2006) was also selected for this study as it complemented Luarn et al.'s (2005) scales. One item used by Wang et al. (2006) conceptually overlapped with an item used by Luarn et al. (2005) (see Table 52 COST2 and COST3). Therefore, a new item was created to complement the remaining items for this construct.

The subjective norm items were borrowed from Chan et al. (2004). These items asked respondents if they would be influenced by friends, family members and/or colleagues. These three items were complemented by one measure from Venkatesh et al. (2003) that had been successfully re-applied to an individual and voluntary use setting (Limayem et al., 2003). This item asked "People who are important to me think I should use Internet banking for financial loan".

It was decided to include 5 items for the intentions to use variable. These items were a combination of the measures used by Lai et al. (2005), as well as Venkatesh et al. (2003). Lai et al. (2005) validated the scales via a sample consisting of consumers using Internet banking applications. Venkatesh et al. (2003) used the scales in a non-voluntary and organizational use context. However, Limayem et al. (2007) revalidated Venkatesh et al. (2003) scales in a voluntary and individual use setting. Thus, they were seen as appropriate for the current study.

Table 53 lists the reduced set of items that were included within the initial draft of the survey questionnaire.

Table 53: Pool of items before judgment rounds

\begin{tabular}{|l|l|}
\hline Construct & Items \\
\hline TCF - task characteristics \\
\hline & A financial loan application (account inquiry) is a: \\
COMP1 & Difficult banking transaction. \\
FREQ1 & Complicated banking transaction. \\
FREQ2 & Banking transaction I do on a daily basis. \\
IMPORT1 & Banking transaction I frequently perform. \\
IMPORT2 & Banking transaction that has a major impact on my life. \\
TIME1 & Time-sensitive banking transaction. \\
TIME2 & Time-critical banking transaction. \\
\hline TCF - channel suitability \\
\hline & Internet banking is well suited for a: \\
COMP1 & Difficult banking transaction. \\
COMP2 & Complicated banking transaction. \\
FREQ1 & Banking transaction I do on a daily basis. \\
FREQ2 & Banking transaction I frequently perform. \\
IMPORT1 & Banking transaction that has a major impact on my life. \\
IMPORT2 & Banking transaction I view as important. \\
TIME1 & Time-sensitive banking transaction. \\
TIME2 & Time-critical banking transaction. \\
\hline
\end{tabular}




\begin{tabular}{|c|c|}
\hline \multicolumn{2}{|c|}{ Perceived usefulness } \\
\hline PU1 & Using Internet banking improves my performance when applying for a financial loan. \\
\hline PU2 & When applying for a financial loan, using Internet banking increases my productivity. \\
\hline PU3 & Using Internet banking enhances my effectiveness in applying for financial loans. \\
\hline PU4 & Overall, Internet banking is useful when applying for financial loans. \\
\hline \multicolumn{2}{|r|}{ - } \\
\hline EOU1 & Internet banking is easy to use when applying for a financial loan. \\
\hline EOU2 & Internet banking is an easy way to apply for financial loans. \\
\hline EOU3* & My interaction with Internet banking is clear and understandable when applying for financial loans. \\
\hline EOU4 & It is easy for me to get Internet banking to do what I want it to do when applying for financial loans. \\
\hline \multicolumn{2}{|c|}{ Attitude towards channel use } \\
\hline ATT1* & I find it is desirable to use Internet Banking for loan applications. \\
\hline ATT2 & I think it is good for me to use Internet Banking for loan applications. \\
\hline ATT3 & My attitude towards Internet Banking is favorable when applying for financial loans. \\
\hline ATT4 & Overall, using Internet banking is a good idea when applying for financial loans. \\
\hline \multicolumn{2}{|r|}{ ( } \\
\hline SEC1 & $\begin{array}{l}\text { Internet banking is a secure means through which to send sensitive information when applying for financial } \\
\text { loans. }\end{array}$ \\
\hline SEC2 & $\begin{array}{l}\text { I feel totally safe providing sensitive information about myself via Internet banking when applying for financial } \\
\text { loans. }\end{array}$ \\
\hline SEC3* & $\begin{array}{l}\text { There is little danger that anything will go wrong when I use Internet banking when applying for financial } \\
\text { loans. }\end{array}$ \\
\hline SEC4 & Overall, Internet banking is a safe place to transmit sensitive information when applying for financial loans. \\
\hline \multicolumn{2}{|c|}{ Costs associated with channel use } \\
\hline COST1 & It costs a lot to use Internet banking when applying for financial loans. \\
\hline $\operatorname{COST} 2$ & Financial costs are a barrier for me in using Internet banking when applying for financial loans. \\
\hline COST3 & $\begin{array}{l}\text { I am not worried about financial costs associated with using Internet banking when applying for financial } \\
\text { loans. }\end{array}$ \\
\hline COST4 & Overall, cost associated with Internet banking use discourages me from using it for loan applications. \\
\hline \multicolumn{2}{|c|}{ Subjective norms } \\
\hline & My decision to use Internet banking for financial loan applications /account inquiry would be influenced by: \\
\hline SN1 & My friends. \\
\hline SN2 & My family/relatives. \\
\hline SN3 & My colleagues/peers. \\
\hline SN4 & $\begin{array}{l}\text { People who are important to me think I should use Internet banking for financial loan applications (account } \\
\text { inquiry). }\end{array}$ \\
\hline \multicolumn{2}{|c|}{ Intentions to use } \\
\hline INT1 & I intend to use Internet banking for loan applications. \\
\hline INT2 & I predict I will use Internet banking for loan applications. \\
\hline INT3 & I plan to use Internet banking for loan applications. \\
\hline INT4 & I will use Internet banking on a regular basis for loan applications. \\
\hline INT5 & I will frequently use Internet banking for loan applications. \\
\hline
\end{tabular}

Next, the above listed items were compiled in a preliminary survey draft consisting of four major sections: 1) an introduction and evaluation of consumers' perceptions of banking tasks, 2) the perceived channel suitability section, 3) precursors of channel utilization, and 4) demographic information.

The demographic questions were included towards the end of the survey questionnaire. The purpose of this section was to check that the sample was stable and that the respondents could be assumed to be qualified in terms of their age, gender, and familiarity with Internet banking.

Table 54 depicts the initial survey questionnaire structure and outlines the goals of each section. 
Table 54: Survey questionnaire outline before the judgment rounds

\begin{tabular}{|l|l|}
\hline \multirow{3}{*}{ Section 1 1} & $\begin{array}{l}\text { Content covered } \\
\text { - Brief questionnaire introduction including the information that HEC approval has been } \\
\text { given by VUW and that all respondents will remain anonymous } \\
\text { The assessment of the respondents familiarity with banking channel (e.g. Internet banking) } \\
\text { and banking tasks (e.g. account inquiry) } \\
\text { - The respondent's perception of the TCF banking task characteristics (e.g. account inquiry) }\end{array}$ \\
\hline Section $\mathbf{2}^{11}$ & $\begin{array}{l}\text { The respondent's perception of the channel suitability to support: } \\
\text { - Complex banking transactions } \\
\text { - Transactions they perform frequently } \\
\text { - Transactions they perceive as important } \\
\text { - Time-critical banking transactions }\end{array}$ \\
\hline Section 3 3 & $\begin{array}{l}\text { Precursors of channel utilization including items on: } \\
\text { - Perceived usefulness } \\
\text { - Ease of use } \\
\text { - Attitudes towards channel } \\
\text { - Channel security } \\
\text { - Costs associated with channel use } \\
\text { - Subjective norms } \\
\text { - Intentions to use channel }\end{array}$ \\
\hline Section $\mathbf{4}$ & $\begin{array}{l}\text { Respondent's demographic variables including: } \\
\text { - Gender } \\
\text { - Age } \\
\text { - Occupation }\end{array}$ \\
\hline
\end{tabular}

The next step of the questionnaire instrument development involved several judgment rounds involving academics, industry experts as well as consumers using electronic banking channels. A major goal of these judgment rounds was to evaluate the content validity of the scales $^{12}$. Secondly, it was anticipated to get an initial feedback on the wording of all items as well as to explore the judges' viewpoints regarding how essential particular items are.

The following section describes the methodology used to conduct the judgment rounds and discusses the findings of each round.

\subsection{Judgment rounds}

The judgment rounds involved two discussion rounds involving several academics and industry judges.

\footnotetext{
${ }^{11}$ During the data collection phase, the items were presented randomly to the research participants.

${ }^{12}$ A central part of the judgment rounds was to assess the content validity of the TCF items/construct.
} 


\subsubsection{Methodology}

A major goal of the judgment rounds was to assess the content validity of the newly developed TCF scales. Content validity refers to the extent to which a scale represents all facets of a given construct (Straub, Gefen et al. 2004).

To organize the judgment rounds, senior researchers from Marketing, Finance, and Information Systems departments were contacted through email or phone. In addition, several banking staff working within the New Zealand financial industry were invited via email to participate within the judgment rounds. Overall, eight judges volunteered to participate in the judgment rounds. To optimize the outcome of the discussions, the interviews were organized in two separate rounds. Following each round, meetings with supervising staff were organized to discuss the feedback gained from the judges. Using this format, the outcome of the first judgment round was included within the second judgment round. Table 55 shows the participants and illustrates the organization of the judgment rounds.

Table 55: The organization of the judgment rounds

\begin{tabular}{|c|c|c|c|}
\hline $1^{\text {st }}$ Judgment Round & $1^{\text {st }}$ Revision Round & $2^{\text {nd }}$ Judgment Round & $2^{\text {st }}$ Revision Round \\
\hline Marketing Professor & Researcher & IS senior lecturer & Researcher \\
\hline Bank Staff & Supervising Staff & Bank Staff & Supervising Staff \\
\hline Finance Professor & & Marketing sen. lecturer & \\
\hline IS senior lecturer & & Currency trader & \\
\hline
\end{tabular}

The judgment rounds were organized as face-to-face interviews. Each discussion lasted between 60 and 90 minutes and most of them were recorded via digital voice recorder. Field notes were also taken during or immediately after the interviews. The recordings and field notes were analyzed and consolidated in order to identify a list of issues raised by the judges.

During each interview, initially the conceptual research model was introduced and the goals of the research were outlined. Next, the TCF construct was defined and explained as the user's understanding of the correspondence between a banking task and the ability of a particular electronic banking channel to support a given banking task. It was emphasized to each judge that the conceptualization of the TCF was based on the literature review as well as on several focus groups conducted as part of this study.

Next any upfront questions were clarified that the judges had regarding the TCF construct or any other construct associated with the research model. Subsequently, the judges were asked to consider the TCF dimensions and if they could think of any further dimensions that describe/measure the perceived TCF of electronic banking channels. Particular emphasis was placed on the most essential characteristics of banking tasks. Next, the preliminary TCF items 
were introduced and the judges were asked if these items would cover the most essential characteristic of electronic banking tasks and the TCF of electronic banking channels.

Afterwards, the same procedure was repeated for the various precursors of channel utilization constructs and the intention to use variable. During this stage, the judges were also asked to identify items that would be described vaguely or worded unclearly. Finally, the judges were asked if they had any further ideas regarding the measurement of the research model and the survey questionnaire instrument.

\subsubsection{Findings - first judgment round}

\subsubsection{Perceived TCF construct}

Overall, all judges agreed with the conceptualized TCF dimensions and they confirmed that each dimension (task complexity, task time criticality, task frequency and task importance) was valid to them. While the bank staff and the IS senior lecturer could not think of any further TCF dimensions in order to assess the TCF construct, the marketing- and finance Professor suggested minor modifications on the conceptualized TCF dimensions.

For example, the finance judge suggested that task impact could be included as part of the task importance dimension. The judge agreed that consumers view some transactions as very important while other banking tasks would be less significant to them. According to her, the items developed for the survey questionnaire would capture the task importance aspect nicely. However, task impact could be seen as another aspect of task importance and should be therefore included within the task importance scale. As an example, she argued that specific banking tasks would have a significant impact on an individual. To elaborate on this, she reasoned that a mortgage would be a long-lasting financial instrument that would tremendously impact on the life of the account holder. The impact would be mainly caused by the long-term commitment and the relatively high value of such transfers. The argument was that the higher the impact a transaction has on somebody's life, the more important individuals would perceive the financial tasks. Thus, it could be considered to include task impact as part of the task importance dimension.

The marketing judge suggested adding another TCF dimension called task effort. According to him, some of the task complexity items would reflect the difficulty of a given task well but not the task comprehensiveness or task effort. He gave two examples to explain that task difficulty should be treated independent from task effort. Applying for a mortgage might be difficult for a consumer as she/he would need to fully comprehend how a mortgage 
works (e.g. determining the interest rate for the mortgage, how long it would take to repay the loan etc.). According to him, most consumers would not be able to answer all questions without getting additional help (be it in written form or face-to-face). On the other hand, international transactions would be a simple task but a bank usually requires much information to process these financial transactions. Filling out wordy payment forms for an overseas remittance would require much effort - making it a comprehensive task. However, these tasks would not be difficult or complicated as the information requirements would be straightforward and consumers would not need to think while filling out these forms. Hence, he would view an international transaction as comprehensive which would take a lot of effort instead of viewing it as a difficult transaction.

This concept has been also often discussed by the existing literature around task complexity. Multiple studies have argued that certain tasks require a considerable amount of effort without requiring much cognitive workload from the person performing the task (Wood 1986; Campbell 1988; Nadkarni and Gupta 2007). Research on electronic banking suggests that consumers do not find it difficult to perform international transactions but instead they believe that it takes a lot effort to complete the remittance forms (Gan, Clemens et al. 2006; Sayar and Wolfe 2007)

What is more, electronic banking research has argued that each electronic banking channel varies in terms of its suitability to input data. For instance much literature has suggested that mobile banking applications and touch-based telephone banking systems lack adequate input mechanisms (Tan and Thompson 2000; Karjaluoto, Mattila et al. 2002; Liao and Cheung 2002; Suh and Han 2002; Sohail and Shanmugham 2003; Wang, Wang et al. 2003; Kleijnen, Wetzels et al. 2004; Tang, Lin et al. 2004; White and Nteli 2004; Eriksson, Kerem et al. 2005; Jaruwachirathanakul and Fink 2005; Lai and Li 2005; Luarn and Lin 2005; Hernandez and Mazzon 2007; Hwang, Chen et al. 2007; Kam and Riquelme 2007; Sayar and Wolfe 2007; Srivastava 2007; Al-Somali, Gholami et al. 2008; Qureshi, Zafar et al. 2008). Since high effort tasks often require much data input (Gan, Clemens et al. 2006; Sayar and Wolfe 2007), it seemed reasonable to assume that perceived TCF would differ depending on the effort the tasks require.

While these two propositions (task impact and task effort) were the only suggestions made related to the task-channel fit construct and its measurement, additional comments were made by the judges regarding the rest of the survey questionnaire instrument (as explained below). 


\subsubsection{Precursors of utilization, intentions to use and questionnaire structure}

Overall, none of the judges suggested adding any additional constructs and they agreed with the suggested measures for each construct. Some of them suggested minor wording issues and commented on the structure/outline of the survey questionnaire. For example, the banking staff suggested mixing the TCF-related items instead of compiling questions in TCF dimension blocks (e.g. having two items on task complexity before asking two more questions on task time criticality). According to him, this would lead to less irritation for consumers as they would view the survey questionnaire as less repetitive.

The information systems researcher suggested adding affinity towards technology items to understand how the consumers view technology per se and how often the respondents would use technology. This would be helpful in understanding the respondents' general perceptions of technology and could be easily captured alongside the standard demographical items such as age, gender, occupation, and education.

\section{Implications for this study - outcome of the first revision round}

The outcomes of the first revision round were discussed with the supervising staff. It was decided not to include task import as part of the TCF dimensions. Task impact was suggested by only one judge. Neither the existing literature nor the focus group discussions suggested that this concept would be important for the TCF conceptualization. Further, the discussions with supervising staff suggested that task impact (as suggested by the finance judge) would be merely a consequence of banking tasks rather than being a task characteristic. Thus, no items for task impact were created.

Due to the comments made by the marketing judge and the literature found on task effort, this concept was included as a new TCF dimension. Two additional items were developed to assess the perceived effort needed to accomplish various banking tasks:

1. I have to provide a lot of information to my bank when applying for a financial loan (account inquiry).

2. A loan application (account inquiry) is a banking transaction that requires filling out many forms.

Lastly, the TCF items were randomly ordered (due to the suggestions made by the banking employee) and items were included to assess consumers' affinity towards technology (as suggested by the Information Systems judge). 
The survey questionnaire was adjusted accordingly and the next draft was created to be used during the second judgment round.

\subsubsection{Findings - second judgment round}

\subsubsection{Perceived TCF construct}

Overall, the judges commented positively on the perceived TCF scales and they regarded the conceptualized dimensions as the most significant features of financial tasks. None of the judges suggested any further TCF dimensions.

One participant initially considered task security as another potential TCF dimension. His main argument was that the level of security of specific banking transactions would impact on the perceived TCF. However, while explaining what he associated with task security, he concluded that this would not be a valid factor to ask consumers. The bank employee said: "I think the security aspect of banking transactions is an important issue for our clients. People must feel safe when transferring money...but I guess they want all financial tasks to be secure and I think they differentiate between the security of banking channels more than the security between specific banking transactions.... and you got the security of channels in your questionnaire already."

Another participant (marketing judge) considered investment risk as an important aspect of investment products such as investment bonds or corporate shares. She argued that consumers face a financial risk when buying these products. Depending on the market situation, clients could either win or lose money when holding these products in their financial accounts. While explaining her thoughts, she corrected her statement and argued that investment risk would only apply to a few (investment related) products. Consumers would not face any investment risks when conducting domestic transaction or performing account inquiries. Therefore, it would not be useful to integrate this notion into the TCF concept.

\subsubsection{Precursors of utilization, intentions to use and questionnaire structure}

In general, the participants welcomed the structure of the survey questionnaire outline and could not think of any further constructs/items to improve the proposed scales. In accordance with the first judgment round, some comments addressed the wording of some of the items. These suggestions were only minor and did not affect the questionnaire draft significantly. For instance, the introduction paragraph of section two of the survey questionnaire included the phrase 'theoretical knowledge'. The marketing judge suggested removing the word 
'theoretical'. She suggested that this would be academic jargon and might confuse respondents when reading this introduction.

Implications for this study-outcome of the second revision round

The second judgment round indicated that the judges agreed with the conceptualization and the measurement of the TCF construct. All judges confirmed the proposed items and they suggested only minor modifications such as the wording of some items. All suggestions were discussed with the supervising staff after the second judgment round and it was decided to adjust the survey questionnaire respectively. The next step in the survey questionnaire development process involved two pretest rounds.

\subsection{Survey questionnaire pretest}

The major goal of pretesting the survey questionnaire was to assess its usability and face validity (Pinsonneault and Kraemer 1993). This included finding out consumers' perceptions of the length of the questionnaire, the wording of the items as well as the questionnaire structure. Ideally, a pretest of the questionnaires should be administered to a sample of respondents who come from the target population (Pinsonneault and Kraemer 1993; Grover 2000; Cavana, Delahaye et al. 2001). Since it was impossible to access the Smilecity.co.nz consumer panel (see section 6.6. for a more detailed explanation) for the pretest, theoretically motivated purposive sampling methods were employed in selecting participants for the pretests (Calder 1977). The participants were selected so as to achieve a wide variety of individual characteristics across the different electronic banking user groups in terms of age, gender, education, and work.

\subsubsection{First testing round}

To conduct the first pretest round, email invitations were sent out to individuals working at the School of Information Management at Victoria University. Five staff volunteered to participate (two administrative staff, one academic staff, and two $\mathrm{PhD}$ students) in this initial pretest. All respondents were asked to complete the survey questionnaire (paper-based) and make notes in cases where items/sections were confusing. Subsequently each respondent was interviewed and questioned if they found items unclear or ambiguous, and the instructions, structure, and length of the questionnaire were discussed.

Overall, the feedback given by the respondents indicated that the structure and length of the survey questionnaire was reasonable. Furthermore, all testers indicated that they did not 
have major issues with the wording of the items. However, every participant suggested minor modifications to improve the quality of the survey questionnaire.

For example, one of the $\mathrm{PhD}$ students suggested personalizing the instructions of the survey questionnaire. For this pretest, all instructions were written from a consumer perspective including sentences such as: "The second section has several questions on how well consumers think Internet banking services are suited to support the banking transactions consumers perform". The student recommended re-wording the instructions approaching respondents directly by stating: "The second section has several questions on how well you think Internet banking services are suited to support the banking transactions you perform”.

The academic staff suggested shortening some of the instruction sections. For instance, the initial wording of the instructions in section one was stated as follows: "The third section aims to understand how consumers view Internet banking in general. You will be asked to rate Internet banking in terms of security, usability, and your attitude towards these services etc". The tester argued that the latter sentence would not add value in this section and could be omitted in order to shorten the instructions. Apart from this, this tester did not point out any further issues with the survey questionnaire and provided positive feedback on the survey questionnaire.

Interestingly, both administrative staff reported no negative issues with the survey questionnaire and they found the structure useful and the length of the survey questionnaire adequate. These testers attempted to answer the questions and they could not think of ways to improve the questionnaire.

\section{Implications for this study}

The first pretest indicated that the survey questionnaire design was straight-forward and that the questionnaire instructions were clear to the respondents. Most comments were minor and only none of the participants suggested modifying survey items. The comments were discussed with supervising staff and the survey questionnaire was adjusted accordingly.

\subsubsection{Second testing round}

The first testing round indicated that the participants had no major issues to follow the instructions of the survey questionnaire. In addition, several suggestions were made by the testers during the initial pretest round with regard to the instructions of the survey questionnaire. Thus, it was reasonable to believe respondents could test the survey questionnaire without getting additional support in form of face-to-face assistance. Due to 
this, it was decided to conduct the second pre-test round in electronic form. By asking the respondents to complete the survey questionnaire online, testers could provide feedback on the usability of the online survey tool as well as giving feedback on the 'look and feel' of the online survey questionnaire (e.g. how long it would take to load the website, visual layout of the online survey, etc.).

To conduct the second pretest round, survey software from qualtrics.com was used and the preliminary survey questionnaire instrument was entered online. The online survey included several text boxes in order to give respondents the opportunity to comment on the survey questionnaire instrument. Before sending out email invitations, supervising staff checked the online survey system.

Next, email invitations were sent out to personal contacts of the researcher. As with the first pretest round, theoretically motivated purposive sampling methods ${ }^{13}$ were employed in selecting participants for the second pretest. The email invitations stated the purpose of the pretest and invited the recipients to follow up the qualtrics - survey URL.

Fifteen individuals volunteered to participate during the second pretest and all testers completed the survey questionnaire. Some of them commented on the survey questionnaire instrument as well as the wording of some of the items. Most comments were provided within the embedded text boxes but some testers chose to send email or provided personal feedback to the researcher. The following comments were made with regard to each of the survey questionnaire sections.

The comments provided for this section were minor and none of the testers suggested major modifications. For instance, one participant suggested using bullet points on the first page to outline the most essential information more precisely. This participant left the following comment in the respective text box: "It may be useful using bullet points here. The full paragraph may scare some people off'. In contrast, another tester commented very differently on this introduction: "Very nice, all good".

The following sections discuss the feedback received for each section of the survey questionnaire instrument ${ }^{14}$.

\footnotetext{
${ }^{13}$ See section 4.3. for more information.

${ }^{14}$ See Table 54 for more information on each section of the survey questionnaire instrument.
} 


\subsubsection{Feedback on section 1 of the questionnaire}

Overall, the comments made with respect to this section mostly aimed to improve the outline and presentation of this section rather than providing specific feedback on the questionnaire items. For instance, one tester suggested: "I would put a title on top of this section - I felt like 'why am I answering these questions'?". Another participant recommended keeping the style of the introduction consistent: "If you say, for example, 'the first section' and 'the third section', maybe you then should say 'the second section' instead of 'secondly". Another comment was made with regard to the wording of the introduction: "I am not sure about this but I think that's incorrect: 'The third section aims to understand...'. A section cannot understand but can deal, address, aim to clarify or focus on. I suggest rewording this by saying: "the third section focuses on how you view....".

Another comment was made regarding the scale levels of the familiarity questions. For this pretest, respondents could choose between and 'not familiar at all' and 'extremely familiar'. One tester argued: "I would use the word 'very' rather than 'extremely'. Very is a notch below and it may capture some people who would otherwise just say they were moderately familiar. Otherwise your survey may bias the middle ground."

None of the respondents commented on the wording of the items.

\subsubsection{Feedback on section 2 of the questionnaire}

While the testers commented exclusively on the outline of the questionnaire in section one, most critique in section two was related to the wording of the items. The responses suggested that the testers found some of the items similar and repetitive. For example, one tester argued: "I found the following items too similar: I frequently perform an account inquiry vs. I often perform an account inquiry...I suggest keeping one and replace the other one with 'I perform account inquiries on a daily basis"'. Three other testers made similar comments with regards to the task frequency items.

Likewise, the respondents found it difficult to differentiate time criticality and time sensitivity. One tester argued: "How does "time sensitive" differ from "time critical" - they seem quite similar...”.

Another participant argued that it might bias respondents when Internet banking is mentioned before they are asked general questions on banking tasks ${ }^{15}$. Her argument was that

\footnotetext{
${ }^{15}$ Electronic banking/Internet banking was mentioned on the first introduction page when explaining the respondents the goal of this research.
} 
people might project the task-specific questions on Internet banking when reading about Internet banking services upfront. She added that there is no value in stating the electronic banking channel before section two and recommended excluding electronic banking channels/Internet banking from section one. Instead, she suggested asking respondents about their familiarity levels with Internet banking exclusively in section two.

\subsubsection{Feedback on section 3 of the questionnaire}

The testers suggested only slight modifications for this section. For instance, one respondent asked if the intentions to use items should include a timeframe (e.g. 6 months). Another participant suggested re-wording the reverse coded item within the costs associated with channel use section. The tester stated: “The question 'I am not worried about financial costs associated with using Internet banking' might be better aligned with the others and be easier to answer if phrased in the positive 'I am worried..."'.

Lastly, one participant suggested including 'back' and 'forward' buttons allowing the respondents to go forth and back in the survey questionnaire.

\subsubsection{Feedback on section 4 of the questionnaire}

Only three testers commented on this section. All comments were made with regards to the survey questionnaire and no critique was mentioned regarding the questions posed in the last section (user demographics). All testers briefly stated that they found the survey questionnaire straight-forward and easy to follow. For instance, one noted: "Looks good - quite straight forward! Well done."

\section{Implications for this study}

Overall, both pretest rounds suggested that the respondents had no major concerns regarding the instructions, structure, and the length of the questionnaire. The second pretest also showed that the respondents found the wording of the items clear and only a few minor suggestions were made regarding specific items. The feedback gained during the first and second pretest round was used to develop the measures tested in the pilot test of the survey questionnaire instrument (explained in more depth in the next section). This pilot study was conducted at Victoria University of Wellington and is explained more detailed in the following section. Prior to the pilot test, HEC approval was gained through the VUW-HEC committee. 


\subsection{Chapter summary}

This chapter initially stated the theoretical assumptions underlying this research. Next, five focus group discussion rounds were organized to re-assess the initial conceptualization of the research model. The discussions re-affirmed that consumers' intentions to use electronic banking channels are influenced by multiple variables previously identified within the existing literature on electronic banking (including the perceived task-channel fit of electronic banking channels and other precursors of channel utilization).

Next, scales were developed to test the conceptualized research model. The development of the measurement scales consisted of three stages.

First, the existing literature was screened for items that had been validated by prior research. Since no adequate scales were available for measuring the TCF dimensions, new items were developed based on the construct definitions.

Existing scales were identified that had previously measured the precursors of utilization constructs - perceived usefulness (Bhattacherjee 2001), ease of use (Chan and Lu 2004), attitude (Taylor and Todd 1995; Lai and Li 2005), subjective norms (Chan and Lu 2004), security (Vatanasombut, Igbaria et al. 2008), costs associated with channel use (Luarn et al. 2005) - and the intention to use construct (Lai and Li 2005). The identified scales were then adapted to the context of this study.

The second stage of the instrument development involved two judgment rounds consisting of eight judges relevant to the study's context. The main goal of these judgment rounds was to assess the content validity of the scales as well as the wording of the items. Each judge was asked to evaluate the content validity of the TCF dimensions as well as to re-examine the items collected for this study. Subsequent to the interviews, the scales were refined appropriately in light of the judges' recommendations.

The third stage of scale development involved two pretests of the survey questionnaire instrument. The first pretest involved five University staff (two administrative staff, one academic staff, and two $\mathrm{PhD}$ students) who were asked to complete the survey questionnaire in paper-based form. The feedback was then used to adjust the survey questionnaire instrument. The second pretest included 15 University staff/PhD students researching information systems. These participants were asked to test the online survey and provide feedback about the structure of the survey and wording of the items. The second pretest led to the final measures used for the pilot study of this research (described in chapter 5). 
Figure 32 illustrates the research model tested during the pilot study. While the hypotheses did not change from the initial model conceptualization, one task-channel fit dimension was integrated into the conceptual research model (see judgment round discussions). The added TCF dimension was termed task effort.

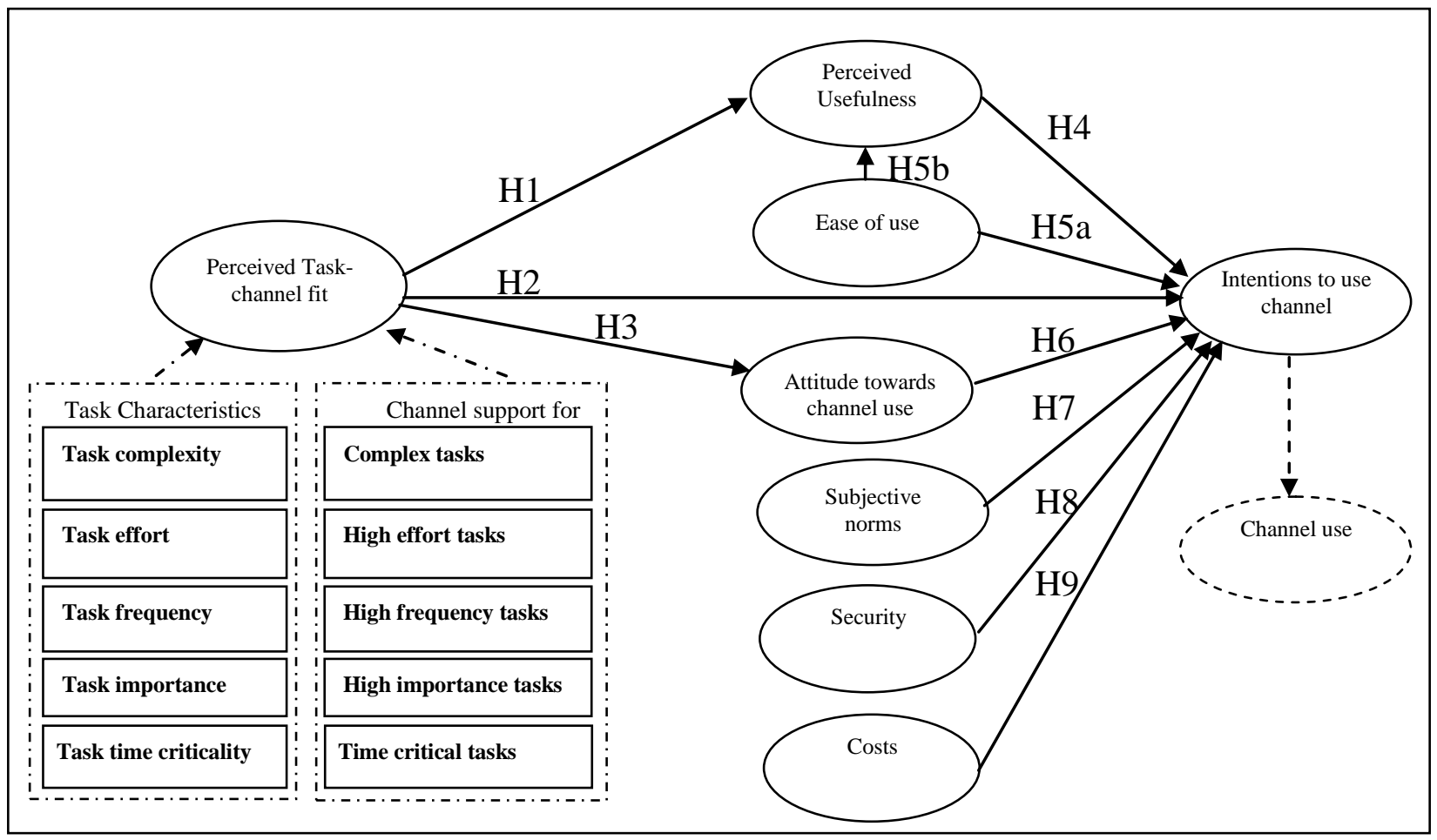

Figure 32: Research model including research hypotheses

Having discussed the development of the survey questionnaire instrument in this chapter, the following section describes the task-channel fit assessment and the pilot test conducted for this research study. 


\section{Fit assessment, pilot-study and data analysis}

\subsection{Chapter Outline}

The previous chapter reported the development of the questionnaire instrument. This chapter will discuss the task-channel fit assessment and report the results of the pilot study conducted to test the questionnaire instrument and the conceptual research model.

Initially, literature on fit theory and measurement is reviewed. Next, the operationalization of the pilot study is outlined before several task-channel fit calculation approaches (e.g. matching and moderation techniques) are discussed to compute the task-channel fit for the data obtained during the pilot study. Fit as moderation was seen to be the most appropriate technique to calculate the task-channel fit.

Subsequently, the data collected during the pilot study is analyzed. This includes assessing the construct validity of the reflective and formative scales, as well as evaluating the structural aspects of the research model. The chapter concludes with a summary of the pilot study.

A key purpose of this research was the assessment and calculation of the fit between a given banking task and electronic banking channels. Matching two or more variables is not unusual and researchers have used various approaches to assess the fit between various variables in different contexts. Thus, literature on fit theory was assessed as it was seen to be influential for the task-channel fit measurement.

\subsection{Fit theory and measurement}

In a seminal article on fit assessment in strategy research, Venkatraman (1989) discussed six alternative measurement approaches for the concept of fit. This section discusses the approaches that are relevant to this study and briefly comments on literature using these techniques.

\subsubsection{Fit as moderation}

According to the moderation perspective, the fit between the predictor and the moderator variable is the primary determinant of the criterion variable (Venkatraman 1989). Figure 33 illustrates this conceptualization of fit. 


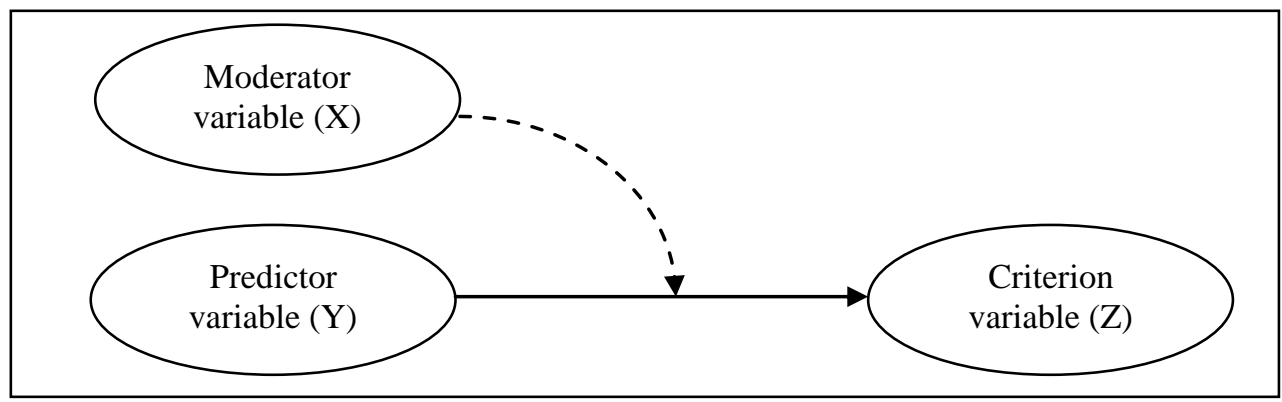

Figure 33: Fit as moderation (Venkatraman 1989)

Mathematically Figure 33 can be represented as:

$$
\mathrm{Z}=f(\mathrm{X} * \mathrm{Y})
$$

Where $\mathrm{Z}=$ criterion variable, $\mathrm{X}=$ moderator variable, and $\mathrm{Y}=$ predictor variable. Researchers applying this approach are assuming that the underlying theory "specifies that the impact of the predictors (e.g. strategy) varies across the different levels of the moderator (e.g. environments)" (Venkatraman 1989).

Chan et al. (1997) applied the moderation approach to investigate IS strategic alignment between business strategic orientation and information systems strategic orientation. The authors developed a parallel instrument to assess the strategic orientation of business enterprises (STROBE) and the strategic orientation of the existing portfolio of information systems applications (STROEPIS) (Chan, Huff et al. 1997). Both instruments tapped into eight distinctive strategic dimensions (aggressiveness, analysis, internal defensiveness, external defensiveness, futurity, proactiviness, risk aversion, and innovativeness) and for each STROBE item a parallel STROEPIS measure was created. The following example illustrates two parallel items for a particular aspect of business strategic orientation.

Table 56: Parallel items used to determine strategic alignment (Chan, Huff et al. 1997)

\begin{tabular}{|l|l|}
\hline STROBE & We are almost always searching for new business opportunities. \\
\hline STROEPIS & $\begin{array}{l}\text { The systems used in this business unit assist in the identification of new business } \\
\text { opportunities. }\end{array}$ \\
\hline
\end{tabular}

Both items were measured using Likert scales with anchors 5 (strongly disagree) to 1 (strongly agree).

The authors assumed that: "STROEPIS moderated the relationship between STROBE and business performance. In a similar fashion, STROBE moderated the relationship between STROEPIS and IS effectiveness. It was the combination of, or synergy between, STROBE and STROEPIS rather than the difference between the two, that was most important". In order to calculate the moderation scores, STROBE*STROEPIS product terms were computed (Chan, 
Huff et al. 1997). The STROBE*STROEPIS fit scores were used to assess the structural aspects of the overall research model.

Hooper et al. (2007) investigated the impact of the alignment between IS and marketing on business performance. In order to determine the alignment, the authors used a parallel instrument which was administered to senior IT/IS and marketing personnel in New Zealand based organizations. Following Chan et al.'s (1997) work, the heads of IS and heads of marketing were asked to complete the original STROBE instrument. The responses were then matched in order to calculate an IS-marketing alignment.

The authors considered deviation score analysis (explained in section 5.2.8.) but this technique was eventually rejected. Similarly, the authors reasoned that Chan's (1997) formula would "not accommodate the 'anti-synergy' which might result from the IT/IS and marketing respondents' scores being very different." To capture the 'anti-synergy' Hooper et al. (2007) developed the following formula:

$$
(4-|x-y|)((x+y) / 2)
$$

Where:

- 4 represented the largest possible difference between the item scores of the IT/IS and marketing respondents, given the 5-point Likert scale.

- It was necessary to subtract the absolute difference from 4 in order to obtain an indication of the alignment, or similarity, between the item scores rather than the nonalignment, or dissimilarity, which would have resulted if it were not subtracted from 4.

- Using the absolute difference between $\mathrm{x}$ and $\mathrm{y}$ removes the implication of order in the subtraction. A negative sign would have been an artifact of such an order.

- $(x+y) / 2$ represents the average of the two scores. It could be assumed that the strength of the manifestation of any aspect of a dimension, as captured by an item, would result from the average strength, or score, of the two.

- The product of the two parts of the formula captures the synergy, or the magnification, between the similarity of the scores and the average strength of each of those scores. (Hooper, Huff et al. 2007)

This formula combined the moderation and matching (explained below) methods, as well as reversing the sign of the result. As an outcome, smaller absolute differences between the marketing and IS responses for any dimension of strategic orientation (i.e., stronger alignments) resulted in larger values for the alignment index (Hooper, Huff et al. 2007). 
Moderation approaches have also been used to assess TTF. For example, Goodhue (1995) investigated user evaluations of IS using task-technology fit theory. As part of the TTF model development, the author argued: “... the strength of the link between a system characteristic and user evaluations of it will depend upon how important that characteristic is, given the task demands and the capabilities of the user. This corresponds exactly to one of Venkatraman's categories of fit, fit as moderation" (Goodhue 1995).

Similarly, Dishaw and Strong (1999) computed TTF by matching task-characteristics and the supporting functionality of technology using the moderation (or interaction) approach. While not explained in detail, the authors argued that: "For the TTF model, task-technology fit is computed by matching characteristics of a maintenance task to supporting functionality in a software maintenance tool, using an interaction approach" (Dishaw and Strong 1999).

\subsubsection{Fit as mediation}

The fit as mediation perspective assumes the "existence of a significant intervening mechanism (e.g. organizational structure) between an antecedent variable (e.g. strategy) and the consequent variable (e.g. performance)" (Venkatraman 1989). Fit as mediation can be represented visually as follows:

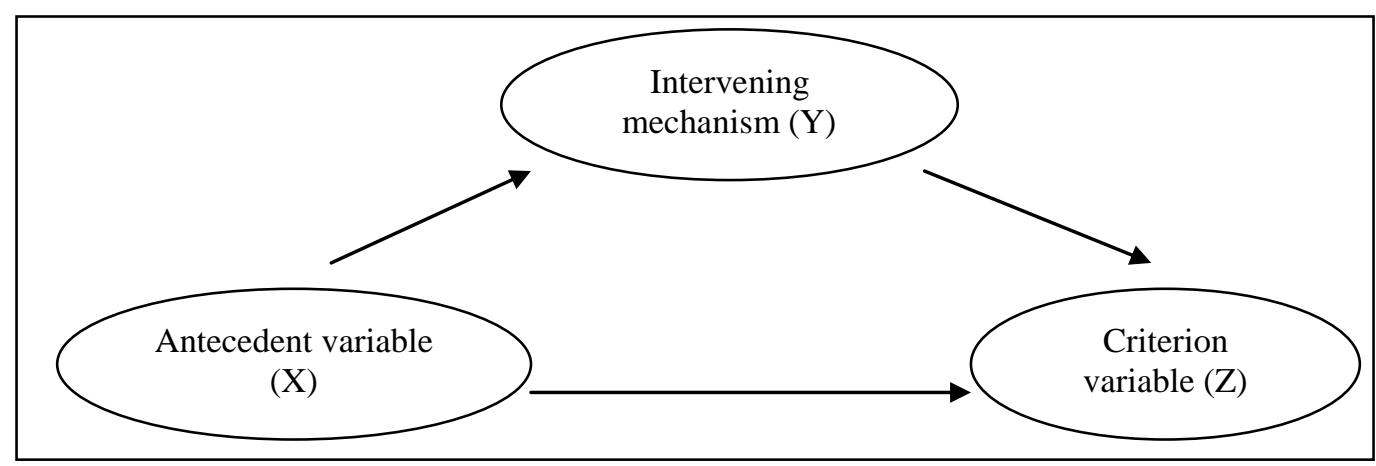

Figure 34: Fit as mediation (Venkatraman 1989)

As with moderation, this perspective is anchored with respect to a specific criterion variable. However, fit is viewed as indirect effects making it less precise than the moderation perspective. The mediator variable (Y) accounts for a significant proportion of the relation between the predictor $(X)$ and criterion variable $(Z)$ (Venkatraman 1989).

Thatcher (2001) studied the extent to which communication media and demographic diversity predict creativity. Identity-fit was predicted to mediate the relationships between the antecedents and creativity (Thatcher 2001). The authors used hierarchal regression analyses to measure the mediation effects. It should be noted that strategy researchers have traditionally 
embraced the moderation approach rather than using the mediation approach to assess fit (Venkatraman 1989).

\subsubsection{Fit as matching}

This perspective of fit suggests that fit is a theoretically defined match between two related variables (Venkatraman 1989). Fit as matching is illustrated in Figure 35.

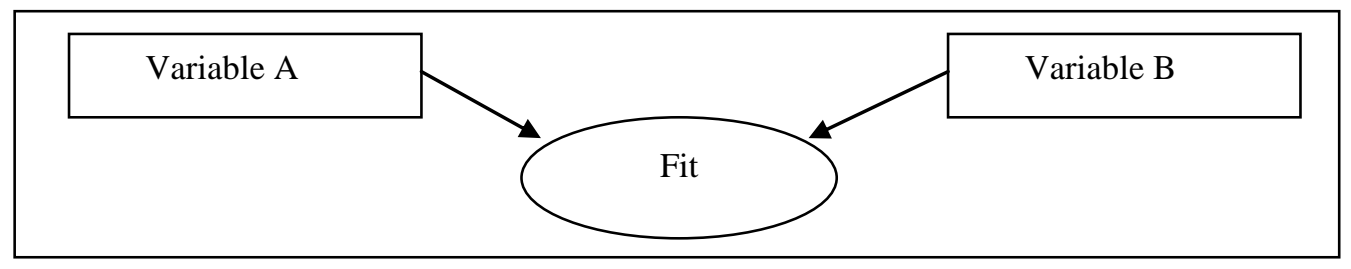

Figure 35: Fit as matching

This approach is "a major point of departure from fit as moderation and fit as mediation because fit is specified without reference to a criterion variable" (Venkatraman 1989). Fit as matching can be operationalized using deviation score analysis or regression residuals. The deviation score analysis is based on the assumption that "the absolute difference between the standardized scores of two variables indicates a lack of fit" (Venkatraman 1989).

This form of fit assessment has been frequently applied in organizational, marketing and IS research. Most commonly, this approach is operationalized via parallel instruments. Parallel instruments can be used to collect responses for variable A (see Figure 35) separately from variable B. By comparing the responses obtained for variable A and variable B a fit score can be computed (Edwards 2001; Klein, Jiang et al. 2009).

For example, Jiang et al. (2002) applied the SERVQUAL instrument to study service quality in an IS setting. The original SERVQUAL instrument consisted of five distinct dimensions (tangibles, reliability, responsiveness, assurance, and empathy) and can be defined as the gap (or fit) between consumer expectations and perceived delivery (Zeithaml, Parasuraman et al. 1990; Jiang, Klein et al. 2002). To assess this gap, Jiang et al. (2002) obtained a sample of IS professionals and matched IS users. Each respondent group answered parallel questions regarding their service expectations and actual service quality perceptions. Using deviation score analysis, the authors computed the fit between service expectations and actual experience. Service quality was measured as follows: "by the gap score $(G)$, where $G$ is the difference between corresponding perception of delivered service $(P)$ and expectation of service (E) for each item (G=P-E)" (Jiang, Klein et al. 2002). 
However, computed difference scores are known to have a variety of measurement issues. These include assumptions about the relative weights of components, the magnitude of components, and the component interaction. Klein et al. (2009) argue that difference scores should be only used if researchers are certain that both component scores have similar weights. Klein et al. (2009) argued that SERVQUAL measures are usually assessed through consumers expectations and their actual perceptions about the service (as demonstrated by Jiang et al.'s (2002) study). The actual perception of service would have higher weights than consumers' expectations. To illustrate this, Klein et al (2009) regressed both sides (actual perceptions and expectations) onto the user satisfaction construct (note that causal correlations between SERVQUAL and user satisfaction constructs are well established in the marketing literature). As a result, Klein et al. (2009) found that actual perceptions loaded much higher onto satisfaction than consumers' expectations. Therefore, the authors recommended using advanced statistical techniques including polynomial regression techniques and surface response modeling to shed more light into the relationship of the fit components (Klein, Jiang et al. 2009).

\subsubsection{Fit as gestalts}

Venkatraman (1989) suggested conceptualizing fit as gestalts when more than two variables are used. Gestalts could be defined as "the degree of internal coherence among a set of theoretical attributes" (Venkatraman 1989). Gestalts could be arrived by cluster-analysing data (Venkatraman 1989). Only few studies in the IS research literature were identified that applied the fit-as-gestalts approach (Lefebvre, Lefebvre et al. 1997; Buttermann, Germain et al. 2008). Since this form of fit does not apply to the current study (TTF/TCF is not being conceptualized as consisting of a set of theoretical attributes), it is not further discussed in here.

\subsubsection{Fit as profile deviation}

In a profile deviation perspective, fit is "the degree of adherence to an externally specified profile" (Venkatraman 1989). This perspective of fit differs from the gestalt perspective in that the profile is anchored to a specific criterion, such as performance (Venkatraman 1989). Evaluating fit as profile deviation is particularly useful for testing the effects of environmentstrategy co-alignment since multiple variables are involved. Using interaction terms or moderating effects of variables can become cumbersome and problematic when multiple variables are involved (Sabberwal and Chan 2001). Fit as profile deviation can be operationalized using pattern analysis, as demonstrated in a business alignment study by 
Sabherwal and Chan (2001). Since fit as profile deviation does not apply to the current study, it is not further discussed here.

\subsubsection{Fit as covariation}

When fit is conceptualized as covariation, "fit is a pattern of covariation or internal consistency among a set of underlying theoretically related variables" (Venkatraman 1989). Covariation can be computed either using factor analysis and/or regression techniques. Fit as covariation involves identifying several dimensions based on the scores along a set of chosen variables.

This form of fit assessment has been frequently used by researchers investigating Information Systems - including studies of TTF. For example, Goodhue and Thompson (1995) assembled fortyeight items representing aspects of the fit between the tasks users perform and the technologies they use to perform these tasks. Using exploratory factor analysis, the authors first excluded fourteen items and collapsed the remaining TTF measures into eight unique factors (quality, locatability, authorization, compatability, product timeliness, ease of use/training, and relationship with users). They argued that each dimension would represent a unique part of the TTF. Using regression techniques, these facets of fit were linked to other constructs within the research model (e.g. utilization and performance impacts).

Staples and Seddon (2004) also used a multi-faceted measure to identify a TTF within the context of their study. They used four facets of TTF originally proposed by Goodhue and Thompson (work compatibility, ease of use, ease of learning as well as information quality). To test these dimensions, twelve questions (three questions per facet) were used. The authors modelled the TTF construct as a second order factor, with each facet of TTF being a firstorder factor that formed the second order factor.

D'Ambra and Wilson (2004a) also used a multidimensional construct to model the fit between web usage and personal travel planning and purchase of flight tickets. To evaluate the TTF construct, the authors developed multiple items that specified the TTF in the context of the study. Next, the authors collected data and factor analyzed the TTF items. Several TTF dimensions (uncertainty reduction, fun/flow, mediation, control, information resounds, and locatability of information) were identified and used as first order constructs. Next, the authors used PLS to assess the structural relationships between these first order dimensions and utilization/performance impacts (D'Ambra and Wilson 2004). 
While not specifically discussed by Venkatraman (1989), many researchers have also made use of direct measures to assess fit. This approach is discussed below.

\subsubsection{Direct (reflective) fit measures}

The direct measurement approach involves developing and utilizing several reflective items that are tailored to elicit individuals' perceptions of the fit between two (or more) variables.

For instance, Bhattacherjee (2001) asked respondents to match their prior expectations to perceived performance of a system. The expectation/confirmation construct was assessed through the following items: 1) My experience with using [the system] was better than what I expected, 2) The service level provided by [the system] was better what I expected, and 3) Overall, most of my expectations from using [the system] were confirmed (Bhattacherjee 2001).

Lin et al. (2005) integrated a playfulness construct into expectation-confirmation theory (ECT) in order to study users' continuous intentions to use web sites. These authors borrowed from Bhattacherjee (2001b) and also used the expectation/confirmation items in this version of the ECT theory.

Likewise, Hsu et al. (2004) studied the motivational factors influencing individuals to continue using web-based applications (Hsu, Chiu et al. 2004). The authors combined social cognitive theory with expectancy disconfirmation theory (the negative synonym to ECT). As part of the research model, the authors also used a perceived disconfirmation construct which was assessed through four reflective measures such as: "The information quality of the $W W W$ was better than what I expected" (Hsu, Chiu et al. 2004). This study also aimed to match individuals' expectations and the perceived service level within one single construct that was assessed through several reflective items.

Similarly, researchers studying TTF have used direct measurement approaches. For example, Klopping et al. (2004) created eight reflective items to assess the fit between Internet based shopping malls and individuals shopping preferences. The TTF construct was assessed through the following items:

1. Sufficiently detailed product information is maintained on product websites.

2. On the websites I visit, product information is either obvious or easy to find out.

3. I can get product information quickly and easily from a website when I need it. 
4. The online product information that I use or would like to use is accurate enough for my purposes.

5. The online product information is up to date for my purposes.

6. The online product information that I need is displayed in a readable and understandable form.

7. The online product information maintained at websites is pretty much what I need to carry out my tasks.

8. The product information is stored in so many forms it is hard to know how to use it effectively. (Klopping and McKinney 2004)

The authors used the eight items to measure TTF. Next, they applied structural equation modelling to test a research model which hypothesized relationships between the TTF construct and other variables such as perceived usefulness and intention to use (Klopping et al. 2004).

Similarly, Ferrat et al. (1998) used five direct TTF items to evaluate how computer-based information systems (CBIS) fit to support managers in their decision making tasks. The measures were designed to assess managers regarding their decision making habits.

The main advantage of the direct measurement approach is its simplicity. Including a set of reflective measures within a survey questionnaire instrument is straightforward. These constructs can be treated as reflectively measured latent variables, and component (PLS) or covariance based (Amos, Lisrel, EQS etc.) structural equation modelling techniques can be used to evaluate the research models.

Despite the widespread acceptance of this approach, this technique has been criticized by various researchers (Edwards 2001; Klein, Jiang et al. 2009; Venkatesh and Goyal 2010). Asking respondents about the perceived direct fit between two or more variables requires the respondents to conceive and mentally 'calculate' their perceptions of fit. Researchers must rely on the respondents' ability to reliably conduct this mental arithmetic as they respond to the fit questions (Kristof 1996).

\subsubsection{Fit theory summary and identification of research gap}

The review of literature on fit theory suggested that researchers have used various approaches to conceptualize fit. Table 57 summarizes the various approaches researchers have employed to assess fit in different research settings. 
Table 57: Fit conceptualization used in reference disciplines and IS research

\begin{tabular}{|c|c|c|}
\hline & Reference Disciplines / IS research & TPC/TTF \\
\hline $\begin{array}{l}\text { Fit as } \\
\text { moderation }\end{array}$ & $\begin{array}{l}\text { (Prescott 1986; Chan, Huff et al. } \\
\text { 1997; Parker and Van Witteloostuijn } \\
\text { 2010) }\end{array}$ & $\begin{array}{l}\text { (Goodhue 1995; Goodhue 1998; } \\
\text { Dishaw and Strong 1999) }\end{array}$ \\
\hline Fit as mediation & $\begin{array}{l}\text { (Thatcher 2001; Parker and Van } \\
\text { Witteloostuijn 2010) }\end{array}$ & N.A. \\
\hline Fit as matching & $\begin{array}{l}\text { (Jiang, Klein et al. 2002; Tesch, Jiang } \\
\text { et al. 2003) }\end{array}$ & N.A. \\
\hline Fit as gestalts & $\begin{array}{l}\text { (Lefebvre, Lefebvre et al. 1997; } \\
\text { Buttermann, Germain et al. 2008) }\end{array}$ & N.A. \\
\hline $\begin{array}{l}\text { Fit as profile } \\
\text { deviation }\end{array}$ & $\begin{array}{c}\text { (Conrad, Brown et al. 1997; } \\
\text { Sabberwal and Chan 2001; Parker and } \\
\text { Van Witteloostuijn 2010) }\end{array}$ & N.A. \\
\hline $\begin{array}{l}\text { Fit as } \\
\text { covariation }\end{array}$ & $\begin{array}{r}\text { (McKinney, Yoon et al. 2002; } \\
\text { Mitchell, Mohammad et al. 2007) }\end{array}$ & $\begin{array}{l}\text { (Goodhue and Thompson 1995; } \\
\text { D'Ambra and Wilson 2004; Staples } \\
\text { and Seddon 2004) }\end{array}$ \\
\hline $\begin{array}{l}\text { Fit directly } \\
\text { assessed }\end{array}$ & $\begin{array}{l}\text { (Bhattacherjee 2001; Lin, Wu et al. } \\
\text { 2005; Limayem, Hirt et al. 2007) }\end{array}$ & $\begin{array}{c}\text { (Ferratt and Vlahos 1998; } \\
\text { Klopping and McKinney 2004) }\end{array}$ \\
\hline
\end{tabular}

Each of the above mentioned fit conceptualization should be carefully scrutinized before applying it in a specific research context. For instance, fit as mediation assumes that the fit variable has a mediating effect on the dependent variable. Given the research model developed in chapter 3, this fit conceptualization seemed to be inappropriate for studying TCF due to the underlying theoretical assumptions. Goodhue and Thompson (1995) theorized that TTF would influence certain precursors of utilization (such as attitude towards technology). Since task-channel fit is based on TTF, reversing this causal relationship would be theoretically unjustified and illogical (e.g. stating that TTF/TCF would be influenced by users' attitudes).

Likewise, fit as gestalts would be inappropriate for measuring task-channel fit since only two variables 'gestalt' (gestalt is the German word for forming) the fit between a given banking channel and specific banking tasks. Fit as gestalts is only appropriate for a set of theoretical attributes involving multiple variables (Venkatraman 1989).

Fit as profile deviation seemed to be an unsuitable fit conceptualization for the current study since it was unclear how to develop an 'ideal' profile for the task-channel fit concept. This is necessary though in order to compute the deviation from the ideal profile.

Further, despite the fact that fit as covariation has been often used in IS research to study TTF, there are conceptual issues with this approach. For instance, Staples and Seddon (2004) 
used this technique to assess the task performance chain theory. Building upon Goodhue and Thompson's (1995) work, Staples and Seddon (2004) conceptualized four different TTF dimensions (work-compatability, ease of use, ease of learning, and information quality). Each TTF dimension was measured through three reflective items. The dimensions were then used as first-order constructs comprising the second-order TTF variable. Next, statistical correlations were investigated between the TTF construct and the remaining variables in the research model. This approach has conceptual flaws as the fit is not specified numerically when investigating causal relationships with other variables. For instance, the authors collected data for three ease of use items as part of their TTF conceptualization: 1) the system is easy to use, 2) the system is user friendly, 3) it is easy to get the system to do what I want it to do (Staples and Seddon, 2004). When scrutinizing these items carefully, it becomes clear that tasks users perform were not considered in these items. The responses collected for these items might co-vary with other variables in the research model (and perhaps the dependent variable - system utilization), however, it appears to be problematic to derive TTF from nontask specific ease of use items ${ }^{16}$. Thus, conceptualizing task-channel fit as covariation appeared to be problematic in context of this study.

Directly assessing fit can also be seen as problematic (Venkatesh and Goyal 2010) because "measures that elicit direct comparisons merely shift the onus of creating a difference score from the researcher to the respondent" (Edwards 2001). Researchers commonly use response scales (ranging from negative to positive numbers) to collect data and they ask the respondent to mentally calculate the difference of the fit components themselves.

Given these arguments, using a parallel instrument appeared to be a superior technique for measuring TTF in an IS research context. This approach would allow collecting responses for 'both sides' of the fit construct separately.

To compute the TCF, either matching or moderation approaches could be used without "priming the respondent to mentally subtract the components" (Edwards 2001). Thus, it was decided to develop a parallel instrument for evaluating the task-channel fit construct. Despite the relatively large number of research studies on task-technology fit, no rigorous study could

\footnotetext{
${ }^{16}$ It is important to note that multiple other TTF related studies (e.g. Goodhue and Thompson, 1995) also used ease of use items to specify TTF.
} 
be identified that attempted to quantify the fit between a given technology and a specific task via parallel instruments ${ }^{17}$.

There are several benefits associated with using parallel instruments analysis. First, it gives the researchers a very detailed and rich view of the fit between two variables. Second, the process of determining/computing the fit is relatively straightforward since the matching and moderation process only requires a basic subtraction / multiplication of the values obtained for the parallel instruments.

It was also assumed that this form of fit determination gives IS researchers a greater flexibility in examining each dimension of fit. This should be also beneficial to practitioners since they know why individuals see a fit between the two variables. The level of data analysis advances the direct fit measures (using several reflective items to measure the fit) by far. The development of the parallel items is explained in more detail in section 4.4.1. while section 5.4.1. discusses the computation of the TCF in depth.

Despite concerns of the accuracy of the measurement, during the pilot study four direct TCF measures were also included asking respondents about their perceived suitability of Internet banking services regarding account inquiries/financial loans. These items should give insights into consumers' overall perceptions of the suitability of Internet banking services for account inquiries/financial loan applications.

Having discussed fit theory, the following section discusses the pilot test conducted to refine the survey questionnaire instrument developed in the previous chapter and test the conceptual research model.

\subsection{Pilot study}

\subsubsection{Survey questionnaire instrument}

In an ideal situation, the TCF scales would be tested by gathering data from respondents for all electronic banking channels, and for a variety of banking tasks. However, this research design appeared infeasible for two reasons. First, combining items for a number of banking transactions (e.g. account inquiries, domestic transactions, international payments, applying for credit cards and/or mortgages) with four electronic banking channels (ATMs, Telephone-,

\footnotetext{
${ }^{17}$ It should be noted though that Dishaw and Strong (1999) reported that they used a parallel instrument in their TAM/TTF study, however, they did not publish the relevant scales.
} 
Internet-, and Mobile Banking) would lead to a very repetitive and lengthy survey questionnaire (Grover 2000; Malhotra 2004).

Second, due to varying adoption rates, it seemed unlikely that respondents would be able to reply to questions related to all electronic banking channels. For instance, mobile banking services are only used by $8 \%$ of banking consumers in New Zealand (AC Nielsen 2008). Considering this, identifying mobile banking users who also use (or have utilized) all other electronic banking channels seemed to be unrealistic.

For the pilot study, then, it was decided to focus on a single banking channel and on two different banking tasks. Internet banking was selected as the banking channel. First, most consumers in New Zealand have experience with Internet banking applications and should have well-formed beliefs about most common functionalities of these services. Second, all New Zealand banks offer a wide range of financial products via Internet banking, including simple-, medium- and complex banking products.

In order to create a meaningful comparison, account inquiries (checking account balance, viewing transaction history, inspecting account statements etc.) and financial loans applications (applying for bank overdrafts, home loans, personal loans, mortgages etc.) were selected to test the perceived TCF scales regarding Internet banking services. The data collection was operationalized by using two different versions of the questionnaire instrument (one for account inquiries and another for financial loan applications). The two versions differed slightly from each other to reflect the nature of the corresponding banking task. Table 58 lists the items used to assess the TCF for financial loan applications. As indicated within the Table, the context of loan applications was replaced with that of account inquiries for the second version of the survey questionnaire.

Table 58: Items used for the pilot study

\begin{tabular}{|l|l|}
\hline Construct & Items \\
\hline TCF - task characteristics \\
\hline COMP1 & A financial loan (account inquiry) is a complicated banking transaction. \\
COMP2 & Applying for a financial loan (account inquiry) is an easy-to-do banking task. \\
EFFORT1 & I have to provide a lot of information to my bank when applying for a financial loan (account inquiry). \\
EFFORT2 & A loan application (account inquiry) is a banking transaction that requires filling out many forms. \\
FREQ1 & I often apply for a financial loan (account inquiry). \\
FREQ2 & A loan application (account inquiry) is a banking transaction I frequently do. \\
IMPORT1 & A loan application (account inquiry) is an ordinary banking transaction to me. \\
IMPORT2 & Applying for a loan (account inquiry) is a commonplace banking task. \\
TIME1 $*$ & I seldom face situations in which I need to apply for a bank loan (account inquiry) urgently. \\
TIME2 & I often need to apply for a financial loan (account inquiry) immediately. \\
\hline TCF - channel suitability \\
\hline \\
CCOMP1 & Internet banking is well suited for: \\
CCOMP2 & Complicated banking transactions. \\
CEFFORT1 & Banking transactions for which I have to provide a lot of information to my bank. \\
\hline
\end{tabular}




\begin{tabular}{|c|c|}
\hline $\begin{array}{l}\text { CEFFORT2 } \\
\text { CFREQ1 } \\
\text { CFREQ2 } \\
\text { CIMPORT1 } \\
\text { CIMPORT2 } \\
\text { CTIME1 } \\
\text { CTIME2 }\end{array}$ & $\begin{array}{l}\text { Banking transactions that do not require filling out many forms. } \\
\text { Banking transactions I often perform. } \\
\text { Banking transactions I perform frequently. } \\
\text { For ordinary banking transactions. } \\
\text { For commonplace banking tasks. } \\
\text { Urgent banking transactions. } \\
\text { Banking transactions I have to do immediately. }\end{array}$ \\
\hline \multicolumn{2}{|c|}{ Perceived usefulness } \\
\hline $\begin{array}{l}\text { PU3 } \\
\text { PU4 }\end{array}$ & $\begin{array}{l}\text { Using Internet banking for financial loan (account inquiry) applications would enhance my effectiveness } \\
\text { in managing personal finances. } \\
\text { The advantages of using Internet banking for financial loan (account inquiry) applications would } \\
\text { outweigh the disadvantages. } \\
\text { Internet banking would be a convenient way to apply for financial loans (account inquiry). } \\
\text { Overall, applying for a financial loan (account inquiry) via Internet banking would be of benefit to me. }\end{array}$ \\
\hline \multicolumn{2}{|l|}{ Ease of use } \\
\hline $\begin{array}{l}\text { EOU1 } \\
\text { EOU2 } \\
\text { EOU3* } \\
\text { EOU4 }\end{array}$ & $\begin{array}{l}\text { Internet banking would be easy to use when applying for financial loan (account inquiry). } \\
\text { Applying for a financial loan (account inquiry) via Internet banking would be clear and understandable. } \\
\text { It would require a lot of mental effort to apply for a financial loan (account inquiry) via Internet banking. } \\
\text { It would be simple for me to apply for a financial loan (account inquiry) through Internet banking. }\end{array}$ \\
\hline \multicolumn{2}{|c|}{ Attitude towards channel use } \\
\hline $\begin{array}{l}\text { ATT1* } \\
\text { ATT2 } \\
\text { ATT3 } \\
\text { ATT4 }\end{array}$ & $\begin{array}{l}\text { I would dislike using Internet banking for a financial loan application (account inquiry). } \\
\text { I think it would be good to use Internet Banking to apply for a financial loan (account inquiry). } \\
\text { My attitude towards financial loan applications (account inquiry) via Internet Banking would be } \\
\text { favorable. } \\
\text { Overall, using Internet banking for financial loan applications (account inquiry) would be a good idea. }\end{array}$ \\
\hline \multicolumn{2}{|l|}{ Security } \\
\hline $\begin{array}{l}\text { SEC1 } \\
\text { SEC2 } \\
\text { SEC3* } \\
\text { SEC4 }\end{array}$ & $\begin{array}{l}\text { Internet banking would be a secure means by which to apply for a financial loan (account inquiry). } \\
\text { I would feel safe applying for a financial loan (account inquiry) via Internet banking. } \\
\text { Applying for a financial loan (account inquiry) on Internet banking would be risky. } \\
\text { Overall, Internet banking would be a safe place to apply for a financial loan. }\end{array}$ \\
\hline \multicolumn{2}{|c|}{ Subjective norms } \\
\hline $\begin{array}{l}\text { SN1 } \\
\text { SN2 } \\
\text { SN3 } \\
\text { SN4 }\end{array}$ & $\begin{array}{l}\text { My decision to use Internet banking for financial loan/account inquiry applications would be influenced } \\
\text { by: } \\
\text { My friends. } \\
\text { My family/relatives. } \\
\text { My colleagues/peers. } \\
\text { People who are important to me think I should use Internet banking for financial loan applications } \\
\text { (account inquiry). }\end{array}$ \\
\hline \multicolumn{2}{|c|}{ Cost associated with channel use } \\
\hline $\begin{array}{l}\text { COST1 } \\
\text { COST2 } \\
\text { COST3 } \\
\text { COST4 }\end{array}$ & $\begin{array}{l}\text { It would cost a lot to apply for financial loans (account inquiry) using Internet banking. } \\
\text { Financial costs would be a barrier for me if applying for financial loans (account inquiry) using Internet } \\
\text { banking. } \\
\text { I would not be worried about the costs associated with financial loan applications (account inquiry) using } \\
\text { Internet banking. } \\
\text { Overall, the cost associated with Internet banking use for financial loan applications (account inquiry) } \\
\text { would discourage me from using it. }\end{array}$ \\
\hline \multicolumn{2}{|c|}{ TCF - global measures } \\
\hline $\begin{array}{l}\text { TCF1 } \\
\text { TCF2 } \\
\text { TCF3 } \\
\text { TCF4 }\end{array}$ & $\begin{array}{l}\text { I think Internet banking would be well suited for loan applications (account inquiry). } \\
\text { Internet banking would be a good medium for loan applications (account inquiry). } \\
\text { Internet banking would fit well for loan applications (account inquiry). } \\
\text { I think Internet banking would be a good way to apply for financial loans (account inquiry). }\end{array}$ \\
\hline \multicolumn{2}{|c|}{ Intentions to use } \\
\hline $\begin{array}{l}\text { INT1 } \\
\text { INT2 } \\
\text { INT3 } \\
\text { INT4 }\end{array}$ & $\begin{array}{l}\text { If I needed to apply for a financial loan (account inquiry) I would use Internet banking. } \\
\text { Assuming I had to apply for a financial loan (account inquiry) I would use Internet banking for it. } \\
\text { I would apply for a financial loan (account inquiry) via Internet banking if I needed one. } \\
\text { I would use Internet banking for loan applications (account inquiry) rather than alternative banking } \\
\text { channels (branch, telephone, letter etc.). }\end{array}$ \\
\hline & \\
\hline
\end{tabular}




\subsubsection{Survey operationalization}

Online questionnaires are similar to mail questionnaires in that they are easy to administer and respondents can complete them at their convenience (Cavana, Delahaye et al. 2001). Another major advantage of online questionnaires is that they can be distributed quickly and inexpensively (Pinsonneault and Kraemer 1993; Cavana, Delahaye et al. 2001).

Due to the questionnaire design described earlier, it was decided to use an online survey system for the pilot study for two reasons. First, it was anticipated to receive useful feedback for the main study regarding the usability of the online survey application (Qualtrics.com). Second, using online survey applications enable researchers to modify the survey questionnaire during the data collection (Cavana, Delahaye et al. 2001). This was necessary in order to collect a similar amount of data for both banking tasks (financial loan applications and account inquiries related to Internet banking).

Qualtrics (qualtrics.com) was used as the software application to collect data for the pilot test. Qualtrics is an industry-leading survey software application and is accessible to all $\mathrm{PhD}$ students at Victoria University of Wellington.

Three major sections were designed to collect data for the pilot test. The first section introduced the research participants to the questionnaire and the purpose and goals of the study were stated. In there, the research participants were also informed about the data confidentiality and it was acknowledged that HEC approval had been gained prior to the study.

This section was posted on a separate URL than the main survey for two reasons. First, the design allowed respondents to re-consider participation in the survey based on the information they read on the first page. By asking each respondent to follow a link (represented by a text based URL link or a > button) to the main survey, consent to participate in the study was obtained from each respondent. Second, this design allowed the researcher to adjust the main part of the questionnaire instrument (section two) by replacing the account inquiry' version with the financial loan version of the questionnaire at any given time during the data collection.

The second section of the survey questionnaire included all items listed in Table 58. To maintain anonymity of the respondents, the third section of the questionnaire was posted on a separate URL link. This separate survey only included the following statement "Please insert a valid email address in the following text-box [.....]." Because this section was setup as a 
separate survey the provided email addresses could not be associated with the answers respondents' provided in the second part of the survey questionnaire as required by the human ethics commitment (see appendix). The email addresses were necessary to collect for the prize draw organized and conducted after the data collection phase of this pilot study (explained more detailed in the following section).

\subsubsection{Data collection}

As explained later (section 6.6.), the data collection for the main study was conducted through a consumer panel surveyed via the smilicity.com web-portal. In a pilot study, the sample of respondents would ideally come from the same target population used for the main study (Pinsonneault and Kraemer 1993; Grover 2000; Cavana, Delahaye et al. 2001). As with the pretest, it was impossible to access the Smilecity.com consumer panel.

Hence, it was decided to pilot-test the survey questionnaire instrument among students, faculty and administrative staff at Victoria University of Wellington. To encourage participation within the study, the survey questionnaire URL was posted in the VicNnews newsletter and on the MyVictoria portal. These sources are accessible to all VUW staff and students at Victoria University.

The survey link was also posted on several Blackboard sites available to undergraduate students at the School of Information Management. In addition, email addresses of VUW staff members were obtained from the VUW web-site in order to invite staff personally to participate within the survey. These email invitations included administrative and academic staff working for the faculty of commerce and administration, humanities and social sciences, architecture and design, education, sciences, and psychology.

To encourage individuals to partake within the study, small rewards were organized. Five book vouchers (worth $\$ 100$ overall) were given out to respondents. To be considered for one of these vouchers all respondents had the opportunity to put their names into a draw by providing a valid email address at the end of the survey. To identify the prize winners, all collected email addresses were pooled within an excel spreadsheet (348 email addresses). Using the following formula $=\operatorname{INT}(\operatorname{RAND}() * 348+1)$ in Microsoft Excel, five respondents were identified randomly. These individuals were contacted via email and provided with a book voucher.

In addition, the first five respondents who provided a valid email address were contacted and offered a concert ticket for the Vector Wellington Orchestra Beethoven \& Stravinsky 
concert which took place on the 17th of April, 2010. Some of the respondents were unable (or not interested) to attend the concert. In such cases, the tickets were offered to the next available person.

\subsubsection{Data preparation for the analysis}

Overall, 148 completed responses were collected for the account inquiry/Internet banking version of the survey questionnaire. In addition, 11 respondents started to complete the survey questionnaire but decided not to respond to all items. In contrast, 227 responses were provided for the financial loan/Internet banking version of the survey questionnaire. 50 additional respondents started to take the survey for financial loans/Internet banking but did not respond to all questions. In order to analyze complete datasets, it was decided to exclude the unfinished responses from further data analysis (for both versions of the survey questionnaire).

During the data collection for the financial loan/Internet banking version of the survey questionnaire, many respondents suggested re-wording the intention to use items. The initial wording of these items asked the respondents if they "intent to apply for financial loans on Internet banking applications". Some respondents argued that they would use Internet banking for loan applications but they had no current need for a loan application (or within the near future). Hence their intentions to use Internet banking for loan application would be low since they had no personal need for financial loans. To avoid confusion, some respondents suggested asking individuals if they "would use Internet banking for financial loans if they had a need for it". This would clarify the meaning of the item and specify consumers' intentions clearer.

The proposed adjustments were discussed with supervising staff and it was decided to include the following items within the survey questionnaire:

1. If I needed to apply for a financial loan I would use Internet banking.

2. Assuming I had to apply for a financial loan I would use Internet banking for it.

3. I would apply for a financial loan via Internet banking if I needed one.

4. I would use Internet banking for loan applications rather than alternative banking channels (branch, telephone, letter etc.).

This adjustment of the survey questionnaire instrument took place after the data collection started. 63 responses were collected using the original wording of the intention to use variable. These responses were excluded since this measurement of the intention to use 
variable seemed to be too imprecise. 164 respondents replied to the adjusted (see items above) intention to use measures for the financial loan/Internet banking version of the survey questionnaire.

In addition, further responses (for both datasets) were excluded from the data analysis since some research participants indicated that they felt either unfamiliar with the banking task in question or Internet banking services. These exclusions resulted in 140 analyzable responses for each banking task. Lastly, the values obtained for the reversed coded items were conversed.

\subsection{Analysis of Pilot Study Data}

Before discussing the data analysis in more detail, this section provides some general information on the respondents and the data collected during the pilot test.

Before performing statistical analyses, the datasets were initially screened for completion. While there was no missing data expected ${ }^{18}$, it was double-checked if all datasets were complete.

Due to the various sources used during the data collection (Blackboard, MyVictoria and email invitations) it was impossible to adequately determine the survey response rate. VUWITS services were approached for daily user data regarding the MyVictoria portal but ITS staff were unable to estimate students' and staff MyVictoria usage rates.

Table 59 provides information on the demographics of the respondents.

Table 59: Demographics of the respondents - pilot test

\begin{tabular}{|c|c|c|c|}
\hline & & Financial loans & Account inquiries \\
\hline Gender & & 53 males, 87 Females & 49 males, 91 Females \\
\hline \multirow{6}{*}{$\begin{array}{c}\text { Age- } \\
\text { groups }\end{array}$} & Under 20: & 4 respondents $(2.9 \%)$ & 17 respondents $(12.1 \%)$ \\
\hline & 20-29: & 36 respondents $(25.7 \%)$ & 50 respondents $(35.7 \%)$ \\
\hline & 30-39: & 31 respondents $(22.1 \%)$ & 30 respondents $(21.4 \%)$ \\
\hline & 40-49: & 28 respondents $(20 \%)$ & 11 respondents $(7.9 \%)$ \\
\hline & 50-59: & 31 respondents $(22.1 \%)$ & 20 respondents $(14.3 \%)$ \\
\hline & 60 or older & 9 respondents $(6.4 \%)$ & 11 respondents $(7.9 \%)$ \\
\hline \multirow{4}{*}{ Education } & Undergraduate & 17 respondents $(12.1 \%)$ & 39 respondents $(27.9 \%)$ \\
\hline & Postgraduate & 40 respondents $(28.6 \%)$ & 42 respondents $(30 \%)$ \\
\hline & Academic staff & 36 respondents $(25.7 \%)$ & 27 respondents $(19.3 \%)$ \\
\hline & Administrative & 18 respondents $(12.9 \%)$ & 17 respondents $(12.1 \%)$ \\
\hline
\end{tabular}

\footnotetext{
${ }^{18}$ The survey system was set up in a way that respondents were required to respond to all items in order to complete the survey questionnaire.
} 


\begin{tabular}{|c|c|c|c|}
\hline & staff & & \\
\hline & Management staff & 12 respondents $(8.6 \%)$ & 6 respondents $(4.3 \%)$ \\
\hline & Support staff & 4 respondents $(2.9 \%)$ & 3 respondents $(2.1 \%)$ \\
\hline & Library staff & 0 respondents $(0 \%)$ & 0 respondents $(0 \%)$ \\
\hline & Other & 12 respondents $(8.6 \%)$ & 5 respondents $(3.6 \%)$ \\
\hline \multirow{9}{*}{$\begin{array}{l}\text { Prime } \\
\text { Bank }\end{array}$} & ANZ & 19 respondents $(13.6 \%)$ & 28 respondents $(20 \%)$ \\
\hline & National Bank & 42 respondents $(30 \%)$ & 40 respondents $(28.6 \%)$ \\
\hline & Westpac & 22 respondents $(15.7 \%)$ & 31 respondents $(22.1 \%)$ \\
\hline & $\mathrm{BNZ}$ & 20 respondents $(14.3 \%)$ & 7 respondents $(5 \%)$ \\
\hline & Kiwibank & 15 respondents $(10.7 \%)$ & 15 respondents $(10.7 \%)$ \\
\hline & ASB & 12 respondents $(8.6 \%)$ & 11 respondents $(7.9 \%)$ \\
\hline & Rabobank & 0 respondents $(0 \%)$ & 0 respondents $(0 \%)$ \\
\hline & TSB & 3 respondents $(2.1 \%)$ & 1 respondent $(0.7 \%)$ \\
\hline & Other & 6 respondents $(4.3 \%$ & 6 respondents $(4.3 \%)$ \\
\hline \multirow{9}{*}{$\begin{array}{c}\text { Secondary } \\
\text { Bank }\end{array}$} & ANZ & 12 respondents & 17 respondents \\
\hline & National Bank & 8 respondents & 20 respondents \\
\hline & Westpac & 13 respondents & 21 respondents \\
\hline & BNZ & 17 respondents & 13 respondents \\
\hline & Kiwibank & 21 respondents & 14 respondents \\
\hline & ASB & 8 respondents & 10 respondents \\
\hline & Rabobank & 12 respondents & 8 respondents \\
\hline & TSB & 2 respondents & 1 respondent \\
\hline & Other & 21 respondents & 22 respondents \\
\hline
\end{tabular}

Table 59 shows that the responses were skewed towards female respondents for both versions of the survey questionnaire instrument. Also, for both versions, more than a quarter of all respondents were between 20 and 29 years old.

On the other hand, the sample included a wide range in terms of respondents' age and education. Further, the respondents' maintained banking accounts with a variety of banking and all major New Zealand banks were represented in the sample.

The respondents were also asked about their familiarity with each banking task and Internet banking. As indicated above, all respondents who indicated to be 'not at all familiar' with either banking task or Internet banking were excluded from the data analysis. The familiarity results are summarized in the following Table 60 .

Table 60: Respondents' familiarity with each banking task and Internet banking

\begin{tabular}{|l|c|c|c|}
\hline & Financial loans & Account inquiries & Internet banking \\
\hline Slightly familiar & $29(20.7 \%)$ & $3(0.7 \%)$ & $14(5 \%)$ \\
\hline Somewhat familiar & $42(30 \%)$ & $14(7.9 \%)$ & $32(11.4)$ \\
\hline Moderately familiar & $46(32.9 \%)$ & $36(25.7 \%)$ & $78(27.9 \%)$ \\
\hline Very familiar & $23(16.4 \%)$ & $92(65.7 \%)$ & $156(55.7 \%)$ \\
\hline
\end{tabular}


Table 60 suggests that more than $90 \%$ of all respondents felt very or moderately familiar with account inquiries. This is consistent with the existing literature on electronic banking suggesting that an account inquiry is a task individuals are familiar with (Tan and Thompson 2000).

On the other hand, fewer respondents felt moderately or very familiar with financial loans. This was also expected since financial loan applications are tasks consumers do less frequently (Tan and Thompson 2000).

More than $75 \%$ of all respondents felt moderately or very familiar with Internet banking services. Given these responses, it was reasonable to assume that all respondents were well suited and capable to respond to the questions of the survey questionnaire.

Despite the fact that PLS is not constrained by normality assumptions (Chin 1998), both datasets were initially tested for normality (Field 2009). Normality can be verified by calculating the skewness and kurtosis ratings in SPSS.

Skewness is a measure of the asymmetry of a distribution whereas Kurtosis measures the degree to which scores cluster in tails the of a distribution (Hair, Anderson et al. 1995; Field 2009). Most authors consider that a data set is normally distributed if the skewness and kurtosis ratings are within the +2 to -2 range (Hair, Anderson et al. 1995; Carver and Nash 2005; Tabachnick and Fidell 2007; Field 2009).

In the account inquiries dataset, the skewness rating was on average at -0.708 . None of the items was above -1.6. The kurtosis statistics in the account inquiries dataset was on average 1.977. Some of the kurtosis scores were slightly higher than 3 which many authors still consider as acceptable (Hair, Anderson et al. 1995; Carver and Nash 2005; Tabachnick and Fidell 2007; Field 2009).

For the financial loan dataset, the skewness statistics was on average -0.292 . The largest skewness rating was -0.764 (SEC4). The Kurtosis statistics was on average -0.559 in the financial loan dataset. The maximum kurtosis score was -1.135 (SN1).

Hence, the data was presumed to be distributed normally in both datasets.

The following sections explain how the task-channel fit construct was operationalized during the pilot study. Initially the differences between formative and reflective measurement are pointed out. Then, the reflective TCF items are explained in section 5.4.1.1. before describing the parallel instrument (formative measurement) in section 5.4.1.2. 


\subsubsection{Task-channel fit operationalization}

When operationalizing a construct one important issue is the nature of the relationship between latent constructs and their indicators (Diamantopoulos, Riefler et al. 2008). The following Figure 36 illustrates two operationalization modes researchers can use to measure a construct.

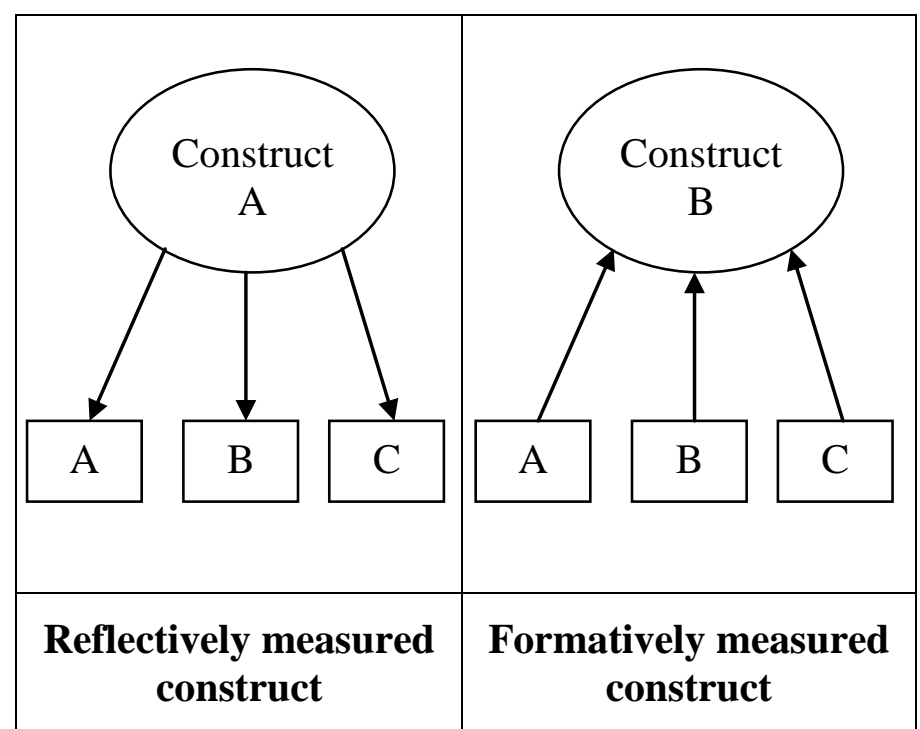

Figure 36: Comparison of reflective and formative model (Diamantopoulos, Riefler et al. 2008)

When using a reflective measurement approach, the indicators are assumed to 'reflect' the variation in the latent variable. Therefore, the direction of causality is assumed to run from the construct to the indicators. Changes in the constructs are expected to impact on all indicators as they are all part of the multi-item scale (Diamantopoulos, Riefler et al. 2008). As a result, multi-collinearity is desired among reflective measures (Petter, Straub et al. 2007).

In contrast, formative measures 'form' the construct, and variation in the measures is assumed to cause variation in the construct rather than the other way round (Diamantopoulos and Winklhofer 2001). Therefore, high correlations among indicators are not desired, since that can result in an instable construct (Petter, Straub et al. 2007). Formative measurement approaches have recently gained increasing attention in the IS research discipline as formative measures capture different aspects of a construct.

For this research, two sets of TCF measures were created, one formative (in combination with a parallel instrument) and one reflective (direct measurement). The formative items intended to capture different aspects (see TCF dimensions developed in section 3.3.1.) of TCF and should individually represent a finer level of measurement granularity compared to the reflective items. 
The formative TCF measures intended to specify why consumers perceive a fit between a given banking task and an electronic banking channel. This approach provides a more detailed, robust and rich picture of the TCF construct. In contrast, the set of reflective items provides a higher-level overview of perceived TCF.

The formative measurement approach should be regarded as superior since it provides a more detailed picture ${ }^{19}$. However, since this is the first attempt to formatively measure the perceived TCF of electronic banking channels, it was decided to retain both sets of measures until more is known about the relationship of each TCF dimension and the perceived TCF construct.

The following section explains the direct TCF measurement more detailed before analyzing the formative TCF measures.

\subsubsection{Direct TCF measures}

As explained in section 5.2.7., many researchers have used direct measures to assess a fit between two variables. This form of fit assessment is relatively straightforward as it only requires developing a few reflective items. The following items were composed and integrated into the survey questionnaire instrument in order to understand the respondents' overall perceptions on the task-channel fit.

Table 61: Direct TCF measures used for the pilot test study

\begin{tabular}{|l|l|l|l|}
\hline Label & \multicolumn{1}{|c|}{ Items } & $\begin{array}{l}\text { Mean- } \\
\text { Loans }\end{array}$ & $\begin{array}{l}\text { Mean- } \\
\text { Acc. Inq. }\end{array}$ \\
\hline TCF1 & I think Internet banking would be well suited for loan applications (account inquiry). & 3.34 & 4.42 \\
\hline TCF2 & Internet banking would be a good medium for loan applications (account inquiry). & 3.41 & 4.40 \\
\hline TCF3 & Internet banking would fit well for loan applications (account inquiry). & 3.31 & 4.31 \\
\hline TCF4 & $\begin{array}{l}\text { I think Internet banking would be a good way to apply for financial loans (account } \\
\text { inquiry). }\end{array}$ & 3.32 & 4.42 \\
\hline
\end{tabular}

The right hand side of the Table illustrates the average score each item obtained during the pilot study. The measures were used in combination with Likert scales whereas 1 represented 'strongly disagree' and 5 equated to 'strongly agree'.

The means were separated into financial loans and account inquires. As expected, the perceived overall suitability of account inquiries for Internet banking was higher than for financial loans.

\footnotetext{
${ }^{19}$ and also avoids the cognitive load on respondents of having to mentally calculate or otherwise determine TCF
} 
The psychometric properties of these measures were assessed alongside the remaining reflectively assessed constructs in the research model (a more thorough discussion is provided in section 5.4.3.).

The TCF measures were also used to check the reliability of the formative measurement approach (see more detailed discussion is section 5.4.3.2.) because the construct reliability of a formative construct can be evaluated through the use of " $a$ two-construct model that integrates an additional 'phantom variable', which represents the construct's reflective operationalization" (Diamantopoulos and Winklhofer 2001; Goetz, Liehr-Gobbers et al. 2010).

While the direct measurement of the TCF appealed due to its simplicity, many researchers have argued that this approach is questionable because the results could be misleading. For instance, Venkatraman (1989) as well as Jiang et al. (2002) suggested that using a few direct measures to represent a fit between two or more variables could present a number of potential flaws including reduced reliability, poor convergent validity and unstable dimensionality. Further, measuring a fit of two or more variables with a few reflective items does not provide researchers with detailed information on 'why' and 'how' two different variables fit together. An alternative to the direct approach is the use of a parallel instrument to formatively measure TCF.

For the current study, the parallel measures intended to specify why consumers perceive a fit between a given banking task and an electronic banking channel. This approach is less generalizable but it provides a more robust and rich picture of the TCF construct.

\subsubsection{Parallel instrument TCF measurement}

The task characteristic and channel suitability items (see Table 62) were designed to parallel each other. For each individual task characteristic item, a parallel channel suitability item was created to determine whether a respondent would perceive a fit between the task and the channel for that specific task dimension. For instance, COMP1 asked individuals whether they viewed financial loan applications as complicated. CCOMP1 then inquired whether the individual viewed Internet banking as well suited for complicated banking transactions.

Table 62: Matching items used to determine the Task-channel Fit of electronic banking channels

\begin{tabular}{|l|l|l|l|}
\hline \multicolumn{1}{|c|}{ Items } & & \\
\hline & \multicolumn{1}{|c|}{ TCF - task characteristics } & $\begin{array}{l}\text { Mean- } \\
\text { Mean- } \\
\text { Acc. } \\
\text { Inq. }\end{array}$ \\
\hline COMP1 & A financial loan (account inquiry) is a complicated banking transaction. & 2.91 & 1.81 \\
\hline COMP2 & Applying for a financial loan (account inquiry) is an easy-to-do banking task. & 2.83 & 4.42 \\
\hline
\end{tabular}




\begin{tabular}{|c|c|c|c|}
\hline EFFORT1 & $\begin{array}{l}\text { I have to provide a lot of information to my bank when applying for a financial loan } \\
\text { (account inquiry). }\end{array}$ & 3.54 & 2.01 \\
\hline EFFORT2 & $\begin{array}{l}\text { A loan application (account inquiry) is a banking transaction that requires filling out } \\
\text { many forms. }\end{array}$ & 3.23 & 1.67 \\
\hline FREQ1 & I often apply for a financial loan (account inquiry). & 1.80 & 3.80 \\
\hline FREQ2 & A loan application (account inquiry) is a banking transaction I frequently do. & 1.70 & 3.86 \\
\hline IMPORT1 & A loan application (account inquiry) is an ordinary banking transaction to me. & 2.13 & 4.38 \\
\hline IMPORT2 & Applying for a loan (account inquiry) is a commonplace banking task. & 3.30 & 4.34 \\
\hline TIME1* & $\begin{array}{l}\text { I seldom face situations in which I need to apply for a bank loan (account inquiry) } \\
\text { urgently.* }\end{array}$ & 4.22 & 3.31 \\
\hline TIME2 & I often need to apply for a financial loan (account inquiry) immediately. & 1.51 & 2.87 \\
\hline & TCF - channel suitability & $\begin{array}{l}\text { Mean- } \\
\text { Loans }\end{array}$ & $\begin{array}{l}\text { Mean- } \\
\text { Acc. } \\
\text { Inq. }\end{array}$ \\
\hline & Internet banking is well suited for: & & \\
\hline CCOMP1 & Complicated banking transactions. & 2.71 & 2.87 \\
\hline CCOMP2 & Easy-to-do banking tasks. & 4.64 & 4.48 \\
\hline CEFFORT1 & Banking transactions for which I have to provide a lot of information to my bank. & 2.26 & 2.45 \\
\hline CEFFORT2 & Banking transactions that do not require filling out many forms. & 4.22 & 4.24 \\
\hline CFREQ1 & Banking transactions I often perform. & 4.56 & 4.44 \\
\hline CFREQ2 & Banking transactions I perform frequently. & 4.48 & 4.49 \\
\hline CIMPORT1 & For ordinary banking transactions. & 4.56 & 4.40 \\
\hline CIMPORT2 & For commonplace banking tasks. & 4.54 & 4.44 \\
\hline CTIME1 & Urgent banking transactions. & 4.21 & 4.05 \\
\hline CTIME2 & Banking transactions I have to do immediately. & 4.43 & 4.29 \\
\hline
\end{tabular}

The fit determination is explained in more detail in section 5.4.1.4. As discussed there, deviation score analysis and moderation approaches were both considered to compute the values obtained for the above mentioned items.

For the initial parallel instrument design, two parallel items were created per TCF dimension. This conceptualization allowed two different TCF measurement approaches: (1). using five individual formative indicators for evaluating the TCF construct (one item per TCF dimension), and (2). combining the items for each TCF dimension and using the accumulated TCF scores as formative measures. Both approaches are explained in more detail in section

\subsubsection{3. and 5.4.1.4.}

On the right hand side of Table 62, the average scores are depicted for financial loans and account inquiries. All items were evaluated using Likert scales ranging from 1 to 5 (1=strongly disagree; $5=$ strongly agree).

Comparing the means of the task characteristics items, it is evident that the averages for financial loan applications and account inquiries differed across the five TCF dimensions (complexity, effort, frequency, importance, and time criticality). This was expected since the literature review on electronic banking tasks (section 2.6.) suggested that financial loans and account inquiries differ across these dimensions. 
For example, the task characteristics items (FREQ1 and FREQ2) scored 1.80 and 1.70 on average for financial loan applications. Considering the setup for the Likert scales, these scores suggest that the respondents do not frequently apply for financial loans. On the other hand, both items received relatively high averages for account inquiries (3.80 and 3.86). This indicates that account inquiries are often done by the respondents.

It was surprising to observe that the average scores for COMP1 and COMP2 were equally high in the financial loan dataset. COMP1 addressed how complicated financial loans are perceived to be, whereas COMP2 asked respondents how easy financial loans would be. In case of account inquiries, both items scored dissimilar means. This was expected since a given banking task should be either complicated or simple, but not both.

It is also important to note that the means for the TCF-channel suitability measures (e.g. CCOMP1, CCOMP2 etc.) did not diverge significantly for the financial loan and account inquiry datasets. This was expected since these items were designed to be neutral without any reference to a given banking task.

This research considered the deviation score analysis and the moderation approach to compute the TCF. Both fit calculation techniques are explained in more detail below.

\subsubsection{Task-channel fit calculation - Deviation score analysis}

The underlying assumption of the deviation score analysis is that fit can be determined by matching the parallel items with each other. When using deviation score analysis, researchers assume that each fit component (task characteristics items, and task suitability items) is equally weighted (Klein et al. 2009).

When subtracting the parallel scores, a fit (or ideal point) can be determined by comparing the parallel items. A fit (or match) is given if the respondent scores both items similarly high or low. If the respondent rates one parallel item high and the other low, then the difference score indicates a misfit.

For instance, COMP1 asked individuals if they view financial loan applications as complicated. CCOMP1 then inquired if the same respondent would view Internet banking as well suited for complicated banking transactions. If the respondent rated both items as 5 (strongly agree) then the fit would be represented by a value of zero for this particular element of the overall TCF. The matching score was calculated by taking the difference between CCOMP1 and COMP1. In contrast, if a respondent rated COMP1 as 5 (since he/she views a financial loan as complicated) while rating CCOMP1 as 1 (indicating Internet banking is not 
suited for complicated banking tasks) then a misfit would be represented by a value of -4 (subtracting COMP1 from CCOMP1).

Some respondents might believe that financial loans are not complicated; they view these transactions as simple. In this case the respondents would rate comp1 as 1 since he/she would strongly disagree with the statement 'a financial loan is a complicated banking transaction'. If the same person, however, believed that complicated banking transactions are well suited for Internet banking, then he/she would rate CCOMP1 as 5. When subtracting COMP1 from CCOMP1, the TCF deviation score for this particular case would be a positive 4 .

The following Table 63 indicates how the deviation scores can be computed.

Table 63: Deviation score analysis - TCF calculation based on the pilot test results

\begin{tabular}{|l|c|c|c|c|c|}
\hline & Resp.1 & Resp.2 & Resp.3 & Resp.4 & Resp.5 \\
\hline COMP1 & 5 & 5 & 3 & 1 & 2 \\
\hline CCOMP1 & 5 & 1 & 3 & 5 & 4 \\
\hline $\begin{array}{l}\text { TCFCOMP1 } \\
\text { (absolute deviation scores) }\end{array}$ & $\mathbf{0}$ & $\mathbf{4}$ & $\mathbf{0}$ & $\mathbf{4}$ & $\mathbf{2}$ \\
\hline $\begin{array}{l}\text { TCFCOMP1 } \\
\text { (signed deviation scores) }\end{array}$ & $\mathbf{0}$ & $\mathbf{- 4}$ & $\mathbf{0}$ & $\mathbf{4}$ & $\mathbf{2}$ \\
\hline
\end{tabular}

The literature on fit theory suggests alternative approaches for computing deviation scores. For example, Venkatraman (1989) suggested that matching works best if taking the absolute difference between the parallel items scores. Others have reasoned that including positive and negative deviation scores could lead to more meaningful results (Chan, Huff et al. 1997). Both approaches are discussed with regard to the current study below.

\section{Computing absolute deviation scores}

The first option is based on the premise that the absolute difference between the components represents a lack of fit (Venkatraman, 1989). For this approach negative matching values are set to positive and then used for further analysis. The larger the difference between the two ratings, the greater the degree of mis-fit. The advantage of this approach is its simplicity since researchers are not required to account for differences in interpretation of over- and underfit scores (Venkatraman, 1989).

For the current study, the absolute deviation scores were computed for all parallel item combination (e.g. CCOMP1-COMP1, CCOMP2-COMP2 etc.). For each TCF dimension one absolute deviation score was subsequently used as a formative indicator for the TCF construct. The TCF measurement process is explained more detailed in the forthcoming sections while the formative item selection criteria are explained in section 5.4.3. 
In addition, the absolute deviation scores were averaged for each TCF dimension [e.g. MEAN_TIME $\left.=\left(A B S \_T I M E 1+A B S \_T I M E 2\right) / 2\right]$. Similar computations were performed for each TCF dimension. Next, the mean scores (one for each TCF dimension) were used as formative indicators for the TCF construct in subsequent analyses. It was anticipated that the exogenous path coefficients from the TCF construct would become stronger when using the average scores since all deviation scores were considered in this approach.

While the absolute deviation score analysis appealed due to its simplicity, it was expected that using positive (to represent overfit) and negative deviation scores (to represent underfit) would lead to more meaningful results in the current study. This was due to the design of the scales.

For example, respondent 2 (Table 63) views a financial loan/account inquiry as complicated and Internet banking as not well suited for account inquiries (high/low combination). The results should be clearly interpreted as a misfit indicated by the -4 . The negative outcome was computed by subtracting COMP1 from CCOMP1. On the other hand, respondent 4 (see Table 63) perceived a financial loan/account inquiry as not complicated and believed that Internet banking is well suited for complicated banking transactions. In this case the absolute difference between the responses also produces a 4 .

When inspecting both answers more closely, it makes sense that they should be treated differently. While respondent 2 clearly views a misfit between financial loans/account inquiries and Internet banking, the answers given by respondent four could be interpreted differently. One could argue that if respondents view Internet banking as well suited for complex banking transactions (e.g. financial loans, superannuation product, mortgages etc.), simple banking transactions (account inquiries, account transfers, one-off payments) should also be well supported by Internet banking. Since respondent 4 indicated that the banking transaction is not complicated but complicated transaction would be well suited for Internet banking, the positive deviation score of four could be interpreted as an 'overfit'. This mechanism is explained more detailed below.

\section{Computing negative and positive deviation scores}

The second approach to operationalize deviation scores involves positive and negative matching scores (Chan 1992). The following Figure 37 visualizes this concept. 


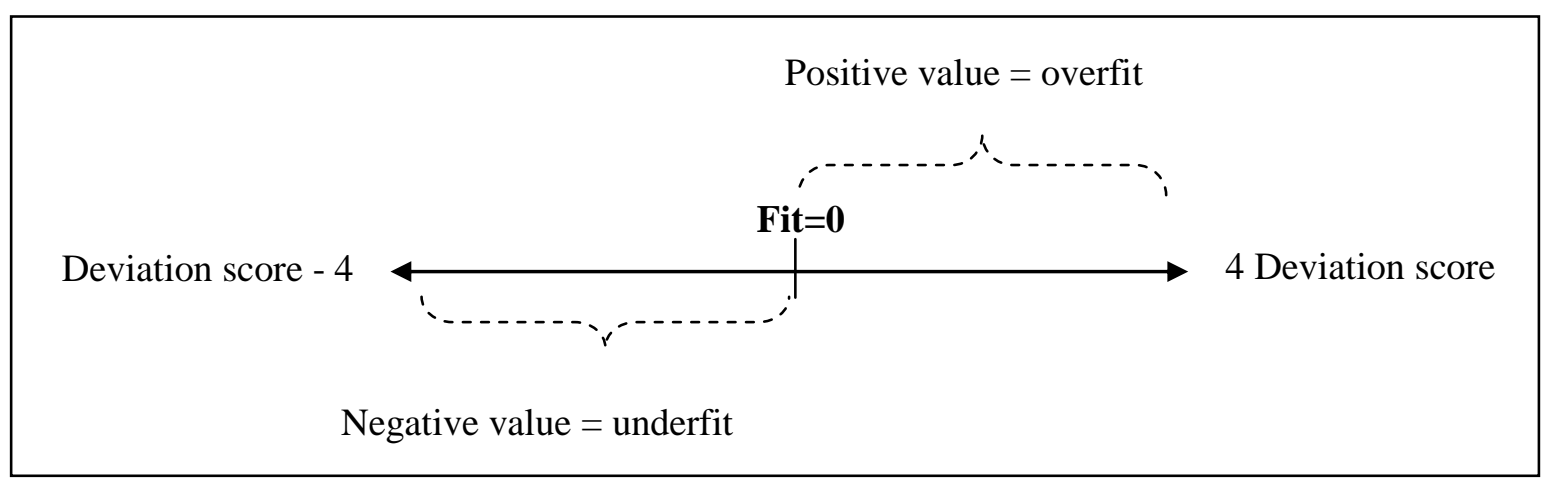

Figure 37: Under and overfit assumption for negative and positive deviation scores

Depending on the anchoring of the scales, the negative or positive deviation score represent either under- or overfit. For this research all positive values are interpreted as overfit indicating that Internet banking provides more than ideal support for a given banking task.

For example, if Internet banking applications support complicated banking transactions, it is reasonable to argue that simple banking transactions are also well supported. The existing literature on electronic banking suggests that financial loans or mortgages are complex banking transactions (Tan and Thompson 2000; Black, Lockett et al. 2002; Van Birgelen, De Jong et al. 2006). When filling out a loan application, consumers are required to read and provide much information to their bank. The banking transactions underlie relatively complicated computations such as repayment rates and loan duration lengths that need to be determined based on financial markets. If a consumer believes that a banking channel supports these complex banking transactions well, it is also reasonable to assume that he/she also views simple banking transactions as well suited for Internet banking. Simple banking transactions do not involve much customer-bank interactions and do not involve complex transaction mechanisms (Tan and Thompson 2000; Black, Lockett et al. 2002; Van Birgelen, De Jong et al. 2006).

Similar over- and underfit assumptions could be made for the remaining TCF dimensions. For example, if Internet banking supports high-effort banking transactions well, it is reasonable to believe that low-effort banking transactions are also well suited for Internet banking. High effort banking transactions (e.g. international transactions) require customers filling out many forms often displayed on multiple pages. In contrast low-effort tasks do not involve much data input and only a few fields need to be filled out by the Internet banking user. If Internet banking is viewed as well suited for high-effort tasks, it seems plausible that respondents also view low-effort tasks as well suited for Internet banking that require only little data input. 
Similarly, if a person believes that Internet banking supports highly time-critical banking transactions well, then he/she should also perceive non-urgent banking transactions as well suited for Internet banking. Likewise, if consumers view banking transactions that they perform infrequently as well suited for Internet banking, then it seems reasonable to assume that they also view banking transactions they frequently perform as well supported by Internet banking. Lastly, if highly important banking transactions (e.g. worth several hundreds of dollars) are seen as well supported by Internet banking, it is reasonable to argue that less important transactions are also well supported by Internet banking.

For this study, all positive and negative deviation scores were computed by subtracting the actual values obtained for the task characteristics items from their parallel channel-suitability item pair (e.g. CCOMP1-COMP1, CCOMP2-COMP2 etc). For each TCF dimension one (positive or negative) deviation score was subsequently used as a formative indicator for the TCF construct.

In addition, the signed deviation scores were averaged for each TCF dimension [e.g. MEAN_TIME=(TCF_TIME1+TCF_TIME2)/2]. Next, the mean scores (one for each TCF dimension) were used as formative indicators for the TCF construct in subsequent data analyses. It was anticipated that the exogenous path coefficients from the TCF construct would become stronger when using the average scores since all deviation scores were considering in this approach (rather than only 5 individual deviation scores as explained above).

As an alternative to absolute or signed deviation scores, it was also tested computing the Euclidean distance between the TCF parallel measures.

\section{Computing Euclidean distance}

To the researcher's best knowledge, so far no rigorous study has used Euclidean distances to match parallel items in order to compute a fit. However, Euclidean distance calculations have been frequently used in strategic alignment studies (Sabberwal and Chan 2001). The Eucledian distance can be computed by taking the square root of the sum of the squares of the differences between the corresponding coordinates of the points.

$$
d(\mathbf{a}, \mathbf{b})=\sqrt{\left(\mathbf{a}_{x}-\mathbf{b}_{x}\right)^{2}+\left(\mathbf{a}_{y}-\mathbf{b}_{y}\right)^{2}}
$$

For this research, two different approaches were tested. First, the above mentioned formula was applied for each TCF dimension. The computations resulted in a single TCF score that 
was computed via the Euclidean distance for each TCF dimension. Next, the Euclidean distances were used as formative indicators as explained in section 5.4.3.

Further, producing a single TCF score for each respondent using the Euclidean distance formula was also tested. Therefore, the TCF deviation scores were squared and subsequently summed. The square root of this value was taken to obtain an overall measure for TCF. This TCF-Euclidean distance was then used as a single reflective measure of TCF and linked to the remaining constructs of the conceptual research model as depicted in Figure 32.

Having discussed the deviation score TCF calculation, the following section discusses the moderation approaches deployed for this study in order to quantify the perceived TCF scores.

\subsubsection{Task-channel fit calculation - Moderation approach}

Fit as moderation has been frequently used by other researchers aiming to compute fit between two variables by capturing interaction effects (Prescott 1986; Goodhue 1995; Chan, Huff et al. 1997; Dishaw and Strong 1999; Parker and Van Witteloostuijn 2010).

Venkatraman (1989) explained such an interaction as moderation:

"According to the moderation perspective, the impact that a predictor variable has on a criterion variable is dependent on the level of a third variable, termed as moderator. The fit between the predictor and the moderator is the primary determinant of the criterion variable".

The underlying argument when determining TCF using a moderation approach is that the varying levels of task characteristics (e.g. level of task complexity, level of task uncertainty etc.) moderate the suitability of a given banking channel for a given banking task.

For instance, some banking transactions are viewed as simple whereas others are perceived as being complicated. It seems reasonable to argue that very simple banking transactions (e.g. account inquiries) are relatively well supported by all electronic banking channels. In contrast, very complex banking transactions appear to be less suited for certain electronic banking channels such as mobile banking.

This indicates that there is an interaction between the complexity level of a given banking task and the degree to which a given banking channel is seen as well suited for a specific task. The more complex a banking task is, the more sophisticated a banking channel needs to be to support that banking tasks. Similar arguments can be made for the remaining task-channel fit dimensions. 
If applying the moderation concept to the current study, the perceived task-channel fit construct (including the TCF-dimensions) should be viewed as the criterion variable. Channel suitability should be understood as the predictor variable whereas task characteristics have a moderating role (see also Figure 33 for further clarification).

In order to compute the TCF using the moderation approach, Venkatraman's formula $\left[x=\left(y^{*} z\right)\right]$ was applied to the data. Venkatraman (1989) recommended using product terms in order to represent fit as moderation. Multiplying the values obtained for the moderator (in context of this study - task characteristics) with the values obtained for the predictor variable (in context of this study - channel suitability) would reflect the joint effect of both 'sides' of the task-channel fit.

A high task-channel fit would be represented by a high product outcome whereas a low product outcome would imply a low task-channel fit. This illustrates why the fit as moderation perspective differentiates from the deviation score analysis which predicts that a low-low response combination (e.g. non-complex tasks are not well suited for IB) would be equivalent to a high-high response combination (e.g. complicated banking tasks are well suited for Internet banking).

For instance, COMP1 asked individuals if they view financial loan applications as complicated. CCOMP1 then inquired if the same respondent would view Internet banking as well suited for complicated banking transactions.

If respondents would rate both items with 5 (strongly agree) then the level of fit would be represented by a value of 25 (multiplying COMP1 and CCOMP1) for this particular dimension of the overall TCF. In contrast, if a respondent would rate COMP1 with 5 (since he/she views a financial loan as complicated) while rating CCOMP1 with 1 (indicating Internet banking is not suited for complicated banking tasks) then a misfit would be represented by a value of 5 (again multiplying COMP1 and CCOMP1). The below mentioned Table 64 illustrates the computation of the product terms.

Table 64: Moderation approach using product terms - TCF calculation based on the pilot test results

\begin{tabular}{|l|c|c|c|c|c|}
\hline & Resp.1 & Resp.2 & Resp.3 & Resp.4 & Resp.5 \\
\hline COMP1 & 5 & 5 & 3 & 4 & 2 \\
\hline CCOMP1 & 5 & 1 & 3 & 4 & 4 \\
\hline TCFCOMP1 & $\mathbf{2 5}$ & $\mathbf{5}$ & $\mathbf{9}$ & $\mathbf{1 6}$ & $\mathbf{8}$ \\
\hline COMP2 & 5 & 4 & 3 & 2 & 2 \\
\hline CCOMP2 & 4 & 3 & 3 & 4 & 4 \\
\hline TCFCOMP2 & $\mathbf{2 0}$ & $\mathbf{1 2}$ & $\mathbf{9}$ & $\mathbf{8}$ & $\mathbf{8}$ \\
\hline TCFCOMP_AVE & $\mathbf{2 2 . 5}$ & $\mathbf{8 . 5}$ & $\mathbf{9}$ & $\mathbf{1 2}$ & $\mathbf{8}$ \\
\hline
\end{tabular}


Inspecting Table 64, it becomes clear that the fit scores imply a fit rating. For example, the values obtained from Resp.1, Resp.3, and Resp.4 were on equal level for task characteristics (COMP1) and channel suitability (CCOMP1) items (Resp.1 - 5/5, Resp.3 - 3/3, and Resp.4 4/4). However, the fit should be interpreted as higher for respondent 1 since the task complexity is high and the channel is well suited for this (leading to a fit score of 25). In contrast, respondent 3 viewed the task as moderately complex. Since less channel support is required to accommodate medium complex banking tasks, the fit score (product term) is also lower (fit score of 9) than for Resp.1.

Following this approach, the task characteristic*channel suitability product scores at the item level were computed. Some of these values were then used as formative indicators as explained in section 5.4.3.

As with the matching approaches, the moderation scores were also averaged for each TCF dimension [e.g. MEAN_TIME=(TCF_TIME1+TCF_TIME2)/2]. Next, the mean scores were used as formative indicators for the TCF construct in subsequent data analyses.

While all the above mentioned TCF computations were conducted and tested, this thesis selected one approach that appeared to be most suitable for the TCF computation. Before discussing the selection criteria, the Table 65 summarizes the key issues of the above discussed fit measurement approaches.

Table 65: Summary of the fit calculation approaches and the underlying theoretical assumptions

\begin{tabular}{|c|c|c|}
\hline Fit approach & Fit score calculation & Theoretical rationale \\
\hline $\begin{array}{l}\text { Fit as } \\
\text { matching - } \\
\text { Absolute } \\
\text { deviation } \\
\text { scores }\end{array}$ & $\begin{array}{l}\text { The absolute distance was calculated } \\
\text { between the scores obtained for the task- } \\
\text { characteristics items and the channel } \\
\text { suitability items [e.g. ABS=(CCOMP1- } \\
\text { COMP1). The absolute deviation scores } \\
\text { were then used for further analysis. }\end{array}$ & $\begin{array}{l}\text { The larger the difference between the two } \\
\text { ratings, the greater the degree of mis-fit. Zero } \\
\text { scores represent a perfect fit whereas four } \\
\text { represent a misfit. Analytical issue: low task- } \\
\text { characteristics/high channel suitability and high } \\
\text { task characteristics/low channel suitability } \\
\text { combination scores are treated similarly. }\end{array}$ \\
\hline $\begin{array}{l}\text { Fit as } \\
\text { matching - } \\
\text { Mean scores } \\
\text { of the ABS } \\
\text { deviation } \\
\text { scores }\end{array}$ & $\begin{array}{l}\text { The absolute deviation scores were } \\
\text { averaged for each TCF dimension (e.g. } \\
\text { mean_ABS_complexity, } \\
\text { mean_ABS_time criticality etc.). The } \\
\text { standardized mean scores were then used } \\
\text { as formative indicators for the TCF } \\
\text { construct. }\end{array}$ & $\begin{array}{l}\text { As above but all absolute deviation scores are } \\
\text { considered within TCF construct rather than a } \\
\text { selective combination. }\end{array}$ \\
\hline $\begin{array}{l}\text { Fit as } \\
\text { matching - } \\
\text { Signed } \\
\text { deviation } \\
\text { scores* }\end{array}$ & $\begin{array}{l}\text { For each parallel item a deviation } \\
\text { score was computed (e.g. CCOMP1- } \\
\text { COMP1). Positive and negative values } \\
\text { were included in further model analyses. }\end{array}$ & $\begin{array}{l}\text { This approach differentiates positive and } \\
\text { negative deviation scores from each other. Positive } \\
\text { scores could be interpreted as 'overfit' (e.g. the } \\
\text { channel provides more support than needed for } \\
\text { given banking transactions). Negative values } \\
\text { represent mis-fit whereas zeros are a perfect }\end{array}$ \\
\hline
\end{tabular}




\begin{tabular}{|c|c|c|}
\hline & & $\begin{array}{l}\text { match. Analytical issue: it was unclear if the } \\
\text { respondents truly agree with the interpretation of } \\
\text { overfit. }\end{array}$ \\
\hline $\begin{array}{l}\text { Fit as } \\
\text { matching - } \\
\text { Mean scores } \\
\text { of the signed } \\
\text { deviation } \\
\text { scores* }\end{array}$ & $\begin{array}{l}\text { The deviation scores were averaged } \\
\text { for each TCF dimension (e.g. } \\
\text { mean_complexity, mean_uncertainty } \\
\text { etc.). The standardized mean scores were } \\
\text { then used as formative indicators for the } \\
\text { TCF construct. }\end{array}$ & $\begin{array}{l}\text { As above but all signed deviation scores are } \\
\text { considered within the TCF construct rather than a } \\
\text { selective combination. }\end{array}$ \\
\hline $\begin{array}{l}\text { Fit as } \\
\text { matching - } \\
\text { Euclidean } \\
\text { distance } \\
\text { (dimension } \\
\text { level)* }\end{array}$ & $\begin{array}{l}\text { A single TCF score was computed via } \\
\text { the Euclidean distance for each TCF } \\
\text { dimension (squared, summed deviation } \\
\text { score } \rightarrow \text { dimension level) }\end{array}$ & $\begin{array}{l}\text { The Euclidean distance is the 'ordinary' } \\
\text { distance between two points. Venkatraman (1989) } \\
\text { suggested computing the Euclidean distance in } \\
\text { combination with profile deviation. It was felt that } \\
\text { the Euclidean distance could advance the } \\
\text { 'standard' matching score. Analytical issue: little } \\
\text { is known how well Euclidean distance works in } \\
\text { combination with parallel instrument and fit } \\
\text { determination. }\end{array}$ \\
\hline $\begin{array}{l}\text { Fit as } \\
\text { matching- } \\
\text { Euclidean } \\
\text { distance (TCF } \\
\text { level)* }\end{array}$ & $\begin{array}{l}\text { A single TCF score was computed via } \\
\text { the Euclidean distance for each } \\
\text { respondent (squared, summed deviation } \\
\text { score } \rightarrow \text { person level) }\end{array}$ & $\begin{array}{l}\text { As above but the Euclidean distance score was } \\
\text { computed as a single indicator of task-channel fit } \\
\text { for each respondent. }\end{array}$ \\
\hline $\begin{array}{l}\text { Fit as } \\
\text { moderation- } \\
\text { Product terms }\end{array}$ & $\begin{array}{l}\text { The moderation scores were } \\
\text { computed by multiplying the task- } \\
\text { characteristic scores with the channel } \\
\text { suitability parallel } \\
\text { (e.g.COMP1*CCOMP1). The values } \\
\text { scores were then used for further analysis. }\end{array}$ & $\begin{array}{l}\text { Instead of the match (or parallelism) between } \\
\text { task-characteristics and channel suitability items } \\
\text { indicate TCF, the theoretical assumption is that } \\
\text { task-characteristics moderate the relationship } \\
\text { between the perceived channel suitability and } \\
\text { theoretically linked constructs and vice versa. } \\
\text { Analytical issue: low task-characteristics/high } \\
\text { channel suitability and high task } \\
\text { characteristics/low channel suitability combination } \\
\text { scores are treated similarly. }\end{array}$ \\
\hline $\begin{array}{l}\text { Fit as } \\
\text { moderation- } \\
\text { Mean scores } \\
\text { of the } \\
\text { computed } \\
\text { product terms }\end{array}$ & $\begin{array}{l}\text { The product scores were averaged for } \\
\text { each TCF dimension (e.g. } \\
\text { mean_complexity, mean_uncertainty } \\
\text { etc.). The standardized mean scores were } \\
\text { then used as formative indicators for the } \\
\text { TCF construct. }\end{array}$ & $\begin{array}{l}\text { As above but all product terms are considered } \\
\text { within the TCF construct rather than a selective } \\
\text { combination. }\end{array}$ \\
\hline
\end{tabular}

*over-and underfit were also considered by setting the low task-characteristics/high channel suitability combination scores (deviation scores and interaction terms) to zero. This resulted in an unacceptable level of multi-collinearity at the TCF dimension level.

The selection of the most appropriate TCF computation for this study was a challenge since the various approaches had different strengths and weaknesses. Venkatraman (1989) stated:

"Is any [fit] perspective better than the others? Although it is tempting to rank the appropriateness of these perspectives for different theoretical questions, this may be a futile exercise because of the intrinsic nature of the links among theory, method, and data. The 
same theoretical question can be used for more than one perspective, which would be useful for cumulative theory building."

Due to this, all above listed approaches were initially considered in an attempt to reach a more complete understanding of the perceived task-channel fit of electronic banking channels. Due to space limitations, it is impossible to examine and discuss all fit computation approaches in depth as part of this thesis. Thus, it was decided to select the most appropriate approach and analyze it in depth. However, the remaining approaches were also tested and the Appendix outlines the key findings when using deviation score analysis to compute the TCF scores (see section 10.5.).

Fit as matching was considered for this thesis using the absolute values obtained for the parallel items. While this approach appealed due to its simplicity, it was felt that the absolute difference scores were inappropriate for the scales used in this research since it treated lowhigh (e.g. if a respondent believed that a financial loan is not complex but complex banking transactions are well suited for Internet banking) and high-low (e.g. if a respondent believed that a financial loan is complex but complex banking transactions are not well suited for Internet banking) response combinations equally, which was judged inappropriate.

Using the signed deviation scores obtained for the parallel items was also considered for this research. The main advantage of this approach was that differentiated low-high and highlow response combinations. However, the disadvantages of this approach were twofold. First, over- and underfit assumptions needed to be made for interpreting the results. While very likely, it was not theoretically or empirically justified that consumers who believe that complex banking transactions are well suited for Internet banking would also view simple banking transactions as equally well suited for Internet banking.

The second issue with this approach was that over-and underfit assumptions were inappropriate for some of the parallel items. For instance, under-and overfit assumptions for COMP1 from CCOMP1 appeared to be reasonable since consumers who view complicated banking tasks might also view simple banking tasks as well suited for Internet banking. On the other hand, FREQU1 and CFREQU1 could lead to meaningless overfit assumptions if consumers state that they would not frequently perform loans/account inquiries but view those transactions they frequently perform as well suited for Internet banking. A more detailed discussion on this is provided in Appendix. 
The Euclidean distance has been often used in combination with fit as profile deviation and appeals to researchers because fit can be represented in a single score (Venkatraman 1989). Thus, the Euclidean distance was also considered for this research. However, one goal of this research was to inform practitioners which of the TCF dimensions were most important for the TCF construct. Using the Euclidean distance would not achieve this goal. Thus, the Euclidean distance was viewed as unsuited for computing the TCF scores.

The fit as moderation approach overcame most of the above mentioned issues and was therefore viewed as the most superior technique for assessing the perceived TCF in this dissertation as it allowed capturing the interaction effects (or synergy) of both fit components. This conclusion was in alignment with other studies that considered fit as moderation as most appropriate for determining fit (Prescott 1986; Goodhue 1995; Chan, Huff et al. 1997; Dishaw and Strong 1999; Parker and Van Witteloostuijn 2010).

On the basis of the discussion above, the fit as moderation scores and averaged moderation scores were judged to be best supported by the survey data gathered. These TCF scores were selected for PLS analyses which will now be described.

\subsubsection{Structural Equation Modeling - PLS}

Structural Equation Modeling (SEM) techniques such as covariance-based LISREL and component-based Partial Least Squares (PLS) are second generation data analysis techniques that can be used to test measurement models as well as specified relationships among multiple independent and dependent constructs simultaneously (Chin 1998; Gefen, Straub et al. 2000).

Due to the advantages SEM provides over $1^{\text {st }}$ generation methods such as linear regression, SEM has become widely accepted in behavioral science research for the causal modeling of multivariate data sets in which the researcher gathers multiple measures of proposed constructs (Gefen, Straub et al. 2000; Straub, Boudreau et al. 2004). The initial step when applying SEM is to choose the best suited technique to analyze the data.

The first choice that has to be made is whether using component-based or co-variance based SEM techniques. Due to the advantages and disadvantages of each approach, the decision whether to use component-based (e.g. PLS Graph, SmartPLS) or co-variance-based (e.g. Lisrel, Amos, M-plus) is often difficult to make. Despite increased interest and the growing literature of SEM models, "there is no comprehensive guide for researchers on when a specific form of SEM should be employed" (Straub, Boudreau et al. 2004). Each SEM technique has distinct capabilities making each more or less appropriate for certain types of 
analysis. Gefen et al. (2000) summarized some of the most important aspects to be considered when choosing a SEM technique. They recommended:

- Firstly, one should thoroughly consider the data to be analyzed for the research. For instance, it is often argued that PLS supports smaller sample sizes (at least 10 times the number of items in the most complex construct) (Gefen, Straub et al. 2000; Qureshi and Compeau 2009). On the other hand, covariance based research usually requires more cases for the data analysis.

- Secondly, many authors have argued that PLS is particularly suited for "predictive applications and theory building" (Gefen, Straub et al. 2000; Straub, Boudreau et al. 2004). On the other hand, covariance-based SEM techniques would be best suited for research models with a strong theoretical base.

- Third, PLS can handle formative indicators which were required for the focal construct (TCF construct) of this study. For covariance-based structural modeling technique the inclusion of formative measures is often seen as problematic and has been shown to lead to identification problems (MacCallum and Browne 1993; Petter, Straub et al. 2007; Qureshi and Compeau 2009).

Given this, component-based SEM appeared to be better suited for this research than covariance-based. The measurement model of this study consists of reflective (e.g. perceived usefulness) and formative elements (task-channel fit construct).

Second, while some parts of the model (including the precursors of utilization and intention to use construct) are well established in theory, the task-channel fit construct is newly created by this research. Hence, it seemed reasonable to argue that this part of the theory is still 'under construction'.

When using PLS, data analysis is usually undertaken in two steps (Hair, Anderson et al. 1998): an assessment of the measurement model, followed by an assessment of the structural model. The evaluation of the measurement model normally involves determining the construct validity and reliability of the scales. The assessment of the structural model includes the examination of strength and significance of the path coefficients between the constructs of the research model. 


\subsubsection{Factor analysis - confirmatory factor analysis (CFA)}

Factor analysis is a general name denoting a class of procedures primarily used for data reduction and testing the construct validity of the measures (Malhotra 2004). This statistical approach can be used to analyze interrelationships among a large number of variables. This technique is also often used to examine the 'correctness' of the measurement model (Straub, Boudreau et al. 2004).

There are two basic types of factor analysis: exploratory and confirmatory. Exploratory factor analysis (EFA) is used when researchers do not know how many factors are necessary to explain the interrelationships among a set of items (Gefen and Straub 2005). Therefore, researchers use this technique to explore the underlying dimensions of the construct of interest.

In contrast, confirmatory factor analysis (CFA) is used to assess the extent to which a set of identified factors fits the data. This type of factor analysis is used by researchers to assess the pattern of loadings of the measurement items specified explicitly in the research model. CFA is recommended when researchers use previously developed instruments (Conway and Huffcutt 2003).

Researchers should be aware of the fact that sometimes EFA leads to misleading results if used inappropriately since: "organizational research can produce too many factors (or too few) or assign some variables to the wrong factors" (Conway and Huffcutt 2003). When using extant scales and the researcher has a clear assumption of factors underlying the data, CFA is more suited for data analysis since it is "less likely to produce the wrong number of factors or to assign variables to the wrong factors" (Conway and Huffcutt 2003).

As explained above, the items to measure the precursors of channel utilization (perceived usefulness, ease of use, attitude, subjective norms, costs associate with channel use, security and intentions to use) were all derived from existing scales that have been previously validated by other researchers. For instance, the use of perceived usefulness, ease of use and attitude towards channel use constructs was influenced by the extant literature around the technology acceptance model. This model is one of the most cited and most established research models within the information systems research discipline. Hence, an exploratory factor analysis seemed inappropriate since EFA could produce misleading results.

Further, formative measures do not require exploratory factor analysis since the measures should not covary (explained in more detail in section 5.4.2.3.). Researchers use the indicator 
weights to assess the structure of formative constructs. Since confirmatory factor analysis (using PLS) produces weights for formative indicators, this technique seemed also well suited to assessing the measures for the newly developed TCF construct.

Given this, confirmatory factor analysis was used to assess the measurement model. The software package SmartPLS (SmartPLS 2010) was selected to evaluate the data collected for the pilot study.

The following section initially discusses the construct validity assessment for the variables measured via reflective items. Subsequently, the formative measures are discussed.

\subsubsection{Construct validity assessment - reflective constructs}

One important aspect to consider when developing a survey instrument is the construct validity of the various scales (Grover 2000). This is an operational issue and "asks whether the measures chosen are true constructs describing the event or merely artifacts of the methodology itself' (Straub 1989). Construct validity concerns whether the instrumentation truly captures the phenomenon of interest and how well the ideas/concepts are translated into the actual measures (Straub 1989; Straub, Boudreau et al. 2004).

To determine construct validity for reflective measures, convergent and discriminant validity should be assessed. Both can be considered as a subcategory of construct validity and identify inter-correlations among the items (Grover 2000).

\section{Convergent validity for reflective indicators}

Convergent validity can be regarded as the extent to which multiple measures of a construct are in agreement. It is established when the scores obtained from two different items measuring the same concept are highly correlated. In other words, convergent validity shows that the assessment is related to what it should theoretically be related to (Straub, Boudreau et al. 2004). For instance, indicators measuring the perceived usefulness construct should be highly correlated with each other (and less strongly correlated with the items measuring the ease of use construct).

Convergent validity is shown when each of the measurement items loads with a significant t-value on its latent construct. As a rule of thumb, these t-values should be significant at least at the 0.05 level (Gefen and Straub 2005). To assess the convergent validity for all reflective indicators, their loadings onto their respective constructs were determined and subsequently analyzed. 


\section{Discriminant validity for reflective indicators}

If items aiming to measure different constructs do not differ from each other as they should, then it is called a discriminate validity problem (Boudreau, Gefen et al. 2001; Cavana, Delahaye et al. 2001; Straub, Gefen et al. 2004; Straub, Boudreau et al. 2004). For example, items PU1-PU3 should be associated with the perceived usefulness construct. If items PU1 and PU2 load higher onto the ease of use construct (rather than on perceived usefulness) then the measure would face a discriminant validity problem. Such an outcome would raise the question about whether respondents really differentiate between the two concepts.

To assess discriminant validity of the measurement model in PLS, an average variance extracted (AVE) analysis should be conducted (Gefen and Straub 2005). AVEs can be calculated using the bootstrap technique offered in SmartPLS. In an AVE analysis, the square root of every AVE is supposed to be larger than the correlation of the specific construct with any of the other constructs in the model (Gefen and Straub 2005).

\subsubsection{Construct validity assessment - formative constructs}

Cenfetelli and Bassellier (2009) suggested guidelines for assessing formative measures in IS research. The authors argued that the primary statistic for assessing a formative indicator is its weight. The combined item weights 'form' the latent variable. Formative measures should not have strong correlations with one another because this suggests multicollinearity (Gefen and Straub 2005; Petter, Straub et al. 2007; Diamantopoulos, Riefler et al. 2008). Multicollinearity in formatively measured variables leads to instability in the construct (Petter, Straub et al. 2007).

When inspecting formative measures, researchers should evaluate formative measures by examining:

1. Multicollinearity

2. The number of indicators and non-significant weights

3. The possible co-occurrence of negative and positive indicator weights

4. The absolute versus relative contributions made by a formative indicator

5. The nomological network effects (Cenfetelli and Bassellier 2009)

\section{Multicollinearity of formative indicators}

High correlations among indicators are not desired as they can destabilize the construct (Petter, Straub et al. 2007). To ensure that multicollinearity is not present, the variance inflation factor (VIF) statistic can be used to determine if formative measures are too highly 
correlated (Petter, Straub et al. 2007; Cenfetelli and Bassellier 2009). If the VIF statistic for a formative measure is greater than 3.3 (Petter, Straub et al. 2007), researchers should check if there is an overlap among the chosen indicators. In case there is an overlap, researchers should consider removing items. The removal of items should be treated carefully as it could alter the meaning of the construct (Petter, Straub et al. 2007).

\section{Number of indicators and non-significant weights}

If formative constructs are measured through a relatively large number of items, it is likely that some indicators have low or even insignificant weights. The number of indicators has implications for the significance and the magnitude of the weights for the indicators (Cenfetelli and Bassellier 2009).

Researchers have three options when formative indicators are non-significant or have very low weights. First, some of the indicators can be grouped together into two or more distinct constructs. Having a smaller set of items for each construct increases the likelihood that indicators become significant (Cenfetelli and Bassellier 2009). Second, the researcher can create a smaller set of items but also include a second-order aggregate construct. This construct can mediate the effects of the separate first order constructs. Third, the researcher can keep all indicators (independent of their weights) and include a discussion about the absolute contribution of each indicator to the construct. If indicators remain insignificant across several studies, researchers should question the inclusion of these measures in further studies (Cenfetelli and Bassellier 2009).

\section{Co-occurrence of negative and positive indicator weights}

When interpreting formative measures, it is possible that positive and negative weights occur. This can be counterintuitive since negative weights would not increase the factor but instead diminish it.

Suppressor effects can potentially cause such negative signs. These effects can occur "when one of the predictor variables explain significant variance in other predictor variables not otherwise associated with the criterion" (Cenfetelli and Bassellier 2009). If such effects exist, Cenfetelli and Bassellier (2009) recommend considering if the suppressor is collinear with other indicators. If so, then they should be grouped together or removed as explained above. If the negative weights are not suppressors and they are not collinear with other items, then they should be kept and potentially culled over time when they repeatedly behave differently than other indicators (Cenfetelli and Bassellier 2009). 


\section{Absolute versus relative indicator contributions}

Measures that have relatively small contribution to the formative constructs may still have an important absolute contribution if that indicator is independently assessed from other indicators (Cenfetelli and Bassellier 2009). Therefore, researchers should report the loadings between the indicators and the formative construct as well.

If the weights are significant, then there is empirical support to keep the items. If the indicator weight is low but the loadings high, then the item should be interpreted as absolutely important. Thus, the theoretical relevance should be questioned and potential overlaps with other items should be investigated. If there is no theoretical overlap, the items should be kept in the remaining analyses. If there is theoretical overlap, the items should be removed or combined with the overlapping items. If item weight and loading are non-significant, researchers should evaluate the theoretical relevance of the measure.

\section{Nomological network effects and construct portability}

An important issue for formatively developed measures is its portability or "its relative invariance of a construct's indicator weights as the construct is used in different nomological networks" (Cenfetelli and Bassellier 2009). While some degree of change in indicator weights should always be expected in the estimation of the formatively measured construct, too much variations implies a lack of portability. This could threaten the generalizability of the results. To test for this, Mathieson et al. (2001) recommend linking a formative construct to another variable measuring a conceptual equivalent concept using reflective measures. Inspecting the structural path between both constructs should indicate whether the formative and reflective measures are tapping into the same context. The magnitude of the structural paths should be ideally 0.80 or more (Mathieson, Peacock et al. 2001; Cenfetelli and Bassellier 2009).

As outlined previously, this thesis investigated the moderation approach for computing the TCF construct in depth. Two different measurement options for assessing the formative TCF construct were used: individual moderation scores, and average moderation scores. To identify the most appropriate individual moderation scores, this research employed a reversed redundancy analysis which is explained in section 5.4.3.2. The following section reports the results of the pilot study.

\subsubsection{Results of the pilot-study}

For the pilot study, the financial loan $(n=140)$ and account inquiries $(n=140)$ dataset were analyzed separately. 


\subsubsection{Construct validity assessment - reflective constructs}

\section{Financial loan dataset $(n=140)$}

To evaluate the construct validity of the pilot test results, the pre-assessed dataset for financial loans was uploaded to SmartPLS. Next, the research model was setup as displayed in Figure 38.

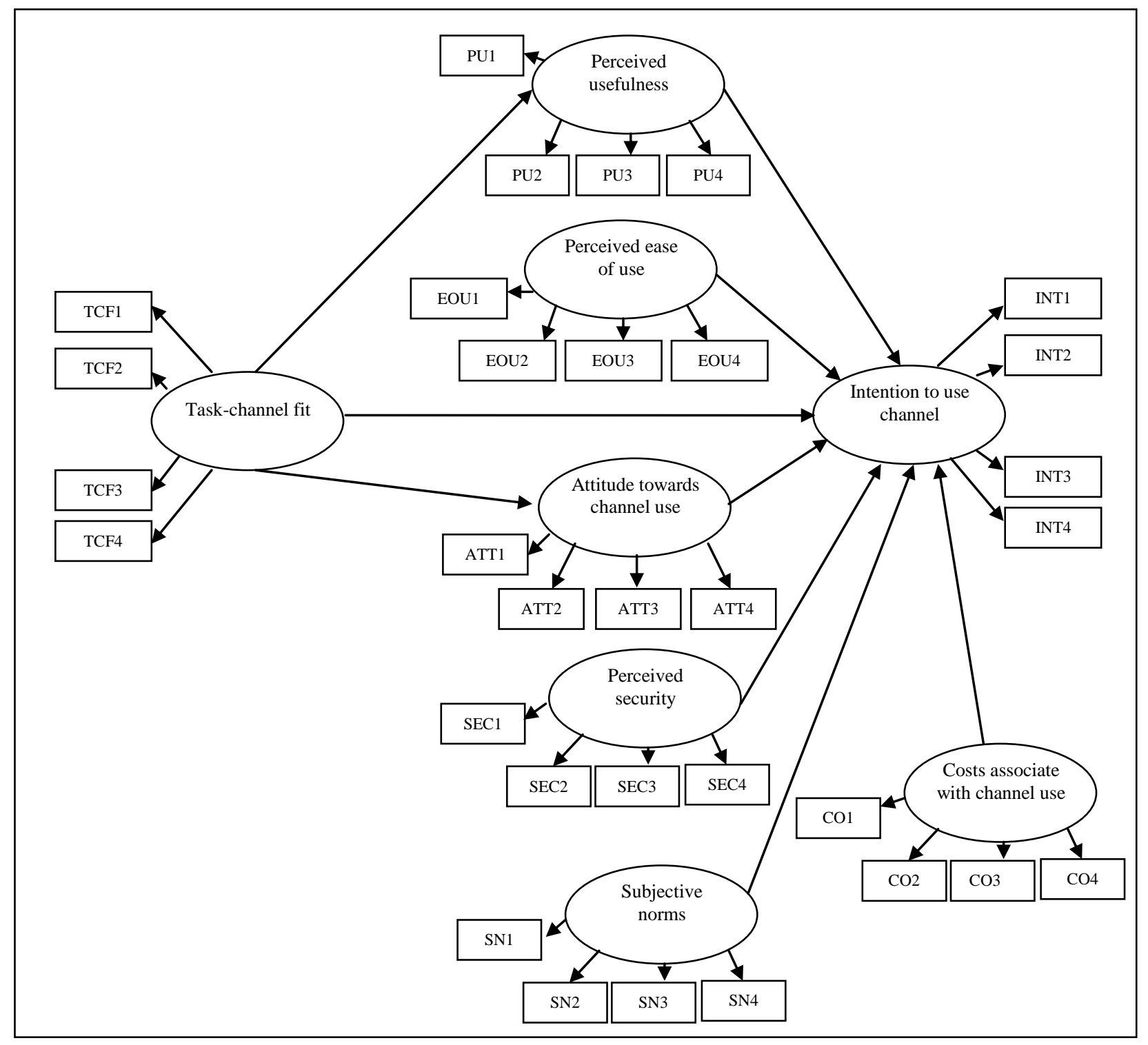

Figure 38: Measurement model

This was followed by using a bootstrapping procedure to obtain the t-values for the items. T-values show the significance levels for each item (Gefen and Straub 2005). It is important to note that only the reflective TCF items were included in this analysis since the formatively measures were assessed differently (see section 5.4.3.3.). Table 66 lists the t-statistics results for the financial loan dataset: 
Table 66: T-values for the reflective measures - Financial loan dataset/Pilot test

\begin{tabular}{|c|c|c|c|}
\hline Item to construct & T Statistics & Item to construct & T Statistics \\
\hline ATT1 <- Attitude & $19.53 * * *$ & PU1 <- Perceived Usefulness & $38.74 * * *$ \\
\hline ATT2 <- Attitude & $131.76 * * *$ & PU2 <- Perceived Usefulness & $42.27 * * *$ \\
\hline ATT3 <- Attitude & $31.49 * * *$ & PU3 <- Perceived Usefulness & $29.70 * * *$ \\
\hline ATT4 <- Attitude & $103.01 * * *$ & PU4 <- Perceived Usefulness & $41.35 * * *$ \\
\hline COST1 <- Costs & $2.50^{*}$ & SEC1 <- Security & $29.21^{* * *}$ \\
\hline COST $2<-$ Costs & $2.15^{*}$ & SEC2 <- Security & $130.57^{* * *}$ \\
\hline COST3 <- Costs & $2.12^{*}$ & SEC3 <- Security & $15.30 * * *$ \\
\hline COST4 <- Costs & $2.04 *$ & SEC4 <- Security & $109.29 * * *$ \\
\hline EOU1 <- Ease of Use & $25.18 * * *$ & SN1 <- Subjective Norms & $6.88 * * *$ \\
\hline EOU2 <- Ease of Use & $33.82 * * *$ & SN2 <- Subjective Norms & $3.74 * * *$ \\
\hline EOU3 <- Ease of Use & $4.39 * * *$ & SN3 <- Subjective Norms & $6.32 * * *$ \\
\hline EOU4 <- Ease of Use & $49.77 * * *$ & SN4 <- Subjective Norms & $3.13 * *$ \\
\hline NINT1 <- Intent & $71.22 * * *$ & TCF1 <- Task-Channel Fit & $124.56 * * *$ \\
\hline NINT2 <- Intent & $107.76 * * *$ & TCF2 <- Task-Channel Fit & $77.32 * * *$ \\
\hline NINT3 <- Intent & $109.15^{* * *}$ & TCF3 <- Task-Channel Fit & $57.03 * * *$ \\
\hline NINT4 <- Intent & $63.87^{* * *}$ & TCF4 <- Task-Channel Fit & $83.93 * * *$ \\
\hline
\end{tabular}

As shown above, the $\mathrm{t}$-values of all items confirmed significance levels at least at the 0.05 level indicating convergent validity among the scales. The next step for the construct validity assessment was the evaluation of the cross-loadings. These values are normally used to assess the discriminant validity of measures and can be determined when applying the PLS algorithm to the data (Gefen and Straub 2005).

The cross loadings for all items were initially obtained for the financial loan dataset. Some of the items loaded high onto other constructs. For instance, the attitude 1 item loaded highly onto the perceived usefulness construct (0.82). Thus, this item was dropped from further analysis. Likewise, perceived usefulness 2 loaded highly onto the attitude construct (0.78). In consequence, this item was also excluded from further data analysis.

Further, ease of use 3 showed a low loading onto the ease of use construct $(0.56)$. Therefore, this item was also dropped from the data analysis since loadings should be higher than 0.60 in CFAs in order to demonstrate convergent validity (Straub 1989).

The PLS algorithm was re-applied to the financial loan dataset without attitude 1, ease of use 3, and perceived usefulness 2 . The results of the cross-loadings are shown in Table 67. 
Table 67: Cross loadings - financial loans dataset/Pilot test

\begin{tabular}{|c|c|c|c|c|c|c|c|c|}
\hline & Attitude & Costs & $\begin{array}{l}\text { Ease of } \\
\text { Use }\end{array}$ & $\begin{array}{l}\text { Intentions } \\
\text { to use }\end{array}$ & $\begin{array}{l}\text { Perceived } \\
\text { Usefulness }\end{array}$ & Security & $\begin{array}{l}\text { Subjective } \\
\text { Norms }\end{array}$ & TCF \\
\hline ATT2 & 0.97 & -0.12 & 0.64 & 0.78 & 0.78 & 0.56 & 0.08 & 0.79 \\
\hline ATT3 & 0.95 & -0.13 & 0.58 & 0.73 & 0.75 & 0.48 & 0.06 & 0.76 \\
\hline ATT4 & 0.96 & -0.14 & 0.61 & 0.76 & 0.78 & 0.54 & 0.00 & 0.80 \\
\hline COST1 & -0.16 & 0.92 & -0.26 & -0.19 & -0.11 & -0.22 & 0.21 & -0.22 \\
\hline COST2 & 0.09 & 0.67 & 0.04 & 0.02 & 0.11 & -0.18 & 0.12 & 0.00 \\
\hline COST3 & -0.01 & 0.61 & -0.04 & -0.08 & 0.00 & -0.14 & -0.01 & -0.06 \\
\hline COST4 & 0.00 & 0.62 & -0.01 & -0.04 & 0.06 & -0.27 & 0.16 & -0.03 \\
\hline EOU1 & 0.52 & -0.16 & 0.88 & 0.59 & 0.54 & 0.20 & 0.06 & 0.56 \\
\hline EOU2 & 0.61 & -0.20 & 0.89 & 0.65 & 0.58 & 0.38 & 0.04 & 0.70 \\
\hline EOU4 & 0.57 & -0.23 & 0.90 & 0.57 & 0.57 & 0.32 & 0.04 & 0.62 \\
\hline NINT1 & 0.75 & -0.17 & 0.66 & 0.95 & 0.62 & 0.58 & 0.13 & 0.73 \\
\hline NINT2 & 0.76 & -0.18 & 0.66 & 0.97 & 0.64 & 0.57 & 0.14 & 0.73 \\
\hline NINT3 & 0.77 & -0.20 & 0.66 & 0.97 & 0.67 & 0.54 & 0.13 & 0.72 \\
\hline NINT4 & 0.72 & -0.16 & 0.63 & 0.94 & 0.65 & 0.51 & 0.15 & 0.66 \\
\hline PU1 & 0.67 & -0.07 & 0.51 & 0.57 & 0.88 & 0.43 & -0.01 & 0.58 \\
\hline PU3 & 0.70 & -0.12 & 0.61 & 0.59 & 0.87 & 0.38 & 0.10 & 0.64 \\
\hline PU4 & 0.74 & -0.04 & 0.55 & 0.62 & 0.89 & 0.38 & 0.08 & 0.61 \\
\hline SEC1 & 0.51 & -0.22 & 0.34 & 0.48 & 0.46 & 0.90 & -0.06 & 0.48 \\
\hline SEC2 & 0.58 & -0.19 & 0.35 & 0.59 & 0.48 & 0.96 & 0.04 & 0.55 \\
\hline SEC3 & 0.30 & -0.29 & 0.19 & 0.42 & 0.18 & 0.81 & -0.13 & 0.33 \\
\hline SEC4 & 0.56 & -0.25 & 0.33 & 0.57 & 0.46 & 0.96 & 0.01 & 0.53 \\
\hline SN1 & 0.05 & 0.18 & 0.08 & 0.14 & 0.09 & -0.05 & 0.94 & 0.11 \\
\hline SN2 & -0.02 & 0.15 & 0.00 & 0.04 & 0.03 & -0.09 & 0.80 & 0.08 \\
\hline SN3 & 0.08 & 0.14 & 0.05 & 0.17 & 0.06 & 0.02 & 0.95 & 0.14 \\
\hline SN4 & -0.06 & 0.19 & -0.05 & 0.04 & -0.03 & -0.11 & 0.74 & -0.03 \\
\hline TCF1 & 0.81 & -0.22 & 0.70 & 0.73 & 0.69 & 0.52 & 0.12 & 0.98 \\
\hline TCF2 & 0.77 & -0.21 & 0.69 & 0.68 & 0.64 & 0.53 & 0.09 & 0.96 \\
\hline TCF3 & 0.75 & -0.17 & 0.67 & 0.70 & 0.67 & 0.49 & 0.11 & 0.95 \\
\hline TCF4 & 0.80 & -0.17 & 0.66 & 0.75 & 0.67 & 0.49 & 0.11 & 0.96 \\
\hline
\end{tabular}

Table 67 shows that all items were more strongly correlated with their intended construct than with any other variable. What is more, the item loadings were very high averaging above 0.85 for all constructs apart from the costs associated with channel use construct.

On the first glance, Table 67 also shows relatively high cross loadings for the attitude and the perceived usefulness constructs. For example, when inspecting the distances between the loading ATT2-PU (0.97-0.78=0.19), ATT3-PU (0.95-0.75=0.20), ATT4-PU (0.96-0.78=0.18) it appears that these constructs do not differ as much as they are supposed to. This indicates a potential discriminant validity issue in the underlying the data.

However, in situations where cross loadings seem to be close in magnitude to the item loading, Chin (2010) suggests considering the square of the loadings and cross loadings. Chin (2010) argued: "While a standardized loading 0.8 compared to a cross loading of 0.7 may raise concerns among naïve researchers pointing out that there is a 0.1 difference, providing squared results gives a more intuitive interpretation since it represents the percentage overlap between an item and any construct." 
For instance, the item relationship ATT4-Attitude has a shared variance of 0.92 percent $\left(0.96^{*} 0.96\right)$ while that shared with perceived usefulness is $0.61\left(0.78^{*} 0.78\right)$. Since the goal is to have a strong nomological network where constructs at the structural level are closely related to each other, this difference seemed to be reasonable (Chin 2010).

In addition, discriminant validity was further assessed with the squared root of the average variance extracted for each construct. In an AVE analysis, the square root of every AVE should be considerably larger than the correlation of the specific construct with any of the other constructs in the model (Gefen, Straub et al. 2000; Gefen and Straub 2005).

The AVE for perceived usefulness appeared to be relatively close to the computed squared AVE values for the attitude and perceived usefulness constructs, raising the question of whether discriminant validity might be compromised in this instance. However, Gefen, Boudreau and Straub (2000) reported equivalently high values in their guidelines for structural equation modeling and regression analysis (Gefen, Straub et al. 2000). Therefore it was concluded that discriminant validity is satisfactory in this instance.

As shown in Table 68, each construct shares greater variance with its own block of measures than with any other construct in the model. Further, all AVEs were consistent with Fornell and Larcker's guidelines exceeding the 0.50 threshold value (Fornell and Larcker 1981). Costs associated with channel use only bypassed this threshold marginally.

Table 68: Correlations of the latent variables and reliability measures for the financial loan dataset

\begin{tabular}{|l|c|c|c|c|c|c|c|c|c|c|c|}
\hline & AVE & CR & $\begin{array}{c}\text { Cron. } \\
\boldsymbol{\alpha}\end{array}$ & Att & Costs & EOU & INT & PU & $\begin{array}{c}\text { Secu } \\
\text { rity }\end{array}$ & SN & TCF \\
\hline Attitude & 0.92 & 0.97 & 0.96 & $\mathbf{0 . 9 6}$ & & & & & & & \\
\hline Costs & 0.51 & 0.80 & 0.82 & -0.13 & $\mathbf{0 . 7 1}$ & & & & & & \\
\hline Ease of use & 0.79 & 0.92 & 0.87 & 0.64 & -0.22 & $\mathbf{0 . 8 9}$ & & & & & \\
\hline Intentions & 0.92 & 0.98 & 0.97 & 0.79 & -0.19 & 0.68 & $\mathbf{0 . 9 6}$ & & & & \\
\hline P. usefulness & 0.78 & 0.91 & 0.86 & 0.80 & -0.09 & 0.63 & 0.68 & $\mathbf{0 . 8 8}$ & & & \\
\hline Security & 0.83 & 0.95 & 0.93 & 0.55 & -0.26 & 0.34 & 0.58 & 0.45 & $\mathbf{0 . 9 1}$ & & \\
\hline Subj. norms & 0.74 & 0.92 & 0.90 & 0.05 & 0.18 & 0.05 & 0.15 & 0.06 & -0.03 & $\mathbf{0 . 8 6}$ & \\
\hline TCF & 0.92 & 0.98 & 0.97 & 0.82 & -0.20 & 0.71 & 0.74 & 0.69 & 0.53 & 0.11 & $\mathbf{0 . 9 6}$ \\
\hline
\end{tabular}

Table 68 also shows that all measures were robust in terms of their internal consistency reliability as indexed by the composite reliability (CR). The composite reliabilities of the reflective measures ranged from 0.80 to 0.98 exceeding the recommended threshold value of 0.70 (Nunnally 1978) for all constructs in the research model. Likewise, all Cronbach Alpha values are above 0.80 , again confirming the reliability of the scales. 


\section{Account inquiries dataset $(n=140)$}

As described in the previous section, the t-values of each item were initially calculated to examine the construct validity for the account inquiry dataset. Therefore, the account inquiries dataset was imported into SmartPLS. Next, the model was set up within the SmartPLS software package as outlined in Figure 38.

This was followed by a bootstrapping procedure performed in SmartPLS. Table 69 lists the results.

Table 69: T-values for the reflective measures - account inquiries dataset/Pilot test

\begin{tabular}{|c|c|c|c|}
\hline Item to construct & T Statistics & Item to construct & T Statistics \\
\hline ATT1 <- Attitude & $8.65 * * *$ & PU1 <- Perceived usefulness & $11.57 * * *$ \\
\hline ATT2 <- Attitude & $54.32 * * *$ & PU2 <- Perceived usefulness & $31.35 * * *$ \\
\hline ATT3 <- Attitude & $9.62 * * *$ & PU3 <- Perceived usefulness & $61.95 * * *$ \\
\hline ATT4 <- Attitude & $28.21 * * *$ & PU4 <- Perceived usefulness & $72.57 * * *$ \\
\hline COST1 <- Costs & $26.69 * * *$ & SEC1 <- Security & $28.29 * * *$ \\
\hline COST2 <- Costs & $7.90 * * *$ & SEC2 <- Security & $49.82 * * *$ \\
\hline COST3 <- Costs & 0.87 & SEC3 <- Security & $3.24 * *$ \\
\hline COST4 <- Costs & $8.78 * * *$ & SEC4 <- Security & $28.21 * * *$ \\
\hline EOU1<- Ease of use & $29.50 * * *$ & SN1 <- Subjective norms & 1.34 \\
\hline EOU2 <- Ease of use & $29.04 * * *$ & SN2 <- Subjective norms & $3.15 * *$ \\
\hline EOU3 <- Ease of use & $7.03 * * *$ & SN3 <- Subjective norms & $2.01 *$ \\
\hline EOU4 <- Ease of use & $30.97 * * *$ & SN4 <- Subjective norms & $3.97 * * *$ \\
\hline INT1 <- Intentions & $61.48 * * *$ & TCF1 <- Task Channel Fit & $113.84 * * *$ \\
\hline INT2 <- Intentions & $66.62 * * *$ & TCF2 <- Task Channel Fit & $102.34 * * *$ \\
\hline INT3 <- Intentions & $13.15 * * *$ & TCF3 <- Task Channel Fit & $13.48 * * *$ \\
\hline INT4 <- Intentions & $67.52 * * *$ & TCF4 <- Task Channel Fit & $74.65 * * *$ \\
\hline
\end{tabular}

As shown above, most t-values of the items confirmed significance levels at least at the 0.05 level. Only the COST3 and SN1 items did not load significantly onto their intended construct. Both items were dropped from further analysis.

The initial inspection of all item-to-construct loadings (apart from COST3 and SN1) showed that SEC3 loaded weakly on the security construct (0.58). Thus, this item was removed from further analysis.

In addition, some of the items had relatively high cross-loadings on other constructs. For instance, ATT4 loaded highly onto the perceived usefulness construct (0.78). This item was also dropped from further analysis. Likewise, PU4 loaded highly onto the attitude construct (0.81) and was therefore also excluded from further data analysis. The remaining item-toconstruct loadings evidenced adequate levels and the cross-loadings suggested sufficient construct validity. 
Table 70 shows the cross-loadings computed for the remaining items of the account inquiry dataset.

Table 70: Cross loadings - account inquiries dataset/Pilot test

\begin{tabular}{|c|c|c|c|c|c|c|c|c|}
\hline & Attitude & Costs & $\begin{array}{l}\text { Ease of } \\
\text { use }\end{array}$ & Intentions & $\begin{array}{l}\text { Perceived } \\
\text { usefulness }\end{array}$ & Security & $\begin{array}{l}\text { Subjective } \\
\text { norms }\end{array}$ & TCF \\
\hline ATT1 & $\mathbf{0 . 7 0}$ & -0.44 & 0.42 & 0.51 & 0.53 & 0.40 & 0.00 & 0.44 \\
\hline ATT2 & $\mathbf{0 . 9 2}$ & -0.31 & 0.60 & 0.72 & 0.75 & 0.47 & 0.07 & 0.66 \\
\hline ATT3 & $\mathbf{0 . 8 6}$ & -0.25 & 0.58 & 0.67 & 0.58 & 0.35 & 0.09 & 0.67 \\
\hline COST1 & -0.42 & $\mathbf{0 . 9 0}$ & -0.39 & -0.44 & -0.40 & -0.36 & 0.05 & -0.47 \\
\hline COST2 & -0.24 & $\mathbf{0 . 8 2}$ & -0.33 & -0.24 & -0.23 & -0.14 & 0.06 & -0.28 \\
\hline COST4 & -0.27 & $\mathbf{0 . 8 1}$ & -0.40 & -0.27 & -0.20 & -0.15 & 0.12 & -0.30 \\
\hline EOU1 & 0.67 & -0.40 & $\mathbf{0 . 8 9}$ & 0.70 & 0.67 & 0.29 & 0.09 & 0.65 \\
\hline EOU2 & 0.50 & -0.34 & $\mathbf{0 . 8 8}$ & 0.51 & 0.52 & 0.27 & 0.03 & 0.55 \\
\hline EOU3 & 0.37 & -0.39 & $\mathbf{0 . 6 7}$ & 0.37 & 0.34 & 0.15 & -0.22 & 0.34 \\
\hline EOU4 & 0.59 & -0.39 & $\mathbf{0 . 9 0}$ & 0.58 & 0.53 & 0.33 & 0.03 & 0.56 \\
\hline INT1 & 0.76 & -0.33 & 0.63 & $\mathbf{0 . 9 6}$ & 0.77 & 0.34 & 0.07 & 0.76 \\
\hline INT2 & 0.76 & -0.43 & 0.60 & $\mathbf{0 . 9 7}$ & 0.76 & 0.41 & 0.02 & 0.72 \\
\hline INT3 & 0.66 & -0.34 & 0.56 & $\mathbf{0 . 9 2}$ & 0.65 & 0.35 & 0.09 & 0.63 \\
\hline INT4 & 0.76 & -0.42 & 0.72 & $\mathbf{0 . 9 6}$ & 0.75 & 0.39 & 0.04 & 0.74 \\
\hline PU1 & 0.52 & -0.27 & 0.50 & 0.56 & $\mathbf{0 . 8 1}$ & 0.28 & 0.10 & 0.58 \\
\hline PU2 & 0.70 & -0.34 & 0.51 & 0.69 & $\mathbf{0 . 9 1}$ & 0.43 & 0.16 & 0.58 \\
\hline PU3 & 0.75 & -0.32 & 0.64 & 0.77 & $\mathbf{0 . 9 2}$ & 0.35 & 0.06 & 0.70 \\
\hline SEC1 & 0.46 & -0.29 & 0.30 & 0.34 & 0.37 & $\mathbf{0 . 9 4}$ & 0.12 & 0.33 \\
\hline SEC2 & 0.49 & -0.32 & 0.31 & 0.42 & 0.42 & $\mathbf{0 . 9 5}$ & 0.08 & 0.39 \\
\hline SEC4 & 0.41 & -0.20 & 0.28 & 0.33 & 0.33 & $\mathbf{0 . 9 4}$ & 0.11 & 0.35 \\
\hline SN2 & 0.03 & 0.10 & 0.01 & 0.01 & 0.07 & 0.11 & $\mathbf{0 . 7 7}$ & 0.08 \\
\hline SN3 & 0.01 & 0.22 & -0.09 & -0.01 & 0.04 & 0.11 & $\mathbf{0 . 7 3}$ & 0.02 \\
\hline SN4 & 0.07 & 0.09 & 0.00 & 0.06 & 0.12 & 0.11 & $\mathbf{0 . 9 9}$ & 0.09 \\
\hline TCF1 & 0.67 & -0.41 & 0.61 & 0.73 & 0.67 & 0.36 & 0.11 & $\mathbf{0 . 9 7}$ \\
\hline TCF2 & 0.70 & -0.45 & 0.59 & 0.73 & 0.67 & 0.41 & 0.11 & $\mathbf{0 . 9 6}$ \\
\hline TCF3 & 0.54 & -0.32 & 0.51 & 0.55 & 0.57 & 0.27 & 0.04 & $\mathbf{0 . 8 2}$ \\
\hline TCF4 & 0.76 & -0.42 & 0.66 & 0.76 & 0.72 & 0.37 & 0.11 & $\mathbf{0 . 9 5}$ \\
\hline & & & & & & & & \\
\hline
\end{tabular}

The cross-loadings generated for the account inquiry dataset suggested convergent and discriminant validity. All items loaded highly onto the intended constructs and indicated discrimant validity ${ }^{20}$. To further evaluate this, an AVE analysis was conducted using the account inquiry dataset. The outcome of this test is outlined in Table 71.

${ }^{20}$ As with the financial loans dataset, some of the cross-loadings appeared relatively high. However, the squared loadings were investigated and there was no compelling reason for assuming a conceptual overlapping between the constructs. 
Table 71: Correlations of the latent variables and reliability measures for the account inquiries dataset

\begin{tabular}{|l|c|c|c|c|c|c|c|c|c|c|c|}
\hline & AVE & CR & $\begin{array}{c}\text { Cron } \\
\boldsymbol{\alpha}\end{array}$ & Att & Costs & EOU & INT & PU & $\begin{array}{c}\text { Secu } \\
\text { rity }\end{array}$ & SN & TCF \\
\hline Attitude & 0.69 & 0.87 & 0.77 & $\mathbf{0 . 8 3}$ & & & & & & & \\
\hline Costs & 0.71 & 0.88 & 0.81 & -0.39 & $\mathbf{0 . 8 4}$ & & & & & & \\
\hline Ease of use & 0.71 & 0.91 & 0.86 & 0.65 & -0.45 & $\mathbf{0 . 8 4}$ & & & & & \\
\hline Intentions & 0.90 & 0.97 & 0.96 & 0.77 & -0.40 & 0.66 & $\mathbf{0 . 9 5}$ & & & & \\
\hline P.usefulness & 0.78 & 0.91 & 0.86 & 0.75 & -0.35 & 0.63 & 0.77 & $\mathbf{0 . 8 8}$ & & & \\
\hline Security & 0.89 & 0.96 & 0.94 & 0.49 & -0.29 & 0.32 & 0.39 & 0.40 & $\mathbf{0 . 9 4}$ & & \\
\hline Subj. norms & 0.71 & 0.88 & 0.87 & 0.07 & 0.08 & 0.01 & 0.06 & 0.12 & 0.11 & $\mathbf{0 . 8 4}$ & \\
\hline TCF & 0.86 & 0.96 & 0.95 & 0.72 & -0.44 & 0.64 & 0.75 & 0.71 & 0.38 & 0.10 & $\mathbf{0 . 9 3}$ \\
\hline
\end{tabular}

Table 71 demonstrates that each construct shares greater variance with its own block of measures than with any other construct in the model. Further, all AVEs were consistent with Fornell and Larcker's guidelines exceeding the 0.50 threshold value (Fornell and Larcker 1981).

Moreover, all measures were strong in terms of their internal consistency reliability as indexed by the composite reliability (CR). The composite reliabilities of the reflective measures (account inquiry dataset) ranged from 0.87 to 0.97 exceeding the recommended threshold value of 0.70 (Nunnally 1978) for all constructs in the research model. Likewise, all Cronbach alpha values were above 0.77 verifying the reliability of the scales.

In summary, the confirmatory factor analysis of both datasets (financial loans and account inquiries) illustrated that most measures loaded cleanly onto their intended constructs. The results of the analyses confirm construct validity since the scales were tested successfully in terms of convergent and discriminant validity. In addition, the composite reliability values and Cronbach's alphas confirmed that the scales were reliable.

\subsubsection{Redundancy analysis - formative TCF}

As indicated in section 5.4.1.2., the parallel instrument design included two corresponding items for each TCF dimension. The major advantage of this design was that the TCF could be modeled in two separate ways. First, one item per TCF dimension could be selected to model the TCF construct formatively. Second, averaging the product scores would consider each moderation score within the TCF computation. While the latter solution was straightforward to implement, the first conceptualization required selecting five out of ten TCF product scores tested during the pilot phase.

To operationalize the item selection process systematically, a variation of a redundancy analysis was developed. Normally, redundancy analyses are used to validate the generalizability of formative measures (Diamantopoulos and Winklhofer 2001; 
Diamantopoulos, Riefler et al. 2008). For instance, Barki et al. (2007) validated a MIMIC construct (IS use related activity) by linking it to two theoretically related constructs (perceived individual benefits and perceived organizational benefits).

To perform the adjusted redundancy analysis for this research, each TCF moderation score was linked to the perceived usefulness and the attitude towards channel use constructs. Given the extant literature on TTF (Goodhue 1995; Dishaw and Strong 1999; Klopping and McKinney 2004; Staples and Seddon 2004), it was thought that a theoretical link between TCF and perceived usefulness and attitude towards channels use exists. The following Figure 39 illustrates the process.

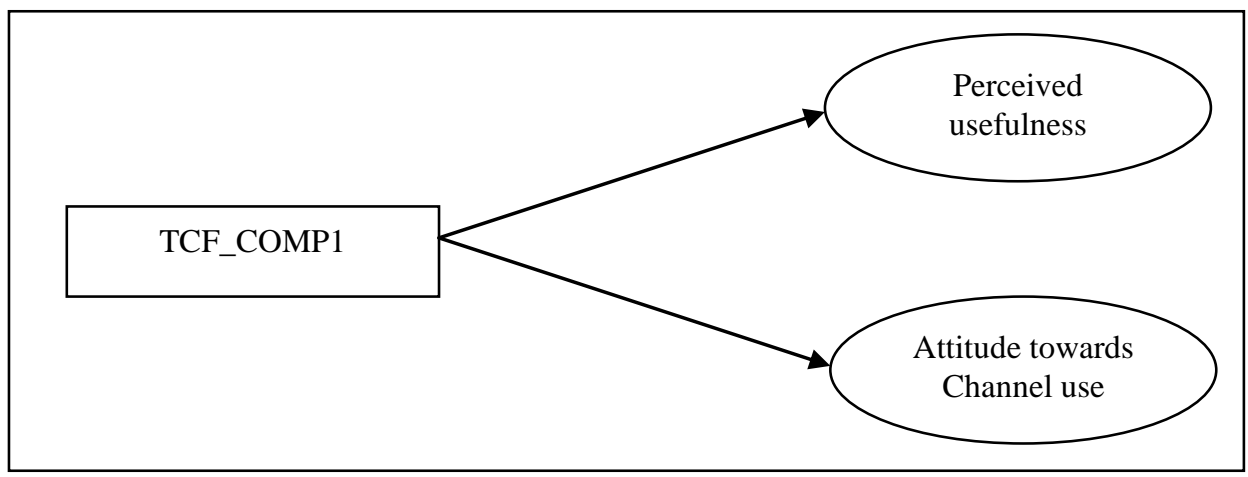

Figure 39: Adapted redundancy analysis for selecting individual moderation scores

Each moderation score was separately linked to the perceived usefulness and attitude towards channel use constructs using both datasets. Next, PLS was used to investigate the predictability of each item in both constructs. The bootstrapping procedure was used to test whether the correlations were statistically significant. whereas the PLS algorithm was used to determine the path coefficients and to compute the variance explained in the perceived usefulness and attitude towards channel use construct. Table 72 shows the results of the tests. 
Table 72: Redundancy analysis - identification of the individual moderation score items

\begin{tabular}{|c|c|c|c|c|c|c|c|c|}
\hline \multicolumn{7}{|c|}{ Account inquiries } & \multirow[b]{3}{*}{$\begin{array}{c}\text { Sum } \mathbf{R}^{2} \\
\text { explained } \\
\text { in ATT } \\
\text { \& PU } \\
\text { (R1) }\end{array}$} & \multirow[b]{3}{*}{$\begin{array}{c}\text { Sum } \mathbf{R}^{2} \\
\text { explained in } \\
\text { ATT\&PU } \\
\text { loans and } \\
\text { account } \\
\text { inquiries ( R2 }\end{array}$} \\
\hline & \multicolumn{3}{|c|}{ Perceived Usefulness } & \multicolumn{3}{|c|}{ Attitude } & & \\
\hline $\begin{array}{l}\text { Moderation } \\
\text { scores }\end{array}$ & $\begin{array}{c}\text { T- } \\
\text { value }\end{array}$ & Beta & $\mathbf{R}^{2}$ & $\begin{array}{c}\text { T- } \\
\text { value }\end{array}$ & Beta & $\mathbf{R}^{2}$ & & \\
\hline TCF_COMP1 & 1.52 & -0.11 & 0.01 & 2.18 & -0.20 & 0.04 & 0.05 & 0.22 \\
\hline TCF_COMP2 & 6.29 & 0.47 & 0.22 & 8.11 & 0.54 & 0.29 & 0.51 & 0.54 \\
\hline TCF_EFFORT1 & 1.92 & -0.09 & 0.01 & 2.89 & -0.23 & 0.05 & 0.06 & 0.20 \\
\hline TCF_EFFORT2 & 1.55 & -0.97 & 0.01 & 2.95 & -0.24 & 0.06 & 0.07 & 0.14 \\
\hline TCF_FREQ1 & 6.12 & 0.45 & 0.20 & 7.93 & 0.53 & 0.28 & 0.48 & 0.60 \\
\hline TCF_FREQ2 & 7.07 & 0.47 & 0.22 & 6.29 & 0.46 & 0.22 & 0.44 & 0.56 \\
\hline TCF_IMPORT1 & 5.21 & 0.46 & 0.21 & 8.17 & 0.51 & 0.26 & 0.47 & 0.59 \\
\hline TCF_IMPORT2 & 6.76 & 0.48 & 0.23 & 7.49 & 0.46 & 0.21 & 0.44 & 0.58 \\
\hline TCF_TIME1 & 2.18 & 0.14 & 0.02 & 2.84 & 0.19 & 0.04 & 0.06 & 0.07 \\
\hline TCF_TIME2 & 3.13 & 0.23 & 0.06 & 3.25 & 0.20 & 0.04 & 0.10 & 0.26 \\
\hline \multicolumn{7}{|c|}{ Financial Loans } & & \\
\hline & \multicolumn{3}{|c|}{ Perceived Usefulness } & \multicolumn{3}{|c|}{ Attitude } & $\begin{array}{c}\text { Sum R}^{2} \\
\text { explained } \\
\text { in ATT } \\
\text { \& PU }\end{array}$ & \\
\hline $\begin{array}{l}\text { Moderation } \\
\text { scores }\end{array}$ & $\begin{array}{c}\text { T- } \\
\text { value }\end{array}$ & Beta & $\mathbf{R}^{2}$ & $\begin{array}{c}\text { T- } \\
\text { value }\end{array}$ & Beta & $\mathbf{R}^{2}$ & & \\
\hline TCF_COMP1 & 3.88 & 0.32 & 0.11 & 2.94 & 0.25 & 0.06 & 0.17 & \\
\hline TCF_COMP2 & 1.97 & 0.15 & 0.02 & 1.63 & 0.12 & 0.02 & 0.04 & \\
\hline TCF_EFFORT1 & 1.34 & 0.08 & 0.01 & 2.75 & -0.36 & 0.13 & 0.13 & \\
\hline TCF_EFFORT2 & 2.96 & 0.23 & 0.05 & 2.35 & 0.15 & 0.02 & 0.07 & \\
\hline TCF_FREQ1 & 3.92 & 0.30 & 0.09 & 2.54 & 0.17 & 0.03 & 0.12 & \\
\hline TCF_FREQ2 & 3.67 & 0.31 & 0.10 & 2.34 & 0.18 & 0.03 & 0.13 & \\
\hline TCF_IMPORT1 & 2.92 & 0.25 & 0.06 & 3.09 & 0.24 & 0.06 & 0.12 & \\
\hline TCF_IMPORT2 & 3.41 & 0.28 & 0.08 & 3.39 & 0.23 & 0.05 & 0.13 & \\
\hline TCF_TIME1 & 0.54 & -0.03 & 0.00 & 1.73 & 0.10 & 0.01 & 0.01 & \\
\hline TCF_TIME2 & 3.72 & 0.32 & 0.10 & 3.29 & 0.25 & 0.06 & 0.16 & \\
\hline
\end{tabular}

In order to select the most suitable formative items, initially the $\mathrm{R}^{2}$ values (PU \& Attitude) for each TCF product score were summed (depicted above in column R1). These values showed which item explained the most variance in perceived usefulness and attitude towards channel use. The computations were repeated for both datasets. In order to identify the most suitable items across both datasets, the R1 values of both datasets were also summed for each item. This led to column R2 shown on the right hand side of the above mentioned Table. Next, the R2 values were compared and for each TCF dimension one item was selected. The selection was made by picking the item (one per dimension) that explained most variance in the perceived usefulness and attitude towards channel use constructs in both datasets. The selected items R2 were highlighted in bold. 


\subsubsection{Construct validity assessment - TCF construct Measurement approach 1 - using individual TCF moderation scores}

The selected individual moderation scores were then used to model the TCF construct formatively. Figure 40 visualizes the TCF construct.

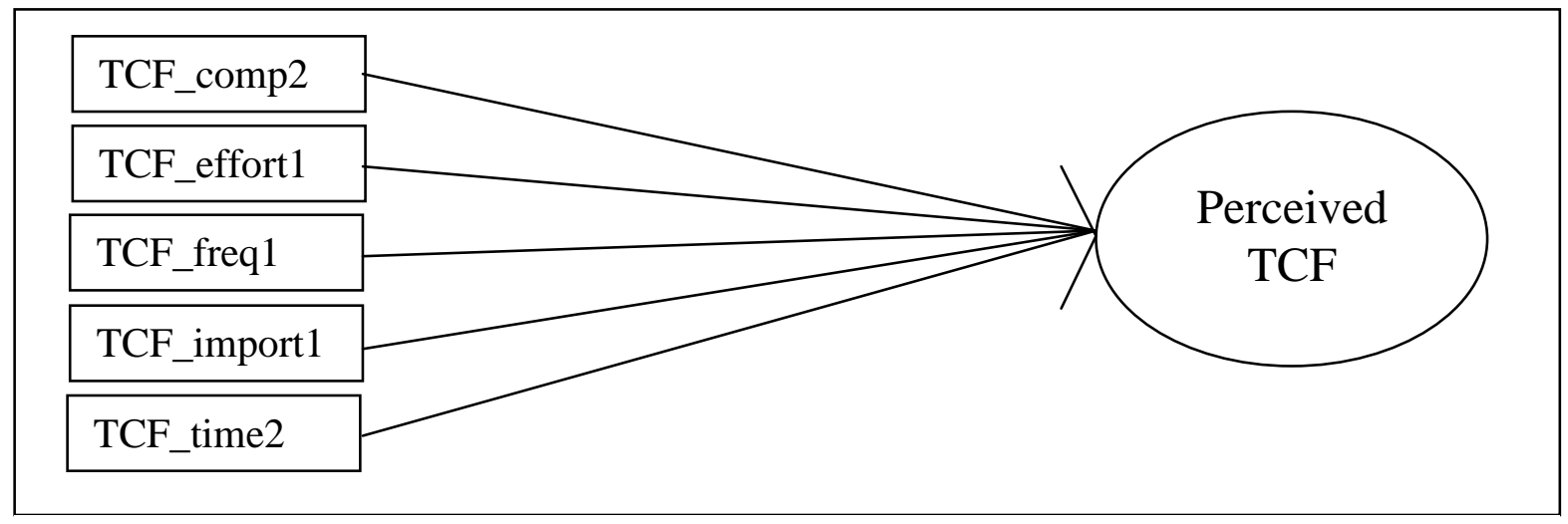

Figure 40: Formative TCF construct: measuring TCF using individual moderation scores

Next, the formative items were then assessed for construct validity. Following Cenfetelli and Bassellier's (2009) guidelines for assessing the construct validity of formative measures, the multicollinearity among the TCF product scores was initially checked. These VIF statistics were calculated using SPSS v17.0. The outcome is shown in Table 73.

Table 73: VIF statistics for individual formative measures (moderation scores)

\begin{tabular}{|c|c|c|}
\hline Formative item & VIF_loans & VIF_account inquiries \\
\hline TCF_comp2 & 1.16 & 2.11 \\
\hline TCF_effort1 & 1.03 & 1.12 \\
\hline TCF_freq1 & 1.40 & 1.83 \\
\hline TCF_import1 & 1.33 & 2.15 \\
\hline TCF_time2 & 1.30 & 1.11 \\
\hline
\end{tabular}

The VIF statistics for both datasets suggested that there was no multicollinearity among the formative measures as all scores met the recommended threshold of 3.3 (Petter et al. 2007).

Next, the t-values were computed through the bootsrapping procedure in PLS. The PLS algorithm was run to obtain the weight distribution of the individual moderation scores. The results are shown in Table 74.

Table 74: Formative measures t-values and item weights - individual moderation scores

\begin{tabular}{|l|c|c|c|c|}
\hline & \multicolumn{2}{|c|}{ Financial loans } & \multicolumn{2}{c|}{ Account inquiries } \\
\hline Formative measure & $\begin{array}{c}\text { T- } \\
\text { statistic }\end{array}$ & $\begin{array}{c}\text { Weight } \\
\text { (loading) }\end{array}$ & $\begin{array}{c}\text { T- } \\
\text { statistic }\end{array}$ & $\begin{array}{l}\text { Weight } \\
\text { (loading) }\end{array}$ \\
\hline TCF_comp2 -> TCF & 0.57 & $0.09(0.37)$ & $2.54^{*}$ & $0.36(0.85)$ \\
\hline TCF_effort1 -> TCF & 0.40 & $-0.05(0.09)$ & 1.10 & $0.08(-0.21)$ \\
\hline TCF_freq1 -> TCF & 1.28 & $0.22(0.67)$ & $3.13^{* *}$ & $0.40(0.85)$ \\
\hline
\end{tabular}




\begin{tabular}{|l|c|c|c|c|}
\hline TCF_import1 -> TCF & 1.72 & $0.37(0.70)$ & $2.37 *$ & $0.37(0.87)$ \\
\hline TCF_time2 -> TCF & $3.25 * *$ & $0.65(0.87)$ & 1.12 & $0.13(0.40)$ \\
\hline \multicolumn{2}{|r|}{$*$ significant at $\mathrm{p}<0.05, * *$ significant at $\mathrm{p}<0.01$ and $* * *$ significant at $\mathrm{p}<0.001$} \\
\hline
\end{tabular}

Table 74 shows that four items tested significantly (TCF_comp2, TCF_freq1, TCF_import1 and TCF_time2). Surprisingly, none of these items tested significantly in both datasets.

While not tested significantly, some of the weights were still quite high. For example, TCF_freq1 led to a 0.22 weight and a 0.67 loading in the financial loan dataset. These values indicate that TCF_freq1 contributed notably to the TCF construct despite the insignificant $\mathrm{t}-$ test.

Likewise, TCF_import1 was not significant in the financial loan dataset, however, the tstatistic was relatively high and the weight was 0.37 . The item loading was 0.70 indicating that the items contributed in absolute terms to the TCF construct.

The weight for TCF_effort1 was negative in the financial loan dataset but positive in the account inquiries dataset. This suggested that the item should be inspected over time and perhaps culled if leading to varying (positive/negative) weights in future studies (Cenfetelli and Bassellier, 2009).

The next step of the analysis included a redundancy test. To this end, all individual product scores were attached to the TCF construct (formatively) in SmartPLS. This construct was then linked to the reflectively measured TCF construct ${ }^{21}$. In the first step, all individual product terms were included within the redundancy analysis. Next, the non-significant formative item (TCF_effort1) was excluded from the redundancy test. Table 75 displays the results:

Table 75: Redundancy analysis - individual moderation score analysis

\begin{tabular}{|c|c|c|c|c|}
\hline & \multicolumn{2}{|c|}{ Financial loans } & \multicolumn{2}{|c|}{ Account inquiries } \\
\hline Construct relations & T-statistic & $\begin{array}{l}\text { Correlation } \\
\text { coefficient) }\end{array}$ & T-statistic & $\begin{array}{l}\text { Correlation } \\
\text { coefficient }\end{array}$ \\
\hline TCF -> TCF reflective & $4.66 * * *$ & $0.38\left(0.120 \mathrm{R}^{2}\right)$ & $9.68 * * *$ & $0.64\left(0.415 R^{2}\right)$ \\
\hline $\begin{array}{l}\text { TCF (no TCF effort1) -> } \\
\text { TCF reflective }\end{array}$ & $4.19 * * *$ & $0.35\left(0.120 \mathrm{R}^{2}\right)$ & $9.66 * * *$ & $0.64\left(0.415 \mathrm{R}^{2}\right)$ \\
\hline
\end{tabular}

As shown above, the formatively measured TCF construct was highly correlated to the reflective TCF construct (for both datasets). All t-values indicated significance levels at the $\mathrm{p}<0.001$ level. When using the account inquiry dataset, the correlation coefficients were 0.64 .

\footnotetext{
${ }^{21}$ Using the reflective TCF measures (TCF1, TCF2, TCF3, TCF4)
} 
These findings confirmed a very high correlation between the formatively and reflectively measured TCF constructs. The formative measures were correlated weaker with their reflective counterparts in the financial loan dataset. Given the exploratory nature of the scales, path coefficients of 0.38 (all individual moderation scores)/0.35 (excl. TCF_effort1) were viewed as adequate.

It is also important to note that excluding TCF_effort 1 led to marginal alterations in the test outcome. Thus, it could be questioned to include the item in future studies.

\section{Measurement approach 2 - examining average moderation scores}

As an alternative to using all product scores, the formative TCF construct was also conceptualized by using the average product scores of each TCF dimension. Figure 41 visualizes the structure of this conceptualization of the TCF construct.

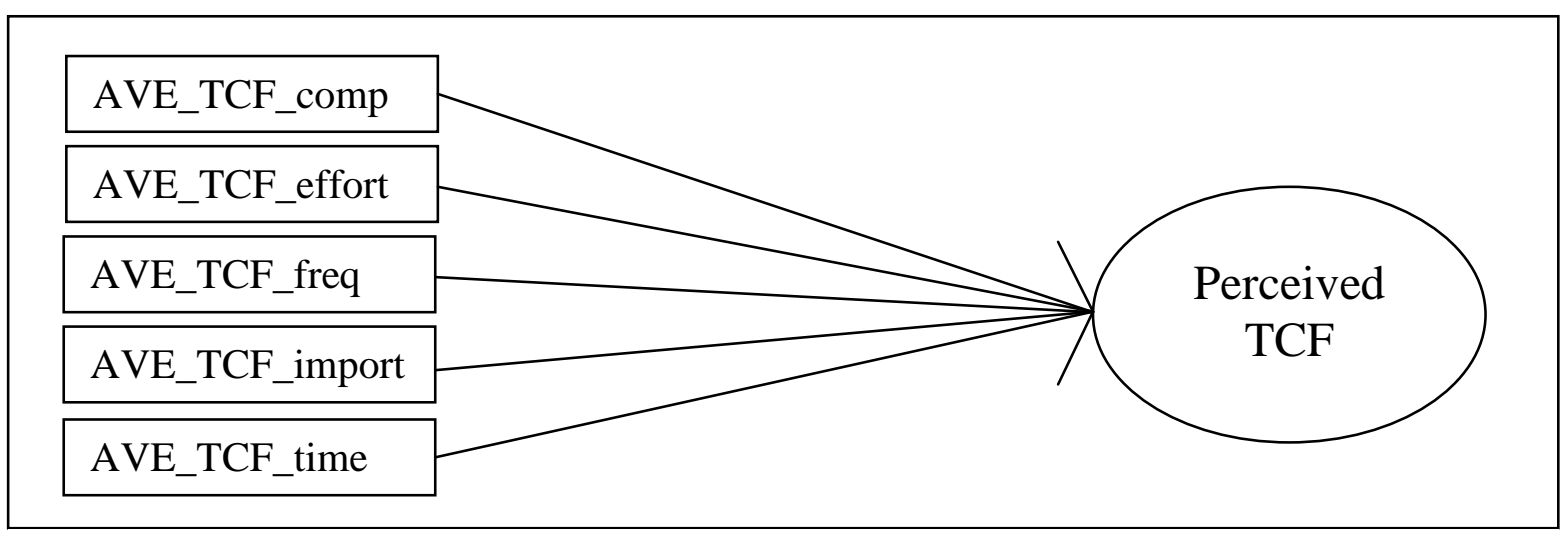

Figure 41: Formative TCF construct: measuring TCF using average moderation scores

It was assumed that this approach would improve the weight structure of the formative construct since this increases the likelihood that indicators become significant (Cenfetelli and Bassellier's 2009). Further, all moderation scores were considered in this approach and not only a selection of individual items.

Thus, the mean scores for TCF_comp1 and TCF_comp2, TCF_effort1 and TCF_effort2, TCF_freq1 and TCF_freq2, TCF_import1 and TCF_import2, as well as TCF_time1 and TCF_time2 were computed manually using Microsoft Excel spreadsheet software. Next, these values were checked for multicollinearity (VIF analysis using SPSS) and their weight contributions for the TCF construct.

The VIF statistics showed that there was no multicollinearity present among the average set of formative measures. All values met the recommended threshold of 3.3 as recommended by Petter et al. (2007). 
Table 76: VIF statistics for formative measures (mean - moderation scores)

\begin{tabular}{|c|c|c|}
\hline Formative item & VIF_loans & VIF_account inquiries \\
\hline AVE_TCF_comp & 1.31 & 1.53 \\
\hline AVE_TCF_effort & 1.07 & 1.14 \\
\hline AVE_TCF_freq & 1.19 & 1.90 \\
\hline AVE_TCF_import & 1.20 & 2.44 \\
\hline AVE_TCF_time & 1.12 & 1.30 \\
\hline
\end{tabular}

The assessment of multicollinearity was followed by analyzing the significance levels of the averaged TCF measures. The t-statistics and item weights were calculated in SmartPLS. Table 77 lists the results.

Table 77: Formative measures t-values and item weights - mean moderation scores

\begin{tabular}{|c|c|c|c|c|}
\hline & \multicolumn{3}{|c|}{ Financial loans } & \multicolumn{2}{c|}{ Account inquiries } \\
\hline Formative measure & $\begin{array}{l}\text { T- } \\
\text { statistic }\end{array}$ & $\begin{array}{l}\text { Weight } \\
\text { (loading) }\end{array}$ & T-statistic & $\begin{array}{l}\text { Weight } \\
\text { (loading) }\end{array}$ \\
\hline AVE_TCF_COMP -> TCF & 1.73 & $0.31(0.70)$ & $3.14^{* *}$ & $0.31(0.74)$ \\
\hline AVE_TCF_EFFORT -> TCF & 1.30 & $0.22(0.40)$ & 0.63 & $0.04(-0.22)$ \\
\hline AVE_TCF_FREQ -> TCF & $2.13^{*}$ & $0.36(0.66)$ & $3.01 * *$ & $0.47(0.86)$ \\
\hline AVE_TCF_IMPORT -> TCF & $2.48^{*}$ & $0.45(0.73)$ & $2.23 *$ & $0.38(0.89)$ \\
\hline AVE_TCF_TIME -> TCF & 1.43 & $0.24(0.54)$ & 0.88 & $0.07(0.48)$ \\
\hline \multicolumn{2}{|r|}{$*$ significant at $p<0.05, * *$ significant at $p<0.01$ and $* * *$ significant at $p<0.001$} \\
\hline
\end{tabular}

Table 77 shows that AVE_TCF_FREQ and AVE_TCF_IMPORT was significantly correlated with the TCF construct for both datasets. The item AVE_TCF_COMP was significantly correlated with the TCF construct when assessing the data for the account inquiry responses. For the financial loan dataset, the weight distributions appeared to be balanced whereas the weights for AVE_TCF_EFFORT and AVE_TCF_TIME were low for the account inquiry dataset. This was also reflected in the relatively low outer loading values suggesting that both items neither contributed relatively nor absolutely to the formative TCF construct. This suggested that these measures could be excluded from future studies.

In order to assess the construct portability a redundancy analyses was performed. The formative TCF construct was initially assessed through all average-moderation scores. Next, AVE_TCF_EFFORT and AVE_TCF_TIME were excluded. As with the previous redundancy analyses, the formative TCF construct was linked to the reflectively measured TCF variable and evaluated in SmartPLS.

Table 78: Redundancy analysis - average moderation score analysis

\begin{tabular}{|l|l|l|l|l|}
\hline & \multicolumn{2}{|c|}{ Financial loans } & \multicolumn{2}{c|}{ Account inquiries } \\
\hline Construct relations & $\begin{array}{l}\text { T- } \\
\text { statistic }\end{array}$ & $\begin{array}{l}\text { Correlation } \\
\text { coefficient) }\end{array}$ & $\begin{array}{l}\text { T- } \\
\text { statistic }\end{array}$ & $\begin{array}{l}\text { Correlation } \\
\text { coefficient }\end{array}$ \\
\hline TCF (all items) $\rightarrow$ TCF & $6.04 * * *$ & $0.420\left(0.176 \mathrm{R}^{2}\right)$ & $11.65 * * *$ & $0.67\left(0.450 \mathrm{R}^{2}\right)$ \\
\hline
\end{tabular}




\begin{tabular}{|l|c|c|c|c|}
\hline reflective & & & & \\
\hline $\begin{array}{l}\text { TCF (no effort+no time) -> } \\
\text { TCF reflective }\end{array}$ & $4.97 * * *$ & $0.40\left(0.164 \mathrm{R}^{2}\right)$ & $10.53 * * *$ & $0.67\left(0.448 \mathrm{R}^{2}\right)$ \\
\hline \multicolumn{2}{|c|}{$*$ significant at $\mathrm{p}<0.05, * *$ significant at $\mathrm{p}<0.01$ and $* * *$ significant at $\mathrm{p}<0.001$} \\
\hline
\end{tabular}

The above Table shows that the formatively measured TCF construct was statistically significant correlated with its reflective counterpart using both datasets. The correlation coefficient was higher when analyzing the account inquiry dataset. When excluding AVE_TCF_EFFORT and AVE_TCF_TIME from the analysis, the correlation coefficient did not change significantly when inspecting the findings of the account inquiry dataset. On the other hand, the coefficient dropped from 0.31 to 0.26 when removing these measures from the analysis in case of the financial loan dataset. This suggested that the portability of the formatively measured TCF construct would improve when including these items.

\section{Summary}

The previous section initially evaluated the convergent validity of the reflective scales. The analyses showed that the items loaded cleanly on the intended constructs and were tested highly reliable.

The moderation scores were then used as formative measures to assess the TCF construct. Initially, individual product scores (one formative item per TCF dimension) were used for modelling the formative TCF construct. Next, the mean moderation scores (by averaging the moderation scores for each TCF dimension) were employed to model the perceived TCF variable. Centefelli and Basselier's (2009) guidelines for handling formative measures in Information Systems research were considered through the data analyzes.

The findings were promising and many of the formative TCF items were statistically significant for the overall TCF construct. In addition, the redundancy analyses demonstrated that the formative constructs were highly predictable for consumers' overall perceptions of the task-channel fit (measured through a reflective TCF construct).

Having analyzed the measurement model using the data obtained during the pilot study, the next section reports the analysis of the structural research model.

\subsubsection{Analysis of the structural model}

Following the previous section, the model was run using individual moderation scores to compute the TCF measures. Next, the same analyses were conducted using the average moderation moderation scores to compute the TCF construct. All analyses were performed in SmartPLS using the bootstrapping resampling procedure to estimate the t-values. The PLS 
algorithm was applied to determine the path coefficients between the constructs of the research model.

\section{Structural model assessment: TCF Measurement approach 1 - examining individual moderation scores}

Initially the individual moderation scores (as explained in section 5.4.3.3.) were used as formative measures for the TCF construct. The structural aspects of the research model were then assessed for financial loans and account inquiries. The results are presented in Table 79.

Table 79: Structural model results - individual moderation scores / pilot study

\begin{tabular}{|c|c|c|c|}
\hline \multicolumn{2}{|c|}{ Hypothesis } & Financial Loans & Account inquiries \\
\hline H1 & TCF $\rightarrow$ PU & T-value: $2.06^{*}$, Coefficient: 0.18 & T-value: $2.85^{* *}$, Coefficient: 0.30 \\
\hline $\mathbf{H 2}$ & TCF $\rightarrow$ INT & T-value: 0.50, Coefficient: -0.02 & T-value: 0.81 , Coefficient: 0.05 \\
\hline H3 & $\mathrm{TCF} \rightarrow \mathrm{ATT}$ & T-value: $4.81^{* * *}$, Coefficient: 0.32 & T-value:10.21***, Coefficient: 0.62 \\
\hline H4 & PU $\rightarrow$ INT & T-value: 0.33 , Coefficient: 0.02 & T-value: $2.88^{* *}$, Coefficient: 0.36 \\
\hline H5a & EOU $\rightarrow$ INT & T-value: $2.65^{* *}$, Coefficient: 0.30 & T-value: $2.01^{*}$, Coefficient: 0.16 \\
\hline H5b & EOU $\rightarrow P U$ & T-value: $6.55^{* * *}$, Coefficient: 0.57 & T-value: $5.71^{* * *}$, Coefficient: 0.45 \\
\hline H6 & ATT $\rightarrow$ INT & T-value: $4.67^{* * *}$, Coefficient: 0.46 & T-value: $3.06^{* *}$, Coefficient: 0.33 \\
\hline H7 & $\mathrm{SN} \rightarrow \mathrm{INT}$ & T-value: $2.12^{*}$, Coefficient: 0.12 & T-value: 0.35 , Coefficient: -0.01 \\
\hline H8 & SEC $\rightarrow$ INT & T-value: $3.35^{* * *}$, Coefficient: 0.21 & T-value: 0.28 , Coefficient: 0.01 \\
\hline H9 & COST->INT & T-value: 0.65 , Coefficient: -0.02 & T-value: 1.09 , Coefficient: -0.07 \\
\hline \multicolumn{4}{|c|}{$*$ significant at $\mathrm{p}<0.05, * *$ significant at $\mathrm{p}<0.01$ and $* * *$ significant at $\mathrm{p}<0.001$} \\
\hline
\end{tabular}

When using the individual moderation scores to assess the formative TCF construct, Hypotheses 1 and 3 were confirmed by the data obtained for account inquiries and financial loans. The t-values confirmed that the TCF impacted statistically significantly on the perceived usefulness and the attitude towards channel use construct (at least at the $\mathrm{p}<0.05$ level for both datasets). The path coefficient between the TCF construct and perceived usefulness was 0.18 in the financial loan dataset. The beta coefficient $(0.32)$ between the TCF construct and the attitude variable was stronger for the same data.

For the account inquiries datasets, both coefficients were stronger and the path between the TCF construct and perceived usefulness was 0.30. There was also a very strong path coefficient between the task-channel fit construct and the attitude variable 0.62.

H2 was disconfirmed in both datasets indicating the there was no direct correlation between the task-channel fit construct and consumers' intentions to use Internet banking. This was not very surprising since the literature on TTF reported divergent findings on such a causal relationship. For instance, Goodhue and Thompson (1995) found no significant path coefficient between the TTF construct and system utilization. When regressing the TTF 
construct onto the utilization, only $0.02 \mathrm{R}^{2}$ was explained in the use construct (Goodhue and Thompson 1995; Goodhue and Thompson 1995).

H4 was confirmed by the account inquiry dataset but not by the responses obtained for financial loans. This was unanticipated since this hypothesis was based on the literature around TAM theory. As expected ease of use was significantly correlated with perceived usefulness in both datasets and attitude towards Internet banking use impacted significantly on consumer intentions to use Internet banking for financial loans and account inquiries (H6). Subjective norms (H7) and security (H8) were not significantly correlated with intentions to use when inspecting the account inquiries dataset. The opposite was the case for financial loans. This suggested that consumers felt more influenced by others -and they were more security aware- when considering loan applications for Internet banking.

H9 was disconfirmed by both datasets suggesting that costs associated with Internet banking use was not an important factor for consumers' intentions to use IB for these banking tasks.

Table 80 shows the variance explained by the perceived usefulness, attitude towards use and intention to use construct.

Table 80: Variance explained by each construct - individual moderation scores / pilot study

\begin{tabular}{|l|c|c|c|}
\hline & $\begin{array}{l}\text { Perceived } \\
\text { usefulness }\end{array}$ & \multicolumn{1}{|l|}{$\begin{array}{l}\text { Attitude towards } \\
\text { use }\end{array}$} & Intention to use \\
\hline Financial Loans & $\left(\mathrm{R}^{2}=0.501\right)$ & $\left(\mathrm{R}^{2}=0.190\right)$ & $\left(\mathrm{R}^{2}=0.720\right)$ \\
\hline Account inquiries & $\left(\mathrm{R}^{2}=0.531\right)$ & $\left(\mathrm{R}^{2}=0.381\right)$ & $\left(\mathrm{R}^{2}=0.702\right)$ \\
\hline
\end{tabular}

More than $50 \%$ of variance in the perceived usefulness construct was explained in both datasets. The $\mathrm{R}^{2} \mathrm{~s}$ computed for the attitude towards use construct suggested that around $19 \%$ of variance was explained by this construct when assessing the responses for financial loans. The $\mathrm{R}^{2}$ results were much higher when computing the model for the account inquiry dataset (0.381). This appeared to be logical given the high path coefficient $(0.60)$ between the TCF construct and the attitude towards construct for account inquiries.

The variance explained in the dependent variable was above $70 \%$ for both datasets when using the individual moderation scores. The variance explained was slightly higher when using the financial loan dataset (0.720). This could be explained by the influence of the security and subjective norms constructs on the intentions to use variable in the financial loan dataset. 


\section{Structural model assessment: TCF Measurement approach 2 - examining average moderation scores}

As an alternative to using individual product scores, the formative TCF construct was also conceptualized by using the average product scores of each TCF dimension. The structural paths of the model were then assessed using SmartPLS. The results are shown in Table 81.

Table 81: Structural model results - average moderation scores / pilot study

\begin{tabular}{|c|c|c|c|}
\hline \multicolumn{2}{|c|}{ Hypothesis } & Financial Loans & \\
\hline H1 & TCF $\rightarrow$ PU & T-value: $2.49^{* *}$, Coefficient: 0.27 & T-value: $3.69 * * *$, Coefficient: 0.27 \\
\hline $\mathbf{H 2}$ & TCF $\rightarrow$ INT & T-value: 1.72 , Coefficient: -0.08 & T-value: 0.95 , Coefficient: 0.05 \\
\hline H3 & $\mathrm{TCF} \rightarrow \mathrm{ATT}$ & T-value: $4.84 * * *$, Coef & T-value:12.51***, Coefficient: 0.62 \\
\hline H4 & PU $\rightarrow$ INT & T-value: 0.79 , Coeffici & le: $2.84 * *, \mathrm{Co}$ \\
\hline H5a & EOU $\rightarrow$ INT & T-value: $2.79 *$ & T-value: $2.01^{*}$ \\
\hline H5b & EOU $\rightarrow$ PU & T-value: $5.82^{* * *}$, Coef & T-value: $5.73^{* * *}, \mathrm{Co}$ \\
\hline H6 & ATT $\rightarrow$ INT & T-value: $4.61 * * *$, Coef & T-value: $2.93^{* *}, \mathrm{Coc}$ \\
\hline H7 & $\mathrm{J} \rightarrow$ INT & T-value: $2.23 *$, Coeffi & e: 0.34, Coeff \\
\hline H8 & SEC $\rightarrow$ INT & *, Coefficient: 0.22 & de: 0.17 , Coefficient: 0.02 \\
\hline H9 & COST->INT & T-value: 0.86 , Coefficient: -0.03 & T-value: 1.19, Coeff \\
\hline
\end{tabular}

$\mathrm{H} 1$ and $\mathrm{H} 3$ were confirmed by the data using both datasets. The t-values verified that the paths were statistically significant at least at the $p<0.01$ level. The path coefficients between the TCF and perceived usefulness were equally strong in both datasets (0.27). TCF also had a very strong influence on the attitude towards Internet banking construct independent of using the data obtained for financial loans or account inquiries. As with the individual moderation score analysis, $\mathrm{H} 2$ was disconfirmed for financial loans as well as for account inquiries. H4 was also disconfirmed by the financial loan data but confirmed when inspecting the account inquiries dataset. H5a, H5b, and H6 were also confirmed by both datasets. Not surprisingly, the hypothesised path coefficients did not change substantially from the individual moderation score analysis (as explained in the previous section). $\mathrm{H} 7$ and $\mathrm{H} 8$ were both confirmed by the financial loans data but not for account inquiries. The costs associated with channel use construct (H9) did not impact significantly on the dependent variable independent of the dataset used.

Table 82 shows the variance explained in each construct.

Table 82: Variance explained by each construct - average moderation scores / pilot study

\begin{tabular}{|l|r|r|c|}
\hline & $\begin{array}{l}\text { Perceived } \\
\text { usefulness }\end{array}$ & \multicolumn{1}{|l|}{$\begin{array}{l}\text { Attitude towards } \\
\text { use }\end{array}$} & Intentions to use \\
\hline Financial Loans & $\left(\mathrm{R}^{2}=0.462\right)$ & $\left(\mathrm{R}^{2}=0.135\right)$ & $\left(\mathrm{R}^{2}=0.722\right)$ \\
\hline Account inquiries & $\left(\mathrm{R}^{2}=0.530\right)$ & $\left(\mathrm{R}^{2}=0.386\right)$ & $\left(\mathrm{R}^{2}=0.701\right)$ \\
\hline
\end{tabular}


The $\mathrm{R}^{2}$-values were high in the perceived usefulness construct explaining more than $46 \%$ of variance in both datasets. In the financial loan dataset, only $13.5 \%$ of variance was explained in the attitude towards channel use construct. This was surprising since the $\mathrm{R}^{2}$-value was lower in comparison to the individual moderation score analysis. This result was even more surprising when inspecting the relatively strong TCF $\rightarrow$ Attitude path coefficient in the financial loan dataset $(0.37)$. Both $\mathrm{R}^{2} \mathrm{~s}$ in the dependent variable were very strong and the results did not differ much from those explained in the previous section.

It was also felt necessary to investigate the data for common method variance as explained below.

\subsubsection{Common method variance threat - pilot study}

Common method variance can be defined as "the amount of spurious covariance shared among variables because of the common method used in collecting data" (Malhotra, Kim et al. 2006). Much research has debated how influential common method variance (CMV) is for studies using surveys questionnaires as a data collection method (Podsakoff, Podsakoff et al. 2003; Malhotra, Kim et al. 2006; Richardson, Simmering et al. 2009; Brannick, Chan et al. 2010; Lance, Dawson et al. 2010; Pace 2010). Most commonly, survey research relies on a single source where research subjects provide their own opinion on the scales and researchers tend not collect data from another perspective (e.g. from an organizational viewpoint).

A review of the literature around CMV suggests that some authors view CMV as a significant threat for self-reported and single-source studies (Cote 1987; Podsakoff, Podsakoff et al. 2003) whereas others disagree with this argument (Lance et al. 2010).

For example, Sharma et al. (2009) conducted a meta-analysis using a method-method paired technique for estimating the effect of CMV in IS research. The authors meta-analyzed TAM studies and found that CMV is a potential validity threat for studies employing perceptually or behaviorally anchored scales.

In contrast, Lance et al. (2010) argue that 'method' is very broad and term and suggest that some of the variance arising from common measurement method is not biased and added to the theoretical findings for self-reported scales. Further, it is seen as problematic to apply " $a$ statistical correction which does not necessarily produce more accurate estimations of the relationships that doing nothing. Overall... when $C M V$ was present in the data, the absolute correction accuracy of all [statistical] techniques tended to be low" (Richardson, Simmering et al. 2009). 
Statistical tests were performed to check for CMV in the current research.

Many researchers suggest using a Harman single-factor test (Podsakoff, MacKenzie et al. 2003; Malhotra, Kim et al. 2006). Typically this test can be performed through exploratory factor analysis. Then, if CMV exists, a single factor should emerge from the unrotated factor solutions.

However, more recent studies showed that a Harman single factor test does not reliably indicate the absence of CMV and many authors recommend against the use of this test (Podsakoff, MacKenzie et al. 2003; Sharma, Yetton et al. 2009). In addition, the un-rotated data matrices in exploratory factor analyses can lead to confusing findings in confirmatory research.

Since this research used confirmatory factor analysis to evaluate the measurement model, the Harman single factor test was regarded as inappropriate for the context of this study.

Following Podsakoff et al. (2003), Liang et al. (2007) introduced a technique in PLS to test for common method bias. The authors suggested including a common method factor whose indicators include all the principal constructs' indicators. Next, each indicator's variances substantively explained by the principal construct and by the method are contrasted (Liang, Saraf et al. 2007).

Researchers have suggested this approach is superior to the Harman single factor test as it provides a more detailed view on the unexplained variance in the artificially created method factor (Podsakoff, MacKenzie et al. 2003; Liang, Saraf et al. 2007) ${ }^{22}$. The following Figure 42 indicates the setup for the PLS tests. Following Lance et al. (2010) the artificially created factor was termed 'unexplained variance' since 'method' appeared inappropriate in light of this procedure.

For clarity reasons, the Figure 42 does not attempt to portray the entire research model. While the procedure is only indicated for the perceived usefulness and subjective norms construct, the unexplained variance construct was linked to all constructs measured by this research

\footnotetext{
${ }^{22}$ It is important to note that Liang et al's (2007) test for CMV has been criticized (Sharma et al, 2009). Sharma et al. (2009) suggested that Podsakoff et al. (2003) originally suggested the procedure for covarianced based SEM techniques rather than PLS. However, given the limitations of the Harman one-factor approach, Liang et al's (2007) test was deemed to be most suitable for the current study.
} 


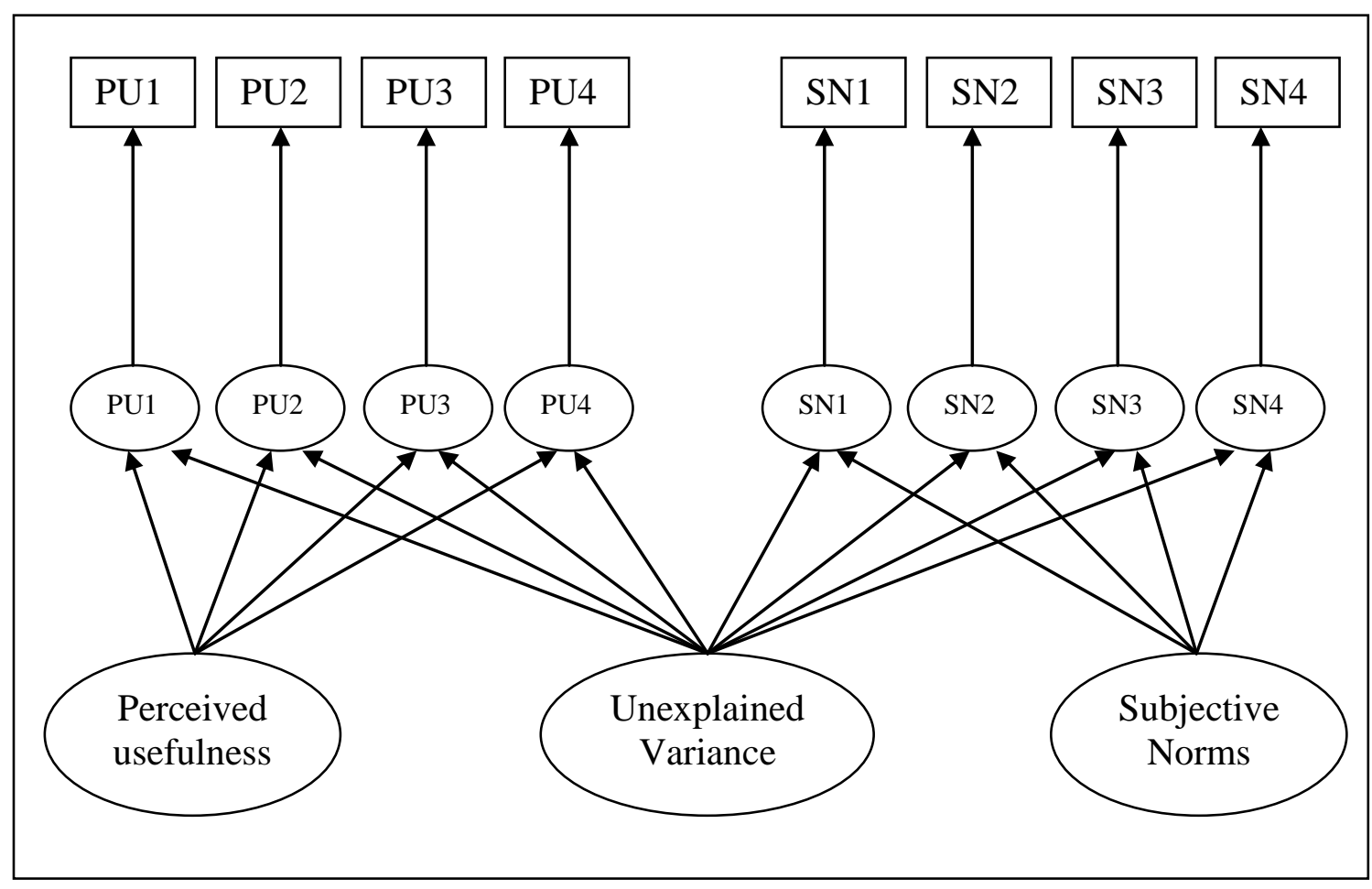

Figure 42: Unexplained variance check - pilot study

Next, the PLS algorithm was used to obtain the substantive factor loading in order to explore how much variance each item explained in the intended construct. The factor loadings of the unexplained variance construct were inspected in order to determine how much variance each item would explain in the created unexplained variance construct.

It should be noted that the reflective TCF items were used for the procedure since it was more meaningful to exclusively test reflective constructs in this procedure (Liang et al. 2007). The CMV results should not differ significantly when testing the formative counterpart since the respondents provided feedback to a conceptually similar concept. Table 83 illustrates the results of the analyses.

Table 83: Results of the unexplained variance check/pilot study

\begin{tabular}{|c|c|c|c|c|c|}
\hline \multicolumn{6}{|c|}{ Account inquiries dataset } \\
\hline Construct & Indicator & $\begin{array}{l}\text { Substantive } \\
\text { factor loading } \\
\text { (R1) }\end{array}$ & $\mathbf{R 1}^{2}$ & $\begin{array}{l}\text { Unexplained } \\
\text { variance factor } \\
\text { loading }(\mathbf{R} 2)\end{array}$ & $\mathbf{R 2}^{2}$ \\
\hline \multirow[b]{3}{*}{ Attitude } & ATT1 & 0.76 & 0.58 & -0.03 & 0.00 \\
\hline & ATT2 & 0.86 & 0.74 & 0.07 & 0.00 \\
\hline & ATT3 & 0.88 & 0.77 & -0.05 & 0.00 \\
\hline \multirow[b]{3}{*}{ Cost } & COST1 & -0.57 & 0.32 & -0.57 & 0.32 \\
\hline & COST2 & -0.37 & 0.14 & -0.37 & 0.14 \\
\hline & COST4 & -0.40 & 0.16 & -0.40 & 0.16 \\
\hline \multirow[b]{3}{*}{ Ease of use } & EOU1 & 0.64 & 0.41 & 0.28 & 0.08 \\
\hline & EOU2 & 0.99 & 0.98 & -0.14 & 0.02 \\
\hline & EOU3 & 0.86 & 0.74 & -0.20 & 0.04 \\
\hline
\end{tabular}




\begin{tabular}{|c|c|c|c|c|c|}
\hline & EOU4 & 0.91 & 0.83 & 0.00 & 0.00 \\
\hline \multirow{4}{*}{\begin{tabular}{|l} 
Intentions \\
to use \\
\end{tabular}} & INT1 & 0.96 & 0.92 & 0.00 & 0.00 \\
\hline & INT2 & 0.97 & 0.94 & 0.03 & 0.00 \\
\hline & INT3 & 0.92 & 0.85 & -0.21 & 0.04 \\
\hline & INT4 & 0.96 & 0.92 & 0.17 & 0.03 \\
\hline \multirow{3}{*}{$\begin{array}{l}\text { Perceived } \\
\text { usefulness }\end{array}$} & PU1 & 0.97 & 0.94 & -0.18 & 0.03 \\
\hline & PU2 & 0.94 & 0.88 & -0.03 & 0.00 \\
\hline & PU3 & 0.76 & 0.58 & 0.18 & 0.03 \\
\hline \multirow[b]{3}{*}{ Security } & SEC1 & 0.95 & 0.90 & -0.01 & 0.00 \\
\hline & SEC2 & 0.90 & 0.81 & 0.07 & 0.00 \\
\hline & SEC4 & 0.98 & 0.96 & -0.06 & 0.00 \\
\hline \multirow{3}{*}{$\begin{array}{l}\text { Subjective } \\
\text { norms }\end{array}$} & SN2 & 0.86 & 0.74 & 0.00 & 0.00 \\
\hline & SN3 & 0.90 & 0.81 & -0.05 & 0.00 \\
\hline & SN4 & 0.92 & 0.85 & 0.04 & 0.00 \\
\hline \multirow[b]{4}{*}{ TCF } & TCF1 & 0.97 & 0.94 & -0.04 & 0.00 \\
\hline & TCF2 & 0.97 & 0.94 & 0.02 & 0.00 \\
\hline & TCF3 & 0.83 & 0.69 & -0.21 & 0.04 \\
\hline & TCF4 & 0.95 & 0.90 & 0.20 & 0.04 \\
\hline \multicolumn{6}{|c|}{ Financial Loans dataset } \\
\hline & Indicator & \begin{tabular}{|l} 
Substantive \\
factor loading \\
(R1)
\end{tabular} & $\mathbf{R 1}^{2}$ & \begin{tabular}{|l|} 
Unexplained \\
variance Factor \\
Loading (R2) \\
\end{tabular} & $\mathbf{R 2}^{2}$ \\
\hline \multirow[b]{3}{*}{ Attitude } & ATT2 & 0.97 & 0.94 & 0.11 & 0.01 \\
\hline & ATT3 & 0.95 & 0.90 & -0.12 & 0.01 \\
\hline & ATT4 & 0.96 & 0.92 & 0.01 & 0.00 \\
\hline \multirow{4}{*}{ Cost } & COST1 & 0.58 & 0.34 & -0.18 & 0.03 \\
\hline & COST2 & 0.94 & 0.88 & 0.10 & 0.01 \\
\hline & COST3 & 0.79 & 0.62 & 0.00 & 0.00 \\
\hline & COST4 & 0.89 & 0.79 & 0.02 & 0.00 \\
\hline \multirow{3}{*}{ Ease of use } & EOU1 & 0.95 & 0.90 & -0.10 & 0.01 \\
\hline & EOU2 & 0.80 & 0.64 & 0.12 & 0.01 \\
\hline & EOU4 & 0.91 & 0.83 & -0.02 & 0.00 \\
\hline \multirow{4}{*}{$\begin{array}{l}\text { Intentions } \\
\text { to use }\end{array}$} & INT1 & 0.92 & 0.85 & 0.04 & 0.00 \\
\hline & INT2 & 0.98 & 0.96 & -0.01 & 0.00 \\
\hline & INT3 & 0.95 & 0.90 & 0.02 & 0.00 \\
\hline & INT4 & 0.98 & 0.96 & -0.05 & 0.00 \\
\hline \multirow{3}{*}{$\begin{array}{l}\text { Perceived } \\
\text { usefulness } \\
\end{array}$} & PU1 & 0.94 & 0.88 & -0.06 & 0.00 \\
\hline & PU3 & 0.82 & 0.67 & 0.06 & 0.00 \\
\hline & PU4 & 0.89 & 0.79 & 0.01 & 0.00 \\
\hline \multirow{4}{*}{ Security } & SEC1 & 0.89 & 0.79 & 0.02 & 0.00 \\
\hline & SEC2 & 0.88 & 0.77 & 0.10 & 0.01 \\
\hline & SEC3 & 0.97 & 0.94 & -0.21 & 0.04 \\
\hline & SEC4 & 0.91 & 0.83 & 0.06 & 0.00 \\
\hline \multirow{4}{*}{$\begin{array}{l}\text { Subjective } \\
\text { norms }\end{array}$} & SN1 & 0.91 & 0.83 & 0.05 & 0.00 \\
\hline & SN2 & 0.88 & 0.77 & -0.04 & 0.00 \\
\hline & SN3 & $\begin{array}{l}0.88 \\
\end{array}$ & 0.77 & 0.07 & 0.00 \\
\hline & SN4 & 0.83 & 0.69 & -0.08 & 0.01 \\
\hline \multirow{4}{*}{ TCF } & TCF1 & 0.97 & 0.94 & 0.05 & 0.00 \\
\hline & TCF2 & 0.96 & 0.92 & -0.06 & 0.00 \\
\hline & TCF3 & 0.95 & 0.90 & -0.04 & 0.00 \\
\hline & TCF4 & 0.96 & 0.92 & 0.05 & 0.00 \\
\hline
\end{tabular}


The results above indicate that the $\mathrm{R}^{2}$ values in the unexplained variance factor were very low for all items. Further, the factor loadings of the unexplained variance variable were very low indicating that CMV was not present among the data obtained during the pilot study.

\subsection{Chapter summary}

This chapter initially reviewed the literature on fit theory and discussed seven approaches for measuring fit between two or more theoretically associated variables.

Next, the pilot study conducted for this research was explained. This included the survey questionnaire instrument, survey operationalization, and data collection procedures. For the pilot study, 280 usable responses (140 for financial loans and 140 for account inquiries) were collected from staff and students at Victoria University of Wellington. The data collected were investigated for normality and descriptive statistics on the data were provided. Subsequently, several fit computations were considered. For this thesis, fit as moderation was then selected as the most appropriate fit computation.

Using PLS regression techniques, the construct validity of the reflective scales were investigated. The results confirmed that the data for account inquiries and financial loans were valid in terms of convergent and discrimant validity. In addition, all scales were tested highly reliable.

Cenfetelli and Bassellier (2009) guidelines for assessing formative constructs were used to evaluate two different modeling approaches for the formative TCF construct. First, individual product scores were used to measure the formative TCF construct. Next, the mean moderation scores were employed to assess the perceived TCF variable.

Independent of the TCF modeling approach, the scales showed no multicollinearity and most of the weights contributed considerably to the TCF construct. Further, the redundancy analyses showed that the formative construct captured a significant portion of consumers' overall perceptions of the TCF. This suggested a relatively high portability of the formative scales.

The assessment of the structural model showed that most hypotheses were confirmed by the data obtained for the pilot study ${ }^{23}$. Task-channel fit was strongly correlated to the perceived usefulness and attitude towards channel use constructs. On the other hand, there

\footnotetext{
${ }^{23}$ Please see Table 79 and 81 for more detailed information
} 
was no empirical support that the perceived task-channel fit directly influences consumers' intentions to use Internet banking for account inquiries/financial loans.

Table 84 summarizes the confirmed and disconfirmed hypotheses when using the analyses approaches discussed in chapter 5 .

Table 84: Summary hypotheses pilot test

\begin{tabular}{|c|c|c|c|c|c|}
\hline \multirow{2}{*}{\multicolumn{2}{|c|}{ Hypothesis }} & \multicolumn{2}{|c|}{ Financial Loans } & \multicolumn{2}{|c|}{ Account Inquiries } \\
\hline & & \multirow{2}{*}{$\begin{array}{c}\begin{array}{c}\text { (individual } \\
\text { moderation scores) }\end{array} \\
+\end{array}$} & \multirow{2}{*}{$\begin{array}{c}\text { (average } \\
\text { moderation scores) } \\
+ \\
\end{array}$} & \multirow{2}{*}{$\begin{array}{c}\begin{array}{c}\text { (individual } \\
\text { moderation scores) }\end{array} \\
+\end{array}$} & \multirow{2}{*}{$\begin{array}{c}\begin{array}{c}\text { (average } \\
\text { moderation scores) }\end{array} \\
+ \\
\end{array}$} \\
\hline H1 & TCF $\rightarrow$ PU & & & & \\
\hline $\mathbf{H 2}$ & TCF $\rightarrow$ INT & - & - & - & - \\
\hline H3 & $\mathbf{T C F} \rightarrow \mathbf{A T T}$ & + & + & + & + \\
\hline H4 & PU $\rightarrow$ INT & - & - & + & + \\
\hline H5a & EOU $\rightarrow$ INT & + & + & + & + \\
\hline H5b & EOU $\rightarrow$ PU & + & + & + & + \\
\hline H6 & $\mathrm{ATT} \rightarrow \mathrm{INT}$ & + & + & + & + \\
\hline H7 & SN $\rightarrow$ INT & + & + & - & - \\
\hline H8 & SEC $\rightarrow$ INT & + & + & - & - \\
\hline H9 & COST $\rightarrow$ INT & - & - & - & - \\
\hline \multicolumn{6}{|c|}{ + confirmed Hypothesis; - disconfirmed hypothesis } \\
\hline
\end{tabular}

Overall, the analysis of the TCF theory suggested that the TCF construct and other antecedents of consumer intentions to use Internet banking explain more than $70 \%$ of variance in the model (regardless of whether the analysis was conducted using individual, or average moderation scores).

These finding have several implications for this study. First, using a parallel instrument to assess the task-channel fit of electronic banking channels appeared to be a suitable technique to quantify a numerically measured TCF. The moderation approach was successfully applied to determine the TCF of electronic banking channels. Thus, it was decided to re-use this approach during the main phase of this study. Second, the analyses of the formative measures showed that some of the formative items did not contribute to a great extent to the TCF. This indicated that further refinement of the scales was required prior to the second data collection round. 


\section{Testing the task-channel fit theory in context of Internet banking}

\subsection{Chapter Outline}

The previous chapter provided an overview of fit theory and reported the pilot-study. This chapter discusses the main study conducted to quantitatively test the task-channel fit theory.

In order to refine the survey questionnaire instrument and the conceptual research model, several steps were undertaken. First, feedback was obtained from several resources including two reviewers from peer-reviewed Information Systems conferences and several senior IS researcher.

Based on the feedback obtained, a literature review was carried out focusing on taskrelated studies in order to refine the formative TCF measures. This led to an adjustment of the research model and the final survey questionnaire instrument (as explained in section 5.3.1.).

The chapter continues with explaining how the new survey instrument was pretested before the data collection procedure is discussed. Subsequently, the data collected is analysed including the fit assessment (reflective and formative), construct validity (reflective and formative scales), and assessment of the structural aspect of the research model. The chapter concludes with a comparison between the account inquiries dataset and the financial loan dataset in section 6.8.7.

The following section explains how the scales were adjusted in light of the pilot test.

\subsection{Research model and survey instrument adjustment}

\subsubsection{Obtaining feedback on the pilot study}

To further improve the scales and refine the research model, several steps were undertaken to obtain constructive feedback on the pilot test design and the results of the data analysis. The results of the pilot study were written up in form of a conference paper and submitted to a leading peer-reviewed IS conference organized by the Association for Information Systems (AIS). The focus of this conference paper was the development and quantitative test of the task-channel fit theory. The findings of the pilot study were used to demonstrate the validity of the measures and the structural aspects of the research model.

A second research paper was written up and submitted to a peer-reviewed Information Systems theory building workshop in Australia. The focus of this paper was on TCF conceptualization and its measurement. The feedback obtained from the reviewers (both conferences) was thoroughly considered and discussed with the supervising staff. 
The results of the pilot study were also presented to faculty members of an Australian University. The audience included several senior Australian and US-based IS researchers who commented on the research design and the scales used during the pilot-study.

The findings of the pilot study were also presented at a New Zealand doctoral conference. This conference was set up as an audience for $\mathrm{NZ}$ based $\mathrm{PhD}$ students who presented their $\mathrm{PhD}$ projects to senior IS staff members from universities in New Zealand.

Some of the senior IS researchers who attended the presentations (at the Australian University and the doctoral conference) were approached for face-to-face interviews. During these meetings, they provided additional constructive feedback on the findings of the pilot study and the research design. Each interview lasted between 45-60 minutes and field notes were taken immediately after the interviews took place.

Some of the comments received from the conference reviewers were very paper-specific and are therefore not included in here. However, much of the feedback was related to the overall study design and is therefore summarized in Table 85 .

Table 85: Feedback obtained on the pilot-test study

\begin{tabular}{|c|c|}
\hline $\begin{array}{l}\text { Feedback } \\
\text { source: }\end{array}$ & Comments \\
\hline $\begin{array}{l}\text { AIS } \\
\text { conference: } \\
\text { Reviewer } 1\end{array}$ & $\begin{array}{l}\text { "Third, in the data analysis, authors analyzed the datasets ('account } \\
\text { inquiries' and 'financial loans') separately. I believe that these two } \\
\text { datasets should be merged and analyzed together unless the goal of the } \\
\text { analysis is to compare the moderating effect of these two activities. Since } \\
\text { the model depicts the relationship between TCF and other constructs, } \\
\text { those relationships should hold for any kinds of tasks. The levels of TCF } \\
\text { for account inquiries and financial loans may differ. Even so, however, the } \\
\text { coefficients in the model should be same in theory. I think the authors } \\
\text { should analyze the merged dataset as well as separated datasets." }\end{array}$ \\
\hline $\begin{array}{l}\text { IS theory } \\
\text { building } \\
\text { workshop: } \\
\text { Reviewer } 2\end{array}$ & $\begin{array}{l}\text { "The author(s) might be thinking along too small lines. Instead of devoting } \\
\text { their theory to task-channel fit for banking, perhaps consider broadening } \\
\text { your theorizing out so that the model addresses multiple types of activity } \\
\text { found in all types of e-commerce? The level of generalizability and } \\
\text { specificity should be balanced, not too broad and not too narrow." }\end{array}$ \\
\hline $\begin{array}{l}\text { Interview 1: } \\
\text { IS researcher }\end{array}$ & $\begin{array}{l}\text { - The TCF scales should be tied to existing theory and she } \\
\text { recommended designing them more abstract. For instance, instead of } \\
\text { measuring task frequency, the researcher suggested measuring task } \\
\text { routine since this concept has been conceptualized by existing IS } \\
\text { theories such as the media synchronicity theory. }\end{array}$ \\
\hline
\end{tabular}




\begin{tabular}{|l|l|l|}
\hline & \begin{tabular}{l} 
- $\begin{array}{l}\text { Additionally, the research suggested creating additional items for each } \\
\text { TCF dimension. This would allow for additional statistical tests in the } \\
\text { data analysis including modelling the TCF construct as second-order } \\
\text { model. }\end{array}$ \\
\cline { 2 - 4 }
\end{tabular} & $\begin{array}{l}\text { - } \\
\text { Task uncertainty and task equivocality should be considered and the } \\
\text { researcher suggested to carefully study task-media fit theory for } \\
\text { potential TCF dimensions. }\end{array}$ \\
\hline Interview 2: & $\begin{array}{l}\text { The researcher suggested pooling the data collected for both banking } \\
\text { tasks. He suggested that the theoretical paths of the research model } \\
\text { would apply to all banking tasks. He also recommended subsequent } \\
\text { group analyses to account for the differences between the data sub-sets } \\
\text { (account inquiries/financial loans). }\end{array}$ \\
\hline Interview 3: & $\begin{array}{l}\text { The researcher was sceptical towards the deviation score analysis } \\
\text { IS researcher }\end{array}$ & $\begin{array}{l}\text { (using absolute values) since it would not account for over- and } \\
\text { underfit. }\end{array}$ \\
\hline Interview 4: & $\begin{array}{l}\text { In accordance with the IS first researcher, this scholar proposed } \\
\text { including additional TCF items in order to evaluate the TCF construct } \\
\text { as a second-order model. } \\
\text { IS researcher } \\
\text { phase of the study. }\end{array}$ \\
\hline
\end{tabular}

The above mentioned comments were then discussed with supervising staff and a variety of steps were taken.

Two researchers suggested extending the existing scales and search for additional TCF dimensions. Therefore, it was decided to review the existing literature on task research more thoroughly for potential new TCF dimensions. The extended literature review and the new item development are discussed in the next section.

The feedback obtained on the pilot study evaluation indicated that the theoretical model should be assessed using three separate datasets: 1. A complete dataset, 2. A financial loan dataset, and 3. An account inquiries dataset. One of the paper reviewers suggested this procedure and similar comments were made by one of the senior IS researchers. Thus, it was decided to follow this advice for the main study of this research and also conduct statistical multi-group analyses in order to compare the sub-datasets (see section 6.8.7. for a more thorough discussion).

One of the IS researchers suggested integrating the concept of task uncertainty and task equivocality into the TCF construct. These notions would be influential for task-media fit theory and the researcher suggested that they would also apply to the TCF construct. Hence, 
the literature was screened for both concepts. Next, the focus group discussion transcripts were re-investigated and research participants' comments were sought to substantiate the IS researcher's arguments. The outcome was then discussed with the supervising staff and it was decided to integrate both concepts into the TCF construct. They are discussed in more detail in the following section.

As suggested by one IS researcher, seven point Likert scales were considered for the main study. Kristensen and Eskildsen (2010) conducted a controlled experiment in which they tested a five-point versus a ten-point scale. As an outcome, the authors argued: "Our general conclusion is that a 10-point scale is preferable to a 5-point scale. This is due to a smaller standard deviation and to the fact that an increasing number of points will bring the scale closer to a continuous scale and thus closer to the assumption of most of the statistical techniques used by the practitioner" (Kristensen and Eskildsen 2010). Therefore, it was decided to use seven-point Likert scales for the main study.

\subsubsection{Adjustment of the formative measures}

The constructive feedback obtained from several senior IS researchers suggested rethinking the TCF measurement scales.

Thus, the literature on task research was revisited to gain additional insight on how other researchers have previously specified tasks in their investigations. Particularly, research on psychology (Latham and Yukl 1975; Payne 1976; Terborg and Miller 1978; Campbell 1984; Wood 1986), task-technology fit (Goodhue and Thompson 1995; Zigurs and Buckland 1998; Dishaw and Strong 1999; Zigurs, Buckland et al. 1999; D'Ambra and Wilson 2004; Gebauer and Tang 2008), as well as theory of media synchronicity (Daft and Macintosh 1981; Daft and Lengel 1986; Daft, Lengel et al. 1987; Dennis and Carte 1998; Dennis and Kinney 1998; Dennis and Valacich 1999; Dennis, Wixom et al. 2001; Dennis, Fuller et al. 2008) often characterized tasks in various contexts.

The identified articles were reviewed with a specific focus on the conceptualization of tasks individuals perform. The task conceptualizations were pooled within a Microsoft Excel spreadsheet. In consultation with supervising staff, the task-conceptualizations were then clustered into eight distinctive dimensions: 1) task complexity, 2) task equivocality, 3) task uncertainty, 4) task routineness, 5) task analyzability, 6) task time criticality, 7) task importance, and 8) task effort. The next section develops each dimension based on the 
reviewed literature. Further, items are suggested to measure each dimension in the main phase of the study.

\subsubsection{Task complexity}

In addition to the literature discussed in chapter three, further research was found which conceptualized tasks according to their complexity (Wood 1986; Campbell 1988; Dennis and Kinney 1998; Zigurs and Buckland 1998; Karimi, Somers et al. 2004; Nadkarni and Gupta 2007). For instance, Wood (1986) argued that task complexity is a "direct function of the number of distinct acts that need to be executed in the performance of the task and the number of distinct information cues that must be processed in the performance of those acts" (Wood 1986). If the number of acts increases the knowledge and skill requirements for a task would also increase. This would be due to the fact that there are more activities individuals need to be aware of and able to perform. In that sense building a house would be more complex and difficult (as it involves more distinct cues and acts) than sawing a log (Wood 1986).

Campbell (1988) reviewed and analyzed the literature on task complexity in order to develop a typology of complex tasks. He argued that task complexity would be normally approached from three different perspectives: complexity as a psychological experience (Pierce and Dunham 1976; Taylor 1981), complexity as a function of objective characteristics (Latham and Yukl 1975; Payne 1976; Terborg and Miller 1978; Campbell 1984), and complexity as a task-person interaction (Frost and Mahoney 1976; Campbell and Gingrich 1980; Huber 1985). As one conclusion, Campbell (1988) reasoned that the perceived difficulty of a task should be considered in any study investigating tasks performed by individuals.

While Wood's and Campbell's frameworks were grounded in the psychology literature, researchers studying information systems have also conceptualized tasks according to their complexity.

For instance, Vessey (1991) conceptualized cognitive fit theory arguing: "Since humans are limited information processors, more effective problem solving will result when the complexity in the task environment is reduced. In this paper, the notion is developed that complexity in the task environment will be effectively reduced when the problem-solving aids (tools, techniques, and/or problem representations) support the task strategies (methods or processes) required to perform that task. This notion is termed cognitive fit. Problem solving with cognitive fit results in increased problem-solving efficiency and effectiveness" (Vessey 
1991). While Vessey's (1991) article did not develop task complexity measures, the author clearly suggested that the complexity of a task influences cognitive fit.

Barki et al. (1993) investigated the risk management related to the software application development process. The authors collected data from 120 software development projects and assessed a research model quantitatively through a survey questionnaire instrument (Barki, Rivard et al. 1993). As part of the instrument, the authors developed 20 items to measure the task-related complexity project manager face when developing software applications.

Dennis and Kinney (1998) used media richness theory to investigate the communication patterns within teams. As part of their research model, task complexity was measured through the following items: 1. "this was a simple task to complete" and 2."this was a difficult task to complete" (Dennis and Kinney 1998). Task complexity would influence the task-media fit of specific communication media within organizations. Highly complex and difficult tasks would require richer media to support effective communication whereas simplistic tasks could also be performed on less rich media such as email.

As part of their TTF conceptualization, Zigurs and Buckland (1998) suggested that task complexity would be highly influential for the perceived task-technology fit of group support systems. While not empirically tested in their study, Zigurs and Buckland (1998) recommended that the difficulty of a task would negatively impact on the task-technology fit of GSS systems. In contrast, simplistic tasks would be better suited for GSS systems.

Karimi et al. (2004) studied the impact of environmental uncertainty and task characteristics on user satisfaction. The focus of this study was the use of information systems in an organizational context. As part of their research framework, Karimi et al. (2004) conceptualized task difficulty as an influential factor for user satisfaction. This study referred task difficulty to the "way individuals respond to problems that arise and it refers to the degree to which a decision maker lacks a formal, well-defined search procedure to solve a given problem" (Karimi, Somers et al. 2004).

Nadkarni et al. (2007) developed and tested a task-based model of perceived website complexity. This model suggested that perceived website complexity impacts on the users' willingness to utilize websites (Nadkarni and Gupta 2007). The authors developed a survey questionnaire instrument following Wood's (1986) framework, and developed task complexity items based on Wood's (1986) task complexity definition. The following two items were used to account for web-site complexity: "The degree to which users find the form 
and content cues at the individual webpages visually dense and dissimilar", and "The clarity between text and images was high-low" (Nadkarni and Gupta 2007).

Watsons-Manheim and Belanger (2007) studied media usage in an organizational context in order to understand "how individuals use various communication media, either simultaneously or sequentially, in organizations in order to communicate with other individuals" (Watson-Manheim and Belanger 2007). The findings suggested that face-to-face meetings are the preferred media over email for difficult tasks. Email on the other hand, would be well suited for simplistic tasks and individuals would select this media over telephone when discussing simple issues with other individuals (Watson-Manheim and Belanger 2007).

\section{Summary}

In summary, many researchers studying task-technology fit and/or task-media fit identified task complexity as an important characteristic of tasks. Within these studies, researchers recurrently used terms such as task difficulty and task simplicity to conceptualize task complexity.

\section{Implications for this study}

This study conceptualized task complexity as one TCF dimension in the conceptual research model (Chapter 3). Two parallel items were pilot tested during the initial test of the survey questionnaire instrument. The product-score analysis suggested that the task complexity dimension was statistically significant related to the TCF construct. To improve the measurement of the task complexity dimension, additional items were created based on the construct definition and the literature reviewed on task complexity. The items were designed to integrate task difficulty and task simplicity since these concepts were recurrently used interchangeably with task complexity by the extant literature. Table 86 defines the task complexity dimension and introduces the newly created item.

Table 86: Adjusted task complexity scales

\begin{tabular}{|c|l|l|}
\hline & & \multicolumn{1}{c|}{ TCF - task characteristics } \\
\hline \multirow{4}{*}{$\begin{array}{c}\text { Task } \\
\text { complexity }\end{array}$} & Definition & $\begin{array}{l}\text { The level of complexity applied to banking tasks is understood as the perceived } \\
\text { difficulty individuals experience while performing a given banking task. Based on } \\
\text { (Wood 1986) }\end{array}$ \\
\cline { 2 - 3 } & COMP1 & In general, applying for a financial loan is complex. \\
\cline { 2 - 3 } & COMP2 & Overall, a financial loan is a complicated banking transaction. \\
\cline { 2 - 3 } & COMP3 & Generally, applying for a financial loan is an easy-to-do banking task. \\
\cline { 2 - 3 } & COMP4 & I would find it straightforward to apply for a financial loan. \\
\hline & & \multicolumn{1}{c|}{ TCF - channel suitability } \\
\hline & & \multicolumn{2}{c|}{ Internet banking is well suited for: } \\
\hline Task & CCOMP1 & Complex banking transactions. \\
\hline
\end{tabular}




\begin{tabular}{|c|l|l|}
\hline complexity & CCOMP2 & Complicated banking transactions. \\
\cline { 2 - 3 } (parallel) & CCOMP3 & Easy-to-do banking task. \\
\cline { 2 - 3 } & CCOMP4 & Straightforward banking transactions. \\
\hline
\end{tabular}

The following section discusses the second major task dimension frequently used by other researchers.

\subsubsection{Task equivocality}

Information equivocality can be defined as: "the multiplicity of meaning conveyed by information about organizational activities" (Daft and Macintosh 1981). Equivocality means ambiguity and it involves the existence of multiple and conflicting interpretations in an organizational context (Daft and Lengel 1986). Particularly studies investigating task-media fit have integrated task equivocality as part of their investigations (Daft and Macintosh 1981; Daft and Lengel 1986; Daft, Lengel et al. 1987; Rice and Shook 1990; Rice 1992; Markus 1994; Dennis and Kinney 1998).

For instance, Daft et al. (1986) argued that individuals performing highly equivocal tasks are often faced with confusion in combination with a lack of understanding. Yes-no questions are not feasible to ask in high equivocal environments and situations are normally ill-defined to the point where solutions are not forthcoming (Daft and Lengel 1986). The authors provided an example for best studying equivocality in laboratory environment: "A laboratory situation analogous to the ambiguity faced by managers would be to provide subjects with partial or contradictory instructions for the experimental game, or to leave it to subjects to figure out and create their own game" (Daft and Lengel 1986).

Rice and Shook (1990) investigated the use of email for performing equivocal tasks in an organizational context. Depending on the task equivocality, managers would select different media for performing managerial tasks. The authors suggested that individuals in higher level positions were found to be more likely to use e-mail for their equivocal tasks (Rice and Shook 1990).

Markus (1994) investigated how managers use email within organizations. The author surveyed managers in an organization and found that managers used lean media such as email for equivocal communication tasks (Markus 1994). In this study, Markus argued: "Communication tasks high in ambiguity (also known as equivocality), such as the settlement of a dispute, require information richness; tasks low in equivocality, such as providing a sales forecast, do not. Communication media vary in their ability to carry rich information. Lean 
media lack adequate support for high equivocality tasks; rich media have more than enough capacity to support low equivocality tasks" (Markus 1994).

Goodhue and Thompson (1995) also integrated this concept in their task-technology fit theory. The authors used three task equivocality measures as part of their TTF construct: " 1 . I frequently deal with ill-defined business problems., 2. I frequently deal with ad-hoc, non routine business problems., 3. Frequently the business problems I work on involve answering questions that have never been asked in quite that form before."

Dennis and Kinney (1998) used media-richness theory to test if team members using richer media for equivocal tasks would perform better than using less rich media. Surprisingly, the results disconfirmed the assumption that rich media would be better suited for high equivocal tasks and matching rich media to task equivocality did not improve team members' performance.

Lim and Benbasat (2000) studied the effect of multimedia on perceived equivocality and perceived usefulness of information systems. The authors investigated several data representation formats and tested which multimedia-representation was most suited for high equivocal tasks. The findings suggested that text-based representation and multimedia representation are equally effective in reducing the perceived equivocality levels. In contrast, multimedia representation was better suited for reducing perceived equivocality levels for less-analyzable tasks (Lim and Benbasat 2000).

\section{Summary}

Task equivocality has been an integral concept for studies around task-media fit theory. Highly equivocal tasks would involve situations in which individuals feel unsure, uncertain, and ambiguous. Goodhue and Thompson (1995) also included task equivocality in their scales suggesting that task equivocality also impacts on the perceived fit between tasks and technologies.

\section{Implications for this study}

So far, little is known how task equivocality impacts on consumers' intentions to use electronic banking channels for performing banking tasks. However, it seemed reasonable to argue that task equivocality would impact on consumers perceptions of the task-channel fit between banking tasks and electronic banking channels. For instance, consumers might feel unsure or ambiguous if applying for a financial loan since they are not absolutely clear about how these transactions work. In contrast, they should feel less unsure when checking their 
account balances since it is unlikely that these basic transactions lead to ambiguity from a consumer perspective. Given the theoretical evidence from task-media fit and TTF, three items were created to test if task equivocality impact on consumers' perceptions of the fit between electronic banking channels and banking tasks. Table 87 lists the items used for the main phase of this study.

Table 87: Adjusted task equivocality scales

\begin{tabular}{|c|c|l|}
\hline & & \multicolumn{1}{c|}{ TCF - task characteristics } \\
\hline \multirow{4}{*}{$\begin{array}{c}\text { Task } \\
\text { equivocality }\end{array}$} & Definition & $\begin{array}{l}\text { Task equivocality is the perceived degree ambiguity that consumer feel when } \\
\text { performing a given banking task. Based on (Daft and Lengel 1986) }\end{array}$ \\
\cline { 2 - 4 } & EQU1 & I would feel unsure of myself if I were to apply for a financial loan. \\
\cline { 2 - 4 } & EQU2 & I would feel uncertain if applying for a financial loan myself. \\
\cline { 2 - 4 } & EQU3 & Applying for a financial loan myself would make me feel ambiguous. \\
\hline & & \\
\hline \multirow{3}{*}{$\begin{array}{c}\text { Task } \\
\text { equivocality }\end{array}$} & TCF - channel suitability \\
\cline { 2 - 4 } & CEQU2 & Banking transactions where I feel uncertain of myself. \\
\cline { 2 - 3 } & CEQU3 & Banking transactions where I feel ambiguous. \\
\hline
\end{tabular}

\subsubsection{Task uncertainty}

Many studies identified the notion of task uncertainty as another important aspect to consider when investigating tasks performed by individuals (Daft and Lengel 1986; Daft, Lengel et al. 1987; Dennis and Kinney 1998; Karimi, Somers et al. 2004). In particular research on task-media richness theory has recurrently conceptualized tasks with regard to their uncertainty.

For example, Daft and Lengel (1986) researched why organizations process information. According to them, organizations constantly process information to reduce task-related uncertainty (Daft and Lengel 1986). Task uncertainty was defined as "The difference between the amount of information required to perform the task and the amount of information already possessed by the organization" (Daft and Lengel 1986). Organizations would perform better if facing less uncertainty within their business related tasks. Organizations facing high uncertainty have to ask a large number of questions in order to acquire more information to learn the answers.

Daft, Lengel and Trevino (1987) investigated the concept of task uncertainty in relation to decision making processes in organizations. The authors' argument was that a major goal of information systems is to provide some structure to unstructured decision making processes (Daft, Lengel et al. 1987). Uncertainty could be best reduced by acquiring additional data. Since communication channels (e.g. email, phone, letter, face-to-face etc.) differ in terms of 
their media richness, their ability to facilitate understanding would also vary (Daft, Lengel et al. 1987). For example, some media would allow users to exchange instant feedback (e.g. face-to-face) whereas other channels would be less synchronous. Also, some communication channels would allow transmitting personal cues whereas others would not offer such functions (Daft, Lengel et al. 1987).

Dennis and Kinney (1998) tested media richness theory through experimental research design. The authors tested low-, medium- and high-uncertainty tasks in a laboratory use setting to investigate students' behavior related to information systems use. Task uncertainty was defined based on Daft and Lengel's (1986) definition. The findings suggested that the use of richer media did not lead to better performance on tasks of higher uncertainty (Dennis and Kinney 1998). This was unexpected considering that other studies established contrary findings (Daft, Lengel et al. 1987).

Karimi et al. (2004) also considered tasks in their research and they argued that uncertainty refers to ambiguity, lack of understanding, and the existence of multiple and conflicting interpretations about an organizational context (Karimi, Somers et al. 2004). The authors explained task uncertainty as follows: "the frequency of unexpected and novel events that occur in performing a task. Low task variety implies that decision makers experience considerably low uncertainty about the occurrence of future activities. On the other hand, high variety implies that decision makers experience cannot predict problems or activities in advance" (Karimi, Somers et al. 2004).

\section{Summary}

In summary, many researchers have considered task uncertainty when researching TTF or task-media fit related to information systems use. When facing uncertainty, individuals would like to obtain additional information so that the task would become less uncertain. This argument could be extended to perceived task-channel fit of electronic banking channels. For instance, if consumers feel uncertain about a given banking task, they would likely aim to obtain additional information before proceeding with the transaction.

\section{Implications for this study}

While little is known how task uncertainty can be integrated into studies researching electronic banking channels, many researchers using TTF or task-media fit theory have used this concept as part of their research models. Since this concept also applies to the context of this study, three items were created to test the concept of uncertainty during the main phase of 
this study. The following Table 88 defines the task uncertainty dimension and lists the newly created item.

Table 88: Adjusted task uncertainty scales

\begin{tabular}{|c|l|l|}
\hline & & \multicolumn{1}{c|}{ TCF - task characteristics } \\
\hline \multirow{4}{*}{$\begin{array}{c}\text { Task } \\
\text { uncertainty }\end{array}$} & Definition & $\begin{array}{l}\text { Task uncertainty is defined as the perceived difference between the amount of } \\
\text { information required to perform a given banking task and the amount of information } \\
\text { already possessed by the task performer (e.g. banking customer). Based on (Daft and } \\
\text { Lengel 1986) }\end{array}$ \\
\cline { 2 - 3 } & UNC1 & $\begin{array}{l}\text { When applying for a financial loan I have many questions that I want to clarify with my } \\
\text { bank before going ahead with the transaction. }\end{array}$ \\
\cline { 2 - 4 } & UNC3 & $\begin{array}{l}\text { Before applying for a financial loan I would require additional information on how the } \\
\text { process works. }\end{array}$ \\
\cline { 2 - 4 } & $\begin{array}{l}\text { Obtaining additional information before applying for a financial loan would be } \\
\text { absolutely essential for me. }\end{array}$ \\
\hline \multirow{2}{*}{$\begin{array}{c}\text { Task } \\
\text { (parallel) }\end{array}$} & CUNC1 & Clarifying questions related to a financial product. \\
\cline { 2 - 4 } & CUNC2 & Finding out additional information on how financial products work. \\
\cline { 2 - 3 } & CUNC3 & Obtaining additional information about financial products. \\
\hline
\end{tabular}

The following section discusses the next revised TCF dimension: task routineness.

\subsubsection{Task routineness}

Routineness was another characteristic that has been frequently used in the IS literature to conceptualize tasks. Many authors have argued that the level of routine with which individuals perform tasks influences their perceptions of it (Goodhue 1995; Goodhue and Thompson 1995; Goodhue 1997; Goodhue 1998; Suh 1999; Zigurs, Buckland et al. 1999; Karimi, Somers et al. 2004). Particularly research on task-media fit and task-technology fit research has established that task routineness impacts the fit between a given media (or technology) and the tasks performed by individuals.

For example, Goodhue and Thompson (1995) argued that task routineness impacts the perceived task-technology fit of information systems. The authors suggested that "the strongest effect of task characteristics on TTF was from non-routine tasks. We found that individuals engaged in more non-routine tasks related their information systems lower on data quality, data compatability, data locatability, training/ease of use, and difficulty of getting authorization to access data" (Goodhue and Thompson 1995).

As part of a study conducted to research the effect of media richness of technologies in organizations, Suh (1999) suggested that routine activities are more appropriate for lean communication channels. Once the task would become routine for the user, individuals would not require a rich media since they would feel familiar with the task. In contrast, non-routine activities would require richer communication media (Suh 1999). 
Karimi et al. (2004) hypothesized that task nonroutineness has a negative effect on user satisfaction with information systems. The authors' argument was that if decision makers experience unfamiliar, unexpected and novel situations, they will require a wide scope of information before making a managerial decision. To test this hypothesis, Karimi et al. (2004) used four items to account for the task nonroutineness in their study: 1) I frequently deal with ad hoc, non-routine business problems, 2) I frequently deal with ill-defined business problems, 3) Frequently, the business problems I work on involve answering questions that have never been asked in quite that form before, 4) Frequently, in the mindset of using data to address some issue, I may decide to restate the problem and access slightly different data than I had at first planned.

\section{Summary}

The above studies emphasized the importance of task routineness when studying use behavior related to information systems. The authors also often mentioned task frequency when conceptualizing task routineness.

\section{Implications for this study}

Since consumers may perform certain banking tasks routinely, task routineness was accepted as another dimension of the TCF construct. The literature also suggests that task frequency conceptually overlaps with task routineness (Karimi, Somers et al. 2004). Thus, the items used to assess task frequency (as developed in chapter 4) were integrated into the more general concept of task routineness.

Table 89: Adjusted task routine scales

\begin{tabular}{|c|l|l|}
\hline & & \multicolumn{1}{c|}{ TCF - task characteristics } \\
\hline \multirow{4}{*}{ Task routine } & Definition & $\begin{array}{l}\text { Task routineness refers to a regular procedure usually followed by banking customers } \\
\text { to perform a given banking transaction. Based on (Goodhue and Thompson 1995) }\end{array}$ \\
\cline { 2 - 4 } & ROUT1 & Applying for a financial loan is a banking transaction I routinely perform. \\
\cline { 2 - 4 } & ROUT2 & I regularly apply for a financial loan. \\
\cline { 2 - 4 } & ROUT3 & I often apply for a financial loan. \\
\cline { 2 - 4 } & ROUT4 & A loan application is a banking transaction I frequently do. \\
\hline \multirow{4}{*}{$\begin{array}{c}\text { Task routine } \\
\text { (parallel) }\end{array}$} & TCF - channel suitability \\
\cline { 2 - 4 } & CROUT2 & Banking transactions I regularly do. \\
\cline { 2 - 4 } & CROUT3 & Banking transactions I often do. \\
\cline { 2 - 3 } & CROUT4 & Banking transactions I frequently do. \\
\hline
\end{tabular}

The next task-channel fit dimension was identified as task analyzability. 


\subsubsection{Task analyzability}

The analyzability of a task was also often conceptualized by various researchers (Perrow 1967; Rice 1992; King and Xia 1997; Lim and Benbasat 2000). Task analyzability refers "to the intellectual effort individuals have to perform while doing a task" (Perrow 1967).

For instance, Perrow (1967) developed a framework to comparatively analyze tasks typically performed by individuals within organizations. As part of this framework, the author identified two major task characteristics: task analyzability and task routineness (Perrow 1967). The latter characteristic was discussed in depth in the previous section. Task analyzability includes the way "individuals are able to respond to problems that arise in the process of task completion" (Perrow 1967). Analyzable tasks would be those for which predetermined responses to potential problems and well-known procedures are available and the outcomes would be commonly well understood by the task-doer (Perrow 1967).

Rice (1992) also discussed task analyzability in a study focusing on media richness theory. The research design involved several organizations using various information systems to organize their day-to-day tasks (e.g. email, video-conferencing, voice mail etc.). To account for the suitability of each communication channel, task conditions were designed to vary in terms of their analyzability. As part of the task conceptualization, the author argued that: "When activities are analyzable, more procedures are established and individuals do not have to turn to past or shared experiences for information about how to accomplish the task. In unanalyzable task environments, processing is more personal, less linear, more ad hoc and improvisational unanalyzable tasks require individuals to think about, create, or find satisfactory solutions to problems outside of the domain of facts, rules, or procedures" (Rice 1992).

King and Xia (1997) investigated the effect of learning experiences with nine communication media, based on perceptional changes of media appropriateness (King and Xia 1997). The authors surveyed 295 MBA students about their perceptions of media appropriateness. The findings indicated that traditionally rich media such as face-to-face, group meetings, and telephone were consistently perceived to be more appropriate for analyzable tasks than lean media such as email. As part of their research framework, the authors characterized tasks in terms of their analyzability. Task analyzability was defined as the "degree to which tasks involve the application of objective, well-understood procedures that do not require novel solutions" (King and Xia 1997). The authors argued that media choice depends on the fit between media richness and the task characteristics (e.g. task 
analyzability). Unanalyzable tasks would often require interpersonal negotiations which would be best performed on rich media. In contrast, analyzable tasks would be better suited for leaner media such as email and written documents since the procedures would be well understood by the task-doer (King and Xia 1997).

Lim and Benbasat (2000) also suggested that for addressing analyzable tasks, individuals would require a common understanding which would be best achieved through rich media. In contrast, less analyzable tasks would be best dealt with via "predefined responses, procedures, and/or knowledge of what is needed to solve the problem or the perform the task" (Lim and Benbasat 2000).

\section{Summary}

Many researchers have integrated the concept of task analyzability when researching TTF or task-media fit. These studies have argued that some tasks require a high level of intellectual effort whereas other tasks are less intellectual intensive.

\section{Implications for this study}

Since banking tasks differ in terms of their analyzability as well, task analyzability was accepted as another TCF dimension. The studies researching task analyzability recurrently emphasized that analyzable tasks require individuals to think about, plan ahead, analyze and thoroughly consider the tasks to be performed. Thus, the following items were created to account for task analyzability of banking services.

Table 90: Adjusted task analyzability scales

\begin{tabular}{|c|l|l|}
\hline & & \multicolumn{1}{c|}{ TCF - task characteristics } \\
\hline \multirow{4}{*}{$\begin{array}{c}\text { Task } \\
\text { analyzability }\end{array}$} & Definition & $\begin{array}{l}\text { Task analyzability is the perceived degree to which electronic banking channel users } \\
\text { require methodologically analyze specific financial banking tasks. Based on (Perrow } \\
1967)\end{array}$ \\
\cline { 2 - 4 } & ANZBL1 & Overall, applying for a financial loan requires a lot of thinking. \\
\cline { 2 - 4 } & ANZBL2 & Applying for a financial loan requires detailed consideration. \\
\cline { 2 - 4 } & ANZBL3 & A financial loan application is a banking transaction I would plan thoroughly. \\
\cline { 2 - 4 } & ANZBL4 & A financial loan application is a banking transaction I would give a lot of thought to. \\
\hline \multirow{4}{*}{$\begin{array}{c}\text { Task } \\
\text { analyzability } \\
\text { (parallel) }\end{array}$} & & \\
\cline { 2 - 4 } & CANZF - channel suitability \\
\cline { 2 - 4 } & CANZBL3 & Banking transactions that require detailed consideration. \\
\cline { 2 - 4 } & CANZBL4 & Banking transactions I would give a lot of thought to. \\
\hline
\end{tabular}

\subsubsection{Task time criticality}

As discussed in chapter 3, extant literature on electronic banking suggested that time criticality is an important factor influencing individuals using electronic banking channels. In 
addition, a considerable amount of research has investigated time criticality in organizational and psychological studies.

For instance, Landry et al. (1991) argued that some people are more concerned about time and its passage than others. Many studies in psychology have also conceptualized time as part of their research and labeled individuals into Type A and Type B behavioral patterns, reflecting their sense of time criticality. Type A are "those individuals who are engaged in a relatively chronic struggle to obtain an unlimited number of poorly defined things from their environment in the shortest period of time and, if necessary, against the opposing effects of other things or persons in this same environment" (Landry, Rastegary et al. 1991). In contrast, individuals labeled as Type B are characterized as a much more relaxed person with a less competitive approach to life (which could be seen as the opposite of Type A individuals) (Landry, Rastegary et al. 1991). Based on these principles, Jenkins et al. (1971) developed the Jenkins Activity Survey (JAS) which was designed as a multi-item survey questionnaire. This instrument was a self-reported instrument developed to evaluate the concepts of time urgency, time awareness, and time use of working individuals (Jenkins, Zyanski et al. 1971). While many of the JAS items were designed to measure individuals' attitudes towards time in general, particularly the time criticality dimension led to more research in the field investigating whether individuals perceive tasks as urgent or not (Landry, Rastegary et al. 1991; Gattiker and Goodhue 2005).

A few researchers investigating the use of information systems have applied time criticality to the context of IS and studied how perceived urgency affects individuals when using IS (Gattiker and Goodhue 2005; Park, Im et al. 2008).

For instance, Park et al. (2008) investigated software development projects and a project member's reluctance to report bad news about a troubled project. The authors focused on two factors that were seen to be particularly important in software development environment: (a) the issue of fault responsibility that arises in the context of outsourced IT projects that involve an external vendor, and (b) the issue of time urgency, which has become more important as firms seek to compete on developing and delivering applications with greater speed (Park, Im et al. 2008). To test this assumption, the authors conducted a controlled laboratory experiment in which information systems students were confronted with different software application development scenarios. The results confirmed that both fault responsibility and time urgency can have significant effects on an individual's willingness to report bad news (Park, Im et al. 2008). To test the time urgency construct, the following items were used by Park et al. (2008): 
1) I believe that this matter is of considerable time urgency given the schedule under which CAPS is to be installed, 2) I believe that the problems must be solved quickly because of the CAPS installation schedule.

Junglas et al. (2009) used task-technology fit theory to investigate the use of mobile technologies in a healthcare context. The authors initially conducted a qualitative study in order to identify several dimensions describing the fit between technology, individuals, and tasks. Among other dimensions, time criticality was found to be an important issue for the TTF in context of this study. This concept was based on a nurse's need to be informed about urgent medical interventions, such as medication administration (Junglas, Abraham et al. 2009). During the second phase of the research, the conceptualized TTF dimensions were tested quantitatively. As part of the overall research model, perceived time criticality was assessed through the following items: 1) The mobile system supports me by alerting me about urgent interventions that are due, 2) The need to be alert of urgent interventions fits nicely what the mobile system provides to me.

Yuan et al. (2010) aimed to identify the ideal fit between mobile work and mobile work support. To do this, the authors developed and tested a mobile task model including three dimensions: mobility, location dependency, and time criticality. Further, four context-related mobile work support functions were examined: location tracking, navigation, notification, and online job dispatching (Yuan, Archer et al. 2010). The ideal fit was analyzed on the basis of empirical data collected from a sample of mobile knowledge- and field-workers. The time criticality construct was assessed through the following items: 1) What is the time urgency for you to start or finish your typical task, 2) It is very important for you to start your task on time, 3) It is very important for you to complete your task on time, 4) It is very important for you to start your task as soon as possible, 5) It is very important for you to complete your task as soon as possible.

\section{Summary}

In summary, literature on electronic banking and information systems has confirmed that the perceived time criticality of tasks impacts on the way individuals use specific information systems. Particularly mobility related research has investigated the effect of perceived time criticality on individuals when using mobile devices.

\section{Implications for this study}

This research tested two items on time criticality during the pilot study. Both formative measures contributed significantly to the perceived TCF construct. Given the pilot test 
analysis, as well as the feedback from the senior IS researchers discussed in the previous section, additional items on time criticality were created for the main data collection round. The development of the new items was based on the literature discussed above. Table 91 illustrates the existing and newly created items.

Table 91: Adjusted task time criticality scales

\begin{tabular}{|c|c|l|}
\hline & & \multicolumn{1}{c|}{ TCF - task characteristics } \\
\hline \multirow{4}{*}{$\begin{array}{c}\text { Task time } \\
\text { criticality }\end{array}$} & Definition & $\begin{array}{l}\text { Task time criticality is defined as the perceived urgency financial transactions require } \\
\text { execution. Based on (Landry, Rastegary et al. 1991) }\end{array}$ \\
\cline { 2 - 3 } & TIME1 & I often want to apply for a financial loan instantly. \\
\cline { 2 - 4 } & TIME2 & I seldom face situations in which I need to apply for a financial loan urgently. \\
\cline { 2 - 4 } & TIME3 & I often need to apply for a financial loan immediately. \\
\cline { 2 - 3 } & TIME4 & Overall, I perceive financial loan applications as very urgent banking transactions. \\
\hline \multirow{4}{*}{$\begin{array}{c}\text { Task time } \\
\text { criticality } \\
\text { (parallel) }\end{array}$} & CTCF - channel suitability \\
\cline { 2 - 4 } & CTIME2 & Banking transactions I want to do instantly. \\
\cline { 2 - 4 } & CTIME3 & Banking transactions I have to do immediately. \\
\cline { 2 - 3 } & CTIME4 & Banking transactions that are very urgent to me. \\
\hline
\end{tabular}

\subsubsection{Task importance and task effort}

The literature search on task importance and task effort did not yield any additional articles that have conceptualized these concepts in more detail (apart from the research already discussed in Chapter (3). However, the task importance and task effort items tested during the pilot test contributed significantly to the TCF construct. Given the outcome of the pilot study data analysis, as well as the received feedback discussed in the previous section, additional items were included to measure both dimensions more precisely. Table 92 lists the items developed for the main data collection round.

Table 92: Adjusted task importance and task effort scales

\begin{tabular}{|c|c|c|}
\hline & & TCF - task characteristics \\
\hline \multirow{8}{*}{$\begin{array}{c}\text { Task } \\
\text { importance }\end{array}$} & Definition & $\begin{array}{l}\text { Task importance is defined as the level of perceived salience individuals view specific } \\
\text { banking transactions. Based on (Reinsch and Beswick 1990) }\end{array}$ \\
\hline & IMPOR1 & A loan application is an ordinary banking transaction to me. \\
\hline & IMPOR2 & Applying for a loan is commonplace banking task. \\
\hline & IMPOR3 & Applying for a financial loan is a major transaction in my mind. \\
\hline & IMPOR4 & A financial loan application is a serious banking transaction for me. \\
\hline & IMPOR5 & Applying for a financial loan will influence my personal finances significantly. \\
\hline & & TCF - channel suitability \\
\hline & & Internet banking is well suited for: \\
\hline \multirow{7}{*}{$\begin{array}{c}\text { Task } \\
\text { importance } \\
\text { (parallel) }\end{array}$} & CIMPOR1 & Ordinary banking transactions. \\
\hline & CIMPOR2 & Commonplace banking transactions. \\
\hline & CIMPOR3 & Major banking transactions \\
\hline & CIMPOR4 & Serious banking transactions. \\
\hline & CIMPOR5 & Banking transactions that influence my personal finances significantly. \\
\hline & & TCF - task characteristics \\
\hline & Definition & Task effort is defined as the perceived effort individuals have to make while performing \\
\hline
\end{tabular}




\begin{tabular}{|c|l|l|}
\hline & & a given banking task. Based on (Wood 1986; Campbell 1988) \\
\hline \multirow{4}{*}{ Task effort } & EFFOR1 & I have to provide a lot of information to my bank when applying for a financial loan. \\
\cline { 2 - 4 } & EFFOR2 & A loan application does not require filling out many forms. \\
\cline { 2 - 4 } & EFFOR3 & There a many steps to go through when applying for a financial loan. \\
\cline { 2 - 4 } & EFFOR4 & Overall, I think it takes a lot of effort to apply for a financial loan. \\
\hline & & \\
\hline \multirow{3}{*}{$\begin{array}{c}\text { Task effort } \\
\text { (parallel) }\end{array}$} & & \\
\cline { 2 - 4 } & CEF - channel suitability \\
\cline { 2 - 4 } & CEFFOR2 & Banking transactions that do not require filling out many forms.* \\
\cline { 2 - 4 } & CEFFOR4 & Banking transactions that require performing many steps. \\
\hline
\end{tabular}

The importance items were created based on the scales of Schneider and Rogers (1996). These authors developed an importance subscale to measure consumer involvement in shopping environments (Schneider and Rodgers 1996). The effort items were based on Campbell's (1988) and Wood's (1986) complexity research frameworks.

\subsubsection{Adjustment of the reflective measures}

Familiarity was assessed through two categorical items during the pilot study 1. Do you feel familiar with Internet banking; 2. Do you feel familiar with account inquiries/financial loans? While these items remained in the first section of the survey questionnaire (see Appendix), it was also felt that the respondents' familiarity with Internet banking/banking tasks should be investigated more thoroughly. Thus, eight reflective familiarity items were included towards the end of the survey questionnaire (four items to check on the respondents' familiarity with the banking task in question and four items to measure their familiarity with Internet banking).

FAMC1 and FAMBT1 (see Table 93) were borrowed from Gefen et al. (2003). FAMC2, FAMBT2, FAMC3, and FAMBT3 were adjusted from Kleiser and Mantel (1994). These original scales were developed to investigate the influence product familiarity on a consumer's purchase decision making process (Kleiser and Manter 1994). FAMC4 and FAMBT4 were adjusted from Lastovicka and Gardner (1979) also investigated the consumers' product familiarity in regards to purchasing behaviour (Lastovicka and Gardner 1979).

Table 93: Familiarity items used during the main study

\begin{tabular}{|c|c|l|}
\hline \multirow{4}{*}{$\begin{array}{c}\text { Channel } \\
\text { familiarity }\end{array}$} & Definition & $\begin{array}{l}\text { Familiarity is an understanding, often based on previous interaction, experiences, } \\
\text { and learning of using an electronic banking channel (Gefen et al., 2003; Gefen, } \\
\text { 2000) }\end{array}$ \\
\cline { 2 - 3 } & FAMC1 & I am familiar with using Internet banking. \\
\cline { 2 - 3 } & FAMC2 & I understand how Internet banking works. \\
\cline { 2 - 3 } & FAMC3 & I consider myself knowledgeable with Internet banking. \\
\cline { 2 - 4 } & FAMC4 & I am not at all familiar with using Internet banking.* \\
\hline $\begin{array}{c}\text { Task } \\
\text { familiarity }\end{array}$ & Definition & $\begin{array}{l}\text { Familiarity is an understanding, often based on previous interaction, experiences, } \\
\text { and learning of using an electronic banking channel (Gefen et al., 2003; Gefen, }\end{array}$ \\
\hline
\end{tabular}




\begin{tabular}{|l|l|l|}
\hline & & $2000)$ \\
\cline { 2 - 3 } & FAMBT1 & I am familiar with financial loans/account inquiries. \\
\cline { 2 - 3 } & FAMBT2 & I understand how financial loans/account inquiries work. \\
\cline { 2 - 3 } & FAMBT3 & I consider myself knowledgeable with financial loans/account inquiries. \\
\cline { 2 - 4 } & FAMBT4 & I am not at all familiar with using financial loans/account inquiries.* \\
\hline
\end{tabular}

The remaining reflective items were not adjusted due to the promising results of the pilot study.

Before discussing how the new items were pretested, the following section displays the adjusted research model and the complete survey instrument used to assess the model.

\subsection{Revised research model and complete survey Instrument}

Figure 43 displays the revised research model. The adjustments discussed in the previous sections particularly influenced the operationalization of the perceived task-channel fit construct. The left hand side of the revised research model included eight task-channel fit dimensions. The remaining constructs (precursors of channel utilization and intention to use) of the research model were not changed. 


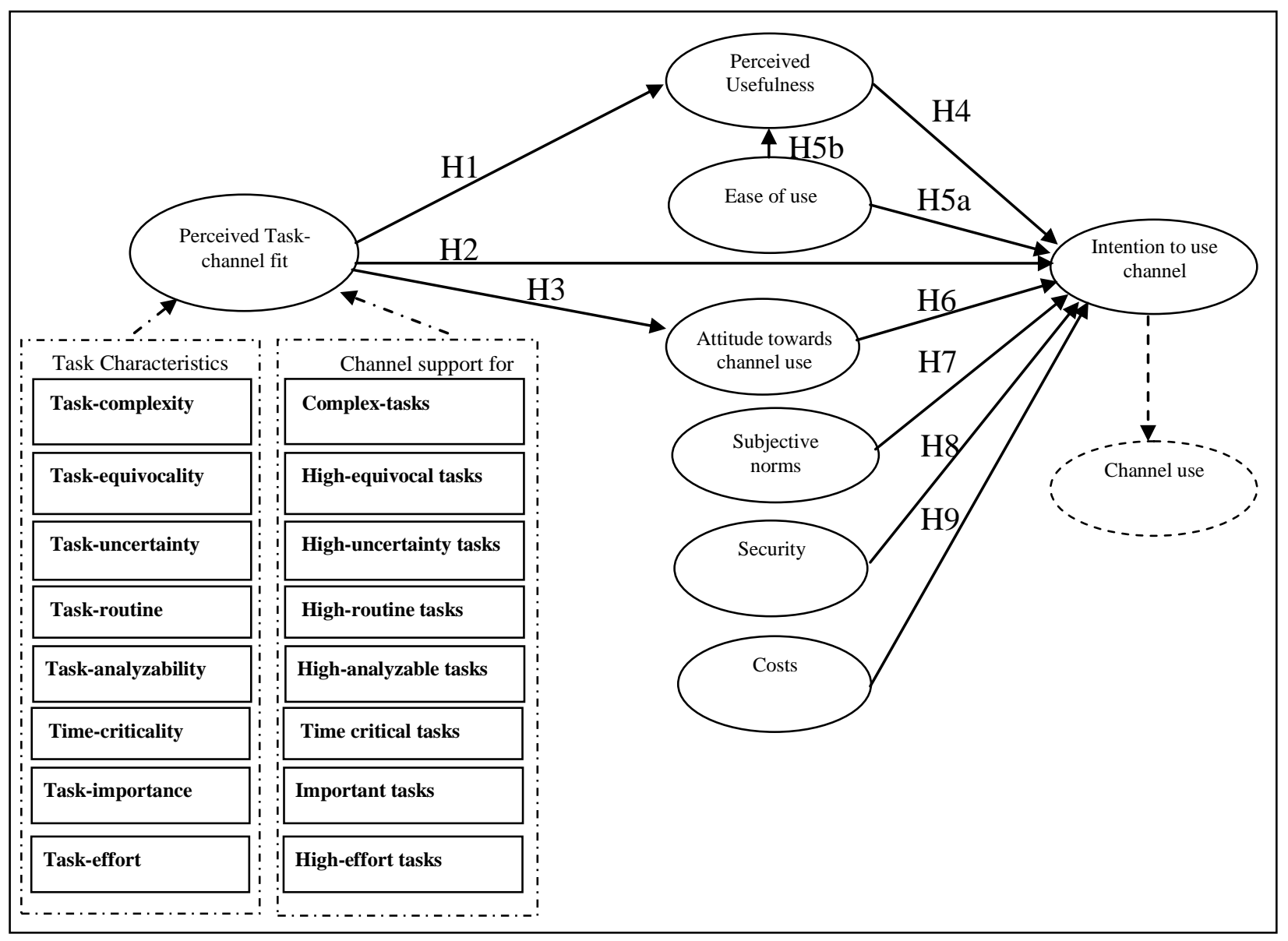

Figure 43: Revised research model

The research questionnaire was modified accordingly. Table 94 displays the complete survey questionnaire instrument used during the main study of this research.

Table 94: Complete survey questionnaire instrument

\begin{tabular}{|c|c|c|}
\hline & \multicolumn{2}{|r|}{ Construct definitions } \\
\hline $\begin{array}{l}\text { Electronic } \\
\text { banking } \\
\text { Channel }\end{array}$ & \multicolumn{2}{|c|}{$\begin{array}{l}\text { An electronic banking channel is an IS artifact that provides representations of one or more banking } \\
\text { task domains. This implies that electronic banking channels provide features that are designed to } \\
\text { support functions in those banking task domain(s). Based on (Burton-Jones and Straub, 2006) }\end{array}$} \\
\hline $\begin{array}{c}\text { Banking } \\
\text { Task }\end{array}$ & \multicolumn{2}{|c|}{$\begin{array}{l}\text { A banking task is a goal-directed banking activity performed by a consumer. Based on (Burton-Jones } \\
\text { and Straub, 2006) }\end{array}$} \\
\hline $\begin{array}{c}\text { Electronic } \\
\text { banking } \\
\text { channel user }\end{array}$ & \multicolumn{2}{|c|}{$\begin{array}{l}\text { An electronic banking channel user is an individual person who employs an electronic banking } \\
\text { channel to perform a banking task. Based on (Burton-Jones and Straub, 2006) }\end{array}$} \\
\hline $\begin{array}{c}\text { Task-channel } \\
\text { Fit } \\
\end{array}$ & \multicolumn{2}{|c|}{$\begin{array}{l}\text { Task-channel fit is defined as the user's perception of the suitability of a particular electronic banking } \\
\text { channel to support a particular banking task. Based on (Goodhue and Thompson 1995) }\end{array}$} \\
\hline & $\begin{array}{l}\text { TCF } \\
\text { dimension }\end{array}$ & Items \\
\hline \multicolumn{3}{|r|}{ TCF - task characteristics } \\
\hline \multirow{4}{*}{$\begin{array}{l}\text { Task } \\
\text { complexity }\end{array}$} & Definition & $\begin{array}{l}\text { The level of complexity applied to banking tasks is understood as the perceived } \\
\text { difficulty individuals experience while performing a given banking task. Based on } \\
\text { (Wood 1986) }\end{array}$ \\
\hline & COMP1 & In general, applying for a financial loan is complex. \\
\hline & COMP2 & Overall, a financial loan is a complicated banking transaction. \\
\hline & COMP3 & Generally, applying for a financial loan is an easy-to-do banking task. \\
\hline
\end{tabular}




\begin{tabular}{|c|c|c|}
\hline & COMP4 & I would find it straightforward to apply for a financial loan. \\
\hline & & TCF - channel suitability \\
\hline & & Internet banking is well suited for: \\
\hline \multirow{5}{*}{$\begin{array}{l}\text { Task } \\
\text { complexity } \\
\text { (parallel) }\end{array}$} & CCOMP1 & Complex banking transactions. \\
\hline & CCOMP2 & Complicated banking transactions. \\
\hline & CCOMP3 & Easy-to-do banking task. \\
\hline & CCOMP4 & Straightforward banking transactions. \\
\hline & & TCF - task characteristics \\
\hline \multirow{6}{*}{$\begin{array}{c}\text { Task } \\
\text { equivocality }\end{array}$} & Definition & $\begin{array}{l}\text { Task equivocality is the perceived degree ambiguity that consumer feel when } \\
\text { performing a given banking task. Based on (Daft and Lengel 1986) }\end{array}$ \\
\hline & EQU1 & I would feel unsure of myself if I were to apply for a financial loan. \\
\hline & EQU2 & I would feel uncertain if applying for a financial loan myself. \\
\hline & EQU3 & Applying for a financial loan myself would make me feel ambiguous. \\
\hline & & TCF - channel suitability \\
\hline & & Internet banking is well suited for: \\
\hline \multirow{3}{*}{$\begin{array}{l}\text { Task } \\
\text { equivocality } \\
\text { (parallel) }\end{array}$} & CEQU1 & Banking transactions where I feel unsure of myself. \\
\hline & CEQU2 & Banking transactions where I feel uncertain of myself. \\
\hline & CEQU3 & Banking transactions where I feel ambiguous. \\
\hline \multirow{6}{*}{$\begin{array}{c}\text { Task } \\
\text { uncertainty }\end{array}$} & Definition & $\begin{array}{l}\text { Task uncertainty is defined as the perceived difference between the amount of } \\
\text { information required to perform a given banking task and the amount of information } \\
\text { already possessed by the task performer (e.g. banking customer). Based on (Daft and } \\
\text { Lengel 1986) }\end{array}$ \\
\hline & UNC1 & $\begin{array}{l}\text { When applying for a financial loan I have many questions that I want to clarify with my } \\
\text { bank before going ahead with the transaction. }\end{array}$ \\
\hline & UNC2 & $\begin{array}{l}\text { Before applying for a financial loan I would require additional information on how the } \\
\text { process works. }\end{array}$ \\
\hline & UNC3 & $\begin{array}{l}\text { Obtaining additional information before applying for a financial loan would be } \\
\text { absolutely essential for me. }\end{array}$ \\
\hline & & TCF - channel suitability \\
\hline & & Internet banking is well suited for: \\
\hline \multirow{4}{*}{$\begin{array}{c}\text { Task } \\
\text { uncertainty } \\
\text { (parallel) }\end{array}$} & CUNC1 & Clarifying questions related to a financial product. \\
\hline & CUNC2 & Finding out additional information on how financial products work. \\
\hline & CUNC3 & Obtaining additional information about financial products. \\
\hline & & TCF - task characteristics \\
\hline \multirow{7}{*}{ Task routine } & Definition & $\begin{array}{l}\text { Task routineness refers to a regular procedure usually followed by banking customers } \\
\text { to perform a given banking transaction. Based on (Goodhue and Thompson 1995) }\end{array}$ \\
\hline & ROUT1 & Applying for a financial loan is a banking transaction I routinely perform. \\
\hline & ROUT2 & I regularly apply for a financial loan. \\
\hline & ROUT3 & I often apply for a financial loan. \\
\hline & ROUT4 & A loan application is a banking transaction I frequently do. \\
\hline & & TCF - channel suitability \\
\hline & & Internet banking is well suited for: \\
\hline \multirow{4}{*}{$\begin{array}{l}\text { Task routine } \\
\text { (parallel) }\end{array}$} & CROUT1 & Banking transaction I routinely perform. \\
\hline & CROUT2 & Banking transactions I regularly do. \\
\hline & CROUT3 & Banking transactions I often do. \\
\hline & CROUT4 & Banking transactions I frequently do. \\
\hline \multirow{6}{*}{$\begin{array}{c}\text { Task } \\
\text { analyzability }\end{array}$} & Definition & $\begin{array}{l}\text { Task analyzability is the perceived degree to which electronic banking channel users } \\
\text { require methodologically analyze specific financial banking tasks. Based on (Perrow } \\
\text { 1967) }\end{array}$ \\
\hline & ANZBL1 & Overall, applying for a financial loan requires a lot of thinking. \\
\hline & ANZBL2 & Applying for a financial loan requires detailed consideration. \\
\hline & ANZBL3 & A financial loan application is a banking transaction I would plan thoroughly. \\
\hline & ANZBL4 & A financial loan application is a banking transaction I would give a lot of thought to. \\
\hline & & Internet banking is well suited for: \\
\hline \multirow{4}{*}{$\begin{array}{l}\text { Task } \\
\text { analyzability } \\
\text { (parallel) }\end{array}$} & CANZBL1 & Banking transactions that require a lot of thinking. \\
\hline & CANZBL2 & Banking transactions that require detailed consideration. \\
\hline & CANZBL3 & Thoroughly planning banking products. \\
\hline & CANZBL4 & Banking transactions I would give a lot of thought to. \\
\hline
\end{tabular}




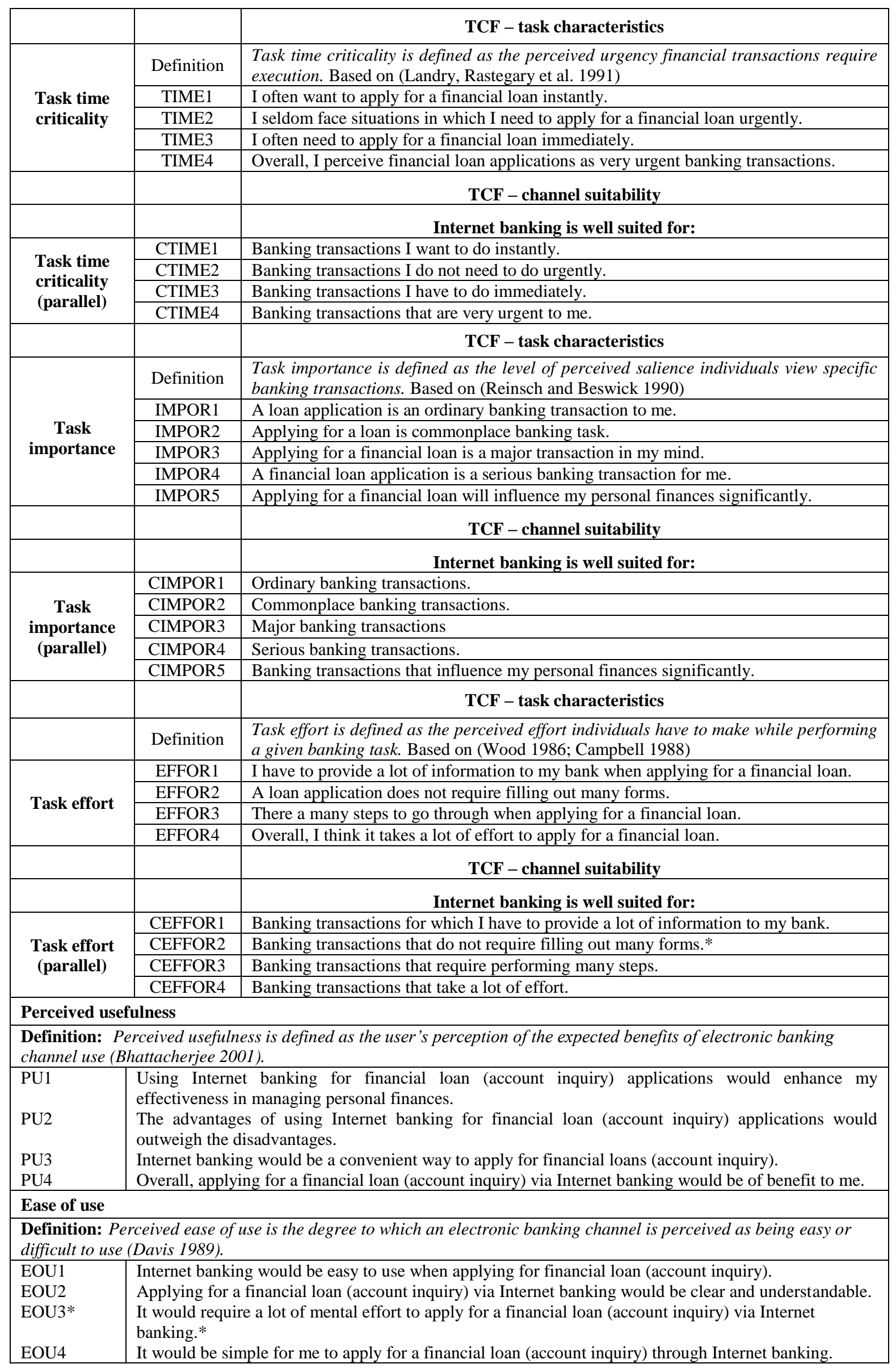




\begin{tabular}{|c|c|}
\hline \multicolumn{2}{|c|}{ Attitude towards channel use } \\
\hline \multicolumn{2}{|c|}{$\begin{array}{l}\text { Definition: Attitude towards channel use is defined as individuals' positive or negative feelings towards behavior using } \\
\text { an electronic banking channel for a given banking task (Cheng et al.2004, Lai et al. 2005). }\end{array}$} \\
\hline ATT1* & I don't think using Internet banking for a loan application (account inquiry) would be a good idea.* \\
\hline ATT2 & I think it would be good to use Internet Banking to apply for a financial loan (account inquiry). \\
\hline ATT3 & $\begin{array}{l}\text { My attitude towards financial loan applications (account inquiry) via Internet Banking would be } \\
\text { favorable. }\end{array}$ \\
\hline ATT4 & Overall, using Internet banking for financial loan applications (account inquiry) would be a good idea. \\
\hline \multicolumn{2}{|l|}{ Security } \\
\hline \multicolumn{2}{|c|}{$\begin{array}{l}\text { Definition: Related to electronic banking channels, perceived security can be understood in financial terms, as well as } \\
\text { in terms of privacy and the protection of data against unauthorized disclosure, modification, and destruction (Liao and } \\
\text { Cheung 2008). }\end{array}$} \\
\hline SEC1 & Internet banking would be a secure means by which to apply for a financial loan (account inquiry). \\
\hline SEC2 & I would feel safe applying for a financial loan (account inquiry) via Internet banking. \\
\hline SEC3* & Applying for a financial loan (account inquiry) on Internet banking would be risky.* \\
\hline SEC4 & Overall, Internet banking would be a safe way to apply for a financial loan. \\
\hline \multicolumn{2}{|c|}{ Subjective norms } \\
\hline \multicolumn{2}{|c|}{$\begin{array}{l}\text { Definition: An individual's subjective norms are perceived normative beliefs regarding the opinions of others (Fishbein } \\
\text { and Ajzen 1975). }\end{array}$} \\
\hline $\begin{array}{l}\text { SN1 } \\
\text { SN2 } \\
\text { SN3 } \\
\text { SN4 }\end{array}$ & $\begin{array}{l}\text { My decision to use Internet banking for financial loan/account inquiry applications would be influenced } \\
\text { by: } \\
\text { My friends. } \\
\text { My family/relatives. } \\
\text { My colleagues/peers. } \\
\text { If I knew that my peers were using Internet banking for obtaining financial loans, I would be more } \\
\text { inclined to do so myself. }\end{array}$ \\
\hline \multicolumn{2}{|c|}{ Cost associated with channel use } \\
\hline \multicolumn{2}{|c|}{ Definition: All costs associated with channel use from a consumer perspective (Luarn and Lin 2005). } \\
\hline COST1 & It would cost a lot to apply for financial loans using Internet banking. \\
\hline COST2 & Financial costs would be a barrier for me if applying for financial loans using Internet banking. \\
\hline COST3 & $\begin{array}{l}\text { I would not be worried about the costs associated with financial loan applications using Internet } \\
\text { banking. }\end{array}$ \\
\hline COST4 & $\begin{array}{l}\text { Overall, the cost associated with Internet banking use for financial loan applications would discourage } \\
\text { me from using it. }\end{array}$ \\
\hline \multicolumn{2}{|c|}{ Task-channel fit - global measures (newly created) } \\
\hline TCF1 & I think Internet banking would be well suited for loan applications (account inquiry). \\
\hline TCF2 & Internet banking would be a good medium for loan applications (account inquiry). \\
\hline TCF3 & Internet banking would fit well for loan applications (account inquiry). \\
\hline TCF4 & I think Internet banking would be a good way to apply for financial loans (account inquiry). \\
\hline \multicolumn{2}{|c|}{ Intentions to use } \\
\hline \multicolumn{2}{|c|}{$\begin{array}{l}\text { Definition: Behavioral intentions indicate how hard people are willing to try to perform a behavior (Sheppard, } \\
\text { Hartwick et al. 1988). }\end{array}$} \\
\hline INT1 & If I needed to apply for a financial loan (account inquiry) I would use Internet banking. \\
\hline INT2 & Assuming I had to apply for a financial loan (account inquiry) I would use Internet banking for it. \\
\hline INT3 & I would apply for a financial loan (account inquiry) via Internet banking if I needed one. \\
\hline INT4 & $\begin{array}{l}\text { I would use Internet banking for loan applications (account inquiry) rather than alternative banking } \\
\text { channels (branch, telephone, letter etc.). }\end{array}$ \\
\hline \multicolumn{2}{|c|}{ Familiarity with Internet banking/banking tasks } \\
\hline \multicolumn{2}{|c|}{$\begin{array}{l}\text { Definition: Familiarity is an understanding, often based on previous interaction, experiences, and learning of using a } \\
\text { specific banking task (Gefen et al., 2003; Gefen, 2000). }\end{array}$} \\
\hline FAMT1 & I am familiar with using Internet banking (banking task). \\
\hline FAMT2 & I understand how Internet banking works (banking task). \\
\hline FAMT3 & I consider myself knowledgeable with Internet banking (banking task). \\
\hline FAMT4* & I am not at all familiar with using Internet banking (banking task).* \\
\hline \multicolumn{2}{|r|}{ *Reverse coded items } \\
\hline & + Demographics (Age, Gender, Bank, Job) \\
\hline
\end{tabular}

Next, the scales were pretested as explained below. 


\subsection{Pretesting the scales}

The scales displayed in Table 94 were pretested prior to the second data collection phase in order to assess their usability and face validity (Pinsonneault and Kraemer 1993). Since the majority of the scales were thoroughly tested during the pilot-study phase (as explained in chapter 5), the main-study pretest concentrated on the usability of the online questionnaire system. For the pretest, the survey questionnaire was setup in qualtrics and email invitations were sent out to personal contacts of the researcher.

Eighteen responses were collected and the survey system recorded all responses correctly and produced adequate data reports. Most volunteers provided written feedback on their perception of the online survey questionnaire. The feedback obtained was positive and mainly focused on minor issues. For instance, one participant commented:

"There is a grammatical error for question 3: 'There a many steps to go through when applying for a financial loan' should it be 'There ARE many steps to go through when applying for a financial loan'?".

This grammatical issue was corrected as suggested by the participant. Another respondent suggested using a percentage bar that indicates the progress of the survey questionnaire. $\mathrm{He}$ wrote in his email: "I wished the percentage bar told me how much percent I had completed". This suggestion was discussed with supervising staff and it was agreed to include a percentage bar during the main study. The adjustments were made in qualtrics prior to the main data collection phase.

Other research participants provided only little feedback since they did not notice any issues with the survey questionnaire. For instance, one participant wrote a short email after she completed the survey questionnaire: "The survey is not too long and I had no problems. Good luck".

\subsection{Main - survey operationalization}

As with the pilot study, qualtrics survey software was used to collect data for the main phase of this study. The structure of the survey was similar to the pilot test study (e.g. initially introducing the participants to the survey and inform them about HEC approval etc.). The introductions for each survey block (e.g. banking tasks, Internet banking suitability for banking tasks, precursors of utilization etc.) were copied from the pilot study. 
Instead of using two separate URLs (as done in the pilot study), the survey system was setup using two different branches - one branch for account inquiries and another branch for financial loans. This survey design was necessary to conform to the Smilecity.co.nz consumer panel system requirements (explained in more detailed in the next section).

The system was set up in a way that it would randomly assign research participant to either branch of the survey questionnaire. To ensure that the respondents qualified for taking the survey, each participant was asked if he/she felt familiar with financial loans and Internet banking or account inquiries and Internet banking at the start of the survey. This question was posed after the software assigned the respondent to each branch.

If the participants indicated that they felt familiar with the banking task in question as well as with Internet banking, they were then routed to the main survey questionnaire. If they indicated that they felt unfamiliar with either the banking task or Internet banking, the system linked these respondents immediately to the end of the survey questionnaire.

As suggested in section 6.2.1., it was also decided to measure the items on a 7-point Likert scale for the main phase of this research. It was assumed that this could positively influence the TCF fit computations since it could lead to more precise TCF scores. The appendix shows both survey questionnaires used during the main study.

\subsection{Data collection - main phase}

The data collection was operationalized through the Smilecity consumer panel (www.smilecity.co.nz). Smilecity is an online rewards program exclusively for New Zealanders, where consumers can earn rewards while participating in market research (Smilecity 2010).

The current research drew on an online consumer panel that is approximately 50,000 individuals strong. Smilecity recruits consumers from a wide range of offline sources including TV, magazine and radio as well as online sources. Smilecity claims that its consumer panels are a fair representation of the general population in New Zealand:

"The diverse sources and scale of recruitment allows Smile City to make a legitimate claim that it has one of the least duplications of members compared to other online panels. Due to these various channels used to recruit Smilecity members, we are confident that we have the NZ market well represented with less "professional" respondents who have joined other panels (often via the same 
source) and more members who are genuinely interested in market research but haven't joined for that sole reason alone." (Smilecity 2010)

Consumer rewards were organized through Smilecity directly once the data collection phase was completed. The survey questionnaire URL was activated on the $20^{\text {th }}$ of September, 2010 and deactivated on the $28^{\text {th }}$ of September, 2010.

To attract potential survey respondents, Smilecity sent out email invitations to its clients. 1050 such invitations were launched during the data collection phase. Once the data collection phase was completed, necessary survey information (e.g. average duration time, screenout responses, completed responses etc.) was provided to Smilecity. The costs associated with Smilecity services were paid for by the researcher.

\subsection{Data preparation for the analysis}

Overall, 533 participants started to complete the survey questionnaire. Out of those, 432 respondents completed the survey questionnaire. Given the email invitations sent out by Smilecity, this accounts for a response rate of more than $40 \%$. Out of those 432 responses, 68 respondents were routed directly to the end of the survey since they felt unfamiliar with either the banking task in question or Internet banking applications.

As with the pilot test, the incomplete responses were deleted from the dataset. Some of the responses were identified as skimmers. These respondents completed the survey questionnaire in a very short period of time by rating most of the items equally.

These responses were identified by comparing the completion time in combination with the responses obtained for the survey questionnaire. For example, one respondent completed the entire survey in $3 \mathrm{~min} .38 \mathrm{sec}$ and all responses were valued with 4 . In contrast, the average duration time of all respondents was $17 \mathrm{~min} 15 \mathrm{sec}$. Given the Smilecity reward system, it seemed that he/she completed the survey only to obtain the survey rewards.

This led to 346 usable responses: 176 for financial loans and 170 for account inquiries. In order to have an equally distributed dataset for further analyses, the formula $=\operatorname{INT}(\operatorname{RAND}() * X$ +1 ) was used to randomly identify instances that could be deleted from the dataset. Six such instances were excluded from the financial loan dataset. This led to 170 analyzable responses for each banking task. 


\subsection{Data analysis}

Before discussing the data analysis in more detail, this section provides some general information on the respondents and the data collected during the main phase of this study. Table 95 provides information on the demographics of the respondents.

Table 95: Demographics of the respondents - main study

\begin{tabular}{|c|c|c|c|}
\hline & & Financial loans & Account inquiries \\
\hline Gender & & 73 males, 97 Females & 73 males, 97 Females \\
\hline \multirow{6}{*}{$\begin{array}{l}\text { Age- } \\
\text { groups }\end{array}$} & Under 20: & 13 respondents $(7.6 \%)$ & 19 respondents $(11.2 \%)$ \\
\hline & 20-29: & 31 respondents $(18.2 \%)$ & 34 respondents $(20 \%)$ \\
\hline & 30-39: & 38 respondents $(22.4 \%)$ & 39 respondents $(22.9 \%)$ \\
\hline & 40-49: & 43 respondents $(25.3 \%)$ & 30 respondents $(17.6 \%)$ \\
\hline & 50-59: & 31 respondents $(18.2 \%)$ & 27 respondents (15.9\%) \\
\hline & 60 or older & 14 respondents $(8.2 \%)$ & 21 respondents $(12.4 \%)$ \\
\hline \multirow{11}{*}{ Job } & ICT & 8 respondents $(4.7 \%)$ & 8 respondents $(4.7 \%)$ \\
\hline & Banking/finance & 5 respondents $(2.9 \%)$ & 5 respondents $(2.9 \%)$ \\
\hline & $\begin{array}{l}\text { Insurance/real } \\
\text { estate/legal }\end{array}$ & 1 respondent $(0.6 \%)$ & 3 respondents $(1.8 \%)$ \\
\hline & $\begin{array}{l}\text { Government } \\
\text { military) }\end{array}$ & 12 respondents $(7.1 \%)$ & 6 respondents $(3.5 \%)$ \\
\hline & Medical Healthcare & 10 respondents $(5.9 \%)$ & 14 respondents $(8.2 \%)$ \\
\hline & $\begin{array}{l}\text { Construction/Architectu } \\
\text { re/Engineering }\end{array}$ & 16 respondents $(9.4 \%)$ & 11 respondents $(6.5 \%)$ \\
\hline & $\begin{array}{l}\text { Wholesale/Retail/Distrib } \\
\text { ution }\end{array}$ & 15 respondents $(8.8 \%)$ & 13 respondents $(7.6 \%)$ \\
\hline & Education & 11 respondents $(6.5 \%)$ & 10 respondents $(5.9 \%)$ \\
\hline & $\begin{array}{l}\text { Marketing/Advertising/ } \\
\text { Entertainment }\end{array}$ & 2 respondents $(1.2 \%)$ & 2 respondents $(1.2 \%)$ \\
\hline & Student & 25 respondents $(14.7 \%)$ & 27 respondents $(15.9 \%)$ \\
\hline & Other & 65 respondents $(38.2 \%)$ & 71 respondents $(41.8 \%)$ \\
\hline \multirow{9}{*}{$\begin{array}{c}\text { Prime } \\
\text { Bank }\end{array}$} & ANZ & 16 respondents $(9.4 \%)$ & 17 respondents $(10 \%)$ \\
\hline & National Bank & 27 respondents $(15.9 \%)$ & 30 respondents $(17.6 \%)$ \\
\hline & Westpac & 40 respondents $(23.5 \%)$ & 40 respondents $(23.5 \%)$ \\
\hline & BNZ & 16 respondents $(9.4 \%)$ & 14 respondents $(8.2 \%)$ \\
\hline & Kiwibank & 28 respondents $(16.5 \%)$ & 27 respondents $(15.9 \%)$ \\
\hline & ASB & 26 respondents $(15.3 \%)$ & 30 respondents $(17.6 \%)$ \\
\hline & Rabobank & 0 respondents $(0 \%)$ & 1 respondent $(0.6 \%)$ \\
\hline & TSB & 5 respondents $(2.9 \%)$ & 3 respondents $(1.8 \%)$ \\
\hline & Other & 12 respondents $(7.1 \%)$ & 8 respondents $(4.3 \%)$ \\
\hline
\end{tabular}

Table 95 shows that the responses were slightly skewed towards female respondents for both versions of the survey questionnaire instrument. 
On the other hand, the research participants were well distributed across age levels and the respondents also worked in a variety of jobs. Further, the respondents maintained bank accounts with all major banks in New Zealand. The demographic profile of the respondents matched the profile of the sampling frame provided by Smilecity.co.nz. Thus, non-response bias did not seem to be an issue with the collected data. Testing for non-response bias by comparing early versus late responses was not felt to be useful since all responses were collected during a single week and no reminders were employed (Churchill 1979).

The familiarity items included towards the end of the survey questionnaire indicated that the respondents felt familiar with Internet banking and with the banking task in question. The non-reverse coded items are shown in the below mentioned Table 96.

Table 96: Respondents familiarity with banking tasks and Internet banking

\begin{tabular}{|l|c|c|c|}
\hline \multirow{2}{*}{} & \multicolumn{3}{|c|}{ Mean scores } \\
\cline { 2 - 4 } & Account inquiries & Financial loans & Internet banking \\
\hline I am familiar with financial loans/account inquiries/IB & 5.74 & 6.04 & 5.40 \\
\hline $\begin{array}{l}\text { I understand how financial loans/account inquiries/IB } \\
\text { work. }\end{array}$ & 5.72 & 5.81 & 5.41 \\
\hline $\begin{array}{l}\text { I consider myself knowledgeable with financial } \\
\text { loans/account inquiries/IB. }\end{array}$ & 5.5 & 5.64 & 5.16 \\
\hline \multicolumn{2}{|l|}{ Likert scale: 1= strongly disagree; 7=strongly agree } \\
\hline
\end{tabular}

Table 96 illustrates that the respondents felt familiar with both - the banking tasks and Internet banking. The average scores were above 5 indicating that all respondents had a good understanding of the questionnaire topic and they were well suited and able to respond to the survey. It was interesting to observe that the average scores were higher for financial loans. This was unexpected because the literature suggested that fewer consumers are familiar with financial loans than with account inquiries (Tan, 2000).

As indicated in the previous section, the datasets were initially screened for completion. While missing data were unexpected (due to the survey questionnaire setup), the dataset was double-checked for completeness.

Despite the fact that PLS is not constrained by normality assumptions (Chin 1998), both datasets were initially tested for a normal distribution of the data (Field 2009). Normality can be verified by calculating the skewness and kurtosis ratings in SPSS.

Skewness evaluates the asymmetry of a distribution whereas Kurtosis assesses the degree to which scores cluster in tails the of a distribution (Hair, Anderson et al. 1995; Field 2009). Most authors consider that data set is normally distributed if the skewness and kurtosis ratings 
are within the +2 to -2 range (Hair, Anderson et al. 1995; Carver and Nash 2005; Tabachnick and Fidell 2007; Field 2009).

Both datasets were investigated for skewness and kurtosis ratings. In the account inquiries dataset, the skewness rating was on average at -0.849 . None of the items was above -1.6 . The kurtosis statistics in the account inquiries dataset was on average 1.091. Some of the kurtosis scores were slightly higher than 2.5 which many authors still consider as acceptable (Hair, Anderson et al. 1995; Carver and Nash 2005; Tabachnick and Fidell 2007; Field 2009).

For the financial loan dataset, the skewness statistics was on average -0.239 . The largest skewness rating was -0.817 (PU3). The Kurtosis statistics was on average -0.509 in the financial loan dataset. The maximum kurtosis score was -1.253.

Hence, it seemed reasonable to assume that the data was distributed normally in both datasets.

The following sections explain how the task-channel fit construct was assessed during the main study. Section 6.8.1.1. explains the direct measurement approach whereas section 6.8.1.2. discusses the parallel instrument evaluation.

\subsubsection{Fit assessment}

\subsubsection{Direct measurement}

During the pilot study, the reflective TCF scales were found to be highly reliable and the phantom TCF variable was successfully used to assess the generalizability of the formative TCF measures. The same four reflective TCF items were re-used during the main study. Table 97 lists the items used to evaluate the respondents' overall perceptions of the task-channel fit.

Table 97: Direct TCF measures used for the pilot test study

\begin{tabular}{|l|l|l|l|}
\hline Label & \multicolumn{1}{|c|}{ Items } & $\begin{array}{l}\text { Mean- } \\
\text { Loans }\end{array}$ & $\begin{array}{l}\text { Mean- } \\
\text { Acc. Inq. }\end{array}$ \\
\hline TCF1 & I think Internet banking would be well suited for loan applications (account inquiry). & 4.27 & 6.17 \\
\hline TCF2 & Internet banking would be a good medium for loan applications (account inquiry). & 4.38 & 6.15 \\
\hline TCF3 & Internet banking would fit well for loan applications (account inquiry). & 4.43 & 5.95 \\
\hline TCF4 & $\begin{array}{l}\text { I think Internet banking would be a good way to apply for financial loans (account } \\
\text { inquiry). }\end{array}$ & 4.44 & 6.17 \\
\hline & \multicolumn{2}{|c|}{ Likert scale: 1= strongly disagree; 7=strongly agree } & \\
\hline
\end{tabular}

The right side of the Table shows the average scores for each item. As expected, the perceived overall suitability of account inquiries for Internet banking was higher than for financial loans. This is in accordance with the pilot study results and with the existing literature on electronic banking (e.g. Tan, 2000). 
The psychometric properties of the direct TCF measures were assessed alongside the remaining reflectively assessed constructs in the research model (discussed in greater detail in section 6.8.2.). Before discussing the formative measurement of the TCF construct more detailed, the following section explains the parallel instrument used during the main study.

\subsubsection{Parallel instrument TCF measurement}

As explained in section 6.2., the parallel instrument was adjusted in accordance with the feedback obtained for the scales during the post-pilot study phase. While the TCF dimensions were refined, the overall procedure did not change and the task characteristic and channel suitability items (see Table 98) were designed to parallel each other. For each individual task characteristic item, a parallel channel suitability item was created to determine whether a respondent would perceive a fit between the task and the channel for that specific task dimension. Table 98 lists the items included within the main data collection phase.

Table 98: Parallel items used to determine the Task-channel Fit of electronic banking channels

\begin{tabular}{|c|c|c|c|}
\hline Construct & Items & & \\
\hline & TCF - task characteristics & $\begin{array}{l}\text { Mean- } \\
\text { Loans }\end{array}$ & $\begin{array}{l}\text { Mean- } \\
\text { Acc. } \\
\text { Inq. }\end{array}$ \\
\hline ANZBL1 & Overall, applying for a financial loan requires a lot of thinking. & 5.39 & 2.25 \\
\hline ANZBL2 & Applying for a financial loan requires detailed consideration. & 5.71 & 2.55 \\
\hline ANZBL3 & A financial loan application is a banking transaction I would plan thoroughly. & 5.82 & 3.04 \\
\hline ANZBL4 & A financial loan application is a banking transaction I would give a lot of thought to. & 5.82 & 3.16 \\
\hline COMP1 & In general, applying for a financial loan is complex. & 4.16 & 2.44 \\
\hline COMP2 & Overall, a financial loan is a complicated banking transaction. & 4.21 & 2.19 \\
\hline COMP3 & Generally, applying for a financial loan is an easy-to-do banking task. & 4.00 & 6.11 \\
\hline COMP4 & I would find it straightforward to apply for a financial loan. & 4.41 & 6.11 \\
\hline EFFOR1 & I have to provide a lot of information to my bank when applying for a financial loan. & 5.01 & 2.55 \\
\hline EFFOR2 & A loan application does not require filling out many forms. & 3.31 & 5.58 \\
\hline EFFOR3 & There a many steps to go through when applying for a financial loan. & 4.76 & 2.54 \\
\hline EFFOR4 & Overall, I think it takes a lot of effort to apply for a financial loan. & 4.45 & 2.12 \\
\hline IMPOR1 & A loan application is an ordinary banking transaction to me. & 2.97 & 5.61 \\
\hline IMPOR2 & Applying for a loan is commonplace banking task. & 4.06 & 5.67 \\
\hline IMPOR3 & Applying for a financial loan is a major transaction in my mind. & 5.38 & 2.93 \\
\hline IMPOR4 & A financial loan application is a serious banking transaction for me. & 5.62 & 3.36 \\
\hline IMPOR5 & Applying for a financial loan will influence my personal finances significantly. & 5.01 & 4.19 \\
\hline ROUT1 & Applying for a financial loan is a banking transaction I routinely perform. & 2.17 & 5.17 \\
\hline ROUT2 & I regularly apply for a financial loan. & 2.02 & 5.78 \\
\hline ROUT3 & I often apply for a financial loan. & 2.02 & 5.67 \\
\hline ROUT4 & A loan application is a banking transaction I frequently do. & 2.11 & 5.14 \\
\hline UNC1 & $\begin{array}{l}\text { When applying for a financial loan I have many questions that I want to clarify with } \\
\text { my bank before going ahead with the transaction. }\end{array}$ & 5.16 & 2.56 \\
\hline UNC2 & $\begin{array}{l}\text { Before applying for a financial loan I would require additional information on how the } \\
\text { process works. }\end{array}$ & 5.19 & 2.38 \\
\hline UNC3 & $\begin{array}{l}\text { Obtaining additional information before applying for a financial loan would be } \\
\text { absolutely essential for me. }\end{array}$ & 5.32 & 2.96 \\
\hline EQU1 & I would feel unsure of myself if I were to apply for a financial loan. & 3.47 & 1.97 \\
\hline EQU2 & I would feel uncertain if applying for a financial loan myself. & 3.61 & 1.90 \\
\hline EQU3 & Applying for a financial loan myself would make me feel ambiguous. & 3.55 & 2.72 \\
\hline TIME1 & I often want to apply for a financial loan instantly. & 2.77 & 4.93 \\
\hline TIME2 & I seldom face situations in which I need to apply for a financial loan urgently. & 5.16 & 4.24 \\
\hline TIME3 & I often need to apply for a financial loan immediately. & 2.31 & 4.26 \\
\hline TIME4 & Overall, I perceive financial loan applications as very urgent banking transactions. & 3.69 & 3.89 \\
\hline
\end{tabular}




\begin{tabular}{|c|c|c|c|}
\hline & TCF - channel suitability & $\begin{array}{l}\text { Mean- } \\
\text { Loans }\end{array}$ & $\begin{array}{l}\text { Mean- } \\
\text { Acc. } \\
\text { Inq. }\end{array}$ \\
\hline & Internet banking is well suited for: & & \\
\hline CANZBL1 & Banking transactions that require a lot of thinking. & 3.86 & 3.98 \\
\hline CANZBL2 & Banking transactions that require detailed consideration. & 3.94 & 4.09 \\
\hline CANZBL3 & Thoroughly planning banking products. & 4.16 & 4.35 \\
\hline CANZBL4 & Banking transactions I would give a lot of thought to. & 4.19 & 4.42 \\
\hline CCOMP1 & Complex banking transactions. & 3.66 & 4.06 \\
\hline CCOMP2 & Complicated banking transactions. & 3.59 & 3.89 \\
\hline CCOMP3 & Easy-to-do banking task. & 6.15 & 6.06 \\
\hline CCOMP4 & Straightforward banking transactions. & 6.18 & 6.06 \\
\hline CEFFOR1 & Banking transactions for which I have to provide a lot of information to my bank. & 3.28 & 3.68 \\
\hline CEFFOR2 & Banking transactions that do not require filling out many forms. & 5.89 & 5.56 \\
\hline CEFFOR3 & Banking transactions that require performing many steps. & 3.91 & 4.21 \\
\hline CEFFOR4 & Banking transactions that take a lot of effort. & 3.71 & 3.96 \\
\hline CIMPOR1 & Ordinary banking transactions. & 6.15 & 5.97 \\
\hline CIMPOR2 & Commonplace banking transactions. & 6.01 & 5.77 \\
\hline CIMPOR3 & Major banking transactions & 4.35 & 4.58 \\
\hline CIMPOR4 & Serious banking transactions. & 4.22 & 4.64 \\
\hline CIMPOR5 & Banking transactions that influence my personal finances significantly. & 4.38 & 4.71 \\
\hline CROUT1 & Banking transaction I routinely perform. & 6.11 & 6.01 \\
\hline CROUT2 & Banking transactions I regularly do. & 6.12 & 5.99 \\
\hline CROUT3 & Banking transactions I often do. & 6.09 & 6.01 \\
\hline CROUT4 & Banking transactions I frequently do. & 6.15 & 5.95 \\
\hline CUNC1 & Clarifying questions related to a financial product. & 4.42 & 4.28 \\
\hline CUNC2 & Finding out additional information on how financial products work. & 4.68 & 4.52 \\
\hline CUNC3 & Obtaining additional information about financial products. & 4.79 & 4.48 \\
\hline CEQU1 & Banking transactions where I feel unsure of myself. & 3.24 & 3.41 \\
\hline CEQU2 & Banking transactions where I feel uncertain of myself. & 3.38 & 3.32 \\
\hline CEQU3 & Banking transactions where I feel ambiguous. & 3.71 & 3.84 \\
\hline CTIME1 & Banking transactions I want to do instantly. & 6.09 & 5.86 \\
\hline CTIME2 & Banking transactions I do not need to do urgently. & 5.39 & 5.34 \\
\hline CTIME3 & Banking transactions I have to do immediately. & 5.94 & 5.77 \\
\hline CTIME4 & Banking transactions that are very urgent to me. & 5.62 & 5.62 \\
\hline
\end{tabular}

The fit determination is explained in more detail in section 5.4.1. Following the argumentation developed in section 5.4.1.4., fit as moderation was used to compute the individual values obtained for the above mentioned items.

On the right hand of Table 98, the average scores are depicted for financial loans and account inquiries. All items were evaluated using Likert scales ranging from 1 to 7 (1=strongly disagree; 7 strongly agree).

Comparing the means of the task characteristics items, it is evident that the averages for financial loan applications and account inquiries differed across the TCF dimensions (analyzability, complexity, effort, importance, routine, equivocality, uncertainty, and timecriticality). This was expected since the literature review on electronic banking tasks (section 2.6.) suggested that financial loans and account inquiries differ across these dimensions.

For example, most respondents agreed that financial loans require much analysis (indicated by the high values for the analyzability measures - all above 5.39). In contrast, the 
task analyzability items were rated lower for account inquiries ranging between 2.25 and 3.16. These findings were in accordance with the literature on electronic banking services (Tan and Thompson 2000; Luarn and Lin 2005; Van Birgelen, De Jong et al. 2006).

Further, when inspecting the mean complexity scores, it becomes evident that respondents viewed account inquiries as less complex than financial loans. The means also indicated that the respondents differentiated between COMP1/COMP2 and COMP3/COMP4 in both datasets. This contrasted the mean scores obtained during the pilot study and could be a positive side effect of using the 7 point Likert scales.

Following the fit computation approaches outlined in Table 65, the TCF moderation scores were computed for all above mentioned parallel items. The individual TCF scores were then used for further analyses as outlined in section 6.8.3.

\subsubsection{Construct validity assessment - reflective constructs}

As indicated in section 6.2.1., the analytical assessment of the data collected for the main study differed slightly from the pilot study. Based on the feedback received on the pilot study, the data collected for the main study was analyzed in three different ways: 1. Using the complete dataset, 2 . Using the financial loan sub-dataset, 3. Using the account inquiry subdataset.

In order to assure that each dataset was adequate in terms of construct validity and reliability, the data analyzes were performed three times to account for the main- and subdatasets. The following section initially discusses the complete dataset $(n=340)$ before investigating the sub-datasets ( $\mathrm{n}=170$-banking task).

\subsubsection{Complete dataset}

The first step of the data analysis included assessing the convergent and discriminant validity of the reflective indicators. The precursors of utilization constructs, intentions to use, and the general TCF variable were assessed through reflective measures. Thus, the items for these constructs were initially assessed for construct validity ${ }^{24}$.

The complete dataset $(n=340)$ was uploaded into SmartPLS. Next, the research model was setup as displayed in Figure 38. This was followed by using a bootstrapping procedure to obtain the t-values for the items. Table 99 lists the $t$-statistics results for the complete $(n=340)$ dataset:

\footnotetext{
${ }^{24}$ note that the formative assessed TCF construct was analyzed separately and is discussed in section 6.8.3.
} 
Table 99: T-values for the reflective measures - complete dataset $(n=340) /$ main study

\begin{tabular}{|c|c|c|c|}
\hline Item to construct & T Statistics & Item to construct & T Statistics \\
\hline ATT1 <- Attitude & $37.66 * * *$ & PU1 <- Perceived usefulness & $47.36 * * *$ \\
\hline ATT2 <- Attitude & $110.92 * * *$ & PU2 <- Perceived usefulness & $31.26 * * *$ \\
\hline ATT3 <- Attitude & $102.16 * * *$ & PU3 <- Perceived usefulness & $68.74 * * *$ \\
\hline ATT4 <- Attitude & $191.01 * * *$ & PU4 <- Perceived usefulness & $80.55 * * *$ \\
\hline COST1 <- Costs & $21.77^{* * *}$ & SEC1 <- Security & $85.09 * * *$ \\
\hline COST2 <- Costs & $35.11 * * *$ & SEC2 <- Security & $136.23 * * *$ \\
\hline COST3 <- Costs & $4.97 * * *$ & SEC3*<- Security & $21.26 * * *$ \\
\hline COST4 <- Costs & $12.00 * * *$ & SEC4 <- Security & $54.38 * * *$ \\
\hline EOU1 <- Ease of Use & $121.55 * * *$ & SN1 <- Subjective norms & $37.28 * * *$ \\
\hline EOU $2<-$ Ease of Use & $106.15^{* * *}$ & SN2 <- Subjective norms & $18.80 * * *$ \\
\hline EOU3 <- Ease of Use & $12.71 * * *$ & SN3 <- Subjective norms & $47.91 * * *$ \\
\hline EOU4 <- Ease of Use & $116.62 * * *$ & SN4 <- Subjective norms & $31.41 * * *$ \\
\hline INT1 <- Intent & $299.62 * * *$ & TCF1 <- TCF & $250.13^{* * *}$ \\
\hline INT2 <- Intent & $282.05 * * *$ & TCF2 <- TCF & $304.19 * * *$ \\
\hline INT3 <- Intent & $85.83 * * *$ & TCF3 $<-$ TCF & $54.70 * * *$ \\
\hline INT4 <- Intent & $51.02 * * *$ & TCF4 <- TCF & $205.34 * * *$ \\
\hline
\end{tabular}

As shown above, the t-values of all items confirmed significance levels at least at the $\mathrm{p}<0.01$ level. The next step for the construct validity assessment was the evaluation of the cross-loadings.

The cross loadings for all items were initially obtained for the complete dataset. Some of the items loaded very highly onto other constructs. For instance, the attitude 2 item loaded highly onto the perceived usefulness construct (0.86). Thus, this item was dropped from further analysis. Likewise, perceived usefulness 3 loaded highly onto the perceived taskchannel fit construct (0.85). Consequently, this item was also excluded from further data analysis.

Further, ease of use 3 showed a relatively low loading onto the ease of use construct (0.64). When inspecting the financial loan dataset only (see the following section), this item was tested with a loading of less than 0.50 . Thus, the item ease of use 3 was also dropped from the data analysis.

Cost 3 loaded weakly onto the cost construct (0.44) and was therefore excluded from further analyses. Lastly, TCF 4 was removed from the dataset since it loaded highly onto the intention to use construct. The PLS algorithm was re-applied to the complete dataset without attitude 2, perceived usefulness 3, cost3, ease of use 3, and TCF4. The results of the crossloadings are shown in Table 99. 
Table 100: Cross loadings - complete dataset $(n=340) /$ main study

\begin{tabular}{|c|c|c|c|c|c|c|c|c|}
\hline & Attitude & Costs & $\begin{array}{l}\text { Ease of } \\
\text { use }\end{array}$ & Intentions & $\begin{array}{l}\text { Perceived } \\
\text { usefulness }\end{array}$ & Security & $\begin{array}{l}\text { Subjective } \\
\text { norms }\end{array}$ & TCF \\
\hline ATT1* & $\mathbf{0 . 8 8}$ & -0.42 & 0.67 & 0.70 & 0.61 & 0.71 & 0.03 & 0.74 \\
\hline ATT3 & $\mathbf{0 . 9 5}$ & -0.28 & 0.76 & 0.80 & 0.75 & 0.76 & 0.19 & 0.83 \\
\hline ATT4 & $\mathbf{0 . 9 6}$ & -0.33 & 0.79 & 0.82 & 0.75 & 0.79 & 0.20 & 0.86 \\
\hline COST1 & -0.35 & $\mathbf{0 . 8 3}$ & -0.41 & -0.40 & -0.30 & -0.41 & 0.13 & -0.37 \\
\hline COST2 & -0.28 & $\mathbf{0 . 8 7}$ & -0.29 & -0.33 & -0.25 & -0.31 & 0.03 & -0.29 \\
\hline COST4 & -0.24 & $\mathbf{0 . 7 4}$ & -0.24 & -0.22 & -0.17 & -0.24 & 0.02 & -0.23 \\
\hline EOU1 & 0.76 & -0.38 & $\mathbf{0 . 9 6}$ & 0.77 & 0.75 & 0.68 & 0.13 & 0.82 \\
\hline EOU2 & 0.77 & -0.37 & $\mathbf{0 . 9 6}$ & 0.78 & 0.76 & 0.70 & 0.16 & 0.83 \\
\hline EOU4 & 0.76 & -0.40 & $\mathbf{0 . 9 5}$ & 0.76 & 0.74 & 0.71 & 0.12 & 0.81 \\
\hline INT1 & 0.82 & -0.40 & 0.80 & $\mathbf{0 . 9 8}$ & 0.75 & 0.74 & 0.18 & 0.87 \\
\hline INT2 & 0.81 & -0.39 & 0.80 & $\mathbf{0 . 9 8}$ & 0.74 & 0.74 & 0.18 & 0.86 \\
\hline INT3 & 0.80 & -0.38 & 0.78 & $\mathbf{0 . 9 6}$ & 0.73 & 0.74 & 0.21 & 0.86 \\
\hline INT4 & 0.76 & -0.38 & 0.71 & $\mathbf{0 . 9 2}$ & 0.69 & 0.68 & 0.14 & 0.80 \\
\hline PU1 & 0.64 & -0.28 & 0.67 & 0.63 & $\mathbf{0 . 9 1}$ & 0.57 & 0.18 & 0.69 \\
\hline PU2 & 0.62 & -0.22 & 0.64 & 0.61 & $\mathbf{0 . 8 9}$ & 0.50 & 0.20 & 0.64 \\
\hline PU4 & 0.78 & -0.31 & 0.79 & 0.77 & $\mathbf{0 . 9 0}$ & 0.62 & 0.23 & 0.80 \\
\hline SEC1 & 0.75 & -0.35 & 0.71 & 0.72 & 0.63 & $\mathbf{0 . 9 4}$ & 0.09 & 0.78 \\
\hline SEC2 & 0.80 & -0.38 & 0.73 & 0.74 & 0.62 & $\mathbf{0 . 9 6}$ & 0.08 & 0.77 \\
\hline SEC3* & 0.61 & -0.37 & 0.44 & 0.51 & 0.38 & $\mathbf{0 . 7 8}$ & -0.05 & 0.53 \\
\hline SEC4 & 0.76 & -0.36 & 0.72 & 0.74 & 0.61 & $\mathbf{0 . 9 3}$ & 0.05 & 0.76 \\
\hline SN1 & 0.13 & 0.10 & 0.11 & 0.15 & 0.18 & 0.05 & $\mathbf{0 . 9 2}$ & 0.15 \\
\hline SN2 & 0.13 & 0.12 & 0.10 & 0.14 & 0.17 & 0.03 & $\mathbf{0 . 8 6}$ & 0.13 \\
\hline SN3 & 0.14 & 0.06 & 0.13 & 0.16 & 0.20 & 0.08 & $\mathbf{0 . 9 2}$ & 0.16 \\
\hline SN4 & 0.16 & 0.05 & 0.16 & 0.20 & 0.24 & 0.04 & $\mathbf{0 . 8 7}$ & 0.20 \\
\hline TCF1 & 0.85 & -0.38 & 0.86 & 0.87 & 0.79 & 0.78 & 0.17 & $\mathbf{0 . 9 8}$ \\
\hline TCF2 & 0.86 & -0.37 & 0.85 & 0.87 & 0.79 & 0.79 & 0.19 & $\mathbf{0 . 9 8}$ \\
\hline TCF3 & 0.84 & -0.35 & 0.80 & 0.82 & 0.74 & 0.76 & 0.18 & $\mathbf{0 . 9 6}$ \\
\hline & & & & & & & & \\
\hline
\end{tabular}

On the first glance, some of the cross-loadings appeared to be relatively high (e.g. TCF2Attitude 0.86). However, as explained in section 5.4.3.1., Chin (2010) suggested considering the square of the loadings and cross loadings. For example, the item relationship TCF2-TCF has a shared variance of 0.96 percent $(0.98 * 0.98)$ while that shared with attitude is 0.73 $\left(0.86^{*} 0.86\right)$. Since the goal of this study is to have a strong nomological network where constructs explain as much variance as possible in the dependent variable, this difference seemed to be adequate (Chin 2010). In any event, the reflective TCF items were not used in the assessment of the structural model as they were substituted in these analyses by the formatively measured TCF construct. The remaining cross-loadings in the above mentioned Table appeared to be adequate in terms of construct validity.

Discriminant validity was further assessed with the squared root of the average variance extracted for each construct. In an AVE analysis, the square root of every AVE is supposed to be larger than the correlation of the specific construct with any of the other constructs in the model (Gefen and Straub 2005). As shown in Table 101, each construct shared greater 
variance with its own block of measures than with any other construct in the model. Further, all AVEs were consistent with Fornell and Larcker's guidelines exceeding the 0.50 threshold value (Fornell and Larcker 1981).

Table 101: Correlations of the latent variables and reliability measures for the complete $(n=340)$ dataset - main study

\begin{tabular}{|l|c|c|c|c|c|c|c|c|c|c|c|}
\hline & AVE & CR & $\begin{array}{c}\text { Cron } \\
\text {, }\end{array}$ & Att & Costs & EOU & INT & PU & $\begin{array}{c}\text { Secu } \\
\text { rity }\end{array}$ & SN & TCF \\
\hline Attitude & 0.86 & 0.95 & 0.92 & $\mathbf{0 . 9 3}$ & & & & & & & \\
\hline Costs & 0.66 & 0.85 & 0.76 & -0.36 & $\mathbf{0 . 8 1}$ & & & & & & \\
\hline Ease of use & 0.91 & 0.97 & 0.95 & 0.80 & -0.40 & $\mathbf{0 . 9 6}$ & & & & & \\
\hline Intentions & 0.93 & 0.98 & 0.97 & 0.83 & -0.40 & 0.80 & $\mathbf{0 . 9 6}$ & & & & \\
\hline P.usefulness & 0.81 & 0.93 & 0.88 & 0.76 & -0.30 & 0.79 & 0.76 & $\mathbf{0 . 9 0}$ & & & \\
\hline Security & 0.82 & 0.95 & 0.92 & 0.81 & -0.40 & 0.73 & 0.76 & 0.63 & $\mathbf{0 . 9 0}$ & & \\
\hline Subj. norms & 0.80 & 0.94 & 0.92 & 0.16 & 0.09 & 0.15 & 0.19 & 0.23 & 0.05 & $\mathbf{0 . 8 9}$ & \\
\hline TCF & 0.95 & 0.98 & 0.97 & 0.87 & -0.38 & 0.86 & 0.88 & 0.79 & 0.80 & 0.19 & $\mathbf{0 . 9 7}$ \\
\hline
\end{tabular}

In addition, Table 101 shows that the all measures were robust in terms of internal consistency reliability (all CR values ranged from $0.85-0.98$ ). The Cronbach alpha values were all above 0.76 re-confirming a high reliability level in the scales.

In order to have a coherent set of items ${ }^{25}$ across the different datasets, the attitude 2 , perceived usefulness 3 , cost 3 , ease of use 3 , and TCF4 items were also excluded from the financial loan and account inquiries sub-datasets. The construct validity assessments for both datasets are discussed below.

\subsubsection{Financial loan dataset}

Initially the sub-dataset for financial loans was uploaded into SmartPLS. Next, the research model was set up as displayed in Figure 38. Bootstrapping procedure was used to obtain the tvalues for the items. Table 102 lists the t-statistics for the financial loan dataset:

Table 102: T-values for the reflective measures - Financial loan dataset $(\mathrm{n}=170) / \mathrm{main}$ study

\begin{tabular}{|c|c|c|c|}
\hline Item to construct & T Statistics & Item to construct & T Statistics \\
\hline ATT1 $*<-$ Attitude & $24.54 * * *$ & PU1 <- Perceived usefulness & $40.56 * * *$ \\
\hline ATT3 <- Attitude & $88.20 * * *$ & PU2 <- Perceived usefulness & $19.19 * * *$ \\
\hline ATT4 <- Attitude & $134.88 * * *$ & PU4 <- Perceived usefulness & $63.29 * * *$ \\
\hline COST1 <- Costs & $5.66 * * *$ & SEC1 <- Security & $58.42 * * *$ \\
\hline COST2 <- Costs & $23.13 * * *$ & SEC2 <- Security & $130.41 * * *$ \\
\hline COST4 <- Costs & $13.56 * * *$ & SEC3 $*<-$ Security & $15.64 * * *$ \\
\hline EOU1 <- Ease of use & $60.43 * * *$ & SEC4 <- Security & $28.25 * * *$ \\
\hline EOU2 <- Ease of use & $56.37 * * *$ & SN1 <- Subjective norms & $42.35 * * *$ \\
\hline EOU4 <- Ease of use & $59.82 * * *$ & SN2 <- Subjective norms & $20.87 * * *$ \\
\hline INT1 <- Intentions & $205.37 * * *$ & SN3 <- Subjective norms & $24.14 * * *$ \\
\hline INT2 <- Intentions & $264.61 * * *$ & SN4 <- Subjective norms & $33.90 * * *$ \\
\hline
\end{tabular}

\footnotetext{
${ }^{25}$ Having a coherent set of items was necessary for the multi-group analyses discussed in section 6.8.7.
} 


\begin{tabular}{|l|c|l|c|}
\hline INT3 <- Intentions & $169.27 * * *$ & TCF1 <- TCF & $138.98^{* * *}$ \\
\hline INT4 <- Intentions & $38.78 * * *$ & TCF2 <- TCF & $179.29 * * *$ \\
\hline \multicolumn{2}{|r|}{} & TCF3 <- TCF & $184.97 * * *$ \\
\hline \multicolumn{2}{|r|}{ significant at $\mathrm{p}<0.05, * *$ significant at $\mathrm{p}<0.01$ and $* * *$ significant at $\mathrm{p}<0.001$} \\
\hline
\end{tabular}

As shown above, the t-values of all items confirmed significance levels at least at the $\mathrm{p}<0.01$ level. The next step for the construct validity assessment was the evaluation of the cross-loadings.

The PLS algorithm was applied to the financial loan dataset without attitude 2, perceived usefulness 3, cost3, ease of use 3, and TCF4. The results of the cross-loadings are shown in Table 103.

Table 103: Cross loadings - financial loans dataset (n=170)/main study

\begin{tabular}{|c|c|c|c|c|c|c|c|c|}
\hline & Attitude & Costs & $\begin{array}{r}\text { Ease of } \\
\text { use }\end{array}$ & Intentions & $\begin{array}{r}\text { Perceived } \\
\text { usefulness }\end{array}$ & Security & $\begin{array}{r}\text { Subjective } \\
\text { norms }\end{array}$ & TCF \\
\hline ATT1* & 0.88 & -0.34 & 0.59 & 0.70 & 0.53 & 0.73 & 0.16 & 0.72 \\
\hline ATT3 & 0.95 & -0.15 & 0.68 & 0.79 & 0.72 & 0.72 & 0.28 & 0.82 \\
\hline ATT4 & 0.96 & -0.22 & 0.71 & 0.78 & 0.71 & 0.76 & 0.28 & 0.86 \\
\hline COST1 & -0.16 & 0.72 & -0.22 & -0.17 & -0.04 & -0.23 & 0.24 & -0.19 \\
\hline COST2 & -0.25 & 0.90 & -0.25 & -0.28 & -0.15 & -0.33 & 0.14 & -0.26 \\
\hline COST4 & -0.21 & 0.88 & -0.22 & -0.23 & -0.06 & -0.27 & 0.15 & -0.20 \\
\hline EOU1 & 0.65 & -0.25 & 0.93 & 0.62 & 0.60 & 0.58 & 0.20 & 0.68 \\
\hline EOU2 & 0.66 & -0.24 & 0.92 & 0.66 & 0.60 & 0.59 & 0.27 & 0.70 \\
\hline EOU4 & 0.65 & -0.27 & 0.92 & 0.63 & 0.62 & 0.66 & 0.16 & 0.70 \\
\hline INT1 & 0.80 & -0.24 & 0.68 & 0.98 & 0.69 & 0.71 & 0.33 & 0.84 \\
\hline INT2 & 0.79 & -0.25 & 0.69 & 0.98 & 0.67 & 0.71 & 0.35 & 0.83 \\
\hline INT3 & 0.82 & -0.28 & 0.70 & 0.98 & 0.68 & 0.76 & 0.35 & 0.86 \\
\hline INT4 & 0.76 & -0.30 & 0.61 & 0.93 & 0.67 & 0.66 & 0.26 & 0.76 \\
\hline PU1 & 0.59 & -0.12 & 0.56 & 0.58 & 0.89 & 0.47 & 0.33 & 0.62 \\
\hline PU2 & 0.54 & 0.00 & 0.54 & 0.57 & 0.86 & 0.40 & 0.32 & 0.54 \\
\hline PU4 & 0.71 & -0.15 & 0.64 & 0.69 & 0.90 & 0.50 & 0.33 & 0.72 \\
\hline SEC1 & 0.73 & -0.25 & 0.65 & 0.69 & 0.54 & 0.93 & 0.22 & 0.78 \\
\hline SEC2 & 0.79 & -0.34 & 0.70 & 0.73 & 0.55 & 0.95 & 0.16 & 0.77 \\
\hline SEC3* & 0.58 & -0.33 & 0.35 & 0.48 & 0.27 & 0.78 & 0.07 & 0.54 \\
\hline SEC4 & 0.72 & -0.31 & 0.62 & 0.69 & 0.46 & 0.92 & 0.11 & 0.72 \\
\hline SN1 & 0.20 & 0.23 & 0.16 & 0.28 & 0.26 & 0.14 & 0.92 & 0.29 \\
\hline SN2 & 0.23 & 0.21 & 0.19 & 0.26 & 0.32 & 0.12 & 0.85 & 0.28 \\
\hline SN3 & 0.19 & 0.18 & 0.17 & 0.25 & 0.30 & 0.14 & 0.90 & 0.27 \\
\hline SN4 & 0.29 & 0.10 & 0.26 & 0.36 & 0.40 & 0.16 & 0.88 & 0.36 \\
\hline TCF1 & 0.83 & -0.26 & 0.74 & 0.83 & 0.69 & 0.78 & 0.32 & 0.97 \\
\hline TCF2 & 0.86 & -0.24 & 0.73 & 0.83 & 0.71 & 0.78 & 0.36 & 0.98 \\
\hline TCF3 & 0.84 & -0.26 & 0.74 & 0.82 & 0.70 & 0.77 & 0.34 & 0.98 \\
\hline
\end{tabular}

Table 103 shows that all items were more strongly correlated with their intended construct than with any other variable. What is more, the item loadings were very high averaging above 0.80 for all constructs.

As expected, the cross-loadings did not differ significantly from the complete dataset and the cross-loadings suggested construct validity among the scales. 
In addition, discriminant validity was assessed through an AVE analysis. Table 104 shows that each construct shared greater variance with its own block of measures than with any other construct in the model. All AVEs were consistent with Fornell and Larcker's guidelines exceeding the 0.50 threshold value (Fornell and Larcker 1981).

Table 104: Correlations of the latent variables and reliability measures for the financial loan dataset - main study

\begin{tabular}{|l|c|c|c|c|r|r|r|r|r|c|c|}
\hline & AVE & CR & $\begin{array}{c}\text { Cron } \\
\boldsymbol{\alpha}\end{array}$ & Att & Costs & EOU & INT & PU & $\begin{array}{c}\text { Secu } \\
\text { rity }\end{array}$ & SN & TCF \\
\hline Attitude & 0.87 & 0.95 & 0.92 & $\mathbf{0 . 9 3}$ & & & & & & & \\
\hline Costs & 0.70 & 0.88 & 0.79 & -0.25 & $\mathbf{0 . 8 4}$ & & & & & & \\
\hline Ease of use & 0.85 & 0.94 & 0.91 & 0.71 & -0.27 & $\mathbf{0 . 9 2}$ & & & & & \\
\hline Intentions & 0.94 & 0.98 & 0.98 & 0.82 & -0.28 & 0.69 & $\mathbf{0 . 9 7}$ & & & & \\
\hline P.usefulness & 0.78 & 0.91 & 0.86 & 0.71 & -0.11 & 0.66 & 0.70 & $\mathbf{0 . 8 8}$ & & & \\
\hline Security & 0.81 & 0.94 & 0.92 & 0.79 & -0.34 & 0.66 & 0.73 & 0.52 & $\mathbf{0 . 9 0}$ & & \\
\hline Subj. norms & 0.79 & 0.94 & 0.91 & 0.26 & 0.19 & 0.23 & 0.33 & 0.37 & 0.16 & $\mathbf{0 . 8 9}$ & \\
\hline TCF & 0.96 & 0.98 & 0.98 & 0.86 & -0.26 & 0.75 & 0.85 & 0.72 & 0.79 & 0.35 & $\mathbf{0 . 9 8}$ \\
\hline
\end{tabular}

Table 104 also shows that all measures were robust in terms of their internal consistency reliability as indexed by the composite reliability (CR). The composite reliabilities of the reflective measures ranged from 0.86 to 0.98 exceeding the recommended threshold value of 0.70 (Nunnally 1978) for all constructs in the research model. Likewise, all Cronbach Alpha values were above 0.78 re-confirming the reliability of the scales.

\subsubsection{Account inquiries dataset}

Initially all t-values were produced to examine the construct validity for the account inquiry dataset. Therefore, the account inquiry sub-dataset was imported into SmartPLS. Next, the model was set up within the SmartPLS software package as outlined in Figure 38 and the data subsequently bootstrapped.

Table 105: T-values for the reflective measures - account inquiries dataset/main study

\begin{tabular}{|c|c|c|c|}
\hline Item to construct & T Statistics & Item to construct & T Statistics \\
\hline ATT1*<- Attitude & $8.95 * * *$ & PU1 <- Perceived usefulness & $29.90 * * *$ \\
\hline ATT3 <- Attitude & $50.10 * * *$ & PU2 <- Perceived usefulness & $15.77 * * *$ \\
\hline ATT4 <- Attitude & $81.26 * * *$ & PU4 <- Perceived usefulness & $32.67 * * *$ \\
\hline COST1 <- Costs & $13.90 * * *$ & SEC1 <- Security & $48.68 * * *$ \\
\hline COST $2<-$ Costs & $10.47 * * *$ & SEC2 <- Security & $55.71 * * *$ \\
\hline COST4 <- Costs & $3.84 * * *$ & SEC3*<- Security & $8.55 * * *$ \\
\hline EOU1 <- Ease of use & $144.49 * * *$ & SEC4 <- Security & $42.41 * * *$ \\
\hline EOU2 <- Ease of use & $114.19 * * *$ & SN1 <- Subjective norms & $4.55 * * *$ \\
\hline EOU4 <- Ease of use & $63.67 * * *$ & SN2 <- Subjective norms & $3.50 * * *$ \\
\hline INT1 <- Intentions & $141.17 * * *$ & SN3 <- Subjective norms & $4.20 * * *$ \\
\hline INT2<- Intentions & $82.57 * * *$ & SN4 <- Subjective norms & $4.54 * * *$ \\
\hline INT3 <- Intentions & $19.82 * * *$ & TCF1<- TCF & $102.24 * * *$ \\
\hline \multirow[t]{2}{*}{ INT4 <- Intentions } & $18.78 * * *$ & TCF2 <- TCF & $137.87 * * *$ \\
\hline & & TCF3 <- TCF & $18.55 * * *$ \\
\hline
\end{tabular}


As shown above, all t-values of the items confirmed significance levels at least at the 0.01 level.

Next, the cross-loadings were computed by running the PLS algorithm for the account inquiries dataset. Table 106 shows the cross-loadings computed for the items of the account inquiry dataset.

Table 106: Cross loadings - account inquiries dataset (n=170)/main study

\begin{tabular}{|c|c|c|c|c|c|c|c|c|}
\hline & Attitude & Costs & $\begin{array}{r}\text { Ease of } \\
\text { use }\end{array}$ & Intentions & $\begin{array}{r}\text { Perceived } \\
\text { usefulness }\end{array}$ & Security & $\begin{array}{r}\text { Subjective } \\
\text { norms }\end{array}$ & TCF \\
\hline ATT1* & 0.69 & -0.30 & 0.45 & 0.37 & 0.39 & 0.45 & -0.19 & 0.46 \\
\hline ATT3 & 0.92 & -0.17 & 0.64 & 0.61 & 0.60 & 0.66 & 0.03 & 0.64 \\
\hline ATT4 & 0.94 & -0.22 & 0.69 & 0.66 & 0.61 & 0.69 & 0.05 & 0.71 \\
\hline COST1 & -0.27 & 0.88 & -0.32 & -0.38 & -0.25 & -0.35 & 0.12 & -0.25 \\
\hline COST2 & -0.12 & 0.83 & -0.17 & -0.23 & -0.15 & -0.15 & -0.02 & -0.15 \\
\hline COST4 & -0.17 & 0.56 & -0.16 & -0.11 & -0.16 & -0.11 & -0.03 & -0.17 \\
\hline EOU1 & 0.67 & -0.28 & 0.97 & 0.75 & 0.77 & 0.59 & 0.00 & 0.87 \\
\hline EOU2 & 0.69 & -0.26 & 0.97 & 0.71 & 0.78 & 0.63 & -0.01 & 0.83 \\
\hline EOU4 & 0.68 & -0.33 & 0.95 & 0.73 & 0.73 & 0.58 & 0.02 & 0.79 \\
\hline INT1 & 0.65 & -0.38 & 0.76 & 0.97 & 0.61 & 0.59 & -0.06 & 0.77 \\
\hline INT2 & 0.64 & -0.35 & 0.75 & 0.96 & 0.61 & 0.59 & -0.08 & 0.75 \\
\hline INT3 & 0.53 & -0.29 & 0.66 & 0.89 & 0.55 & 0.52 & 0.01 & 0.68 \\
\hline INT4 & 0.55 & -0.26 & 0.58 & 0.83 & 0.49 & 0.49 & -0.07 & 0.66 \\
\hline PU1 & 0.47 & -0.22 & 0.60 & 0.44 & 0.87 & 0.46 & -0.02 & 0.58 \\
\hline PU2 & 0.46 & -0.19 & 0.52 & 0.40 & $\mathbf{0 . 8 3}$ & 0.36 & 0.07 & 0.51 \\
\hline PU4 & 0.64 & -0.21 & 0.82 & 0.67 & 0.85 & 0.53 & 0.05 & 0.72 \\
\hline SEC1 & 0.61 & -0.28 & 0.58 & 0.57 & 0.53 & 0.93 & -0.10 & 0.63 \\
\hline SEC2 & 0.69 & -0.27 & 0.59 & 0.55 & 0.49 & 0.94 & -0.07 & 0.63 \\
\hline SEC3* & 0.46 & -0.28 & 0.26 & 0.31 & 0.22 & 0.65 & -0.23 & 0.26 \\
\hline SEC4 & 0.68 & -0.26 & 0.66 & 0.60 & 0.58 & 0.93 & -0.10 & 0.66 \\
\hline SN1 & -0.02 & 0.06 & 0.00 & -0.07 & 0.04 & -0.12 & 0.96 & -0.08 \\
\hline SN2 & 0.05 & 0.08 & 0.02 & -0.01 & 0.05 & -0.09 & 0.85 & -0.05 \\
\hline SN3 & 0.00 & 0.04 & 0.01 & -0.04 & 0.04 & -0.08 & 0.94 & -0.07 \\
\hline SN4 & -0.05 & 0.06 & 0.01 & -0.03 & 0.03 & -0.16 & 0.82 & -0.03 \\
\hline TCF1 & 0.68 & -0.25 & 0.87 & 0.78 & 0.74 & 0.62 & -0.07 & 0.96 \\
\hline TCF2 & 0.67 & -0.27 & 0.86 & 0.78 & 0.72 & 0.65 & -0.06 & 0.97 \\
\hline TCF3 & 0.66 & -0.20 & 0.68 & 0.64 & 0.58 & 0.57 & -0.07 & 0.88 \\
\hline
\end{tabular}

The cross-loadings generated for the account inquiry dataset suggested convergent and discriminant validity. All items loaded highly onto the intended constructs and indicated discriminant validity. To further evaluate this, an AVE analysis was conducted using the account inquiry dataset. The outcome of this test is outlined in Table 107.

Table 107: Correlations of the latent variables and reliability measures for the account inquiries dataset - main study

\begin{tabular}{|l|c|c|c|r|r|r|r|r|r|l|l|}
\hline & AVE & CR & $\begin{array}{c}\text { Cron } \\
\boldsymbol{\alpha}\end{array}$ & Att & Costs & EOU & INT & PU & $\begin{array}{c}\text { Secu } \\
\text { rity }\end{array}$ & SN & TCF \\
\hline Attitude & 0.74 & 0.89 & 0.82 & $\mathbf{0 . 8 6}$ & & & & & & & \\
\hline Costs & 0.59 & 0.81 & 0.70 & -0.25 & $\mathbf{0 . 7 7}$ & & & & & & \\
\hline Ease of use & 0.93 & 0.97 & 0.96 & 0.71 & -0.30 & $\mathbf{0 . 9 6}$ & & & & & \\
\hline Intentions & 0.83 & 0.95 & 0.93 & 0.65 & -0.35 & 0.76 & $\mathbf{0 . 9 1}$ & & & & \\
\hline P.usefulness & 0.72 & 0.89 & 0.81 & 0.64 & -0.25 & 0.79 & 0.62 & $\mathbf{0 . 8 5}$ & & & \\
\hline
\end{tabular}




\begin{tabular}{|l|r|r|r|r|r|r|r|r|r|r|r|}
\hline Security & 0.76 & 0.92 & 0.89 & 0.71 & -0.31 & 0.63 & 0.60 & 0.55 & $\mathbf{0 . 8 7}$ & & \\
\hline Subj. norms & 0.80 & 0.94 & 0.92 & -0.02 & 0.06 & 0.00 & -0.05 & 0.04 & -0.13 & $\mathbf{0 . 8 9}$ & \\
\hline TCF & 0.88 & 0.96 & 0.93 & 0.71 & -0.26 & 0.86 & 0.78 & 0.73 & 0.65 & -0.07 & $\mathbf{0 . 9 4}$ \\
\hline
\end{tabular}

Table 107 demonstrates that each construct shared greater variance with its own block of measures than with any other construct in the model. Further, all AVEs were consistent with Fornell and Larcker's guidelines exceeding the 0.50 threshold value (Fornell and Larcker 1981).

Moreover, all measures were strong in terms of their internal consistency reliability as indexed by the composite reliability (CR). The composite reliabilities of the reflective measures (account inquiry dataset) ranged from 0.81 to 0.97 exceeding the recommended threshold value of 0.70 (Nunnally 1978). Likewise, all Cronbach alpha values were above 0.70 verifying the reliability of the scales.

\subsubsection{Construct validity assessment - formative TCF}

As with the pilot study, an adjusted redundancy analysis was used to select the most appropriate TCF items for modeling the TCF construct with individual moderation scores. While the redundancy analysis for the pilot study was performed for both sub-datasets, the redundancy analysis for the main study was only performed for the complete $(n=340)$ dataset $^{26}$. The following Table 108 shows the results of the tests.

Table 108: Item selection: redundancy analysis / main study / complete dataset $(n=340)$

\begin{tabular}{|c|c|c|c|c|c|c|c|}
\hline \multicolumn{7}{|c|}{ Complete dataset $(n=340)$} & \multirow[b]{3}{*}{$\begin{array}{l}\text { Sum } \mathbf{R}^{2} \\
\text { explained } \\
\text { in ATT } \\
\text { \& PU }\end{array}$} \\
\hline & & ved Use & ness & & Attitud & & \\
\hline Product scores & T-value & Beta & $\mathbf{R}^{2}$ & $\begin{array}{l}\text { T- } \\
\text { value }\end{array}$ & Beta & $\mathbf{R}^{2}$ & \\
\hline TCF_ANZBL1 & 4.238 & -0.188 & 0.035 & 7.019 & -0.314 & 0.098 & 0.13 \\
\hline TCF_ANZBL2 & 2.483 & -0.144 & 0.021 & 6.961 & -0.277 & 0.077 & 0.10 \\
\hline TCF_ANZBL3 & 1.587 & -0.094 & 0.009 & 4.401 & -0.216 & 0.047 & 0.06 \\
\hline TCF_ANZBL4 & 2.632 & -0.142 & 0.020 & 6.578 & -0.304 & 0.092 & 0.11 \\
\hline TCF_COMP1 & 0.400 & -0.030 & 0.001 & 3.963 & -0.208 & 0.043 & 0.04 \\
\hline TCF_COMP2 & 3.174 & -0.163 & 0.026 & 4.882 & -0.262 & 0.068 & 0.09 \\
\hline TCF_COMP3 & 14.013 & 0.587 & 0.344 & 11.796 & 0.570 & 0.325 & 0.67 \\
\hline TCF_COMP4 & 13.523 & 0.569 & 0.324 & 11.344 & 0.553 & 0.306 & 0.63 \\
\hline TCF_EFFOR1 & 0.976 & -0.131 & 0.017 & 3.882 & -0.174 & 0.030 & 0.05 \\
\hline TCF_EFFOR2 & 13.092 & 0.502 & 0.252 & 10.854 & 0.480 & 0.231 & 0.48 \\
\hline TCF_EFFOR3 & 1.307 & -0.111 & 0.012 & 4.505 & -0.223 & 0.050 & 0.06 \\
\hline TCF_EFFOR4 & 2.920 & -0.146 & 0.022 & 5.261 & -0.263 & 0.069 & 0.09 \\
\hline TCF_IMPOR1 & 15.639 & 0.598 & 0.356 & 13.927 & 0.579 & 0.336 & 0.69 \\
\hline TCF_IMPOR2 & 10.599 & 0.490 & 0.240 & 10.882 & 0.478 & 0.228 & 0.47 \\
\hline
\end{tabular}

\footnotetext{
${ }^{26}$ This approach seemed reasonable since all datasets used similar items during the main study.
} 


\begin{tabular}{|l|l|l|l|l|l|l|l|} 
TCF_IMPOR3 & 0.676 & -0.057 & 0.003 & 1.359 & -0.113 & 0.013 & 0.02 \\
\hline TCF_IMPOR4 & 0.862 & -0.082 & 0.007 & 1.315 & -0.109 & 0.012 & 0.02 \\
\hline TCF_IMPOR5 & 5.288 & 0.298 & 0.086 & 4.709 & 0.214 & 0.046 & 0.13 \\
\hline TCF_ROUT1 & 12.501 & 0.549 & 0.301 & 11.985 & 0.555 & 0.308 & 0.61 \\
\hline TCF_ROUT2 & $\mathbf{1 8 . 6 4 4}$ & $\mathbf{0 . 6 1 0}$ & $\mathbf{0 . 3 7 2}$ & $\mathbf{2 2 . 7 0 4}$ & $\mathbf{0 . 6 3 6}$ & $\mathbf{0 . 4 0 4}$ & $\mathbf{0 . 7 8}$ \\
\hline TCF_ROUT3 & 20.546 & 0.636 & 0.405 & 16.275 & 0.607 & 0.369 & 0.77 \\
\hline TCF_ROUT4 & 17.744 & 0.581 & 0.338 & 16.589 & 0.571 & 0.326 & 0.66 \\
\hline TCF_UNC1 & 3.834 & -0.223 & 0.050 & 6.923 & -0.336 & 0.113 & 0.16 \\
\hline TCF_UNC2 & $\mathbf{4 . 9 2 5}$ & $\mathbf{- 0 . 2 6 5}$ & $\mathbf{0 . 0 7 0}$ & $\mathbf{4 . 7 6 1}$ & $\mathbf{- 0 . 3 2 1}$ & $\mathbf{0 . 1 0 3}$ & $\mathbf{0 . 1 7}$ \\
\hline TCF_UNC3 & 3.548 & -0.174 & 0.030 & 4.680 & -0.228 & 0.052 & 0.08 \\
\hline TCF_EQU1 & 2.083 & -0.109 & 0.012 & 5.599 & -0.248 & 0.061 & 0.07 \\
\hline TCF_EQU2 & $\mathbf{2 . 9 1 9}$ & $\mathbf{- 0 . 1 5 1}$ & $\mathbf{0 . 0 2 3}$ & $\mathbf{5 . 2 3 5}$ & $\mathbf{- 0 . 2 5 8}$ & $\mathbf{0 . 0 6 6}$ & $\mathbf{0 . 0 9}$ \\
\hline TCF_EQU3 & 0.600 & 0.048 & 0.002 & 3.872 & -0.177 & 0.031 & 0.03 \\
\hline TCF_TIME1 & $\mathbf{1 5 . 3 2 8}$ & $\mathbf{0 . 5 5 8}$ & $\mathbf{0 . 3 1 2}$ & $\mathbf{1 2 . 3 9 2}$ & $\mathbf{0 . 4 9 1}$ & $\mathbf{0 . 2 4 1}$ & $\mathbf{0 . 5 5}$ \\
\hline TCF_TIME2 & 0.872 & -0.150 & 0.022 & 1.129 & -0.105 & 0.011 & 0.03 \\
\hline TCF_TIME3 & 15.816 & 0.524 & 0.274 & 12.293 & 0.469 & 0.220 & 0.49 \\
\hline TCF_TIME4 & 4.821 & 0.270 & 0.077 & 3.317 & 0.173 & 0.030 & 0.11 \\
\hline
\end{tabular}

As with the pilot study, the item selection criterion was the most variance explained in the attitude and perceived usefulness construct. For more information on the selection process, please refer to section 5.4.3.2. The selected items are bolded in Table 108.

\subsubsection{Measurement approach 1 - examining individual moderation scores}

The identified moderation scores were used as formative measures to evaluate the perceived TCF construct. Figure 44 portrays the TCF construct.

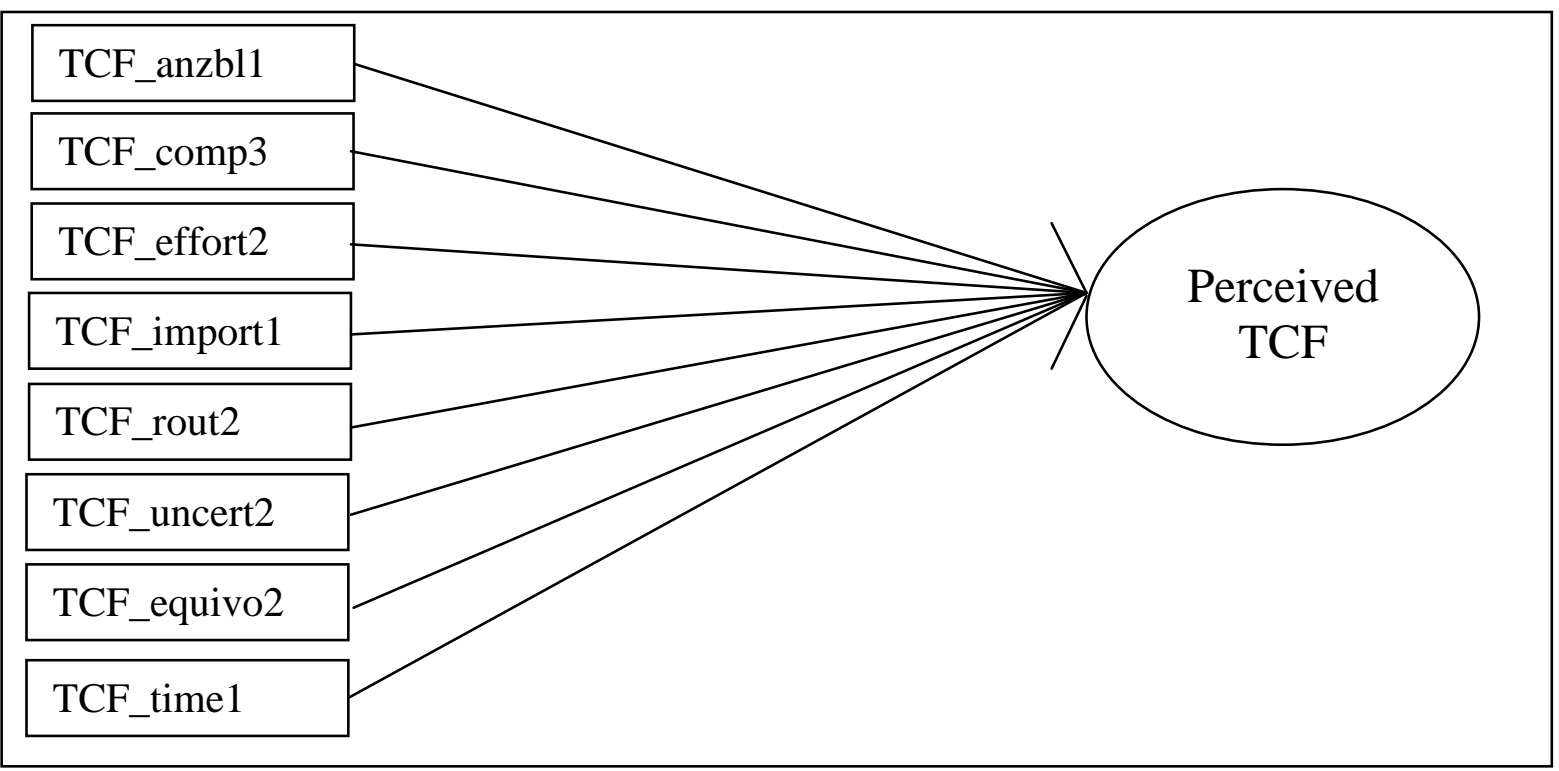

Figure 44: Formative TCF construct/individual moderation scores - main study

Following Cenfetelli and Bassellier's (2009) guidelines, the formative measures were initially assessed for multicollinearity. Therefore, VIF statistics were computed using linear regression methods using SPSS. Table 109 shows the scores obtained for these tests. 
Table 109: VIF statistics for formative measures (individual product scores)/main study

\begin{tabular}{|c|c|c|c|}
\hline Formative item & $\begin{array}{l}\text { VIF_complete } \\
\text { dataset }\end{array}$ & VIF_loans & $\begin{array}{c}\text { VIF_account } \\
\text { inquiries }\end{array}$ \\
\hline TCF_ANZBL1 & 1.48 & 1.13 & 1.38 \\
\hline TCF_COMP3 & 2.39 & 1.43 & 2.28 \\
\hline TCF_EFFORT2 & 1.81 & 1.20 & 1.72 \\
\hline TCF_IMP1 & 2.62 & 1.39 & 2.01 \\
\hline TCF_ROUT2 & 3.11 & 1.21 & 2.21 \\
\hline TCF_EQU2 & 1.46 & 1.23 & 1.48 \\
\hline TCF_UNC2 & 1.77 & 1.20 & 1.39 \\
\hline TCF_TIME1 & 1.83 & 1.31 & 1.55 \\
\hline
\end{tabular}

As shown above, all VIF values [for the complete $(n=340)$, the financial loan $(n=170)$ and account inquiry $(\mathrm{n}=170)$ data sub-sets] ranged between 1.46 and 3.11 indicating that multicollinarity was not a concern among the formative measurement items, as the scores were all lower than the threshold of 3.3. (Petter, Straub et al. 2007).

Next, the t-values and weights for the formative measures were generated in SmartPLS. The t-values were computed through a bootstrapping procedure whereas the weights were obtained through the PLS algorithm. Table 110 lists the t-values as well as the associated item weights.

Table 110: Formative measures t-values and item weights - individual moderation scores/main study

\begin{tabular}{|c|c|c|c|c|c|c|}
\hline & \multicolumn{2}{|c|}{ Complete dataset } & \multicolumn{2}{|c|}{ Financial loans } & \multicolumn{2}{|c|}{ Account inquiries } \\
\hline Formative measure & T-stat. & $\begin{array}{l}\text { Weight } \\
\text { (loading) }\end{array}$ & $\begin{array}{l}\text { T- } \\
\text { statistic }\end{array}$ & $\begin{array}{l}\text { Weight } \\
\text { (loading) }\end{array}$ & $\begin{array}{l}\text { T- } \\
\text { statistic }\end{array}$ & $\begin{array}{l}\text { Weight } \\
\text { (loading) }\end{array}$ \\
\hline TCF_ANZBL1 & 1.21 & $0.07(-0.32)$ & 1.68 & $0.21(0.38)$ & $2.34 *$ & $0.14(-0.02)$ \\
\hline TCF_COMP3 & $2.65 * *$ & $0.23(0.81)$ & 1.72 & $0.27(0.53)$ & $3.47 * * *$ & $0.30(0.85)$ \\
\hline TCF_EFFORT2 & 1.71 & $0.10(0.70)$ & 0.92 & $0.12(0.38)$ & $2.24 *$ & $0.15(0.67)$ \\
\hline TCF_IMP1 & $3.05 * *$ & $0.25(0.84)$ & $1.98 *$ & $0.28(0.57)$ & $2.69 * *$ & $0.24(0.80)$ \\
\hline TCF_ROUT2 & $5.57 * * *$ & $0.44(0.91)$ & $2.32 *$ & $0.31(0.59)$ & $4.39 * * *$ & $0.38(0.87)$ \\
\hline TCF_UNC2 & 0.99 & $0.05(-0.41)$ & 1.71 & $0.19(0.33)$ & 1.33 & $-0.07(-0.17)$ \\
\hline TCF_EQU2 & 0.06 & $0.01(-0.29)$ & 0.03 & $0.01(0.24)$ & 1.53 & $-0.09(-0.34)$ \\
\hline TCF_TIME1 & $4.16 * * *$ & $0.23(0.75)$ & $3.65 * * *$ & $0.47(0.71)$ & $2.05^{*}$ & $0.12(0.62)$ \\
\hline
\end{tabular}

Table 110 shows that TCF_COMP3, TCF_IMP1, TCF_ROUT2, and TCF_TIME1 were $\mathrm{t}$ statistically significant when performing the t-test for the complete dataset. Further, TCF_EFFORT2 had a relatively high t-value and an item loading of 0.70 . This suggested that these items contributed significantly to the TCF construct when inspecting the complete dataset.

Three items were found to be significant in the financial loan dataset (TCF_IMP1, TCF_ROUT2, and TCF_TIME1) whereas six measures were significant when using the account inquiry dataset (all apart from TCF_EQU2 and TCF_UNC2). 
What is more, many of the weights were relatively high despite not being significant. For example, TCF_COMP3 insignificant in the financial loan dataset. The t-value was 1.72 $(\mathrm{t}=1.96$ is the threshold for $\mathrm{p}<0.05)$ and the weight was 0.27 . Therefore, it is reasonable to conclude that the TCF_COMP3 strongly contributed to the TCF construct in the financial loan dataset. Besides, the item loading was 0.53 which is also relatively high. The same item was significant in the remaining datasets.

Overall, the weight distribution seemed relatively balanced (shown by high and positive weights) and most items contributed strongly to the TCF construct apart from TCF_EQU2 and TCF_UNC2. Those items were insignificant in all datasets indicating that that the items did not strongly contribute to the TCF construct.

Lastly, the scales were inspected for their portability or generalizability. Mathieson et al. (2001) suggested linking the formatively measured construct to a reflectively measured variable measuring a conceptually equivalent concept. Therefore, the inter-construct correlation between the formatively measured TCF construct and its reflectively evaluated counterpart was assessed. SmartPLS was used for this purpose. Initially all individual deviation scores were included within the analysis. Next, a reduced set of items was used excluding TCF_EQU2 and TCF_UNC2 (due to their insignificant weights). Table 111 displays the results:

Table 111: Redundancy analysis - individual moderation score analysis/main study

\begin{tabular}{|c|c|c|c|c|c|c|}
\hline \multirow[b]{2}{*}{ Construct relations } & \multicolumn{2}{|c|}{$\begin{array}{l}\text { Complete } \\
\text { dataset }\end{array}$} & \multicolumn{2}{|c|}{ Financial loans } & \multicolumn{2}{|c|}{ Account inquiries } \\
\hline & $\begin{array}{l}\text { T- } \\
\text { statist } \\
\text { ic }\end{array}$ & $\begin{array}{l}\text { Correlation } \\
\text { coefficient) }\end{array}$ & $\begin{array}{l}\text { T- } \\
\text { statistic }\end{array}$ & $\begin{array}{l}\text { Correlation } \\
\text { coefficient) }\end{array}$ & $\begin{array}{l}\text { T- } \\
\text { statistic }\end{array}$ & $\begin{array}{l}\text { Correlation } \\
\text { coefficient }\end{array}$ \\
\hline $\begin{array}{l}\text { TCF (all items) } \rightarrow \text { TCF } \\
\text { reflective }\end{array}$ & 33.145 & $\begin{array}{c}0.729(0.531 \\
\left.\mathrm{R}^{2}\right) \\
\end{array}$ & $\begin{array}{c}10.460 * * \\
* \\
\end{array}$ & $0.51\left(0.254 \mathrm{R}^{2}\right)$ & $\begin{array}{c}18.986^{* *} \\
* \\
\end{array}$ & $\begin{array}{c}0.78(0.613 \\
\left.\mathrm{R}^{2}\right) \\
\end{array}$ \\
\hline $\begin{array}{l}\text { TCF (reduced set of } \\
\text { items) -> TCF reflective }\end{array}$ & 33.268 & $\begin{array}{c}0.727(0.529 \\
\left.\mathrm{R}^{2}\right)\end{array}$ & $9.230 * * *$ & $0.50\left(0.245 \mathrm{R}^{2}\right)$ & $16.10 * * *$ & $\begin{array}{c}0.77(0.603 \\
\left.\mathrm{R}^{2}\right)\end{array}$ \\
\hline \multicolumn{7}{|c|}{$*$ significant at $\mathrm{p}<0.05, * *$ significant at $\mathrm{p}<0.01$ and $* * *$ significant at $\mathrm{p}<0.001$} \\
\hline \multicolumn{7}{|c|}{ Reduced set - only ANZBL1, COMP3, EFFORT2, IMP1, ROUT2, and TIME1 } \\
\hline
\end{tabular}

Table 111 shows that the formatively measured TCF construct was highly correlated with the reflective TCF construct (for all datasets). Cenfetelli and Bassellier's (2009) suggested that inter-construct correlation coefficients should exceed a 0.80 threshold. This guideline was provided in combination with the SERVQUAL instrument. Since the TCF survey questionnaire instrument was newly developed, correlation coefficients ranging from 0.50 to 0.78 were accepted as adequate in the current study. It is important to note that the threshold was almost reached when investigating the complete and account inquiries datasets. 
Furthermore, the correlation coefficients and the $\mathrm{R}^{2}$ values were much higher and more consistent than those obtained during the pilot study. This suggests that the formative scales increased in terms of their generalizability and portability.

What is more, the inter-construct correlations did not differ significantly when using the reduced set of formative measures (excluding TCF_EQU2, and TCF_UNC2). This indicated that these items could be potentially excluded in future studies when conceptualizing the TCF construct with individual moderation scores.

The following section explains the second conceptualization of the formative TCF construct.

\subsubsection{Measurement approach 2 - examining average moderation scores}

As outlined in section 5.2.8., the average moderation scores were also computed and then used as formative items for assessing the perceived TCF construct. The underlying argument for this approach was that all moderation scores could contribute to the TCF construct - not only a few selected items.

The average TCF scores were computed as outlined in section 5.2. This led to eight average formative measures for assessing the TCF construct. The conceptualization of the TCF construct is visualized in Figure 45.

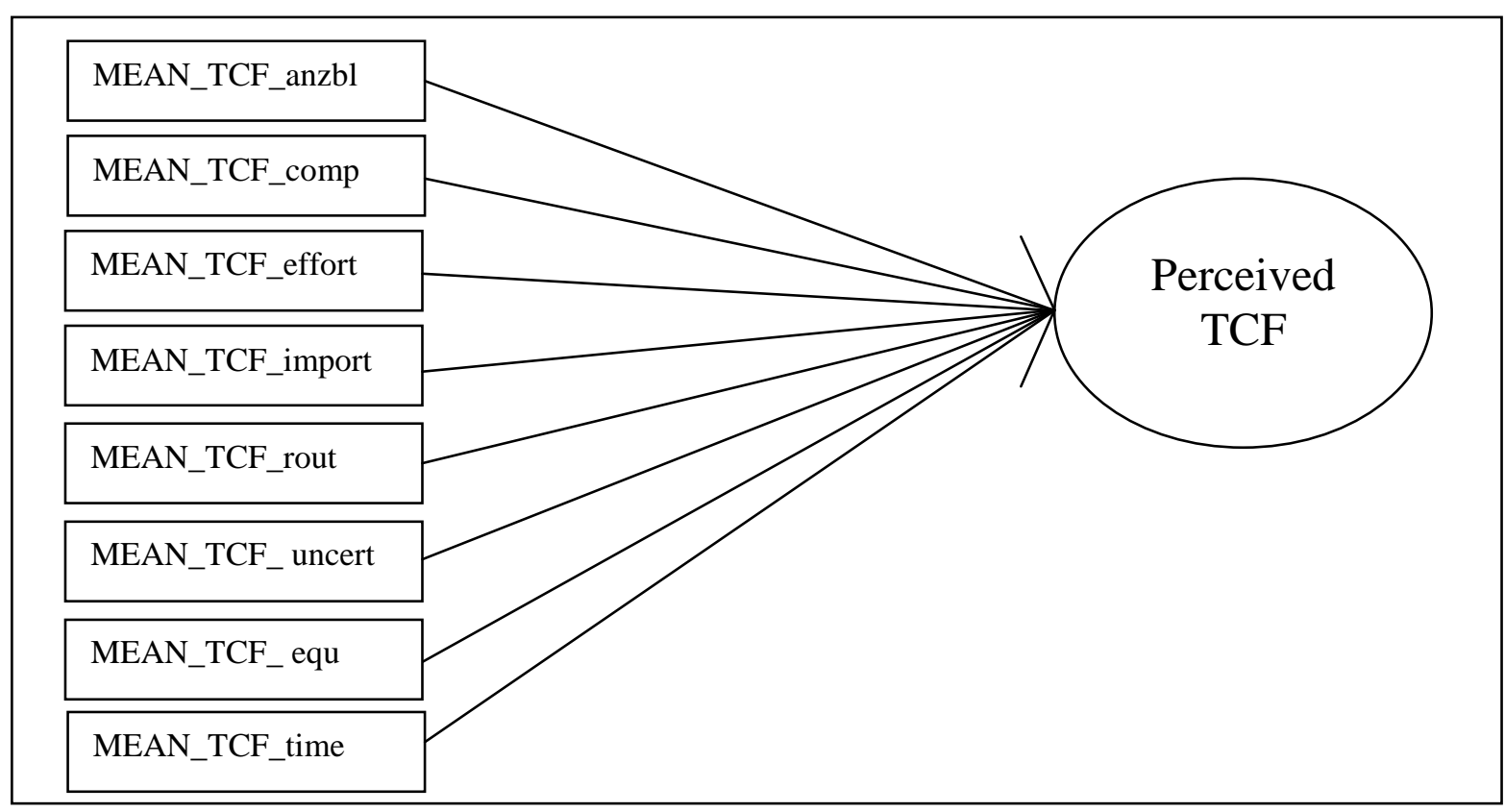

Figure 45: Formative TCF construct/average moderation scores - main study 
The average deviation scores were initially checked for multicollinearity (VIF analysis using SPSS).

Table 112: VIF statistics for the reduced set of formative measures/main study

\begin{tabular}{|c|c|c|c|}
\hline Formative item & $\begin{array}{l}\text { Complete } \\
\text { dataset }\end{array}$ & VIF_loans & $\begin{array}{l}\text { VIF_account } \\
\text { inquiries }\end{array}$ \\
\hline MEAN_TCF_anzbl & 3.01 & 2.01 & 2.38 \\
\hline MEAN_TCF_comp & 1.99 & 1.83 & 2.12 \\
\hline MEAN_TCF_effort & 2.03 & 2.21 & 1.76 \\
\hline MEAN_TCF_import & 1.91 & 1.77 & 2.27 \\
\hline MEAN_TCF_rout & 2.97 & 1.36 & 2.25 \\
\hline MEAN_TCF_equ & 2.14 & 1.34 & 1.77 \\
\hline MEAN_TCF_uncert & 1.67 & 1.46 & 1.65 \\
\hline MEAN_TCF_time & 2.00 & 1.56 & 2.23 \\
\hline
\end{tabular}

The computed VIF statistics confirmed that multicollinearity was not present among the average moderation scores. All values ranged between 1.3 and 3.01, below the recommended threshold of 3.3 (Petter, Straub et al. 2007). Next, the t-values and weights for the averaged TCF measures were computed using PLS.

Table 113: Formative measures t-values and item weights -average moderation scores/main study

\begin{tabular}{|l|c|c|c|c|c|c|}
\hline & \multicolumn{2}{|c|}{$\begin{array}{l}\text { Complete } \\
\text { dataset }\end{array}$} & \multicolumn{2}{c|}{ Financial loans } & \multicolumn{2}{c|}{ Account inquiries } \\
\hline Formative measure & $\begin{array}{l}\text { T- } \\
\text { statist } \\
\text { ic }\end{array}$ & $\begin{array}{l}\text { Weight } \\
\text { (loading) }\end{array}$ & $\begin{array}{l}\text { T- } \\
\text { statist } \\
\text { ic }\end{array}$ & $\begin{array}{l}\text { Weight } \\
\text { (loading) }\end{array}$ & $\begin{array}{l}\text { T- } \\
\text { statisti } \\
\text { c }\end{array}$ & $\begin{array}{l}\text { Weight } \\
\text { (loading) }\end{array}$ \\
\hline MEAN_ANZ -> TCF & 1.02 & $-0.10(-0.31)$ & 0.03 & $-0.01(0.53)$ & 0.38 & $-0.03(0.01)$ \\
\hline MEAN_COMP-> TCF & $2.27 *$ & $0.25(0.70)$ & 1.72 & $0.30(0.78)$ & $3.36^{* * *}$ & $0.30(0.75)$ \\
\hline MEAN_EFFORT-> TCF & 1.10 & $0.09(0.14)$ & 1.00 & $0.20(0.61)$ & 0.50 & $0.04(0.31)$ \\
\hline MEAN_IMP -> TCF & $2.20^{*}$ & $0.21(0.61)$ & $2.84^{* *}$ & $0.48(0.87)$ & $2.01^{*}$ & $0.18(0.72)$ \\
\hline MEAN_ROUT -> TCF & $5.47^{* *}$ & $0.61(0.93)$ & $2.13^{*}$ & $0.32(0.64)$ & $6.60^{* * *}$ & $0.47(0.91)$ \\
\hline MEAN_EQU -> TCF & 1.33 & $-0.10(-0.24)$ & 0.89 & $-0.14(0.28)$ & $2.35^{*}$ & $-0.18(-0.19)$ \\
\hline MEAN_UNC -> TCF & 0.43 & $-0.04(-0.40)$ & 0.47 & $0.09(0.36)$ & 1.03 & $-0.08(-0.07)$ \\
\hline MEAN_TIME -> TCF & 0.91 & $0.06(0.69)$ & 0.46 & $0.07(0.58)$ & $2.68^{* *}$ & $0.22(0.77)$ \\
\hline \multicolumn{7}{|l|}{$*$ significant at $\mathrm{p}<0.05, * *$ significant at p<0.01 and *** significant at p< 0.001} \\
\hline
\end{tabular}

Unexpectedly, fewer weights tested significantly when using the mean moderation scores. Given that each moderation score could potentially contribute to the TCF construct (since the mean computation considered all TCF moderation score), this was somewhat surprising.

In the complete dataset three formative measures tested statistically significant. Two formative items tested significantly in the financial loan dataset whereas five moderation scores were statistically significant for the TCF construct in the account inquiries dataset. 
Apart from MEAN_ANZ, MEAN_EFF, and MEAN_EQU, the formative items resulted in high weights (and/or high item-to-construct loadings) in all three datasets. This suggested that most mean scores contributed substantially to the formatively measured TCF construct.

Moreover, MEAN_COMP and MEAN_EFFORT both tested statistically insignificantly for the financial loan dataset. However, both items had higher weight scores than 0.20 and the item loadings were above 0.60 . This suggested that they were both important contributors for the TCF construct in the financial loan dataset despite being statistically insignificant.

On the other hand, the weights for MEAN_ANZ and MEAN_EQU were low when inspecting the results for all datasets. Further, the loadings for the analyzability and equivocality dimensions were also relatively low. This suggested that these items did not substantially contribute to the TCF construct. Future studies could consider excluding these measures.

The scales were also inspected for their portability. Initially all mean moderation scores were included within the redundancy analysis and the formatively measured TCF construct was linked to the reflectively assessed counterpart. Next, a reduced set of items was used excluding MEAN_ANZ, MEAN_EFF, and MEAN_EQU (due to their insignificant weights). Table 114 displays the results:

Table 114: Redundancy analysis -mean moderation score analysis/main study

\begin{tabular}{|c|c|c|c|c|c|c|}
\hline \multirow[b]{2}{*}{ Construct relations } & \multicolumn{2}{|c|}{$\begin{array}{l}\text { Complete } \\
\text { dataset }\end{array}$} & \multicolumn{2}{|c|}{ Financial loans } & \multicolumn{2}{|c|}{ Account inquiries } \\
\hline & $\begin{array}{l}\text { T- } \\
\text { statistic }\end{array}$ & $\begin{array}{l}\text { Correlati } \\
\text { on } \\
\text { coefficie } \\
\text { nt) }\end{array}$ & $\begin{array}{l}\text { T- } \\
\text { statis } \\
\text { tic }\end{array}$ & $\begin{array}{l}\text { Correlatio } \\
\text { n } \\
\text { coefficient) }\end{array}$ & $\begin{array}{l}\text { T- } \\
\text { statistic }\end{array}$ & $\begin{array}{l}\text { Correlation } \\
\text { coefficient }\end{array}$ \\
\hline $\begin{array}{c}\text { TCF (all items) -> TCF } \\
\text { reflective }\end{array}$ & 28.529 & $\begin{array}{c}0.723 \\
\left(0.522 \mathrm{R}^{2}\right)\end{array}$ & $\begin{array}{c}10.253 \\
* * *\end{array}$ & $\begin{array}{c}0.498(0.254 \\
\left.\mathrm{R}^{2}\right)\end{array}$ & $\begin{array}{l}19.789 * \\
* *\end{array}$ & $0.75\left(0.562 \mathrm{R}^{2}\right)$ \\
\hline $\begin{array}{c}\text { TCF (reduced set of } \\
\text { items) -> TCF reflective }\end{array}$ & 30.693 & $\begin{array}{c}0.718 \\
\left(0.516 R^{2}\right) \\
\end{array}$ & $\begin{array}{c}10.145 \\
* * *\end{array}$ & $\begin{array}{c}0.488(0.238 \\
\left.\mathrm{R}^{2}\right)\end{array}$ & $\begin{array}{l}19.839 * \\
* *\end{array}$ & $\begin{array}{c}0.739(0.546 \\
\left.\mathrm{R}^{2}\right) \\
\end{array}$ \\
\hline
\end{tabular}

As shown above, the formatively measured TCF construct was highly correlated with the reflective TCF construct (in all datasets). All t-values indicated significance levels at the $\mathrm{p}<0.001$ level. The path coefficients were slightly lower than using individual moderation scores (as explained in the previous section). However, for all datasets the coefficients were above 0.48 demonstrating a high portability level in the formatively measured TCF construct. In addition, the correlation coefficients were above 0.7 in the complete and account inquiries 
dataset. This confirmed that the formative measures captured the most essential content of the reflectively measured TCF construct.

The inter-construct correlations did not differ significantly when excluding MEAN_ANZ, MEAN_EFF, and MEAN_EQU. These findings suggested that it would be acceptable to exclude these measures in future studies when conceptualizing the TCF construct with mean average scores.

\section{Summary}

The previous section initially assessed the convergent validity of the reflective scales. The analyses showed that the items loaded cleanly on the intended constructs and were tested highly reliable.

The moderation scores were then used as formative measures to assess the TCF construct. Initially, individual product scores (one formative item per TCF dimension) were used for modelling the formative TCF construct. Next, the mean moderation scores (by averaging the moderation scores for each TCF dimension) were employed to model the perceived TCF variable.

The findings confirmed that the formative TCF items produced consistently high weights apart from the newly created TCF dimension uncertainty and task-equivocality. Also, the redundancy analyses showed that the TCF scales were highly 'portable' indicating a high degree of generalizability.

As explained in section 6.2.1., it was decided to pool the responses for account inquiries and financial loans in order to assess the structural aspects of the research model (see the following section). 


\subsubsection{Structural model: Complete dataset - individual and mean moderation scores}

For ease of reading, Figure 42 is reproduced here before discussing the results of the structural model assessment.

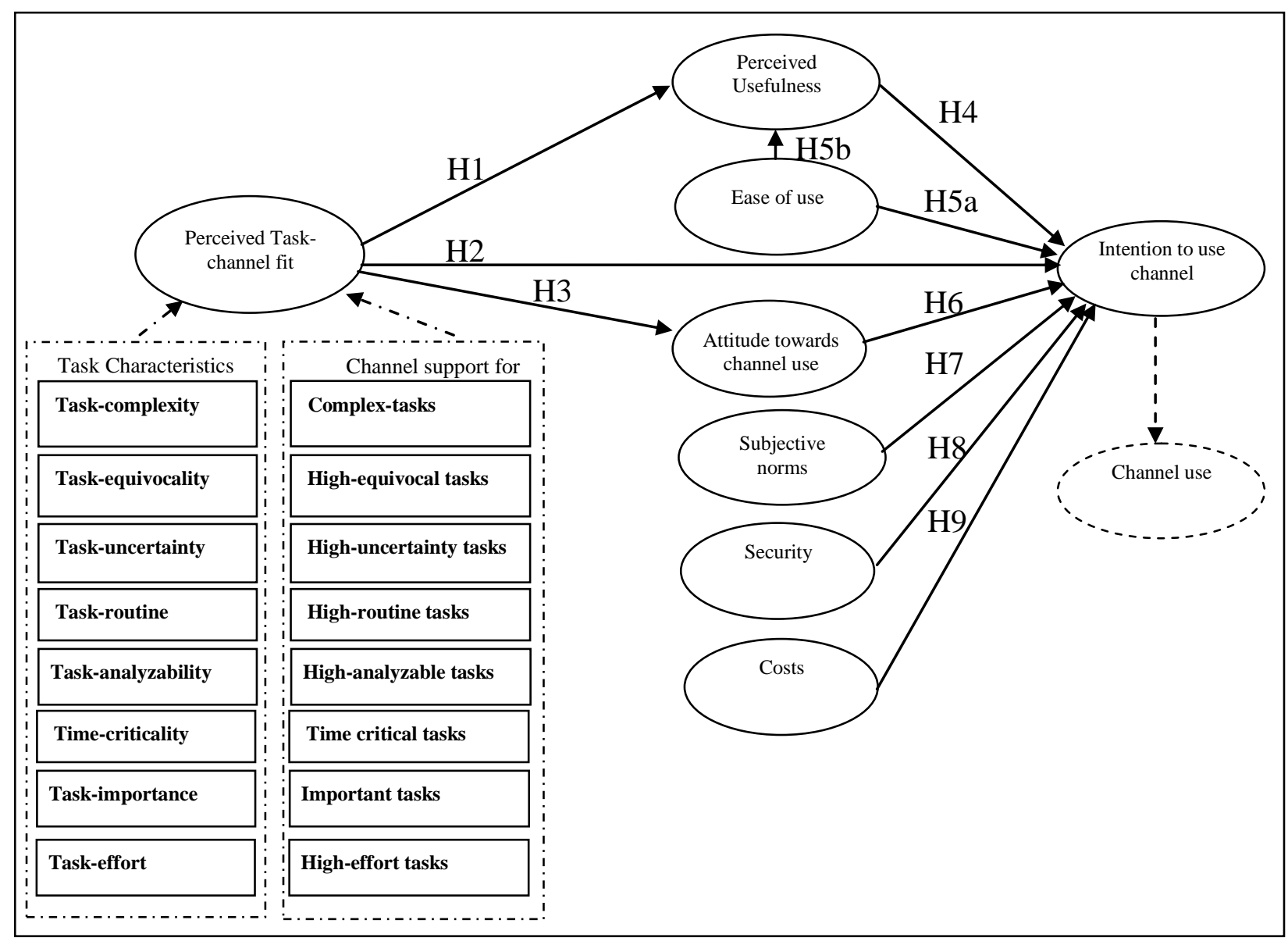

The significance levels of the structural paths were tested via t-tests using the bootstrapping procedure in PLS. The associated path coefficients were computed via the PLS algorithm. The results of the analyses are presented in Table 115. 
Table 115: Structural model results - complete dataset $(n=340) /$ main study

\begin{tabular}{|c|c|c|c|}
\hline \multirow{2}{*}{\multicolumn{2}{|c|}{ Hypothesis }} & \multicolumn{2}{|c|}{ Complete dataset $(n=340)$} \\
\hline & & \multirow{2}{*}{$\begin{array}{c}\text { (individual moderation scores) } \\
\text { T-value: } 3.66^{* * *}, \text { Coefficient: } 0.26\end{array}$} & \multirow{2}{*}{$\begin{array}{c}\text { (average moderation scores) } \\
\text { T-value: } 2.69 * * \text {, Coefficient: } 0.26\end{array}$} \\
\hline H1 & TCF $\rightarrow P U$ & & \\
\hline $\mathbf{H 2}$ & TCF $\rightarrow$ INT & T-value: $2.62 * *$ Coefficient: 0.13 & T-value: 1.25 Coefficient: 0.07 \\
\hline H3 & TCF $\rightarrow$ ATT & T-value: $23.19 * * *$, Coefficient: 0.68 & T-value:17.54***,Coefficient: 0.68 \\
\hline H4 & $\mathrm{J} \rightarrow \mathrm{INT}$ & , Coefficien & $: 2.20 *, \mathrm{Cc}$ \\
\hline H5a & EOU $\rightarrow$ INT & T-va & $: 2.57 * *, \mathrm{C}$ \\
\hline H5b & EOU $\rightarrow$ PU & , Coefficient: 0.59 & T-value: $5.55^{* * *}$, Coeffici \\
\hline H6 & ATT $\rightarrow$ INT & ***, Coefficient: & T-value: $3.52 * * *$, Coeffici \\
\hline H7 & SN $\rightarrow$ INT & T-value: $2.03^{*}$, Coefficient: 0.05 & T-value: 1.60, Coeff \\
\hline H8 & SEC $\rightarrow$ INT & T-value: $3.25^{* *}$, Coefficient: 0.16 & T-value: $1.96^{*}$, Coeff \\
\hline H9 & COST $\rightarrow$ INT & T-value: 1.83 , Coefficient: -0.06 & T-value: $1.31, \mathrm{Co}$ \\
\hline
\end{tabular}

Hypothesis 1 was confirmed. The path coefficient between the TCF construct and the perceived usefulness construct was significant at the 0.01 level. The t-value was estimated slightly higher when using the individual moderation scores, with the path coefficient statistically significant at the $\mathrm{p}<0.001$ level. The path coefficient was 0.26 (independent of using individual or average moderation scores) indicating that there is a strong causal relationship between the perceived TCF and perceived usefulness.

Hypothesis 2 was confirmed when modeling the TCF construct with individual moderation scores and the path coefficient between TCF and intentions to use was statistically significant at the 0.01 level. In contrast, the average moderation scores led to a non-significant path coefficient and the second Hypothesis was disconfirmed when using the average moderation scores. Interestingly, previous research on TTF also found contrasting findings for the structural correlations between TTF constructs and use variables (Goodhue 1995; Goodhue 1998; Shirani, Tafti et al. 1999; Goodhue, Klein et al. 2000; Staples and Seddon 2004).

Hypothesis 3 was confirmed (independent of the TCF evaluation) and the t-value was very high for the path between the TCF construct and the attitude variable (and significant at the 0.001 level). Moreover, the path coefficient was 0.68 indicating a very strong relationship between the perceived TCF construct and consumers' attitudes towards Internet banking.

As expected, H4, H5a, and H5b were also confirmed by the data and the path coefficients diverged only slightly between the individual and average moderation scores. These theoretical correlations were based on the extant literature around electronic banking and the acceptance studies such as the TAM model. The path coefficient between the ease of use 
construct and perceived usefulness was very strong (0.58) indicating that the ease of use variable accounts for much variance explained in the perceived usefulness construct.

Hypothesis 6 was confirmed and there was a relatively strong path coefficient between the attitude construct and the dependent variable. The path tested statistically significant at the 0.001 level confirming the strong influence of consumers' attitudes on their intentions to use Internet banking.

Hypothesis 7 was also confirmed when inspecting the individual moderation scores although the path coefficient was relatively low (0.05). Further, the t-value (2.03) just surpassed the significance cut-off value of $\mathrm{t}=1.96$. H7 was disconfirmed when using the average moderation scores.

H8 was also confirmed suggesting that perceived security is an important factor for consumers to use electronic banking channels. The significance level was above the 0.01 cutoff value when using individual moderation scores and just reached the 0.05 level when using the average moderation scores for the TCF construct.

H9 was the only hypothesis to be disconfirmed in the analysis of the complete $(n=340)$ dataset in both TCF modeling approaches). The path coefficient (-0.06) was very low and the $\mathrm{t}$-value was below the 1.96 significance threshold.

The overall predictive validity of the model was indicated by the high $\mathrm{R}^{2}$ values of the endogenous latent variables. More than $64 \%$ of variance was explained in the perceived usefulness construct (independent of using individual or average moderation scores for modeling the formative TCF construct). More than $46 \%$ of variance in attitude towards use was explained. This was a very positive finding since the TCF construct was the only construct influencing the attitude variable. Lastly, more than $75 \%$ of variance in intention to use was accounted for by the research model. Table 116 displays the $\mathrm{R}^{2}$ values.

Table 116: Variance explained by each construct - individual moderation scores/main study/complete dataset

\begin{tabular}{|l|c|c|c|}
\hline & $\begin{array}{l}\text { Perceived } \\
\text { usefulness }\end{array}$ & $\begin{array}{l}\text { Attitude } \\
\text { towards use }\end{array}$ & $\begin{array}{l}\text { Intention to } \\
\text { use }\end{array}$ \\
\hline $\begin{array}{l}\text { Complete dataset } \\
\text { (individual moderation scores) }\end{array}$ & $\left(\mathrm{R}^{2}=0.645\right)$ & $\left(\mathrm{R}^{2}=0.465\right)$ & $\left(\mathrm{R}^{2}=0.776\right)$ \\
\hline $\begin{array}{l}\text { Complete dataset } \\
\text { (average moderation scores) }\end{array}$ & $\left(\mathrm{R}^{2}=0.646\right)$ & $\left(\mathrm{R}^{2}=0.465\right)$ & $\left(\mathrm{R}^{2}=0.771\right)$ \\
\hline
\end{tabular}

It is important to note that the $\mathrm{R}^{2}$ values did not substantially differ using either the individual- or average moderation scores. 


\subsubsection{Structural model: task specific - individual moderation scores}

Initially the individual moderation scores were used as formative measures for the TCF construct. The structural aspects of the research model were then assessed for financial loans and account inquiries. The t-values were generated through a bootstrapping procedure in PLS whereas the path coefficient scores were determined through the PLS algorithm. The results of the analyses are presented in Table 117.

Table 117: Structural model results - individual moderation scores/main study

\begin{tabular}{|c|c|c|c|}
\hline \multicolumn{2}{|c|}{ Hypothesis } & Financial Loans & Account inquiries \\
\hline H1 & TCF $\rightarrow$ PU & T-value: $2.92 * *$, Coefficient: 0.23 & T-value: $2.99 * *$, Coefficient: 0.26 \\
\hline $\mathbf{H 2}$ & TCF $\rightarrow$ INT & T-value: 1.83 Coefficient: 0.09 & T-value: $2.22 *$, Coefficient: 0.25 \\
\hline H3 & TCF $\rightarrow$ ATT & T-value: $6.85^{* * *}$, Coefficient: 0.43 & T-value:9.78***,Coefficient: 0.69 \\
\hline H4 & PU $\rightarrow$ INT & T-value: $2.43^{*}$, Coefficient: 0.18 & T-value: 0.72 , Coefficient: -0.04 \\
\hline H5a & EOU $\rightarrow$ INT & T-value: 0.75 , Coefficient: 0.06 & T-value: $2.66^{* *}$, Coefficient: 0.41 \\
\hline H5b & EOU $\rightarrow$ PU & T-value: $5.73^{* * *}$, Coefficient: 0.54 & T-value: $6.76^{* * *}$, Coefficient: 0.58 \\
\hline H6 & ATT $\rightarrow$ INT & T-value: $4.12^{* * *}$, Coefficient: 0.39 & T-value: 1.38 , Coefficient: 0.13 \\
\hline H7 & SN $\rightarrow$ INT & T-value: $2.16^{*}$, Coefficient: 0.10 & T-value: 1.13 , Coefficient: -0.04 \\
\hline H8 & SEC $\rightarrow$ INT & T-value: $2.46^{*}$, Coefficient: 0.22 & T-value: 1.43 , Coefficient: 0.08 \\
\hline H9 & COST $\rightarrow$ INT & T-value: 1.81 , Coefficient: -0.08 & T-value: 1.51 , Coefficient: -0.12 \\
\hline & ${ }^{2}$ & $\mathrm{n}<005=$ & significant at $\mathrm{p}<0.001$ \\
\hline
\end{tabular}

When using the individual moderation scores to assess the formative TCF construct, Hypotheses 1 and 3 were confirmed by the data obtained for account inquiries and financial loans. The t-values confirmed that the TCF impacted statistically significant on the perceived usefulness and the attitude towards channel use construct (at least at the $p<0.01$ level for both datasets). The path coefficients were also very strong between the TCF construct and PU as well as Attitude. For instance, both inter-construct correlations between the TCF construct and PU were above 0.23 in both datasets. The coefficients between the TCF and attitude construct were even stronger ( 0.43 in the financial loan dataset and 0.69 in the account inquiries dataset). These findings confirmed that the formatively measured TCF impacts strongly on perceived usefulness and consumers attitudes towards Internet banking for financial loan applications/account inquiries.

$\mathrm{H} 2$ was not confirmed in the financial loan dataset but was tested positively in the account inquiries dataset. This suggested a direct influence of perceived TCF on consumers' intentions to use Internet banking applications for account inquiries. Interestingly, the linkage between TTF and the utilization construct was also tested insignificantly in previous TTF studies (e.g. Goodhue and Thompson, 1995). 
H4 was confirmed by the financial loan dataset but not by the responses obtained for account inquiries. This was surprising since the hypothesis was based on the literature around the well established technology acceptance model $^{27}$.

H5a was disconfirmed by the data obtained for financial loans but not for the account inquiries dataset. This was also surprising since much literature on electronic banking validated this path in the past (e.g. Tang et. al, 2004). H5b was confirmed and ease of use was significantly correlated with perceived usefulness (in both datasets).

Attitude impacted significantly on consumer intentions to use Internet banking for financial loans (H6). The beta coefficients were strong for these hypothesised paths confirming strong causal correlations between the variables. Surprisingly, there was no statistical significance between the attitude and the intention to use variable in the account inquiries dataset. This was despite a relatively high coefficient (0.13).

Subjective norms (H7), security (H8) and costs associated with channel use (H9) were not significantly correlated with intentions to use in the account inquiries dataset. In contrast, the same paths were confirmed by the data obtained for financial loans. This suggested that consumers are more security- and cost aware and when applying for financial loans online. Similarly, subjective norms were important for consumers when applying for loans online.

Table 118 shows the variance explained by the perceived usefulness, attitude towards use, and intention to use construct.

Table 118: Variance explained by each construct - individual moderation scores/main study

\begin{tabular}{|c|c|c|c|}
\hline & $\begin{array}{l}\text { Perceived } \\
\text { usefulness }\end{array}$ & $\begin{array}{l}\text { Attitude towards } \\
\text { use }\end{array}$ & Intentions to use \\
\hline Financial Loans & $\left(\mathrm{R}^{2}=0.473\right)$ & $\left(\mathrm{R}^{2}=0.183\right)$ & $\left(\mathrm{R}^{2}=0.745\right)$ \\
\hline Account inquiries & $\left(\mathrm{R}^{2}=0.648\right)$ & $\left(\mathrm{R}^{2}=0.478\right)$ & $\left(\mathrm{R}^{2}=0.645\right)$ \\
\hline
\end{tabular}

More than $47 \%$ of variance in the perceived usefulness construct was explained in both datasets. The $\mathrm{R}^{2} \mathrm{~s}$ computed for the attitude towards use construct suggested that around $18 \%$ of variance was explained by this construct when assessing the responses for financial loans. The $\mathrm{R}^{2}$ values were higher when inspecting the account inquiries dataset $\left(\mathrm{R}^{2}=0.478\right)$.

The $\mathrm{R}^{2}$ results for perceived usefulness were above 0.473 in both datasets. The variance explained in the dependent variable was above $64 \%$ for both datasets when using the

\footnotetext{
${ }^{27}$ These results are discussed in more depth in section 6.8.7.5
} 
individual moderation product scores. The variance explained was slightly higher when using the financial loan dataset (74 percent variance explained).

Having discussed the individual moderation score analysis, the following section discusses the results of the structural model when examining the average moderation scores.

\subsubsection{Structural model: task specific - mean moderation scores}

As explained in section 5.2.8., the formative TCF construct was also conceptualized by using the average moderation scores of each TCF dimension. The structural paths of the model were then assessed using SmartPLS. The results are shown in Table 119.

Table 119: Structural model results - average moderation scores/main study

\begin{tabular}{|c|c|c|c|}
\hline \multicolumn{2}{|c|}{ Hypothesis } & Financial Loans & Account inquiries \\
\hline H1 & TCF $\rightarrow$ PU & T-value: $2.65^{* *}$, Coefficient: 0.20 & T-value: $5.06^{* * *}$, Coefficient: 0.28 \\
\hline H2 & TCF $\rightarrow$ INT & T-value: 0.37 , Coefficient: 0.02 & T-value: $2.14^{*}$, Coefficient: 0.18 \\
\hline H3 & TCF $\rightarrow$ ATT & T-value: $8.03^{* * *}$, Coefficient: 0.47 & T-value:15.62***, Coefficient: 0.66 \\
\hline H4 & PU $\rightarrow$ INT & T-value: $2.51^{*}$, Coefficient: 0.19 & T-value: 0.35 , Coefficient: -0.04 \\
\hline H5a & EOU $\rightarrow$ INT & T-value: $2.37^{*}$, Coefficient: 0.09 & T-value: $2.96^{* *}$, Coefficient: 0.44 \\
\hline H5b & EOU $\rightarrow P U$ & T-value: $6.18^{* * *}$, Coefficient: 0.55 & T-value: $6.83^{* * *}$, Coefficient: 0.57 \\
\hline H6 & ATT $\rightarrow$ INT & T-value: $5.13^{* * *}$, Coefficient: 0.40 & T-value: $2.28^{*}$, Coefficient: 0.15 \\
\hline H7 & SN $\rightarrow$ INT & T-value: $2.37^{*}$, Coefficient: 0.12 & T-value: 0.71 , Coefficient: -0.04 \\
\hline H8 & SEC $\rightarrow$ INT & T-value: $1.97^{*}$, Coefficient: 0.21 & T-value: 1.29 , Coefficient: 0.08 \\
\hline H9 & COST->INT & T-value: $2.76^{* *}$, Coefficient: -0.09 & T-value: 1.03 , Coefficient: -0.12 \\
\hline
\end{tabular}

$\mathrm{H} 1$ and $\mathrm{H} 3$ were confirmed in both datasets. $\mathrm{H} 2$ was disconfirmed for the financial loan dataset but confirmed for the account inquiries dataset. This was expected given the results discussed in the previous section. If using the average moderation scores for assessing the structural model, the path coefficients for $\mathrm{H} 1$ and $\mathrm{H} 2$ became stronger than using individual moderation scores. This was also expected since all TCF scores contributed to the formatively measured TCF construct - rather than only a few selected items.

H5a was also confirmed when using the average moderation scores. Considering that ease of use was not at all influenced by the TCF construct, this was an unexpected finding (the only difference between this section and the previous one was the different TCF modelling approach). It should be also mentioned that H6 was confirmed in both datasets suggesting that attitude towards channel use was influential for respondents' intention to use Internet banking.

Subjective norms (H7), security (H8) and costs associated with channel use (H9) were significantly correlated with intentions to use in the financial loan dataset. In contrast, the same paths were rejected by the data obtained for account inquiries. This suggested that 
subjective norms were important for consumers when applying for loans online. Similarly, consumers are more security- and cost aware and when applying for financial loans online.

In comparison to the individual moderation score analysis, the average moderation scores led to more variance explained in each construct (apart from the $\mathrm{R}^{2}$ values in the perceived usefulness construct/financial loan dataset).

Table 120 lists the variance explained by each construct.

Table 120: Variance explained by each construct - average moderation scores/main study

\begin{tabular}{|l|l|r|c|}
\hline & $\begin{array}{l}\text { Perceived } \\
\text { usefulness }\end{array}$ & $\begin{array}{l}\text { Attitude towards } \\
\text { use }\end{array}$ & Intentions to use \\
\hline Financial Loans & $\left(\mathrm{R}^{2}=0.461\right)$ & $\left(\mathrm{R}^{2}=0.222\right)$ & $\left(\mathrm{R}^{2}=0.741\right)$ \\
\hline Account inquiries & $\left(\mathrm{R}^{2}=0.652\right)$ & $\left(\mathrm{R}^{2}=0.438\right)$ & $\left(\mathrm{R}^{2}=0.636\right)$ \\
\hline
\end{tabular}

\section{Summary}

The analysis of the measurement model demonstrated that the scales used during the main study advanced the findings of the pilot study. The reflective items all loaded very cleanly onto the intended constructs and were all tested highly reliable. Apart from task equivocality and task uncertainty, all formative measures continually contributed to the TCF construct as indicated by strong item weights and/or item loadings. Further, the redundancy analyses showed that the formative TCF construct was portable indicating a high degree of generalizability.

The structural model assessment demonstrated the overall validity of the research model. When pooling the data of both banking tasks together, only one research hypothesis was disconfirmed (H9) when using individual moderation scores to model the formative TCF construct. Furthermore, the $\mathrm{R}^{2}$ values were constantly above 0.70 for the intention to use variable. This indicates high predictive validity for the research model and suggests that it captures a number of important factors impacting on consumers' intention to use electronic banking channels. Further, task-channel fit had a very strong influence on the perceived usefulness and the attitude towards channel use constructs. In the analysis of the complete dataset, TCF also influenced consumers' intentions to use electronic banking channels directly.

When comparing the analyses of the sub-datasets (account inquiries and financial loans), it seemed that the model differed across the banking tasks investigated by this research (account inquiries/financial loans). This assumption was tested through statistical analyses as outlined in the following section. 


\subsubsection{Multi-group comparison - an analysis of task-specific TCF models}

Chin and Dibbern (2010) stated: "To date, multi-group comparisons of PLS models where differences in path estimates for different sample population have been relatively naïve. Often, researchers simply examine and discuss the difference in magnitude of specific model path estimates from two or more data sets."

One approach for rigorously comparing groups in PLS is the use of subsamples and t-tests suggested by Keil et al. (2000). This approach involves using standard errors obtained through a bootstrapping procedure in PLS as the input for a parametric test (Henseler et al. 2009). The following formula can be used to statistically determine the $t$-value for the difference in paths between groups.

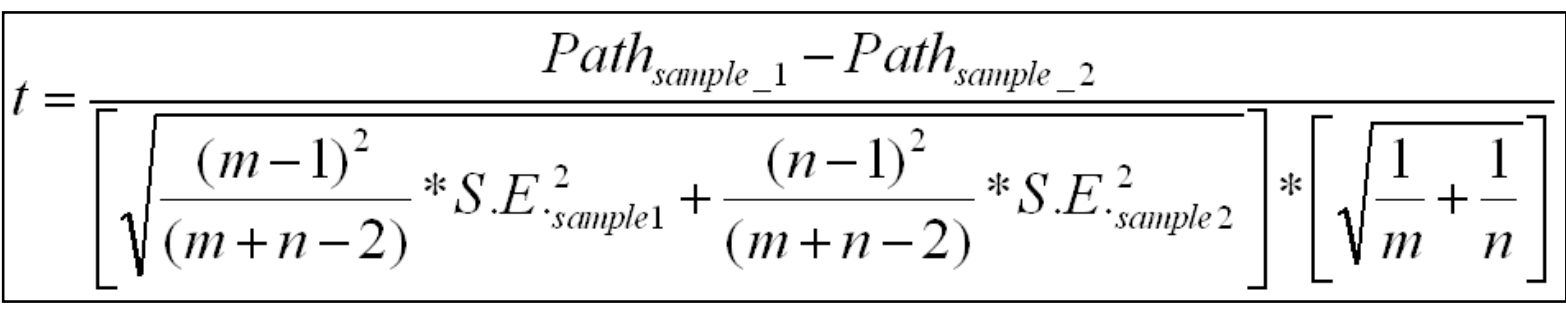

Figure 46: T-value formula used by Keil et al. 2000

Where:

$$
\begin{gathered}
\text { Path_sample_1=Path coefficient of } 1^{\text {st }} \text { sample } \\
\text { Path_sample_2=Path coefficient of } 2^{\text {nd }} \text { sample } \\
\text { SE_sample1=Standard error of } 1^{\text {st }} \text { sample } \\
\text { SE_sample2=Standard error of } 2^{\text {nd }} \text { sample } \\
\text { m=Number of observation in } 1^{\text {st }} \text { sample } \\
n=\text { Number of observation in } 2^{\text {nd }} \text { sample }
\end{gathered}
$$

Keil et al. (2000) collected data in several countries to study the influence of cultural differences on project management related to software development. The authors ran four different models to evaluate the differences between the path coefficients in each model. Initially, the authors pooled all datasets and evaluated a complete dataset. Next, three subdatasets were formed for: 1. Data collected in Finland, 2. Data collected in the Netherlands and 3. Data collected in Singapore. Each sub-model was then compared using the above 
mentioned formula with the standard errors and path coefficients obtained via PLS (Keil, Tan et al. 2000).

However, the procedure of comparing the financial loan dataset with the account inquiries dataset is subject to underlying assumptions about the data and the models: "1) data should not be too non-normal, 2) each sub-model considered has to achieve an acceptable goodness of fit, and 3) there should be measurement invariance" (Eberl 2010). If these criteria are not met, the analysis can produce misleading results (Chin and Dibbern 2010).

It is argued that these assumptions were met by this research. Each prerequisite is discussed below with regards to the data collected for the main study.

\subsubsection{Data normality}

The data obtained during the main study were initially checked for normality assumptions. QQ-Plots were initially used to inspect for normality. In addition, the skewness and kurtosis values discussed earlier suggested that the data was not too non-normal. Thus, it was reasonable to conclude that the first requirement for group comparisons in PLS (through the tvalue procedure) was met since the data did not appear too non-normal.

\subsubsection{Acceptable goodness of fit}

In contrast to covariance based SEM, PLS does not provide a goodness of fit measure. As suggested by Eberl (2010), the $\mathrm{R}^{2}$ values in the endogenous variables were used as substitutes for an overall parametric criterion.

Table 121 shows all $\mathrm{R}^{2}$ values in the endogenous constructs. All values were very acceptable and many constructs explained more than $50 \%$ of variance. When inspecting the financial loan data-subsets (both TCF modelling options), the $\mathrm{R}^{2}$ values were around $20 \%$ in the attitude constructs. When comparing these results with the variance explained in the remaining constructs these values appeared relatively low. However, 20\% variance explained in a construct with one endogenous path appeared to be acceptable.

In addition, the very high $\mathrm{R}^{2}$ values in the perceived usefulness construct (all above $47 \%$ variance explained) and the $\mathrm{R}^{2}$ values in the intentions to use construct substantiated the overall strength of the research model. 
Table 121: Variance explained by each construct - sub-group comparison

\begin{tabular}{|l|c|c|c|}
\hline & $\begin{array}{l}\text { Perceived } \\
\text { usefulness }\end{array}$ & $\begin{array}{l}\text { Attitude } \\
\text { towards use }\end{array}$ & $\begin{array}{l}\text { Intentions to } \\
\text { use }\end{array}$ \\
\hline $\begin{array}{l}\text { Complete dataset } \\
\text { (individual moderation scores) }\end{array}$ & $\left(\mathrm{R}^{2}=0.645\right)$ & $\left(\mathrm{R}^{2}=0.465\right)$ & $\left(\mathrm{R}^{2}=0.776\right)$ \\
\hline $\begin{array}{l}\text { Complete dataset } \\
\text { (average moderation scores) }\end{array}$ & $\left(\mathrm{R}^{2}=0.646\right)$ & $\left(\mathrm{R}^{2}=0.465\right)$ & $\left(\mathrm{R}^{2}=0.771\right)$ \\
\hline $\begin{array}{l}\text { Financial Loans } \\
\text { (individual moderation scores) }\end{array}$ & $\left(\mathrm{R}^{2}=0.473\right)$ & $\left(\mathrm{R}^{2}=0.183\right)$ & $\left(\mathrm{R}^{2}=0.745\right)$ \\
\hline $\begin{array}{l}\text { Financial Loans } \\
\text { (average moderation scores) }\end{array}$ & $\left(\mathrm{R}^{2}=0.461\right)$ & $\left(\mathrm{R}^{2}=0.222\right)$ & $\left(\mathrm{R}^{2}=0.741\right)$ \\
\hline $\begin{array}{l}\text { Account inquiries } \\
\text { (individual moderation scores) }\end{array}$ & $\left(\mathrm{R}^{2}=0.648\right)$ & $\left(\mathrm{R}^{2}=0.478\right)$ & $\left(\mathrm{R}^{2}=0.645\right)$ \\
\hline $\begin{array}{l}\text { Account inquiries } \\
\text { (average moderation scores) }\end{array}$ & $\left(\mathrm{R}^{2}=0.652\right)$ & $\left(\mathrm{R}^{2}=0.438\right)$ & $\left(\mathrm{R}^{2}=0.636\right)$ \\
\hline
\end{tabular}

Lastly, the Cronbach alpha values for the endogenous construct were all above 0.80 and well within the accepted thresholds (Straub 1989). These findings also suggested that the model achieved acceptable goodness of fit. Thus, it was reasonable to assume that the second prerequisite for employing multiple t-tests for group comparisons was also met.

\subsubsection{Measurement invariance}

Measurement invariance is given if the loadings and weights of the construct measurement models do not differ significantly from each other (Eberl 2010). This is essential as the paths compared in the group comparisons need to be comparable in terms of causal relationships that they represent.

The analysis of the measurement model indicated that the item loadings were consistently high and the reliability values (CR \& Cronbach's alphas) were consistently above 0.7. This indicated a low level of measurement invariance. While some of the formative weights differed slightly in both datasets, the overall measurement invariance of the model should not be affected significantly. Thus, it was felt that the third criterion for pair-wise t-value group comparisons was also met.

More recently, Henseler et al. (2009) suggested an alternative PLS-based group comparison approach that does not rely on distributional assumptions. To perform the multigroup analysis (PLS-MGA) each subsample should be bootstrapped. The bootstrap outcome then serves as a basis for the hypotheses tests of group differences (Henseler, Ringle et al. 2009). Rather than relying on distributional assumptions, the PLS-MGA approach evaluates the observed distribution of the bootstrap outcome. The parameter estimates of two subsamples can be used to quantify the probability that two subpopulations are different. 
To perform the p-tests, Henseler et al. (2009) suggested the following formula.

$$
P\left(b^{(1)}>b^{(2)} \mid \beta^{(1)} \leq \beta^{(2)}\right)=1-\sum_{\forall j, i} \frac{\Theta\left(2 \bar{b}^{(1)}-b_{j}^{(1)}-2 \bar{b}^{(2)}+b_{i}^{(2)}\right)}{J^{2}}
$$

Figure 47: PLS-MGA formula developed by Henseler et al. (2009)

Where:

$\mathrm{J}=$ the number of bootstrap samples

$\operatorname{Bj}(1)$ and $b i(2)=$ the bootstrap parameter estimates

B-(1) and b-(2) the means of the focal parameter over the bootstrap samples

$\Theta$ the unit step function, which has a value of 1 if its argument exceeds 0 , otherwise 0

The superscript in parentheses signifies the respective group to be compared. According to Henseler et al. (2009) this formula is equivalent to the Mann-Whitney-Wilcoxon test.

For this study, it was thought that the group comparison requirements for the t-test approach were all met. Given the fact that the PLS-MGA approach disregards any distributional assumptions, this test was also seen as well suited for this research. Therefore, both approaches were tested and the results were subsequently compared.

The above mentioned formulas were used and computed using Microsoft Excel spreadsheet software. Table 122 depicts the outcome of the both analyses.

Table 122: Group comparison results / moderation scores

\begin{tabular}{|c|c|c|c|c|c|c|}
\hline & $\begin{array}{l}\text { Loans/co } \\
\text { efficient }\end{array}$ & $\begin{array}{c}\text { Acc } \\
\text { inquiries/ } \\
\text { coefficien } \\
\mathrm{t}\end{array}$ & $\begin{array}{l}\text { Absolute } \\
\text { path } \\
\text { difference }\end{array}$ & $\begin{array}{l}\text { PLS- } \\
\text { MGA } \\
\text { formula }\end{array}$ & \multirow[t]{2}{*}{$\begin{array}{c}\text { Pairwise } \\
\text { t-test }\end{array}$} \\
\hline \multicolumn{6}{|c|}{ Individual moderation scores } & \\
\hline \multicolumn{2}{|c|}{ Hypothesis } & & & & P-value & t-value \\
\hline H1 & $\mathbf{T C F} \rightarrow \mathrm{PU}$ & $0.23 * *$ & $0.26^{* *}$ & 0.03 & 0.59 & -1.27 \\
\hline $\mathbf{H 2}$ & TCF $\rightarrow$ INT & 0.09 & $0.25 *$ & 0.16 & $0.90 *$ & $-5.74 * * *$ \\
\hline $\mathbf{H 3}$ & TCF $\rightarrow$ ATT & $0.43 * * *$ & $0.69 * * *$ & 0.26 & $0.99 * * *$ & $-9.68 * * *$ \\
\hline H4 & PU $\rightarrow$ INT & $0.18 *$ & -0.04 & 0.22 & $0.96 * *$ & $5.13 * * *$ \\
\hline H5a & EOU $\rightarrow$ INT & 0.06 & $0.41 * *$ & 0.35 & $0.98 * *$ & $-3.87 * * *$ \\
\hline H5b & EOU $\rightarrow$ PU & $0.54 * * *$ & $0.58 * * *$ & 0.04 & 0.62 & 0.36 \\
\hline H6 & ATT $\rightarrow$ INT & $0.39 * * *$ & 0.13 & 0.26 & $0.97 * *$ & $4.81 * * *$ \\
\hline H7 & SN $\rightarrow$ INT & $0.10^{*}$ & -0.04 & 0.14 & $0.97 * *$ & $4.04 * * *$ \\
\hline H8 & SEC $\rightarrow$ INT & $0.22 *$ & 0.08 & 0.14 & $0.91 *$ & $2.26^{*}$ \\
\hline H9 & COST->INT & -0.08 & -0.12 & 0.04 & 0.38 & 0.00 \\
\hline
\end{tabular}




\begin{tabular}{|c|l|l|l|l|l|l|}
\hline \multicolumn{6}{|l|}{ Average moderation scores } \\
\hline Hypothesis & & & & & \\
\hline H1 & TCF $\rightarrow$ PU & $0.20^{* *}$ & $0.28^{* * *}$ & 0.04 & 0.76 & $-2.12^{*}$ \\
\hline H2 & TCF $\rightarrow$ INT & 0.02 & $0.18^{*}$ & 0.16 & $0.96^{* *}$ & $-5.01^{* * *}$ \\
\hline H3 & TCF $\rightarrow$ ATT & $0.45^{* * *}$ & $0.66^{* * *}$ & 0.21 & $0.97^{* *}$ & $-6.83^{* * *}$ \\
\hline H4 & PU $\rightarrow$ INT & $0.19^{*}$ & -0.04 & 0.23 & $0.98^{* *}$ & $5.89^{* * *}$ \\
\hline H5a & EOU $\rightarrow$ INT & $0.09^{*}$ & $0.44^{* *}$ & 0.35 & $0.99^{* *}$ & $-8.61^{* * *}$ \\
\hline H5b & EOU $\rightarrow$ PU & $0.55^{* * *}$ & $0.57^{* * *}$ & 0.02 & 0.56 & -0.47 \\
\hline H6 & ATT $\rightarrow$ INT & $0.40^{* * *}$ & $0.15^{*}$ & 0.25 & $0.96^{* *}$ & $5.04^{* * *}$ \\
\hline H7 & SN $\rightarrow$ INT & $0.12^{*}$ & -0.04 & 0.16 & $0.98^{* *}$ & $5.70^{* * *}$ \\
\hline H8 & SEC $\rightarrow$ INT & $0.21 *$ & 0.08 & 0.13 & $0.99^{* * *}$ & $2.98^{* *}$ \\
\hline H9 & COST->INT & $-0.09^{* *}$ & -0.12 & 0.03 & 0.43 & 1.06 \\
\hline \multicolumn{7}{|c|}{$*$ significant at $\mathrm{p}<0.10, * *$ significant at p<0.05. $* * * \mathrm{p}<0.001$} \\
\hline
\end{tabular}

\subsubsection{Interpreting group differences}

As this part of the thesis is more explanatory in nature, no separate hypotheses were formulated to compare the path differences between the sub-groups. Instead, a general rationale was applied which assumes that individuals perceive electronic banking channel use differently depending on the banking tasks they perform on them.

If a lack of structural invariance between the sub-groups (different banking tasks) exists, it seemed that the specified factors in the TCF research model would influence consumers' intentions to use Internet banking to a greater (or lesser) extent depending on the tasks they perform. This conclusion would be highly important for banks since it implies that they should tailor their banking applications differently for each banking task.

For example, Hypothesis 8 postulated a positive correlation between the security construct and consumers' intentions to use Internet banking. Independent of the TCF conceptualization (using individual or average moderation scores), H8 was confirmed for financial loan dataset but not for the account inquiries data. Both group comparison tests confirmed that the path coefficients were statistically significantly different from each other. This suggests that consumers are more security aware when considering loan applications for Internet banking (and less security aware when considering account inquiries for Internet banking).

Naturally, banking managers should not conclude that security mechanisms are unimportant for customers performing account inquiries online. Instead, they could emphasize the security mechanisms on websites displaying financial loan applications by using written information about security systems or perhaps employing signs that indicate the security of the webpage - something that would be less important to do when only displaying customers' 
account information. Similar rationales could be made for the remaining hypotheses. The following section discusses the results of the group-comparisons in more detail.

\subsubsection{Financial loan dataset vs. account inquiries dataset}

Hypothesis 1 was confirmed by the financial loan and account inquiries datasets alike. When modeling the TCF construct with individual moderation scores, the path coefficients between both datasets did not differ significantly from each other. When using the average moderation scores to evaluate the TCF construct, the pair-wise t-test suggested a lack of path invariance at the 0.05 level. Given the absolute path difference of 0.04 and the results of the PLS-MGA group comparison technique, the path invariance should be interpreted with care.

Hypothesis 2 was confirmed by the data obtained for account inquiries but not for the financial loan dataset. Independent of using the individual or average moderation scores, the absolute path difference was 0.16. If using the PLS-MGA formula, the p-value was significant at the 0.10 level (inspecting the individual moderation scores) and at the 0.05 level (inspecting the average moderation scores) indicating a lack of invariance for this path in the sub-groups. A lack of statistical invariance was also confirmed by the t-values (-5.74 individual moderation scores; -5.01 average moderation scores) obtained through the pairwise t-test. These results confirmed that the perceived TCF had a stronger influence on consumers' intentions to use Internet banking when inspecting the account inquiries dataset.

The third hypothesis was confirmed in both datasets. The path coefficients between the TCF construct and the attitude towards channel use construct were very high independent of the underlying banking task. Comparing the absolute path difference, the beta coefficient in the account inquiries dataset was much stronger than in the financial loan dataset. The group comparisons showed a lack of statistical path invariance for this causal relationship at least at the 0.05 level independent of the TCF modeling approach.

The path coefficient between perceived usefulness and intentions to use Internet banking (H4) also differed significantly when comparing both banking tasks. The absolute path differences were 0.22 (individual moderation scores) and 0.23 (average moderation scores). The group comparisons showed statistical significance levels at least at the $p<0.05$ level. This was a very surprising finding since this hypothesis was based on the TAM model - which is 
normally tested without any reference to specific tasks (e.g. asking respondents whether a system is perceived as useful) ${ }^{28}$.

There was also a lack of path invariance for the hypothesized causal relationships between ease of use and intentions to use Internet banking (H5a). Independent of the TCF conceptualization (individual or average moderation scores), the absolute path difference between the datasets was 0.35 . The PLS-MGA and pairwise t-tests statistically disconfirmed the relevant path invariance at the $\mathrm{p}<0.05$ level.

The path between ease of use and perceived usefulness (H5b) was very strong in both datasets. The absolute path difference was 0.04 (individual moderation scores) and 0.02 (average moderation scores). Not surprisingly, both group comparison tests confirmed that there was no statistical evidence that the paths were different.

Hypothesis 6 was strongly supported by the financial loan dataset (beta 0.39/0.40) but it was rejected when inspecting the account inquiry dataset/individual moderation scores. The path between attitude and intentions to use was 0.15 (significant at $\mathrm{p}<0.05$ ) when modeling the TCF as average moderation scores. The PLS-MGA and pairwise t-test results suggested that there was a lack of path invariance (statistically significant). As with $\mathrm{H} 4$ and H5a, these results were surprising since much IS research has validated this path in the past measuring non-task specific research models (e.g. TAM).

Hypothesis 7 was confirmed by the financial loan dataset but not by the data collected for account inquiries. Both group comparison techniques confirmed a lack of path invariance between both datasets demonstrating statistical significances at least at the $p<0.05$ level. One could argue that consumers feel influenced by normative beliefs when considering loan application via Internet banking but not when checking their account balances.

Hypothesis 8 was confirmed by the financial loan dataset and the path coefficient between the security construct and intentions to use was stronger (0.21) than using the account inquiries dataset. Both group comparison techniques demonstrated a lack of path invariance at the $\mathrm{p}<0.05$ level. This indicated that consumers might be more security aware when considering applying for a financial loan online rather than checking their account balance.

There was no path coefficient invariance in the path between costs associated with channel use and intentions to use.

\footnotetext{
${ }^{28}$ A more thorough discussion on these finding can be found in chapter 7 .
} 


\section{Summary}

The group comparison tests suggested that the structural paths in the research model varied across both banking tasks. Both group comparison techniques verified a lack of path invariance for most of the hypothesized paths in the research model. This has implications for practitioners and researchers. Practitioners could pursue different strategies for each product category they distribute via electronic banking channels (explained in greater detail in section 7.4.).

Researchers should be alarmed by these findings since most of the IS theories are tested without reference to specific tasks. It was felt that this issue required a more thorough discussion which is provided in chapter 7.

The data collected for the main study was also checked for common method variance.

\subsubsection{Common method variance threat}

As detailed in section 5.4.3.5., the data obtained for the main study was assessed for CMV. The statistical tests were reproduced for the data collected during the main study as outlined in section 5.4.3.5. Table 123 reports the results of the tests performed in PLS

Table 123: Results of the unexplained variance check/main study

\begin{tabular}{|c|c|c|c|c|c|}
\hline \multicolumn{3}{|c|}{ Complete dataset } & \multirow[b]{2}{*}{$\mathbf{R} 1^{2}$} & \multirow[b]{2}{*}{$\begin{array}{l}\text { Unexplained } \\
\text { variance factor } \\
\text { loading }(\mathbf{R} 2)\end{array}$} & \multirow[b]{2}{*}{$\mathbf{R} 2^{2}$} \\
\hline Construct & Indicator & $\begin{array}{l}\text { Substantive } \\
\text { factor loading } \\
\text { (R1) }\end{array}$ & & & \\
\hline \multirow{3}{*}{ Attitude } & ATT2 & 0.88 & 0.77 & -0.17 & 0.03 \\
\hline & ATT3 & 0.95 & 0.90 & 0.04 & 0.00 \\
\hline & ATT4 & 0.96 & 0.92 & 0.11 & 0.01 \\
\hline \multirow{3}{*}{ Cost } & COST1 & 0.74 & 0.55 & -0.15 & 0.02 \\
\hline & COST2 & 0.9 & 0.81 & 0.04 & 0.00 \\
\hline & COST4 & 0.82 & 0.67 & 0.10 & 0.01 \\
\hline \multirow{3}{*}{ Ease of use } & EOU1 & 0.96 & 0.92 & -0.05 & 0.00 \\
\hline & EOU2 & 0.95 & 0.90 & 0.04 & 0.00 \\
\hline & EOU4 & 0.95 & 0.90 & 0.02 & 0.00 \\
\hline \multirow{4}{*}{$\begin{array}{l}\text { Intentions to } \\
\text { use }\end{array}$} & INT1 & 0.98 & 0.96 & 0.04 & 0.00 \\
\hline & INT2 & 0.98 & 0.96 & 0.03 & 0.00 \\
\hline & INT3 & 0.96 & 0.92 & 0.04 & 0.00 \\
\hline & INT4 & 0.92 & 0.85 & -0.11 & 0.01 \\
\hline \multirow{3}{*}{$\begin{array}{l}\text { Perceived } \\
\text { usefulness }\end{array}$} & PU1 & 0.92 & 0.85 & -0.14 & 0.02 \\
\hline & PU3 & 0.89 & 0.79 & -0.20 & 0.04 \\
\hline & PU4 & 0.88 & 0.77 & 0.32 & 0.10 \\
\hline \multirow{3}{*}{ Security } & SEC1 & 0.94 & 0.88 & 0.07 & 0.00 \\
\hline & SEC2 & 0.95 & 0.90 & 0.10 & 0.01 \\
\hline & SEC3 & 0.79 & 0.62 & -0.32 & 0.10 \\
\hline \multirow{3}{*}{$\begin{array}{l}\text { Subjective } \\
\text { norms }\end{array}$} & SN1 & 0.93 & 0.86 & -0.02 & 0.00 \\
\hline & SN2 & 0.88 & 0.77 & -0.03 & 0.00 \\
\hline & SN3 & 0.93 & 0.86 & 0.00 & 0.00 \\
\hline
\end{tabular}




\begin{tabular}{|l|c|c|c|c|c|}
\cline { 2 - 6 } \multicolumn{1}{c|}{} & SN4 & 0.84 & 0.71 & 0.04 & 0.00 \\
\hline \multirow{3}{*}{ TCF } & TCF1 & 0.97 & 0.94 & 0.08 & 0.01 \\
\cline { 2 - 6 } & TCF2 & 0.98 & 0.96 & 0.07 & 0.00 \\
\cline { 2 - 6 } & TCF3 & 0.96 & 0.92 & -0.16 & 0.03 \\
\hline
\end{tabular}

The Table shows that the substantive factor loadings were very high in all cases and the items were weakly correlated with the unexplained variance factor. The results above also indicate that the $\mathrm{R}^{2}$ values in the unexplained variance factor were very low for all items. These finding suggested that CMV/unexplained variance should not bias the findings of the main study significantly.

\subsection{Chapter summary}

This chapter initially discussed feedback obtained on the pilot study. The feedback was received through anonymous reviewers from two peer-reviewed IS conferences and additional senior IS researchers who were interviewed with regards to the pilot study. The feedback was thoroughly considered and the following steps were decided in conjunction with supervising staff.

- Expand TCF scales and TCF dimensions

- Compare a pooled dataset (all responses) with two sub-datasets (account inquiries/financial loans)

- Use 7-point Likert scales for collecting data during the main study

To expand the TCF scales and dimensions, task-specific literature was re-investigated. Task uncertainty, task equivocality, and task analyzability were included as new TCFdimensions. Next, the scales were adjusted accordingly and additional items were added to measure the TCF construct.

The final version of the survey questionnaire was then pretested using eighteen respondents who tested the survey questionnaire online. Subsequently, 340 analyzable responses (170 for account inquiries and170 for financial loans) were collected through the consumer panel Smilecity.co.nz.

The reflective scales were then assessed for construct validity using commonly accepted statistical techniques. The results showed that the scales were very valid in terms of convergent and discriminant validity. What is more, the scales were tested highly reliable.

The assessment of the formative scales suggested that there was no multicollinearity among the TCF items. All items produced consistently high weights apart from the newly 
created TCF dimension uncertainty and task equivocality. The items for these two dimensions led to low item weights/loadings in all TCF modelling approaches.

Also, the redundancy analyses showed that the TCF scales were highly 'portable' indicating a high degree of generalizability.

The results of the structural model assessments confirmed all hypotheses apart from H9 when inspecting the complete dataset. The results for the sub-datasets were slightly weaker but most structural paths in the research model were nevertheless confirmed. TCF had a consistently strong influence on the perceived usefulness and attitude towards Internet banking constructs. Table 124 summarizes the confirmed and disconfirmed hypotheses when using the analyses approaches discussed in chapter 6 .

Table 124: Summary hypotheses main study

\begin{tabular}{|c|c|c|c|c|c|c|c|}
\hline \multirow{2}{*}{\multicolumn{2}{|c|}{ Hypothesis }} & \multicolumn{2}{|c|}{ Complete dataset } & \multicolumn{2}{|c|}{ Financial Loans } & \multicolumn{2}{|c|}{$\begin{array}{l}\text { Account } \\
\text { Inquiries }\end{array}$} \\
\hline & & $\begin{array}{c}\text { (individual } \\
\text { moderation } \\
\text { scores) }\end{array}$ & $\begin{array}{c}\text { (average } \\
\text { moderation } \\
\text { scores) }\end{array}$ & $\begin{array}{c}\text { (individual } \\
\text { moderation } \\
\text { scores) }\end{array}$ & $\begin{array}{c}\text { (average } \\
\text { moderation } \\
\text { scores) }\end{array}$ & $\begin{array}{c}\text { (individual } \\
\text { moderation } \\
\text { scores) }\end{array}$ & $\begin{array}{c}\text { (average } \\
\text { moderation } \\
\text { scores) }\end{array}$ \\
\hline H1 & TCF $\rightarrow$ PU & + & + & + & + & + & + \\
\hline H2 & TCF $\rightarrow$ INT & + & -- & - & -- & + & + \\
\hline H3 & $\mathrm{TCF} \rightarrow \mathrm{ATT}$ & + & + & + & + & + & + \\
\hline H4 & PU $\rightarrow$ INT & + & + & + & + & - & - \\
\hline H5a & EOU $\rightarrow$ INT & + & + & - & + & + & + \\
\hline H5b & EOU $\rightarrow$ PU & + & + & + & + & + & + \\
\hline H6 & ATT $\rightarrow$ INT & + & + & + & + & - & + \\
\hline $\mathbf{H 7}$ & $\mathrm{SN} \rightarrow$ INT & + & - & + & + & - & - \\
\hline H8 & SEC $\rightarrow$ INT & + & + & + & + & - & - \\
\hline H9 & COST $\rightarrow$ INT & - & - & - & + & - & - \\
\hline
\end{tabular}

Overall, the variance explained in each endogenous variable was high: sixty three percent of the variance in intention to use. These are strong findings, and lend substantial support to the research model.

Lastly, two group comparison techniques were employed to account for the structural invariance in the model when considering the sub-datasets. The results confirmed that most of 
the structural paths differed across the two datasets ${ }^{29}$. These findings were very interesting since most IS technology adoption models have been tested non-task centric.

${ }^{29}$ See Table 121 for more detailed information 


\section{Discussion and interpretation of the findings}

\subsection{Chapter Outline}

The findings of this research have several implications for information systems research and practitioners. This chapter first outlines how this study contributes to IS utilization research. This is followed be the implications of this research for task-technology fit theory. Lastly, this chapter provides recommendations for practitioners who are involved with the distribution of product and services via electronic banking channels (discussed in section 7.4.).

\subsection{Implications for IS utilization research}

As indicated in section 2.2., much research has been developed on technology adoption and the utilization of information systems research at the individual level. Venkatesh et al. (2007) referred individual-level technology adoption/utilization as one the most mature research streams in the information system discipline.

For instance, Davis (1989) developed the TAM model which was based on a more general social psychology theory of reasoned action. TAM theorizes that perceived usefulness, ease of use, and attitude toward information systems are the main factors influencing individuals to use information systems. The two TAM papers published by Davis (1989) have been frequently cited by information systems researchers and scholars in reference disciplines (Venkatesh, Davis et al. 2007).

Thompson, Higgins, and Howell (1990) drew upon Triandis' (1977) work on interpersonal behavior and developed a research model to predict PC utilization on an individual level. The authors reasoned that long-term consequences of PC use, job fit with PC use, complexity of PC use, affect towards PC use, social factors influencing PC use, and facilitating conditions would influence PC usage (Thompson, Higgins et al. 1991).

Moore and Benbasat (1991) developed a survey questionnaire instrument to apply Roger's (1960) diffusion of innovations theory to the context of information systems adoption. The authors specified various characteristics of information systems that would influence individuals' use behavior (Moore and Benbasat 1991).

Taylor and Todd (1995) tested the TAM model and two variations of the theory of planned behavior to investigate which model predicts most of information technology usage. The decomposed theory of planned behavior included several antecedent constructs to measure the 
original TPB variables more accurately (Taylor and Todd 1995). The results showed that the decomposed TPB provided a fuller understanding of behavioral intentions to use technologies.

Compeau, Higgins, and Huff (1999) used social cognitive theory to predict information technology usage at the individual level. Their research model included affect, anxiety, computer self-efficacy, and outcome expectation (performance \& personal) constructs to predict usage behavior (Compeau, Higgins et al. 1999). Most of these constructs significantly impacted on the IS usage construct and the model explained a relatively large amount of variance in the dependent variable.

Venkatesh et al. (2003) set another milestone in adoption research by integrating eight competing models and theories of individual acceptance in the unified theory of acceptance and use of technology (UTAUT). The theory aimed to converge the competing adoption models previously developed by other IS researchers. The eight integrated models included:

- Theory of reasoned action (Fishbein and Ajzen 1975)

- Technology acceptance model (Davis 1989; Davis, Bagozzi et al. 1989)

- Motivational model (Davis, Bagozzi et al. 1992)

- Theory of planned behavior (Ajzen 1991)

- Combined TAM and TPB (Taylor and Todd 1995)

- Model of PC utilization (Thompson, Higgins et al. 1991)

- Innovation diffusion theory (Moore and Benbasat 1991)

- Social cognitive theory (Compeau and Higgins 1995; Compeau, Higgins et al. 1999)

Additional information on the UTUAT model is also presented in section 2.2.4.

More recently, a branch of adoption research has examined factors that influence the continuous, or ongoing, use of technology (Bhattacherjee 2001). Synthesizing the concepts of expectation-confirmation theory (Oliver 1977; Oliver 1980; Spreng, MacKenzie et al. 1996) with the IS related adoption and acceptance literature, Bhattacherjee (2001b) investigated the key drivers of consumers' continuous intentions to use information systems in an electronic banking context.

Google scholar confirms that each of the above mentioned models has been cited well over 500 times thus underscoring the impact on the information systems research discipline and beyond. Not surprisingly, much research studying electronic banking adoption has also made 
use of the above mentioned theories to test the attitudinal and motivational factors influencing consumers to use electronic banking channels (see more discussion on this in section 2.6.).

There are three ongoing debates in the Information Systems research discipline that concern most of the above mentioned utilizations theories. First, traditional adoption/acceptance theories might be overused. Second, traditional adoption/acceptance theories are too general and lack precision. Third, few of the traditional adoption/acceptance theories integrate the IT artifact successfully as part of their models. Each debate in now briefly summarized:

\subsubsection{Overuse of traditional adoption/acceptance theories}

As a result of the widespread application of the above mentioned theories, concerns have been raised regarding the overuse of the traditional adoption/acceptance models in the Information Systems research discipline. As part of the special issue Quo Vadis TAM in the Journal of the Association for Information Systems, Venkatesh, Davis, and Morris (2007) debated whether technology adoption research is dead. The authors argued: "Our typical answer to the question, 'Is technology adoption research is dead? has been, 'Yes and no.' The answer is 'yes' if the inquiry implies a continuation of replications with no substantive theoretical advance. Such a state is clearly undesirable in any area of research, and technology adoption research seems to see a lot of replication with minor 'tweaking.' This is perhaps due to the parsimony of TAM, the robustness of its scales, and the strong generalizability of the model " (Venkatesh, Davis et al. 2007). Comparable concerns were also raised in the remaining articles of this special issue in JAIS (Bagozzi 2007; Benbasat and Barki 2007; Goodhue 2007; Lucas, Swanson et al. 2007; Schwarz and Chin 2007; Silva 2007; Straub and Burton-Jones 2007; Venkatesh, Davis et al. 2007).

More recently, Morris (2010) addressed Australian scholars at the fifth theory building workshop held at the Australian National University. He argued that "tweaking" TAM/TRA or TPB models marginally could be viewed as beating a dead horse. His keynote address "Building a Cumulative Tradition or Beating a Dead Horse? Ideas on Reinvigorating Mature Streams of Research" evoked much discussion among the audience (Morris 2010).

\subsubsection{Genralizability vs. precision of traditional IS adoption/ acceptance theories}

Another ongoing debate in the IS research discipline concerns the generalizability of adoption/acceptance research models such as TAM. For instance, Robey and Markus (1998) 
argued that many IS theories are too general to support practitioners developing and conceptualizing Information Systems. The authors questioned if IS theories are "well positioned to recommend actions for improving the intervention of information systems" (Robey and Markus 1998).

In their opinion piece in 2007, Benbasat and Barki continued to critique IS utilization theories arguing that "The extensive TAM research has reinforced our knowledge of the underlying TAM relationships without substantially extending that knowledge to a broader or more specific set of relationships, especially those about design. We believe that this is both creating an illusion of knowledge accumulation and acting as a barrier to fruitfully extending the model backward toward IT, implementation, and design factors, leading to research that is unable to provide actionable advice."

Seddon and Lyytinen (2008) debated the generalizability of TAM (and other adoption/acceptance theories) at the $19^{\text {th }}$ Australasian Conference on Information Systems. The panelist questioned whether practitioners if informed that Information Systems was easy to use or not - such information is simply too broad to be actionable (Seddon and Lyytinen 2008). Similarly, knowing that a system is viewed as useful would not inform practitioners how to develop more advanced Information Systems.

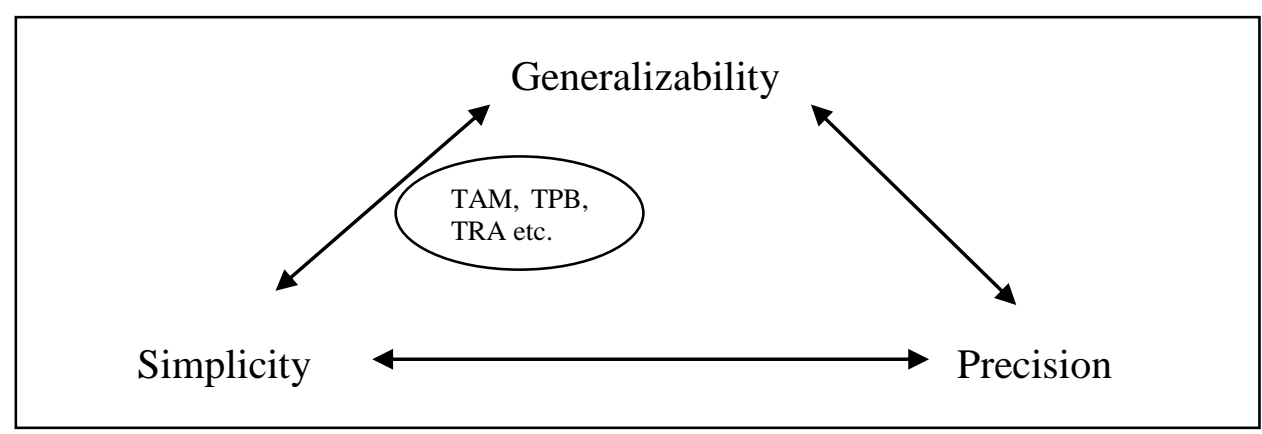

Figure 48: Interplay between generalizability, precision and simplicity in IS theories

Seddon (2008) questioned if traditional adoption/acceptance model sacrifice too much precision in order to maintain simplicity and generalizability. Figure 48 illustrates this issue.

More recently, Tate and Evermann (2010) repeated this call and argued: "Overall, there is a tension between parsimonious models which are inherently reductionist, and information systems, which as social phenomena are inherently complex. Salience for practice is likely to require a richer and more holistic understanding of the phenomena than our parsimonious models typically provide” (Tate and Evermann 2010). 
Another ongoing debate is the IT artifact crisis as outlined in the following paragraphs.

\subsubsection{IT artifact crisis}

Benbasat and Zmud (2003) agitated the IS research community with their editorial 'identity crisis in the IS discipline". The authors recommended that our research models and theories should concentrate on the IT artifact which can be defined as "as the application of IT to enable or support some task(s) embedded within a structure(s) that itself is embedded within a context(s)" (Benbasat and Zmud 2003). The authors argued that too few IS studies focus on the interplay between the IT artifact, task, structure and context.

This spurred an ongoing debate in the IS research discipline (Benbasat and Weber 1996; Orlikowski and Lacono 2001; Weber 2003; Sidorova, Evangelopoulos et al. 2008) and much research has debated Benbasat and Zmud's concern. For instance, Evermann and Tate (2009) reviewed the extant research models in IS discipline and they argued that TAM ignores the IT artifact completely: "there is nothing in the concepts, or in their operationalization, that is specific to the IT artifact. For example, items like "I would find ... useful in my job" and "I would find it easy to get ... to do what I want it to do" may be applied to bicycles just as well as computer systems" (Evermann and Tate 2009).

Others view this issue less drastic since TAM studies are normally undertaken with regards to information systems. Respondents participating in IS research studies would normally understand that the items refer to an IS artifact [e.g. GSS support systems] (Goodhue 2007).

However, Goodhue (2007) applauded Benbasat and Zmud's concerns and he also stressed that the IT artifact is an application of IT to enable or support some task(s) individuals perform. Including tasks would be essential when studying the IT artifact. Goodhue wrote: "I would argue that although the IT artifact is almost always a part of our models (if not as a box on the diagram, at least prominently in our minds), a key missing construct that is too often not part of our thinking is the task of the user, and the fit of the IT artifact to that task. I might go so far as to say the fit of the IT artifact with the task requirements is the number one determinant of usefulness. To state this another way, it would be foolish to focus too intensely on how the design of the hammer affects its usefulness, without first asking whether the task is to drive in a nail or to saw off a piece of wood. A consequence of this primacy of task would be that no one should ever design or recommend an information system without first conducting a thorough study of the actual tasks in which users are engaged"(Goodhue 2007). 
When the three debates ${ }^{30}$ are closely scrutinized, a consensus emerges for how to go forward in IS utilization research. First, no further research is required that uses traditional adoption/acceptance models with only marginal adjustments (e.g. adding a single new construct to the TAM model). Second, traditional IS adoption and acceptance models are very general and it appears that $2^{\text {nd }}$ generation utilization theories should strive for greater precision in order to inform practitioners more effectively. Third, the IT artifact should remain the focus of IS adoption theories and the models should ideally integrate IT and tasks users perform.

The debates have been ongoing for some time and it should be acknowledged that much effort has been made to address these concerns. For example, several studies have researched the antecedents of the traditional IS utilization models thereby providing a more detailed picture of IS utilization at the individual level.

For instance, TAM2 (explained in greater detail in section 2.2.3.) predicted that subjective norms, image, job relevance, output quality, and result demonstrability precede perceived usefulness of Information Systems (Venkatesh and Davis 2000).

Likewise, TAM $3^{31}$ is currently 'under construction' and promises to provide a more detailed interpretation of the perceived ease of use construct (Venkatesh 2010). Venkatesh and Bala (2010) state that computer self-efficacy, perceptions of external control, computer anxiety, computer playfulness, perceived enjoyment, and objective usability precede the perceived ease of use construct (Venkatesh 2010). Combining the newly developed ease of use antecedents with the forerunners of the perceived usefulness construct (TAM2), this model will provide a much more precise picture of IS utilization.

Pavlou and Fygenson (2006) used the theory of planned behavior in order to understand and predict electronic commerce adoption. The authors tested two different tasks (getting information and purchasing in an e-commerce context) and developed eight antecedent constructs which they hypothesized would influence the traditionally used TPB variables (Pavlou and Fygenson 2006). This research also demonstrated that research efforts are made in order to develop more precise and focused models.

${ }^{30}$ 1. Overuse of traditional adoption/acceptance models, 2. Generalizability of IS theories, 3. IT artifact inclusion in US theories.

${ }^{31}$ TAM 3 is explained in greater detail in here: http://www.vvenkatesh.com/IT/organizations/Theoretical_Models.asp 
In addition to attaching antecedent constructs on the left side of the traditional IS research models, other researchers have attempted to advance the traditional IS utilization theories differently. For instance Burton-Jones and Straub (2006) systematically reconceptualized the use of Information Systems. The authors argued that system usage involves three major elements that are essential considering when studying IS usage:

- A user is an individual person who employs an IS in a task. This implies that although users are social actors, we assume that it is possible to study user behavior at a purely individual level.

- An IS is an artifact that provides representations of one or more task domains. This implies that ISs provide features that are designed to support functions in those task $\operatorname{domain}(s)$

- A task is a goal-directed activity performed by a user. This implies that task outputs can be assessed in terms of predefined task requirements (Burton-Jones and Straub 2006).

The authors asked IS users to build a spreadsheet model in Microsoft Excel to determine the best approach for financing an asset purchase. The task was assumed to be well supported by the spreadsheet software as it contains features that directly support building the decision making tool (Burton-Jones and Straub 2006).

The measurement scales were specifically adjusted to the task domain and each item included the three major components of systems usage. Table 125 exemplifies some of the items used by Burton-Jones and Straub (2006):

Table 125: Some measurement scales used by Burton-Jones and Straub 2006)

\begin{tabular}{|c|c|c|c|c|}
\hline Construct & Items & I & IS & $\mathbf{T}$ \\
\hline \multirow{5}{*}{$\begin{array}{c}\text { Deep } \\
\text { structure } \\
\text { usage }\end{array}$} & $\begin{array}{l}\text { When I was using MS Excel, I did not use features that would } \\
\text { help me analyze my data. }\end{array}$ & Yes & Yes & Yes \\
\hline & $\begin{array}{l}\text { When I was using MS Excel, I used features that helped me } \\
\text { compare and contrast aspects of the data. }\end{array}$ & Yes & Yes & Yes \\
\hline & $\begin{array}{l}\text { When I was using MS Excel, I used features that helped me test } \\
\text { different assumptions in the data. }\end{array}$ & Yes & Yes & Yes \\
\hline & $\begin{array}{l}\text { When I was using MS Excel, I used features that helped me } \\
\text { derive insightful conclusions from the data. }\end{array}$ & Yes & Yes & Yes \\
\hline & $\begin{array}{l}\text { When I was using MS Excel, I used features that helped me } \\
\text { perform calculations on my data. }\end{array}$ & Yes & Yes & Yes \\
\hline
\end{tabular}


As shown above, the items all explicitly dealt with an individual using the IT artifact as well as the IT artifact itself (Microsoft Excel). More importantly, all items specified the tasks users would perform in order to accomplish their goals (inspecting/scrutinizing the data).

Including a specific task is relatively uncommon in utilization research and is normally reserved for studies employing TTF (Benbasat and Barki 2007). To examine this assertion, all items used to develop the UTAUT model ${ }^{32}$ were scrutinized for Burton-Jones and Straub's major elements of usage. Table 126 lists the items discussed in the UTAUT article. Each item was investigated for Burton-Jones and Straub's major components of IS usage: individuals (I), IS artifact (IS), and technology (T)

Table 126: Inspection of the traditional acceptance and adoption theories with regards to individuals, IS artifacts, and technology

\begin{tabular}{|c|c|c|c|c|c|}
\hline & Construct & Items & $\mathbf{I}$ & IS & $\mathbf{T}$ \\
\hline \multirow{21}{*}{ 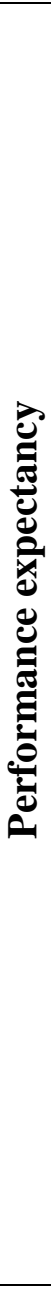 } & \multirow{6}{*}{$\begin{array}{l}\text { Perceived } \\
\text { Usefulness } \\
\text { (Davis 1989; } \\
\text { Davis, Bagozzi } \\
\text { et al. 1989) }\end{array}$} & $\begin{array}{l}\text { Using the system in my job would enable me to accomplish tasks } \\
\text { more quickly. }\end{array}$ & Yes & Yes & No \\
\hline & & Using the system would improve my job performance. & Yes & Yes & No \\
\hline & & Using the system in my job would increase my productivity. & Yes & Yes & No \\
\hline & & Using the system would enhance my effectiveness on the job. & Yes & Yes & No \\
\hline & & Using the system would make it easier to do my job. & Yes & Yes & No \\
\hline & & I would find the system useful in my job. & Yes & Yes & No \\
\hline & $\begin{array}{l}\text { Extrinsic } \\
\text { motivation } \\
\text { (Davis, Bagozzi } \\
\text { et al. 1992) } \\
\end{array}$ & Same items were used as above & & & \\
\hline & \multirow{6}{*}{$\begin{array}{l}\text { Job Fit } \\
\text { (Thompson, } \\
\text { Higgins et al. } \\
\text { 1991) }\end{array}$} & $\begin{array}{l}\text { Use of the system will have no effect on the performance of my job } \\
\text { (reverse scored). }\end{array}$ & Yes & Yes & No \\
\hline & & $\begin{array}{l}\text { Use of the system can decrease the time needed for my important } \\
\text { job responsibilities. }\end{array}$ & Yes & Yes & No \\
\hline & & $\begin{array}{l}\text { Use of the system can significantly increase the quality of output on } \\
\text { my job. }\end{array}$ & Yes & Yes & No \\
\hline & & $\begin{array}{l}\text { Use of the system can increase the effectiveness of performing job } \\
\text { tasks. }\end{array}$ & Yes & Yes & No \\
\hline & & $\begin{array}{l}\text { Use can increase the quantity of output for the same amount of } \\
\text { effort. }\end{array}$ & Yes & No & No \\
\hline & & $\begin{array}{l}\text { Considering all tasks, the general extent to which use of the system } \\
\text { could assist on the job. }\end{array}$ & No & Yes & No \\
\hline & \multirow{5}{*}{$\begin{array}{l}\text { Relative } \\
\text { advantage } \\
\text { (Moore and } \\
\text { Benbasat 1991) }\end{array}$} & Using the system enables me to accomplish tasks more quickly. & Yes & Yes & No \\
\hline & & Using the system improves the quality of the work I do. & Yes & Yes & No \\
\hline & & Using the system makes it easier to do my job. & Yes & Yes & No \\
\hline & & Using the system enhances my effectiveness on the job. & Yes & Yes & No \\
\hline & & Using the system increases my productivity. & Yes & Yes & No \\
\hline & \multirow{3}{*}{$\begin{array}{l}\text { Outcome } \\
\text { expectations } \\
\text { (Compeau and }\end{array}$} & If I use the system... & & & \\
\hline & & I will increase my effectiveness on the job. & Yes & Yes & No \\
\hline & & I will spend less time on routine job tasks. & Yes & Yes & No \\
\hline
\end{tabular}

${ }^{32}$ UTAUT was selected as a reference model because it was based on eight major adoption/acceptance studies. 


\begin{tabular}{|c|c|c|c|c|c|}
\hline & Higgins 1995; & I will increase the quality of output of my job. & Yes & Yes & No \\
\hline & Compeau, & I will increase the quantity of output for the same amount of effort. & Yes & Yes & No \\
\hline & Higgins et al. & My coworkers will perceive me as competent. & Yes & Yes & No \\
\hline & & I will increase my chances of obtaining a promotion. & Yes & Yes & No \\
\hline & & I will increase my chances of getting a raise. & Yes & Yes & No \\
\hline & & Learning to operate the system would be easy for me. & Yes & Yes & No \\
\hline & Perceived ease & I would find it easy to get the system to do what I want it to do. & Yes & Yes & No \\
\hline & of use & My interaction with the system would be clear and understandable. & Yes & Yes & No \\
\hline & (Davis 1989; & I would find the system to be flexible to interact with. & Yes & Yes & No \\
\hline & $\begin{array}{l}\text { Davis, DagOLL1 } \\
\text { et al } 1989)\end{array}$ & It would be easy for me to become skillful at using the system. & Yes & Yes & No \\
\hline ह & & I would find the system easy to use. & Yes & Yes & No \\
\hline 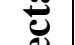 & & Using the system takes too much time from my normal duties. & Yes & Yes & No \\
\hline$\sum_{0}^{\infty}$ & Complexity & $\begin{array}{l}\text { Working with the system is so complicated, it is difficult to } \\
\text { understand what is going on. }\end{array}$ & Yes & Yes & No \\
\hline 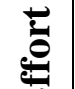 & $\begin{array}{l}\text { Higgins et al. } \\
\text { Hag1) }\end{array}$ & $\begin{array}{l}\text { Using the system involves too much time doing mechanical } \\
\text { operations (e.g., data input). }\end{array}$ & Yes & Yes & No \\
\hline & & $\begin{array}{l}\text { It takes too long to learn how to use the system to make it worth the } \\
\text { effort. }\end{array}$ & Yes & Yes & No \\
\hline & Ease & My interaction with the system is clear and understandable. & Yes & Yes & No \\
\hline & (Moore and & I believe that it is easy to get the system to do what I want it to do. & Yes & Yes & No \\
\hline & Benbasat 1991) & Overall, I believe that the system is easy to use. & Yes & Yes & No \\
\hline & & Learning to operate the system is easy for me. & Yes & Yes & No \\
\hline & $\begin{array}{l}\text { Subjective } \\
\text { Norm } \\
\text { (Fishbein and } \\
\text { Ajzen 1975; }\end{array}$ & $\begin{array}{l}\text { People who influence my behavior think that I should use the } \\
\text { system. }\end{array}$ & Yes & Yes & No \\
\hline$\underset{\mathscr{E}}{\mathscr{E}}$ & $\begin{array}{l}\text { Davis 1989; } \\
\text { Ajzen 1991; } \\
\text { Taylor and Todd } \\
\text { 1995) }\end{array}$ & People who are important to me think that I should use the system. & Yes & Yes & No \\
\hline ב & & $\begin{array}{l}\text { I use the system because of the proportion of coworkers who use } \\
\text { the system. }\end{array}$ & Yes & Yes & No \\
\hline$\frac{\bar{T}}{\mathscr{8}}$ & Social factors & $\begin{array}{l}\text { The senior management of this business has been helpful in the use } \\
\text { of the system. }\end{array}$ & Yes & Yes & No \\
\hline & 1991) & $\begin{array}{l}\text { My supervisor is very supportive of the use of the system for my } \\
\text { job. }\end{array}$ & Yes & Yes & No \\
\hline & & In general, the organization has supported the use of the system. & Yes & Yes & No \\
\hline & Image & $\begin{array}{l}\text { People in my organization who use the system have more prestige } \\
\text { than those who do not. }\end{array}$ & Yes & Yes & No \\
\hline & & People in my organization who use the system have a high profile. & Yes & Yes & No \\
\hline & & Having the system is a status symbol in my organization. & Yes & Yes & No \\
\hline & Perceived & I have control over using the system. & Yes & Yes & No \\
\hline & behavioral & I have the resources necessary to use the system. & Yes & Yes & No \\
\hline ฮี & control & I have the knowledge necessary to use the system. & Yes & Yes & No \\
\hline 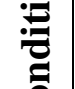 & $\begin{array}{l}\text { (Ajzen 1991; } \\
\text { Taylor and Todd }\end{array}$ & $\begin{array}{l}\text { Given the resources, opportunities and knowledge it takes to use the } \\
\text { system, it would be easy for me to use the system. }\end{array}$ & Yes & Yes & No \\
\hline$\overline{8}$ & 1995) & The system is not compatible with other systems I use. & Yes & Yes & No \\
\hline $\mathscr{\theta} 0$ & Facilitating & Guidance was available to me in the selection of the system. & Yes & Yes & No \\
\hline 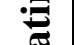 & conditions & Specialized instruction concerning the system was available to me. & Yes & Yes & No \\
\hline 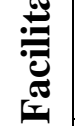 & $\begin{array}{l}\text { (Thompson, } \\
\text { Higgins et al. } \\
\text { 1991) }\end{array}$ & $\begin{array}{l}\text { A specific person (or group) is available for assistance with system } \\
\text { difficulties. }\end{array}$ & No & Yes & No \\
\hline & Compatability & Using the system is compatible with all aspects of my work. & Yes & Yes & No \\
\hline & (Moor & I think that using the system fits well with the way I like to work. & Yes & Yes & No \\
\hline & Benbasat 1991) & Using the system fits into my work style. & Yes & Yes & No \\
\hline$\varangle$ & At & Using the system is a bad/good idea. & No & Yes & No \\
\hline & towards & Using the system is a foolish/wise idea. & No & Yes & No \\
\hline
\end{tabular}




\begin{tabular}{|c|c|c|c|c|c|}
\hline & $\begin{array}{l}\text { behavior } \\
\text { (Fishbein and }\end{array}$ & $\begin{array}{l}\text { I dislike/like the idea of using the } \\
\text { system. }\end{array}$ & Yes & Yes & $\mathrm{No}$ \\
\hline & $\begin{array}{l}\text { Ajzen 1975; } \\
\text { Davis, Bagozzi } \\
\text { et al. 1989; } \\
\text { Taylor and Todd } \\
\text { 1995) }\end{array}$ & $\begin{array}{l}\text { Using the system is unpleasant/ } \\
\text { pleasant. }\end{array}$ & No & Yes & $\mathrm{No}$ \\
\hline & Intrinsic & I find using the system to be enjoyable & Yes & Yes & No \\
\hline & motivation & \begin{tabular}{|l|} 
The actual process of using the system is pleasant. \\
\end{tabular} & No & Yes & No \\
\hline & $\begin{array}{l}\text { (Davis, Bagozzi } \\
\text { et al. 1992) }\end{array}$ & I have fun using the system. & Yes & Yes & No \\
\hline & Affect towards & The system makes work more interesting. & No & Yes & $\mathrm{No}$ \\
\hline & & Working with the system is fun. & No & Yes & $\mathrm{No}$ \\
\hline & $\begin{array}{l}\text { (Thompson, } \\
\text { Higgins et al. } \\
\text { 1991) }\end{array}$ & The system is okay for some jobs, but not the kind of job I want. & Yes & Yes & No \\
\hline & & I like working with the system. & Yes & Yes & $\mathrm{No}$ \\
\hline & Affect & $\begin{array}{l}\text { I look forward to those aspects of my job that require me to use the } \\
\text { system. }\end{array}$ & Yes & Yes & $\mathrm{No}$ \\
\hline & Higgins 1995; & Using the system is frustrating for me. (R) & Yes & Yes & No \\
\hline & Comp & \begin{tabular}{|l|} 
Once I start working on the system, I find it hard to stop. \\
\end{tabular} & Yes & Yes & No \\
\hline & $\begin{array}{l}\text { Higgins et al. } \\
\text { 1999) }\end{array}$ & $\begin{array}{l}\text { I get bored quickly when using the } \\
\text { system. (R) }\end{array}$ & Yes & Yes & $\mathrm{No}$ \\
\hline & & I would find the system useful in my job. & Yes & Yes & $\mathrm{No}$ \\
\hline & & \begin{tabular}{|l} 
Using the system enables me to accomplish ta \\
\end{tabular} & Yes & Yes & No \\
\hline & cy & \begin{tabular}{|l} 
Using the system increases my productivity. \\
\end{tabular} & Yes & Yes & No \\
\hline & & If I use the system, I will increase my chances of getting a raise. & Yes & Yes & No \\
\hline & & My interaction with the system would be clear and understandable. & Yes & Yes & $\mathrm{No}$ \\
\hline & Effort & It would be easy for me to become skillful at using the system. & Yes & Yes & $\mathrm{No}$ \\
\hline & expectancy & I would find the sy & Yes & Yes & No \\
\hline & & Learning to operate tl & Yes & Yes & No \\
\hline & $\mathbf{A t t}$ & Using the system is a bad/good idea. & No & Yes & $\mathrm{No}$ \\
\hline & towards using & The system makes work more interes & No & Yes & No \\
\hline & technology & \begin{tabular}{|l} 
Working with the system is fun. \\
\end{tabular} & No & Yes & No \\
\hline & & I like working with the system. & Yes & Yes & $\mathrm{No}$ \\
\hline & & $\begin{array}{l}\text { People who influence my behavior think that I should use the } \\
\text { system. }\end{array}$ & Yes & Yes & No \\
\hline & Social Influence & People who are important to me think that I should use the system. & Yes & Yes & $\mathrm{No}$ \\
\hline & & $\begin{array}{l}\text { The senior management of this business has been helpful in the use } \\
\text { of the system. }\end{array}$ & No & Yes & No \\
\hline & & In general, the organization has supported the use of the system. & No & Yes & No \\
\hline & & I have the resources necessary to use the system. & Yes & Yes & $\mathrm{No}$ \\
\hline & Facilit & I have the knowledge 1 & Yes & Yes & No \\
\hline & & $\begin{array}{l}\text { The system is not compatible with other systems I use. } \\
\end{array}$ & Yes & Yes & No \\
\hline & & $\begin{array}{l}\text { A specific person (or group) is available for assistance with system } \\
\text { difficulties. }\end{array}$ & No & Yes & No \\
\hline & & I could complete a job or task using the system... & Yes & Yes & No \\
\hline & & e around to tell me what to do as I go. & Yes & Yes & No \\
\hline & Self-efficacy & \begin{tabular}{|l|} 
If I could call someone for help if I got stuck. \\
\end{tabular} & Yes & Yes & No \\
\hline & & $\begin{array}{l}\text { If I had a lot of time to complete the job for which the software was } \\
\text { provided. }\end{array}$ & Yes & Yes & No \\
\hline & & If I had just the built-in help facility for assistance. & Yes & Yes & No \\
\hline & & I feel apprehensive about using the system. & Yes & Yes & No \\
\hline & & $\begin{array}{l}\text { It scares me to think that I could lose a lot of information using the } \\
\text { system by hitting the wrong key. }\end{array}$ & Yes & Yes & No \\
\hline & (UTUAT) & $\begin{array}{l}\text { I hesitate to use the system for fear of making mistakes I cannot } \\
\text { correct. }\end{array}$ & Yes & Yes & $\mathrm{No}$ \\
\hline & & The system is somewhat intimidating to me. & Yes & Yes & No \\
\hline & Intentions to & I intend to use the system in the next $\langle\mathrm{n}>$ months. & Yes & Yes & $\mathrm{No}$ \\
\hline
\end{tabular}




\begin{tabular}{|c|c|c|c|c|}
\hline & I predict I would use the system in the next $<\mathrm{n}>$ months. & Yes & Yes & No \\
\hline (UTUAT) & I plan to use the system in the next $<\mathrm{n}>$ months. & Yes & Yes & No \\
\hline
\end{tabular}

The outcome shows that most items were explicitly linked to individuals (86\%) using the IT artifact itself. For some items, the individual/IT artifact utilization components were less obvious. In line with Evermann and Tate (2009), one could argue that some of the items had neither reference to the user nor to the IT artifact. For instance, Thompson et al. (1991) used the following measure to test their research model: "Use can increase the quantity of output for the same amount of effort" (Thompson, Higgins et al. 1991). However, given the survey introductions researchers normally provide to the respondents, it is reasonable to believe that the respondents were aware of the fact that the survey inquired them to respond with respect to their usage of a given Information System.

In contrast, none of the items included any reference to a precise task users perform while using an Information System. For instance, "Using the system is compatible with all aspects of my work" (Moore and Benbasat, 1991) solicits responses conceiving whether a system is compatible with all work related aspects. Most white-collar workers perform a wide variety of tasks on Information Systems to complete their work related goals. For example, using Microsoft Office to write a short email to a colleague has fundamentally different characteristics than designing a new template for corporate powerpoint presentations. Writing emails is most likely perceived as straightforward and easy-to-do by most office workers whereas the powerpoint task would be viewed as much more complicated and complex (designing a PPT template). If confronting a respondent who uses an IS system at work for both tasks (which seems relatively normal for a white-collar worker) with Moore and Benbasat's (1991) item (Using the system is compatible with all aspects of my work), how should he/she respond? What if the respondent felt that the system is compatible for writing emails as the system supports the task well but not for developing corporate powerpoint templates since the IS does not provide any guidance and is everything else but selfexplanatory for this given task?

This example shows why Burton-Jones and Straub's (2006) items are fundamentally different from the traditional measures used in IS theories. Instead of asking students regarding the compatability of Microsoft Office for their studies, Burton-Jones and Straub narrowed down the items to a very precisely defined task (developing a decision-making tool using MS Excel spreadsheet software). 
This shows why Burton-Jones and Straub's conceptualization of IS use differed significantly from the traditional utilization theories. First, the article brought a novel perspective on the utilization of information systems. Second, by integrating tasks and the IT artifact within the measures, the findings become less generalizable but more applicable and precise. The items developed by Burton-Jones and Straub (2006) are specifically linked to using Microsoft Excel for developing a decision making tool. Practitioners developing spreadsheet software will benefit from the findings since the students' perceptions are linked to a single software application (IT artifact) for a specific task (developing a financial decision making tool). Traditional adoption and utilization theories have used less precise but more general measures. The latter issue has been also addressed by TAM2/TAM3/TPB-extended by introducing additional constructs to explain the original adoption/acceptance theories more precisely.

Considering these developments, it seems that there is a tendency in utilization research aiming to develop more precise though less general theories. The following Figure 49 indicates this generation shift for IS utilization theories.

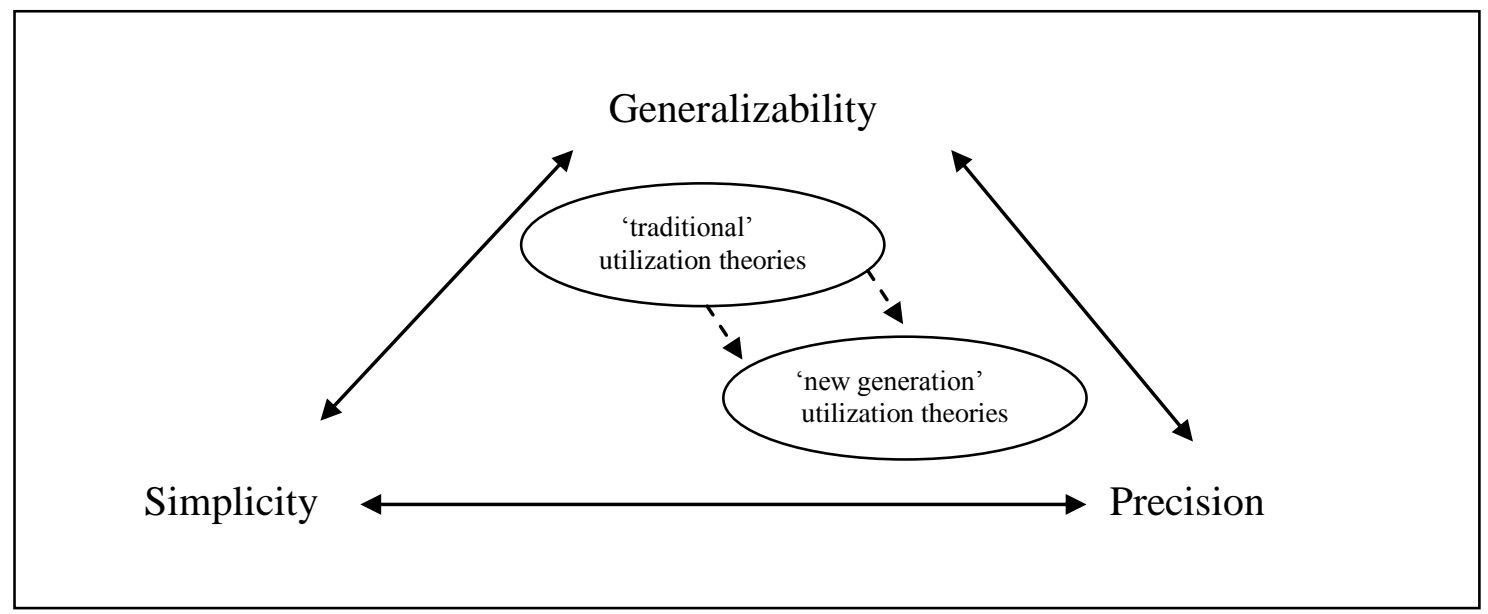

Figure 49: Generation shift of IS utilization theories: Interplay between generalisability, precision and simplicity in IS theories

Task-channel fit theory applies both strategies to develop a more precise picture of IS utilization. First, the detailed conceptualization of the TCF construct aimed to understand the preceding factors of the perceived usefulness, intentions to use, and attitude towards channel use constructs. Interpreting the contribution of each TCF dimension (weights) in combination with the exogenous path coefficients of the TCF construct provide answers to the questions why consumers view Internet banking as useful for financial loans or account inquiries. 
Likewise, the weights explain why individuals have a positive attitude towards Internet banking in consideration of financial loans/account inquires.

The TCF conceptualization can be seen as somewhat comparable to the construct extensions used in TAM2 and TAM3 as well as the extended TPB theory. Adapting tasktechnology fit theory for this purpose appeared to be well suited for extending the well theorized utilization constructs since: "it is clear from extensive work on TAM that usefulness is a key, if not the key, influential belief influencing use. Therefore, it would be fruitful to investigate the antecedents of usefulness in order to provide design-oriented advice. However, to be able do so in a systematic fashion, we first have to develop a taxonomy, or preferably a theory, of usefulness. A good conceptual starting point for such an endeavor may be an augmented task-technology fit model (Goodhue 1995) that would provide finer and more focused design advice in specific task contexts" (Benbasat and Barki 2007).

Second, the research model was tested using two very specific tasks (applying for a financial loan or making an account inquiry) in order to "provide finer and more focused design advice in specific task context" (Benbasat and Barki 2007). Using Burton-Jones and Straub's (2006) definition of systems utilization, this research intentionally included individuals, IT artifact (Internet banking) and tasks (account inquiries/financial loans) ${ }^{33}$ within the scales. In light of the preceding discussion, it is believed that the findings are more precise than would be the case using non-task specific items.

Having task-centric items should be helpful for practitioners since they are not left with the message "Internet banking is useful for my personal finances". Instead the findings argue whether "Internet banking is useful for account inquiries" and if consumers believe that "Internet banking is useful for financial loans". Practitioners can apply the study's findings on a single product category (e.g. financial loans) rather than trying to interpret and apply more general conclusions e.g. on the use of Internet banking (section 7.4. also discusses this issue in more depth).

The empirical evidence presented by this research suggests that it is important to include the user, IT artifact, and tasks within the scales when investigating IS utilization at the individual level (as suggested by Burton-Jones and Straub, 2006). The analysis of the structural model demonstrated a lack of path invariance in the structural model when

\footnotetext{
${ }^{33}$ See Table 94 to inspect the items used during the main phase of this study.
} 
comparing both banking tasks. This confirmed that individuals truly differentiate IS usage when performing different tasks.

It was particularly surprising that a few previously-researched structural paths theorized by TAM were found to be inconsistently supported across both banking tasks (see Table 122). This suggests that the traditional utilization theories should be scrutinized for their appropriateness to study task-specific IS utilization at the individual level. Future studies should shed more light into how traditional IS research models are affected when the tasks users perform is specifically taken into consideration.

Naturally, the approach chosen for this research involves additional administrative effort since it was required to collect data for each banking tasks using two different versions the survey questionnaire. This approach seems especially problematic to pursue if not having access to a large consumer sample (e.g. when collecting data in organizational environments).

\subsection{Implications for task-technology fit research}

As explained in section 2.4., task-technology fit research investigates how well technologies (IT artifacts) assist individuals in performing their portfolio of tasks. More specifically, TTF can be defined as the correspondence between task requirements, individual abilities, and the functionality of the technology (Goodhue 1995).

As indicated within the previous section, the definition of TTF integrates the individual, the task users perform, and the IT artifact. In a way, it appears that Goodhue and Thompson's (1995) definition of TTF was ahead of time since it integrated all key components for developing second generation utilization theories. TTF also precedes well theorized constructs including perceived usefulness (or the expected consequences of technology use) and attitude towards technology $\mathrm{y}^{34}$.

The literature review on TTF (section 2.4.) demonstrated that many researchers have applied TTF to various contexts (Goodhue and Thompson 1995; Goodhue 1998; Zigurs and Buckland 1998; Dishaw and Strong 1999; Zigurs, Buckland et al. 1999; D'Ambra and Wilson 2004; D'Ambra and Wilson 2004; Karimi, Somers et al. 2004).

Goodhue and Thompson's (1995) seminal TTF article has been cited over 1250 times on Google Scholar. This indicates that the theory is similarly influential for the IS research discipline as some of the traditional acceptance and adoption theories outlined in the previous

\footnotetext{
${ }^{34}$ Sections 2.4. and 2.5. include a more thorough discussion on TTF theory.
} 
section. Not surprisingly, TTF has been referred to as "one of the few prominent theories in our research discipline" (Evermann and Tate 2009).

Moreover, those scholars debating the inclusion of the IT artifact in IS theories have often termed TTF a reference theory. For example, Benbasat and Barki (2007) suggested that Goodhue and Thompson's (1995) model is one of the few IS theories that focuses on the IT artifact and tasks users perform. Evermann and Tate (2009) argued that TTF: “acknowledges that the generic nature of its focal construct needs to be adapted and operationalized for specific technologies" (Evermann and Tate 2009). Goodhue (2007) also stressed the unique standing of TTF in Information Systems research as it would correspond to Benbasat and Zmud's (2003) view of the IT artifact as it integrates technologies and tasks users perform to pursue their goals.

While performing the literature review on TTF, approximately twenty-five articles were identified that rigorously studied task-technology fit in various contexts. Many of these studies were published in $\mathrm{A}^{*}$ ranked journals such as MISQ, ISR, Information and Management, and European Journal of Information Systems. Some of the studies were more conceptual (e.g. Zigurs et al. 1998) whereas others tested TTF using empirical evidence (e.g. Seddon and Staples). Most of the studies using empirical data defined the TTF construct based on Goodhue and Thompson's (1995) TTF definition.

On the other hand, the operationalization of TTF diverged significantly and the fit computations between tasks and technologies were often described vaguely. Inspecting these studies more carefully, it seemed that there was no consensus among IS researchers of how to best measure task-technology fit.

For instance, Goodhue and Thompson (1995) used 48 questions to measure 21 dimensions of TTF. One of the 21 dimensions was labeled as ease of use/training. The authors used the following four items to measure this facet of TTF:

- It is easy to learn how to use the computer systems I need.

- The computer systems I use are convenient and easy to use.

- There is not enough training for me or my staff on how to find, understand, access or use the company computer systems.

- I am getting training I need to be able to use company computer systems, languages, procedures and data effectively. 
Multiple-regression techniques were applied to evaluate the correlations between each TTF dimension and "some measures of task" (non-routine and inter-dependence) as well as "some measure of technology" (groups of dummy variables for systems used or department).

Comparing the above mentioned items and the Goodhue and Thompson's (1995) definition of TTF, it appears that there is some discrepancy. First, the above mentioned items are nontask specific and are similar to those used by traditional utilization theories (e.g. TAM, DOI/IS etc.). Second, it seems questionable why user training should be viewed as part of task-technology fit. Perhaps user training positively influences perceived TTF but it appears debatable that it should be seen as part of TTF (given the definition Goodhue and Thompson stated in their article).

Dishaw and Strong (1998) used task-technology fit theory to explain the factors leading to the use of software maintenance support tools. In their research model, the authors investigated the nature of the fit between software tool functionality and maintenance tasks users perform while using the system. The authors tested two major TTF dimensions (production fit and coordination fit) using a parallel instrument in combination with fit as moderation analysis. While the concept of the fit measurement does not differ from the current study, the execution of the parallel instrument was dissimilar. Table 127 lists the items used by Dishaw and Strong (1998):

Table 127: Parallel items used by Dishaw and Strong (1998) to measure TTF

\begin{tabular}{|l|l|}
\hline Production task activities & Production tool functionality \\
\hline To what extent did you perform the following? & $\begin{array}{l}\text { To what extent do the maintenance software tools } \\
\text { available to you supply the following functions? }\end{array}$ \\
\hline $\begin{array}{l}\text { I had to weigh and evaluate a large volume of } \\
\text { information about the system I was maintaining. }\end{array}$ & $\begin{array}{l}\text { Construct representations of entities, relationships, } \\
\text { or processes in a diagram or model. }\end{array}$ \\
\hline $\begin{array}{l}\text { I made extensive use of my knowledge of the } \\
\text { programming language(s) and data base system in } \\
\text { which the software is written. }\end{array}$ & $\begin{array}{l}\text { Represent the objects, relationships, or processes of } \\
\text { the system or part of the system in terms of models } \\
\text { (data flow diagrams, entity-relationship diagrams, } \\
\text { Flowcharts, etc.). }\end{array}$ \\
\hline $\begin{array}{l}\text { I learned a great deal about the system by mentally } \\
\text { processing parts of the system code. }\end{array}$ & $\begin{array}{l}\text { Model a system in terms of process, flow, or data } \\
\text { models. }\end{array}$ \\
\hline $\begin{array}{l}\text { I examined samples of the input data. } \\
\text { I frequently consulted system documentation. }\end{array}$ & $\begin{array}{l}\text { Produce a high level specification (e.g., diagram) } \\
\text { from a lower level, or more detailed representation. }\end{array}$ \\
\hline $\begin{array}{l}\text { I obtained information about the system from } \\
\text { comments in the body of the programs. }\end{array}$ & \\
\hline $\begin{array}{l}\text { I learned a great deal about the system by mentally } \\
\text { processing parts of the system code. }\end{array}$ & \\
\hline $\begin{array}{l}\text { I added new functions to this system. I consulted } \\
\text { manuals to obtain information about the } \\
\text { programming language(s) and / or database sys- tem. }\end{array}$ & \\
\hline $\begin{array}{l}\text { I obtained information about the system through } \\
\text { examining the source code. }\end{array}$ & \\
\hline I asked a colleague for technical information during & \\
\hline
\end{tabular}


this project.

The scales were anchored on a 7-point Likert scale. To compute the TTF scores, the authors multiplied the production task activities values with the production tool functionality scores. The procedure was adapted from Venkatraman's (1989) fit as moderation approach as explained in more detail in section 5.2.

The underlying logic of this approach is plausible and a parallel instrument seemed well suited to measure TTF in context of Dishaw and Strong's research. On the other hand, parallel instruments (as outlined by Venkatraman, 1989) should include identical items in order to compute a fit score. A good example for using parallel scores in combination with fit as moderation approach was provided by Chan et al. (1997). Chan et al's (1997) instrument had identical items and IS practitioners' answers were multiplied with those responses gained from business managers.

Dishaw and Strong's parallel items, however, were not worded similarly and it could be questioned if both sides of the fit were identifying theoretically similar concepts. What is more, the overall number of items for task activities was larger than the number of items created to measure the tool functionalities. For these reasons, it seems unclear how Dishaw and Strong (1998) computed the TTF scores. A similar issue was also apparent in Dishaw and Strong's (1999) Information \& Management article in which the authors used the same scales but applied deviation score analysis to compute the task-technology fit scores - rather than using moderation score analysis.

D'Ambra and Wilson (2004a) proposed a model integrating the concept of uncertainty and information seeking to the task-technology fit (TTF) model. The goal of the study was to evaluate Web usage within the non-work domain of personal travel planning and purchase. As part of the TTF measures, the authors included items such as "More likely to find information on the web", "Can avoid going to a store", "Complete control of sites I visit". Inspecting these items closely it is unclear how the authors accounted for task-technology fit. Evermann and Tate's (2009) comments would be well suited to describe the aforementioned measures used to study TTF: "there is nothing in the concepts, or in their operationalization, that is specific to the IT artifact". In fact, it could be added that tasks are also ignored in these items. Comparable scales were used by Dambra et al. (2004b).

As discussed in section 2.5., Klopping et al. (2004) used direct measures to evaluate TTF. This approach appeals due to its simplicity but requires the respondent to mentally 
calculate the TTF. Staples and Seddon (2004) approach also seemed questionable in light of the original TTF definition since items such ease of use were declared as TTF measures. Using TAM measures under the umbrella of TTF does not seem to be conceptually appropriate.

Another problematic issue was apparent among all the above mentioned articles. While some of the TTF items were task-specific, none of the research models tested the remaining constructs in their models in a task-specific manner.

For instance, Dishaw and Strong (1999) linked the task-technology fit construct to a perceived ease of use variable. In their article, the authors argued: "A weakness of TAM for understanding IT utilization is its lack of task focus. IT is a tool by which users accomplish organizational tasks. The lack of task focus in evaluating IT and its acceptance, use, and performance contributes to the mixed results in IT evaluations" (Dishaw and Strong 1999). This argument is in agreement with Goodhue and Thompson's (1995) TTF definition, and one would have expected that Dishaw and Strong (1999) tested the ease of use construct in a taskspecific fashion. However, the operationalization of the survey questionnaire showed that the authors linked the TTF construct to perceived ease of use items that were identical to original TAM items. The following items were used to measure perceived ease of use:

- I will find it easy to get the software maintenance tools to do what I want them to do.

- My interaction with the software maintenance tools will be clear and understandable.

- I will find the software maintenance tools to be flexible to interact with.

- I will find the software maintenance tools easy to use. (Dishaw and Strong 1999)

This appears to be an imprecise measurement procedure since one construct is assumed to be task-specific (TTF) whereas perceived ease of use is system-specific. Linking concepts that are not conceptually similar can be problematic. Similar measurement approaches were found in the remaining articles identified in the extant literature around task-technology fit.

The current research advances existing task-technology fit research in two ways. First, it thoroughly uses a parallel instrument for measuring task-channel fit of electronic banking channels. The items were developed to parallel each other and during the developmental phase, much attention was paid to the wording of the items. This is not a trivial task since it must be assured that the concepts in question work well in context of banking tasks and channels. The parallel instrument was guided by the work on fit theory (Venkatraman 1989) and previous research on strategic alignment (Chan 1992; Chan, Huff et al. 1997). 
Second, as outlined in the previous section, the entire research model was tested in a taskspecific context. This meant that all items were either linked to account inquiries or financial loans. Rather than asking "I find Internet banking easy to use", this research asked if "I find Internet banking easy to use for account inquiries/financial loan applications". This allowed this research to link the TCF construct to the remaining constructs in the research model since they were all conceptually similar (i.e., task-specific).

As previously mentioned, the task-specific research design created additional administrative effort since separate data were required to assess both versions of the research model. On the other hand, sacrificing some generalizability for measurement precision (see Figure 49) seemed to be worthwhile. More precise theories should lead to more actionable recommendations for practitioners. These are explained in the following section.

\subsection{Implications for practitioners}

Many senior IS scholars have debated whether Information Systems research has practical implications for mangers working in the IT related industry. The reasoning is that classical research presentations are difficult (and too time consuming) to interpret for practitioners who have to manage their time effectively (Keen 1980; Weber 1997; Robey and Markus 1998; Luftman and McLean 2004; Lyytinen and King 2004). Thus, it was assumed that it would helpful to dedicate one section of this thesis to translate the theoretical findings into managerial implications.

While chapters five and six discussed the measurement and structural aspects of the research model, the following section analyzes each hypothesis of this research in more detail. This construct centric analysis is complemented by actionable recommendations for practitioners.

\subsubsection{TCF-construct: task complexity}

As shown below, none of the weights obtained for the complexity measures in the financial loan dataset were statistically significant. However, despite not being statistical significant at the $\mathrm{p}<0.05$ level, the weights were reasonably high in the financial loan dataset. The weights obtained for the complexity measures in the account inquiry dataset and complete dataset were all statistically significant. Thus, it was reasonable to conclude that task complexity 
contributed considerably to the task-channel fit construct. Table 128 summarizes the results obtained for this aspect of the task-channel fit construct ${ }^{35}$.

Table 128: Summary of the research findings: task complexity

\begin{tabular}{|c|c|c|c|}
\hline \multicolumn{2}{|c|}{ Task complexity } & Financial Loans & Account inquiries \\
\hline \multirow{3}{*}{ Pilot test } & Individual moderation scores & Weight: 0.09 & Weight: $0.36^{*}$ \\
\cline { 2 - 4 } & Mean moderation scores & Weight: 0.31 & Weight: $0.31^{* *}$ \\
\hline Main Study & Individual moderation scores & Weight: 0.27 & Weight: $0.30^{* * *}$ \\
\cline { 2 - 4 } & Mean moderation scores & Weight: 0.30 & Weight: $0.30^{* * *}$ \\
\cline { 2 - 4 } & Individual moderation scores & Complete dataset & Weight: $0.23^{* *}$ \\
\cline { 2 - 4 } & Mean moderation scores & Complete dataset & Weight: $0.25^{*}$ \\
\hline
\end{tabular}

These findings confirmed that consumers' perceptions of the task-channel fit are influenced by the perceived complexity of a specific banking task. Practitioners should take these results into consideration when developing strategies for product and service distribution via electronic banking channels.

For instance, Table 98 shows that consumers viewed Internet banking as well suited for simple banking transactions and less suited for complicated banking tasks. The Table also suggested that account inquiries were viewed as being simple whereas financial loans were more complicated.

The message for banks is relatively clear: an increase in perceived task complexity leads to a decrease in the perceived task-channel fit of electronic banking channels. Banks could pursue different strategies to act in response to these findings. First, they could offer only simple to medium complex banking products on electronic banking channels and deliver the more sophisticated banking products only via face-to-face branch banking. That way, consumers could manage simple to medium-complicated transactions via self service technologies and visit the branch only if they were interested in more sophisticated transactions. Since the consumers indicated that simple transactions are well suited for Internet banking, banks could also consider discouraging consumers from performing these transactions in physical branches. This would positively impact on the cost structure of banks since cost saving could be achieved due to less staff involvement and reduced overhead costs. A possible managerial instrument for managers could be to impose marginal transaction costs (e.g. \$0.10) for simple banking transaction consumers perform in a physical branch (e.g. account inquiries/domestic transactions). If the same transaction incurs no fee when

\footnotetext{
${ }^{35}$ The weights were equally high in the financial loan and account inquiries datasets though none of the weights were tested significant in the financial loan dataset. Cenfetelli and Bassellier (2009) argued that it is acceptable if some indicators have insignificant weights when using multiple formative items. Section 5.4.2.3. provides more information on this.
} 
conducted via electronic banking channels, customers would have an incentive to perform these transactions electronically ${ }^{36}$.

A second strategy for banks could involve trying to convince consumers that banking products such as financial loans are not complicated. This could be operationalized through educational video clips on the bank's Internet portal or perhaps simple and straightforward explanations on how these transactions work. This could result in reducing the perceived complexity of financial loans, thus rendering this task more suitable for Internet banking delivery.

\subsubsection{TCF-construct: task effort}

The below mentioned Table demonstrates that the task effort dimension did not significantly contribute to the TCF construct. The weights obtained for the financial loan/account inquiries sub-datasets were relatively low suggesting that this facet of TCF was less significant than the remaining dimensions.

Table 129: Summary of the research findings: task effort

\begin{tabular}{|c|c|c|c|}
\hline \multicolumn{2}{|c|}{ Task effort } & Financial Loans & Account inquiries \\
\hline \multirow{3}{*}{ Pilot test } & Individual moderation scores & Weight: -0.05 & Weight: 0.08 \\
\cline { 2 - 4 } & Mean moderation scores & Weight: 0.22 & Weight: 0.04 \\
\hline Main Study & Individual moderation scores & Weight: 0.12 & Weight: $0.15^{*}$ \\
\cline { 2 - 4 } & Mean moderation scores & Weight: 0.20 & Weight: 0.04 \\
\cline { 2 - 4 } & Individual moderation scores & Complete dataset & Weight: 0.10 \\
\cline { 2 - 4 } & Mean moderation scores & Complete dataset & Weight: 0.09 \\
\hline
\end{tabular}

This suggested that consumers do not associate task effort with their perceptions of the task-channel fit of electronic banking channels. While unexpected, these findings are important for banks and could be interpreted positively by managers. If the perceived taskchannel fit is not influenced by task effort, banks could safely offer high and low effort banking tasks via self-service technologies. In other words, consumers appeared to be willing to fill out many forms, provide a lot of information to the bank, or performing many steps online.

Banks could use this information and integrate it into their product and service distribution strategies via electronic banking channels. For instance, international transactions were often referred to be uncomplicated but such transactions would require much effort. Since consumers' perceptions of the task effort did not negatively influence their perceptions of

\footnotetext{
${ }^{36}$ While this recommendation appears to be meaningful in isolation, it is important to note that banks operate in competitive environments. Consumers might switch to competitors if one bank imposes such transaction fees whereas the competition does not.
} 
task-channel fit, banks could try to push customers to perform these transactions online rather than via face-to-face banking. This could allow banks to work more profitable. As explained in the previous sections, banks could test how consumers' react if they offer incentives for them to perform these transactions online rather than involving branch personnel.

\subsubsection{TCF-construct: task importance}

The weights obtained for the task importance TCF dimension indicated that consumers' perceptions of the task-channel fit are influenced by the perceived importance of banking tasks. The weights were tested statistically significant in the financial loan/account inquiries and complete datasets alike.

Table 130: Summary of the research findings: task importance

\begin{tabular}{|c|c|c|c|}
\hline \multicolumn{2}{|c|}{ Task importance } & Financial Loans & Account inquiries \\
\hline \multirow{3}{*}{ Pilot test } & Individual moderation scores & Weight: 0.37 & Weight: $0.37^{*}$ \\
\cline { 2 - 4 } & Mean moderation scores & Weight: $0.45^{*}$ & Weight: $0.38^{*}$ \\
\hline \multirow{3}{*}{ Main Study } & Individual moderation scores & Weight: $0.28^{*}$ & Weight: $0.24^{*}$ \\
\cline { 2 - 4 } & Mean moderation scores & Weight: $0.48^{*}$ & Weight: $0.18^{*}$ \\
\cline { 2 - 4 } & Individual moderation scores & Complete dataset & Weight: $0.25^{* *}$ \\
\cline { 2 - 4 } & Mean moderation scores & Complete dataset & Weight: $0.21^{*}$ \\
\hline
\end{tabular}

This indicated that consumers view less important banking tasks (account inquiries) as well suited for electronic banking channels but more important tasks (financial loans) as less suited for electronic banking channels. This means that if consumers want to perform banking transactions that are significant in their mind -or that affect their personal finances significantly- they consider Internet banking as less suited for those transactions. In contrast, ordinary or commonplace banking transactions were seen as well suited for Internet banking applications by the research participants (see Table 98 for further information).

Banks can use these findings and integrate them in their strategies for high-importance tasks and those banking transactions that have a long lasting impact on consumers' finances including superannuation products, financial loans, insurance products etc.

The most obvious recommendation would be for banks to tailor their electronic banking applications towards high importance banking products. For instance, the focus group discussions and literature on electronic banking illustrated that consumers appreciate personal assistance for banking transactions that they view as highly important (Reinsch and Beswick 1990). Thus, alternative technologies/applications could be used to guide customers when performing high-importance transactions via self-service technologies. For instance, if consumers visit a banking website where they can purchase superannuation products, banks could offer chat rooms or perhaps call-centre support via Skype or 0800 numbers in order to 
support customers during the product selection process. These mechanisms could potentially positively influence consumers' perceptions of the task-channel fit of Internet banking for high-importance banking tasks. It should be also mentioned that such support applications are very common in other industries such as telecommunication providers. For instance, Telstraclear (Australian/New Zealand based telecommunication provider) offers online chat support for customers who require support. The following screenshot was taken from Telstraclear's New Zealand based website (www.telstraclear.co.nz.)

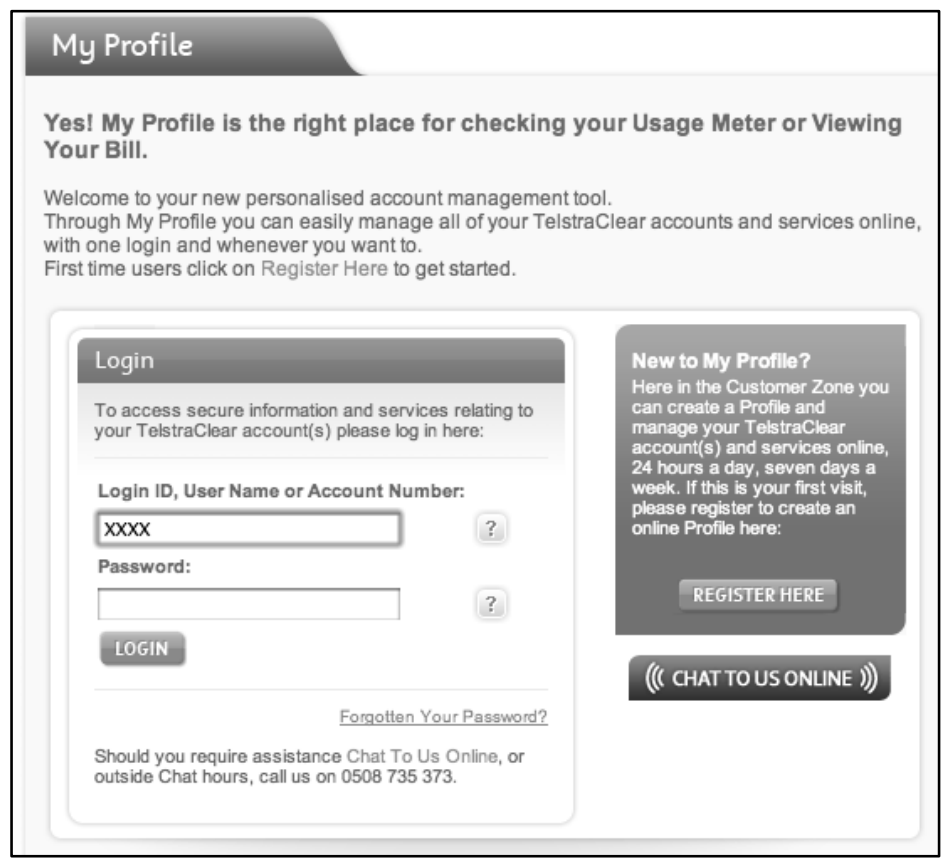

Figure 50: Telstraclear example of how to support customers' via chat technologies

So far, none of the major banks in New Zealand offers such support services which the current study suggests to be particularly useful for high importance banking transactions.

\subsubsection{TCF-construct: task routineness}

The weights obtained for the task routineness measures suggested that the TCF task routine dimension significantly impacted on consumers perceptions of the task-channel fit of electronic banking channels. The weights were highly significant independent of the dataset and TCF conceptualization. Table 131 summarizes the results.

Table 131: Summary of the research findings: task routineness

\begin{tabular}{|c|c|c|c|}
\hline \multicolumn{2}{|c|}{ Task routineness } & Financial Loans & Account inquiries \\
\hline \multirow{3}{*}{ Pilot test } & Individual moderation scores & Weight: 0.22 & Weight: $0.40^{* *}$ \\
\cline { 2 - 4 } & Mean moderation scores & Weight: $0.36^{*}$ & Weight: $0.47^{* *}$ \\
\hline Main Study & Individual moderation scores & Weight: $0.31^{*}$ & Weight: $0.38^{* * *}$ \\
\cline { 2 - 4 } & Mean moderation scores & Weight: $0.32^{*}$ & Weight: $0.47^{* * *}$ \\
\cline { 2 - 4 } & Individual moderation scores & Complete dataset & Weight: $0.44^{* * *}$ \\
\cline { 2 - 4 } & Mean moderation scores & Complete dataset & Weight: $0.61^{* *}$ \\
\hline
\end{tabular}


Banks can benefit from these findings since they possess historic data on the customer-tobank relationship. Therefore, they know which kind of products customers have purchased in the past.

If using data-mining tools, banks could provide personalized support for those products a customer performs routinely/non-routinely. For instance, if customers frequently use Internet banking for account inquiries it is likely that they have developed a routine for those transactions. Thus, a chat function (see section above) seems to be inappropriate to display for customers who frequently use these transactions. On the other hand, if consumers have no routine with a banking task at all (e.g. loan applications/international transactions) a chat function appears to be well suited since it could increase the customer's perception of the task-channel fit for non-routine banking transactions.

In spite of consumer affinity for personalization, few companies other than Amazon.com and Netflix utilize personalization in an efficient and effective way (Mulpuru 2007). According to Forrester Research this is surprising since personalizing web applications can be very rewarding for companies (Mulpuru 2007). Given the findings discussed above, this research assumes that banks could gain rewards through personalizing their Internet banking applications.

\subsubsection{TCF-construct: task time criticality}

Table 132 illustrates that the results for the time criticality dimension differed across the pilot study/main study and data subsets. During the pilot study, only the individual moderation score analysis suggested that task time criticality would significantly impact on consumers' perceptions of the task-channel fit. Inspecting the results of the main study, the opposite was the case since most weights were statistically significant. These results suggested that the newly developed time criticality items (see section 6.2.2.6.) measured the concept more precisely. Given the results of the main study, this research assumes that consumers' perceptions of the task-channel are influenced significantly by task time criticality.

Table 132: Summary of the research findings: task time criticality

\begin{tabular}{|c|c|c|c|}
\hline \multicolumn{2}{|c|}{ Task time criticality } & Financial Loans & Account inquiries \\
\hline \multirow{3}{*}{ Pilot test } & Individual moderation scores & Weight: $0.65^{* *}$ & Weight: 0.13 \\
\cline { 2 - 4 } & Mean moderation scores & Weight: 0.24 & Weight: 0.07 \\
\hline \multirow{3}{*}{ Main Study } & Individual moderation scores & Weight: $0.47 * * *$ & Weight: $0.12^{*}$ \\
\cline { 2 - 4 } & Mean moderation scores & Weight: 0.07 & Weight: $0.22^{* *}$ \\
\cline { 2 - 4 } & Individual moderation scores & Complete dataset & Weight: $0.23^{* * *}$ \\
\cline { 2 - 4 } & Mean moderation scores & Complete dataset & Weight: 0.06 \\
\hline
\end{tabular}


The respondents viewed urgent and non-urgent banking tasks as well supported by Internet banking (see Table 98). This suggested that banks can offer banking products online that are normally characterized as urgent (e.g. purchasing corporate stocks, currency trading etc.). Given the findings of this study, Internet banking supports such transactions well.

Since the current study solely tested Internet banking in combination with two given banking tasks, it is inappropriate to attempt to derive meaningful assumptions about other task-channel fit combinations (e.g. whether urgent banking products are also well suited for mobile banking - or perhaps not).

\subsubsection{TCF-construct: task analyzability}

The research findings of this study suggested that the task analyzability dimension did not significantly contribute to the TCF construct during the main study.

Table 133: Summary of the research findings: task analyzability

\begin{tabular}{|c|c|c|c|}
\hline \multicolumn{2}{|c|}{ Task analyzability } & Financial Loans & Account inquiries \\
\hline Main Study & Individual moderation scores & Weight: 0.21 & Weight: $0.14^{*}$ \\
\cline { 2 - 4 } & Mean moderation scores & Weight: -0.01 & Weight: -0.03 \\
\cline { 2 - 4 } & Individual moderation scores & Complete dataset & Weight: 0.07 \\
\cline { 2 - 4 } & Mean moderation scores & Complete dataset & Weight: -0.10 \\
\hline
\end{tabular}

These findings suggested that consumers' do not associate task analyzability with their perceptions of the task-channel fit. In addition, Table 133 shows that the respondents viewed analyzable banking tasks as only moderately suited for Internet banking. Due to the nonsignificant results, it would be difficult to derive managerial suggestion from these findings.

\subsubsection{TCF-construct: task uncertainty}

The task uncertainty dimension did not significantly contribute to the task-channel fit construct. Task uncertainty was also included after the pilot study and the findings of the main study could not be compared to the pilot study.

Table 134: Summary of the research findings: task uncertainty

\begin{tabular}{|c|c|c|c|}
\hline \multicolumn{2}{|c|}{ Task uncertainty } & Financial Loans & Account inquiries \\
\hline \multirow{3}{*}{ Main Study } & Individual moderation scores & Weight: 0.19 & Weight: -0.07 \\
\cline { 2 - 4 } & Mean moderation scores & Weight: 0.09 & Weight: -0.08 \\
\cline { 2 - 4 } & Individual moderation scores & Complete dataset & Weight: 0.05 \\
\cline { 2 - 4 } & Mean moderation scores & Complete dataset & Weight: -0.04 \\
\hline
\end{tabular}

These results suggested that consumers who have additional questions or require finding out additional information on how banking products work do not believe that Internet banking is well suited for these transactions. As with the previous TCF dimension, it appeared to be questionable to conclude managerial implications from these non-significant findings. 


\subsubsection{TCF-construct: task equivocality}

The results of the data analysis showed that the task equivocality dimension did not influence consumers' perceived task-channel fit of electronic banking channels. Most of the weights were very low and they were statistically insignificant.

Table 135: Summary of the research findings: task equivocality

\begin{tabular}{|c|c|c|c|}
\hline \multicolumn{2}{|c|}{ Task equivocality } & Financial Loans & Account inquiries \\
\hline \multirow{3}{*}{ Main Study } & Individual moderation scores & Weight: 0.01 & Weight: -0.09 \\
\cline { 2 - 4 } & Mean moderation scores & Weight: -0.14 & Weight: $-0.18^{*}$ \\
\cline { 2 - 4 } & Individual moderation scores & Complete dataset & Weight: 0.01 \\
\cline { 2 - 4 } & Mean moderation scores & Complete dataset & Weight: -0.10 \\
\hline
\end{tabular}

Since the findings were insignificant, no managerial recommendations are provided with regards to task equivocality.

\subsubsection{H1: TCF $\rightarrow$ Perceived usefulness.}

The results of the pilot and main study confirmed that the perceived task-channel fit of Internet banking positively impacted on consumers' perceptions of the usefulness of Internet banking for financial loan applications/account inquires. Table 136 summarizes the findings for the first hypothesis.

Table 136: Summary of the research findings: Hypothesis 1 (TCF-->PU)

\begin{tabular}{|c|c|c|c|}
\hline \multicolumn{2}{|c|}{ TCF $\rightarrow$ PU } & Financial Loans & Account inquiries \\
\hline \multirow{3}{*}{ Pilot test } & Individual moderation scores & Coefficient: $0.18^{*}$ & Coefficient: $0.30^{* *}$ \\
\cline { 2 - 4 } & Mean moderation scores & Coefficient: $0.27^{* *}$ & Coefficient: $0.27^{* * *}$ \\
\hline Main Study & Individual moderation scores & Coefficient: $0.23^{* *}$ & Coefficient: $0.26^{* *}$ \\
\cline { 2 - 4 } & Mean moderation scores & Coefficient: $0.20^{* *}$ & Coefficient: $0.28^{* * *}$ \\
\cline { 2 - 4 } & Individual moderation scores & Complete dataset & Coefficient: $0.26^{* * *}$ \\
\cline { 2 - 4 } & Mean moderation scores & Complete dataset & Coefficient: $0.26^{* *}$ \\
\hline
\end{tabular}

These findings are important for banks as they confirm that if consumers perceive a fit between Internet banking and account inquiries/financial loans, they will also perceive personal benefits of using Internet banking for both banking tasks. This illustrates why banks should try to increase consumers' perceptions of the task-channel fit. If banks understand how to improve customers' perceptions of the task-channel fit (detailed recommendations were provided in section 7.4.1.-7.4.8.), consumers' perceptions of the usefulness of online banking for both banking tasks should improve as well. The coefficients between the TCF construct and perceived usefulness were all relatively high and they were statistically significant independent of the TCF conceptualization or the banking task. 


\subsubsection{H2: TCF $\rightarrow$ Intentions to use.}

This hypothesis was disconfirmed by the data collected during the pilot and the main study. This was surprising since it was reasonable to assume that consumers who see Internet banking as well suited for account inquiries/financial loan applications would also form intentions to use that given channel for these banking tasks. Table 137 summarizes the findings of the pilot and main study for the second hypothesis.

Table 137: Summary of the research findings: Hypothesis 2 (TCF-->INT)

\begin{tabular}{|c|c|c|c|}
\hline \multicolumn{2}{|c|}{ TCF $\rightarrow$ INT } & Financial Loans & Account inquiries \\
\hline \multirow{3}{*}{ Pilot test } & Individual moderation scores & Coefficient: -0.02 & Coefficient: 0.05 \\
\cline { 2 - 4 } & Mean moderation scores & Coefficient: -0.08 & Coefficient: 0.05 \\
\hline Main Study & Individual moderation scores & Coefficient: 0.09 & Coefficient: $0.25^{*}$ \\
\cline { 2 - 4 } & Mean moderation scores & Coefficient: 0.02 & Coefficient: $0.18^{*}$ \\
\cline { 2 - 4 } & Individual moderation scores & Complete dataset & Coefficient: $0.13^{* *}$ \\
\cline { 2 - 4 } & Mean moderation scores & Complete dataset & Coefficient: 0.07 \\
\hline
\end{tabular}

While there was no statistical evidence for a direct correlation, banks should still aim to positively influence consumers' perceptions of the task-channel fit. Given the strong influence of TCF on perceived usefulness and attitude towards channel use, it is reasonable to assume that consumers' intentions to use Internet banking for these products are indirectly influenced by their perceptions of the task-channel fit.

\subsubsection{H3: TCF $\rightarrow$ Attitudes towards channel use.}

The datasets confirmed that consumers' attitudes towards Internet banking for account inquiries/financial loans were highly influenced by consumers' perceptions of the taskchannel fit. The correlation coefficients were high, reflecting the strong influence of taskchannel fit on consumers' attitudes towards Internet banking.

Table 138: Summary of the research findings: Hypothesis 3 (TCF-->ATT)

\begin{tabular}{|c|c|c|c|}
\hline \multicolumn{2}{|c|}{ TCF $\rightarrow$ ATT } & Financial Loans & Account inquiries \\
\hline \multirow{3}{*}{ Pilot test } & Individual moderation scores & Coefficient: $0.32^{* * *}$ & Coefficient: $0.62^{* * *}$ \\
\cline { 2 - 4 } & Mean moderation scores & Coefficient: $0.37 * *$ & Coefficient: $0.62^{* * *}$ \\
\hline Main Study & Individual moderation scores & Coefficient: $0.43^{* * *}$ & Coefficient: $0.69^{* * *}$ \\
\cline { 2 - 4 } & Mean moderation scores & Coefficient: $0.47^{* * *}$ & Coefficient: $0.66^{* * *}$ \\
\cline { 2 - 4 } & Individual moderation scores & Complete dataset & Coefficient: $0.68^{* * *}$ \\
\cline { 2 - 4 } & Mean moderation scores & Complete dataset & Coefficient: $0.68^{* * *}$ \\
\hline
\end{tabular}

This is important to understand for banks since consumers' attitudes influenced their intentions to use Internet banking for account inquiries/financial loan applications. Thus, banks should try to positively influence consumers' perceptions of the task-channel fit. The data clearly showed that higher levels of perceived task-channel fit led to more positive attitudes regarding Internet banking to perform both banking tasks. 


\subsubsection{H4: Perceived usefulness $\rightarrow$ Intentions to use.}

The findings for hypothesis 4 were surprising since it was unclear if consumers' intentions to use Internet banking for account inquiries/financial loans would be truly influenced by consumers' perceived usefulness of Internet banking for these banking tasks. The analyzes for the financial loan dataset revealed that perceived usefulness did not significantly impact on consumers intentions to use Internet banking during the pilot study - the opposite was the case when inspecting the account inquiries sub-dataset. If considering the data collected for the main study, the account inquiries sub-dataset produced insignificant path coefficients whereas the same coefficients were significant in the financial loan dataset.

Table 139 summarized the results obtained for hypothesis 4 .

Table 139: Summary of the research findings: Hypothesis 4 (PU-->INT)

\begin{tabular}{|c|c|c|c|}
\hline \multicolumn{2}{|c|}{ PU $\rightarrow$ INT } & Financial Loans & Account inquiries \\
\hline \multirow{3}{*}{ Pilot test } & Individual moderation scores & Coefficient: 0.02 & Coefficient: $0.36^{* *}$ \\
\cline { 2 - 4 } & Mean moderation scores & Coefficient: 0.05 & Coefficient: $0.42^{* *}$ \\
\hline Main Study & Individual moderation scores & Coefficient: $0.18^{*}$ & Coefficient: -0.04 \\
\cline { 2 - 4 } & Mean moderation scores & Coefficient: $0.19^{*}$ & Coefficient: -0.04 \\
\cline { 2 - 4 } & Individual moderation scores & Complete dataset & Coefficient: $0.13^{*}$ \\
\cline { 2 - 4 } & Mean moderation scores & Complete dataset & Coefficient: $0.14^{*}$ \\
\hline
\end{tabular}

These inconsistent findings indicated that further research is required to confirm/disconfirm this hypothesis. Given that the path coefficients were statistically significant when inspecting the complete dataset (in combination with the strong theoretical evidence for this hypothesis), banks should still try to increase consumers' perceived usefulness for both banking transactions. This could then positively influence consumers' intentions to use Internet banking for these banking transactions.

\subsubsection{H5a: Perceived ease of use $\rightarrow$ Intentions to use.}

Given the findings for hypothesis five, it is reasonable to conclude that consumers' intentions to use Internet banking for account inquiries/financial loan applications are positively influenced by their perceived ease of use of the channel. Table 140 summarizes the findings for this hypothesis.

Table 140: Summary of the research findings: Hypothesis 5a (EOU-->INT)

\begin{tabular}{|c|c|c|c|}
\hline \multicolumn{2}{|c|}{ EOU $\rightarrow$ INT } & Financial Loans & Account inquiries \\
\hline \multirow{3}{*}{ Pilot test } & Individual moderation scores & Coefficient: $0.30^{* *}$ & Coefficient: $0.16^{*}$ \\
\cline { 2 - 4 } & Mean moderation scores & Coefficient: $0.30^{* *}$ & Coefficient: $0.12^{*}$ \\
\hline \multirow{3}{*}{ Main Study } & Individual moderation scores & Coefficient: 0.06 & Coefficient: $0.41^{* *}$ \\
\cline { 2 - 4 } & Mean moderation scores & Coefficient: $0.09^{*}$ & Coefficient: $0.44^{* *}$ \\
\cline { 2 - 4 } & Individual moderation scores & Complete dataset & Coefficient: $0.18^{* *}$ \\
\cline { 2 - 4 } & Mean moderation scores & Complete dataset & Coefficient: $0.21^{* *}$ \\
\hline
\end{tabular}


Banks should, therefore, aim to improve the usability of Internet banking applications. The findings of the main study suggested that this would be particularly important for account inquiries since it would strongly influence consumers' intentions to use Internet banking for checking their account balances online.

\subsubsection{H5b: Perceived ease of use $\rightarrow$ Perceived usefulness.}

The data showed that the perceived ease of use construct strongly influenced the perceived usefulness construct independent of the dataset/TCF modeling approach. This suggests that consumers' perceive more advantages in using an electronic banking channel if they believe that the channel is easy to use. Table 141 lists the path coefficients obtained for hypothesis $5 \mathrm{~b}$.

Table 141: Summary of the research findings: Hypothesis 5b (EOU-->PU)

\begin{tabular}{|c|c|c|c|}
\hline \multicolumn{2}{|c|}{ EOU $\rightarrow$ PU } & Financial Loans & Account inquiries \\
\hline \multirow{3}{*}{ Pilot test } & Individual moderation scores & Coefficient: $0.57 * * *$ & Coefficient: $0.45^{* * *}$ \\
\cline { 2 - 4 } & Mean moderation scores & Coefficient: $0.54 * * *$ & Coefficient: $0.54 * * *$ \\
\hline \multirow{3}{*}{ Main Study } & Individual moderation scores & Coefficient: $0.54 * * *$ & Coefficient: $0.58^{* * *} *$ \\
\cline { 2 - 4 } & Mean moderation scores & Coefficient: $0.55^{* * *} *$ & Coefficient: $0.57 * * *$ \\
\cline { 2 - 4 } & Individual moderation scores & Complete dataset & Coefficient: $0.59^{* * *}$ \\
\cline { 2 - 4 } & Mean moderation scores & Complete dataset & Coefficient: $0.59^{* * *}$ \\
\hline
\end{tabular}

Banks should therefore aim to improve the usability of electronic banking channels (with regards to account inquiries/financial loans).

\subsubsection{H6: Attitude $\rightarrow$ Intentions to use.}

Consumers' attitudes towards Internet banking for financial loan applications/account inquiries positively impacted on their intentions to use Internet banking for these banking tasks. Table 142 outlines the structural path coefficients for the sixth hypothesis.

Table 142: Summary of the research findings: Hypothesis 6 (ATT-->INT)

\begin{tabular}{|c|c|c|c|}
\hline \multicolumn{2}{|c|}{ ATT $\rightarrow$ INT } & Financial Loans & Account inquiries \\
\hline \multirow{3}{*}{ Pilot test } & Individual moderation scores & Coefficient: $0.46^{* * *}$ & Coefficient: $0.33^{* *}$ \\
\cline { 2 - 4 } & Mean moderation scores & Coefficient: $0.45^{* * *}$ & Coefficient: $0.28^{* *}$ \\
\hline \multirow{3}{*}{ Main Study } & Individual moderation scores & Coefficient: $0.39^{* * *}$ & Coefficient: 0.13 \\
\cline { 2 - 4 } & Mean moderation scores & Coefficient: $0.40^{* * *}$ & Coefficient: $0.15^{*}$ \\
\cline { 2 - 4 } & Individual moderation scores & Complete dataset & Coefficient: $0.34^{* * *}$ \\
\cline { 2 - 4 } & Mean moderation scores & Complete dataset & Coefficient: $0.34 * *$ \\
\hline
\end{tabular}

Hence, banks should pursue strategies to positively influence consumers' attitudes towards electronic banking channels (given the high influence of TCF on attitude towards Internet banking for both banking tasks, banks could follow the recommendations made related to the TCF construct - see previous sections). It is noteworthy that the influence of consumers' attitudes on their intentions to use Internet banking was higher in the financial loan subdataset. 


\subsubsection{H7: Subjective norms $\rightarrow$ Intentions to use.}

Hypothesis 7 was confirmed for the financial loan sub-dataset but not for account inquiries. This suggested that consumers' normative beliefs regarding the opinion of others influenced their intentions to apply for financial loans online. On the other hand, the respondents indicated that they did not feel influenced by others when performing account inquiries on Internet banking applications. Table 143 lists the findings for the seventh hypothesis.

Table 143: Summary of the research findings: Hypothesis 7 (SN-->INT)

\begin{tabular}{|c|c|c|c|}
\hline \multicolumn{2}{|c|}{ SN $\rightarrow$ INT } & Financial Loans & Account inquiries \\
\hline \multirow{3}{*}{ Pilot test } & Individual moderation scores & Coefficient: $0.12^{*}$ & Coefficient: -0.01 \\
\cline { 2 - 4 } & Mean moderation scores & Coefficient: $0.12^{*}$ & Coefficient: -0.01 \\
\hline \multirow{3}{*}{ Main Study } & Individual moderation scores & Coefficient: $0.10^{*}$ & Coefficient: -0.04 \\
\cline { 2 - 4 } & Mean moderation scores & Coefficient: $0.12^{*}$ & Coefficient: -0.04 \\
\cline { 2 - 4 } & Individual moderation scores & Complete dataset & Coefficient: $0.05^{*}$ \\
\cline { 2 - 4 } & Mean moderation scores & Complete dataset & Coefficient: 0.06 \\
\hline
\end{tabular}

Banks could use this information and try to positively influence consumers' subjective norms. This could be possibly achieved through setting up TV/Radio/Newspaper advertisements in which they advertise loan applications via online banking. Such word of mouth marketing campaigns could positively impact on consumers' subjective norms regarding Internet banking and financial loans.

\subsubsection{H8: Perceived security $\rightarrow$ Intentions to use.}

Perceived security positively influenced consumers' intentions to use Internet banking for financial loan applications but not for account inquiries. The path coefficients for hypothesis eight were consistently high for the financial loan dataset ranging between 0.21 and 0.22 in the pilot/main study of this research. In contrast, the coefficients were low in the account inquires dataset indicating that consumers were less security aware when checking their account balance online. Table 144 summarizes the findings made for the eighth hypothesis.

Table 144: Summary of the research findings: Hypothesis 8 (SEC-->INT)

\begin{tabular}{|c|c|c|c|}
\hline \multicolumn{2}{|c|}{ SEC $\rightarrow$ INT } & Financial Loans & Account inquiries \\
\hline \multirow{3}{*}{ Pilot test } & Individual moderation scores & Coefficient: $0.21^{* * *}$ & Coefficient: 0.01 \\
\cline { 2 - 4 } & Mean moderation scores & Coefficient: $0.22^{* * *}$ & Coefficient: 0.02 \\
\hline \multirow{3}{*}{ Main Study } & Individual moderation scores & Coefficient: $0.22^{*}$ & Coefficient: 0.08 \\
\cline { 2 - 4 } & Mean moderation scores & Coefficient: $0.21^{*}$ & Coefficient: 0.08 \\
\cline { 2 - 4 } & Individual moderation scores & Complete dataset & Coefficient: $0.16^{* *}$ \\
\cline { 2 - 4 } & Mean moderation scores & Complete dataset & Coefficient: $0.16^{*}$ \\
\hline
\end{tabular}

Banks could use this information to promote the security mechanisms of online loan applications. Perhaps security signs or logos on those websites where consumers read about financial loans would positively impact on their security perceptions regarding these banking tasks. 


\subsubsection{H9: Costs associated with use $\rightarrow$ Intentions to use.}

Overall, the costs associated with channel use construct consistently impacted negative on consumers' intentions to use Internet banking for financial loan applications/account inquiries - but not statistically significant. This suggested that consumers were not particularly cost aware when performing both transaction types via Internet banking applications. Table 145 summarizes the findings for the ninth hypothesis.

Table 145: Summary of the research findings: Hypothesis 9 (COST-->INT)

\begin{tabular}{|c|c|c|c|}
\hline \multicolumn{2}{|c|}{ COST $\rightarrow$ INT } & Financial Loans & Account inquiries \\
\hline \multirow{3}{*}{ Pilot test } & Individual moderation scores & Coefficient: -0.02 & Coefficient: -0.07 \\
\cline { 2 - 4 } & Mean moderation scores & Coefficient: -0.03 & Coefficient: -0.08 \\
\hline \multirow{3}{*}{ Main Study } & Individual moderation scores & Coefficient: -0.08 & Coefficient: -0.12 \\
\cline { 2 - 4 } & Mean moderation scores & Coefficient: $-0.09^{* *}$ & Coefficient: -0.12 \\
\cline { 2 - 4 } & Individual moderation scores & Complete dataset & Coefficient: -0.06 \\
\cline { 2 - 4 } & Mean moderation scores & Complete dataset & Coefficient: -0.06 \\
\hline
\end{tabular}

Overall, the foregoing discussion shows that the task-channel fit dimensions allowed specific recommendations for practitioners. This was due to the fact that TCF was measured precisely and several dimensions were specified to determine the overall TCF construct. On the other hand, the remaining constructs of the research model were more general and they were based on the traditional IS utilization theories. Unless specifying these construct more detailed (e.g. using several unique variables/dimensions to better comprehend perceived usefulness as outlined in TAM2), it is difficult to provide specific managerial recommendations. It seems to be essential for banking managers to know that perceived ease of use is a positive predictor for perceived usefulness and intentions to use Internet banking for account inquiries/financial loan applications. However, banking managers still have to figure out how to improve the perceived ease of use of Internet banking for both banking tasks. This illustrates why IS utilization research should move on with more precise research models in future. The well established traditional constructs (ease of use, perceived usefulness, attitude towards systems use, subjective norms etc.) are helpful as they can be used as the theoretical base in future research attempts in this area.

\subsection{Chapter summary}

This chapter discussed the implications of this research. The current study should be interesting for three major audiences.

First, researchers studying Information Systems utilization at the individual level should be intrigued by the research design and findings. This study is among few utilization studies that has specifically integrated Burton-Jones and Straub's (2006) three major components of IS 
utilization including the user, the IS artifact, and tasks. By doing so, the research has arguably produced a more precise model than traditional IS utilization theories and task-channel fit theory revolves around the IT artifact and tasks users perform to achieve their goals.

Second, this research should be of interest to researchers studying task-technology fit. The second section of this chapter outlined that there was no coherent understanding among IS researchers of how to best measure task-technology fit. This research presented a new approach drawing from earlier studies on fit-theory and strategic alignment.

Thirdly, practitioners working for financial institutions and banks should benefit from the research findings. Specific recommendations were made for managers who are involved with the service and product distribution via electronic banking channels.

The next chapter concludes this thesis. 


\section{Conclusion}

\subsection{Chapter Outline}

The last chapter of this thesis concludes the dissertation. First, a brief overview of the research process, from the identification of the research gap to a summary of the main findings, is presented. Subsequently, the contributions of the research, both in terms of academic value and practitioner value are identified and discussed. The delimitation and limitations of the research are then considered. Finally, directions for future research are explored.

\subsection{Overview of the Research}

\subsubsection{Research Gap}

Electronic banking channels have been deployed by banks for more than three decades. The literature review revealed that research on information systems/marketing has not developed a theory assessing the factors influencing consumers' intentions to use electronic banking channel in combination with the perceived task-channel fit of electronic banking channels. Given this research gap, the overarching research question guiding this study was stated as: What factors influence consumer intentions to use electronic banking channels?

\subsubsection{Research Objectives}

While much research has been developed around the adoption and utilization of electronic banking channels, it appeared that there was a lack of understanding of why consumers use specific electronic banking channels in combination with certain banking tasks. The current utilization rates for each electronic banking channel suggested that consumers view certain electronic banking channels as more suited than other for specific banking tasks. Furthermore, it seemed reasonable to assume that the better the perceived 'fit' between an electronic banking channel and banking task, the higher would be the utilization of the channel/task combination.

Thus, this research developed a conceptual research model based on Goodhue and Thompson's (1995) task-technology fit theory. Central to the conceptual research model was the task-channel fit construct which was defined as the user's perception of the suitability of a particular electronic banking channel to support a particular banking task.

Based on existing literature and the research findings of the focus group discussions, it was hypothesized that 
- The perceived task-channel fit of electronic banking channels impacts on consumers' perceptions of the usefulness of a given electronic banking channel for a particular banking task.

- The perceived task-channel fit of electronic banking channels impacts on consumers' attitudes towards a given electronic banking channel for a particular banking task.

- The perceived task-channel fit of electronic banking channels impacts on consumers' intentions to use a given electronic banking channels for a particular banking task.

- Several other precursors of utilization impact on consumers' intentions to use electronic banking channels to perform banking tasks.

Table 146 summarizes the findings for all hypothesis investigated during the pilot and the main study of this research.

Table 146: Summary of the hypotheses investigated by this study

\begin{tabular}{|c|c|c|c|c|c|c|c|c|c|c|c|}
\hline \multirow{3}{*}{\multicolumn{2}{|c|}{ Hypothesis }} & \multicolumn{4}{|c|}{ Pilot study } & \multicolumn{6}{|c|}{ Main study } \\
\hline & & \multicolumn{2}{|c|}{$\begin{array}{l}\text { Financial } \\
\text { Loans }\end{array}$} & \multicolumn{2}{|c|}{$\begin{array}{l}\text { Account } \\
\text { Inquiries }\end{array}$} & \multicolumn{2}{|c|}{$\begin{array}{c}\text { Complete } \\
\text { dataset }\end{array}$} & \multicolumn{2}{|c|}{$\begin{array}{c}\text { Financial } \\
\text { Loans }\end{array}$} & \multicolumn{2}{|c|}{$\begin{array}{l}\text { Account } \\
\text { Inquiries }\end{array}$} \\
\hline & & $\begin{array}{c}\text { (indivi } \\
\text { dual } \\
\text { moder } \\
\text { ation } \\
\text { scores) } \\
\end{array}$ & $\begin{array}{c}\text { (avera } \\
\text { ge } \\
\text { moder } \\
\text { ation } \\
\text { scores) } \\
\end{array}$ & $\begin{array}{c}\text { (indivi } \\
\text { dual } \\
\text { moder } \\
\text { ation } \\
\text { scores) } \\
\end{array}$ & $\begin{array}{l}\text { (aver } \\
\text { age } \\
\text { mode } \\
\text { ration } \\
\text { score } \\
\text { s) }\end{array}$ & $\begin{array}{c}\text { (individ } \\
\text { ual } \\
\text { modera } \\
\text { tion } \\
\text { scores) } \\
\end{array}$ & $\begin{array}{c}\text { (avera } \\
\text { ge } \\
\text { moder } \\
\text { ation } \\
\text { scores) } \\
\end{array}$ & $\begin{array}{l}\text { (indivi } \\
\text { dual } \\
\text { moder } \\
\text { ation } \\
\text { scores) } \\
\end{array}$ & $\begin{array}{c}\text { (avera } \\
\text { ge } \\
\text { moder } \\
\text { ation } \\
\text { scores) } \\
\end{array}$ & $\begin{array}{c}\text { (indivi } \\
\text { dual } \\
\text { moder } \\
\text { ation } \\
\text { scores) } \\
\end{array}$ & $\begin{array}{c}\text { (avera } \\
\text { ge } \\
\text { moder } \\
\text { ation } \\
\text { scores) }\end{array}$ \\
\hline H1 & $\mathrm{TCF} \rightarrow \mathrm{PU}$ & + & + & + & + & + & + & + & + & + & + \\
\hline $\mathbf{H} 2$ & TCF $\rightarrow$ INT & - & - & - & - & + & - & - & - & + & + \\
\hline H3 & $\mathbf{T C F} \rightarrow \mathbf{A T T}$ & + & + & + & + & + & + & + & + & + & + \\
\hline H4 & PU $\rightarrow$ INT & - & - & + & + & + & + & + & + & - & - \\
\hline H5a & EOU $\rightarrow$ INT & + & + & + & + & + & + & - & + & + & + \\
\hline H5b & EOU $\rightarrow$ PU & + & + & + & + & + & + & + & + & + & + \\
\hline H6 & ATT $\rightarrow$ INT & + & + & + & + & + & + & + & + & - & + \\
\hline H7 & $\mathrm{SN} \rightarrow \mathrm{INT}$ & + & + & - & - & + & - & + & + & - & - \\
\hline H8 & SEC $\rightarrow$ INT & + & + & - & - & + & + & + & + & - & - \\
\hline H9 & $\mathrm{COST} \rightarrow \mathrm{INT}$ & - & - & - & - & - & - & - & + & - & - \\
\hline
\end{tabular}

Another objective of this study was the conceptualization and measurement of the taskchannel fit construct. The literature around task-technology fit theory suggested that there was no coherent approach for computing the fit between tasks and technologies. Thus, literature on strategic alignment and fit theory was analyzed and it was decided to formatively measure 
the TCF construct using several unique dimensions determining the TCF construct. To operationalize the TCF construct, a parallel instrument was developed using fit as moderation to align the obtained parallel scores.

\subsubsection{The Research Design}

Initially, a comprehensive literature review was completed to identify the research gap around the concept of task-channel fit of electronic banking channels. Subsequently, a relevance check was performed to ensure that the outcome of this research project is valuable to practitioners. Overall, the discussions with German banking managers indicated that the research participants perceived TCF as a valuable concept for banks. The results also confirmed that the interviewed managers did not have any analytical approaches for determining which product category to distribute via each electronic banking channel.

Next, five focus groups consisting of New Zealand consumers were conducted to confirm the conceptual research model. Overall, the focus group discussions re-affirmed that consumers' intentions to use electronic banking channels are influenced by task-channel fit and multiple alternative precursors of channel utilization.

The quantitative phase of this research consisted of two stages. The first stage aimed to conduct a pilot study of the developed survey questionnaire instrument and to initially inspect the quality of the conceptual research model. For the pilot study, 280 usable responses (140 for financial loans and 140 for account inquiries) were collected from staff and students at Victoria University of Wellington using Internet banking to manage account inquiries and financial loan applications.

Next, the scales were refined in light of the pilot study and then used during the main study. For the main study 340 responses were collected through a consumer panel consisting of New Zealand consumers using Internet banking for their personal finances. PLS was used to assess the measurement and structural research models during the pilot and main study.

\subsubsection{The Research Findings and Model Evaluation}

Overall, the scales demonstrated construct validity and the measures were found to be highly reliable. What is more, most hypotheses were confirmed by the data obtained for the pilot and main studies, and the TCF construct and other antecedents of consumer' intentions to use Internet banking explained at least $63 \%$ of variance in the dependent variable (independent of using individual or average moderation scores to evaluate the task-channel fit construct). The high predictive validity of the research model is supported by Table 147 
listing the variances explained in the three constructs perceived ease of use, attitude towards use, and intention to use.

Table 147: Summary of the r-square values explained by each construct

\begin{tabular}{|c|c|c|c|c|}
\hline & & $\begin{array}{l}\text { Perceived } \\
\text { usefulness }\end{array}$ & $\begin{array}{l}\text { Attitude } \\
\text { towards use }\end{array}$ & $\begin{array}{l}\text { Intentions to } \\
\text { use }\end{array}$ \\
\hline \multirow{4}{*}{$\begin{array}{l}\text { Pilot } \\
\text { study }\end{array}$} & $\begin{array}{l}\text { Financial Loans } \\
\text { (individual moderation scores) }\end{array}$ & $\left(\mathrm{R}^{2}=0.501\right)$ & $\left(\mathrm{R}^{2}=0.190\right)$ & $\left(\mathrm{R}^{2}=0.720\right)$ \\
\hline & $\begin{array}{l}\text { Financial Loans } \\
\text { (average moderation scores) }\end{array}$ & $\left(\mathrm{R}^{2}=0.462\right)$ & $\left(\mathrm{R}^{2}=0.135\right)$ & $\left(\mathrm{R}^{2}=0.722\right)$ \\
\hline & $\begin{array}{l}\text { Account inquiries } \\
\text { (individual moderation scores) }\end{array}$ & $\left(\mathrm{R}^{2}=0.531\right)$ & $\left(\mathrm{R}^{2}=0.381\right)$ & $\left(\mathrm{R}^{2}=0.702\right)$ \\
\hline & $\begin{array}{l}\text { Account inquiries } \\
\text { (average moderation scores) }\end{array}$ & $\left(\mathrm{R}^{2}=0.530\right)$ & $\left(\mathrm{R}^{2}=0.386\right)$ & $\left(\mathrm{R}^{2}=0.701\right)$ \\
\hline \multirow{6}{*}{$\begin{array}{l}\text { Main } \\
\text { study }\end{array}$} & $\begin{array}{l}\text { Complete dataset } \\
\text { (individual moderation scores) }\end{array}$ & $\left(\mathrm{R}^{2}=0.645\right)$ & $\left(\mathrm{R}^{2}=0.465\right)$ & $\left(\mathrm{R}^{2}=0.776\right)$ \\
\hline & $\begin{array}{l}\text { Complete dataset } \\
\text { (average moderation scores) }\end{array}$ & $\left(\mathrm{R}^{2}=0.646\right)$ & $\left(R^{2}=0.465\right)$ & $\left(\mathrm{R}^{2}=0.771\right)$ \\
\hline & $\begin{array}{l}\text { Financial Loans } \\
\text { (individual moderation scores) }\end{array}$ & $\left(\mathrm{R}^{2}=0.473\right)$ & $\left(\mathrm{R}^{2}=0.183\right)$ & $\left(\mathrm{R}^{2}=0.745\right)$ \\
\hline & $\begin{array}{l}\text { Financial Loans } \\
\text { (average moderation scores) }\end{array}$ & $\left(\mathrm{R}^{2}=0.461\right)$ & $\left(\mathrm{R}^{2}=0.222\right)$ & $\left(\mathrm{R}^{2}=0.741\right)$ \\
\hline & $\begin{array}{l}\text { Account inquiries } \\
\text { (individual moderation scores) }\end{array}$ & $\left(\mathrm{R}^{2}=0.648\right)$ & $\left(\mathrm{R}^{2}=0.478\right)$ & $\left(\mathrm{R}^{2}=0.645\right)$ \\
\hline & $\begin{array}{l}\text { Account inquiries } \\
\text { (average moderation scores) }\end{array}$ & $\left(\mathrm{R}^{2}=0.652\right)$ & $\left(\mathrm{R}^{2}=0.438\right)$ & $\left(\mathrm{R}^{2}=0.636\right)$ \\
\hline
\end{tabular}

In line with previous research on task-technology fit theory, the task-channel fit construct positively impacted on consumers' perceived usefulness of Internet banking for both banking tasks (account inquiries and financial loans). Further, the perceived task-channel fit of electronic banking strongly influenced consumers attitudes towards Internet banking for both banking tasks.

\subsection{Contributions of the Research}

This research investigated an important conceptual issue which also has significant practical value for banks and financial institutions. The following section first highlights the key contributions of this study for academia before outlining how practitioners can benefit from this study.

\subsubsection{Theoretical value}

An important theoretical contribution of this research was the development of a parsimonious model to measure the impact of task-channel fit and other precursors of utilization on consumers' intentions to use electronic banking channels. The measures developed to assess the quality of the research model demonstrated validity and reliability, irrespective of the task-channel fit conceptualization. This study extended the work of 
Goodhue and Thompson (1995) by adapting the TTF to examine not specific technologies, but rather delivery channels. The specific context was voluntary use of electronic banking channels at the individual level.

Another important feature of this research is that the research model was tested in taskspecific contexts. This design permitted testing the research model using two different subgroup datasets (account inquiries/financial loans). The group analyses demonstrated that there was a lack of structural invariance in the research model when comparing the responses for account inquiries and financial loans. These findings were surprising since most major IS research models were developed and tested without reference to specific task context. Thus, further research in this area is required to determine how essential it is to include tasks when developing and testing Information Systems theories.

\subsubsection{Construct and measurement value}

This study also contributes to construct specification and measurement.

Task-technology fit theory was originally developed to explain IS utilization within an organizational context characterized by involuntary use. So far, very little is known how this concept can be applied at the individual level (Staples and Seddon 2004). To address this shortcoming, this study developed and validated a survey questionnaire instrument to measure the TCF of electronic banking channels.

Further, the existing literature around TTF suggested that there was no coherent understanding of how to best determine fit between tasks and technologies. Borrowing from strategic alignment studies and fit theory, this research developed a parallel instrument to measure the perceived fit between banking tasks and electronic banking channels. This procedure demonstrated to be a reliable method to evaluate the task-channel fit construct. This approach should be also helpful for researchers aiming to assess task-technology fit in future studies.

\subsubsection{Practitioner value}

The most valuable contribution for practitioners from this research is the evidence that perceived task-channel fit strongly influences consumers' attitudes towards electronic banking as well as their perceptions of the usefulness of Internet banking for account inquiries/financial loans. The empirical data gathered in two collection rounds confirmed these hypotheses. 
The specification of several unique task-channel fit dimensions allowed making detailed recommendations for improving consumers perceptions of the task-channel fit. These suggestions should help financial institutions and banks to streamline the service and product provision via electronic banking channels.

The entire research model was tested in task-specific contexts. This research design led to actionable recommendations for practitioners. For instance, consumers were less security aware when checking their account balance online rather than applying for financial loans via Internet banking. This suggests that practitioners should carefully consider the banking task domain when designing electronic banking applications.

Lastly, this research also provides a validated and reliable survey questionnaire instrument. The survey questionnaire was cross-validated in two stages and tested with regards to Internet banking and account inquiries/financial loans. Practitioners who need to understand which banking products to offer via each electronic banking channel could use the survey tool to explore additional task/channel combinations.

\subsection{Delimitations of the Research}

This research focuses solely on electronic banking channels; neither traditional branch banking nor person-to-person telephone banking services were considered in the research model. However, future studies, could extend the TCF instrument to these traditional banking channels.

It is also noteworthy that this research purposefully tested the research model only in context of one electronic banking channel (Internet banking) in combination with two banking tasks (account inquiries/financial loans). Future studies should validate the task-channel fit theory in context of other electronic banking channels (e.g. ATMs, phone and mobile banking).

\subsection{Limitations of the Research}

This study faces several potential limitations. The data used to test the hypotheses were cross-sectional, so causality can only be inferred, not proven. Future studies may be conducted in a longitudinal fashion, which would make possible stronger causal conclusions.

There are also potential sources of error when executing survey research. These errors include measurement error, sampling error, internal validity error, and statistical conclusion error (Straub 1989). This research was cognizant of these errors and attempted to mitigate them by using commonly accepted methods such as judgment rounds, a pilot study and 
several pretests to develop the survey instrument thoroughly. In addition, statistical techniques including confirmatory factor analysis and structural equation modeling assessed the validity of the survey instrument.

The confirmatory factor analyses results of the pilot and main study lead to high crossloadings among theoretically well-established constructs such as perceived usefulness, attitudes towards use, and intentions towards use. These findings indicate that the respondents did not interpret these variables as conceptually different (Gefen, Straub et al. 2000; Straub, Boudreau et al. 2004). While theory suggests that these constructs are conceptually different, future studies should shed more light into this issue.

A concern might be raised about the research sample being comprised of New Zealanders, and the consequent generalizability of the findings to other countries. Financial systems and technology infrastructures (e.g. availability of broadband Internet) vary across countries and regions around the world. Thus, it is likely that consumers' perceptions of the task-channel fit also vary between countries.

Another limitation of this study is that some of the task-channel fit dimensions did not contribute significantly to the TCF construct. This was despite the fact that theoretical evidence suggested these facets to be important for the perceived task-channel fit construct.

The formative TCF scores were computed using the fit as moderation perspective as outlined by Venkatraman (1989). While many researchers have successfully employed this technique (Prescott 1986; Goodhue 1995; Chan, Huff et al. 1997; Dishaw and Strong 1999; Parker and Van Witteloostuijn 2010), there are some shortcomings associated with moderation approaches. For instance, low-high and high-low response combinations for the parallel instrument lead to the same moderation scores since the scores obtained for the parallel items are determined through a simple multiplication technique. However, as outlined in section 5.2., each fit computation approach includes positive and negative attributes. In light of this study, the fit as moderation perspective appeared to be the most appropriate technique.

Lastly, while the use of Partial Least Squares modeling is widely accepted among the Information Systems research community (Qureshi and Compeau 2009), recent studies have questioned the efficacy of statistical significant tests in PLS for analyzing structural path models (Rönkkö and Ylitalo 2010). Rönkkö and Ylitalo (2010) found that the computing techniques underlying PLS are not fully capable to detect measurement error in the analysis 
results. Further studies would be required to test this assumption (Rönkkö and Ylitalo 2010). The findings of this study should be viewed in this light.

\subsection{Directions for Future Research}

\subsubsection{Testing the task-channel fit theory in different industries and countries}

As part of the relevance checks conducted as part of the current study, a CIO of a major airline company in Germany was interviewed using similar questions that were employed during the interviews with senior bank managers. The main purpose of the conversation was to inquire if task-channel fit theory would be an interesting tool for airlines as well. The faceto-face interview lasted approximately one hour and the manager confirmed that airlines could be interested in such a measure since airlines invest into similar electronically mediated selfservice channels as banks. Therefore, future studies could test the task-channel fit theory in different research contexts including the airline industry. Furthermore, it would be also interesting to test the boundaries of task-channel fit theory in another country.

\subsubsection{Extending the task-channel fit theory to the corporate banking environment}

Most commercial banks provide financial services to private and corporate clients. This thesis solely investigated the task-channel fit theory in a non-organizational context. Future studies should test if the TCF theory holds true in a corporate banking context. Corporate treasurers could be surveyed with regards to their perceptions of task-channel fit for banking transactions they perform for companies. This should be interesting since corporate banking transactions have distinct characteristics and should significantly differ from those consumers usually perform. For instance, companies who export goods and services overseas often require much more sophisticated banking products such as cross-currency swaps, letters of credits, guarantees, and/or asset backed securities. While very different in nature, these financial products should also vary alongside the developed task-channel fit dimensions. For instance, cross-currency swaps should be viewed as urgent since the timing of the purchase is a key aspect of the product. In contrast, letter of credits or guarantees often do not require immediate execution and they are normally planned well ahead by corporate treasurers. Asset backed securities are very complex banking transactions and it is likely that corporate treasurers require much support from a bank since these tasks are highly equivocal. Enterprises also perform less sophisticated tasks such as domestic transactions and account inquiries. Since these tasks are day-to-day tasks, it is likely that they are routinely performed 
whereas some of the aforementioned banking tasks are less often performed by corporate clients.

\subsubsection{Task driven theories}

The group comparison (account inquiries/financial loan applications) demonstrated that the banking tasks moderated the path coefficients conceptualized in the research model significantly. It seems that similar effects could occur if testing other existing IS theories in a task-centric fashion as well. For instance, TAM theory predicts that IS users' attitudes influence their intentions to use IS. In the current study, this path coefficient differed significantly between the account inquiries and the financial loan datasets (see Table 122). Likewise, TAM argues that perceived usefulness is influential for users' intentions to deploy IS. The group comparison affirmed that this path is also moderated by the tasks users perform. Further research seems to be essential since the vast majority of IS utilization theories ${ }^{37}$ do not consider a specific task context within their conceptual frameworks.

\subsubsection{Polynomial regression techniques in combination with surface response modeling}

Venkatesh and Goyal (2010) used polynomial regression techniques in combination with surface response modeling to advance IS continuance theory. These advanced mathematical applications were viewed as specifically useful to match a prioi users expectations with postexperience confirmations. The authors argued that "Polynomial modeling permits the examination of complex relationships between component measures and an outcome variable". These techniques could potentially address some of the major issues deviation score analysis/moderation scores generate. The data collected for this research could be investigated using polynomial regression techniques in combination with surface response modeling. Perhaps this could shed additional light into how best evaluate the perceived taskchannel fit of electronic banking channels.

\subsection{Chapter Summary}

The last chapter of the dissertation provided a brief overview and summarized some of the most important aspects of the research. The research gap, the research objective, the research design, and the research findings were revisited.

\footnotetext{
${ }^{37}$ Task-technology fit, cognitive fit and task-media fit are excluded from this assumption.
} 
The contributions of the research were then discussed, both with regard to the academic value of the research and the practitioner value. Next, the delimations and limitations of the research were outlined. Finally, directions for future research were identified and discussed. 


\section{References}

AC Nielsen. (2008). "New Zealand Consumer Finance Monitor." Retrieved 27.01., 2009, from http://nz.nielsen.com/news/CFM_Jun08.shtml.

Agarwal, R., S. Rastogi, et al. (2009). "Customers' perspectives regarding e-banking in an emerging economy." Journal of Retailing and Consumer Services May.

Ahmad, R. and F. Buttle (2002). "Retaining telephone banking customers at Frontier Bank " International Journal of Bank Marketing 20(1): 5-16.

Ajzen, I. (1991). "The Theory of Planned Behavior." Organizational Behavior and Human Decision Processes 50(2): 179-211.

Al-Ashban, A. and M. A. Burney (2001). "Customer adoption of tele-banking technology: The case of Saudi Arabia." International Journal of Bank Marketing 19(4/5): 191-200.

Al-Somali, A. S., R. Gholami, et al. (2008). "An investigation into the acceptance of online banking in Saudi Arabia." Technovation August(in Press).

Alam, S. S., A. Khatibi, et al. (2007). "Development and prospects of internet banking in Bangladesh." Competitiveness Review 17(1/2): 56-66.

Alavi, M. and P. Carlson (1992). " A Review of MIS Research and Disciplinary Development." Journal of Management Information Systems: JMIS 8(4 (Spring)): 4562.

Albesa, J. G. (2007). "Interaction channel choice in a multichannel environment, an empirical study." Internationl Journal of Bank Marketing 25(7): 490-506.

Almossawi, M. (2001). "Bank selection criteria employed by college students in Bahrain: An empirical analysis." The International Journal of Bank Marketing 19(3): 115.

Amin, H. (2007). "Internet Banking Adoption Among Young Intellectuals." Journal of Internet Banking and Commerce 12(3): 1-13.

Anderson, E. and B. A. Weitz (1986). "Make-or-buy decision: vertical integration and marketing productivity." Sloan Management Review 27(3): 3-19.

Antonides, G., H. B. Amesz, et al. (1999). "Adoption of payment systems in ten countries--a case study of diffusion of innovations." European Journal of Marketing 33(11/12): 1123-1135.

Bagozzi, R. P. (1982). "A Field Investigation of Causal Relations Among Cognitions, Affect, Intentions and Behavior." Journal of Marketing Research 19(November): 562-584.

Bagozzi, R. P. (2007). "The Legacy of the Technology Acceptance Model and a Proposal for a Paradigm Shift." Journal of the Association for Information Systems 8(4).

Balasubramanian, S. (1998). "Mail versus mall: a strategic analysis of competition between direct marketers and conventional retailers." Marketing Science 17(3): 181-195.

Balasubramanian, S., R. Raghunathan, et al. (2005). "Consumers in a multichannel environment: Product utility, process utility, and channel choice." Journal of Interactive Marketing 19(2): 12.

Barczak, G., P. E. Scholder, et al. (1997). "Developing typologies of consumer motives for use of technologically based banking services." Journal of Business Research 38(2): 131-139. 
Barki, H., S. Rivard, et al. (1993). "Toward an assessment of software development risk." Journal of Management Information Systems 10(2): 203-225.

Barnes, S. J. (2003). mBusiness: The Strategic Implications of Wireless Communications. Oxford, Elsevier/Butterworth-Heinemann.

Barnes, S. J. and B. Corbitt (2003). "Mobile banking: concept and potential." International Journal of Mobile Communications 1(3): 273-288.

Baroudi, J. J., M. H. Olson, et al. (1986). "An Empirical Study of the Impact of User Involvement on System Usage and Information Satisfaction." Communications of the

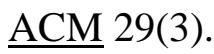

Benbasat, I. and H. Barki (2007). "Quo vadis, TAM?" Journal of the Association for Information Systems 8(4): 211-218.

Benbasat, I., A. S. Dexter, et al. (1986). "An experimental program investigating colorenhanced and graphical information presentation: an integration of the findings." Communications of the ACM 29(11): 1094-1105.

Benbasat, I., D. K. Goldstein, et al. (1987). "The case Research Strategy in Studies of Information Systems." MIS Quarterly: 369 - 386.

Benbasat, I. and R. Weber (1996). "Research commentary: Rethinking "diversity" in information systems research." Information Systems Research 7(4): 389.

Benbasat, I. and R. W. Zmud (2003). "The identity crisis within thee IS discipline: Defining and communicating the diciplines core properties." MIS Quarterly 27(2): 183-194.

Berman, B. (1996). Marketing Channels. New York, Wiley.

Bhattacherjee, A. (2001). "An empirical analysis of the antecedents of electronic commerce service continuance." Decision Support Systems 32: 201-214.

Bhattacherjee, A. (2001). "Understanding information systems continuance: an expectationconfirmation model." MIS Quarterly 25(3): 351-370.

Bhatti, T. (2007). "Exploring factors influencing the adoption of mobile commerce." Journal of Internet Banking and Commerce 12(3): 1-13.

Birch, G. (1999). "Mobile Financial Services: The internet isn't the only digital channel to consumers." Journal of Internet Banking and Commerce 4(1).

Black, N. J., A. Lockett, et al. (2002). "Modelling consumer choice of distribution channels: an illustration from financial services." Internationl Journal of Bank Marketing 20(4): 161-173.

Borreguero, F. J. M. and J. C. Peláez (2005). Spanish Mobile Banking Services: An Adoption Study. Proceedings of the Fourth International Conference on Mobile Business, Sydney, Australia, IEEE Computer Society.

Boudreau, M., D. Gefen, et al. (2001). "Validation in IS Research: A State-of-the-Art Assessment." MIS Quarterly 25(1 March,): 1-23.

Bradley, L. and K. Stewart (2002). "A delphi study of the drivers and inhibitors of Internet Banking." International Journal of Bank Marketing 20(6): 250-260.

Brannick, M. T., D. Chan, et al. (2010). "What is Method variance and How Can we Cope with It? A Panel Discussion." Organisational Research Methods 13(3): 407-420. 
Brown, I., Z. Cajee, et al. (2003). "Cell phone banking: predictors of adoption in South Africa-an exploratory study." International Journal of Information management 23: 381-394.

Burton-Jones, A. and D. Straub (2006). "Reconceptualizing System Usage: an Approach and Empirical Test." Information Systems Research 17(3): 228-246.

Buttermann, G., R. Germain, et al. (2008). "Contingency theory "fit" as gestalt: An application to supply chain management " Transportation Research Part E: Logistics and Transportation Review 44(6): 955-969.

Calder, B. J. (1977). "Focus Groups and the Nature of Qualitative Marketing Research." Journal of Marketing Research 14(3): 353-165.

Campbell, D. I. and K. Gingrich (1980). "The interactive effects of task complexity and participation on task performance: A field experiment." Organizational Behavior and Human Decision Processes(38): 162-180.

Campbell, D. J. (1984). "The effects of goal-contingent payment on the performance of a complex task." Personell Psychology 37: 23-40.

Campbell, D. J. (1988). "Task complexity: a review and analysis." Academy of Management Review 13(1): 40-52.

Carver, R. H. and J. G. Nash (2005). Doing data analysis with SPSS version 12. Southbank, Victoria, Australia, Thomson Learning.

Cavana, R. Y., B. L. Delahaye, et al. (2001). Applied Business Research: Qualitative and Quantitative Methods, John Wiley \& Sons.

Cenfetelli, R. T. and G. Bassellier (2009). "Interpretation of formative measurement in Information Systems Research." MIS Quarterly 33(4): 689-707.

Chan, C. C. H., A. W. K. Wong, et al. (2008). "Modified automatic teller machine prototype for older adults: A case study of participative approach to inclusive design." Applied Ergonomics May(2008).

Chan, S. C. and M. T. Lu (2004). "Understanding Internet Banking Adoption and Use Behavior: A Hong Kong Perspective." Journal of Global Information Management 12(3): 21-43.

Chan, Y. E. (1992). Business strategy, information systems strategy, and strategic fit: measurement and performance impacts. London, The University of Western Ontario. Doctor of Philosophy.

Chan, Y. E., S. Huff, et al. (1997). "Business Strategic Orientation, Information Systems Strategic Orientation, and Strategic Alignment." Information Systems Research 8(2): $125-150$.

Cheney, P. H., R. I. Mann, et al. (1986). "Organizational Factors Affecting the Success of End-User Computing." Journal of Management Information Systems 3(1): 65-80.

Cheng, T. C. E., D. Y. C. Lam, et al. (2006). "Adoption of internet banking: An empirical study in Hong Kong." Decision Support Systems 42(3): 1558-1572.

Chin, W. W. (1998). "(1) Issues and Opinion on Structural Equation Modeling." MIS Quarterly 22(1 (March)): vii-xvi.

Chin, W. (2010). How to write up and report PLS analyses. Handbook of Partial Least Sqares. Heidelberg, Springer. 
Choudhury, V. and E. Karahanna (2008). "The relative advantage of electronic channels: a multidimensional view." MIS Quarterly 32(1): 179-200.

Churchill, G. A., Jr. (1979). "A Paradigm for Developing Better Measures of Marketing Constructs." Journal of Marketing Research 16(1, February): 64-73.

Claessens, J., V. Dem, et al. (2002). "On the Security of Today's Online Electronic Banking Systems." Computers \& Security 3(1): 253-265.

Coley, K., S. Wright, et al. (1997). "Optimizing the usability of automated teller machines for older adults." Computers and Industrial Engineering 33(1-2): 209-212.

Compeau, D. R. and C. A. Higgins (1995). "Computer Self-Efficacy: Development of a Measure and Initial Test." MIS Quarterly 19(2): 189-211.

Compeau, D. R., C. A. Higgins, et al. (1999). "Social Cognitive Theory and Individual Reactions to Computing Technology: A Longitudinal Study." MIS Quarterly 23(2): 145-158.

Conrad, C. A., G. Brown, et al. (1997). "Customer satisfaction and corporate culture: A profile deviation analysis of a relationship marketing outcome." Psychology and Marketing 14(7): 663-674.

Conway, J. M. and A. I. Huffcutt (2003). "A review and evaluation of exploratory factor analysis practices in organizational research." Organizational Research Methods 6(2): 147-168.

Cooper, R. B. and R. Zmud (1990). "Information Technology implementation research: a technological diffusion approach." Management Science 36(2): 123-139.

Corrocher, N. (2006). "Internet adoption in Italian banks: An empirical investigation." Research Policy 35(4): 533-544.

Cote, J. A., \& Buckley, R (1987). "Estimating Trait, method and error variance: generalizing across 70 construct validation studies " Journal of Marketing Research 24 315-318.

Coventry, L., A. Angeli, et al. (2003). Usability and biometric verification at the ATM interface. Proceedings of the SIGCHI conference on Human factors in computing systems. Ft. Lauderdale, Florida, USA, ACM.

Creswell, J. W. (2003). Research Design: Qualitative, Quantitative, and Mixed Methods Approaches Lincoln-University of Nebraska.

Crotty, M. J. (1998). The Foundations of Social Research: Meaning and Perspective in the Research Process, SAGE Publications.

Curran, J. M. and M. L. Meuter (2005). "Self-service technology adoption: comparing three technologies." The Journal of Services Marketing 19(2): 103-113.

Curran, K. and D. King (2008). "Investigating the human computer interaction problems with automated teller machine navigation menus." Interactive Technology and Smart Education 5(1): 59-79.

D'Ambra, J. and R. E. Rice (2001). "Emerging factors in user evaluation of the World Wide Web." Information and Management 38(6): 373-384.

D'Ambra, J. and C. S. Wilson (2004). "Explaining perceived performance of the World Wide Web: uncertainty and the task-technology fit model." Internet Research 1(4): 294-310. 
D'Ambra, J. and C. S. Wilson (2004). "Use of the World Wide Web for international travel: Integrating the construct of uncertainty in information seeking and the task-technology fit (TTF) model." Journal of the American Society for Information Science and Technology 55(8): 731-742.

Dabholkar, P. A. and R. P. Bagozzi (2002). "An attitudinal model of technology-based selfservice: Moderating effects of consumer traits and situational factors." Academy of Marketing Science 30(3): 184.

Daft, R., R. Lengel, et al. (1987). "Message Equivocality, Media Selection, and Manager Performance: Implications for Information Systems." MIS Quarterly 11(3).

Daft, R. and R. H. Lengel (1986). "Organizational information requirements, media richness and structural design." Management Science 32(5): 554-571.

Daft, R. L. and N. B. Macintosh (1981). "Tentative Exploration into the Amount and Equivocality of Information Processing in Organizational Work Units." Administrative Science Quarterly 26: 207-224.

Davies, F., L. A. Moutinho, et al. (1996). "ATM user attitudes: a neural network analysis." Marketing Intelligence \& Planning 14(2): 26-32.

Davis, F. D. (1989). "Perceived Usefulness, Perceived Ease of Use, and User Acceptance of Information Technology." MIS Quarterly 13(3): 319-339.

Davis, F. D., R. P. Bagozzi, et al. (1989). "User Acceptance of Computer Technology: A Comparison of Two Theoretical Models." Management Science 35(8): 982-1002.

Davis, F. D., R. P. Bagozzi, et al. (1992). "Extrinsic and Intrinsic Motivation to Use Computers in the Workplace." Journal of Applied Social Psychology 22(14): 11111132.

DB Research. (2006). "DB research: Banking online boosts and curbs customer loyalty." Retrieved 13.04., 2009.

De, P., A. P. Sinha, et al. (2001). "An empirical investigation of factors influencing objectoriented database querying." Information Technology and Management 2(1).

Dean, D. H. (2008). "Shopper age and the use of self-service technologies." Managing Service Quality 18(3): 225-238.

Dennis, A. R. and T. A. Carte (1998). "Using geographical information systems for decision making: Extending cognitive fit theory to map-based presentations." Information System Research 9(2): 194-203.

Dennis, A. R., R. M. Fuller, et al. (2008). "Media, Task, and Communication Processes: A Theory of Media Synchronicity." MIS Quarterly 32(3): 575-600.

Dennis, A. R. and S. T. Kinney (1998). "Testing Media Richness Theory in the New Media: The Effects of Cues, Feedback, and Task Equivocality." Information Systems Research 9(3): 256-274.

Dennis, A. R. and J. S. Valacich (1999). Rethinking media richness: towards a theory of media synchronicity. 32nd Hawaii International Conference on System Sciences, Hawaii.

Dennis, A. R., B. H. Wixom, et al. (2001). "Understanding Fit and Appropriation Effects in Group Support Systems Via Meta-Analysis." MIS Quarterly 25(2): 167-193. 
Denzin, N. K. and Y. S. Lincoln (1994). Introduction: Entering the Field of Qualitative Research. Handbook of Qualitative Research. N. K. Denzin and Y. S. Lincoln. London, Sage: 1-18.

Diamantopoulos, A., P. Riefler, et al. (2008). "Advancing formative measurement models." Journal of Business Research 61: 1203-1218.

Diamantopoulos, A. and H. M. Winklhofer (2001). "Index Construction with Formative Indicators: An Alternative to Scale Development." Journal of Marketing Research 38(2): 269-277.

Dickson, G. W., G. DeSanctis, et al. (1986). "Understanding the effectiveness of computer graphics for decision support: a cumulative experimental approach." $\underline{\text { Communications }}$ of the ACM 29(1): 40-47.

Dishaw, M. T. and D. M. Strong (1998). "Assessing software maintenance tool utilization using task-technology fit and fitness-for-use models." Journal of Software Maintenance: Research and Practice 10(3): 151-179.

Dishaw, M. T. and D. M. Strong (1998). "Supporting software maintenance with software engineering tools: A Computed task-technology fit analysis." Journal of Systems and Software 44(2): 107-120.

Dishaw, M. T. and D. M. Strong (1999). "Extending the technology acceptance model with task-technology fit constructs." Information and Management 36(1): 9-21.

Doll, W. J. and G. Torkzadeh (1988). "The Measurement of End-User Computing Satisfaction: Theoretical and Methodological Issues." MIS Quarterly 15(1): 5-12.

Durkin, M. (2004). "In search of the Internet-banking customer: exploring the use of decision styles." International Journal of Bank Marketing 22(6/7): 484-502.

Durkin, M., D. Jennings, et al. (2008). "Key influencers and inhibitors on adoption of the Internet for banking." Journal of Retailing and Consumer Services 15(5): 348-357.

Eberl, M. (2010). An application of PLS in Multi-Group analysis: The need for differentiated corporate-level marketing in the mobile communication industry. Handbook of Partial Least Squares. V. E. Vinzi. Heidelberg, Springer Verlag: 487-514.

Edwards, J. E. (2001). "Ten Difference Score Myths." Operational Research Methods 4(3): 265-287.

El-Haddad, A. B. and A. A. Mohammed (1992). "ATM Banking Behaviour in Kuwait: A Consumer Survey." International Journal of Bank Marketing 10(3): 25-32.

Ensor, B. (2007). European Mobile Banking: An Inconvenient Truth. Forrester Research.

Eriksson, K., K. Kerem, et al. (2005). "Customer acceptance of internet banking in Estonia." The International Journal of Bank Marketing 23(2/3): 200-216.

Eriksson, K. and D. Nilsson (2007). "Determinants of the continued use of self-service technology: The case of Internet banking." Technovation 27(4): 159-167.

Evermann, J. and M. Tate (2009). Constructs in the Mist: The Lost World of the IT Artifact. International conference on Information Systems (ICIS), Phoenix.

Ferratt, T. W. and G. E. Vlahos (1998). "An investigation of task-technology fit for managers in Greece and the US." European Journal of Information Systems 7(2): 123-136. 
Field, A. P. (2009). Discovering statistics using SPSS :(and sex and drugs and rock 'n' roll). London, Sage.

Fishbein, M. and I. Ajzen (1975). Belief, Attitude, Intention and Behavior: An Introduction to Theory and Research. Addison-Wesley, Reading, MA.

Flavian, C., M. Guinaliu, et al. (2005). "The influence of corporate image on consumer trust: a comparative analysis in traditional versus internet banking." Internet Research 15(4): 447-470.

Fornell, C. and D. Larcker (1981). "Evaluating Structural Equation Models with Unobservable Variables and Measurement Error." Journal of Marketing Research 18: $39-50$.

Forrester Research (2007). European Mobile Banking: An Inconvenient Truth. Forrester $\underline{\text { Research. }}$

Forrester Research (2009) "Technographics survey highlight: Canadian online trust and mobile banking (Matiesanu, C.)."

Forsyth, A. M. (2004). "Lloyds TSB banks on call-center quality " Management 12(1): 14-16.

Frost and Sullivan (2011). How E*TRADE Boosted Customer Success by Tellme.

Frost, P. and T. Mahoney (1976). "Goal-setting and the task process: An interactive influence on individual performance." Organizational Behavior and Human Performance 17: 328-350.

Fuller, R. M. and A. R. Dennis (2009). "Does fit matter? The impact of task-technology fit and appropriation on team performance in repeated tasks." Information Systems Research 20(1): 2-17.

Gan, C., M. Clemens, et al. (2006). "A logit analysis of electronic banking in New Zealand." International Journal of Bank Marketing 24(6): 360-383.

Gattiker, T. F. and D. L. Goodhue (2005). "What happens after ERP implementation: understanding the impact of inter-dependence and differentiation on plant-level outcomes." MIS Quarterly 29(3): 559-585.

Gebauer, J. and Y. Tang (2008). "Applying the theory of task-technology fit to mobile technology: the role of user mobility." International Journal of Mobile Communications 6(3): 321-344.

Gefen, D. (2002). "Customer Loyalty in E-commerce." Journal of the Association for Information Systems 3(2002): 27-51.

Gefen, D., D. Straub, et al. (2000). "Structural Equation Modeling Techniques and Regression: Guidelines for Research Practice." Communications of AIS 7(7 August,): $1-78$.

Gefen, D. and D. W. Straub (2005). "A Practical Guide to Factorial Validity Using PLSGraph: Tutorial and Annotated Example." Communication of the AIS 16: 91-109.

Gerrard, P. and J. B. Cunningham (2003). "The diffusion of Internet banking among Singapore consumers." The International Journal of Bank Marketing 21(1): 16-28.

Gerrard, P., J. B. Cunningham, et al. (2006). "Why consumers are not using internet banking: a qualitative study." The Journal of Services Marketing 20(3): 160-168. 
Goetz, O., K. Liehr-Gobbers, et al. (2010). Evaluation of Structural Equation Models using the Partial Least Squares (PLS) approach. Handbook of Partial Least Squares. V. E. Vinnzi, W. Chin, J. Henseler and H. Wang. Heidelberg, Springer.

Goode, M. M. H., L. A. Moutinho, et al. (1996). "Structural equation modelling of overall satisfaction and full use of services for ATMs." The International Journal of Bank Marketing 14(7): 4.

Goode, M. M. H., H. R. Snee, et al. (2001). "Modeling satisfaction with ATMs: A crosscountry comparison." Journal of Financial Services Marketing 5(3): 8.

Goodhue, D. (2007). "Comment on Benbasat and Barki’s "Quo Vadis TAM" article." Journal of the Association for Information Systems 8(4).

Goodhue, D. L. (1995). "Understanding user evaluations of information systems." Management Science 41(12): 1827-1844.

Goodhue, D. L. (1997). "The Model Underlying the Measurement of the Impacts of the IIC on the End-Users." Journal of the American Society for Information Science 48(5): 449453.

Goodhue, D. L. (1998). "Development and measurement validity of a task-technology fit instrument for user evaluations of information systems." Decision Sciences 29(1): 105-138.

Goodhue, D. L., B. D. Klein, et al. (2000). "User evaluations of IS as surrogates for objective performance." Information and Management 38(2): 87-101.

Goodhue, D. L. and R. L. Thompson (1995). "Task Technology Fit and individual Performance." MIS Quarterly 19(2): 213-236.

Grover, V. (2000). "A Tutorial on Survey Research: From Constructs to Theory." from http://theweb.badm.sc.edu/grover/survey/MIS-SUVY.html.

Hair, J. F., Jr., R. E. Anderson, et al. (1998). Multivariate Data Analysis with Readings. Englewood Cliffs, NJ, Prentice Hall.

Hamilton, R. and P. Hewer (2000). "Electronic commerce and the marketing of Internet banking in the UK." Journal of Financial Services Marketing 5(2): 135-149.

Hartwick, J. and H. Barki (1994). "Explaining the Role of User Participation in Information System Use." Management Science 40(4): 440-465.

Heaney, J.-G. (2007). "Generations X and Y's internet banking usage in Australia." Journal of Financial Services Marketing 11(3): 196-210.

Henseler, J., C. M. Ringle, et al. (2009). "The use of partial least squares path modeling in international marketing." Advances in International Marketing 20: 277-319.

Hernandez, J. M. C. and J. A. Mazzon (2007). "Adoption of internet banking: proposition and implementation of an integrated methodology approach." The International Journal of Bank Marketing 25(2): 72-88.

Herzberg, A. (2003). "Payments and banking with mobile personal devices." Communications of the ACM 46(5): 53-58.

Hoehle, H. and H. Lehmann (2008). Exploring the state-of-the art of mobile banking literature. 7th Global Mobility Roundtable Conference, Auckland. 
Hooper, V. A., S. L. Huff, et al. (2007). Determination of the Alignment between Information Systems and Marketing. PACIS 2007, Auckland.

Howcroft, B., P. Hewer, et al. (2003). "Banker-Customer Interactions in Financial Services." Journal of Marketing Management 19(9/10): 1001-1020.

Hsu, M. H., C. M. Chiu, et al. (2004). "Determinants of continued use of the WWW: An integration of two theoretical models." Industrial Management \& Data Systems 104(9).

Huang, J., E. Makoju, et al. (2003). "Opportunities to learn from 'failure' with electronic commerce: a case study of electronic banking." Journal of Information Technology 18: 17-26.

Huber, G. P. (1983). "Cognitive Style as a Basis for MIS and DSS Designs: Much ado about Nothing?" Management Science 29(5): 567-579.

Huber, V. (1985). "Effects of task difficulty, goal setting and strategy on performance of a heuristic task." Journal of Applied Psychology 70: 492-504.

Hufnagel, E. M. and C. Conca (1994). "User Response Data: The Potential for Errors and Biases." Information Systems Research 5(1): 48-73.

Hwang, H. G., R. F. Chen, et al. (2007). "Measuring customer satisfaction with internet banking: an exploratory study." International Journal of Electronic Finance 1(3): 321335 .

Hyvärinen, T., A. Kaikkonen, et al. (2005). Placing links in mobile banking application. 7th international conference on Human computer interaction with mobile devices \& services.

Jaruwachirathanakul, B. and D. Fink (2005). "Internet banking adoption strategies for a developing country: the case of Thailand." Internet Research 15(3): 295-311.

Jarvenpaa, S. L. (1989). "The Effect of Task Demands and Graphical Format on Information Processing Strategies." Management Science 35(3): 285-303.

Jasper, C. and S. Ouellette (1994). "Consumers' perception of risk and the purchase of apparel from catalogues." Journal of Direct Marketing 8(2): 23-36.

Jenkins, C. D., S. J. Zyanski, et al. (1971). "Progress toward validation of a computer-scored test for the Type A coronary-prone behavior pattern." Psychometric Medicine 33: 193202.

Jiang, J. J., G. Klein, et al. (2002). "Measuring Information System Service Quality: Servqual from the other side." MIS Quarterly 26(2): 145-166.

Jiang, Z. and I. Benbasat (2007). "The effects of presentation formats and task complexity on online consumers' product understanding." MIS Quarterly 31(3).

John, G. and B. A. Weitz (1988). "Forward integration Into Distribution: An Empirical Test of Transaction Cost Analysis." Journal of Law, Economics, and Organization 4(2): 337 354.

Junglas, I., C. Abraham, et al. (2009). "Mobile technology at the frontlines of patient care: Understanding Fit and human drives in utilization decisions and performance." Decision Support Systems 46: 634-647. 
Kam, B. H. and H. Riquelme (2007). "An Exploratory Study of Length and Frequency of Internet Banking Usage." Journal of Theoretical and Applied Electronic Commerce Research 2(1): 76-85.

Karahanna, E., D. W. Straub, et al. (1999). "Information Technology Adoption Across Time: A Cross Sectional Comparison of Pre-adoption and Post-Adoption Beliefs." MIS Quarterly 23(2): 183-213.

Karimi, J., T. M. Somers, et al. (2004). "Impact of Environmental Uncertainty and Task Characteristics on User Satisfaction with Data." Information Systems Research 15(2): 175-193.

Karjaluoto, H., M. Mattila, et al. (2002). "Electronic banking in Finland: Consumer beliefs and reactions to a new delivery channel." Journal of Financial Services Marketing 6(4): 346-361.

Kassim, N. M. and A. K. M. A. Abdulla (2006). "The influence of attraction on internet banking: an extension to the trust-relationship commitment model " The International Journal of Bank Marketing 24(6): 424-442.

Katuri, S. and M. Lam (2003). Factors Affecting Internet Banking Activities: A case study of a community Bank. Ninth Americas Conference on Information Systems, Tampa, Florida.

Katuri, S. and M. Lam (2007). "Switching customers from branches to internet: A credit union's journey." Journal of Financial Services Marketing 11(3): 229-248.

Keen, P. (1980). MIS research: Reference disciplines and a cumulative tradition. Proceedings of the First International Conference on Information Systems, Philadelphia.

Keil, M., B. C. Tan, et al. (2000). "A cross-cultural study on escalation of commitment behavior in software projects." MIS Quarterly 24(2): 299-325.

Khanfar, M. R. (2007). "The Growing Popularity of Internet Banking Among UAE Consumers." The Business Review - Cambridge 7(1).

Kim, K. and B. Prabhakar (2000). Initial Trust, Perceived Risk, and the Adoption of Internet Banking. Twenty first international conference on Information systems, Brisbane, Australia.

King, R. C. and W. D. Xia (1997). "Media Appropriateness: Effects of Experience on Communication Media Choice." Decision Sciences 28(4): 877-910.

Kleijnen, M., M. Wetzels, et al. (2004). "Consumer acceptance of wireless finance." Journal of Financial Services Marketing 8(3): 206-217.

Klein, G., J. J. Jiang, et al. (2009). "Resolving difference score issues in Information Systems Research " MIS Quarterly 3(4): 811-826.

Klein, S., G. L. Frazier, et al. (1990). "A Transaction Cost Analysis Model of Channel Integration in International Markets." Journal of Marketing Research 27(196-208).

Kleiser, S. B. and S. P. Manter (1994). The dimensions of consumer expertise: a scale development. AMA Summer Educators' Proceedings, Chicago, American Marketing Association.

Klopping, I. M. and E. McKinney (2004). "Extending the Technology Acceptance Model and the Task-Technology Fit Model to Consumer E-Commerce." Information Technology, Learning, and Performance Journal 22(1): 35-48. 
Kristensen, K. and J. Eskildsen (2010). Design of PLS-Based Satisfaction Studies. Handbook of Partial Least Squares. V. E. Vinzi, W. Chin, J. Henseler and H. Wang. Heidelberg, Springer.

Kristof, A. L. (1996). "Person-Organization Fit: An integrative review of its conceptualization, measurement, and implications." Personell Psychology 49(1): 1-49.

Krueger, R. A. (1994). Focus Groups: A Practical Guide for Applied Research. Thousand Oaks, CA, Sage.

Kuisma, T., T. Laukkanen, et al. (2007). "Mapping the reasons for resistance to Internet banking: A means-end approach." International Journal of Information Management 27(2): 75-85.

Laforet, S. and L. Xiaoyan (2005). "Consumers' attitudes towards online and mobile banking in China." International Journal of Bank Marketing 23(5): 362-380.

Lai, V. S. and H. Li (2005). "Technology acceptance model for internet banking: an invariance analysis." Information \& Management 42(2): 373-386.

Lake, K., A. Mehta, et al. (1998). "Cashing in on your ATM network." McKinsey Quarterly 1998(1): 173-178.

Lallmahamood, M. (2007). "An Examination of Individual's Perceived Security and Privacy of the Internet in Malaysia and the Influence of This on Their Intention to Use ECommerce: Using An Extension of the Technology Acceptance Model." Journal of Internet Banking and Commerce 12(3): 1-26.

Lance, C. E., B. Dawson, et al. (2010). "Method Effects, Measurement Error, and Substantive Conclusions." Organisational Research Methods 13(3): 435-455.

Landry, F. J., H. Rastegary, et al. (1991). "Time Urgency: The Construct and Its Measurement." Journal of Applied Psychology 76(5): 644-657.

Lassar, W. M., C. Manolis, et al. (2005). "The relationship between consumer innovativeness, personal characteristics, and online banking adoption " International Journal of Bank Marketing 23(2/3): 176-199.

Lastovicka, J. L. and D. M. Gardner (1979). Handbook of Marketing Scales. Thousand Oaks, SAGE Publications.

Latham, G. and G. Yukl (1975). "A review of research on the application of goal-setting in organizations." Academy of Management Journal 18: 824-845.

Laukkanen, T. (2007). "Internet vs mobile banking: comparing customer value perceptions." Business Process Management Journal 13(6): 788-797.

Laukkanen, T. and J. Lauronen (2005). "Consumer value creation in mobile banking services." International Journal of Mobile Communications 3(4): 325 - 338.

Laukkanen, T., S. Sinkkonen, et al. (2007). "Innovation resistance among mature consumers." Journal of Consumer Marketing 24(7): 419-427.

Laukkanen, T., S. Sinkkonen, et al. (2008). "Segmenting bank customers by resistance to mobile banking." International Journal of Mobile Communications 6(3): 309-320.

Leblanc, G. (1990). "Customer Motivations: Use and Non-use of Automated Banking." International Journal of Bank Marketing 8(4): 36-40. 
Lee, C. P., M. Mattila, et al. (2007). An Exploratory Study of Mobile Banking Systems Resistance in Korea and Finland. Americas Conference on Information Systems 2007.

Lee, D. T. (2004). "Re-examining the security issues of ATM systems." Computer Fraud \& Security 2004-February(2): 13-15.

Lee, E.-J., K.-N. Kwon, et al. (2005). "Segmenting the non-adopter category in the diffusion of internet banking." International Journal of Bank Marketing 23(4/5): 414-437.

Lee, J. (2002). "A Key to Marketing Financial Services: The Right Mix of Products, Services, Channels and Customers." Journal of Services Marketing 16(3): 238-258.

Lee, K. S., H. S. Lee, et al. (2007). "Factors Influencing the Adoption Behavior of Mobile Banking: A South Korean perspective." Journal of Internet Banking and Commerce 12(2).

Lee, M. C. (2009). "Factors influencing the adoption of internet banking: An integration of TAM and TPB with perceived risk and perceived benefit." Electronic Commerce Research and Applications 8(3).

Lee, M. S. Y., P. F. McGoldrick, et al. (2003). "Using ZMET to explore barriers to the adoption of $3 \mathrm{G}$ mobile banking services." International Journal of Retail and Distribution Management 31(6): 340-348.

Lefebvre, E., L. A. Lefebvre, et al. (1997). Technological Learning and Organizational Context: Fit and Performance in SMES. 30th Hawaii International Conference on System Sciences (HICSS).

Liang, H., N. Saraf, et al. (2007). "Assimilation of enterprise systems: the effect of institutional pressures and the mediating role of top-management." MIS Quarterly 31(1): 59-87.

Liao, S., Y. P. Shao, et al. (1999). "The adoption of virtual banking: An empirical study." International Journal of Information Management 19(1): 63-74.

Liao, Z. (2005). Trust Building and Sustainable Internet Banking. Eleventh Americas Conference on Information Systems, Omaha.

Liao, Z. and M. T. Cheung (2002). "Internet-based e-banking and consumer attitudes: an empirical study." Information \& Management 39(4): 283-295.

Liao, Z. and M. T. Cheung (2008). "Measuring consumer satisfaction in internet banking: a core framework." Communications of the ACM 51(4): 47-51.

Lichtenstein, S. and K. Williamson (2006). "Understanding consumer adoption of Internet Bankin: An Interpretive study in the Australian Banking context." Journal of Electronic Commerce Research 7(2): 50-66.

Lim, K. and I. Benbasat (2000). "The Effect of Multimedia on Perceived Equivocality and Perceived Usefulness of Information Systems." MIS Quarterly 24(3): 449-471.

Limayem, M., C. Cheung, et al. (2003). Explaining Information Systems Adoption and PostAdoption: Toward an Integrative Model. 24th International Conference on Information Systems, Seattle.

Limayem, M., S. G. Hirt, et al. (2007). "How habit limits the predictive power of intention: the case of information systems continuance." MIS Quarterly 31(4): 705-737. 
Lin, C. S., S. Wu, et al. (2005). "Integrating perceived playfulness into expectationconfirmation model for web portal context." Information \& Management 42(5): 683693.

Lin, Z., W. Ke, et al. (2007). Understanding Internet Banking: An Empirical Investigation of Potential Customers' Acceptance in Mainland China. Americas Conference on Information Systems.

Little, L. (2003). Attitudes towards technology use in public zones: the influence of external factors on ATM use. CHI ' 03 extended abstracts on Human factors in computing systems. Ft. Lauderdale, Florida, USA, ACM.

Littler, D. and D. Melanthiou (2006). "Consumer perceptions of risk and uncertainty and the implications for behaviour towards innovative retail services: The case of Internet Banking." Journal of Retailing and Consumer Services 13(6): 431-443.

Luarn, P. and H. H. Lin (2005). "Toward an understanding of the behavioral intention to use mobile banking." Computers in Human Behavior 21: 873-891.

Lucas, H. C., E. B. Swanson, et al. (2007). "Implementation, Innovation, and Related Themes Over The Years In Information Systems Research." Journal of the Association for Information Systems 4(8).

Luftman, J. and E. R. McLean (2004). "Key Issues for IT executives." MIS Quarterly 3(2): 89-104.

Lyytinen, K. and J. L. King (2004). "Nothing at the centre? Academic legitimatcy in the Information Systems field." Journal of the Association of Information Systems 5(6): 220-264.

MacCallum, R. C. and M. W. Browne (1993). "The use of causal indicators in covariance structure models: some practical issues." Psychological Bulletin 114(3): 533-541.

Mäenpää, K., S. H. Kale, et al. (2008). "Consumer perceptions of Internet banking in Finland: The moderating role of familiarity." Journal of Retailing and Consumer Services 15(4): 266-276.

Malhotra, N. K. (2004). Marketing Research - An Applied Orientation. Upper Saddle River, Pearson Prentice Hall.

Malhotra, N. K., S. S. Kim, et al. (2006). "Common Method Variance in IS Research: A Comparison of Alternative Approaches and a Reanalysis of Past Research." Management Science 52(12): 1865-1883.

Malhotra, P. and B. Singh (2007). "Determinants of Internet banking adoption by banks in India." Internet Research 17(3): 323-339.

Mallat, N., M. Rossi, et al. (2004). "Mobile banking services." Communications of the ACM 47(5): 42-46.

Markus, M. L. (1994). "Electronic Mail as Medium of Managerial Choice." Organization Science 5(4): 502-527.

Marr, N. E. and G. Prendergast (1991). "Human Tellers: Who Needs Them?" International Journal of Bank Marketing 8(2): 32-40.

Marshall, J. J. and L. A. Heslop (1988). "Technology Acceptance in Canadian Retail Banking: A Study of Consumer Motivations and Use of ATMs." International Journal of Bank Marketing 6(4): 31-41. 
Maruping, L. M. and R. Agarwal (2004). "Managing Team Interpersonal Processes Through Technology: A Task-Technology Fit Perspective." The Journal of Applied Psychology 89(6): 975-990.

Mathieson, K. (1991). "Predicting User Intensions: Comparing the Technology Acceptence Model with the Theory of Planned Behavior." Information Systems Research 2(3): 173-191.

Mathieson, K. and M. Keil (1998). "Beyond the interface: Ease of use and task/technology fit." Information and Management 34(4): 221-230.

Mathieson, K., E. Peacock, et al. (2001). "Extending the Technology Acceptance Model: The influence of perceived user resources." The DataBase for Advances in Information Systems 32(3).

Mattila, A. S. and J. Wirtz (2004). "Consumer complaining to firms: The determinants of channel choice." The Journal of Services Marketing 18(2/3).

Mattila, M. (2003). "Factors affecting the adoption of mobile banking services." Journal of Internet Banking and Commerce 8(1).

Mattila, M., H. Karjaluoto, et al. (2003). "Internet banking adoption among mature customers: Early majority or laggards? ." The Journal of Services Marketing 17(4/5): 514-528.

McKinney, V., K. Yoon, et al. (2002). "The measurement of web-customer satisfaction: An expectation and disconfirmation approach." Information Systems Research 13(3).

Meyers, M. D. (2004). "Qualitative Research in Information Systems - Website." Retrieved 10.01.2009, 2009, from http://www.qual.auckland.ac.nz/.

Miles, M. B. and A. M. Huberman (1994). Qualitative Data Analysis: An Expanded Sourcebook. Thousand Oaks, CA, Sage Publications, Inc.

Mitchell, V., H. Mohammad, et al. (2007). Fit Perspectives and Theory Building in Information Systems. 40th Annual Hawaii International Conference on System Sciences (HICSS).

Mols, N. P. (2001). "Organizing for the effective introduction of new distribution channels in retail banking." European Journal of Marketing 5(6): 661-686.

Moore, G. C. and I. Benbasat (1991). "Development of an Instrument to Measure the Perceptions of Adopting an Information Technology Innovation." Information Systems Research 2(3): 192-222.

Morisi, T. L. (1996). "Commercial banking transformed by computer technology." Monthly Labor Review 119(8).

Morris, M. G. (2010). Building a Cumulative Tradition or Beating a Dead Horse? Ideas on Reinvigorating Mature Streams of Research. Fifth ISF theory building workshop, Canberra, ANU press.

Morrison, P. D. and J. H. Roberts (1998). "Matching Electronic Distribution Channels to Product Characteristics: The Role of Congruence in Consideration Set Formation. ." Journal of Business Research 41: 223-229.

Moutinho, L. A. (1992). "Customer Satisfaction Measurement: Prolonged Satisfaction with ATMs." International Journal of Bank Marketing 10(7): 30-37.

Moutinho, L. A. and A. Meidan (1989). "Bank Customers' Perceptions, Innovations and New Technology." International Journal of Bank Marketing 7(2): 22-27. 
Moutinho, L. A. and A. Smith (2000). "Modelling bank customer satisfaction through mediation of attitudes towards human and automated banking." International Journal of Bank Marketing 18(2/3).

Mulpuru, S. (2007). Forrester Research - Which Personalization Tools Work For eCommerce - And Why.

Muntermann, J. and A. Güttler (2004). Mobile financial information services: Capabilities of suitable push services. 8th Pacific Asia Conference on Information Systems, Shanghai, China.

Muntermann, J., H. Rossnagel, et al. (2005). Mobile brokerage infrastructures - Capabilities and security requirements. 13th European Conference on Information Systems, Regensburg, Germany.

Nadkarni, S. and R. Gupta (2007). "A task-based model of perceived website complexity." MIS Quarterly 31(3).

Ndubisi, N. O. and Q. Sinti (2006). "Consumer attitudes, system's characteristics and internet banking adoption in Malaysia." Management Research News 29(1/2): 16-27.

Nunnally, J. C. (1978). Psychometric Theory. New York, McGraw Hill.

O'Reilly, P., P. Finnegan, et al. (2001). Dealing with consolidation and virtual banks: an exploration of Internet banking in the "brick and mortar" sector. Seventh Americas Conference on Information Systems, Boston, Massachusetts, USA.

Oliver, R. L. (1977). "Effect of Expectation and Disconfirmation on Postexposure Product Evaluations - an Alternative Interpretation." Journal of Applied Psychology 62(4).

Oliver, R. L. (1980). "A Cognitive Model of the Antecedents and Consequences of Satisfaction Decisions." Journal of Marketing Research 17(4).

Orlikowski, W. and J. J. Baroudi (1991). "Studying Information Technology in Organizations: Research Approaches and Assumptions." Information Systems Research 2(1).

Orlikowski, W. J. and C. S. Lacono (2001). "Research Commentary: Desperately Seeking the 'IT' in IT Research--A Call to Theorizing the IT Artifact." Information System Research 12(2).

Ortiz de Guinea, A. and M. L. Markus (2009). "Why Break the Habit of a Lifetime? Rethinking the Roles of Intention, Habit, and Emotion in Continuing Information Technology Use." MIS Quarterly 33(3): 433-444.

Pace, V., L (2010). "method Variance from the Perspectives of Reviewers: Poorly Understood Problem or Overemphasized Complaint?" Organisational Research Methods 13(3): 421-434.

Panigyrakis, G. G., P. K. Theodoridis, et al. (2002). "All customers are not treated equally: Financial exclusion in isolated Greek islands." Journal of Financial Services Marketing 7(1): 54.

Park, C. W., G. Im, et al. (2008). "Overcoming the Mum Effect in IT Project Reporting: Impacts of Fault Responsibility and Time Urgency." Journal of the Association for Information Systems 9(7): 409-431.

Parker, S. C. and A. Van Witteloostuijn (2010). "A General Framework for Estimating Multidimensional Contingency Fit." Organization Science 21(2). 
Patricio, L., R. P. Fisk, et al. (2003). "Improving satisfaction with bank service offerings: measuring the contribution of each delivery channel." Managing Service Quality 13(6): 471-482.

Pavlou, P. A. and M. Fygenson (2006). "Understanding and Predicting Electronic Commerce Adoption: An Extension of the Theory of Planned Behavior." MIS Quarterly 30(1): 115-144.

Payne, J. (1976). "Task complexity and contingent processing in decision-making: An information search and protocol analysis." Organizational Behavior and Human Performance 16: 366-387.

Pepermans, R., G. Verleye, et al. (1996). "'Wallbanking', innovativeness and computer attitudes: 25-40-year-old ATM-users on the spot." Journal of Economic Psychology 17(6): 731-748.

Perrow, C. (1967). "A Framework for the Comparative Analysis of Organizations." American Sociological Review 32: 194-208.

Petter, S., D. W. Straub, et al. (2007). "Specifying formative constructs in Information Systems research." MIS Quarterly 31(4): 623-656.

Pezullo, M. A. (1998). Marketing Financial Services, Kogan Page Publishers.

Pierce, J. and R. Dunham (1976). "Task design: A literature review." Academy of Management Review 1: 83-97.

Pinsonneault, A. and K. Kraemer (1993). "Survey Research Methodology in Management Information Systems: An Assessment." Journal of Management Information Systems 10: $75-105$.

Podsakoff, P. M., S. B. MacKenzie, et al. (2003). "Common method biases in behavioral research: A critical review of the literature and recommended remedies." Journal of Applied Psychology 88(5): 879-903.

Podsakoff, P. M., N. P. Podsakoff, et al. (2003). "Common Methods Biases in Behavioural Research: A Critical Review of the Literature and Recommended Remedies." Journal of Applied Psychology 88(5): 879-903.

Polatoglu, V. N. and S. Ekin (2001). "An empirical investigation of the Turkish consumers' acceptance of Internet banking services." The International Journal of Bank Marketing 19(4/5): 156-165.

Popper, K. (1980). The Logic of Scientific Discovery. London, Unwin Hyman.

Prager, R. A. (2001). "The Effects of ATM Surcharges on Small Banking Organizations." Review of Industrial Organization 18(2): 161.

Prescott, J. E. (1986). "Environments as Moderators of the Relationship Between Strategy and Performance." Academy of Management Journal 29(2): 329-346.

Putcha, C. and J. Potter (2004). Focus Group Practice. London, Sage Publications.

Qureshi, I. and D. R. Compeau (2009). "Assessing Between-Group Differences in Information Systems Research: A Comparision of Covariance- and Component-Based SEM." MIS Quarterly 33(1).

Qureshi, T. M., K. Zafar, et al. (2008). "Customer Acceptance of Online Banking in Developing Economies." Journal of Internet Banking and Commerce 13(1): 1-9. 
Rahman, Z. (2006). "Customer experience management - A case study of an Indian bank." Journal of Database Marketing \& Customer Strategy Management 13(3): 203.

Railton, J. (1985). "Automated Teller Machines." Computer Law \& Security 1(4).

Rangan, V., E. Corey, et al. (1993). "Transaction cost theory: inferences from clinical field research on downstream vertical integration." Organization Science 4(3): 454-477.

Rangan, V. K., M. A. J. Menezes, et al. (1992). "Channel Selection for New Industrial Products: A Framework, Mehtod, and Application." Journal of Marketing 56(3): 6982.

Reinsch, N. L. and R. W. Beswick (1990). "Voice mail versus conventional channels: a cost minimization analysis of individuals' preferences." Academy of Management Journal 33(4): 801-816.

Rice, R. (1992). "Task Analyzability, Use of New Media, and Effectiviness: A Multi-Site Exploration of Media Richness." Organization Science 3(4): 475-500.

Rice, R. E. and D. Shook (1990). "Relationships of Job Categories and Organizational Levels to Use of Communication Channels, Including Electronic Mail: A Meta-Analysis and Extension." Journal of Management Studies 27(2): 195-229.

Richardson, H. A., M. J. Simmering, et al. (2009). "A Tale of Three Perspectives: Examining Post Hoc Statistical Techniques for detection and Correction of Common Method Variance." Organisational Research Methods 12(4): 762-800.

Robey, D. (1979). "User Attitudes and Management Information System Use." Academy of Management Journal 22(3): 527-538.

Robey, D. and M. L. Markus (1998). "Beyond rigor and relevance: producing consumable research about information systems." Information Resources Management Journal 11(1): 7-15.

Rogers, E. (1995). Diffusion of Innovations. New York.

Rogers, W. A., E. F. Cabrera, et al. (1996). " A survey of automatic teller machine usage across the adult life span." Human Factors 38(1): 156-167.

Rönkkö, M. and K. Ylitalo (2010). Construct validity in Partial Least Squares Path Modeling. Internation Conference on Information Systems, St. Louis.

Rosemann, M. and I. Vessey (2008). "Toward improving the relevance of Information Systems Research to practice: the role of applicability checks." MIS Quarterly 32(1): $1-22$.

Rotchanakitmnuai, S. and M. Speece (2003). "Barriers to Internet banking adoption: a qualitative study among corporate customers in Thailand " The International Journal of Bank Marketing 21(6/7): 312-323.

Rotchanakitumnuai, S. and M. Speece (2004). Balancing Business Value of Thai Internet Banking Services: The Corporate Customers' Perspectives. Ninth Pacific Asia Conference on Information Systems, Shanghai.

Rugimbana, R. (1995). "Predicting automated teller maching usage." International Journal of Bank Marketing 13(4): 26-33.

Rugimbana, R. and P. Iversen (1994). "Perceived attributes of ATMs and their marketing implications." International Journal of Bank Marketing 12(2): 30-36. 
Sabberwal, R. and Y. E. Chan (2001). "Alignment Between Business and IS Strategies: A Study of Prospectors, Analyzers, and Defenders. ." Information Systems Research 12(1): 11-34.

Sayar, C. and S. Wolfe (2007). "Internet banking market performance: Turkey versus the UK." The International Journal of Bank Marketing 25(3): 122-141.

Schneider, K. C. and W. C. Rodgers (1996). An 'importance' subscale for the consumer involvement profile Advances in Consumer Research. K. Corfman and J. Lynch. Provo, UT, Association for Consumer Research. 23: 249-254.

Schwarz, A. and W. Chin (2007). "Looking Forward: Toward an Understanding of the Nature and Definition of IT Acceptance." Journal of the Association for Information Systems $8(4)$.

Scornavacca, E. and S. J. Barnes (2004). "M-banking services in Japan: a strategic perspective." International Journal of Mobile Communications 2(1): 51-66.

Scornavacca, E., S. J. Barnes, et al. (2006). "Mobile Business Research Published in 20002004: Emergence, Current Status, and Future Opportunities." Communications of the Association for Information Systems (AIS) 17: 635-646.

Scornavacca, E. and H. Hoehle (2007). "Mobile Banking in Germany: a strategic perspective." International Journal of Electronic Finance (IJEF) 1(3): 304-320.

Scornavacca, E. and H. Hoehle (2009). "A new broom sweeps clean: developing a learning cycle tailored for e-commerce courses." Int. J. Management in Education 3(2): 149161.

Seddon, P. B. and K. Lyytinen (2008). Generalization in IS Research - Discussion panel. ACIS 2008, Christchurch.

Shaft, T. M. and I. Vessey (2006). "The Role of Cognitive Fit in the Relationship between Software Comprehension and Modification." MIS Quarterly 30(1): 29-55.

Sharma, R., P. Yetton, et al. (2009). "Estimating the Effect of Common Method Variance: The Method-Method Pair Technique with an Illustration from TAM Research." $\underline{\text { MIS }}$ Quarterly 33(3): 473-490.

Sheppard, B. H., J. Hartwick, et al. (1988). "The Theory of Reasoned Action: A MetaAnalysis of Past Research with Recommendations for Modifications and Future Research." Journal of Consumer Research 15(3): 325-343.

Shih, Y. Y. and K. Fang (2004). "The use of a decomposed theory of planned behavior to study Internet banking in Taiwan." Internet Research 14(3): 213-223.

Shim, J. P., U. Varshney, et al. (2006). "Mobile and wireless networks: services, evolution and issues." International Journal of Mobile Communications 4(4): 405-417.

Shirani, A. I., M. H. A. Tafti, et al. (1999). "Task and technology fit: a comparison of two technologies for synchronous and asynchronous group communication." Information and Management 36(3): 139-150.

Sidorova, A., N. Evangelopoulos, et al. (2008). "Uncovering the Intellectual Core of the Information Systems Discipline." MIS Quarterly 32(3): 476-482.

Silva, L. (2007). "Post-positivist Review of Technology Acceptance Model." Journal of the Association for Information Systems 8(4).

SmartPLS (2010). http://smartpls.de/. 
Smilecity (2010). Smilecity - about us.

Sohail, M. S. and B. Shanmugham (2003). "E-banking and customer preferences in Malaysia: An empirical investigation." Information Sciences 150(3-4): 207-217.

Southard, P. B. and S. Keng (2004). "A survey of online e-banking retail initiatives." Communication of the ACM October: 99-102.

Spreng, R. A., S. B. MacKenzie, et al. (1996). "A reexamination of the determinants of consumer satisfaction." Journal of Marketing 60(3).

Srivastava, R. K. (2007). "Customer's perception on usage of internet banking." Innovative Marketing 3(4): 66-72.

Staples, D. S. and P. Seddon (2004). "Testing the Technology-to-Performance Chain Model." Journal of Organizational and End User Computing 16(4): 17-36.

Straub, D. and A. Burton-Jones (2007). "Veni, Vidi, Vici: Breaking the TAM Logjam." Journal of the Association for Information Systems 8(4).

Straub, D., D. Gefen, et al. (2004). "The ISWorld Quantitative, Positivist Research Methods Website." Retrieved 10.01., 2009, from http://dstraub.cis.gsu.edu:88/quant/.

Straub, D. W. (1989). "Validating Instruments in MIS Research." MIS Quarterly 13(2 (June)): 147-169.

Straub, D. W., M. Boudreau, et al. (2004). "Validation Guidelines for IS positivist research." Communication of the AIS 13(24): 1-78.

Strauss, A. and J. Corbin (1990). Basics of Qualitative Research: Grounded Theory Procedures and Techniques. Newbury Park, CA, Sage Publications.

Suh, B. and I. Han (2002). "Effect of trust on customer acceptance of Internet banking." Electronic Commerce Research and Applications 1(3-4): 247-263.

Suh, K. S. (1999). "Impact of communication medium on task performance and satisfaction: an examination of media-richness theory." Information and Management 35(5): 295312 .

Sulaiman, A., N. I. Jaafar, et al. (2007). "An overview of mobile banking adoption among the urban community." International Journal of Mobile Communications 5(2): 157-167.

Suoranta, M. and M. Mattila (2004). "Mobile banking and consumer behaviour: New insights into the diffusion pattern." Journal of Financial Services Marketing 8(4): 354-366.

Swanson, E. B. (1987). "Information Channel Disposition and Use." Decision Sciences 18(1): 131-145.

Tabachnick, B. G. and L. S. Fidell (2007). Using multivariate statistics. Boston, Pearson/Allyn and Bacon.

Tan, M. and S. H. T. Thompson (2000). "Factors Influencing the Adoption of Internet Banking." Journal of the Association for Information Systems 1(July): 1-43.

Tang, T., H. Lin, et al. (2004). Toward an understanding of the behavioral intention to use mobile banking services. 8th Pacific Asia Conference on Information Systems, Shanghai, China.

Tarasewich, P. (2003). "Designing mobile commerce applications." Communications of the ACM 46(12): 57-60. 
Tate, M. and J. Evermann (2010). Obstacles to building effective theory about attitudes and behaviours towards technology. ISF theory building workshop, Canberra, ANU press.

Taylor, M. S. (1981). "The motivational effects of task challenge: A laboratory investigation." Organizational Behavior and Human Performance 27: 255-278.

Taylor, S. and P. A. Todd (1995). "Assessing IT Usage: The Role of Prior Experience." MIS Quarterly 19(2): 561-570.

Taylor, S. and P. A. Todd (1995). "Understanding Information Technology Usage: A Test of Computing Models." Information Systems Research 6(4): 144-176.

Terborg, J. and H. Miller (1978). "Motivation, behavior and performance: A closer examination of goal-setting and monetary incentives." Journal of Applied Psychology 63(29-39).

Tesch, D., J. Jiang, et al. (2003). "The Impact of Information System Personnel Skill Discrepancies on Stakeholder Satisfaction." Decision Sciences 34(1).

Thatcher, S. (2001). The Mediating Role of Identity Fit: Understanding the Relationship between Communication Media, Demographic Differences, and Creativity. 34th Annual Hawaii International Conference on System Sciences ( HICSS-34).

Thompson, R., D. Compeau, et al. (2006). "Intentions to Use Information Technologies: An Integrative Model." Journal of Organizational and End User Computing 18(3): 25-48.

Thompson, R. L., C. A. Higgins, et al. (1991). "Personal Computing: Towards a Conceptual Model of Utilization." MIS Quarterly 15(1): 124-143.

Thornton, J. and L. White (2001). "Customer orientations and usage of financial distribution channels." The Journal of Services and Marketing 15(3): 168-185.

Tiwari, R., S. Buse, et al. (2006). Customer on the Move: Strategic Implications of Mobile Banking for Banks and Financial Enterprises. 8th IEEE International Conference on and Enterprise Computing.

Tornatzky, L. G. and K. J. Klein (1982). "Innovation Characteristics and Innovation Adoption-Implementation: A Meta-Analysis of Findings." IEEE Transactions on Engineering Management 29(1): 28-45.

Turban, E., D. King, et al. (2008). Electronic Commerce 2006: a managerial perspective. New Jersey, Prentice Hall.

Van Birgelen, M., A. D. Jong, et al. (2006). "Multi-channel service retailing: The effects of channel performance satisfaction on behavioral intentions " Journal of Retailing 82(4): 367-377.

Vatanasombut, B., M. Igbaria, et al. (2008). "Information systems continuance intention of web-based applications customers: The case of online banking." Information \& Management November(7).

Venkatesh, V. (2010). "TAM 3: Advancing the Technology Acceptance Model with a Focus on Interventions." Retrieved 22.11., 2010, from http://www.vvenkatesh.com/IT/organizations/Theoretical_Models.asp.

Venkatesh, V. and F. D. Davis (2000). "A Theoretical Extension of the Technology Acceptance Model: Four Longitudinal Field Studies." Management Science 45(2): 186-204. 
Venkatesh, V. and F. D. Davis (2000). "A theoretical extension of the technology acceptance model: Four longitudinal field studies." Management Science 46(2): 186-204.

Venkatesh, V., F. D. Davis, et al. (2007). "Dead Or Alive? The Development, Trajectory And Future Of Technology Adoption Research." Journal of the Association for Information Systems 8(4).

Venkatesh, V. and S. Goyal (2010). "Expectation Disconfirmation and Technology Adoption: Polynomial Modeling and Response Surface Analysis." MIS Quarterly 34(2): 281303.

Venkatesh, V., M. G. Morris, et al. (2003). "User acceptance of information technology: Toward a unified view." MIS Quarterly 27(3): 425.

Venkatesh, V. and V. Ramesh (2006). "Web and wireless site usability: Understanding differences and modeling use." MIS Quarterly 30(1): 181-205.

Venkatraman, N. (1989). "The Concept of Fit in Strategy Research: Toward Verbal and Statistical Correspondence." The Academy of Management Review 14(3): 423-444.

Vessey, I. (1991). "Cognitive Fit: A Theory-Based Analysis of the Graphs Versus Tables Literature." Decision Sciences 22(2): 219-241.

Walker, R. H. and L. W. Johnson (2005). "Towards understanding attitudes of consumers who use internet banking services." Journal of Financial Services 10(1): 84-94.

Wan, W. W. N., C. L. Luk, et al. (2005). "Customers' adoption of banking channels in Hong Kong " International Journal of Bank Marketing 23(2/3): 255-272.

Wang, Y., H. H. Lin, et al. (2006). "Predicting consumer intention to use mobile service." Information Systems Journal 16(157-179).

Wang, Y. S., Y. M. Wang, et al. (2003). "Determinants of user acceptance of Internet banking: an empirical study." International Journal of Service Industry Management 14(5): 501-519.

Wareham, J., J. G. Zheng, et al. (2005). "Critical themes in electronic commerce research: a meta-analysis." Journal of Information Technology 20: 1-19.

Watson-Manheim, M. B. and F. Belanger (2007). "Communication Media Repertoires: Dealing with the Multiplicity of Media Choices." MIS Quarterly 31(2).

Weber, R., Ed. (1997). Ontological Foundations of Information Systems, Australia: Coopers \& Lybrand.

Weber, R. (2003). "Theoretically Speaking - Editors Comment." MIS Quarterly 27(3).

White, H. and F. Nteli (2004). "Internet banking in the UK: Why are there not more customers?" Journal of Financial Services 9(1): 49-56.

Wood, R. E. (1986). "Task Complexity: Definition of a Construct." Organizational Behavior and Human Decision Processes 31(1): 60-82.

Yiu, C. S., K. Grant, et al. (2007). "Factors affecting the adoption of Internet Banking in Hong Kong-implications for the banking sector." International Journal of Information Management 27(5): 336-351.

Yuan, Y., N. Archer, et al. (2010). "Identifying the ideal fit between mobile work and mobile work support." Information and Management in press. 
Zeithaml, V. A. and M. C. Gilly (1987). "Characteristics Affecting the Acceptance of Retailing Technologies: A Comparison of Elderly and Non-Elderly Consumer." Journal of Retailing 63(1): 49-68.

Zeithaml, V. A., A. Parasuraman, et al. (1990). Delivering quality service; Balancing customer perceptions and expectations. New York, NY, The Free Press.

Zhang, J. J. and Y. Yuan (2002). M-commerce versus internet-based E-commerce: the key differences. Americas Conference on Information Systems 2002, Dallas, Texas.

Zigurs, I. and B. K. Buckland (1998). "A theory of task/technology fit and group support systems effectiveness." MIS Quarterly 22(3): 313-334.

Zigurs, I., B. K. Buckland, et al. (1999). "A test of task-technology fit theory for group support systems." Data Base for Advances in Information Systems 30(3/4): 34-50. 


\title{
10. Appendices
}

\subsection{Participant information sheet: relevance checks with German banks}

\author{
VICTORIA UNIVERSITY OF WELLINGTON \\ Te Whare Wānanga o te Ûpoko o te Ika a Māui

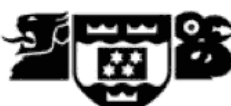 \\ SCHOOL OF INFORMATION MANAGEMENT
}

\section{Participant Information Sheet}

Project title: Exploring the strategic value of electronic communication channels in Europe

Researcher: Hartmut Hoehle, School of Information Management, Victoria University of Wellington

Dear Participant XYZ,

Thank you for showing an interest in participating in this research study exploring the strategic value of electronic communication channels in Europe. I am currently studying towards a PhD degree at Victoria University of Wellington, New Zealand.

\section{Research Goal}

This research project aims to understand the perceived organizational impacts of electronic communication channels and the strategic value of these services for banks. This project may form part of my $\mathrm{PhD}$ thesis.

The participation within this research will involve audio-recorded face-to-face interviews anticipated to last approximately $30-45$ minutes each. The interviews will take place in June/July 2008. Participants will be provided with exact dates closer to the dates of the interviews.

\section{Confidentiality}

Confidentiality of information shared within each interview is of fundamental importance. Throughout the project, raw data will be kept under password protection and destroyed 2 years after the conclusion. All raw data will be kept confidential to the researcher and his supervisor. Only data in aggregated form will be used in the thesis and in any articles published in academic journal or presentations at conference. A copy of my PhD thesis will be deposited in the VUW library, and may be available electronically in the institutional repository. Any information that participants provide will not be attributed to individuals and participants will not be able to be identified in any way.

You have the right to withdraw from this study at any time within three weeks after the interview was conducted. Any contributions you have made up until that time will be withdrawn from the research data.

If you have any further questions regarding this project please contact me via email: hartmut.hoehle@vuw.ac.nz. Alternatively you can contact my supervisor Hans Lehmann via email:hans.lehmann@vuw.ac.nz.

Regards,

Hartmut Hoehle

Email:Hartmut.hoehle@vuw.ac.nz 


\subsection{Interview guide: relevance checks with German banks}

\section{Interview Questions to gather data}

\section{Participant Questions:}

a. How would you describe or define electronic communication channels? In other words, what is it?

b. How would you describe your work experience with electronic banking channels and how does your current occupation related to electronic banking channels?

c. How do you personally perceive electronic banking channels and what services do you perform on which channel?

\section{Characteristics of each electronic banking channel}

a. What are the most important features/characteristics of each electronic banking channel:

- ATM

- Phone Banking

- Internet Banking

- Mobile Banking

3. Tasks to be performed on each electronic banking channel

a. Which banking services/products should be performed on each electronic banking channel?

- ATM

- Phone Banking

- Internet Banking

- Mobile Banking

4. Organizational impacts/goals of electronic banking channels

a. What do you believe are the advantages/benefits of electronic banking channels for your organization?

b. What do you believe are the disadvantages/drawbacks of electronic banking channels for your organization?

c. What do you believe are the advantages/benefits of electronic banking channels for your customers?

d. What do you believe are the disadvantages/drawbacks of electronic banking channels for your customers? 


\title{
10.3. Participant information sheet: focus group discussions
}

\author{
VICTORIA UNIVERSITY OF WELLINGTON \\ Te Whare Wänanga o te Ûpoko o te Ika a Māui

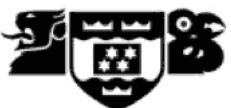 \\ SCHOOL OF INFORMATION MANAGEMENT
}

\author{
Participant Information Sheet
}

Project title: Consumer continuous intentions to use electronic banking channels: the role of task-channel fit

Researcher: Hartmut Hoehle, School of Information Management (SIM), Victoria University of Wellington

Dear Participant XYZ,

Thank you for your interest in participating in this research study exploring consumer continuous intentions to use electronic banking channels. I am currently studying towards a $\mathrm{PhD}$ degree at Victoria University of Wellington, New Zealand. This project forms a part of my PhD thesis.

\section{Research Goal}

This research project aims to understand users' perceptions of the correspondence between a banking task and the functionality of a particular electronic banking channel. The outcome of this study will be used to develop a survey questionnaire to collect data during the second phase of my research.

Your participation in this research will involve an audio-recorded focus group discussion anticipated to last approximately 60-90 minutes. The focus group discussion will take place between July and September 2009. Since the focus group involves several research participants, each participant will be asked to indicate time-slots for which he/she is available for the focus group session. Based on this, I will organize a time that accommodates every research participant's availability. You will be invited with an email including the exact date and location closer to the date of the focus group session.

\section{Confidentiality}

Confidentiality of information shared within each focus group session is of fundamental importance. It is essential that any information discussed within the focus groups will be treated confidential by all research participants. Throughout the project, electronic raw data will be stored password protected whereas any written material will be kept in a locked file. All data will be destroyed 2 years after the conclusion of the study. All raw data will be kept confidential, and only accessible for the researcher and his supervisor. Only data in aggregated form will be used in the thesis and in any articles published in academic journals or presentations at conferences. A copy of my $\mathrm{PhD}$ thesis will be deposited in the VUW library, and may be available electronically in the institutional repository. Any information that participants provide will not be attributed to individuals or organizations in which they work. None of the participants will be identifiable in any way.

You have the right to withdraw at any point up to the start of the focus group session or during the focus group session, but any data collected up to that point of withdrawal cannot be removed.

This research study has been reviewed by the SIM human ethics committee and approval has been granted. 
If you wish to receive an electronic copy of a research report summarizing my analysis of the focus group sessions, please indicate this on the attached 'consent to participation' form.

If you have any further questions regarding this project please contact me via email: hartmut.hoehle@vuw.ac.nz or on my cellphone 0211204902. Alternatively you can contact my supervisor Professor Sid Huff via email: $\underline{\text { sid.huff@vuw.ac.nz }}$ or on landline 044635819.

Regards,

Hartmut Hoehle

Email: Hartmut.hoehle@vuw.ac.nz 


\title{
10.4. Interview guide: focus group discussions
}

\author{
Focus Group Protocol
}

1. Introduction:

- Welcoming the research participants and thanking for participation

- Brief introduction to the research study

- Explain the purpose of the focus groups and clarify the central role of the task-channel fit for the overall study

- Explain why this research aims to identify "Task-channel fit" dimensions

2. Questions directed to the research participants - experience with electronic banking channel

- What are your experiences with electronic banking channels (ATMs, telephone banking services, and mobile banking)?

- How often do you use them?

- Why -and why not- do you use them?

- Could you please elaborate on your goals/intentions if you use each electronic banking channel?

- What banking products do you perform on each electronic banking channel?

\section{Brainstorming: Task-channel Fit Dimensions}

- What are the most important characteristics/features of each electronic banking channel?

- What are the most important characteristics/features of electronic banking tasks/banking products?

- Given your comments above, what do you believe are good "TCF dimensions"? (e.g. capturing the most important features of electronic banking channels \& electronic banking tasks)

4. Task-channel fit dimensions: matching the literature and the "brainstormed" TCF dimensions

- Brief introduction (Hartmut) on the TCF dimensions identified within the literature review (task-complexity, task-time criticality, channel-ease of use, channel-security, and canneldata representation).

- Given the TCF dimensions identified in the previous section, what do you think about these TCF dimensions found in the literature?

- Comparing both - yours and these TCF dimension- do you see any overlappings/similarities?

- How could these dimensions be merged together (if they differ)?

\section{Other comments / concerns}

- Do you have any further comments or concerns related to the task-channel fit dimensions that have not been addressed yet?

- 'Wrap up' of the findings / discussion (Hartmut)

- Thank you very much for your time (Hartmut) and please do not hesitate to contact me or my supervisor in case of further questions. 


\subsection{Discussion on the deviation score analysis}

Matching approach - considerations for signed deviation scores and under- and overfit assumptions

As outlined in section 5.2., deviation score analysis was also considered as an approach for determining the TCF scores. While the absolute difference seemed inappropriate for the current research, a signed deviation score analysis appeared useful for this study. The signed deviation score analysis was appealing particularly since it allowed under- and overfit assumptions (see section 5.2.8 for a more thorough discussion on both approaches).

However, when inspecting the scales used during the main study more closely, it was felt that underand overfit assumptions did not comply with some of the parallel items used during the main study.

To develop a rationale for this, each TCF dimension can be graphically displayed on a line as shown in the following graph.
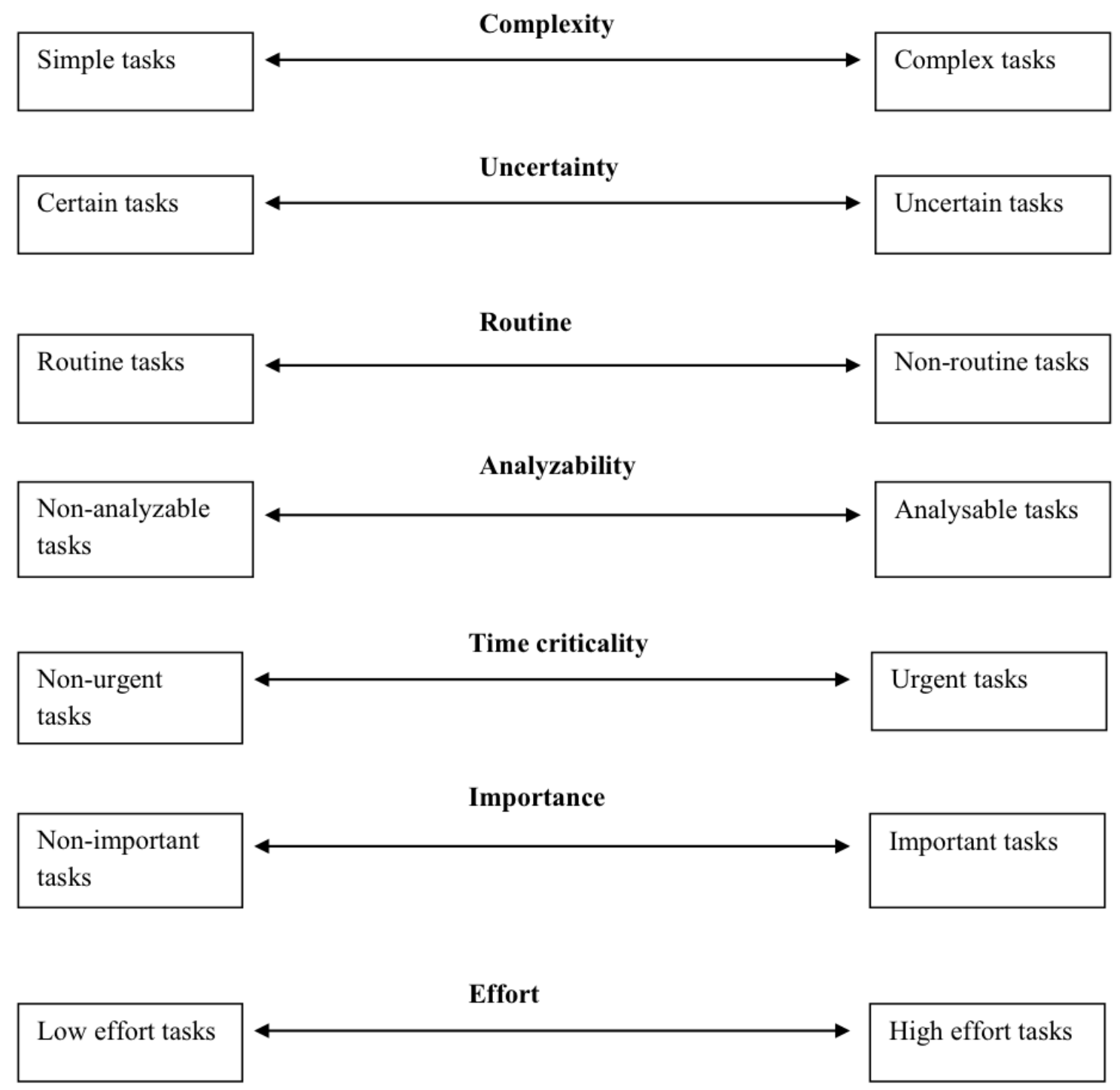
While responding to the survey questionnaire, each respondent was asked to rate account inquiries/financial loans with regards to the above mentioned dimensions.

When inspecting the above mentioned graphs closer, one could argue that the right hand shows those tasks that are challenging to perform whereas the left hand side lists the tasks that are normally perceived as straightforward. Challenging tasks are usually difficult to support from a bank's perspective, whereas straightforward tasks do not require as much support.

In scrutinizing the parallel items used during the main study more thoroughly, one could argue that some of the items were worded towards the 'right side' whereas others were oriented towards the 'left side'. For example, COMP1 and COMP2 asked consumers whether they view account inquiries/loans as complex or difficult banking transactions. These items were clearly anchored on the 'right side' since it would be challenging for banks to support such transactions. In contrast, COMP3 and COMP4 asked respondents about easy-to-do and straightforward banking transactions. These items were oriented towards the 'left side' since it would be easier to support such banking transactions via electronic banking channels.

If applying this rationale to all items used during the main study, one could separate the measures into the 'left' and 'right' side. The following table includes all parallel items used during the main study (note that for simplicity the parallel items are not repeated in here).

\begin{tabular}{|c|c|c|c|}
\hline \multicolumn{2}{|c|}{ Left hand (simple to support) } & \multicolumn{2}{|c|}{ Right hand (difficult to support) } \\
\hline & & COMP1 & $\begin{array}{l}\text { In general, applying for a financial loan is } \\
\text { complex. }\end{array}$ \\
\hline & & COMP2 & $\begin{array}{l}\text { Overall, a financial loan is a complicated } \\
\text { banking transaction. }\end{array}$ \\
\hline COMP3 & $\begin{array}{l}\text { Generally, applying for a financial loan is an } \\
\text { easy-to-do banking task. }\end{array}$ & & \\
\hline \multirow[t]{7}{*}{ COMP4 } & $\begin{array}{l}\text { I would find it straightforward to apply for a } \\
\text { financial loan. }\end{array}$ & & \\
\hline & & $\mathrm{UNC1}$ & $\begin{array}{l}\text { When applying for a financial loan I have many } \\
\text { questions that I want to clarify with my bank } \\
\text { before going ahead with the transaction. }\end{array}$ \\
\hline & & $\mathrm{UNC} 2$ & $\begin{array}{l}\text { Before applying for a financial loan I would } \\
\text { require additional information on how the } \\
\text { process works. }\end{array}$ \\
\hline & & UNC3 & $\begin{array}{l}\text { Obtaining additional information before } \\
\text { applying for a financial loan would be } \\
\text { absolutely essential for me. }\end{array}$ \\
\hline & & EQU1 & $\begin{array}{l}\text { I would feel unsure of myself if I were to apply } \\
\text { for a financial loan. }\end{array}$ \\
\hline & & EQU2 & $\begin{array}{l}\text { I would feel uncertain if applying for a financial } \\
\text { loan myself. }\end{array}$ \\
\hline & & EQU3 & $\begin{array}{l}\text { Applying for a financial loan myself would } \\
\text { make me feel ambiguous. }\end{array}$ \\
\hline ROUT1 & $\begin{array}{l}\text { Applying for a financial loan is a banking } \\
\text { transaction I routinely perform. }\end{array}$ & & \\
\hline ROUT2 & I regularly apply for a financial loan. & & \\
\hline ROUT3 & I often apply for a financial loan. & & \\
\hline \multirow[t]{5}{*}{ ROUT4 } & $\begin{array}{l}\text { A loan application is a banking transaction I } \\
\text { frequently do. }\end{array}$ & & \\
\hline & & ANZBL1 & $\begin{array}{l}\text { Overall, applying for a financial loan requires a } \\
\text { lot of thinking. }\end{array}$ \\
\hline & & ANZBL2 & $\begin{array}{l}\text { Applying for a financial loan requires detailed } \\
\text { consideration. }\end{array}$ \\
\hline & & ANZBL3 & $\begin{array}{l}\text { A financial loan application is a banking } \\
\text { transaction I would plan thoroughly. }\end{array}$ \\
\hline & & ANZBL4 & $\begin{array}{l}\text { A financial loan application is a banking } \\
\text { transaction I would give a lot of thought to. }\end{array}$ \\
\hline
\end{tabular}




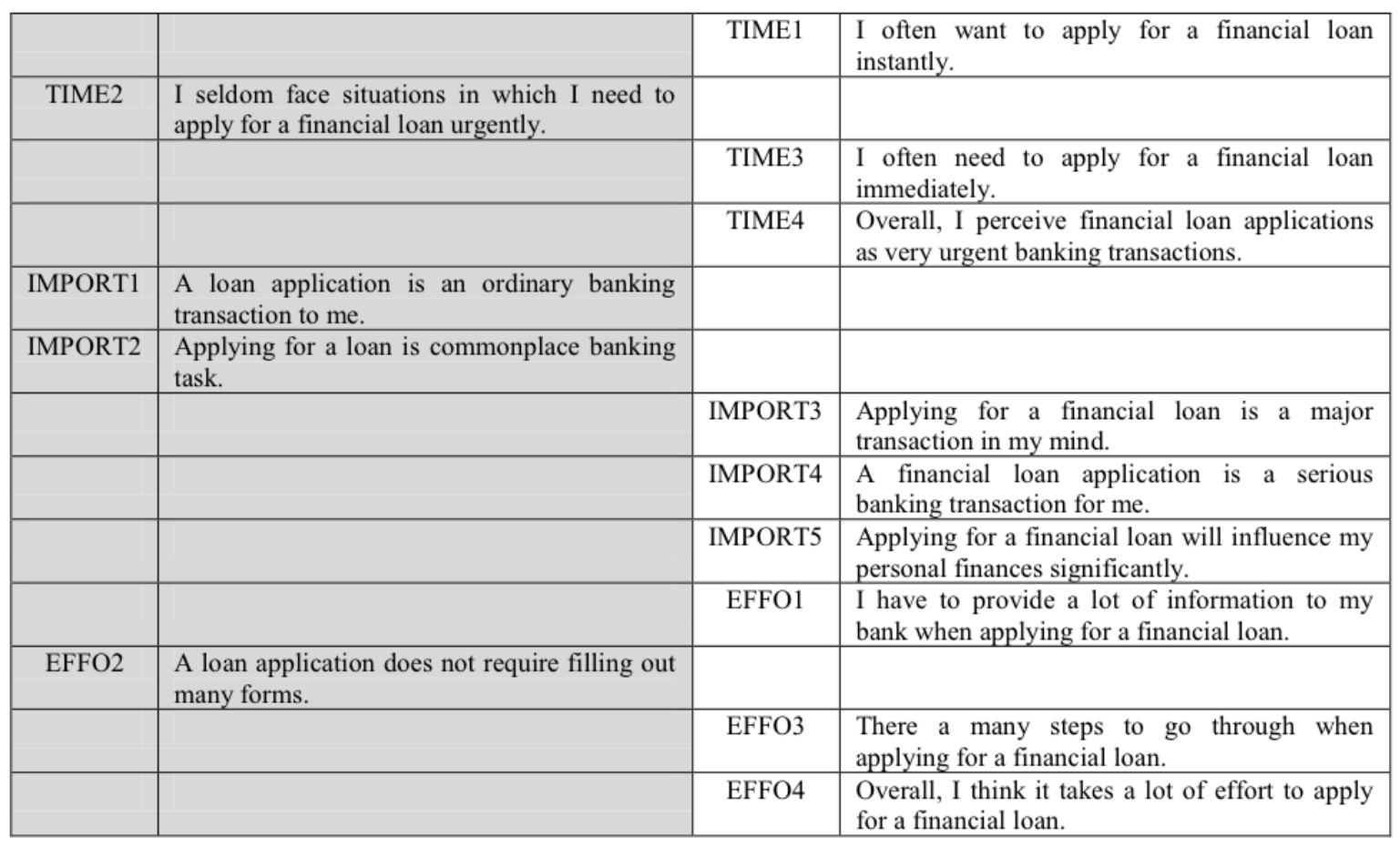

The items on the left side ask respondents about banking tasks that are commonly perceived as straightforward. The right hand side includes the things people usually find challenging to perform (and thus more difficult to support from a bank's perspective).

If making under and overfit assumptions, the 'left side' items do not work due to their wording. For example, CCOMP1 asks whether Internet banking is well suited for complex banking transactions. Respondent 1 (R1 below mentioned Table) indicates that a loan is complex and complex banking tasks are well suited for Internet banking. The matching score is zero (subtracting 7 from 7) indicating a clear fit.

R2 suggests that a loan is not complex but complex transactions are well supported by Internet banking. The fit score would be 6 since 1 (COMP) would be subtracted from 7 (CCOMP1). That could be interpreted as overfit since it is reasonable to argue that Internet banking applications supporting complex tasks also support simple tasks.

R3 views a financial loan as a very complex (indicated by a 7) and believes that complex banking transactions are not well suited for Internet banking. This is a clear misfit since the respondent clearly indicates that the complex banking transactions are not well suited for Internet banking.

Similar under- and overfit assumptions could be made for the remaining 'right side' item combinations.

In contrast, the 'left side' item combinations are problematic if making assumptions regarding underand overfit. For instance, COMP3 inquired respondents of they view a financial loan/account inquiry as an easy-to-do banking task. CCOMP3 then asked if an easy-to-do banking task is well suited for Internet banking. 
Respondent 1 suggests that a financial loan is an easy-to-do banking task and Internet banking is well suited for easy-to-do banking tasks. This response combination should be interpreted as a perfect fit as indicated by a zero deviation score.

Respondent 3 suggests that a financial loan is a straightforward banking task (indicated by a 7) and disagrees with the statement that straightforward banking tasks are well suited for Internet banking applications. This response combination is a misfit and the negative six (deviation score) could be interpreted as such.

However, respondent 2 indicates that he disagrees with the statement that a financial loan application is a straightforward banking task. On the other hand, the same person suggests that straightforward banking tasks are well suited for Internet banking. Thus, respondent 2 is arguing that a financial loan is a difficult banking tasks and that the Internet is well suited for straightforward banking tasks. Logically, there is no connection between the two responses.

Similar issues were apparent for the remaining 'left side' item combinations. The Table below lists all item combinations and provides some response examples to illustrate the issue.

Table: Inspecting the parallel items for over- and underfit assumptions

\begin{tabular}{|c|c|c|c|c|c|}
\hline & \multicolumn{4}{|l|}{$1=$ disagree; $7=$ agree } & \multirow[t]{2}{*}{ Actions taken } \\
\hline & & R1 & $\mathrm{R} 2$ & R3 & \\
\hline COMP1 & $\begin{array}{l}\text { In general, applying for a financial loan is } \\
\text { complex. }\end{array}$ & 7 & 1 & 7 & \multirow{3}{*}{$\begin{array}{l}\text { Set positive values equal to } \\
\text { zero }\end{array}$} \\
\hline CCOMP1 & $\begin{array}{l}\text { IB is well suited for complex banking } \\
\text { transactions. }\end{array}$ & 7 & 7 & 1 & \\
\hline \multicolumn{2}{|c|}{ Fit $(\mathrm{F})=$ Fit, $(\mathrm{O})=$ Overfit, $(\mathrm{U})=$ Underfit } & $0(\mathrm{~F})$ & $6(\mathrm{O})$ & $-6(\mathrm{U})$ & \\
\hline COMP2 & $\begin{array}{l}\text { Overall, a financial loan is a complicated } \\
\text { banking transaction. }\end{array}$ & 7 & 1 & 7 & \multirow{3}{*}{$\begin{array}{l}\text { Set positive values equal to } \\
\text { zero }\end{array}$} \\
\hline CCOMP2 & $\begin{array}{l}\text { IB is well suited for complicated banking } \\
\text { transactions. }\end{array}$ & 7 & 7 & 1 & \\
\hline \multicolumn{2}{|c|}{ Fit $(\mathrm{F})=$ Fit, $(\mathrm{O})=$ Overfit, $(\mathrm{U})=$ Underfit } & $0(\mathrm{~F})$ & $6(\mathrm{O})$ & $-6(U)$ & \\
\hline COMP3* & $\begin{array}{l}\text { Generally, applying for a financial loan is } \\
\text { an easy-to-do banking task. }\end{array}$ & 7 & 1 & 7 & \multirow{3}{*}{ Overfit doesn’t work } \\
\hline CCOMP3* & $\begin{array}{l}\text { Internet is well suited for easy-to-do } \\
\text { banking task. }\end{array}$ & 7 & 7 & 1 & \\
\hline \multicolumn{2}{|c|}{ Fit $(\mathrm{F})=$ Fit, $(\mathrm{O})=$ Overfit, $(\mathrm{U})=$ Underfit } & $0(\mathrm{~F})$ & $6(\mathrm{O})$ & $-6(U)$ & \\
\hline COMP4* & $\begin{array}{l}\text { I would find it straightforward to apply for } \\
\text { a financial loan. }\end{array}$ & 7 & 1 & 7 & \multirow{3}{*}{ Overfit doesn't work } \\
\hline CCOMP4* & $\begin{array}{l}\text { Internet banking is well suited for } \\
\text { straightforward banking transactions. }\end{array}$ & 7 & 7 & 1 & \\
\hline \multicolumn{2}{|c|}{ Fit $(\mathrm{F})=$ Fit, $(\mathrm{O})=$ Overfit, $(\mathrm{U})=$ Underfit } & $0(\mathrm{~F})$ & $6(\mathrm{O})$ & $-6(\mathrm{U})$ & \\
\hline UNC1 & $\begin{array}{l}\text { When applying for a financial loan I have } \\
\text { many questions that I want to clarify with } \\
\text { my bank before going ahead with the } \\
\text { transaction. }\end{array}$ & 7 & 1 & 7 & \multirow{3}{*}{$\begin{array}{l}\text { Set positive values equal to } \\
\text { zero }\end{array}$} \\
\hline CUNC1 & $\begin{array}{l}\text { Internet banking is well suited for } \\
\text { clarifying questions related to a financial } \\
\text { product. }\end{array}$ & 7 & 7 & 1 & \\
\hline \multicolumn{2}{|c|}{ Fit $(\mathrm{F})=$ Fit, $(\mathrm{O})=$ Overfit, $(\mathrm{U})=$ Underfit } & $0(\mathrm{~F})$ & $6(\mathrm{O})$ & $-6(\mathrm{U})$ & \\
\hline UNC2 & $\begin{array}{l}\text { Before applying for a financial loan I } \\
\text { would require additional information on } \\
\text { how the process works. }\end{array}$ & 7 & 1 & 7 & \multirow{3}{*}{$\begin{array}{l}\text { Set positive values equal to } \\
\text { zero }\end{array}$} \\
\hline CUNC2 & $\begin{array}{l}\text { Internet banking is well suited for finding } \\
\text { out additional information on how financial } \\
\text { products work. }\end{array}$ & 7 & 7 & 1 & \\
\hline \multicolumn{2}{|c|}{ Fit $(\mathrm{F})=$ Fit, $(\mathrm{O})=$ Overfit, $(\mathrm{U})=$ Underfit } & $0(\mathrm{~F})$ & $6(\mathrm{O})$ & $-6(\mathrm{U})$ & \\
\hline UNC3 & $\begin{array}{l}\text { Obtaining additional information before } \\
\text { applying for a financial loan would be }\end{array}$ & 7 & 1 & 7 & Set positive values equal to \\
\hline
\end{tabular}




\begin{tabular}{|c|c|c|c|c|c|}
\hline & absolutely essential for me. & & & & \multirow{3}{*}{ zero } \\
\hline CUNC3 & $\begin{array}{l}\text { Internet banking is well suited for obtaining } \\
\text { additional information about financial } \\
\text { products. }\end{array}$ & 7 & 7 & 1 & \\
\hline \multicolumn{2}{|c|}{ Fit $(\mathrm{F})=$ Fit, $(\mathrm{O})=$ Overfit, $(\mathrm{U})=$ Underfit } & $0(\mathrm{~F})$ & $6(\mathrm{O})$ & $-6(U)$ & \\
\hline EQU1 & $\begin{array}{l}\text { I would feel unsure of myself if I were to } \\
\text { apply for a financial loan. }\end{array}$ & 7 & 1 & 7 & \multirow{3}{*}{$\begin{array}{l}\text { Set positive values equal to } \\
\text { zero }\end{array}$} \\
\hline CEQU1 & $\begin{array}{l}\text { Internet banking is well suited for banking } \\
\text { transactions where I feel unsure of myself. }\end{array}$ & 7 & 7 & 1 & \\
\hline \multicolumn{2}{|r|}{ Fit $(\mathrm{F})=$ Fit, $(\mathrm{O})=$ Overfit, $(\mathrm{U})=$ Underfit } & $0(\mathrm{~F})$ & $6(\mathrm{O})$ & $-6(U)$ & \\
\hline EQU2 & $\begin{array}{l}\text { I would feel uncertain if applying for a } \\
\text { financial loan myself. }\end{array}$ & 7 & 1 & 7 & \multirow{3}{*}{$\begin{array}{l}\text { Set positive values equal to } \\
\text { zero }\end{array}$} \\
\hline CEQU2 & $\begin{array}{l}\text { Internet banking is well suited for banking } \\
\text { transactions where I feel uncertain of } \\
\text { myself. }\end{array}$ & 7 & 7 & 1 & \\
\hline \multicolumn{2}{|c|}{ Fit $(\mathrm{F})=$ Fit, $(\mathrm{O})=$ =verfit, $(\mathrm{U})=$ Underfit } & $0(\mathrm{~F})$ & $6(0)$ & $-6(U)$ & \\
\hline EQU3 & $\begin{array}{l}\text { Applying for a financial loan myself would } \\
\text { make me feel ambiguous. }\end{array}$ & 7 & 1 & 7 & \multirow{3}{*}{$\begin{array}{l}\text { Set positive values equal to } \\
\text { zero }\end{array}$} \\
\hline CEQU3 & $\begin{array}{llll}\begin{array}{l}\text { Banking transactions } \\
\text { ambiguous. }\end{array} & \text { where } & \text { I feel } \\
\end{array}$ & 7 & 7 & 1 & \\
\hline \multicolumn{2}{|c|}{ Fit $(\mathrm{F})=$ Fit, $(\mathrm{O})=$ Overfit, $(\mathrm{U})=$ Underfit } & $0(\mathrm{~F})$ & $6(\mathrm{O})$ & $-6(U)$ & \\
\hline ROUT1 & $\begin{array}{l}\text { Applying for a financial loan is a banking } \\
\text { transaction I routinely perform. }\end{array}$ & 7 & 1 & 7 & \multirow{3}{*}{ Overfit doesn't work } \\
\hline CROUT1 & $\begin{array}{l}\text { Internet banking is well suited for banking } \\
\text { transaction I routinely perform. }\end{array}$ & 7 & 7 & 1 & \\
\hline \multicolumn{2}{|c|}{ Fit $(\mathrm{F})=$ Fit, $(\mathrm{O})=$ Overfit, $(\mathrm{U})=$ Underfit } & $0(\mathrm{~F})$ & $6(\mathrm{O})$ & $-6(U)$ & \\
\hline ROUT2 & I regularly apply for a financial loan. & 7 & 1 & 7 & \multirow{3}{*}{ Overfit doesn't work } \\
\hline CROUT2 & $\begin{array}{l}\text { Internet banking is well suited for banking } \\
\text { transactions I regularly do. }\end{array}$ & 7 & 7 & 1 & \\
\hline \multicolumn{2}{|c|}{ Fit $(\mathrm{F})=$ Fit, $(\mathrm{O})=$ =verfit, $(\mathrm{U})=$ Underfit } & $0(\mathrm{~F})$ & $6(\mathrm{O})$ & $-6(U)$ & \\
\hline ROUT3 & I often apply for a financial loan. & 7 & 1 & 7 & \multirow{3}{*}{ Overfit doesn't work } \\
\hline CROUT3 & $\begin{array}{l}\text { Internet banking is well suited for banking } \\
\text { transactions I often do. }\end{array}$ & 7 & 7 & 1 & \\
\hline \multicolumn{2}{|c|}{ Fit $(\mathrm{F})=$ Fit, $(\mathrm{O})=$ Overfit, $(\mathrm{U})=$ Underfit } & $0(\mathrm{~F})$ & $6(\mathrm{O})$ & $-6(U)$ & \\
\hline ROUT4 & I frequently apply for a financial loan. & 7 & 1 & 7 & \multirow{3}{*}{ Overfit doesn't work } \\
\hline CROUT4 & $\begin{array}{l}\text { Internet banking is well suited for banking } \\
\text { transactions I frequently do. }\end{array}$ & 7 & 7 & 1 & \\
\hline \multicolumn{2}{|c|}{ Fit $(\mathrm{F})=$ Fit, $(\mathrm{O})=$ Overfit, $(\mathrm{U})=$ Underfit } & $0(\mathrm{~F})$ & $6(\mathrm{O})$ & $-6(U)$ & \\
\hline ANZBL1 & $\begin{array}{l}\text { Overall, applying for a financial loan } \\
\text { requires a lot of thinking. }\end{array}$ & 7 & 1 & 7 & \multirow{3}{*}{$\begin{array}{l}\text { Set positive values equal to } \\
\text { zero }\end{array}$} \\
\hline CANZBL1 & $\begin{array}{l}\text { Banking transactions that require a lot of } \\
\text { thinking. }\end{array}$ & 7 & 7 & 1 & \\
\hline \multicolumn{2}{|c|}{ Fit $(\mathrm{F})=$ Fit, $(\mathrm{O})=$ Overfit, $(\mathrm{U})=$ Underfit } & $0(\mathrm{~F})$ & $6(\mathrm{O})$ & $-6(U)$ & \\
\hline ANZBL2 & $\begin{array}{l}\text { Applying for a financial loan requires } \\
\text { detailed consideration. }\end{array}$ & 7 & 1 & 7 & \multirow{3}{*}{$\begin{array}{l}\text { Set positive values equal to } \\
\text { zero }\end{array}$} \\
\hline CANZBL2 & $\begin{array}{l}\text { Banking transactions that require detailed } \\
\text { consideration. }\end{array}$ & 7 & 7 & 1 & \\
\hline \multicolumn{2}{|c|}{ Fit $(\mathrm{F})=$ Fit, $(\mathrm{O})=$ Overfit, $(\mathrm{U})=$ Underfit } & $0(\mathrm{~F})$ & $6(\mathrm{O})$ & $-6(U)$ & \\
\hline ANZBL3 & $\begin{array}{l}\text { A financial loan application is a banking } \\
\text { transaction I would plan thoroughly. }\end{array}$ & 7 & 1 & 7 & \multirow{3}{*}{$\begin{array}{l}\text { Set positive values equal to } \\
\text { zero }\end{array}$} \\
\hline CANZBL3 & Thoroughly planning banking products. & 7 & 7 & 1 & \\
\hline \multicolumn{2}{|c|}{ Fit $(\mathrm{F})=$ Fit, $(\mathrm{O})=$ Overfit, $(\mathrm{U})=$ Underfit } & $0(\mathrm{~F})$ & $6(\mathrm{O})$ & $-6(U)$ & \\
\hline ANZBL4 & $\begin{array}{l}\text { A financial loan application is a banking } \\
\text { transaction I would give a lot of thought to. }\end{array}$ & 7 & 1 & 7 & \multirow{3}{*}{$\begin{array}{l}\text { Set positive values equal to } \\
\text { zero }\end{array}$} \\
\hline CANZBL4 & $\begin{array}{l}\text { Banking transactions I would give a lot of } \\
\text { thought to. }\end{array}$ & 7 & 7 & 1 & \\
\hline \multicolumn{2}{|c|}{ Fit $(\mathrm{F})=$ Fit, $(\mathrm{O})=$ =verfit, $(\mathrm{U})=$ Underfit } & $0(\mathrm{~F})$ & $6(\mathrm{O})$ & $-6(U)$ & \\
\hline TIME1 & $\begin{array}{l}\text { I often want to apply for a financial loan } \\
\text { instantly. }\end{array}$ & 7 & 1 & 7 & \multirow{3}{*}{$\begin{array}{l}\text { Set positive values equal to } \\
\text { zero }\end{array}$} \\
\hline CTIME1 & Banking transactions I want to do instantly. & 7 & 7 & 1 & \\
\hline \multicolumn{2}{|c|}{ Fit $(\mathrm{F})=$ Fit, $(\mathrm{O})=$ Overfit, $(\mathrm{U})=$ Underfit } & $0(\mathrm{~F})$ & $6(\mathrm{O})$ & $-6(U)$ & \\
\hline
\end{tabular}




\begin{tabular}{|c|c|c|c|c|c|}
\hline TIME2* & $\begin{array}{l}\text { I seldom face situations in which I need to } \\
\text { apply for a financial loan urgently.* }\end{array}$ & 7 & 1 & 7 & \multirow{3}{*}{ Overfit doesn’t work } \\
\hline CTIME2* & $\begin{array}{l}\text { Banking transactions I do not need to do } \\
\text { urgently.* }\end{array}$ & 7 & 7 & 1 & \\
\hline \multicolumn{2}{|c|}{ Fit $(\mathrm{F})=$ Fit, $(\mathrm{O})=$ Overfit, $(\mathrm{U})=$ =Underfit } & $0(\mathrm{~F})$ & $6(\mathrm{O})$ & $-6(U)$ & \\
\hline TIME3 & $\begin{array}{l}\text { I often need to apply for a financial loan } \\
\text { immediately. }\end{array}$ & 7 & 1 & 7 & \multirow{3}{*}{$\begin{array}{l}\text { Set positive values equal to } \\
\text { zero }\end{array}$} \\
\hline CTIME3 & $\begin{array}{l}\text { Banking transactions I have to do } \\
\text { immediately. }\end{array}$ & 7 & 7 & 1 & \\
\hline \multicolumn{2}{|c|}{ Fit $(\mathrm{F})=$ Fit, $(\mathrm{O})=$ Overfit, $(\mathrm{U})=$ Underfit } & $0(\mathrm{~F})$ & $6(\mathrm{O})$ & $-6(\mathrm{U})$ & \\
\hline TIME4 & 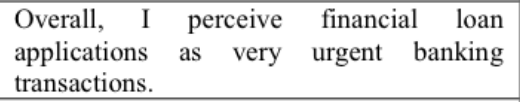 & 7 & 1 & 7 & \multirow{3}{*}{$\begin{array}{l}\text { Set positive values equal to } \\
\text { zero }\end{array}$} \\
\hline CTIME4 & $\begin{array}{l}\text { Banking transactions that are very urgent to } \\
\text { me. }\end{array}$ & 7 & 7 & 1 & \\
\hline \multicolumn{2}{|c|}{ Fit $(\mathrm{F})=$ Fit, $(\mathrm{O})=$ Overfit, $(\mathrm{U})=$ Underfit } & $0(\mathrm{~F})$ & $6(\mathrm{O})$ & $-6(U)$ & \\
\hline IMPOR1* & $\begin{array}{l}\text { A loan application is an ordinary banking } \\
\text { transaction to me.* }\end{array}$ & 7 & 1 & 7 & \multirow{3}{*}{ Overfit doesn't work } \\
\hline CIMPOR ${ }^{*}$ & Ordinary banking transactions. ${ }^{*}$ & 7 & 7 & 1 & \\
\hline \multicolumn{2}{|c|}{ Fit $(\mathrm{F})=$ Fit, $(\mathrm{O})=$ Overfit, $(\mathrm{U})=$ Underfit } & $0(\mathrm{~F})$ & $6(\mathrm{O})$ & $-6(U)$ & \\
\hline IMPOR2* & $\begin{array}{l}\text { Applying for a loan is commonplace } \\
\text { banking task.* }\end{array}$ & 7 & 1 & 7 & \multirow{3}{*}{ Overfit doesn't work } \\
\hline CIMPOR2* & Commonplace banking transactions. ${ }^{*}$ & 7 & 7 & 1 & \\
\hline \multicolumn{2}{|c|}{ Fit $(\mathrm{F})=$ Fit, $(\mathrm{O})=$ Overfit, $(\mathrm{U})=$ Underfit } & $0(\mathrm{~F})$ & $6(\mathrm{O})$ & $-6(U)$ & \\
\hline IMPOR3 & $\begin{array}{l}\text { Applying for a financial loan is a major } \\
\text { transaction in my mind. }\end{array}$ & 7 & 1 & 7 & \multirow{3}{*}{$\begin{array}{l}\text { Set positive values equal to } \\
\text { zero }\end{array}$} \\
\hline CIMPOR3 & Major banking transactions & 7 & 7 & 1 & \\
\hline \multicolumn{2}{|c|}{ Fit $(\mathrm{F})=$ Fit, $(\mathrm{O})=$ =verfit, $(\mathrm{U})=$ Underfit } & $0(\mathrm{~F})$ & $6(\mathrm{O})$ & $-6(U)$ & \\
\hline IMPOR4 & $\begin{array}{l}\text { A financial loan application is a serious } \\
\text { banking transaction for me. }\end{array}$ & 7 & 1 & 7 & \multirow{3}{*}{$\begin{array}{l}\text { Set positive values equal to } \\
\text { zero }\end{array}$} \\
\hline CIMPOR4 & Serious banking transactions. & 7 & 7 & 1 & \\
\hline \multicolumn{2}{|c|}{ Fit $(\mathrm{F})=$ Fit, $(\mathrm{O})=$ Overfit, $(\mathrm{U})=$ Underfit } & $0(\mathrm{~F})$ & $6(\mathrm{O})$ & $-6(U)$ & \\
\hline IMPOR5 & $\begin{array}{l}\text { Applying for a financial loan will influence } \\
\text { my personal finances significantly. }\end{array}$ & 7 & 1 & 7 & \multirow{3}{*}{$\begin{array}{l}\text { Set positive values equal to } \\
\text { zero }\end{array}$} \\
\hline CIMPOR5 & $\begin{array}{l}\text { Banking transactions that influence my } \\
\text { personal finances significantly. }\end{array}$ & 7 & 7 & 1 & \\
\hline \multicolumn{2}{|c|}{ Fit $(\mathrm{F})=$ Fit, $(\mathrm{O})=$ Overfit, $(\mathrm{U})=$ Underfit } & $0(\mathrm{~F})$ & $6(\mathrm{O})$ & $-6(U)$ & \\
\hline EFFOR1 & $\begin{array}{l}\text { I have to provide a lot of information to my } \\
\text { bank when applying for a financial loan. }\end{array}$ & 7 & 1 & 7 & \multirow{3}{*}{$\begin{array}{l}\text { Set positive values equal to } \\
\text { zero }\end{array}$} \\
\hline CEFFOR1 & $\begin{array}{l}\text { Banking transactions for which I have to } \\
\text { provide a lot of information to my bank. }\end{array}$ & 7 & 7 & 1 & \\
\hline \multicolumn{2}{|c|}{ Fit $(\mathrm{F})=$ Fit, $(\mathrm{O})=$ Overfit, $(\mathrm{U})=$ Underfit } & $0(\mathrm{~F})$ & $6(0)$ & $-6(U)$ & \\
\hline EFFOR2* & $\begin{array}{l}\text { A loan application does not require filling } \\
\text { out many forms.* }\end{array}$ & 7 & 1 & 7 & \multirow{3}{*}{ Overfit doesn't work } \\
\hline CEFFOR2* & $\begin{array}{l}\text { Banking transactions that do not require } \\
\text { filling out many forms.* }\end{array}$ & 7 & 7 & 1 & \\
\hline \multicolumn{2}{|c|}{ Fit $(\mathrm{F})=$ Fit, $(\mathrm{O})=$ Overfit, $(\mathrm{U})=$ Underfit } & $0(\mathrm{~F})$ & $6(\mathrm{O})$ & $-6(U)$ & \\
\hline EFFOR3 & $\begin{array}{l}\text { There a many steps to go through when } \\
\text { applying for a financial loan. }\end{array}$ & 7 & 1 & 7 & \multirow{3}{*}{$\begin{array}{l}\text { Set positive values equal to } \\
\text { zero }\end{array}$} \\
\hline CEFFOR3 & $\begin{array}{l}\begin{array}{l}\text { Banking transactions that } \\
\text { performing many steps. }\end{array} \\
\end{array}$ & 7 & 7 & 1 & \\
\hline \multicolumn{2}{|c|}{ Fit $(\mathrm{F})=$ Fit, $(\mathrm{O})=$ Overfit, $(\mathrm{U})=$ Underfit } & $0(\mathrm{~F})$ & $6(\mathrm{O})$ & $-6(U)$ & \\
\hline EFFOR4 & $\begin{array}{l}\text { Overall, I think it takes a lot of effort to } \\
\text { apply for a financial loan. }\end{array}$ & 7 & 1 & 7 & \multirow{3}{*}{$\begin{array}{l}\text { Set positive values equal to } \\
\text { zero }\end{array}$} \\
\hline CEFFOR4 & $\begin{array}{l}\text { Banking transactions that take a lot of } \\
\text { effort. }\end{array}$ & 7 & 7 & 1 & \\
\hline \multicolumn{2}{|c|}{ Fit $(\mathrm{F})=$ Fit, $(\mathrm{O})=$ Overfit, $(\mathrm{U})=$ Underfit } & $0(\mathrm{~F})$ & $6(0)$ & $-6(U)$ & \\
\hline
\end{tabular}

This issue was realized after the data collection took place. It was concluded that including the deviation scores computed via the responses obtained for the 'left side' items would generate 
inaccurate results. Thus, these items were excluded from the deviation score analysis. Next, the steps outlined in section were repeated as outlined in Chapter 6 with the signed deviation scores.

Table: Item selection: redundancy analysis / main study / complete dataset $(n=340)$

\begin{tabular}{|c|c|c|c|c|c|c|c|}
\hline \multirow[b]{3}{*}{ Product scores } & \multicolumn{6}{|c|}{ Complete dataset $(n=340)$} & \multirow[b]{3}{*}{$\begin{array}{l}\text { Sum } \mathbf{R}^{2} \\
\text { explained } \\
\text { in ATT } \\
\& \mathrm{PU}\end{array}$} \\
\hline & \multicolumn{3}{|c|}{ Perceived Usefulness } & \multicolumn{3}{|c|}{ Attitude } & \\
\hline & T-value & Beta & $\mathbf{R}^{2}$ & $\begin{array}{l}\text { T- } \\
\text { value }\end{array}$ & Beta & $\mathbf{R}^{2}$ & \\
\hline TCF_ANZBL1 & 12.905 & 0.528 & 0.279 & 12.039 & 0.525 & 0.275 & 0.55 \\
\hline TCF_ANZBL2 & 12.527 & 0.519 & 0.269 & 12.018 & 0.528 & 0.279 & 0.55 \\
\hline TCF_ANZBL3 & 17.687 & 0.567 & 0.321 & 14.503 & 0.533 & 0.284 & 0.61 \\
\hline TCF_ANZBL4 & 12.433 & 0.495 & 0.245 & 11.792 & 0.487 & 0.237 & 0.48 \\
\hline TCF_COMP1 & 9.624 & 0.417 & 0.174 & 10.177 & 0.480 & 0.231 & 0.41 \\
\hline TCF_COMP2 & 9.393 & 0.431 & 0.186 & 10.008 & 0.460 & 0.211 & 0.40 \\
\hline TCF_EFFOR1 & 10.106 & 0.448 & 0.211 & 10.282 & 0.453 & 0.210 & 0.42 \\
\hline TCF_EFFOR3 & 9.575 & 0.424 & 0.180 & 10.940 & 0.482 & 0.232 & 0.41 \\
\hline TCF_EFFOR4 & 8.232 & 0.396 & 0.156 & 8.898 & 0.446 & 0.199 & 0.36 \\
\hline TCF_IMPOR3 & 12.439 & 0.482 & 0.232 & 11.042 & 0.481 & 0.231 & 0.46 \\
\hline TCF_IMPOR4 & 9.233 & 0.440 & 0.193 & 10.452 & 0.479 & 0.230 & 0.42 \\
\hline TCF_IMPOR5 & 6.812 & 0.326 & 0.107 & 7.693 & 0.373 & 0.139 & 0.25 \\
\hline TCF_UNC1 & 11.333 & 0.449 & 0.202 & 17.729 & 0.584 & 0.341 & 0.54 \\
\hline TCF_UNC2 & 14.447 & 0.516 & 0.266 & 18.201 & 0.599 & 0.359 & 0.63 \\
\hline TCF_UNC3 & 10.125 & 0.434 & 0.188 & 11.941 & 0.516 & 0.266 & 0.45 \\
\hline TCF_EQU1 & 6.449 & 0.321 & 0.103 & 6.963 & 0.381 & 0.145 & 0.25 \\
\hline TCF_EQU2 & 6.342 & 0.351 & 0.123 & 7.677 & 0.392 & 0.153 & 0.28 \\
\hline TCF_EQU3 & 3.976 & 0.228 & 0.051 & 5.536 & 0.279 & 0.078 & 0.13 \\
\hline TCF_TIME1 & 6.471 & -0.320 & 0.103 & 5.091 & -0.270 & 0.073 & 0.18 \\
\hline TCF_TIME3 & 5.372 & -0.267 & 0.071 & 4.123 & -0.212 & 0.045 & 0.12 \\
\hline TCF_TIME4 & 0.765 & 0.083 & 0.007 & 2.064 & 0.110 & 0.012 & 0.02 \\
\hline
\end{tabular}

Table: VIF statistics for formative measures (individual ct scores)/main study

\begin{tabular}{|c|c|c|c|}
\hline Formative item & $\begin{array}{l}\text { VIF_complete } \\
\text { dataset }\end{array}$ & VIF_loans & $\begin{array}{l}\text { VIF_account } \\
\text { inquiries }\end{array}$ \\
\hline TCF_ANZBL3 & 2.12 & 1.42 & 1.42 \\
\hline TCF_COMP1 & 2.07 & 1.55 & 1.84 \\
\hline TCF_EFFORT1 & 2.09 & 1.46 & 1.35 \\
\hline TCF_IMP3 & 1.89 & 1.46 & 1.41 \\
\hline TCF_UNC2 & 1.81 & 1.22 & 1.40 \\
\hline TCF_EQU2 & 1.56 & 1.25 & 1.48 \\
\hline TCF_TIME1 & 1.18 & 1.02 & 1.10 \\
\hline
\end{tabular}


Table: Formative measures t-values and item weights - individual deviation scores/main study

\begin{tabular}{|c|c|c|c|c|c|c|}
\hline & \multicolumn{2}{|c|}{ Complete dataset } & \multicolumn{2}{c|}{ Financial loans } & \multicolumn{2}{c|}{ Account inquiries } \\
\hline Formative measure & T-stat. & $\begin{array}{l}\text { Weight } \\
\text { (loading) }\end{array}$ & $\begin{array}{l}\text { T- } \\
\text { statistic }\end{array}$ & $\begin{array}{l}\text { Weight } \\
\text { (loading) }\end{array}$ & $\begin{array}{l}\text { T- } \\
\text { statistic }\end{array}$ & $\begin{array}{l}\text { Weight } \\
\text { (loading) }\end{array}$ \\
\hline TCF_ANZBL3->TCF & $3.79 * * *$ & $0.31(0.84)$ & $3.25 * *$ & $0.21(0.73)$ & $2.33 *$ & $0.14(0.70)$ \\
\hline TCF_COMP1->TCF & $2.14 *$ & $0.15(0.69)$ & 1.38 & $0.27(0.52)$ & 1.58 & $0.30(0.68)$ \\
\hline TCF_EFFORT1->TCF & 0.41 & $0.02(0.69)$ & 1.30 & $0.12(0.29)$ & 0.68 & $0.15(0.47)$ \\
\hline TCF_IMP3->TCF & $2.10^{*}$ & $0.18(0.75)$ & 1.54 & $0.28(0.60)$ & 1.74 & $0.24(0.63)$ \\
\hline TCF_UNC2->TCF & $6.66 * * *$ & $0.46(0.87)$ & $4.62 * * *$ & $0.47(0.79)$ & $4.60 * * *$ & $0.38(0.84)$ \\
\hline TCF_EQU2->TCF & 0.36 & $0.02(0.56)$ & 0.07 & $0.31(0.34)$ & 0.82 & $0.12(0.52)$ \\
\hline TCF_TIME1->TCF & $2.41 *$ & $-0.17(-0.46)$ & 1.80 & $-0.19(-0.28)$ & 1.75 & $-0.07(0.36)$ \\
\hline \multicolumn{7}{|c|}{$*$ significant at p<0.05, $* *$ significant at p<0.01 and *** significant at p<0.001 } \\
\hline
\end{tabular}

Table: Redundancy analysis - individual deviation score analysis/main study

\begin{tabular}{|l|c|c|c|l|l|l|}
\hline & \multicolumn{2}{|c|}{ Complete dataset } & \multicolumn{2}{c|}{ Financial loans } & \multicolumn{2}{c|}{ Account inquiries } \\
\hline Construct relations & $\begin{array}{l}\text { T- } \\
\text { statistic }\end{array}$ & $\begin{array}{l}\text { Correlation } \\
\text { coefficient) }\end{array}$ & $\begin{array}{l}\text { T- } \\
\text { statistic }\end{array}$ & $\begin{array}{l}\text { Correlation } \\
\text { coefficient) }\end{array}$ & $\begin{array}{l}\text { T- } \\
\text { statistic }\end{array}$ & $\begin{array}{l}\text { Correlation } \\
\text { coefficient }\end{array}$ \\
\hline $\begin{array}{l}\text { TCF (all items) -> TCF } \\
\text { reflective }\end{array}$ & 21.60 & $\begin{array}{c}0.64(0.407 \\
\left.\mathrm{R}^{2}\right)\end{array}$ & $7.766^{* * *}$ & $0.43\left(0.183 \mathrm{R}^{2}\right)$ & $8.877^{* * *}$ & $0.45\left(0.20 \mathrm{R}^{2}\right)$ \\
\hline $\begin{array}{l}\text { TCF (reduced set of } \\
\text { items) -> TCF reflective }\end{array}$ & 21.79 & $\begin{array}{c}0.637(0.406 \\
\left.\mathrm{R}^{2}\right)\end{array}$ & $6.076^{* * *}$ & $0.424(0.180$ & $8.423 * * *$ & $0.434(0.188$ \\
\hline \multicolumn{7}{|c|}{ * significant at p<0.05, ** significant at p<0.01 and *** significant at p<0.001 } \\
\hline \multicolumn{7}{|c|}{ Reduced set - excluding TCF_effort1 and TCF_EQU2 } \\
\hline
\end{tabular}

Table: VIF statistics for the reduced set of formative measures/main study

\begin{tabular}{|l|c|c|c|}
\hline Formative item & $\begin{array}{l}\text { Complete } \\
\text { dataset }\end{array}$ & VIF_loans & $\begin{array}{l}\text { VIF_account } \\
\text { inquiries }\end{array}$ \\
\hline MEAN_TCF_anzbl & 3.06 & 2.31 & 2.30 \\
\hline MEAN_TCF_comp & 2.04 & 1.33 & 1.50 \\
\hline MEAN_TCF_effort & 2.08 & 1.53 & 1.91 \\
\hline MEAN_TCF_import & 4.23 & 2.39 & 2.38 \\
\hline MEAN_TCF_rout & 1.10 & 1.03 & 1.28 \\
\hline MEAN_TCF_equi & 2.48 & 1.93 & 1.86 \\
\hline MEAN_TCF_uncert & 3.86 & 2.62 & 2.18 \\
\hline MEAN_TCF_time & 3.06 & 2.31 & 2.30 \\
\hline
\end{tabular}


Table: Formative measures t-values and item weights - 'average' deviation scores/main study

\begin{tabular}{|l|c|c|c|l|c|l|}
\hline & \multicolumn{2}{|c|}{ Complete dataset } & \multicolumn{2}{c|}{ Financial loans } & \multicolumn{2}{c|}{ Account inquiries } \\
\hline Formative measure & $\begin{array}{l}\text { T- } \\
\text { statistic }\end{array}$ & $\begin{array}{l}\text { Weight } \\
\text { (loading) }\end{array}$ & $\begin{array}{l}\text { T- } \\
\text { statisti } \\
\text { c }\end{array}$ & $\begin{array}{l}\text { Weight } \\
\text { loading) }\end{array}$ & $\begin{array}{l}\text { T- } \\
\text { statistic }\end{array}$ & $\begin{array}{l}\text { Weight } \\
\text { (loading) }\end{array}$ \\
\hline MEAN_ANZ -> TCF & $3.52^{* * *}$ & $0.35(0.90)$ & 1.72 & $0.28(0.70)$ & 1.35 & $0.19(0.78)$ \\
\hline MEAN_COMP-> TCF & 1.41 & $0.12(0.74)$ & 1.01 & $0.13(0.45)$ & $1.98^{*}$ & $0.40(0.80)$ \\
\hline MEAN_EFFORT-> TCF & 0.87 & $-0.07(0.76)$ & 1.42 & $-0.28(0.40)$ & 0.06 & $0.01(0.62)$ \\
\hline MEAN_IMP -> TCF & $2.51^{*}$ & $0.22(0.79)$ & $2.30^{*}$ & $0.35(0.68)$ & 1.20 & $0.14(0.70)$ \\
\hline MEAN_UNC -> TCF & $6.84^{* * *}$ & $0.50(0.89)$ & $5.57^{* * *}$ & $0.68(0.86)$ & $3.32 * * *$ & $0.47(0.83)$ \\
\hline MEAN_EQU -> TCF & 0.65 & $-0.04(0.60)$ & 0.55 & $-0.05(0.35)$ & 0.81 & $-0.10(0.55)$ \\
\hline MEAN_TIME -> TCF & $3.13 * *$ & $-0.17(-0.33)$ & $1.96 *$ & $-0.21(-0.18)$ & $1.96 *$ & $0.18(0.52)$ \\
\hline \multicolumn{6}{|c|}{$*$ significant at p<0.05, ** significant at p<0.01 and *** significant at p<0.001 } \\
\hline
\end{tabular}

Table: Redundancy analysis - 'mean' deviation score analysis/main study

\begin{tabular}{|c|c|c|c|c|c|c|}
\hline \multirow[b]{2}{*}{ Construct relations } & \multicolumn{2}{|c|}{ Complete dataset } & \multicolumn{2}{|c|}{ Financial loans } & \multicolumn{2}{|c|}{ Account inquiries } \\
\hline & $\begin{array}{l}\text { T- } \\
\text { statistic }\end{array}$ & $\begin{array}{l}\text { Correlation } \\
\text { coefficient) }\end{array}$ & $\begin{array}{l}\text { T- } \\
\text { statistic }\end{array}$ & $\begin{array}{l}\text { Correlation } \\
\text { coefficient) }\end{array}$ & $\begin{array}{l}\text { T- } \\
\text { statistic }\end{array}$ & $\begin{array}{l}\text { Correlation } \\
\text { coefficient }\end{array}$ \\
\hline $\begin{array}{c}\text { TCF (all items) -> TCF } \\
\text { reflective }\end{array}$ & 22.105 & $\begin{array}{c}0.651(0.424 \\
\left.\mathrm{R}^{2}\right)\end{array}$ & $\begin{array}{c}8.568^{* *} \\
*\end{array}$ & $\begin{array}{c}0.467(0.218 \\
\left.\mathrm{R}^{2}\right)\end{array}$ & $\begin{array}{c}8.418^{* *} \\
*\end{array}$ & $\begin{array}{c}0.464(0.215 \\
\left.\mathrm{R}^{2}\right)\end{array}$ \\
\hline $\begin{array}{c}\text { TCF (reduced set of } \\
\text { items) -> TCF reflective }\end{array}$ & 21.826 & $\begin{array}{c}0.651 \\
\left(0.423 \mathrm{R}^{2}\right)\end{array}$ & $\begin{array}{c}8.358 * * \\
*\end{array}$ & $\begin{array}{c}0.465(0.216 \\
\left.\mathrm{R}^{2}\right)\end{array}$ & $\begin{array}{l}7.827 * * \\
*\end{array}$ & $\begin{array}{c}0.440(0.194 \\
\left.\mathrm{R}^{2}\right)\end{array}$ \\
\hline \multicolumn{7}{|c|}{${ }^{*}$ significant at $\mathrm{p}<0.05,{ }^{* *}$ significant at $\mathrm{p}<0.01$ and ${ }^{* * *}$ significant at $\mathrm{p}<0.001$} \\
\hline & Reduced & 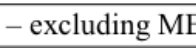 & EFFO & d MEAN & & \\
\hline
\end{tabular}

Table: Structural model results - complete dataset $(n=340) /$ main study

\begin{tabular}{|c|c|c|c|}
\hline \multirow{2}{*}{\multicolumn{2}{|c|}{ Hypothesis }} & \multicolumn{2}{|c|}{ Complete dataset $(n=340)$} \\
\hline & & \multirow{2}{*}{$\begin{array}{c}\text { (individual deviation scores) } \\
\text { T-value: } 3.29^{* * *} \text {, Coefficient: } 0.20\end{array}$} & \multirow{2}{*}{$\begin{array}{c}\text { (average deviation scores) } \\
\text { T-value: } 2.99^{* *}, \text { Coefficient: } 0.17\end{array}$} \\
\hline H1 & $\mathrm{TCF} \rightarrow \mathrm{PU}$ & & \\
\hline H2 & TCF $\rightarrow$ INT & T-value: 1.75 Coefficient: 0.05 & T-value: 2.42 Coefficient: 0.09 \\
\hline H3 & TCF $\rightarrow$ ATT & T-value: $22.08^{* * *}$,Coefficient: 0.66 & T-value:22.63***,Coefficient: 0.67 \\
\hline H4 & PU $\rightarrow$ INT & T-value: $2.42 *$, Coefficient: 0.15 & T-value: $2.79^{* *}$, Coefficient: 0.15 \\
\hline H5a & EOU $\rightarrow$ INT & T-value: $3.16^{* *}$, Coefficient: 0.23 & T-value: $3.29 * * *$, Coefficient: 0.22 \\
\hline H5b & $\mathbf{E O U} \rightarrow \mathbf{P U}$ & T-value: $10.27^{* * *}$, Coefficient: 0.66 & T-value: $10.32 * * *$, Coefficient: 0.67 \\
\hline H6 & ATT $\rightarrow$ INT & T-value: $4.16^{* * *}$, Coefficient: 0.33 & T-value: $4.23^{* * *}$, Coefficient: 0.32 \\
\hline H7 & SN $\rightarrow$ INT & T-value: $2.20^{*}$, Coefficient: 0.06 & T-value: 2.07 , Coefficient: 0.06 \\
\hline H8 & SEC $\rightarrow$ INT & T-value: $3.16^{* *}$, Coefficient: 0.16 & T-value: $3.06^{*}$, Coefficient: 0.16 \\
\hline H9 & COST $\rightarrow$ INT & T-value: 1.54 , Coefficient: -0.06 & T-value: 1.70 , Coefficient: -0.06 \\
\hline \multicolumn{4}{|c|}{$*$ significant at $\mathrm{p}<0.05, * *$ significant at $\mathrm{p}<0.01$ and $* * *$ significant at $\mathrm{p}<0.001$} \\
\hline
\end{tabular}


Table: Variance explained by each construct - individual deviation scores/main study/complete dataset

\begin{tabular}{|l|l|c|c|}
\hline & $\begin{array}{l}\text { Perceived } \\
\text { usefulness }\end{array}$ & $\begin{array}{l}\text { Attitude } \\
\text { towards use }\end{array}$ & $\begin{array}{l}\text { Intentions } \\
\text { use }\end{array}$ \\
\hline $\begin{array}{l}\text { Complete dataset } \\
\text { (individual deviation scores) }\end{array}$ & $\left(\mathrm{R}^{2}=0.639\right)$ & $\left(\mathrm{R}^{2}=0.433\right)$ & $\left(\mathrm{R}^{2}=0.771\right)$ \\
\hline $\begin{array}{l}\text { Complete dataset } \\
\text { (average deviation scores) }\end{array}$ & $\left(\mathrm{R}^{2}=0.633\right)$ & $\left(\mathrm{R}^{2}=0.447\right)$ & $\left(\mathrm{R}^{2}=0.773\right)$ \\
\hline
\end{tabular}

Table: Structural model results - individual deviation scores/main study

\begin{tabular}{|c|c|l|l|}
\hline \multicolumn{2}{|c|}{ Hypothesis } & \multicolumn{1}{c|}{ Financial Loans } & \multicolumn{1}{c|}{ Account inquiries } \\
\hline H1 & TCF $\rightarrow$ PU & T-value: $2.36^{*}$, Coefficient: 0.17 & T-value: $2.20^{*}$, Coefficient: 0.12 \\
\hline H2 & TCF $\rightarrow$ INT & T-value: 1.68 Coefficient: 0.08 & T-value: 0.83 , Coefficient: 0.04 \\
\hline H3 & TCF $\rightarrow$ ATT & T-value: $7.49^{* * *}$, Coefficient: 0.45 & T-value: $10.48^{* * *}$,Coefficient: 0.54 \\
\hline H4 & PU $\rightarrow$ INT & T-value: $2.45^{*}$, Coefficient: 0.18 & T-value: 0.08 , Coefficient: 0.01 \\
\hline H5a & EOU $\rightarrow$ INT & T-value: $3.18^{* *}$, Coefficient: 0.08 & T-value: $4.60^{* * *}$, Coefficient: 0.74 \\
\hline H5b & EOU $\rightarrow$ PU & T-value: $6.50^{* * *}$, Coefficient: 0.59 & T-value: $16.59^{* * *}$, Coefficient: 0.53 \\
\hline H6 & ATT $\rightarrow$ INT & T-value: $3.57^{* * *}$, Coefficient: 0.38 & T-value: 1.52 , Coefficient: 0.15 \\
\hline H7 & SN $\rightarrow$ INT & T-value: $2.67^{* *}$, Coefficient: 0.12 & T-value: 0.85 , Coefficient: -0.03 \\
\hline H8 & SEC $\rightarrow$ INT & T-value: $2.64^{* *}$, Coefficient: 0.21 & T-value: 1.85 , Coefficient: 0.11 \\
\hline H9 & COST $\rightarrow$ INT & T-value: 1.57 , Coefficient: -0.08 & T-value: 1.30 , Coefficient: -0.11 \\
\hline \multicolumn{4}{|c}{$*$ significant at $p<0.05, * *$ significant at $p<0.01$ and $* * *$ significant at $p<0.001$} \\
\hline
\end{tabular}

Table: Variance explained by each construct - individual deviation scores/main study

\begin{tabular}{|l|c|c|c|}
\hline & $\begin{array}{l}\text { Perceived } \\
\text { usefulness }\end{array}$ & $\begin{array}{l}\text { Attitude towards } \\
\text { use }\end{array}$ & Intentions to use \\
\hline Financial Loans & $\left(\mathrm{R}^{2}=0.458\right)$ & $\left(\mathrm{R}^{2}=0.204\right)$ & $\left(\mathrm{R}^{2}=0.745\right)$ \\
\hline Account inquiries & $\left(\mathrm{R}^{2}=0.636\right)$ & $\left(\mathrm{R}^{2}=0.285\right)$ & $\left(\mathrm{R}^{2}=0.625\right)$ \\
\hline
\end{tabular}

Table: Structural model results - average deviation scores/main study

\begin{tabular}{|c|c|c|c|}
\hline \multicolumn{2}{|c|}{ Hypothesis } & Financial Loans & Account inquiries \\
\hline H1 & TCF $\rightarrow$ PU & T-value: $1.94 * *$, Coefficient: 0.15 & T-value: 0.72 , Coefficient: 0.03 \\
\hline H2 & TCF $\rightarrow$ INT & T-value: $2.52^{*}$, Coefficient: 0.13 & T-value: 0.07 , Coefficient: 0.01 \\
\hline H3 & $\mathrm{TCF} \rightarrow \mathrm{ATT}$ & T-value: $9.60^{* * *}$, Coefficient: 0.48 & T-value: $10.65^{* * *}$, Coefficient: 0.55 \\
\hline H4 & PU $\rightarrow$ INT & T-value: $2.65^{* *}$, Coefficient: 0.19 & T-value: 0.22 , Coefficient: 0.01 \\
\hline H5a & EOU $\rightarrow$ INT & T-value: 1.41 , Coefficient: 0.07 & T-value: $4.03^{* * *}$, Coefficient: 0.54 \\
\hline H5b & $\mathbf{E O U} \rightarrow \mathbf{P U}$ & T-value: $6.48^{* * *}$, Coefficient: 0.59 & T-value: $19.95^{* * *}$, Coefficient: 0.78 \\
\hline H6 & ATT $\rightarrow$ INT & T-value: $3.73^{* * *}$, Coefficient: 0.37 & T-value: 1.35 , Coefficient: 0.16 \\
\hline H7 & SN $\rightarrow$ INT & T-value: $2.58^{* *}$, Coefficient: 0.12 & T-value: 0.88 , Coefficient: -0.03 \\
\hline H8 & SEC $\rightarrow$ INT & T-value: $2.79 * *$, Coefficient: 0.21 & T-value: 1.84 , Coefficient: 0.11 \\
\hline H9 & COST->INT & T-value: 1.66 , Coefficient: -0.07 & T-value: 1.34 , Coefficient: -0.12 \\
\hline
\end{tabular}


Table: Variance explained by each construct - average deviation scores/main study

\begin{tabular}{|l|c|c|c|}
\hline & $\begin{array}{l}\text { Perceived } \\
\text { usefulness }\end{array}$ & $\begin{array}{l}\text { Attitude towards } \\
\text { use }\end{array}$ & Intentions to use \\
\hline Financial Loans & $\left(\mathrm{R}^{2}=0.453\right)$ & $\left(\mathrm{R}^{2}=0.239\right)$ & $\left(\mathrm{R}^{2}=0.752\right)$ \\
\hline Account inquiries & $\left(\mathrm{R}^{2}=0.628\right)$ & $\left(\mathrm{R}^{2}=0.303\right)$ & $\left(\mathrm{R}^{2}=0.624\right)$ \\
\hline
\end{tabular}




\subsection{Survey questionnaire: main study}

\section{Smile City":)}

Block 1

\section{Consumer Intentions to Use Banking Services}

Information to participants

Thank you for accessing this questionnaire - before you proceed, please read the information below:

My name is Hartmut Hoehle and I am a PhD student at the School of Information Management at Victoria University of Wellington, New Zealand. The goal of this research is to understand the factors influencing consumer intentions to use banking services. This survey is being undertaken as part of my $\mathrm{PhD}$ degree.

Ethics approval has been obtained for this research from the Victoria University Human Ethics Committee. The following questionnaire is completely voluntary. The survey software does not collect any identifying information from participants thus it is not possible for any respondent to be identified. The questionnaire should take around 15-20 minutes to complete. All of the material related to this survey will be kept confidential and accessible only to me and my supervisors Professor Sid Huff and Associate Professor Hans Lehmann. Throughout the project, electronic data will be kept under password protection and printed material will be stored in locked filing cabinets. All data will be destroyed 2 years after completion of the dissertation. Results of this questionnaire will contribute to my thesis and may appear in academic journals or may be presented at academic conferences. However, only aggregated results will be reported, no individuals will be identified. When responding to the questions, please answer them from a general perspective.

If you have any queries or need further information please contact me: hartmut.hoehle@vuw.ac.nz or my supervisor sid.huff@vuw.ac.nz.

Before starting the survey questionnaire, please note that some of the questions may sound similar as this is part of the research design. Thank you for your collaboration!

Block 2 - Gender-quota

Could you please indicate your gender:

$\odot$ Male

$\ominus$ Female

Block 3 - Financial loan and Internet banking

Before starting the survey, please confirm:

- Do you feel (at least) slightly familiar with financial loans?

- Have you used Internet banking services in the past?

$\Theta$ Yes

No

Your perceptions of financial loans 
The following statements will help us understand how you perceive financial loans (bank overdrafts, home loans, personal loans, mortgages etc.). It is important for us that you respond to these questions from a general perspective. Please do not associate your responses with technologies such as Internet banking.

Please indicate the extent to which you agree with the following statements:

In general:

\begin{tabular}{|c|c|c|c|c|c|c|c|}
\hline & $\begin{array}{l}\text { Strongly } \\
\text { Disagree }\end{array}$ & Disagree & $\begin{array}{l}\text { Somewhat } \\
\text { Disagree }\end{array}$ & $\begin{array}{l}\text { Neither } \\
\text { Agree } \\
\text { nor } \\
\text { Disagree }\end{array}$ & $\begin{array}{l}\text { Somewhat } \\
\text { Agree }\end{array}$ & Agree & $\begin{array}{l}\text { Strongly } \\
\text { Agree }\end{array}$ \\
\hline $\begin{array}{l}\text { Overall, I perceive financial loan applications } \\
\text { as very urgent banking transactions. }\end{array}$ & 0 & 0 & 0 & 0 & 0 & 0 & 0 \\
\hline $\begin{array}{l}\text { I seldom face situations in which I need to } \\
\text { apply for a financial loan urgently. }\end{array}$ & 0 & 0 & 0 & 0 & 0 & 0 & 0 \\
\hline $\begin{array}{l}\text { Applying for a loan is a commonplace banking } \\
\text { task. }\end{array}$ & 0 & 0 & 0 & 0 & 0 & 0 & 0 \\
\hline $\begin{array}{l}\text { Generally, applying for a financial loan is an } \\
\text { easy-to-do banking task. }\end{array}$ & 0 & 0 & 0 & 0 & 0 & 0 & 0 \\
\hline $\begin{array}{l}\text { A financial loan application is a banking } \\
\text { transaction I would plan thoroughly. }\end{array}$ & 0 & 0 & 0 & 0 & 0 & 0 & 0 \\
\hline $\begin{array}{l}\text { Obtaining additional information before } \\
\text { applying for a financial loan would be } \\
\text { absolutely essential for me. }\end{array}$ & 0 & 0 & 0 & 0 & 0 & 0 & 0 \\
\hline $\begin{array}{l}\text { Overall, applying for a financial loan requires } \\
\text { a lot of thinking. }\end{array}$ & 0 & 0 & 0 & 0 & 0 & 0 & 0 \\
\hline \multirow[t]{3}{*}{$\begin{array}{l}\text { A loan application is an ordinary banking } \\
\text { transaction to me. }\end{array}$} & 0 & 0 & 0 & $\mathrm{O}$ & 0 & 0 & 0 \\
\hline & & & & $\begin{array}{l}\text { Neither } \\
\text { Agree }\end{array}$ & & & \\
\hline & $\begin{array}{l}\text { Strongly } \\
\text { Disagree }\end{array}$ & Disagree & $\begin{array}{c}\text { Somewhat } \\
\text { Disagree }\end{array}$ & $\begin{array}{c}\text { nor } \\
\text { Disagree }\end{array}$ & $\begin{array}{l}\text { Somewhat } \\
\text { Agree }\end{array}$ & Agree & $\begin{array}{l}\text { Strongly } \\
\text { Agree }\end{array}$ \\
\hline $\begin{array}{l}\text { A loan application does not require filling out } \\
\text { many forms. }\end{array}$ & 0 & 0 & 0 & 0 & 0 & 0 & 0 \\
\hline $\begin{array}{l}\text { A loan application is a banking transaction I } \\
\text { frequently do. }\end{array}$ & 0 & 0 & 0 & 0 & 0 & 0 & 0 \\
\hline $\begin{array}{l}\text { Applying for a financial loan myself would } \\
\text { make me feel ambiguous. }\end{array}$ & 0 & 0 & 0 & 0 & 0 & 0 & 0 \\
\hline $\begin{array}{l}\text { I often need to apply for a financial loan } \\
\text { immediately. }\end{array}$ & 0 & 0 & 0 & 0 & 0 & 0 & 0 \\
\hline $\begin{array}{l}\text { I often want to apply for a financial loan } \\
\text { instantly. }\end{array}$ & 0 & 0 & 0 & 0 & 0 & 0 & 0 \\
\hline $\begin{array}{l}\text { Applying for a financial loan is a banking } \\
\text { transaction I routinely perform. }\end{array}$ & 0 & 0 & 0 & 0 & 0 & 0 & 0 \\
\hline $\begin{array}{l}\text { Before applying for a financial loan I would } \\
\text { require additional information on how the } \\
\text { process works. }\end{array}$ & 0 & 0 & 0 & 0 & 0 & 0 & 0 \\
\hline $\begin{array}{l}\text { In general, applying for a financial loan is } \\
\text { complex. }\end{array}$ & 0 & 0 & 0 & 0 & 0 & 0 & 0 \\
\hline
\end{tabular}




\begin{tabular}{|c|c|c|c|c|c|c|c|}
\hline & $\begin{array}{l}\text { Strongly } \\
\text { Disagree }\end{array}$ & Disagree & $\begin{array}{l}\text { Somewhat } \\
\text { Disagree }\end{array}$ & $\begin{array}{l}\text { Neither } \\
\text { Agree } \\
\text { nor } \\
\text { Disagree }\end{array}$ & $\begin{array}{l}\text { Somewhat } \\
\text { Agree }\end{array}$ & Agree & $\begin{array}{l}\text { Strongly } \\
\text { Agree }\end{array}$ \\
\hline & $\begin{array}{l}\text { Strongly } \\
\text { Disagree }\end{array}$ & Disagree & $\begin{array}{l}\text { Somewhat } \\
\text { Disagree }\end{array}$ & $\begin{array}{l}\text { Neither } \\
\text { Agree } \\
\text { nor } \\
\text { Disagree }\end{array}$ & $\begin{array}{l}\text { Somewhat } \\
\text { Agree }\end{array}$ & Agree & $\begin{array}{l}\text { Strongly } \\
\text { Agree }\end{array}$ \\
\hline I regularly apply for a financial loan. & 0 & 0 & 0 & 0 & 0 & 0 & 0 \\
\hline $\begin{array}{l}\text { I would feel unsure of myself if I were to apply } \\
\text { for a financial loan. }\end{array}$ & 0 & 0 & 0 & $\mathrm{O}$ & 0 & 0 & 0 \\
\hline $\begin{array}{l}\text { Overall, I think it takes a lot of effort to apply } \\
\text { for a financial loan. }\end{array}$ & 0 & 0 & 0 & $\mathrm{O}$ & 0 & 0 & 0 \\
\hline $\begin{array}{l}\text { There are many steps to go through when } \\
\text { applying for a financial loan. }\end{array}$ & 0 & 0 & 0 & 0 & $\mathrm{O}$ & 0 & 0 \\
\hline $\begin{array}{l}\text { Overall, a financial loan is a complicated } \\
\text { banking transaction. }\end{array}$ & 0 & 0 & 0 & 0 & 0 & 0 & 0 \\
\hline I often apply for a financial loan. & 0 & $\mathrm{O}$ & 0 & 0 & 0 & 0 & 0 \\
\hline $\begin{array}{l}\text { I would find it straightforward to apply for a } \\
\text { financial loan. }\end{array}$ & 0 & 0 & 0 & 0 & 0 & 0 & 0 \\
\hline $\begin{array}{l}\text { Applying for a financial loan is a major } \\
\text { transaction in my mind. }\end{array}$ & 0 & 0 & 0 & 0 & $\mathrm{O}$ & 0 & 0 \\
\hline & $\begin{array}{l}\text { Strongly } \\
\text { Disagree }\end{array}$ & Disagree & $\begin{array}{l}\text { Somewhat } \\
\text { Disagree }\end{array}$ & $\begin{array}{l}\text { Neither } \\
\text { Agree } \\
\text { nor } \\
\text { Disagree }\end{array}$ & $\begin{array}{l}\text { Somewhat } \\
\text { Agree }\end{array}$ & Agree & $\begin{array}{c}\text { Strongly } \\
\text { Agree }\end{array}$ \\
\hline $\begin{array}{l}\text { A financial loan application is a serious } \\
\text { banking transaction for me. }\end{array}$ & 0 & 0 & 0 & 0 & 0 & 0 & 0 \\
\hline $\begin{array}{l}\text { Applying for a financial loan will influence my } \\
\text { personal finances significantly. }\end{array}$ & 0 & 0 & 0 & 0 & 0 & 0 & 0 \\
\hline $\begin{array}{l}\text { When applying for a financial loan I have } \\
\text { many questions that I want to clarify with my } \\
\text { bank before going ahead with the transaction. }\end{array}$ & 0 & 0 & 0 & 0 & 0 & 0 & 0 \\
\hline $\begin{array}{l}\text { I would feel uncertain if applying for a } \\
\text { financial loan myself. }\end{array}$ & 0 & 0 & 0 & 0 & 0 & 0 & 0 \\
\hline $\begin{array}{l}\text { I have to provide a lot of information to my } \\
\text { bank when applying for a financial loan. }\end{array}$ & 0 & 0 & 0 & 0 & 0 & 0 & 0 \\
\hline $\begin{array}{l}\text { A financial loan application is a banking } \\
\text { transaction I would give a lot of thought to. }\end{array}$ & 0 & 0 & 0 & 0 & 0 & 0 & 0 \\
\hline $\begin{array}{l}\text { Applying for a financial loan requires detailed } \\
\text { consideration. }\end{array}$ & 0 & 0 & 0 & 0 & 0 & 0 & 0 \\
\hline \multicolumn{8}{|l|}{ Your perceptions of Internet banking } \\
\hline \multicolumn{8}{|c|}{$\begin{array}{l}\text { This section of the survey focuses on how you believe Internet banking is suited to support specific banking } \\
\text { transactions. }\end{array}$} \\
\hline
\end{tabular}


In general, Internet banking is well suited for:

\begin{tabular}{|c|c|c|c|c|c|c|c|}
\hline & $\begin{array}{l}\text { Strongly } \\
\text { Disagree }\end{array}$ & Disagree & $\begin{array}{l}\text { Somewhat } \\
\text { Disagree }\end{array}$ & $\begin{array}{l}\text { Neither } \\
\text { Agree } \\
\text { nor } \\
\text { Disagree }\end{array}$ & $\begin{array}{l}\text { Somewhat } \\
\text { Agree }\end{array}$ & Agree & $\begin{array}{l}\text { Strongly } \\
\text { Agree }\end{array}$ \\
\hline $\begin{array}{l}\text { Banking transactions where I feel unsure of } \\
\text { myself. }\end{array}$ & 0 & 0 & 0 & 0 & 0 & 0 & 0 \\
\hline Straightforward banking transactions. & 0 & 0 & 0 & 0 & 0 & 0 & 0 \\
\hline Banking transactions I often do. & 0 & 0 & 0 & 0 & 0 & 0 & 0 \\
\hline $\begin{array}{l}\text { Banking transactions where I feel uncertain of } \\
\text { myself. }\end{array}$ & 0 & 0 & 0 & $\mathrm{O}$ & 0 & 0 & 0 \\
\hline \multirow[t]{2}{*}{ Easy-to-do banking task. } & 0 & 0 & 0 & 0 & 0 & 0 & 0 \\
\hline & $\begin{array}{l}\text { Strongly } \\
\text { Disagree }\end{array}$ & Disagree & $\begin{array}{l}\text { Somewhat } \\
\text { Disagree }\end{array}$ & $\begin{array}{l}\text { Neither } \\
\text { Agree } \\
\text { nor } \\
\text { Disagree }\end{array}$ & $\begin{array}{l}\text { Somewhat } \\
\text { Agree }\end{array}$ & Agree & $\begin{array}{l}\text { Strongly } \\
\text { Agree }\end{array}$ \\
\hline Banking transactions where I feel ambiguous. & 0 & 0 & 0 & 0 & 0 & 0 & 0 \\
\hline $\begin{array}{l}\text { Clarifying questions related to a financial } \\
\text { product. }\end{array}$ & 0 & 0 & 0 & 0 & 0 & 0 & 0 \\
\hline Banking transactions I routinely perform. & 0 & 0 & 0 & 0 & 0 & 0 & O \\
\hline $\begin{array}{l}\text { Obtaining additional information about } \\
\text { financial products. }\end{array}$ & 0 & 0 & $\mathrm{O}$ & 0 & $\mathrm{O}$ & 0 & 0 \\
\hline \multirow[t]{2}{*}{$\begin{array}{l}\text { Finding out additional information on how } \\
\text { financial products work. }\end{array}$} & 0 & 0 & 0 & 0 & 0 & 0 & 0 \\
\hline & $\begin{array}{l}\text { Strongly } \\
\text { Disagree }\end{array}$ & Disagree & $\begin{array}{l}\text { Somewhat } \\
\text { Disagree }\end{array}$ & $\begin{array}{l}\text { Neither } \\
\text { Agree } \\
\text { nor } \\
\text { Disagree }\end{array}$ & $\begin{array}{l}\text { Somewhat } \\
\text { Agree }\end{array}$ & Agree & $\begin{array}{l}\text { Strongly } \\
\text { Agree }\end{array}$ \\
\hline Banking transactions I frequently do. & 0 & 0 & 0 & 0 & 0 & 0 & 0 \\
\hline Banking transactions I regularly do. & 0 & 0 & 0 & $\mathrm{O}$ & 0 & 0 & 0 \\
\hline Complicated banking transactions. & 0 & 0 & 0 & $\mathrm{O}$ & 0 & 0 & 0 \\
\hline Complex banking transactions. & 0 & 0 & 0 & 0 & 0 & 0 & 0 \\
\hline
\end{tabular}

In general, Internet banking is well suited for:

\begin{tabular}{|c|c|c|c|c|c|c|c|}
\hline & $\begin{array}{l}\text { Strongly } \\
\text { Disagree }\end{array}$ & Disagree & $\begin{array}{l}\text { Somewhat } \\
\text { Disagree }\end{array}$ & $\begin{array}{c}\text { Neither } \\
\text { Agree } \\
\text { nor } \\
\text { Disagree }\end{array}$ & $\begin{array}{c}\text { Somewhat } \\
\text { Agree }\end{array}$ & Agree & $\begin{array}{l}\text { Strongly } \\
\text { Agree }\end{array}$ \\
\hline $\begin{array}{l}\text { Banking transactions that influence my } \\
\text { personal finances significantly. }\end{array}$ & 0 & 0 & 0 & 0 & 0 & 0 & 0 \\
\hline Banking transactions that take a lot of effort. & 0 & 0 & 0 & 0 & 0 & 0 & 0 \\
\hline $\begin{array}{l}\text { Banking transactions that require performing } \\
\text { many steps. }\end{array}$ & 0 & 0 & 0 & 0 & 0 & 0 & 0 \\
\hline $\begin{array}{l}\text { Banking transactions for which I have to } \\
\text { provide a lot of information to my bank. }\end{array}$ & 0 & 0 & 0 & 0 & 0 & 0 & 0 \\
\hline Ordinary banking transactions. & 0 & 0 & 0 & 0 & 0 & 0 & 0 \\
\hline Commonplace banking transactions. & 0 & 0 & 0 & 0 & 0 & 0 & 0 \\
\hline
\end{tabular}




\begin{tabular}{|c|c|c|c|c|c|c|c|}
\hline & $\begin{array}{l}\text { Strongly } \\
\text { Disagree }\end{array}$ & Disagree & $\begin{array}{l}\text { Somewhat } \\
\text { Disagree }\end{array}$ & $\begin{array}{c}\text { Neither } \\
\text { Agree } \\
\text { nor } \\
\text { Disagree }\end{array}$ & $\begin{array}{l}\text { Somewhat } \\
\text { Agree }\end{array}$ & Agree & $\begin{array}{l}\text { Strongly } \\
\text { Agree }\end{array}$ \\
\hline & $\begin{array}{l}\text { Strongly } \\
\text { Disagree }\end{array}$ & Disagree & $\begin{array}{l}\text { Somewhat } \\
\text { Disagree }\end{array}$ & $\begin{array}{c}\text { Neither } \\
\text { Agree } \\
\text { nor } \\
\text { Disagree }\end{array}$ & $\begin{array}{l}\text { Somewhat } \\
\text { Agree }\end{array}$ & Agree & $\begin{array}{l}\text { Strongly } \\
\text { Agree }\end{array}$ \\
\hline Major banking transactions & 0 & 0 & 0 & 0 & 0 & 0 & 0 \\
\hline $\begin{array}{l}\text { Banking transactions I have to do } \\
\text { immediately. }\end{array}$ & 0 & 0 & 0 & 0 & 0 & 0 & 0 \\
\hline $\begin{array}{l}\text { Banking transactions I do not need to do } \\
\text { urgently. }\end{array}$ & 0 & 0 & 0 & 0 & 0 & 0 & 0 \\
\hline $\begin{array}{l}\text { Banking transactions that are very urgent to } \\
\text { me. }\end{array}$ & $\mathrm{O}$ & $\mathrm{O}$ & $\mathrm{O}$ & $\mathrm{O}$ & 0 & 0 & 0 \\
\hline $\begin{array}{l}\text { Banking transactions that require detailed } \\
\text { consideration. }\end{array}$ & 0 & 0 & 0 & $\mathrm{O}$ & 0 & 0 & 0 \\
\hline \multirow[t]{2}{*}{$\begin{array}{l}\text { Banking transactions that require a lot of } \\
\text { thinking. }\end{array}$} & 0 & 0 & 0 & 0 & 0 & 0 & 0 \\
\hline & $\begin{array}{l}\text { Strongly } \\
\text { Disagree }\end{array}$ & Disagree & $\begin{array}{l}\text { Somewhat } \\
\text { Disagree }\end{array}$ & $\begin{array}{l}\text { Neither } \\
\text { Agree } \\
\text { nor } \\
\text { Disagree }\end{array}$ & $\begin{array}{l}\text { Somewhat } \\
\text { Agree }\end{array}$ & Agree & $\begin{array}{l}\text { Strongly } \\
\text { Agree }\end{array}$ \\
\hline Serious banking transactions. & $\mathrm{O}$ & 0 & $\mathrm{O}$ & 0 & 0 & 0 & 0 \\
\hline Banking transactions I want to do instantly. & 0 & 0 & 0 & 0 & 0 & 0 & 0 \\
\hline Thoroughly planning banking products. & 0 & 0 & 0 & 0 & 0 & 0 & 0 \\
\hline $\begin{array}{l}\text { Banking transactions I would give a lot of } \\
\text { thought to. }\end{array}$ & $\mathrm{O}$ & $\mathrm{O}$ & 0 & $\mathrm{O}$ & $\mathrm{O}$ & $\mathrm{O}$ & 0 \\
\hline $\begin{array}{l}\text { Banking transactions that do not require filling } \\
\text { out many forms. }\end{array}$ & 0 & 0 & $\mathrm{O}$ & 0 & 0 & 0 & 0 \\
\hline
\end{tabular}

\section{Internet banking and financial loans}

This section of the questionnaire will help us to understand how you perceive the extent to which Internet banking is suited to supporting financial loans.

Please indicate the extent to which you agree with the following statements:

\begin{tabular}{|c|c|c|c|c|c|c|c|}
\hline & $\begin{array}{l}\text { Strongly } \\
\text { Disagree }\end{array}$ & Disagree & $\begin{array}{l}\text { Somewhat } \\
\text { Disagree }\end{array}$ & $\begin{array}{l}\text { Neither } \\
\text { Agree } \\
\text { nor } \\
\text { Disagree }\end{array}$ & $\begin{array}{c}\text { Somewhat } \\
\text { Agree }\end{array}$ & Agree & $\begin{array}{c}\text { Strongly } \\
\text { Agree }\end{array}$ \\
\hline $\begin{array}{l}\text { Using Internet banking for financial loan } \\
\text { applications would enhance my effectiveness } \\
\text { in managing personal finances. }\end{array}$ & 0 & 0 & 0 & 0 & 0 & 0 & 0 \\
\hline $\begin{array}{l}\text { The advantages of using Internet banking for } \\
\text { financial loan applications would outweigh the } \\
\text { disadvantages. }\end{array}$ & 0 & 0 & 0 & 0 & 0 & 0 & 0 \\
\hline $\begin{array}{l}\text { Internet banking would be a convenient way } \\
\text { to apply for financial loans. }\end{array}$ & 0 & 0 & 0 & 0 & 0 & 0 & 0 \\
\hline
\end{tabular}




\begin{tabular}{|c|c|c|c|c|c|c|c|}
\hline & $\begin{array}{l}\text { Strongly } \\
\text { Disagree }\end{array}$ & Disagree & $\begin{array}{l}\text { Somewhat } \\
\text { Disagree }\end{array}$ & $\begin{array}{c}\text { Neither } \\
\text { Agree } \\
\text { nor } \\
\text { Disagree }\end{array}$ & $\begin{array}{l}\text { Somewhat } \\
\text { Agree }\end{array}$ & Agree & $\begin{array}{l}\text { Strongly } \\
\text { Agree }\end{array}$ \\
\hline \multirow[t]{3}{*}{$\begin{array}{l}\text { Overall, applying for a financial loan via } \\
\text { Internet banking would be of benefit to me. }\end{array}$} & 0 & 0 & 0 & 0 & 0 & 0 & 0 \\
\hline & e with the $f$ & following & statements: & & & & \\
\hline & $\begin{array}{l}\text { Strongly } \\
\text { Disagree }\end{array}$ & Disagree & $\begin{array}{l}\text { Somewhat } \\
\text { Disagree }\end{array}$ & $\begin{array}{c}\text { Neither } \\
\text { Agree } \\
\text { nor } \\
\text { Disagree }\end{array}$ & $\begin{array}{l}\text { Somewhat } \\
\text { Agree }\end{array}$ & Agree & $\begin{array}{l}\text { Strongly } \\
\text { Agree }\end{array}$ \\
\hline $\begin{array}{l}\text { Internet banking would be easy to use when } \\
\text { applying for a financial loan. }\end{array}$ & 0 & 0 & 0 & 0 & 0 & 0 & 0 \\
\hline $\begin{array}{l}\text { Applying for a financial loan via Internet } \\
\text { banking would be clear and understandable. }\end{array}$ & 0 & 0 & 0 & 0 & 0 & 0 & 0 \\
\hline $\begin{array}{l}\text { It would require a lot of mental effort to apply } \\
\text { for a financial loan via Internet banking. }\end{array}$ & 0 & 0 & 0 & 0 & 0 & 0 & 0 \\
\hline $\begin{array}{l}\text { It would be simple for me to apply for a } \\
\text { financial loan through Internet banking. }\end{array}$ & 0 & 0 & 0 & 0 & 0 & 0 & 0 \\
\hline
\end{tabular}

Please indicate the extent to which you agree with the following statements:

\begin{tabular}{|c|c|c|c|c|c|c|c|}
\hline & $\begin{array}{l}\text { Strongly } \\
\text { Disagree }\end{array}$ & Disagree & $\begin{array}{l}\text { Somewhat } \\
\text { Disagree }\end{array}$ & $\begin{array}{c}\text { Neither } \\
\text { Agree } \\
\text { nor } \\
\text { Disagree }\end{array}$ & $\begin{array}{l}\text { Somewhat } \\
\text { Agree }\end{array}$ & Agree & $\begin{array}{l}\text { Strongly } \\
\text { Agree }\end{array}$ \\
\hline $\begin{array}{l}\text { Internet banking would be a secure means by } \\
\text { which to apply for a financial loan. }\end{array}$ & 0 & 0 & 0 & 0 & 0 & 0 & 0 \\
\hline $\begin{array}{l}\text { I would feel safe applying for a financial loan } \\
\text { via Internet banking. }\end{array}$ & 0 & 0 & 0 & 0 & 0 & 0 & 0 \\
\hline $\begin{array}{l}\text { Applying for a financial loan on Internet } \\
\text { banking would be risky. }\end{array}$ & 0 & 0 & 0 & 0 & 0 & 0 & 0 \\
\hline $\begin{array}{l}\text { Overall, Internet banking would be a safe way } \\
\text { to apply for a financial loan. }\end{array}$ & 0 & 0 & 0 & 0 & 0 & 0 & 0 \\
\hline
\end{tabular}

Please indicate the extent to which you agree with the following statements:

\begin{tabular}{|c|c|c|c|c|c|c|c|}
\hline & $\begin{array}{l}\text { Strongly } \\
\text { Disagree }\end{array}$ & Disagree & $\begin{array}{l}\text { Somewhat } \\
\text { Disagree }\end{array}$ & $\begin{array}{c}\text { Neither } \\
\text { Agree } \\
\text { nor } \\
\text { Disagree }\end{array}$ & $\begin{array}{l}\text { Somewhat } \\
\text { Agree }\end{array}$ & Agree & $\begin{array}{l}\text { Strongly } \\
\text { Agree }\end{array}$ \\
\hline $\begin{array}{l}\text { I don't think using Internet banking for a loan } \\
\text { application would be a good idea. }\end{array}$ & 0 & 0 & 0 & 0 & 0 & 0 & 0 \\
\hline $\begin{array}{l}\text { I think it would be good to use Internet } \\
\text { Banking to apply for a financial loan. }\end{array}$ & 0 & 0 & 0 & 0 & $\mathrm{O}$ & 0 & 0 \\
\hline $\begin{array}{l}\text { My attitude towards financial loan applications } \\
\text { via Internet Banking would be favorable. }\end{array}$ & 0 & 0 & 0 & 0 & 0 & 0 & 0 \\
\hline $\begin{array}{l}\text { Overall, using Internet banking for financial } \\
\text { loan applications would be a good idea. }\end{array}$ & 0 & 0 & 0 & 0 & 0 & 0 & 0 \\
\hline
\end{tabular}


My decision to use Internet banking for financial loan applications would be influenced by:

\begin{tabular}{|c|c|c|c|c|c|c|c|}
\hline & $\begin{array}{c}\text { Strongly } \\
\text { Disagree }\end{array}$ & Disagree & $\begin{array}{c}\text { Somewhat } \\
\text { Disagree }\end{array}$ & $\begin{array}{l}\text { Neither } \\
\text { Agree } \\
\text { nor } \\
\text { Disagree }\end{array}$ & $\begin{array}{c}\text { Somewhat } \\
\text { Agree }\end{array}$ & Agree & $\begin{array}{c}\text { Strongly } \\
\text { Agree }\end{array}$ \\
\hline My friends. & 0 & 0 & 0 & $\mathrm{O}$ & 0 & 0 & 0 \\
\hline My family/relatives. & 0 & 0 & 0 & $\mathrm{O}$ & 0 & 0 & 0 \\
\hline My colleagues/peers. & 0 & $\mathrm{O}$ & 0 & $\mathrm{O}$ & $\mathrm{O}$ & 0 & 0 \\
\hline $\begin{array}{l}\text { If I knew that my peers were using Internet } \\
\text { banking for obtaining financial loans, I would } \\
\text { be more inclined to do so myself. }\end{array}$ & $\mathrm{O}$ & 0 & 0 & 0 & 0 & 0 & 0 \\
\hline
\end{tabular}

Please indicate the extent to which you agree with the following statements:

\begin{tabular}{|c|c|c|c|c|c|c|c|}
\hline & $\begin{array}{l}\text { Strongly } \\
\text { Disagree }\end{array}$ & Disagree & $\begin{array}{l}\text { Somewhat } \\
\text { Disagree }\end{array}$ & $\begin{array}{l}\text { Neither } \\
\text { Agree } \\
\text { nor } \\
\text { Disagree }\end{array}$ & $\begin{array}{l}\text { Somewhat } \\
\text { Agree }\end{array}$ & Agree & $\begin{array}{l}\text { Strongly } \\
\text { Agree }\end{array}$ \\
\hline $\begin{array}{l}\text { It would cost a lot to apply for financial loans } \\
\text { using Internet banking. }\end{array}$ & 0 & 0 & 0 & 0 & 0 & 0 & 0 \\
\hline $\begin{array}{l}\text { Financial costs would be a barrier for me if } \\
\text { applying for financial loans using Internet } \\
\text { banking. }\end{array}$ & 0 & 0 & 0 & 0 & 0 & 0 & 0 \\
\hline $\begin{array}{l}\text { I would not be worried about the costs } \\
\text { associated with financial loan applications } \\
\text { using Internet banking. }\end{array}$ & 0 & 0 & 0 & 0 & 0 & 0 & 0 \\
\hline $\begin{array}{l}\text { Overall, the cost associated with Internet } \\
\text { banking use for financial loan applications } \\
\text { would discourage me from using it. }\end{array}$ & 0 & 0 & 0 & 0 & 0 & 0 & 0 \\
\hline
\end{tabular}

Please indicate the extent to which you agree with the following statements:

\begin{tabular}{|c|c|c|c|c|c|c|c|}
\hline & $\begin{array}{l}\text { Strongly } \\
\text { Disagree }\end{array}$ & Disagree & $\begin{array}{l}\text { Somewhat } \\
\text { Disagree }\end{array}$ & $\begin{array}{c}\text { Neither } \\
\text { Agree } \\
\text { nor } \\
\text { Disagree }\end{array}$ & $\begin{array}{l}\text { Somewhat } \\
\text { Agree }\end{array}$ & Agree & $\begin{array}{c}\text { Strongly } \\
\text { Agree }\end{array}$ \\
\hline $\begin{array}{l}\text { I think Internet banking would be well suited } \\
\text { for loan applications. }\end{array}$ & 0 & 0 & 0 & 0 & 0 & 0 & 0 \\
\hline $\begin{array}{l}\text { Internet banking would be a good medium for } \\
\text { loan applications. }\end{array}$ & 0 & 0 & 0 & 0 & 0 & 0 & 0 \\
\hline $\begin{array}{l}\text { Internet banking would fit well for loan } \\
\text { applications. }\end{array}$ & 0 & 0 & 0 & 0 & 0 & 0 & 0 \\
\hline $\begin{array}{l}\text { I think Internet banking would be a good way } \\
\text { to apply for financial loans. }\end{array}$ & 0 & 0 & 0 & 0 & 0 & 0 & 0 \\
\hline
\end{tabular}

Please indicate the extent to which you agree with the following statements:

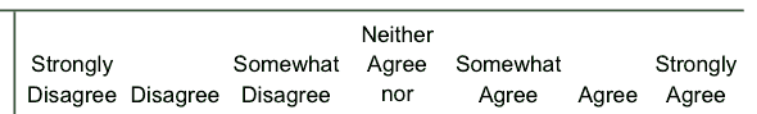




\begin{tabular}{|c|c|c|c|c|c|c|c|}
\hline & \multicolumn{7}{|c|}{ Disagree } \\
\hline $\begin{array}{l}\text { If I needed to apply for a financial loan I would } \\
\text { use Internet banking. }\end{array}$ & 0 & 0 & 0 & 0 & 0 & 0 & O \\
\hline $\begin{array}{l}\text { Assuming I had to apply for a financial loan I } \\
\text { would use Internet banking for it. }\end{array}$ & 0 & 0 & 0 & 0 & 0 & 0 & 0 \\
\hline $\begin{array}{l}\text { I would apply for a financial loan via Internet } \\
\text { banking if I needed one. }\end{array}$ & 0 & 0 & 0 & 0 & 0 & 0 & 0 \\
\hline $\begin{array}{l}\text { I would use Internet banking for loan } \\
\text { applications rather than alternative banking } \\
\text { channels (branch, telephone, letter etc.). }\end{array}$ & 0 & 0 & 0 & 0 & 0 & 0 & 0 \\
\hline
\end{tabular}

\section{Your perceptions of Internet banking in general}

This section of the questionnaire will help us to understand how you perceive Internet banking in general for managing your personal finances. Please do not associate your responses with specific banking transactions and answer the responses regarding your overall experience with Internet banking.

Please indicate the extent to which you agree with the following statements:

\begin{tabular}{|c|c|c|c|c|c|c|c|}
\hline & $\begin{array}{l}\text { Strongly } \\
\text { Disagree }\end{array}$ & Disagree & $\begin{array}{l}\text { Somewhat } \\
\text { Disagree }\end{array}$ & $\begin{array}{l}\text { Neither } \\
\text { Agree } \\
\text { nor } \\
\text { Disagree }\end{array}$ & $\begin{array}{l}\text { Somewhat } \\
\text { Agree }\end{array}$ & Agree & $\begin{array}{l}\text { Strongly } \\
\text { Agree }\end{array}$ \\
\hline $\begin{array}{l}\text { Using Internet banking enhances my } \\
\text { effectiveness in managing my personal } \\
\text { finances. }\end{array}$ & 0 & 0 & 0 & 0 & $\mathrm{O}$ & 0 & $\mathrm{O}$ \\
\hline $\begin{array}{l}\text { The advantages of using Internet banking for } \\
\text { managing my personal finances outweigh the } \\
\text { disadvantages. }\end{array}$ & 0 & 0 & 0 & 0 & $\mathrm{O}$ & 0 & 0 \\
\hline $\begin{array}{l}\text { Internet banking is a convenient way to } \\
\text { manage my personal finances. }\end{array}$ & 0 & 0 & 0 & 0 & 0 & 0 & 0 \\
\hline Overall, Internet banking is of benefit to me. & 0 & 0 & 0 & 0 & 0 & 0 & 0 \\
\hline
\end{tabular}

Please indicate the extent to which you agree with the following statements:

\begin{tabular}{|c|c|c|c|c|c|c|c|}
\hline & $\begin{array}{l}\text { Strongly } \\
\text { Disagree }\end{array}$ & Disagree & $\begin{array}{c}\text { Somewhat } \\
\text { Disagree }\end{array}$ & $\begin{array}{c}\text { Neither } \\
\text { Agree } \\
\text { nor } \\
\text { Disagree }\end{array}$ & $\begin{array}{l}\text { Somewhat } \\
\text { Agree }\end{array}$ & Agree & $\begin{array}{l}\text { Strongly } \\
\text { Agree }\end{array}$ \\
\hline Internet banking is easy to use. & 0 & 0 & 0 & 0 & O & $\mathrm{O}$ & 0 \\
\hline Internet banking is clear and understandable. & 0 & 0 & 0 & 0 & 0 & 0 & 0 \\
\hline $\begin{array}{l}\text { It requires a lot of mental effort to use Internet } \\
\text { banking. }\end{array}$ & 0 & 0 & 0 & 0 & 0 & 0 & 0 \\
\hline It is simple for me to use Internet banking. & 0 & 0 & 0 & 0 & $\mathrm{O}$ & 0 & 0 \\
\hline
\end{tabular}

Please indicate the extent to which you agree with the following statements:

\begin{tabular}{l|lccc}
\hline & \multicolumn{3}{c}{ Neither } \\
& Strongly & Somewhat & Agree Somewhat & Strongly \\
Disagree Disagree & Disagree & Agree Agree Agree
\end{tabular}




\begin{tabular}{l|l|l} 
& \multicolumn{5}{c}{ nor } \\
& Disagree \\
I don't think using Internet banking is a good \\
idea. \\
$\begin{array}{l}\text { I think it is good to use Internet Banking for } \\
\text { managing my personal finances. }\end{array}$
\end{tabular}

Please indicate the extent to which you agree with the following statements:

\begin{tabular}{|c|c|c|c|c|c|c|c|}
\hline & $\begin{array}{l}\text { Strongly } \\
\text { Disagree }\end{array}$ & Disagree & $\begin{array}{l}\text { Somewhat } \\
\text { Disagree }\end{array}$ & $\begin{array}{c}\text { Neither } \\
\text { Agree } \\
\text { nor } \\
\text { Disagree }\end{array}$ & $\begin{array}{l}\text { Somewhat } \\
\text { Agree }\end{array}$ & Agree & $\begin{array}{c}\text { Strongly } \\
\text { Agree }\end{array}$ \\
\hline $\begin{array}{l}\text { My experience with Internet banking was } \\
\text { better than what I expected. }\end{array}$ & 0 & 0 & 0 & 0 & 0 & 0 & 0 \\
\hline $\begin{array}{l}\text { The service level provided by Internet } \\
\text { banking was better than what I expected. }\end{array}$ & 0 & 0 & 0 & 0 & 0 & 0 & 0 \\
\hline $\begin{array}{l}\text { Overall, most of my expectations from using } \\
\text { Internet banking were confirmed. }\end{array}$ & 0 & 0 & 0 & 0 & 0 & 0 & 0 \\
\hline $\begin{array}{l}\text { My banking experience via Internet banking } \\
\text { falls short of my expectations. }\end{array}$ & 0 & 0 & 0 & 0 & 0 & 0 & 0 \\
\hline
\end{tabular}

Please indicate the extent to which you agree with the following statements:

\begin{tabular}{|c|c|c|c|c|c|c|c|}
\hline & $\begin{array}{l}\text { Strongly } \\
\text { Disagree }\end{array}$ & Disagree & $\begin{array}{l}\text { Somewhat } \\
\text { Disagree }\end{array}$ & $\begin{array}{c}\text { Neither } \\
\text { Agree } \\
\text { nor } \\
\text { Disagree }\end{array}$ & $\begin{array}{l}\text { Somewhat } \\
\text { Agree }\end{array}$ & Agree & $\begin{array}{l}\text { Strongly } \\
\text { Agree }\end{array}$ \\
\hline $\begin{array}{l}\text { I feel very satisfied about my overall } \\
\text { experience of Internet banking use. }\end{array}$ & 0 & 0 & 0 & 0 & 0 & 0 & 0 \\
\hline $\begin{array}{l}\text { Overall, I am very pleased with Internet } \\
\text { banking. }\end{array}$ & 0 & 0 & 0 & 0 & 0 & 0 & 0 \\
\hline $\begin{array}{l}\text { I am dissatisfied with my overall experience } \\
\text { Internet banking. }\end{array}$ & 0 & 0 & 0 & 0 & 0 & 0 & 0 \\
\hline $\begin{array}{l}\text { I am absolutely delighted with my experience } \\
\text { of Internet banking. }\end{array}$ & 0 & 0 & 0 & 0 & 0 & 0 & 0 \\
\hline
\end{tabular}

Please indicate the extent to which you agree with the following statements:

\begin{tabular}{|c|c|c|c|c|c|c|c|}
\hline & $\begin{array}{l}\text { Strongly } \\
\text { Disagree }\end{array}$ & Disagree & $\begin{array}{c}\text { Somewhat } \\
\text { Disagree }\end{array}$ & $\begin{array}{c}\text { Neither } \\
\text { Agree } \\
\text { nor } \\
\text { Disagree }\end{array}$ & $\begin{array}{c}\text { Somewhat } \\
\text { Agree }\end{array}$ & Agree & $\begin{array}{c}\text { Strongly } \\
\text { Agree }\end{array}$ \\
\hline I believe Internet banking is trustworthy. & 0 & $\mathrm{O}$ & 0 & 0 & 0 & 0 & 0 \\
\hline I trust Internet banking. & 0 & 0 & 0 & 0 & 0 & 0 & 0 \\
\hline $\begin{array}{l}\text { Based on my previous experience, I know } \\
\text { Internet banking is trustworthy. }\end{array}$ & 0 & 0 & 0 & 0 & 0 & 0 & 0 \\
\hline
\end{tabular}




\begin{tabular}{|c|c|c|c|c|c|c|c|}
\hline & $\begin{array}{l}\text { Strongly } \\
\text { Disagree }\end{array}$ & Disagree & $\begin{array}{l}\text { Somewhat } \\
\text { Disagree }\end{array}$ & $\begin{array}{l}\text { Neither } \\
\text { Agree } \\
\text { nor } \\
\text { Disagree }\end{array}$ & $\begin{array}{l}\text { Somewhat } \\
\text { Agree }\end{array}$ & Agree & $\begin{array}{l}\text { Strongly } \\
\text { Agree }\end{array}$ \\
\hline \multirow[t]{3}{*}{$\begin{array}{l}\text { I don't think that Internet banking is } \\
\text { trustworthy. }\end{array}$} & 0 & 0 & 0 & 0 & 0 & 0 & 0 \\
\hline & e with the & following & statements: & & & & \\
\hline & $\begin{array}{l}\text { Strongly } \\
\text { Disagree }\end{array}$ & Disagree & $\begin{array}{l}\text { Somewhat } \\
\text { Disagree }\end{array}$ & $\begin{array}{l}\text { Neither } \\
\text { Agree } \\
\text { nor } \\
\text { Disagree }\end{array}$ & $\begin{array}{l}\text { Somewhat } \\
\text { Agree }\end{array}$ & Agree & $\begin{array}{l}\text { Strongly } \\
\text { Agree }\end{array}$ \\
\hline $\begin{array}{l}\text { I think Internet banking is well suited for } \\
\text { managing my personal finances. }\end{array}$ & 0 & 0 & 0 & 0 & 0 & 0 & 0 \\
\hline $\begin{array}{l}\text { Internet banking is a good medium for } \\
\text { managing my personal finances. }\end{array}$ & 0 & 0 & 0 & 0 & 0 & 0 & 0 \\
\hline $\begin{array}{l}\text { Internet banking fits well for managing my } \\
\text { personal finances. }\end{array}$ & 0 & 0 & 0 & 0 & 0 & 0 & 0 \\
\hline $\begin{array}{l}\text { I think Internet banking is a good way to } \\
\text { managing my personal finances. }\end{array}$ & 0 & 0 & 0 & 0 & 0 & 0 & $\mathrm{O}$ \\
\hline
\end{tabular}

Please indicate the extent to which you agree with the following statements:

\begin{tabular}{l|ccccccc}
\hline & \multicolumn{8}{c}{$\begin{array}{c}\text { Neither } \\
\text { Agree } \\
\text { nor }\end{array}$} \\
& $\begin{array}{c}\text { Strongly } \\
\text { Disagree }\end{array}$ & $\begin{array}{c}\text { Somewhat } \\
\text { Disagree } \\
\text { Disagree }\end{array}$ & $\begin{array}{c}\text { Strongly } \\
\text { Disagree }\end{array}$ \\
& Agree & Agree & Agree \\
\hline $\begin{array}{l}\text { Using Internet banking has become automatic } \\
\text { to me. }\end{array}$ & 0 & 0 & 0 & 0 & 0 & 0 & 0 \\
Using Internet banking is natural to me. & 0 & 0 & 0 & 0 & 0 & 0 & 0 \\
I use Internet banking as a matter of habit. & 0 & 0 & 0 & 0 & 0 & 0 & 0 \\
I do not use Internet banking habitually. & 0 & 0 & 0 & 0 & 0 & 0 & 0
\end{tabular}

Please indicate the extent to which you agree with the following statements:

\begin{tabular}{|c|c|c|c|c|c|c|c|}
\hline & $\begin{array}{l}\text { Strongly } \\
\text { Disagree }\end{array}$ & Disagree & $\begin{array}{l}\text { Somewhat } \\
\text { Disagree }\end{array}$ & $\begin{array}{c}\text { Neither } \\
\text { Agree } \\
\text { nor } \\
\text { Disagree }\end{array}$ & $\begin{array}{l}\text { Somewhat } \\
\text { Agree }\end{array}$ & Agree & $\begin{array}{l}\text { Strongly } \\
\text { Agree }\end{array}$ \\
\hline I intend to continue using Internet banking. & $\mathrm{O}$ & 0 & $\mathrm{O}$ & $\mathrm{O}$ & $\mathrm{O}$ & $\mathrm{O}$ & $\mathrm{O}$ \\
\hline $\begin{array}{l}\text { I predict I would continue using Internet } \\
\text { banking. }\end{array}$ & 0 & 0 & $\mathrm{O}$ & 0 & $\mathrm{O}$ & 0 & 0 \\
\hline $\begin{array}{l}\text { I plan to continue using Internet banking for } \\
\text { managing my personal finances. }\end{array}$ & $\mathrm{O}$ & $\mathrm{O}$ & $\mathrm{O}$ & $\mathrm{O}$ & 0 & $\mathrm{O}$ & 0 \\
\hline $\begin{array}{l}\text { I want to continue using Internet banking } \\
\text { rather than discontinue its use. }\end{array}$ & $\mathrm{O}$ & 0 & $\mathrm{O}$ & 0 & $\mathrm{O}$ & 0 & $\mathrm{O}$ \\
\hline
\end{tabular}

\section{Some additional information about you.}


Please indicate the extent to which you agree with the following statements:

\begin{tabular}{|c|c|c|c|c|c|c|c|}
\hline & $\begin{array}{l}\text { Strongly } \\
\text { Disagree }\end{array}$ & Disagree & $\begin{array}{l}\text { Somewhat } \\
\text { Disagree }\end{array}$ & $\begin{array}{c}\text { Neither } \\
\text { Agree } \\
\text { nor } \\
\text { Disagree }\end{array}$ & $\begin{array}{l}\text { Somewhat } \\
\text { Agree }\end{array}$ & Agree & $\begin{array}{l}\text { Strongly } \\
\text { Agree }\end{array}$ \\
\hline I like using information technology. & 0 & 0 & 0 & 0 & $\mathrm{O}$ & 0 & 0 \\
\hline $\begin{array}{l}\text { Using information technology is frustrating for } \\
\text { me. }\end{array}$ & $\mathrm{O}$ & 0 & 0 & $\mathrm{O}$ & $\mathrm{O}$ & $\mathrm{O}$ & $\mathrm{O}$ \\
\hline Using information technology is fun. & $\mathrm{O}$ & 0 & $\mathrm{O}$ & $\mathrm{O}$ & 0 & 0 & $\mathrm{O}$ \\
\hline I find using information technology enjoyable. & $\mathrm{O}$ & 0 & $\mathrm{O}$ & 0 & $\mathrm{O}$ & 0 & 0 \\
\hline
\end{tabular}

Please indicate the extent to which you agree with the following statements:

\begin{tabular}{|c|c|c|c|c|c|c|c|}
\hline & $\begin{array}{l}\text { Strongly } \\
\text { Disagree }\end{array}$ & Disagree & $\begin{array}{l}\text { Somewhat } \\
\text { Disagree }\end{array}$ & $\begin{array}{l}\text { Neither } \\
\text { Agree } \\
\text { nor } \\
\text { Disagree }\end{array}$ & $\begin{array}{l}\text { Somewhat } \\
\text { Agree }\end{array}$ & Agree & $\begin{array}{l}\text { Strongly } \\
\text { Agree }\end{array}$ \\
\hline I am familiar with using Internet banking. & 0 & 0 & 0 & $\mathrm{O}$ & $\mathrm{O}$ & 0 & $\mathrm{O}$ \\
\hline I understand how Internet banking works. & 0 & 0 & 0 & $\mathrm{O}$ & $\mathrm{O}$ & 0 & 0 \\
\hline $\begin{array}{l}\text { I consider myself knowledgeable with Internet } \\
\text { banking. }\end{array}$ & $\mathrm{O}$ & $\mathrm{O}$ & 0 & 0 & 0 & $\mathrm{O}$ & 0 \\
\hline $\begin{array}{l}\text { I am not at all familiar with using Internet } \\
\text { banking. }\end{array}$ & 0 & 0 & 0 & 0 & 0 & 0 & 0 \\
\hline
\end{tabular}

Please indicate the extent to which you agree with the following statements:

\begin{tabular}{|c|c|c|c|c|c|c|c|}
\hline & $\begin{array}{l}\text { Strongly } \\
\text { Disagree }\end{array}$ & Disagree & $\begin{array}{l}\text { Somewhat } \\
\text { Disagree }\end{array}$ & $\begin{array}{c}\text { Neither } \\
\text { Agree } \\
\text { nor } \\
\text { Disagree }\end{array}$ & $\begin{array}{l}\text { Somewhat } \\
\text { Agree }\end{array}$ & Agree & $\begin{array}{l}\text { Strongly } \\
\text { Agree }\end{array}$ \\
\hline I am familiar with financial loans. & 0 & 0 & 0 & 0 & $\mathrm{O}$ & 0 & 0 \\
\hline I understand how financial loans work. & 0 & 0 & 0 & 0 & $\mathrm{O}$ & 0 & 0 \\
\hline $\begin{array}{l}\text { I consider myself knowledgeable with } \\
\text { financial loans. }\end{array}$ & $\mathrm{O}$ & 0 & $\mathrm{O}$ & $\mathrm{O}$ & 0 & 0 & $\mathrm{O}$ \\
\hline I am not at all familiar with financial loans. & 0 & 0 & 0 & 0 & 0 & 0 & 0 \\
\hline
\end{tabular}

What is your age?
under 20
20-29
O $30-39$
O $40-49$
O $50-59$
O 60 or older

What is your primary bank? 


$\begin{array}{ccccccccc}\text { ANZ } & \text { National } & & & & & & & \\ 0 & \text { Bank } & \text { Westpac } & \text { BNZ } & \text { Kiwibank } & \text { ASB } & \text { Rabobank } & \text { TSB } & \text { Other } \\ 0 & 0 & 0 & 0 & 0 & 0 & 0 & 0 & 0\end{array}$

Which of the options would best decribe your job? (Select one only)
Information and communication technology
Banking/Finance/Accounting
Insurance/Real Esate/Legal
Government (including military)
O Medical/Dental/Healthcare
O Construction/Architecture/Engineering
Wholesale/Retail/Distribution
Education
Marketing/Advertising/Entertainment
Student
Other

\section{Block 4 - Account inquiries and Internet banking}

Before starting the survey, please confirm:

- Do you feel (at least) slightly familiar with account inquiries?

- Have you used Internet banking services in the past?

\section{Yes}

O No

\section{Your perceptions of account inquiries}

The following statements will help us understand how you perceive account inquiries (checking account balance, viewing transaction history, inspecting account statements etc.). It is important for us that you respond to these questions from a general perspective. Please do not associate your responses with technologies such as Internet banking.

Please indicate the extent to which you agree with the following statements:

In general:

\begin{tabular}{|c|c|c|c|c|c|c|c|}
\hline & $\begin{array}{l}\text { Strongly } \\
\text { Disagree }\end{array}$ & Disagree & $\begin{array}{l}\text { Somewhat } \\
\text { Disagree }\end{array}$ & $\begin{array}{l}\text { Neither } \\
\text { Agree } \\
\text { nor } \\
\text { Disagree }\end{array}$ & $\begin{array}{l}\text { Somewhat } \\
\text { Agree }\end{array}$ & Agree & $\begin{array}{l}\text { Strongly } \\
\text { Agree }\end{array}$ \\
\hline $\begin{array}{l}\text { Obtaining additional information before } \\
\text { checking my account balance would be } \\
\text { absolutely essential for me. }\end{array}$ & 0 & 0 & 0 & 0 & 0 & 0 & 0 \\
\hline $\begin{array}{l}\text { An account inquiry is a banking transaction I } \\
\text { would give a lot of thought to. }\end{array}$ & 0 & 0 & 0 & 0 & 0 & 0 & 0 \\
\hline
\end{tabular}




\begin{tabular}{|c|c|c|c|c|c|c|c|}
\hline & $\begin{array}{l}\text { Strongly } \\
\text { Disagree }\end{array}$ & Disagree & $\begin{array}{c}\text { Somewhat } \\
\text { Disagree }\end{array}$ & $\begin{array}{l}\text { Neither } \\
\text { Agree } \\
\text { nor } \\
\text { Disagree }\end{array}$ & $\begin{array}{l}\text { Somewhat } \\
\text { Agree }\end{array}$ & Agree & $\begin{array}{c}\text { Strongly } \\
\text { Agree }\end{array}$ \\
\hline $\begin{array}{l}\text { Before checking my account balance I would } \\
\text { require additional information on how the } \\
\text { process works. }\end{array}$ & 0 & 0 & 0 & 0 & 0 & 0 & 0 \\
\hline I often check my account balance. & 0 & 0 & $\mathrm{O}$ & 0 & 0 & 0 & 0 \\
\hline I regularly check my account balance. & 0 & 0 & 0 & $\mathrm{O}$ & 0 & 0 & 0 \\
\hline $\begin{array}{l}\text { I would find it straightforward to check my } \\
\text { account balance. }\end{array}$ & 0 & $\mathrm{O}$ & 0 & $\mathrm{O}$ & 0 & $\mathrm{O}$ & 0 \\
\hline $\begin{array}{l}\text { Generally, checking my account balance is an } \\
\text { easy-to-do banking task. }\end{array}$ & 0 & 0 & 0 & 0 & 0 & 0 & 0 \\
\hline \multirow[t]{2}{*}{$\begin{array}{l}\text { An account inquiry is a banking transaction I } \\
\text { would plan thoroughly. }\end{array}$} & 0 & 0 & 0 & 0 & 0 & 0 & 0 \\
\hline & $\begin{array}{l}\text { Strongly } \\
\text { Disagree }\end{array}$ & Disagree & $\begin{array}{l}\text { Somewhat } \\
\text { Disagree }\end{array}$ & $\begin{array}{l}\text { Neither } \\
\text { Agree } \\
\text { nor } \\
\text { Disagree }\end{array}$ & $\begin{array}{l}\text { Somewhat } \\
\text { Agree }\end{array}$ & Agree & $\begin{array}{l}\text { Strongly } \\
\text { Agree }\end{array}$ \\
\hline $\begin{array}{l}\text { I seldom face situations in which I need to } \\
\text { check my account balance urgently. }\end{array}$ & 0 & 0 & 0 & $\mathrm{O}$ & 0 & 0 & 0 \\
\hline $\begin{array}{l}\text { I often want to check my account balance } \\
\text { instantly. }\end{array}$ & 0 & $\mathrm{O}$ & 0 & $\mathrm{O}$ & 0 & 0 & $\mathrm{O}$ \\
\hline $\begin{array}{l}\text { When checking my account balance I have } \\
\text { many questions that I want to clarify with my } \\
\text { bank before going ahead with the transaction. }\end{array}$ & 0 & 0 & 0 & $\mathrm{O}$ & 0 & 0 & 0 \\
\hline In general, an account inquiry is complex. & 0 & $\mathrm{O}$ & 0 & $\mathrm{O}$ & 0 & $\mathrm{O}$ & 0 \\
\hline $\begin{array}{l}\text { I would feel unsure of myself if I were to } \\
\text { check my account balance. }\end{array}$ & 0 & 0 & 0 & $\mathrm{O}$ & $\mathrm{O}$ & 0 & 0 \\
\hline $\begin{array}{l}\text { An account inquiry does not require filling out } \\
\text { many forms. }\end{array}$ & 0 & $\mathrm{O}$ & 0 & $\mathrm{O}$ & 0 & 0 & 0 \\
\hline $\begin{array}{l}\text { Checking my account balance is a major } \\
\text { transaction in my mind. }\end{array}$ & 0 & 0 & 0 & 0 & 0 & 0 & $\mathrm{O}$ \\
\hline \multirow[t]{3}{*}{$\begin{array}{l}\text { Checking my account balance myself would } \\
\text { make me feel ambiguous. }\end{array}$} & 0 & 0 & 0 & 0 & 0 & 0 & 0 \\
\hline & & & & $\begin{array}{l}\text { Neither } \\
\text { Agree }\end{array}$ & & & \\
\hline & $\begin{array}{l}\text { Strongly } \\
\text { Disagree }\end{array}$ & Disagree & $\begin{array}{l}\text { Somewhat } \\
\text { Disagree }\end{array}$ & $\begin{array}{c}\text { nor } \\
\text { Disagree }\end{array}$ & $\begin{array}{l}\text { Somewhat } \\
\text { Agree }\end{array}$ & Agree & $\begin{array}{c}\text { Strongly } \\
\text { Agree }\end{array}$ \\
\hline $\begin{array}{l}\text { Checking my account balance requires } \\
\text { detailed consideration. }\end{array}$ & 0 & 0 & 0 & 0 & 0 & 0 & 0 \\
\hline $\begin{array}{l}\text { Checking my account balance will influence } \\
\text { my personal finances significantly. }\end{array}$ & 0 & 0 & 0 & 0 & 0 & 0 & 0 \\
\hline $\begin{array}{l}\text { Overall, an account inquiry is a complicated } \\
\text { banking transaction. }\end{array}$ & 0 & 0 & 0 & 0 & 0 & 0 & 0 \\
\hline $\begin{array}{l}\text { I would feel uncertain if checking my account } \\
\text { balance myself. }\end{array}$ & 0 & 0 & 0 & 0 & 0 & 0 & 0 \\
\hline
\end{tabular}




\begin{tabular}{|c|c|c|c|c|c|c|c|}
\hline & $\begin{array}{l}\text { Strongly } \\
\text { Disagree }\end{array}$ & Disagree & $\begin{array}{l}\text { Somewhat } \\
\text { Disagree }\end{array}$ & $\begin{array}{l}\text { Neither } \\
\text { Agree } \\
\text { nor } \\
\text { Disagree }\end{array}$ & $\begin{array}{l}\text { Somewhat } \\
\text { Agree }\end{array}$ & Agree & $\begin{array}{l}\text { Strongly } \\
\text { Agree }\end{array}$ \\
\hline $\begin{array}{l}\text { An account inquiry is a serious banking } \\
\text { transaction for me. }\end{array}$ & 0 & 0 & 0 & 0 & 0 & 0 & 0 \\
\hline $\begin{array}{l}\text { An account inquiry is a banking transaction I } \\
\text { frequently do. }\end{array}$ & 0 & 0 & 0 & 0 & 0 & 0 & 0 \\
\hline $\begin{array}{l}\text { Overall, checking my account balance } \\
\text { requires a lot of thinking. }\end{array}$ & 0 & 0 & 0 & 0 & 0 & 0 & 0 \\
\hline \multirow[t]{2}{*}{$\begin{array}{l}\text { I often need to check my account balance } \\
\text { immediately. }\end{array}$} & 0 & 0 & 0 & 0 & 0 & 0 & 0 \\
\hline & $\begin{array}{l}\text { Strongly } \\
\text { Disagree }\end{array}$ & Disagree & $\begin{array}{l}\text { Somewhat } \\
\text { Disagree }\end{array}$ & $\begin{array}{l}\text { Neither } \\
\text { Agree } \\
\text { nor } \\
\text { Disagree }\end{array}$ & $\begin{array}{l}\text { Somewhat } \\
\text { Agree }\end{array}$ & Agree & $\begin{array}{l}\text { Strongly } \\
\text { Agree }\end{array}$ \\
\hline $\begin{array}{l}\text { I have to provide a lot of information to my } \\
\text { bank when checking my account balance. }\end{array}$ & 0 & 0 & 0 & 0 & 0 & 0 & 0 \\
\hline $\begin{array}{l}\text { An account inquiry is a banking transaction I } \\
\text { routinely perform. }\end{array}$ & 0 & 0 & 0 & 0 & 0 & 0 & 0 \\
\hline $\begin{array}{l}\text { An account inquiry is an ordinary banking } \\
\text { transaction to me. }\end{array}$ & 0 & 0 & 0 & 0 & 0 & 0 & 0 \\
\hline $\begin{array}{l}\text { Overall, I think it takes a lot of effort to check } \\
\text { my account balance. }\end{array}$ & 0 & 0 & 0 & 0 & 0 & 0 & 0 \\
\hline $\begin{array}{l}\text { Checking my account balance is a } \\
\text { commonplace banking task. }\end{array}$ & 0 & 0 & 0 & 0 & 0 & 0 & 0 \\
\hline $\begin{array}{l}\text { Overall, I perceive account inquiries as very } \\
\text { urgent banking transactions. }\end{array}$ & 0 & 0 & 0 & 0 & 0 & 0 & 0 \\
\hline $\begin{array}{l}\text { There are many steps to go through when } \\
\text { checking my account balance. }\end{array}$ & 0 & 0 & 0 & 0 & 0 & 0 & 0 \\
\hline
\end{tabular}

\section{Your perceptions of Internet banking}

This section of the survey focuses on how you believe Internet banking is suited to support specific banking transactions.

In general, Internet banking is well suited for:

\begin{tabular}{|c|c|c|c|c|c|c|c|}
\hline & $\begin{array}{l}\text { Strongly } \\
\text { Disagree }\end{array}$ & Disagree & $\begin{array}{l}\text { Somewhat } \\
\text { Disagree }\end{array}$ & $\begin{array}{c}\text { Neither } \\
\text { Agree } \\
\text { nor } \\
\text { Disagree }\end{array}$ & $\begin{array}{l}\text { Somewhat } \\
\text { Agree }\end{array}$ & Agree & $\begin{array}{l}\text { Strongly } \\
\text { Agree }\end{array}$ \\
\hline $\begin{array}{l}\text { Banking transactions where I feel unsure of } \\
\text { myself. }\end{array}$ & $\mathrm{O}$ & $\mathrm{O}$ & $\mathrm{O}$ & $\mathrm{O}$ & 0 & $\mathrm{O}$ & 0 \\
\hline Complex banking transactions. & 0 & 0 & 0 & 0 & 0 & 0 & 0 \\
\hline Banking transactions where I feel ambiguous. & 0 & 0 & $\mathrm{O}$ & 0 & 0 & 0 & 0 \\
\hline Banking transactions I often do. & $\mathrm{O}$ & 0 & 0 & 0 & 0 & 0 & $\mathrm{O}$ \\
\hline
\end{tabular}




\begin{tabular}{|c|c|c|c|c|c|c|c|}
\hline & $\begin{array}{l}\text { Strongly } \\
\text { Disagree }\end{array}$ & Disagree & $\begin{array}{c}\text { Somewhat } \\
\text { Disagree }\end{array}$ & $\begin{array}{c}\text { Neither } \\
\text { Agree } \\
\text { nor } \\
\text { Disagree }\end{array}$ & $\begin{array}{c}\text { Somewhat } \\
\text { Agree }\end{array}$ & Agree & $\begin{array}{l}\text { Strongly } \\
\text { Agree }\end{array}$ \\
\hline \multirow[t]{4}{*}{ Easy-to-do banking task. } & 0 & 0 & 0 & 0 & 0 & 0 & 0 \\
\hline & & & & $\begin{array}{l}\text { Neither } \\
\text { Agree }\end{array}$ & & & \\
\hline & Strongly & & Somewhat & nor & Somewhat & & Strongly \\
\hline & Disagree & Disagree & Disagree & Disagree & Agree & Agree & Agree \\
\hline $\begin{array}{l}\text { Finding out additional information on how } \\
\text { financial products work. }\end{array}$ & 0 & 0 & 0 & 0 & 0 & 0 & 0 \\
\hline $\begin{array}{l}\text { Obtaining additional information about } \\
\text { financial products. }\end{array}$ & 0 & 0 & $\mathrm{O}$ & 0 & 0 & 0 & 0 \\
\hline Banking transactions I routinely perform. & 0 & 0 & 0 & 0 & 0 & 0 & 0 \\
\hline $\begin{array}{l}\text { Clarifying questions related to a financial } \\
\text { product. }\end{array}$ & 0 & 0 & 0 & 0 & $\mathrm{O}$ & 0 & 0 \\
\hline \multirow[t]{3}{*}{ Banking transactions I frequently do. } & 0 & 0 & 0 & $\mathrm{O}$ & 0 & 0 & 0 \\
\hline & & & & $\begin{array}{l}\text { Neither } \\
\text { Agree }\end{array}$ & & & \\
\hline & $\begin{array}{l}\text { Strongly } \\
\text { Disagree }\end{array}$ & Disagree & $\begin{array}{l}\text { Somewhat } \\
\text { Disagree }\end{array}$ & $\begin{array}{c}\text { nor } \\
\text { Disagree }\end{array}$ & $\begin{array}{l}\text { Somewhat } \\
\text { Agree }\end{array}$ & Agree & $\begin{array}{l}\text { Strongly } \\
\text { Agree }\end{array}$ \\
\hline Straightforward banking transactions. & 0 & 0 & 0 & 0 & $\mathrm{O}$ & 0 & 0 \\
\hline Banking transactions I regularly do. & 0 & 0 & 0 & $\mathrm{O}$ & 0 & 0 & 0 \\
\hline Complicated banking transactions. & 0 & 0 & 0 & $\mathrm{O}$ & 0 & 0 & 0 \\
\hline $\begin{array}{l}\text { Banking transactions where I feel uncertain of } \\
\text { myself. }\end{array}$ & 0 & 0 & $\mathrm{O}$ & 0 & 0 & 0 & 0 \\
\hline
\end{tabular}

In general, Internet banking is well suited for:

\begin{tabular}{|c|c|c|c|c|c|c|c|}
\hline & $\begin{array}{l}\text { Strongly } \\
\text { Disagree }\end{array}$ & Disagree & $\begin{array}{l}\text { Somewhat } \\
\text { Disagree }\end{array}$ & $\begin{array}{c}\text { Neither } \\
\text { Agree } \\
\text { nor } \\
\text { Disagree }\end{array}$ & $\begin{array}{l}\text { Somewhat } \\
\text { Agree }\end{array}$ & Agree & $\begin{array}{c}\text { Strongly } \\
\text { Agree }\end{array}$ \\
\hline $\begin{array}{l}\text { Banking transactions I have to do } \\
\text { immediately. }\end{array}$ & 0 & 0 & 0 & $\mathrm{O}$ & $\mathrm{O}$ & 0 & 0 \\
\hline $\begin{array}{l}\text { Banking transactions that require detailed } \\
\text { consideration. }\end{array}$ & 0 & 0 & 0 & 0 & 0 & 0 & 0 \\
\hline Ordinary banking transactions. & 0 & 0 & 0 & 0 & 0 & 0 & 0 \\
\hline $\begin{array}{l}\text { Banking transactions that require a lot of } \\
\text { thinking. }\end{array}$ & 0 & 0 & 0 & 0 & 0 & 0 & 0 \\
\hline $\begin{array}{l}\text { Banking transactions that are very urgent to } \\
\text { me. }\end{array}$ & 0 & 0 & 0 & 0 & $\mathrm{O}$ & 0 & 0 \\
\hline \multirow[t]{2}{*}{ Thoroughly planning banking products. } & 0 & 0 & $\mathrm{O}$ & $\mathrm{O}$ & 0 & 0 & $\mathrm{O}$ \\
\hline & $\begin{array}{l}\text { Strongly } \\
\text { Disagree }\end{array}$ & Disagree & $\begin{array}{l}\text { Somewhat } \\
\text { Disagree }\end{array}$ & $\begin{array}{c}\text { Neither } \\
\text { Agree } \\
\text { nor } \\
\text { Disagree }\end{array}$ & $\begin{array}{l}\text { Somewhat } \\
\text { Agree }\end{array}$ & Agree & $\begin{array}{l}\text { Strongly } \\
\text { Agree }\end{array}$ \\
\hline $\begin{array}{l}\text { Banking transactions for which I have to } \\
\text { provide a lot of information to my bank. }\end{array}$ & 0 & 0 & 0 & 0 & 0 & 0 & 0 \\
\hline Banking transactions that take a lot of effort. & 0 & 0 & 0 & 0 & 0 & 0 & 0 \\
\hline
\end{tabular}




\begin{tabular}{|c|c|c|c|c|c|c|c|}
\hline & $\begin{array}{l}\text { Strongly } \\
\text { Disagree }\end{array}$ & Disagree & $\begin{array}{l}\text { Somewhat } \\
\text { Disagree }\end{array}$ & $\begin{array}{c}\text { Neither } \\
\text { Agree } \\
\text { nor } \\
\text { Disagree }\end{array}$ & $\begin{array}{l}\text { Somewhat } \\
\text { Agree }\end{array}$ & Agree & $\begin{array}{l}\text { Strongly } \\
\text { Agree }\end{array}$ \\
\hline $\begin{array}{l}\text { Banking transactions I would give a lot of } \\
\text { thought to. }\end{array}$ & 0 & 0 & 0 & $\mathrm{O}$ & $\mathrm{O}$ & $\mathrm{O}$ & 0 \\
\hline $\begin{array}{l}\text { Banking transactions that influence my } \\
\text { personal finances significantly. }\end{array}$ & 0 & 0 & $\mathrm{O}$ & $\mathrm{O}$ & $\mathrm{O}$ & 0 & $\mathrm{O}$ \\
\hline Major banking transactions & 0 & 0 & $\mathrm{O}$ & 0 & 0 & 0 & 0 \\
\hline \multirow[t]{4}{*}{$\begin{array}{l}\text { Banking transactions that do not require filling } \\
\text { out many forms. }\end{array}$} & 0 & 0 & $\mathrm{O}$ & 0 & $\mathrm{O}$ & 0 & 0 \\
\hline & & & & $\begin{array}{l}\text { Neither } \\
\text { Agree }\end{array}$ & & & \\
\hline & Strongly & & Somewhat & nor & Somewhat & & Strongly \\
\hline & Disagree & Disagree & Disagree & Disagree & Agree & Agree & Agree \\
\hline $\begin{array}{l}\text { Banking transactions that require performing } \\
\text { many steps. }\end{array}$ & 0 & 0 & 0 & $\mathrm{O}$ & 0 & 0 & 0 \\
\hline Serious banking transactions. & $\mathrm{O}$ & 0 & $\mathrm{O}$ & $\mathrm{O}$ & 0 & $\mathrm{O}$ & $\mathrm{O}$ \\
\hline Commonplace banking transactions. & $\mathrm{O}$ & 0 & 0 & $\mathrm{O}$ & 0 & $\mathrm{O}$ & $\mathrm{O}$ \\
\hline Banking transactions I want to do instantly. & $\mathrm{O}$ & $\mathrm{O}$ & 0 & $\mathrm{O}$ & $\mathrm{O}$ & $\mathrm{O}$ & 0 \\
\hline $\begin{array}{l}\text { Banking transactions I do not need to do } \\
\text { urgently. }\end{array}$ & 0 & 0 & 0 & 0 & 0 & 0 & 0 \\
\hline
\end{tabular}

\section{Internet banking and account inquiries}

This section of the questionnaire will help us to understand how you perceive the extent to which Internet banking is suited to supporting account inquiries.

Please indicate the extent to which you agree with the following statements:

\begin{tabular}{|c|c|c|c|c|c|c|c|}
\hline & $\begin{array}{l}\text { Strongly } \\
\text { Disagree }\end{array}$ & Disagree & $\begin{array}{l}\text { Somewhat } \\
\text { Disagree }\end{array}$ & $\begin{array}{l}\text { Neither } \\
\text { Agree } \\
\text { nor } \\
\text { Disagree }\end{array}$ & $\begin{array}{l}\text { Somewhat } \\
\text { Agree }\end{array}$ & Agree & $\begin{array}{l}\text { Strongly } \\
\text { Agree }\end{array}$ \\
\hline $\begin{array}{l}\text { Using Internet banking for account inquiries } \\
\text { would enhance my effectiveness in managing } \\
\text { personal finances. }\end{array}$ & 0 & 0 & 0 & 0 & 0 & 0 & 0 \\
\hline $\begin{array}{l}\text { The advantages of using Internet banking for } \\
\text { account inquiries would outweigh the } \\
\text { disadvantages. }\end{array}$ & 0 & 0 & 0 & 0 & 0 & 0 & 0 \\
\hline $\begin{array}{l}\text { Internet banking would be a convenient way } \\
\text { to check my account balance. }\end{array}$ & 0 & 0 & 0 & 0 & 0 & 0 & 0 \\
\hline $\begin{array}{l}\text { Overall, checking my account balance via } \\
\text { Internet banking would be of benefit to me. }\end{array}$ & 0 & 0 & 0 & 0 & 0 & 0 & 0 \\
\hline
\end{tabular}

Please indicate the extent to which you agree with the following statements:

\begin{tabular}{|lcccc}
\multicolumn{4}{c}{ Neither } \\
Strongly & Somewhat & Agree & Somewhat & Strongly \\
Disagree & Disagree & Disagree & & Agree Agree Agree
\end{tabular}




\begin{tabular}{l|lllll} 
& \multicolumn{7}{c}{ Disagree } \\
\hline $\begin{array}{l}\text { Internet banking would be easy to use when } \\
\text { checking my account balance. }\end{array}$ & 0 & 0 & 0 & 0 & 0 \\
$\begin{array}{l}\text { Checking my account balance via Internet } \\
\text { banking would be clear and understandable. }\end{array}$ & 0 & 0 & 0 & 0 & 0 \\
$\begin{array}{l}\text { It would require a lot of mental effort to check } \\
\text { my account balance via Internet banking. }\end{array}$ & 0 & 0 & 0 & 0 & 0
\end{tabular}

Please indicate the extent to which you agree with the following statements:

\begin{tabular}{|c|c|c|c|c|c|c|c|}
\hline & $\begin{array}{l}\text { Strongly } \\
\text { Disagree }\end{array}$ & Disagree & $\begin{array}{l}\text { Somewhat } \\
\text { Disagree }\end{array}$ & $\begin{array}{c}\text { Neither } \\
\text { Agree } \\
\text { nor } \\
\text { Disagree }\end{array}$ & $\begin{array}{l}\text { Somewhat } \\
\text { Agree }\end{array}$ & Agree & $\begin{array}{l}\text { Strongly } \\
\text { Agree }\end{array}$ \\
\hline $\begin{array}{l}\text { Internet banking would be a secure means by } \\
\text { which to check my account balance. }\end{array}$ & 0 & 0 & 0 & 0 & 0 & 0 & 0 \\
\hline $\begin{array}{l}\text { I would feel safe checking my account } \\
\text { balance via Internet banking. }\end{array}$ & 0 & 0 & 0 & 0 & 0 & 0 & 0 \\
\hline $\begin{array}{l}\text { Checking my account balance on Internet } \\
\text { banking would be risky. }\end{array}$ & 0 & 0 & 0 & 0 & 0 & 0 & 0 \\
\hline $\begin{array}{l}\text { Overall, Internet banking would be a safe way } \\
\text { to check my account balance. }\end{array}$ & 0 & 0 & 0 & 0 & 0 & 0 & 0 \\
\hline
\end{tabular}

Please indicate the extent to which you agree with the following statements:

\begin{tabular}{|c|c|c|c|c|c|c|c|}
\hline & $\begin{array}{l}\text { Strongly } \\
\text { Disagree }\end{array}$ & Disagree & $\begin{array}{l}\text { Somewhat } \\
\text { Disagree }\end{array}$ & $\begin{array}{c}\text { Neither } \\
\text { Agree } \\
\text { nor } \\
\text { Disagree }\end{array}$ & $\begin{array}{l}\text { Somewhat } \\
\text { Agree }\end{array}$ & Agree & $\begin{array}{l}\text { Strongly } \\
\text { Agree }\end{array}$ \\
\hline $\begin{array}{l}\text { I don't think using Internet banking for } \\
\text { account inquiries would be a good idea. }\end{array}$ & 0 & 0 & 0 & 0 & 0 & 0 & 0 \\
\hline $\begin{array}{l}\text { I think it would be good to use Internet } \\
\text { Banking to check my account balance. }\end{array}$ & 0 & 0 & 0 & 0 & 0 & 0 & 0 \\
\hline $\begin{array}{l}\text { My attitude towards account inquiries via } \\
\text { Internet Banking would be favorable. }\end{array}$ & 0 & 0 & 0 & 0 & 0 & 0 & 0 \\
\hline $\begin{array}{l}\text { Overall, using Internet banking for account } \\
\text { inquiries would be a good idea. }\end{array}$ & 0 & 0 & 0 & 0 & 0 & 0 & 0 \\
\hline
\end{tabular}

My decision to use Internet banking for account inquiries would be influenced by:

\begin{tabular}{|c|c|c|c|c|c|c|c|}
\hline & $\begin{array}{l}\text { Strongly } \\
\text { Disagree }\end{array}$ & Disagree & $\begin{array}{c}\text { Somewhat } \\
\text { Disagree }\end{array}$ & $\begin{array}{c}\text { Neither } \\
\text { Agree } \\
\text { nor } \\
\text { Disagree }\end{array}$ & $\begin{array}{c}\text { Somewhat } \\
\text { Agree }\end{array}$ & Agree & $\begin{array}{c}\text { Strongly } \\
\text { Agree }\end{array}$ \\
\hline My friends. & 0 & 0 & 0 & 0 & 0 & 0 & $\mathrm{O}$ \\
\hline My family/relatives. & $\mathrm{O}$ & 0 & 0 & 0 & 0 & 0 & 0 \\
\hline My colleagues/peers. & 0 & 0 & 0 & 0 & 0 & 0 & 0 \\
\hline
\end{tabular}




\begin{tabular}{|c|c|c|c|c|c|c|c|}
\hline & $\begin{array}{l}\text { Strongly } \\
\text { Disagree }\end{array}$ & Disagree & $\begin{array}{l}\text { Somewhat } \\
\text { Disagree }\end{array}$ & $\begin{array}{l}\text { Neither } \\
\text { Agree } \\
\text { nor } \\
\text { Disagree }\end{array}$ & $\begin{array}{c}\text { Somewhat } \\
\text { Agree }\end{array}$ & Agree & $\begin{array}{c}\text { Strongly } \\
\text { Agree }\end{array}$ \\
\hline $\begin{array}{l}\text { If I knew that my peers were using Internet } \\
\text { banking for account inquiries, I would be more } \\
\text { inclined to do so myself. }\end{array}$ & 0 & 0 & 0 & 0 & 0 & 0 & 0 \\
\hline
\end{tabular}

Please indicate the extent to which you agree with the following statements:

\begin{tabular}{|c|c|c|c|c|c|c|c|}
\hline & $\begin{array}{l}\text { Strongly } \\
\text { Disagree }\end{array}$ & Disagree & $\begin{array}{l}\text { Somewhat } \\
\text { Disagree }\end{array}$ & $\begin{array}{l}\text { Neither } \\
\text { Agree } \\
\text { nor } \\
\text { Disagree }\end{array}$ & $\begin{array}{l}\text { Somewhat } \\
\text { Agree }\end{array}$ & Agree & $\begin{array}{c}\text { Strongly } \\
\text { Agree }\end{array}$ \\
\hline $\begin{array}{l}\text { It would cost a lot to check my account } \\
\text { balance using Internet banking. }\end{array}$ & 0 & 0 & 0 & 0 & 0 & 0 & 0 \\
\hline $\begin{array}{l}\text { Financial costs would be a barrier for me if } \\
\text { checking my account balance using Internet } \\
\text { banking. }\end{array}$ & 0 & 0 & 0 & 0 & 0 & 0 & 0 \\
\hline $\begin{array}{l}\text { I would not be worried about the costs } \\
\text { associated with account inquiries using } \\
\text { Internet banking. }\end{array}$ & 0 & 0 & 0 & 0 & 0 & 0 & 0 \\
\hline $\begin{array}{l}\text { Overall, the cost associated with Internet } \\
\text { banking use for account inquiries would } \\
\text { discourage me from using it. }\end{array}$ & 0 & 0 & 0 & 0 & 0 & 0 & 0 \\
\hline
\end{tabular}

Please indicate the extent to which you agree with the following statements:

\begin{tabular}{|c|c|c|c|c|c|c|c|}
\hline & $\begin{array}{l}\text { Strongly } \\
\text { Disagree }\end{array}$ & Disagree & $\begin{array}{l}\text { Somewhat } \\
\text { Disagree }\end{array}$ & $\begin{array}{l}\text { Neither } \\
\text { Agree } \\
\text { nor } \\
\text { Disagree }\end{array}$ & $\begin{array}{l}\text { Somewhat } \\
\text { Agree }\end{array}$ & Agree & $\begin{array}{c}\text { Strongly } \\
\text { Agree }\end{array}$ \\
\hline $\begin{array}{l}\text { I think Internet banking is well suited for } \\
\text { obtaining account balances. }\end{array}$ & $\mathrm{O}$ & 0 & $\mathrm{O}$ & 0 & 0 & $\mathrm{O}$ & 0 \\
\hline $\begin{array}{l}\text { Internet banking is a good medium for } \\
\text { checking my account balance. }\end{array}$ & 0 & 0 & $\mathrm{O}$ & 0 & 0 & 0 & 0 \\
\hline Internet banking fits well for account inquires. & $\mathrm{O}$ & 0 & 0 & $\mathrm{O}$ & 0 & 0 & 0 \\
\hline $\begin{array}{l}\text { I think Internet banking is a good way to } \\
\text { check my account balance. }\end{array}$ & $\mathrm{O}$ & 0 & $\mathrm{O}$ & $\mathrm{O}$ & $\mathrm{O}$ & 0 & 0 \\
\hline
\end{tabular}

Please indicate the extent to which you agree with the following statements:

\begin{tabular}{|c|c|c|c|c|c|c|c|}
\hline & $\begin{array}{l}\text { Strongly } \\
\text { Disagree }\end{array}$ & Disagree & $\begin{array}{l}\text { Somewhat } \\
\text { Disagree }\end{array}$ & $\begin{array}{l}\text { Neither } \\
\text { Agree } \\
\text { nor } \\
\text { Disagree }\end{array}$ & $\begin{array}{l}\text { Somewhat } \\
\text { Agree }\end{array}$ & Agree & $\begin{array}{l}\text { Strongly } \\
\text { Agree }\end{array}$ \\
\hline $\begin{array}{l}\text { If I needed to check my account balance I } \\
\text { would use Internet banking. }\end{array}$ & 0 & 0 & 0 & 0 & 0 & 0 & 0 \\
\hline $\begin{array}{l}\text { Assuming I needed to check my account } \\
\text { balance I would use Internet banking for it. }\end{array}$ & 0 & 0 & 0 & 0 & 0 & 0 & 0 \\
\hline
\end{tabular}




\begin{tabular}{|c|c|c|c|c|c|c|c|}
\hline & $\begin{array}{l}\text { Strongly } \\
\text { Disagree }\end{array}$ & Disagree & $\begin{array}{c}\text { Somewhat } \\
\text { Disagree }\end{array}$ & $\begin{array}{l}\text { Neither } \\
\text { Agree } \\
\text { nor } \\
\text { Disagree }\end{array}$ & $\begin{array}{c}\text { Somewhat } \\
\text { Agree }\end{array}$ & Agree & $\begin{array}{c}\text { Strongly } \\
\text { Agree }\end{array}$ \\
\hline $\begin{array}{l}\text { I would check my account balance via } \\
\text { Internet banking if I needed my account } \\
\text { statement. }\end{array}$ & 0 & 0 & $\mathrm{O}$ & 0 & 0 & 0 & 0 \\
\hline $\begin{array}{l}\text { I would use Internet banking for account } \\
\text { inquiries rather than alternative banking } \\
\text { channels (branch, telephone, letter etc.). }\end{array}$ & 0 & 0 & 0 & 0 & 0 & 0 & 0 \\
\hline
\end{tabular}

Please indicate the extent to which you agree with the following statements:

\begin{tabular}{|c|c|c|c|c|c|c|c|}
\hline & $\begin{array}{l}\text { Strongly } \\
\text { Disagree }\end{array}$ & Disagree & $\begin{array}{c}\text { Somewhat } \\
\text { Disagree }\end{array}$ & $\begin{array}{c}\text { Neither } \\
\text { Agree } \\
\text { nor } \\
\text { Disagree }\end{array}$ & $\begin{array}{l}\text { Somewhat } \\
\text { Agree }\end{array}$ & Agree & $\begin{array}{l}\text { Strongly } \\
\text { Agree }\end{array}$ \\
\hline I like using information technology. & O & O & 0 & O & 0 & 0 & 0 \\
\hline $\begin{array}{l}\text { Using information technology is frustrating for } \\
\text { me. }\end{array}$ & 0 & 0 & 0 & 0 & 0 & 0 & 0 \\
\hline Using information technology is fun. & 0 & 0 & 0 & 0 & 0 & 0 & 0 \\
\hline I find using information technology enjoyable. & 0 & 0 & 0 & 0 & 0 & 0 & 0 \\
\hline
\end{tabular}

Please indicate the extent to which you agree with the following statements:

\begin{tabular}{|c|c|c|c|c|c|c|c|}
\hline & $\begin{array}{l}\text { Strongly } \\
\text { Disagree }\end{array}$ & Disagree & $\begin{array}{l}\text { Somewhat } \\
\text { Disagree }\end{array}$ & $\begin{array}{c}\text { Neither } \\
\text { Agree } \\
\text { nor } \\
\text { Disagree }\end{array}$ & $\begin{array}{l}\text { Somewhat } \\
\text { Agree }\end{array}$ & Agree & $\begin{array}{l}\text { Strongly } \\
\text { Agree }\end{array}$ \\
\hline I am familiar with account inquiries. & 0 & 0 & 0 & 0 & 0 & 0 & 0 \\
\hline I understand how account inquiries work. & 0 & 0 & 0 & 0 & 0 & 0 & 0 \\
\hline $\begin{array}{l}\text { I consider myself knowledgeable with account } \\
\text { inquiries. }\end{array}$ & 0 & 0 & 0 & 0 & 0 & 0 & 0 \\
\hline I am not at all familiar with account inquiries. & 0 & 0 & 0 & 0 & 0 & 0 & 0 \\
\hline
\end{tabular}

Please indicate the extent to which you agree with the following statements:

\begin{tabular}{|c|c|c|c|c|c|c|c|}
\hline & $\begin{array}{l}\text { Strongly } \\
\text { Disagree }\end{array}$ & Disagree & $\begin{array}{c}\text { Somewhat } \\
\text { Disagree }\end{array}$ & $\begin{array}{c}\text { Neither } \\
\text { Agree } \\
\text { nor } \\
\text { Disagree }\end{array}$ & $\begin{array}{l}\text { Somewhat } \\
\text { Agree }\end{array}$ & Agree & $\begin{array}{c}\text { Strongly } \\
\text { Agree }\end{array}$ \\
\hline I am familiar with using Internet banking. & 0 & 0 & 0 & $\mathrm{O}$ & 0 & 0 & 0 \\
\hline I understand how Internet banking works. & 0 & $\mathrm{O}$ & 0 & 0 & 0 & $\mathrm{O}$ & 0 \\
\hline $\begin{array}{l}\text { I consider myself knowledgeable with Internet } \\
\text { banking. }\end{array}$ & $\mathrm{O}$ & 0 & 0 & O & 0 & 0 & 0 \\
\hline $\begin{array}{l}\text { I am not at all familiar with using Internet } \\
\text { banking. }\end{array}$ & $\mathrm{O}$ & $\mathrm{O}$ & 0 & $\mathrm{O}$ & $\mathrm{O}$ & $\mathrm{O}$ & 0 \\
\hline
\end{tabular}

What is your age?
under 20
20-29
O $30-39$
- $40-49$
50-59
60 or older 